\title{
Philosophical Perspectives on Galen of Pergamum: Four Case-Studies on Human Nature and the Relation Between Body and Soul
}

Filosofische perspectieven op Galenus van Pergamum: vier 'case-studies' over de menselijke natuur en de verhouding tussen lichaam en ziel (met een samenvatting in het Nederlands)

\footnotetext{
Proefschrift

ter verkrijging van de graad van doctor aan de Universiteit Utrecht op gezag van de rector magnificus, prof. dr. H.R.B.M. Kummeling, ingevolge het besluit van het college voor promoties in het openbaar te verdedigen op vrijdag 27 maart 2020 des middags te 2.30 uur.

door

Robert Vinkesteijn
}

geboren op 21 november 1986 te Leiderdorp 
Promotor: $\quad$ prof. dr. T.L. Tieleman

This work is part of the research project Human Nature: Medical and Philosophical Perspectives in the Work of Galen of Pergamum, which is financed by the Netherlands Organisation for Scientific Research (NWO) 


\section{Contents}

Acknowledgments

Abbreviations and other notes 6

$\begin{array}{ll}\text { Introduction } & 7\end{array}$

\section{Case-Study I:}

The Cultivation of the Soul in a 'Physicalist' World:

Ethical Philosophy in Galen's $Q A M$

Introduction

1. Aristotle and the non-rational parts of the soul

$\begin{array}{ll}\text { a. Introduction of the argument } & 16\end{array}$

b. The soul as form of the homoeomerous body 18

c. The homoeomerous bodies as primarily active 27

d. The substance of the soul as mixture $\quad 35$

e. Soul and nature $\quad 42$

$\begin{array}{ll}\text { Conclusion } & 47\end{array}$

2. Plato and the rational part of the soul

a. The substance of the rational soul as mixture 48

b. The mixture of the rational soul 55

Conclusion 63

3. Positioning in the scholarly debate

a. Preliminary remarks 63

b. QAM and Prop. Plac. $\quad 66$

c. Critical discussion of some previous scholarship on QAM 71

4. The possible continuity in the divine and human formation

$\begin{array}{ll}\text { of the mixture } & 76\end{array}$

$\begin{array}{ll}\text { Conclusion } & 90\end{array}$

\section{Case-Study II:}

\section{Galen on the Nature of Man}

Introduction $\quad 92$

1. The primary substance $\quad 97$

2. Divisio ad principes: a Hippocratic-Platonic method 105

3. Elements and qualities $\quad 112$

4. Grades and shades of nature $\quad 117$

5. Nature of the body, nature of the soul 130

$\begin{array}{ll}\text { Conclusion } & 137\end{array}$ 


\section{Case-Study III:}

Soul, Mixture and Galen's Timaeus

$\begin{array}{ll}\text { Introduction } & 139\end{array}$

1. Sources 143

2. Scope of the commentary 152

3. Basic tendencies in Galen's interpretation of the Timaeus 156

4. Comparing Galen's Timaeus to the Larrain fragments

$\begin{array}{ll}\text { a. Aristotelianizing Plato } & 163\end{array}$

b. Somatising the soul 168

c. The soul as a dry and hot substance that exudes light 182

d. Substance, activity and soul in Plato's and Galen's Timaeus 193

Conclusion 197

\section{Case-Study IV:}

\section{Galen on Black Bile and Melancholy}

Introduction

1. Precedents
a. Hippocratic precedents
202
b. Aristotle and the Problemata XXX,1 209
$\begin{array}{ll}\text { c. Rufus of Ephesus } & 219\end{array}$
$\begin{array}{ll}\text { Conclusion } & 225\end{array}$

2. Galen on black bile

Introduction 226

a. The normal and the harmful I: the normal 229

b. The normal and the harmful II: the normal that is 235 potentially harmful

c. The normal and the harmful III: the harmful that 243 used to be normal

d. Spleen 248

$\begin{array}{ll}\text { e. The end of summer } & 258\end{array}$

$\begin{array}{ll}\text { Conclusion } & 271\end{array}$

3. Galen on melancholy $\quad 272$

$\begin{array}{ll}\text { Conclusion } & 288\end{array}$

$\begin{array}{ll}\text { Conclusion } & 289\end{array}$

$\begin{array}{ll}\text { Bibliography } & 302\end{array}$

$\begin{array}{ll}\text { Samenvatting } & 313\end{array}$

$\begin{array}{ll}\text { Curriculum Vitae } & 325\end{array}$ 


\section{Acknowledgements}

The research on which this dissertation is based was carried out within the NWOfunded project Human Nature: Medical and Philosophical Perspectives in the Work of Galen of Pergamum, directed by prof. dr. Teun Tieleman. I am grateful to the NWO for the funding and to Teun for the he trust placed in me.

The frequent reading group and research seminar meetings with the project-group in Utrecht have contributed greatly to my research. I would like to thank Aiste Celkyte, Albert Joosse, Chiara Cecconi, Clarine Rijpstra-van Daal and Julia Trompeter for their many useful comments and expert feedback on my research, as well as for everything I learned during these meetings.

The Philosophy Department in Utrecht was a very fruitful environment for me during my time as a PhD student, for which I would like to particularly thank Jaap Mansfeld, Jan van Ophuijsen, Maarten van Houte, Mauro Bonazzi, and Paul Ziche. Of the many visiting scholars our department welcomed during my time as a PhD student, I would like to thank in particular Jim Hankinson and Riccardo

Chiaradonna for reading my work-in-progress and providing many relevant and stimulating comments.

I thank my friends Paul Trouerbach, Rob Heller, and Ype de Boer, for an ongoing philosophical conversation that always manages to provide both stimulus and distraction; and Sophie Spaan for the delightful company during all of those early train rides from Amsterdam to Utrecht.

I owe many thanks to my supervisor, Teun Tieleman, not only for his ever extensive and knowledgeable input and comments, but also for his truly exceptional kindness and support.

Last but not least, I thank my loving partner Donya, who managed to improve much of my English to a level I hope is acceptable. Any faults that remain are mine, alone. More importantly, her love and support in the last years of my PhD-period has lifted my spirit like nothing else. 


\begin{abstract}
Abbreviations and other notes
For references to Galen's works I have used the standard abbreviations listed in Singer (2013) 429-42. The most frequently referenced works are listed below with their Latin and English title and page numbers in C.G. Kühn's (K) Opera Omnia edition (Leipzig 1821-1833). For other works, such as those of Plato and Aristotle, I have used the standard abbreviations in footnotes. Translations are my own unless otherwise indicated. For references to the other case-studies I will use the abbreviation 'CS' with the respective number, subsection and page numbers.
\end{abstract}

At. Bil. = De Atra Bile (V 104-148 K), On Black Bile

Hipp. Elem. $=$ De Elementis ex Hippocrate $(\mathrm{I} 413-508$ K), The Elements According to Hippocrates

$H N H=$ In Hippocratis de Natura Hominis (XV 1-223 K), Commentary on Hippocrates' Nature of Man

Loc. Aff. = De Locis Affectis (VIII 1-452 K), On the Affected Places

$M M=$ De Methodo Medendi (X 1-1021 K), The Therapeutic Method

Nat. Fac. = De Naturalibus Facultatibus (II 1-214 K), Natural Capacities

PHP = De Placitis Hippocratis et Platonis (V 181-805 K), The Doctrines of Hippocrates and Plato

$Q A M=$ Quod Animi Mores Corporis Temperamenta Sequuntur (IV 767-822 K), That the Capacities of the Soul Follow the Mixtures of the Body

$U P=$ De Usu Partium (II 1-939; IV 1-366 K), On the Usefulness of the Parts of the Body

Temp. $=$ De Temperamentis $(\mathrm{I} 509-694 \mathrm{~K})$, On Mixtures 


\section{Introduction}

Galen of Pergamum (129-c. 215 AD) is still mostly known for his medical works, though the philosophical worth and depth of his writings has come to be appreciated better in recent decades. New editions and translations of Galen's work are appearing by the year and recent volumes such as Galien et la philosophie, Galen and the World of Knowledge and Philosophical Themes in Galen testify to the growing interest in Galen's work as not only a valuable source for the study of ancient thought and philosophy in general, but as an interesting thinker in his own right. ${ }^{1}$

The aim of this dissertation is to build further on this recent work and contribute to the understanding of Galen's thinking, with a particular focus on his views on the nature of man and the relation between body and soul. These subjects are arguably among the most interesting from a philosophical perspective on Galen's work. As a philosophically schooled medical practitioner who is both fully acquainted with the previous and contemporary philosophical tradition as well as thoroughly experienced with the intricacies of the human body and as a scientist keenly interested in the physiological underpinnings of the human psyche, Galen has unique contributions to these subjects.

Galen's work is voluminous, complex and diverse. His scope, discerning scepticism, eclectic tendencies, his pragmatic approach with regard to the specific and varying aims of his writings, and last but not least his scornful attitude towards dogmatism and his refusal to adhere to any particular philosophical school - all of these make ordering his entire work into a systematic 'philosophy of Galen' an ungrateful task bound to encounter innumerable complications and likely to produce simplifications. Besides these complicating factors, there is also the sheer volume of Galen's work. According to Jouanna, Galen's work 'comprises more than ten percent of all Greek literature that has survived from Homer to the end of the second century AD'. ${ }^{2}$ Quite a few of these works, moreover, have not (yet) been translated into a modern language.

For these reasons, the methodological approach I have taken in this dissertation is as follows. I have conducted four separate 'Case-Studies' concerned with the fundamental question: what is Galen's view of human nature? This question is inextricably related, as we shall see, to the questions of the (substance) of the soul, and the relation between body and soul. Each case-study, however, departs from a different treatise or set of treatises to discuss these questions. I have selected these texts on the basis of the questions. That is to say, I have principally selected works in which Galen actually discusses the subject of the soul and human nature, in order to

\footnotetext{
${ }^{1}$ Barnes, J. and Jouanna, J. (2003); Gill, C., Whitmarsh, T. and Wilkins, J. (2009); Adamson, P., Hansberg, R. and Wilberding, J. (2014). Besides these landmark volumes, the work of Jim Hankinson, Jacques Jouanna, Inna Kupreeva, Peter Singer, Teun Tieleman, Philip van der Eijk and Mario Vegetti, in particular, has done much to further our understanding of Galen's thought over recent decades and provided much impetus for the underlying work.

${ }^{2}$ Jouanna (2012) 313
} 
then relate his discussion of these questions to other relevant works or passages from other works, often with help of the TLG. In this manner, I hope to avoid a problematic over-systematization of Galen's work, while at the same time making an attempt to do justice to the connections between some of his works that treat of human nature and the soul and to their embeddedness in Galen's general oeuvre. In each of these four case-studies, I will undertake a close analysis of a particular text or set of texts and will aim for an understanding of Galen's views on these subjects that is supported by other works. For example, if we are close-reading the treatise That the Capacities of the Soul Follow the Mixtures of the Body (QAM) in Case-Study I, it will turn out that Galen develops a notion of soul as the form of a homoeomerous body there, which can only be understood against the background of the role of homoeomerous bodies in his general analysis of the human body, for which we need to consult other works. In this way, I hope to gain an understanding of the selected key-texts that form the point of departure for each case-study that is as rich and as informed by other Galenic works as possible, while at the same time guarding against over-systematization by taking a single text or limited amount of texts as a reference point without claiming the conclusions with regard to this text or set of texts as valid for Galen's work as a whole.

The case-studies offer philosophical perspectives on Galen's work. By that I mean two different but related things: (1) I will depart from philosophical questions (what is Galen's view on human nature, the soul and the relation between body and soul?) and (2) I will analyse Galen as a philosopher. By that I do not mean that I will not take Galen's specific medical focus and background into account, which in any case seems impossible. Rather, this is a methodological point designed to deal with the aforementioned complexity of Galen's work as well as to do justice to Galen's own aspirations as a philosopher. Someone else might well take different perspectives on Galen, often even with regard to the same works. I believe that Galen's work lends itself well to such various approaches, which may be viewed as complementary rather than contradictory in the same way as Galen saw the study of philosophy and medicine as complementary rather than contradictory. When we are dealing with a body of work that by its very nature crosses the boundaries of genres, we should be careful not to reduce it to any of those preconceived genres in particular. Therefore, the word perspectives in the title of this dissertation may be considered equally worthy of emphasis as the word philosophical.

Some overlap between the different case-studies will be unavoidable, since the general questions underlying them are the same and since some passages in Galen's work will be crucial for an understanding of several of the key-texts which we shall discuss. With regard to all case-studies I will undertake a close-reading of the relevant texts, which takes the form of quotations from and subsequent discussions of Galen's text.

The first case-study will depart from $Q A M$, since Galen appears to be much more open to discuss the issue of the substance of the soul there than anywhere else. 
Moreover, Galen bases his discussion of the soul in $Q A M$ on some of his earlier works, as I hope to show. Therefore, it makes sense to depart from QAM and then see how it relates to the rest of the Galenic corpus. In $Q A M$, Galen enters somewhat more speculative philosophical terrain and uses his general physiological framework, developed in work such as On the Elements According to Hippocrates (Hipp. Elem.), to argue not merely for the thesis that the capacities of the soul follow the mixtures of the body', but also for the stronger thesis that the substance of the soul is a specific mixture of the four elemental qualities.

This apparently rather physicalist position has been found problematic by scholars, both because of its supposedly radical reductionism and because Galen has quite consistently expressed his ignorance with regard to the substance of the soul elsewhere. Therefore, it has been argued that this stronger thesis was not actually held by Galen or in any case should not be taken seriously. This, in broad strokes, is the position taken by Donini, Garcia-Ballester, Lloyd and Singer. ${ }^{3}$ However, as I hope to show, a close-reading of the text that takes into account its relation to other Galenic work will add significantly to our understanding of $Q A M$ as a treatise that is more experimental and speculative but still firmly based in Galen's own work. For this analysis I build on the previous work by Hankinson, Tieleman and Vegetti. ${ }^{4}$ I will argue that Galen, through an integration of his Platonic-Hippocratic tripartition and trilocation of the soul with an Aristotelian hylomorphist notion of the soul as form of the body, together with his fundamental assumption that the nature or substance of beings is to be found at the most elemental level of a their constitution, works out a notion of the substance of the soul as a specific mixture of elemental qualities that is in strong agreement with much of his other works. In this case-study on $Q A M$ we shall take up its stronger thesis in particular, in order to see to what extent Galen is committed to it, how he understands it and what he regards as its consequences for the possibility of ethics and self-amelioration. The latter part is important, since Galen himself presents his work in $Q A M$ explicitly as being 'beneficial for those who wish to improve their soul' 5 and since it has been suggested that Galen's views in $Q A M$ rather amount to a kind of determinism and a rejection of the free will. ${ }^{6}$ I will argue that Galen reserves a special place for the rational part of the soul in his discussion. He argues that the rational soul is a mixture as the other parts of the soul are, but also ascribes to this particular mixture a creative capacity that could be viewed as a likeness to the creative capacity of divine nature. In this likeness to divine nature lies the possibility for a philosophical life.

The second case-study will focus on Galen's commentary on the Hippocratic On the Nature of Man, which is quite understudied compared to other Galenic works,

\footnotetext{
${ }^{3}$ Donini (2008); Garcia-Ballester (1988); Lloyd (1988); Singer (2013)

${ }^{4}$ Particularly, Hankinson (2006); Tieleman (2003); Vegetti (2000)

${ }^{5}$ QAM 32,5-7 Müller (IV 767,6-7 K)

${ }^{6} \mathrm{Cf}$. Donini (2008), 202: ' $\ldots$ the consequence is that a man is genuinely the product of a series of factors in which his own free will and voluntary initiative may play a very minor or even non-existent part...'; Singer (2013) 335 note 1 for further references
} 
perhaps because no good translation of it has been published yet (though this will soon change with the appearance of Jim Hankinson's new translation in the Galen on Human Nature volume edited by Singer and van der Eijk). It is a key-text for Galen himself, clearly, since he presents this commentary as a more accessible follow-up on his Hipp. Elem., an earlier work which was written for an audience already familiar with some of his views and arguments. ${ }^{7}$ That is to say: with this work Galen undertakes a non-specialist exposition of his basic views on (human) nature, which makes it one of the most suitable texts for our purposes here. The word 'human' is bracketed in the previous sentence because the commentary is in fact concerned with the nature of all beings, rather than merely or specifically with the nature of human beings. The work shows much similarity to $Q A M$, since it develops a notion of a hylomorphic primary substance as the common nature of all beings, consisting of a mixture of the four elemental qualities (the form) in a matter without quality in itself. It is also rather different from $Q A M$, since the soul seems to be almost entirely absent from it. Why it is that the soul is not discussed by Galen in this treatise and how that fact relates to his notion of human nature as a hylomorphic substance, will be our main question in discussing this treatise. Galen puts much emphasis on the right method for uncovering the common nature of things: a method of analysis, or division until no further division is possible. Again, it will turn out that in order to know what something is, we need to analyse its smallest constituent parts. Galen presents this method of division as a kind of Hippocratic-Platonic concord:

Hippocrates used this method to discover the nature of the body and Plato stated that the same method must be used to discover the nature of the soul. I argue that Galen, as he does elsewhere, presents his own work as a Hippocratic-Platonic synthesis, which does not merely take either the nature of the body or the nature of the soul into account, but instead, using his Aristotelian hylomorphic perspective, develops a notion of the nature of 'the whole' in which the two are integrated. In this case-study, I build on the work of Hankinson, Kupreeva, Tieleman and van der Eijk, in order to develop a new interpretation of Galen's commentary. ${ }^{8}$ I shall also relate the concept of nature that we can derive from $H N H$ to my analysis of $Q A M$ in Case-Study I.

In the third case-study we shall look into Galen's dealings with Plato's Timaeus, which must have been one of his favourite works. The Timaeus recurs often in Galen's writings on human nature and the soul and must have played a fundamental role in the development of his views on these subjects. In his interpretation of the Timaeus, Galen develops what I would call a 'somatisation' of the soul, or more specifically: a recasting of the Platonic opposition between body and soul into an opposition between different elemental qualities. Therefore, his several writings on the Timaeus, namely his commentary and summary as well as the interpretations put

\footnotetext{
${ }^{7}$ HNH 3,4-19 Mewaldt (XV 1-2 K)

${ }^{8}$ Hankinson (2008, 2014a, 2017); Kupreeva (2014); Tieleman (2018, forthcoming); van der Eijk (2014)
} 
forth in PHP and $Q A M$, form a good follow-up on the two previous case-studies, in which we find that Galen develops a notion of the nature of man or the nature of the soul of man as constituted by specific mixtures of the elemental qualities. I shall argue that Galen's often quite idiosyncratic interpretation of the Timaeus is an attempt to anchor this notion of the nature of man in the work of Plato. This perhaps comes to the fore most clearly in his interpretation of the metaphor of the river, which Timaeus uses to describe the confusion to which the soul is subjected upon its union with the body, but which Galen interprets as a kind of allegorical description of the predominance of wetness as one of the four elemental qualities making up the hylomorphic substance of the body. In this way, one of the elemental qualities which constitute the body comes to take over the role that the body as a whole plays in Plato, so that other elemental qualities which are opposed to it, dryness and heat, come to be associated with the soul as the Platonic antagonist of the body.

In this case-study we shall have a special focus on the contested and therefore almost completely neglected fragments published by Carlos Larrain in $1992 .{ }^{9}$ Larrain thought these fragments were excerpts from the first two books of Galen's commentary on the Timaeus but his view has been problematized by Diethard Nickel. ${ }^{10}$ More recent research by Aileen Das, however, suggests that a 'reevaluation' of the status of these fragments is needed. ${ }^{11}$ We shall depart from some general tendencies in Galen's interpretation of the Timaeus as we find it in his attested work, to then compare and see how Larrain's fragments relate to Galen's attested work. Larrain's fragments are particularly suitable for such comparison in the context of this dissertation since they often display the same 'somatising' tendency we find in some of Galen's attested work on the Timaeus. This case-study develops new insights with regard to Galen's interpretation of the Timaeus, provides a much needed contribution to the study of Larrain's fragments and their relation to the attested Galenic corpus, and relates its findings back to those of the two previous case-studies. Systematic study of Galen's dealings with the Timaeus is scarce, but the work of Aileen Das and Mario Vegetti in particular provide a point of departure. ${ }^{12}$

In the fourth and final case-study I shall analyse Galen's notions of black bile and melancholy. I have chosen to focus on black bile and melancholy to explore the relation between body and soul in Galen through a more concrete theme and to see whether Galen's views on the nature of man and the nature of the soul as they emerged from the previous three case-studies find any concrete application when we look at a specific affliction of the human body or soul. The subject of black bile and melancholy is eminently suited to this purpose, because it is not only fairly well documented in Galen, but also crosses and problematizes the boundaries between the physical and the mental.

\footnotetext{
${ }^{9}$ Larrain (1992)

${ }^{10}$ Nickel (2002)

${ }^{11}$ Das (2014)

${ }^{12}$ Das (2014); Vegetti (2000)
} 
Galen's views on black bile and melancholy are to a large extent shaped by the previous medical and philosophical tradition, particularly by the Hippocratic Corpus, Aristotle and Rufus. In order to adequately understand Galen's views on the subject, therefore, we will first need to analyse and discuss these precedents. In this way, we are also able to determine what is innovative about Galen's writing on black bile and melancholy. For the discussion of Galen's precedents we can build on an excellent body of literature on the ancient history of melancholy, particularly by Flashar, Jouanna, Klibansky, Panofsky and Saxl, Kudlien, Pormann and van der Eijk. ${ }^{13}$

The main questions of this case-study will be: to what extent does Galen attempt to understand melancholy in terms of the (elemental) qualities of the substance of black bile? - how does the causation between body and soul or mind work in his analysis of melancholy? - how can black bile be both a natural or normal part of our body as well as a dangerous substance causing mental illnesss? - what factors cause the black bile to become so dangerous and how do they relate to its (elemental) qualities? what therapies does Galen propose for melancholy and how do they relate to the (elemental) qualities of the black bile?

In treating these questions, I hope to provide more substance to the notion of the nature of man and the nature of the soul as it developed in the previous three casestudies by zooming into a more concrete theme. At the same time, I aim to contribute to the study of black bile and melancholy in Galen, a subject which has remained surprisingly understudied despite Galen's lasting influence on humoural theory in general and the notions of black bile and melancholy in particular. In part, this relative neglect might be because scholars have thought that Galen did not provide innovate contributions to the ancient understanding of melancholy. ${ }^{14}$ We can assess the extent to which this is true by comparing Galen to his aforementioned precedents. As I hope to show, the importance of Galen's contribution to the understanding of black bile and melancholy has been underestimated. Galen's writings on black bile and melancholy are spread throughout several texts. The keytexts for this case-study will be On Black Bile (At. Bil.), Galen's commentary on the Hippocratic On the Nature of Man (HNH) and chapters 9-10 from book III of his On the Affected Places (Loc. Aff.). As in the previous case-studies, we shall try to gain an understanding of what Galen has to say in these key-texts by continous comparison with other Galenic works.

We shall close off with a general conclusion, in which we bring the results of the individual case-studies together.

\footnotetext{
${ }^{13}$ Flashar (1966); Jouanna (2009, 2012); Klibansky, Panofsky and Saxl (1990); Kudlien (1967, 1973); Pormann (2008); van der Eijk $(2005,2008)$

${ }^{14}$ Bell (2014) 42, states that Galen had a 'relative lack of interest in melancholia'; cf. Pormann and van der Eijk (2008), Appendix 1, who see Galen's discussion of melancholy in Loc. Aff. as possibly 'little more than a Galenic summary of Rufus' ideas on the topic without proper acknowledgement.' and state that 'Galen appears to have added very little to Rufus' clinically as well as therapeutically impressive account of melancholy.'
} 


\section{Case-Study I: The Cultivation of the Soul in a 'Physicalist' World: Ethical Philosophy in Galen's QAM}

\section{Introduction}

In one of his best-known works, Galen argues for the thesis - expressed in its title -

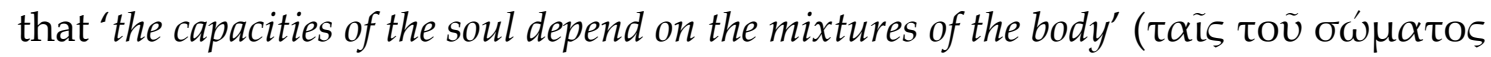

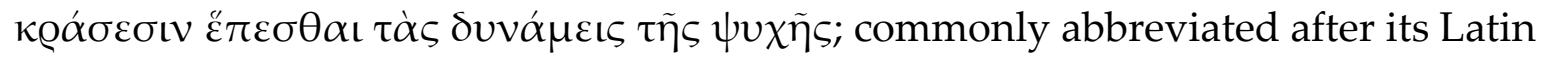
title as $Q A M) \cdot{ }^{15}$ However, he also argues for a stronger and more speculative thesis, namely that the substance of the soul is such a mixture. This is remarkable, since Galen usually tends to refrain from speculating about the substance of soul. Since he seems to be more outspoken on the subject in $Q A M$, this text can provide us with a good point of departure for our understanding of body and soul in Galen. In this first case-study, we shall interpret $Q A M$ through close text-analysis and comparison with other Galenic works, focusing on (1) the conception of soul and its relation to the body Galen develops in this work (2) the exceptional position of the rational part within this conception of the soul (3) the consequences of Galen's position for the possibility of ethics and transformation of the self, which are, as we shall see, connected to his thesis in an important way.

It is not always easy to pinpoint Galen's position in $Q A M$ since he extensively quotes and discusses Aristotelian, Platonic, Stoic and Hippocratic views on the soul in order to develop his own views. ${ }^{16}$ Yet, as we shall see below, close text-analysis permits us to find some positive doctrine which expresses a conception of the soul that is both more 'materialistic' (we shall see presently why the quotation marks are necessary) and more outspoken than in Galen's other works and which, at the same time, develops the possibility of a causal reciprocity between the body and the (rational part of the) soul. With this combination, Galen strongly dissociates himself from both complete material determinism and Platonic metaphysics, through an original version of the Aristotelian, hylomorphic conception of the soul. As we shall see, such a conception builds on other, earlier Galenic writings. This is important to note, particularly since QAM has often been taken as the odd one out, as a work that does not present genuine Galenic doctrine. ${ }^{17}$ By showing how QAM relates to Galen's

\footnotetext{
${ }^{15} Q A M$ is not only one of Galen's best-known works in modern scholarship, but might have also been one of the best-known ones in antiquity, since we find references to it in several Neoplatonists, see below, section 4, 85-6. The full Latin title is Quod Animi Mores Corporis Temperamenta Sequantur, so the Latin translation 'mores' translates $\dddot{\eta} \theta \eta$ instead of $\delta v v \alpha ́ \mu \varepsilon 1 \zeta$, which Galen also has in his commentary on the Hippocratic On the Nature of

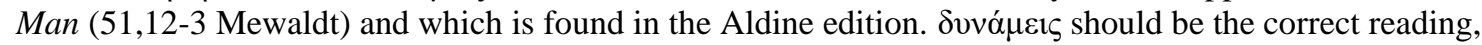
however, as it is supported by Galen's other references and by the MSS tradition, as well as by the text and its general line of argumentation. $Q A M$ has simply remained the standard reference despite being erroneous. Cf. Singer (2013) Textual Note 4.1 and Jouanna (2009) $190 \mathrm{ff.}$

${ }^{16}$ Singer (2013) $335 \mathrm{ff}$., has argued that we can discern a plurality of strategic aims Galen may have had with this text - giving a clear-cut account of his own views of the soul not being one of them - and that it has a public and rhetorical context that further complicates the disentangling of Galen's own views on the soul. We shall engage with this reading in the third section of this case-study.

${ }^{17}$ See section 3, 71-6 below
} 
other work, we shall arrive at a better understanding of the treatise itself. Right after the introduction of the central thesis expressed in the title, at the beginning of the text, Galen remarks that he has often examined this thesis in many ways, even in the company of the best philosophers, and always found it to be not only true, but also 'beneficial to those who wish to improve their own souls' ${ }^{18}$. This addition immediately shows how the thesis of $Q A M$ is, for Galen, tied to ethics. It is

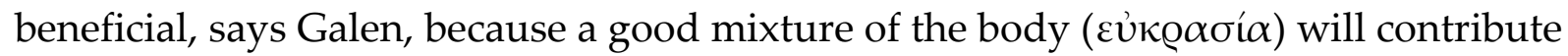
to the virtue of the soul, meaning that those who come to realize the truth of his thesis can henceforth put it into practice by shaping the mixture of their body in such a way that it is beneficial for the cultivation of the virtue of their soul, 'as those around Pythagoras and Plato and some others among the ancients are reported to have done.' These introductory lines reveal what seems to be a fundamentally reciprocal view on the relationship between body and soul: the mixtures of the body have a causal influence on the state of the soul, but at the same time a certain kind of knowledge (the realization of the truth of the central thesis) and its subsequent deliberations on the way in which we live our lives, can be the cause of dramatic alterations in the mixture of the body (which then, in turn, again change the soul). It is also important to note that by mentioning the Pythagoreans and Platonists as examples, Galen suggests that this self-imposed altering of the mixtures of the body in order to improve the soul is a philosophical activity. ${ }^{19}$

After the introduction of the thesis, a large part of $Q A M$ is taken up with showing how it is supported by the works of Aristotle, Plato and Hippocrates. But, as we shall see, Galen's separate discussions of Aristotelian and Platonic doctrine serve another purpose than simply accumulating the support of the two greatest philosophical authorities. In the Aristotelian section (IV 773-75 K; discussed in section 1 of this casestudy) the proposed thesis is validated for the lower two parts of the soul (the tripartition familiar from On the Doctrines of Hippocrates and Plato $(P H P)$ is presupposed throughout $Q A M)$. However, a further step is also taken: it is demonstrated that the substance (ov́rí $\alpha$ ) of these parts of the soul is itself a bodily mixture. In the Platonic section (IV 775-82 K; discussed in section 2 of this case-study) Galen discusses the rational part of the soul. Although he seems to draw the same conclusions for this part, he is less explicit here, and the possibility of a transformation of the body through the agency of the soul is also introduced.

\footnotetext{
${ }^{18}$ QAM 32,5-7 Müller (IV 767, 6-7 K). For all references to QAM I shall refer to Müller's edition and give the Kühn pages as well, as is customary, except for when I refer to more more general divisions of the text, where it suffices to give the Kühn pages, which are in every other edition. I will often also use Athena Bazou's edition (2011), however, which is less well-known but sometimes provides a good alternative to Müller. Peter Singer's translation and notes (2013) have also proven very useful and will often be referred to as well. Choices with regard to the Greek are discussed ad locum when they deviate from Müller's text.

${ }^{19}$ Cf. Foucault (1984) 69-70: 'Selon une tradition qui remonte fort loin dans la culture grecque, le souci de soi est en corrélation étroite avec la pensée et la pratique médicales. Cette correlation ancienne a pris de plus en plus d'ampleur. Au point que Plutarque pourra dire, au début des Préceptes de santé, que philosophie et medicine ont affaire à 'un seul et meme domaine' (mia chôra).'
} 
Galen's flirtation with the notion that the substance of the soul is nothing but a specific bodily mixture has sparked controversy and debate among scholars. There has been a tendency to downplay the validity of this conclusion and to argue that it should not be accepted as serious Galenic doctrine. Indeed, there are some obvious problems with it. Galen has become renowned for his agnosticism on the substance of the soul, which he has also clearly expressed in works dated later than QAM. For some reason, he appears willing to be somewhat more speculative in $Q A M$ on this subject. To a certain extent a more speculative attitude might also be expected from this particular text, however. After all, according to Galen himself it is a work on 'Plato's philosophy'. ${ }^{20}$ I consider it plausible, for reasons to be discussed below, that in $Q A M$ Galen was working out the philosophical consequences of some of his earlier work on the human constitution and human nature. Perhaps merely by way of experiment, but certainly in a way that builds upon, and is mostly in accordance with, the rest of his work. That is to say, as opposed to most of the modern scholarly tradition, I do want to interpret $Q A M^{\prime}$ 's thesis on the substance of the soul as Galenic doctrine. Because a majority of the scholarly tradition is in disagreement with this approach, I will discuss alternative readings and possible objections in a separate section (section 3) after my own analysis of the text.

One of the reasons why scholars have taken issue with the stronger thesis in $Q A M$ is that it is considered radical and deterministic. However, it will turn out that the worry about radical consequences of 'material determinism' that have been said to follow Galen's identification of the substance of the soul with a bodily mixture, is unjustified. As we shall see, Galen rather ascribes to the rational part of the soul a divine-like capacity to transform the bodily mixture and to thus develop the virtues of the soul (section 4). After being allotted certain natural capacities, dependent on the naturally given mixture of the body, man can and should initiate a second stage of formation by training and disciplining himself. It follows, however, given Galen's critique of the Platonic notion of the rational soul as a separate or non-bodily entity, that this capacity to form itself is finally a capacity of the naturally given mixture itself. This leads to a notion of ethics which might seem paradoxical to some and which in any case poses some serious restrictions on the possible application of the ancient ideal Galen proposes: it appears as if the likelihood or even possibility of this second stage of formation depends upon a specific kind of natural mixture already. That is to say, in simpler terms: only those with the right natural predisposition for it will take upon themselves a project of self-ameliorization.

To summarize: what I propose to do in what follows is to give a reading of $Q A M$ that is supported by other Galenic works and that takes the thesis of the substance of the soul being a mixture completely serious, without accepting the implied lack of human freedom and impossibility of traditional ethics as a necessary consequence. ${ }^{21}$ I hope to show that such a reading is possible when grounded in some of Galen's

\footnotetext{
${ }^{20}$ Lib. Prop. XIX 46,11-20 K

${ }^{21}$ See for these objections Donini (1996), 202. Cf. also the objections that philosophers in his own day make according to Galen himself, QAM 73 Müller (IV 814-15 K).
} 
views on human nature or the human constitution, which he elaborates upon elsewhere and presupposes in QAM. This notion of human nature builds on a combination of Aristotelian hylomorphism and the Hippocratic-Platonic tripartition and trilocation, with an exceptional and somewhat ambiguous status for the rational part of the soul.

For the aim of this case-study, some parts of $Q A M$ are more relevant to analyze than others. It may be helpful to give my overall view of the structure of the text at the outset. As we have noted, after a short introduction Galen first argues for the substance of the soul being a bodily mixture. The argument is divided into an Aristotelian section on the lower two parts (773-5 K) and a Platonic section on the rational part of the soul (775-82 K), culminating in the acceptance of the position of Andronicus regarding the soul as a whole (782-3 K). Then, he states that the Stoics are on the same side, because they also hold that the substance of the soul is a certain mixture (783-4 K). In the part on the Stoics Galen first mentions the ethical debate his position is likely to spark, only to state that he will return to this matter later (785 K; he will return to it at the end of the treatise, 814-822 K). In the text between 785 and $814 \mathrm{~K}$, Galen argues for the central thesis of QAM (mostly through quotations from Plato, Aristotle and Hippocrates), that the capacities of the soul follow the mixture of the body, and not for the stronger thesis that the substance of the soul is itself a mixture, as he did in the part between 773 and $783 \mathrm{~K}$. Therefore, the text between 785 and $814 \mathrm{~K}$ is less relevant to our analysis and will not be discussed in detail. As we shall see, however, the arguments for the thesis that the substance of the soul is a mixture should be understood in light of Galen's central thesis that the capacities of the soul follow the mixtures of the body. That is to say, it fulfils a function within the overall argumentation for the central thesis (which does not imply that we should simply reduce its value to this function, especially when it can be shown that the stronger thesis coheres with other works).

\section{Aristotle and the non-rational parts of the soul}

\section{a. Introduction of the argument}

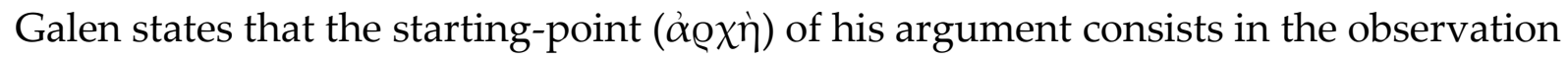
of the differences in actions and affections of small children. Such observation makes us realize that we are always already given a certain nature that is decisive for the state of our soul.22 This realization is of central importance to Galen and will conflict with what he presents as the Stoic view, namely that everyone has the potential for virtue. ${ }^{23}$ The apparent differences in those actions and affections imply a difference in

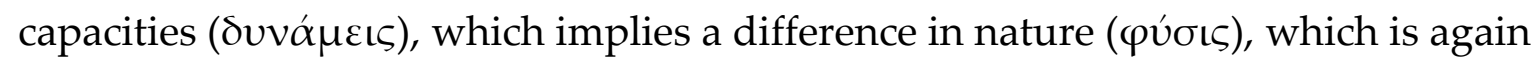
equated to substance (ovjoí $\alpha$ ), for nature and substance 'refer to the same in these

\footnotetext{
${ }^{22}$ QAM 32,14 f. Müller (IV $768 \mathrm{~K}$ ); cf. Character Traits 30,5-10 Kraus

${ }^{23}$ Galen returns to this point at the end of the treatise, QAM 74,21 f. Müller (IV 816-9 K)
} 


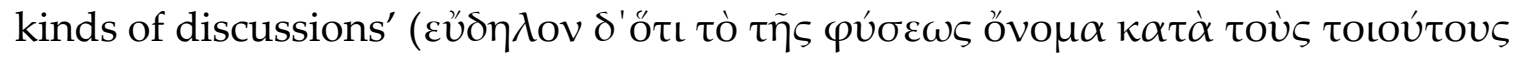

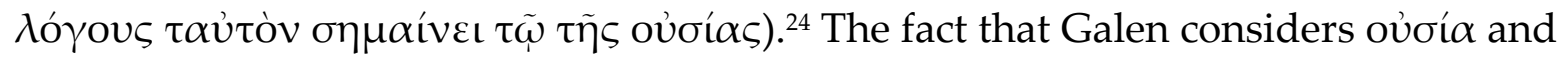
$\varphi v ́ \sigma ı s$ to be synonymous here is noteworthy, and will be important for our later discussion. Thus, having established on the basis of a simple empirical observation that the substances of our souls differ and that 'substance' here refers to the same as 'nature', Galen will now move on to the question: what is the substance (or nature) of the soul? In this context, Galen's use of the word ovoí $\alpha$ might cause some confusion, since it could either refer to a certain stuff or material or to what something essentially is. The equation with nature and the later consideration that the substance of the soul might be immaterial make it clear that Galen must be concerned with the latter sense of oú $\sigma i \alpha$ here, although, as we shall see, given Galen's physiological perspective on the matter these two senses of ov́ $\sigma$ í $\alpha$ will converge to a certain extent. Since the differences between children forms the starting-point of the argument, the answer to the question about the substance of the soul will somehow have to do justice to the observed differences in the natures of children. Thus, although we are in a sense asking about one 'thing', the substance or nature of the soul, this has to be something that is itself qualitatively variant to such a degree that it can account for the entire range of differences we observe in the capacities of small children. Given this point of departure, we can safely assume that whatever explanation of the substance or nature of the soul Galen turns out to prefer, it will have some emphasis on inherent qualitative variation.

Galen's next step is the introduction of the tripartition familiar from PHP: there are three forms and parts ( $\tau \tilde{\omega} v \varepsilon \dot{\imath} \delta \tilde{\omega} v \tau \varepsilon \kappa \alpha i \mu \varepsilon \tilde{\imath} \tilde{\omega})$ of the soul, differing in kind and located in the three main organs, the liver, heart and brain. Each of these organs has its own specific substance (iðí $\alpha v$ oúoí $\alpha v$ ), states Galen, which seems to take us from the question of the substance of the soul to that of the substance of the three main organs. ${ }^{25}$ The discussion of the substance of the rational part of the soul, located in the brain, is immediately related to Plato and postponed because of its particularly problematic character (it may or may not be immortal) and it will be taken up after the discussion of the substance of the other two parts:

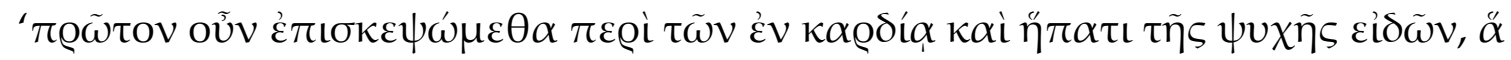

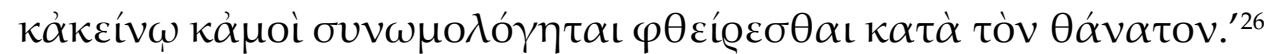

'Let us first, then, examine the forms of the soul in heart and liver, which are agreed by both him and me to perish at death.' (tr. Singer, modified)

These other two forms and parts are discussed in a kind of exchange with Aristotelian philosophy, while the discussion of the substance of the rational part of

\footnotetext{
${ }^{24}$ QAM 33,9-10 Müller (IV $769 \mathrm{~K}$ ); both Müller and Bazou bracket this sentence as supposedly being an interpolation, but I think Singer is right in his analysis that there are no strong grounds for this and that the sentence fulfils an important role in Galen's argument (2013, note 10 ad locum and Textual Note 4,5). Besides, there are parallels in other texts, such as PHP VII 440,11-2 De Lacy (V $601 \mathrm{~K})$

${ }^{25}$ QAM 36,9-20 Müller (IV 772-3 K)

${ }^{26}$ QAM 36,16-9 Müller (IV $773 \mathrm{~K}$ )
} 
the soul will take the form of an argument against the Platonic doctrine of its immortality and non-bodily existence. Thus, Galen chose to divide his discussion of the soul into a discussion of the lower parts according to Aristotle, and the higher part according to Plato. Perhaps this points to a Platonist tendency, but it could also be a way to first establish Galen's particular interpretation of Aristotelian hylomorphism, i.e. of the soul as form of the body. After all, Galen's discussion of the rational part of the soul mostly takes the form of arguments against the Platonic doctrine of the soul's existence as a substance separate from the body, leaving the by then established - hylomorphic interpretation of the soul as the only alternative.

\section{b. The soul as form of the homoeomerous body}

In this paragraph, we shall delve further into the Aristotelian discussion of the lower two parts. Although it is only a relatively small piece of the overall text, it requires a lot of explanation because it presupposes much from other Galenic works.

Galen starts the discussion of the lower two parts of the soul with the remark that the

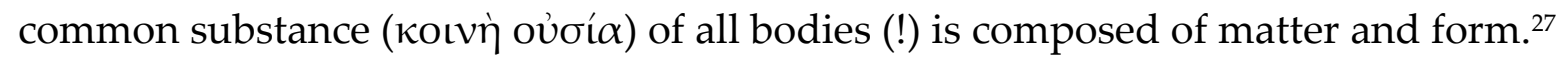
The leap from the substance and nature of the soul to the substance of all bodies is only mediated by the brief mention of the main organs, the bodily parts 'in' which the soul resides. The difference between the substance of the organ and the substance of the soul that resides 'in' the organ will, in turn, become obscured to the point of non-existence in $Q A M$. The reason for this is not negligent arguing, however, but an underlying general theory of human nature that we find in a set of other Galenic works as well (to be discussed below). This general theory consists in a combination of Peripatetic hylomorphism and Galen's tripartition-cum-trilocation. As we shall see below, the soul is indeed defined as something that resides 'in' the three main organs, but therefore not as something separable from it that does not at the same time form the substance of the organ itself (both in the sense of the 'stuff' and the 'essence' but especially in the sense of principle of movement). That is to say, the oú $\sigma$ í $\alpha$ of the soul, in the sense of what the soul is, is conflated with the oú $\sigma$ í $\alpha$ of the organ in the sense of what constitutes its nature. More specifically, the soul is located at the micro-level of our constitution, as the formal aspect of the smallest perceivable hylomorphic unit, formed by nature. Since the form of this smallest hylomorphic unit also determines the activity of the organ that exercises psychic functions, the substance of the soul and the substance within the organ seem to be identified. With regard to soul itself, this is how these two senses of ovं $\alpha$ í become conflated: what

\footnotetext{
${ }^{27}$ QAM 36,21 f. (IV $773 \mathrm{~K}$ ); Cf. Hipp. Elem. 128,1 f. De Lacy (I 481-2 K): 'My present purpose is to give an account of the higher elements, those that escape sense-perception; Hippocrates too spoke of them in his work

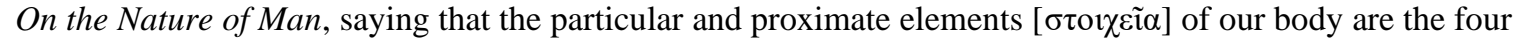
humors, and that the common elements of all things [ $\tau \grave{\alpha}$ kovvò $\pi \alpha ́ v \tau \omega v$ ] are wet, dry, hot, and cold. He gives to the elements the names of the qualities by virtue of which they became elements; for when extreme heat has entered matter, the body will now be an element...' (tr. De Lacy, slightly modified). This common substance underlying everything is the main subject of Galen's commentary on the Hippocratic On the Nature of Man $(H N H)$, see infra, CS II, particularly section 1, 97-105. For Galen on elements and elemental qualities see also infra, CS II section 3, 112-7, and Kupreeva (2014) and Hankinson (2017)
} 
the soul is, is a specific mixture of qualities (i.e. form) that is always already mixed in matter. The interaction between the different qualities that make up the mixture, takes place on this micro-level. It is not perceivable with our senses itself, but causally determines the possible functions of the organs and the actions and affections of the soul, which Galen presented as the starting-point of his argument. Much of the background for this reasoning on the soul is consistent with Galen's view on human nature as we find it in other works, but is simply presumed or implied in QAM itself. Therefore, to understand this (Aristotelian) section of the text, we will have to take recourse to some of Galen's earlier work, in which a more or less consistent doctrine of the constitution of human nature is developed. The relevant works are especially On the Elements according to Hippocrates (Hipp. Elem.), to which Galen refers in QAM (46,16-7 Müller), On Mixtures (Temp.), On the Natural Faculties (Nat. Fac.), On the Usefulness of the Parts (UP) and The best Constitution of our Bodies (Opt. Corp. Const.). These texts are all dated close to each other and connected by several explicit references and programmatic resemblance. ${ }^{28}$ Galen's commentary on the Hippocratic On the Nature of Man (HNH; the subject of Case-Study II) is also relevant, though presumably of later date, as are his various interactions with Plato's Timaeus (the subject of Case-Study III).

In his discussion of the lower two parts of the soul in the Aristotelian section (QAM IV 773-5 K), Galen assumes with 'Aristotle and his followers' that the soul is the form of the body. Thus, besides his familiar Platonic-Hippocratic tripartition, he adopts, at the same time, a hylomorphic approach to the question of the nature and substance

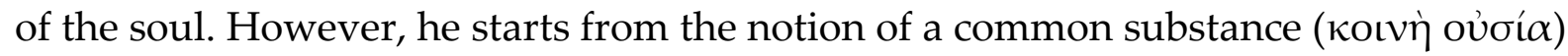
of all bodies, and explains the matter of this common substance as a kind of prima materia: it is matter without any perceivable quality, that functions (conceptually) as a receptacle for a mixture ( $\kappa \tilde{\alpha} \sigma \varsigma \varsigma)$ of the four basic qualities of hotness, coldness, dryness and wetness. ${ }^{29}$ A homoeomerous body ( $\sigma \tilde{\omega} \mu \alpha$ ó $\mu$ oเo $\left.\mu \varepsilon \varrho \varepsilon ́ \varsigma\right)$ comes to be through a mixing of these four qualities in the prime matter. These homoeomerous

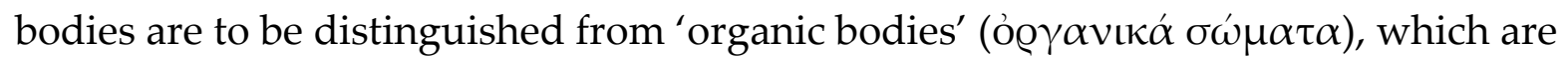
made up of a quantity of homoeomerous bodies and form a more complex unit. ${ }^{30}$

\footnotetext{
${ }^{28}$ Cf. particularly Temp. I 509-10 K; Opt. Corp. Const. IV 740-41 K. For the dating: Ilberg (1979) 49 f. The Different Kinds of Homogeneous Part (Part. Hom. Diff.) is also relevant, but more difficult to date, cf. Strohmaier (1970) 32, 33. Cf. Kupreeva (2014) 154: 'Galen wrote De Elementis ex Hipporate during his second sojourn in Rome, when he composed a series of physiological treatises which included als Mixtures, Natural Capacities, The best constitution of our bodies, Semen, and The shaping of the embryo. Along with The doctrines of Hippocrates and Plato and The function of the parts of the body, these works are regarded as programmatic for his rationalist outlook in medical philosophy.'

${ }^{29}$ QAM 36,21-37,2 Müller (IV $773 \mathrm{~K}$ ): '.. but let us remember, regarding the common substance of all bodies, that this was shown by us to be composed of two principles, matter and form, matter being conceptually without quality, but having in itself a mixture of four qualities, hotness, coldness, dryness and wetness.' (tr. Singer); cf. Hipp. Elem. 114,16 f. De Lacy (I 469-70 K): 'And indeed that the first principles of the generation of fire are the matter which underlies all the elements and is without qualities, and the extreme heat that enters into it, this too has been similarly agreed to...' (tr. De Lacy); HNH 17,20 f. Mewaldt (XV 29 f. K); Prop. Plac. ed. Lami and Garofalo 86

${ }^{30}$ Galen introduces the distinction loosely in $Q A M 37$ Müller (IV 773-74 K). Cf. HNH 6,10 f. Mewaldt (XV 7-8 K); PHP VIII,4 500,3 f. De Lacy (V 673 K); Part. Hom. 45 f. Strohmaier; Hipp. Elem. 126,1 f. De Lacy (I 479$81 \mathrm{~K}) ;$ Opt. Med. 6,14-9 Müller
} 
Some examples of homoeomerous bodies, which Galen gives here or in other places are flesh, fat, nerve, membrane, bone, marrow and ligament. ${ }^{31}$

Now, at this point Galen does not yet conclude that the form of the body, and thus the soul, is the mixture of elemental qualities that constitutes the homoeomerous bodies:

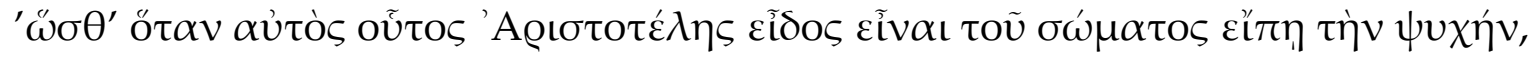

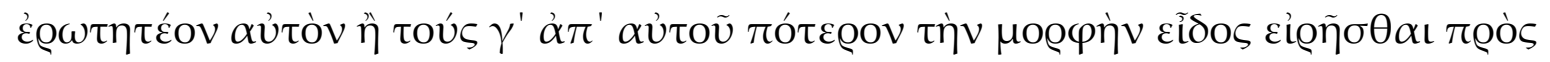

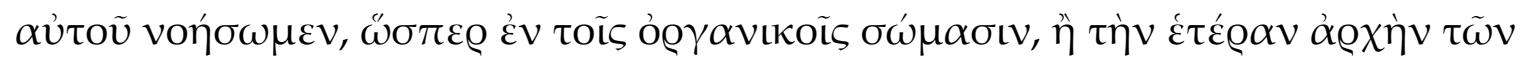

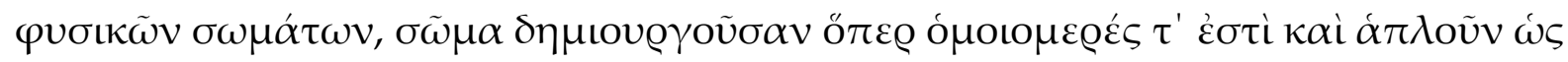

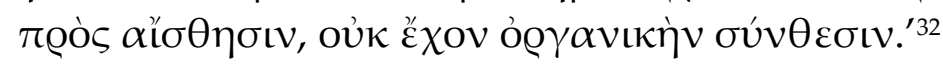

'Therefore when this Aristotle himself says that the soul is form of the body, one must ask him, or his followers, whether we should understand form here to have been used by him in the sense of shape, as in the organic bodies, or in the sense of the other principle of natural bodies, that which crafts a body that is homoeomerous and simple in terms of perception, not having organic composition.' (tr. Singer, modified)

Apparently, at this point in the argument, there are two options for the definition of the soul as the form of the body: the shape of organic bodies and that which 'crafts' the homoeomerous bodies. Also, both are considered a principle or cause ( $\dot{\alpha} \chi \grave{\eta})$. It

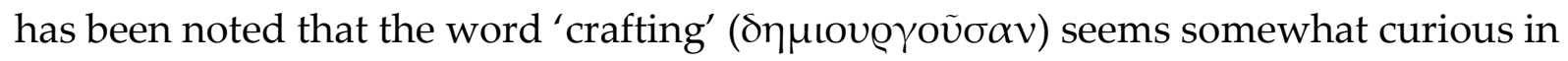
this context, and that it is not clear how Galen arrives at these two options, which are introduced by him without any further explanation, as if self-evident. ${ }^{33}$ As we shall see, the necessary background for this passage can be obtained from earlier work in which Galen develops a theory of the constitution of human nature that can explain both the choice for these two options and the curious notion of 'crafting'. The two options Galen presents refer to two different levels in the constitution of the human body. In this particular case, they refer to different levels in the constitution of the organs, since we are in the specific context of a discussion of the substance of the soul within the framework of the Platonic-Hippocratic tripartition, in which the soul is located in the three main organs. Galen takes the distinction between these two levels of composition, homoeomerous bodies and anhomoeomerous bodies (which include the organs) from Aristotle. His interpretation differs from that of Aristotle in several respects, though, and there were others using the distinction after Aristotle, to whom Galen sometimes responds. ${ }^{34}$ However, both share the basic notion that the homoeomerous bodies are made up of a mixture of the four elemental qualities (or of

\footnotetext{
${ }^{31}$ See note 30 above for such examples

${ }^{32}$ QAM 37,5-12 Müller (IV 773-4 K), with different interpunction

${ }^{33}$ Singer (2013) 380 note 35

${ }^{34}$ Cf. Aristotle's PA II; Meteor. IV; GC II. For Galen, as we shall see, this is basic physics and should as such also be an elemental part of the education of a doctor, see The Best Doctor is also a Philosopher I 60 K (II, 6,1418 Müller). Leith (2015) has shown how the same compositional hierarchy is also used by Alexandrian physicians Erasistratus and Herophilus, with the difference that they emphasize that the elemental level is not for the doctor to study, which is clearly opposite to Galen's view (cf. Galen's MM X 184-6 K)
} 
the elements that are in turn made up of the elemental qualities) and form the basic building blocks of the more complex parts of our body, called anhomoeomerous parts, examples of which are the hand, the arm, the brain, liver, and other such parts or organs. These elementary substances are called 'homoeomerous' because the mixing of the four qualities in the primary matter takes place in such a thorough manner that it is impossible to actually (as opposed to conceptually) separate them again from each other, so that every part taken from such a particular body would be exactly like any other to our perception. ${ }^{35}$ The larger corporeal units, which are formed by the homoeomerous substances in turn, are called anhomoeomerous, because they consist of different homoeomerous parts that can be separated when we analyze the anhomoeomerous part. Thus, at the lowest compositional level, there is the prime matter in which the four qualities are mixed to form a homoeomerous unity. Specific to man (and other sanguineous animals), is that the four qualities form the four humours when they are mixed, and that men's homoeomerous substances are thus made out of the four humours. ${ }^{36}$ In portraying this general compositional picture, Galen does not consistently include the humours - as opposed to the homoeomerous and organical bodies - but from the passages where he does their position in the overall scheme seems clear. ${ }^{37}$ The basis of four elemental qualities and prime matter applies not just to human beings but to everything in the cosmos: everything is eventually formed through the mixing of these four qualities in the prime matter. ${ }^{38}$ This is why Galen could take such a general definition of the substance of all bodies (the кoเví ov́oí $\alpha$ ) as his point of departure: at the micro-level, all beings can be described and analysed in the same basic terms (although in different constellations, of course, which results in all the differences we observe). This is important for several reasons. First of all, it constitutes the unity of the cosmos and man's kinship with the rest of creation (especially in the absence of an identifiable creator-god). Second, it seems to imply that an analysis of the nature and substance of the human soul does not require a fundamentally different approach than the analysis of any other being in the cosmos, since all beings, including man, are made up of the same kind of hylomorphic combination. Thus, the introduction of

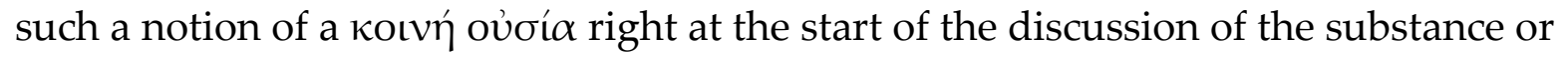
nature of the soul betrays that, for Galen, there is not necessarily anything metaphysical about the analysis of the ovoí $\alpha$ of the soul. That is to say, the soul may

\footnotetext{
${ }^{35}$ Part. Hom. Diff. 49-50 Strohmaier and his commentary, 109-10. In Temp. I 562-3 K, Galen remarks that such a thorough mixture can only be achieved by God and nature: 'A total mixture of one with the other [ö $\lambda \alpha \delta$ ' ő $\lambda \omega v$ $\alpha \hat{\tau} \tau \dot{\alpha} \kappa \varepsilon \rho \alpha ́ \sigma \alpha 1]$ - of hot, cold, dry, and wet, that is - is not humanly possible to achieve ...The total mixture of substances is however possible for God, and in Nature...' (tr. Singer)

${ }^{36}$ Hipp. Elem. 126,1-7 De Lacy (I 479-80 K): 'Now let me go through the account as it applies to a human being: he is made of the primary and simplest visible elements, those called homoeomerous, fiber, membrane, flesh, fat, bone and cartilage, ligament, nerve, marrow, and all the other (structures) whose parts have the same form. These in turn have been generated from certain other elements closest to themselves, blood, phlegm, and the two kinds of bile, yellow and black.' (tr. De Lacy); Hipp. Elem. 138,15-140,14 De Lacy (I 491-3 K); HNH 28,8-24 (XV 51-2 K); PHP VIII 502,19 f. De Lacy (I 676 K)

${ }^{37}$ See infra, CS II section 1, 102-5

${ }^{38}$ Hipp. Elem. 138,15-17 De Lacy (I 492 K); Nat. Fac. II 134 K; HNH 17,20 f. Mewaldt (XV 29-30 K), 22,4-8 Mewaldt (XV $38 \mathrm{~K}), 28,10-4$ Mewaldt (XV $51 \mathrm{~K}$ )
} 
perhaps not be of a fundamentally different nature than the other things and beings in the cosmos. When Galen further on in QAM relates the dryness of an intelligent soul to the dryness of the stars (see below), he can do so because of this basic doctrine of a кoเví oủoí $\alpha$ of all bodies.

The distinction between 'homoeomerous bodies' and 'organic bodies' employed by Galen in $Q A M$ is hierarchically the same as the difference between homoeomerous and anhomoeomerous bodies. In the context of $Q A M$, where the substance of the soul is under consideration from the perspective of the tripartition related to the three main organs, the compositional level of the anhomoeomerous bodies is restricted to organs. This means that the second candidate for the form of the body, or the soul, the 'other cause' that 'crafts' a body that is homoeomerous and simple, must be (the mixing interaction of) the four elemental qualities. Again, this kind of cause is not unique to human beings but common to all bodies in the cosmos:

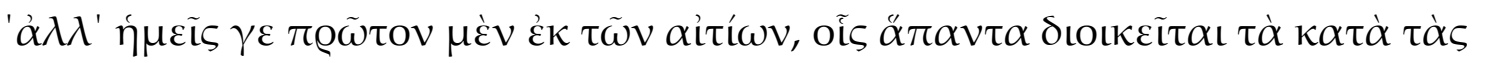

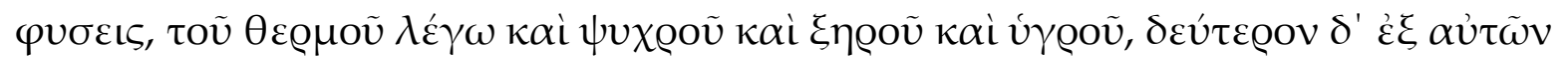

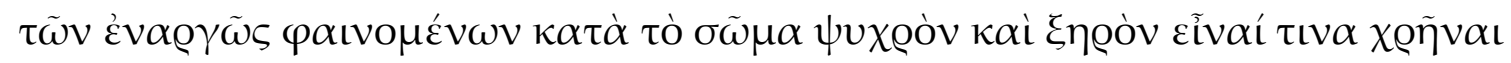

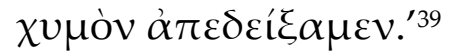

'But we have demonstrated, firstly from the causes by which everything throughout nature is governed, that is to say from the warm and the cold and the dry and the moist, and secondly, from obvious bodily phenomena, that there must be a cold and dry humour.' (tr. Brock, modified)

Galen considers the elemental qualities as the governing causes of all beings, since they, in their mutual interaction, decide the form (literally) that the smallest elements of those beings take. Therefore, in $U P$, Galen states that the mixture of qualities

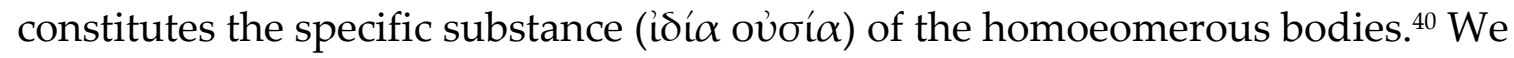
have observed how Galen mentioned the iói $\alpha$ oúcí $\alpha$ of the organs in QAM before. What constitutes the specific substance of the homoeomerous body is the mixture of its qualities and what constitutes the specific substance of an organ is its homoeorous bodies. ${ }^{41}$ There is a kind of causal hierarchy here, according to which the more elemental level decides what the more complex level is, that is to say, in which the ov́'í $\alpha$ in terms of the component stuff, determines the ov́ $\sigma i \alpha$ in terms of 'what something is'.

As Galen proceeds to explain in the passage in $U P$, the nature of a part (i.e. a homoemerous body in this context) is determined by the specific state of its elemental qualities. The smallest bodies in turn determine the specific form of the larger ones, and thus also the specific functions and activities of these larger bodies. ${ }^{42}$

\footnotetext{
${ }^{39}$ Nat. Fac. II $134 \mathrm{~K}$, see note 38 above for other references

${ }^{40}$ UP I 18,24-5 Helmreich (III $26 \mathrm{~K}$ )

${ }^{41}$ Cf. HNH 6,10-20 Mewaldt (XV 7-8 K)

42 There are some exceptions to this general rule, as Galen remarks, sometimes the action of a thing is derived not from its specific substance, formed by the four elemental qualities, but from qualities that follow upon the

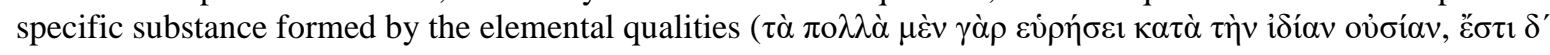




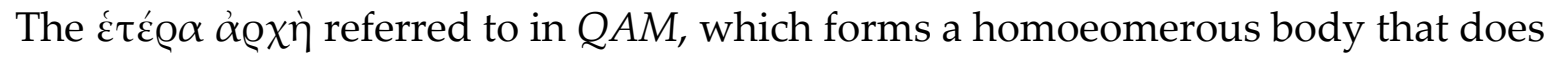
not yet have organic composition and that is identified by Galen as soul, refers to the mixture of the elemental qualities. At this point one may be inclined, as Socrates in the Phaedo, to ask whether there should not be something governing this mixing itself, something steering and perhaps intelligent. ${ }^{43}$ The question seems to come down to this one: what exactly is the 'demiurge' doing the crafting here? After all, it seems difficult to account for the notion of a teleologically structured cosmos, and perhaps particularly for something as complex as the human soul, on the basis of a random gathering of elemental qualities. This is indeed a crucial point for Galen, as is well known, since the answer to this question makes the difference between his doctrine and forms of what he considers to be random material determinism (represented by atomists for example) which are always firmly rejected by him. But we shall return to this point below, at the very end of this paragraph. First, let us summarize what we have found so far. We have two levels of composition: the formation of the homoeomerous substances through the mixture of the four elemental qualities and the construction of anhomoeomerous substances through the combination of several homoeomerous substances (sometimes Galen differentiates between more basic and complex organs as well, the complex ones being made up of a combination of basic ones, see the citation below). If we consider man more specifically, we might add the formation of the four humours as a compositional phase between the four elemental qualities and the homoeomerous substances. When Galen asks about the substance or nature of the soul from his specific hylomorphic and tripartitional perspective, two possible answers are presented, corresponding to these two general levels of composition, each functioning as a cause at its respective level. So, what we have here lurking behind the brief and somewhat enigmatic discussion in $Q A M$ is the presupposition of a doctrine of the human constitution from the prime matter to the whole, summarized in Hipp. Elem. as follows:

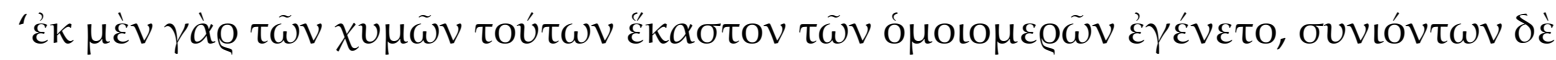

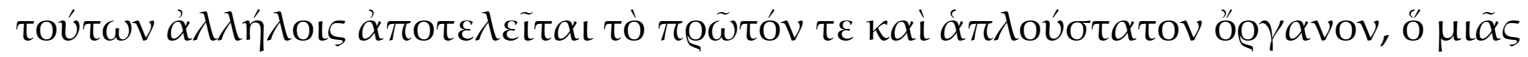

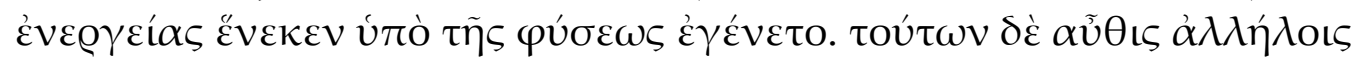

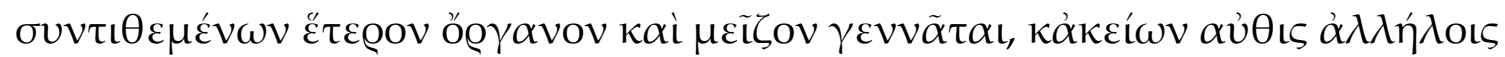

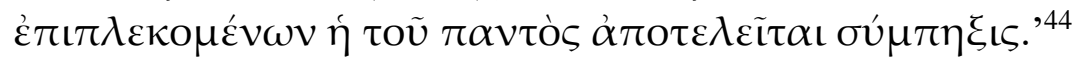

'Each of the homoeomerous parts came to be from these humours, and when they are conjoined with each other they produce the first and simplest organ, which was brought into being by nature for the sake of a single activity. When these [organs] are combined with each other in turn, another, larger organ is produced, and when these

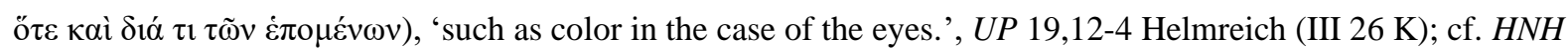
22,27 f. Mewaldt (XV $40 \mathrm{~K}$ ) for an enumeration of secondary qualities (among which also color) which follow upon the activity of the elementary qualities.

${ }^{43}$ Phaedo $98 \mathrm{~b}$ ff.

${ }^{44}$ Hipp. Elem. 126,19-24 De Lacy (I $\left.481 \mathrm{~K}\right)$ 
[larger organs] are joined with each other again, the structure of the whole is completed.' (tr. De Lacy, modified)

Galen adopts an hierarchical structure, in which the more complex level is produced from, or even by the more simple level. In this way, the structure of the whole seems in the end to a large extent determined by the way the elemental qualities interact at the most basic level and form or alter the homoeomerous parts. In $H N H$, Galen relates this causal hierarchy to his discussion of the soul in QAM:

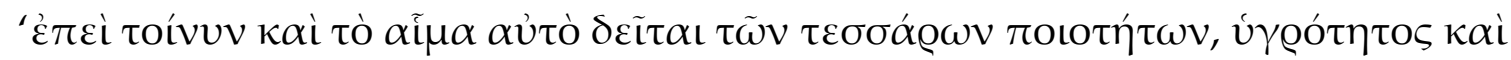

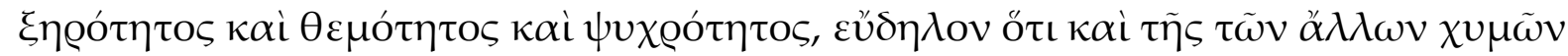

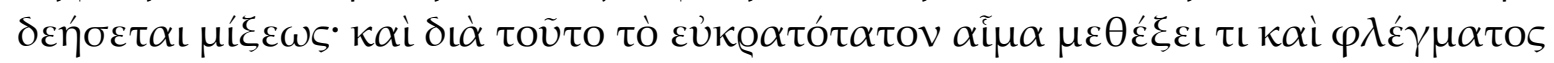

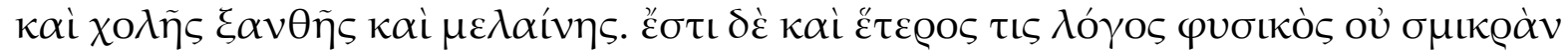

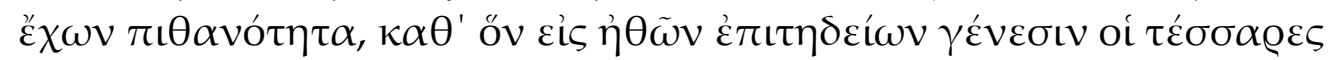

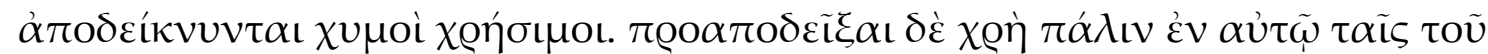

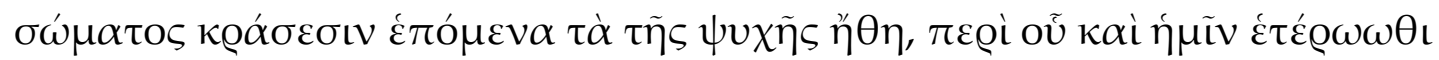
$\gamma \varepsilon \dot{\gamma} \varrho \alpha \pi \tau \alpha \mathrm{L}^{\prime}{ }^{45}$

'But since, then, blood too itself requires the four qualities (wet, dry, hot and cold), it is clear that it will also require a mixture of the other humours. So for this reason the most well-tempered blood will have a share to some extent of phlegm, and of yellow and black bile. There is also another physical account which has no little plausibility, according to which the four humours are proved to be effective in the generation of the states of character which are appropriate to them. In it we first need to establish that the states of character of the soul are consequent upon the mixtures of the body, about which we have written elsewhere.' (tr. Hankinson)

The qualities mix to form humours, the basic building blocks of the constitution of man, and the humours, in turn, are instrumental in the formation of character traits, which follow upon the specific mixture formed by the qualities. Thus, in this passage, with reference to $Q A M$, we notice how the more simple level of physical composition does not only determine the more complex level of physical composition, but also the 'psychic' category of character.

In On the Natural Faculties (Nat. Fac.) Galen also elaborates on the two phases of composition, describing how both come to be through different capacities of nature:

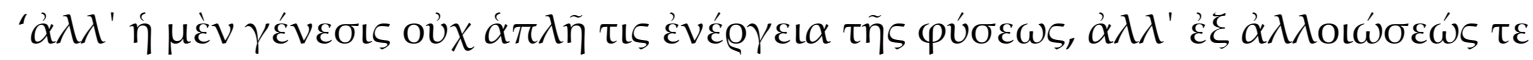

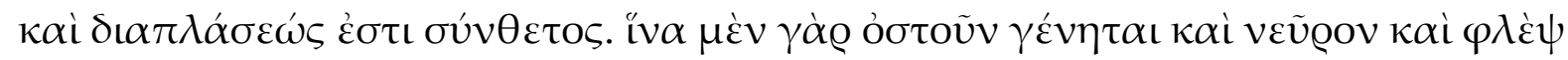

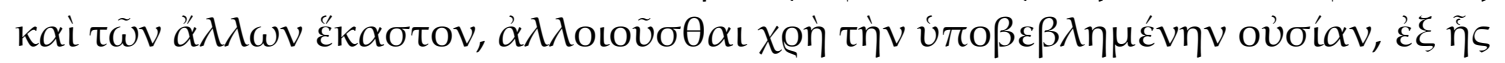

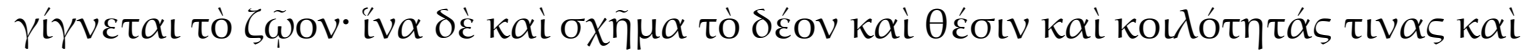

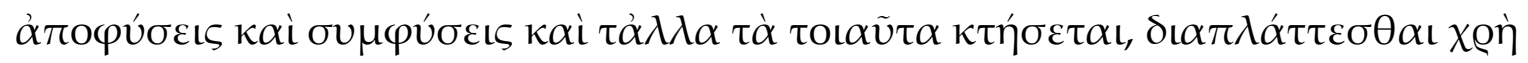

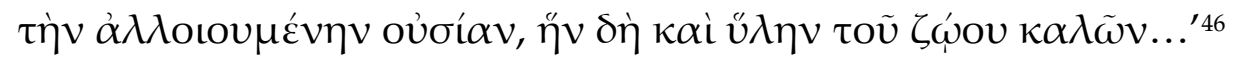

\footnotetext{
${ }^{45}$ HNH 51,6-13 Mewaldt (XV $97 \mathrm{~K}$ )

${ }^{46}$ Nat. Fac. II 10-1 K
} 
'Generation, however, is not a simple activity of Nature, but is compounded of alteration and of shaping. That is to say, in order that bone, nerve, veins, and all other parts may come into being, the underlying substance from which the animal comes to be must be altered; and in order that the substance so altered (which we also call the material of the animal) may acquire its appropriate shape and position, its cavities, outgrowths, attachments, and so forth, it needs to be shaped.' (tr. Brock, modified)

These two capacities of nature involved in the genesis of beings correspond to the two compositional phases of homoeomerous and anhomoeomerous parts. The homoeomerous substances, such as bone, nerve and veins, come to be because of a mixing of the qualities in an underlying substance and subsequently require the right shape and position within the body, as well as the proper connections to other parts. The first stage is conceived as a capacity of nature described as generative and alterative:

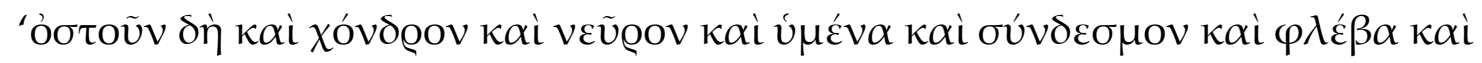

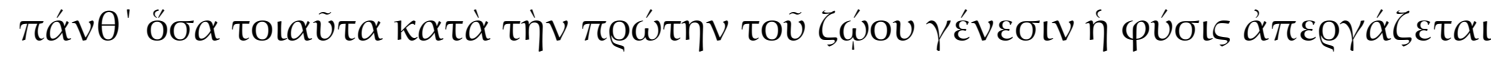

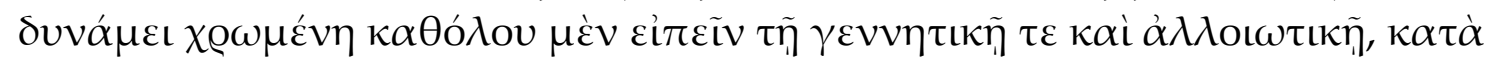

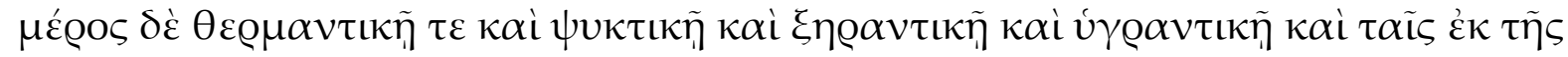

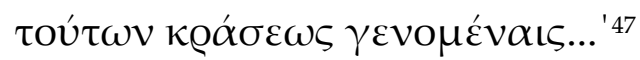

'Now Nature constructs bone, cartilage, nerve, membrane, ligament, vein, and so forth, at the first stage of the animal's generation, using a power which is, in general terms, generative and alterative, and, in more detail, warming, chilling, drying, or moistening; or such as spring from the blending of these...' (tr. Brock, modified)

Notably, Galen adds that the particular flesh ( $\dot{\eta} i \delta i \alpha \sigma \dot{\alpha} \varrho \xi)$ of the organs, such as the

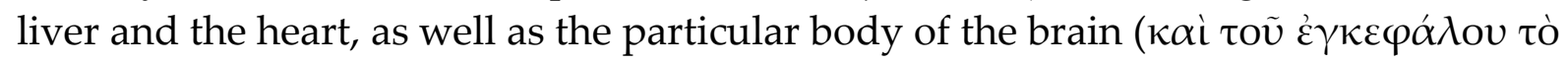
isıov $\sigma \tilde{\omega} \mu \alpha$ ) are also of this kind. Thus, we can deduct from this passage that the three main organs, which are the seats of the soul, are made up of homoeomerous bodies generated by nature's mixing of the elemental qualities. This substance, explains Galen, is something entirely peculiar to the specific organ..$^{48}$ The second phase, the construction of anhomoeomerous bodies through the combination of homoeomerous ones, is effected by the 'shaping' capacity:

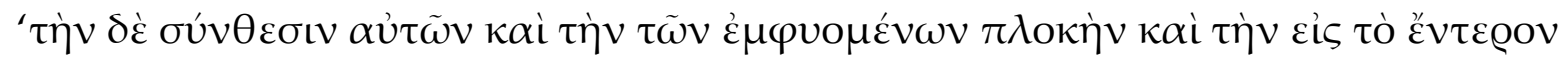
Ěk

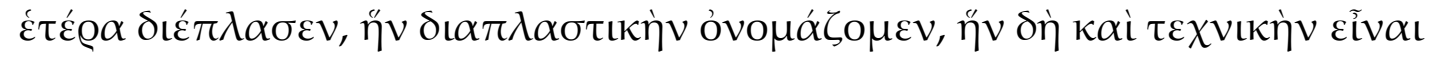
$\lambda \dot{\gamma} \gamma \mathrm{O} \mu \varepsilon . . .{ }^{\prime}{ }^{4}$

\footnotetext{
${ }^{47}$ Nat. Fac. II 12-3 K

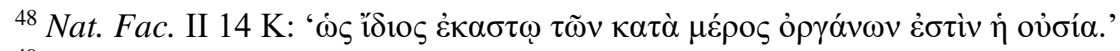

${ }^{49}$ Nat. Fac. II $15 \mathrm{~K}$
} 
'... while the bringing of these together, the combination therewith of the structures which are inserted into them, the outgrowth into the intestine, the shape of the inner cavities, and the like, have all been determined by a power which we call the shaping or formative power; this power we also state to be artistic...' (tr. Brock, modified)

The shaping power puts the homoeomerous parts together in such a manner that complex beings capable of exercising particular functions arise. This is the power Galen praises throughout $U P$ and which will be known in later tradition as the

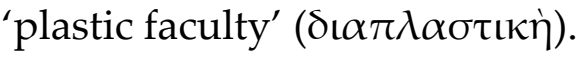

Galen describes both of these phases of generation as capacities of the same nature. Since this nature is wise, that is to say, since it operates according to a certain systematic teleology, the exercise of these two respective capacities would logically require a sufficient extent of coordination. The exercise of the first capacity must already anticipate the second..$^{50}$ In $Q A M$, both of these capacities of nature, are considered as causes for the formation of the human body. Through the first, nature manifests itself as cause of the generation of homoeomerous bodies, through the second, as cause of the shaping of organs and their interconnections.

But why, we may ask, is Galen so preoccupied with elaborating such a hierarchy of parts of our body? This is because he assumes that the simplest parts of our body hold the key to the question of our nature. Here we have to bring to mind a passage from the beginning of Hipp. Elem.:

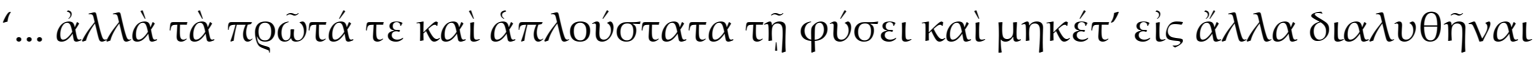

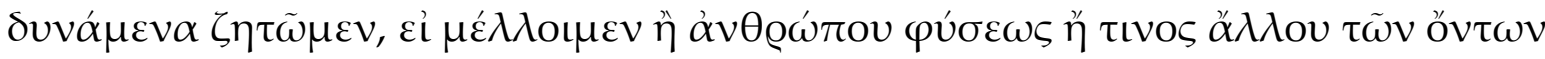
$\dot{\varepsilon} \pi \iota \tau \tau \dot{\mu} \mu \eta \dot{\alpha} \kappa \varrho \iota \beta \tilde{\eta} \lambda \dot{\eta} \psi \varepsilon \sigma \theta \alpha \iota^{\prime}{ }^{51}$

'... but let us find the parts that are first and simplest by nature and that are no longer capable of being dissolved into other parts, if we are to obtain precise knowledge of the nature of man or any other being.' (tr. De Lacy, slightly modified)

Apparently, Galen assumes that knowledge of the nature of any being can only be obtained by analysis of its smallest parts. Therefore, an investigation into the nature of man, or whatever other entity, would have to take the form of a structural analysis of its component parts. ${ }^{52}$ This becomes particularly relevant when we remember the

\footnotetext{
${ }^{50}$ It has been suggested by Havrda (2017) that the the first capacity, the alterative one, arises from the mixture and has a certain randomness to it, while the latter arises from nature and is intelligent. The problem with this view, however, is that it would lead to a completely paradoxical view of nature, since Galen clearly states that both of these capacities are capacities of nature (thus nature, in its generative activity, would have to be intelligent on the one hand and random on the other). The correct view, in my opinion, is that the alterative capacity does not arise only from the mixture, but is exercised by nature in the particular mixing of the qualities of which the mixture is a result. This is in line with the text quoted from Nat. Fac. above where the chilling, heating, moistening and drying are presented as specifications of the alterative capacity of nature. That is to say, the mixture is already a result of intelligent nature, and as such is not random (for, as Galen often asks, how could some random mixing process form beings such as those we observe?).

${ }^{51}$ Hipp. Elem. 58,2-5 De Lacy (I 414-5 K)

52 This is also the general tendency of $H N H$, where this method is presented by Galen as that of Hippocrates and Plato, through the repeated reference to Phaedrus 270C-D, see infra CS II sections 2 and 5, 105-12 and 130-7.
} 
identification of nature and substance in QAM referred to earlier: Galen stated that the words nature and substance mean the same in 'these kind of discussions' ( $\tau$ où

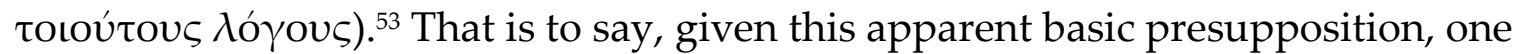
would expect the question for the nature or substance of the human soul in $Q A M$ to also take the direction of an analysis of the smallest elements of man's constitution, and in fact, given the hylomorphic outline: of an analysis of the formal aspect of the most elemental body. And as we shall see, that is exactly the direction Galen takes, identifying as the substance of the soul the second of the two presented options, namely the mixture of elemental qualities that generates homoeomerous bodies.

\section{c. The homoeomerous bodies as primarily active}

Basically, Galen's question now is whether we should look for the soul on a macroor a more micro-level of the formal organisation of our bodies. When we bear the quoted passage from Hipp. Elem. in mind, it is not surprising that Galen's choice falls on the micro-level. The answer to the question of the nature or substance of a being must be sought in its smallest parts, after all. He adds however:

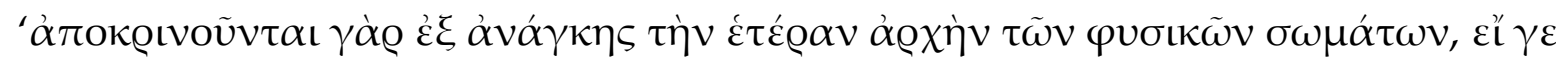

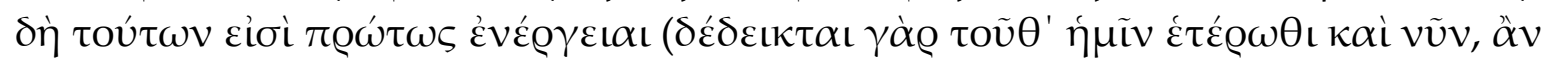

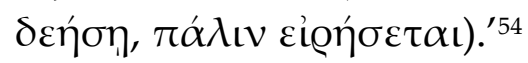

'For they [Aristotle and his followers] have to answer, necessarily, that it [the form of the soul] is the other principle of the natural bodies - since, indeed, to these the activities primarily belong (this has been shown by us elsewhere, and will be stated again now, if you require).' (tr. Singer, modified)

Galen's justification for the choice in favour of the micro-level of our composition is that the 'activities' primarily belong to this level. What does this mean? It may seem striking that the activity of our soul would primarily take place at the level of the elemental mixture that forms the homoeomerous body. In fact, it seems even more striking from an Aristotelian perspective, since it is stated in Aristotle's work that the homoeomerous parts are for the sake of the anhomoeomerous ones exactly because actions and functions belong to the latter. ${ }^{55}$ Again, Galen is presupposing a lot of his own doctrine, and he now simply states that he has already explained this elsewhere. Singer notes that there is a parallel for the notion that the activities primarily belong to the homoeomerous bodies in Loc. Aff., where the same compositional hierarchy of

\footnotetext{
${ }^{53}$ See also further in Hipp. Elem. itself, 136,1-3 De Lacy (I $488 \mathrm{~K}$ ), where Galen remarks that it doesn't matter whether the treatise is called 'On the elements', 'On nature' or 'On substance'.

${ }^{54}$ QAM 37,12-15 Müller (IV $774 \mathrm{~K}$ )

${ }^{55}$ Aristotle, PA II, 646b10 f.; the fact that this is such a strange choice from an Aristotelian perspective seems to make a case against Singer's suggestion (2013, introduction and notes ad locum) that Galen is here simply presenting Aristotelian doctrine, rather than his own.
} 
man's constitution appears as well, and where we find references to QAM. ${ }^{56}$ Unfortunately, however, the explanation remains missing there also, although it is clear that in this context Galen is speaking about the powers of the rational soul. The passage is about affections of the rational soul that damage the power of reasoning and memory. These affections are caused by a humoral imbalance (i.e. finally by an imbalance of the elemental qualities), which affects the homoeomerous parts of the brain, which 'primarily act'. In this passage, Galen explains affections of the rational soul, such as lethargy, in terms of the homoeomerous bodies of the brain being affected by too much coldness or wetness.

There is another useful passage in this regard in Nat. Fac., in the same context as the quotations above on the generative and shaping powers of nature. In this passage, Galen explains how each animal has as many alterative powers ( $\dot{\alpha} \lambda \lambda \operatorname{ot} \omega \tau \iota \kappa \dot{\alpha} \varsigma$

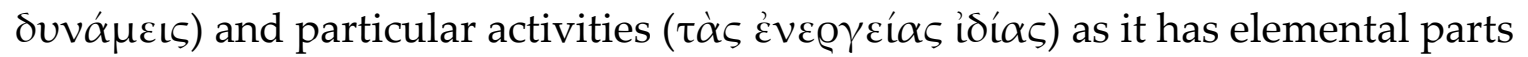
$\left(\sigma \tau о\llcorner\chi \varepsilon \iota \omega \delta \delta \eta \mu o ́ \varrho \iota \alpha) .{ }^{57} \mathrm{He}\right.$ says this in the context of a discussion of homoeomerous parts, and it is clear from the preceding text that these elemental parts must refer to homoeomerous parts (also defined as $\alpha \hat{\imath} \sigma \theta \eta \tau \dot{\alpha} \sigma \tau o \iota \chi \varepsilon \tilde{\varepsilon} \alpha) .{ }^{58}$ Therefore, what he seems to imply here, as well as in the passages from $Q A M$ and Loc. Aff. discussed above, is that each of the homoeomerous parts exercises a particular function in a primary fashion, so that, for example, the activities of the brain, which are the activities of the rational part of the soul, are each primarily exercised by particular homoeomerous bodies in the organ of the brain.

We find more evidence of this privileged role of the homoeomerous bodies when it comes to the substance and activities of our functions in other works as well. In Opt. Corp. Const., Galen asks what the best constitution of our bodies is. He refers to Hipp. Elem. and Temp., and presupposes the theoretical framework which he has developed there. ${ }^{59}$ The question turns out to be whether the micro-level of the composition of homoeomerous bodies or rather the macro-level of organic composition is responsible for the optimal constitution. In the end, the answer is that both are indispensable. As in $Q A M$, both levels of composition are considered to be causes for our functioning, though not in exactly the same manner:

‘

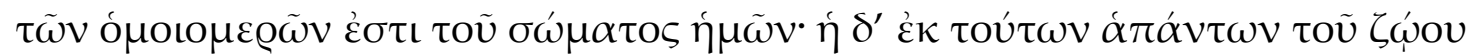

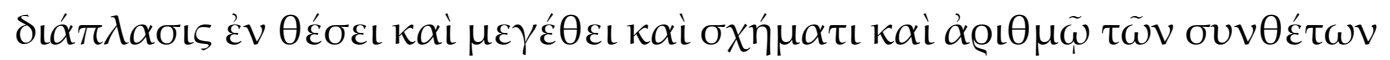

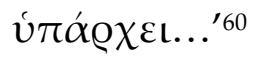

'For a healthy state of our body consists in a well proportioned mixture of the homoeomerous parts out of the hot, cold, dry, and wet, but the shaping of the animal from all of these [parts] consists in the position, magnitude, configuration and

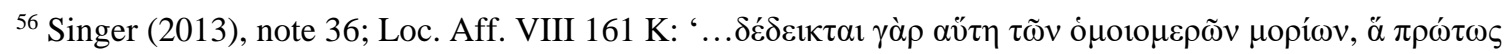

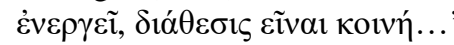

${ }^{57} \mathrm{Cf}$. Hankinson (2014a) 961 for discussion of this passage

${ }^{58}$ Nat. Fac. II 12-14 K

${ }^{59}$ Opt. Corp. Const. IV $741 \mathrm{~K}$

${ }^{60}$ Opt. Corp. Const. IV. 737-8 K
} 
number of the component elements.'

Clearly, the second level of composition is described in quantitative and spatial terms. Once the homoeomerous parts themselves are constituted through a specific mixture of the various qualities, at the second compositional level it is about how these parts relate to each other in terms of position, magnitude, configuration and number. ${ }^{61}$ In UP, these characteristics of the second stage of composition are called accidental, as opposed to the mixture of the elemental qualities, which forms the

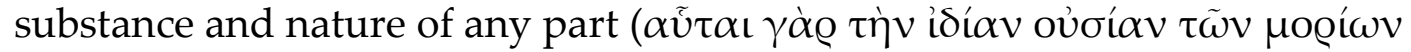
$\sigma v \mu \pi \lambda \eta \emptyset 0 \tilde{v} \sigma \iota v) .{ }^{62}$ First, Galen mentions how there are secondary qualities such as

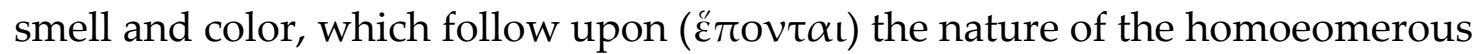
bodies (which nature properly consists in the mixture of the four elemental qualities). Then, he adds that other things also result or follow of necessity ( $\varepsilon \tau_{\varepsilon} \alpha \alpha \delta^{\prime} \dot{\varepsilon} \xi$ $\dot{\alpha} v \alpha \dot{\gamma} \kappa \eta \varsigma \sigma v \mu \beta \varepsilon \dot{\beta} \eta \kappa \varepsilon)$, namely position, magnitude, structure and shape ( $\theta \dot{\varepsilon} \sigma \iota \varsigma \kappa \alpha i$

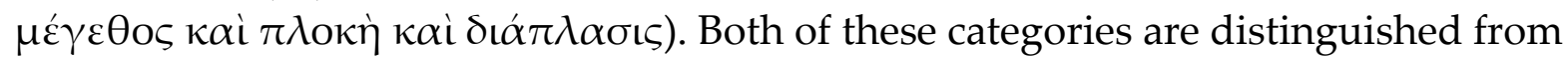
that of the mixture that constitutes the homoeomerous bodies, as secondary features that follow upon the mixture itself. ${ }^{63}$ A few lines further, he describes how, when one wants to determine the usefulness of a body part, one needs to first look at its particular activity, which is in most cases derived from its peculiar substance (i $\delta$ í $\alpha$ oú $\left.{ }^{\prime} \alpha\right)$. This clearly refers back to the mixture of the homoeomerous parts. Then, one

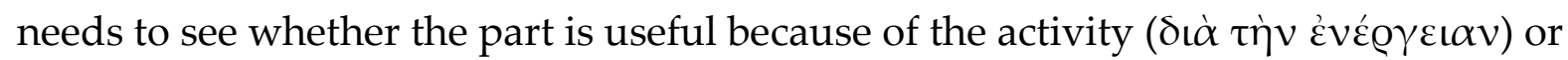

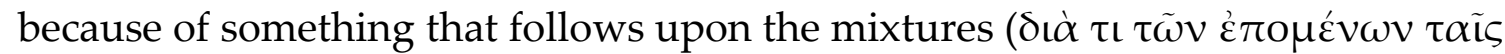
$@ \alpha ́ \alpha \varepsilon \sigma \mathrm{v})$. Again, the implication is that the activity belongs primarily to the mixture itself. Finally, one needs to look at each of the accidental attributes ( $\tau \tilde{\omega} \nu \sigma v \mu \beta \varepsilon \beta \eta \kappa o ́ \tau \omega \nu)$, which Galen again specifies as position, size, structure and shape.

All of this corresponds to what Galen does in $Q A M$, where he refers to the particular

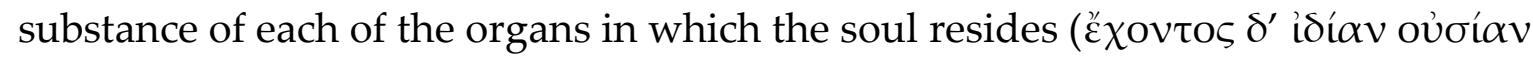
$\dot{\varepsilon} \kappa \alpha \tau \varepsilon \dot{\varepsilon} \operatorname{lov} \tau \tilde{\omega} \nu \sigma \pi \lambda \dot{\alpha} \gamma \chi \nu \omega \nu)$. The elemental qualities make up the substance and nature of a part (e.g. one of the organs in which the soul resides) and determine its activities. We find the same idea in another passage from Opt. Corp. Const., where Galen asks about the substance (ov́rí $\alpha$ ) of the body when it is functioning at its best. He refers to Hipp. Elem., Temp. and UP and gives a similar distinction between organs and their constituent parts with regard to activities, as the one we saw above:

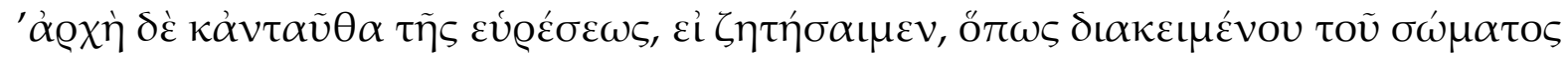

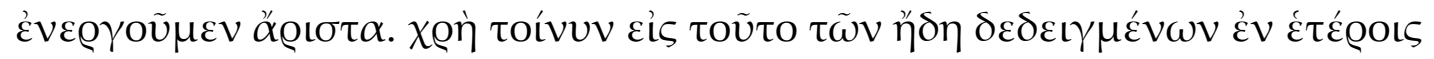

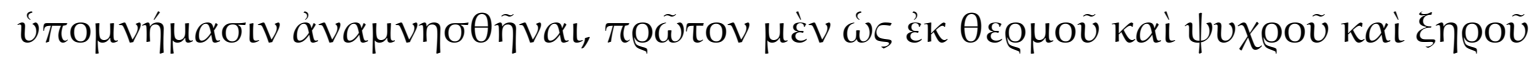

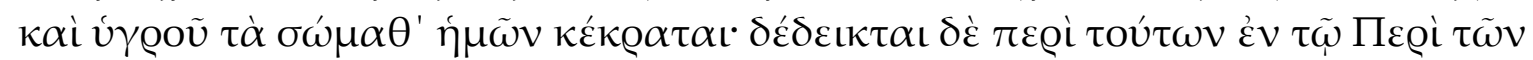

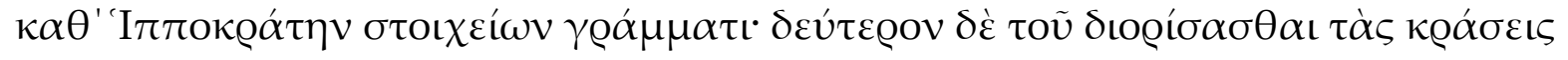

\footnotetext{
${ }^{61}$ In The Art of Medicine I $312 \mathrm{~K}$, the distinction is described in similar terms.

${ }^{62}$ UP 18-9 Helmreich (III 26-7 K)

${ }^{63}$ Cf. Hankinson (2014a) $959 \mathrm{f}$.
} 


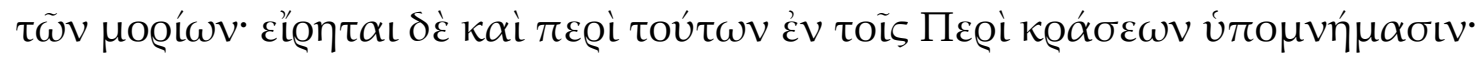

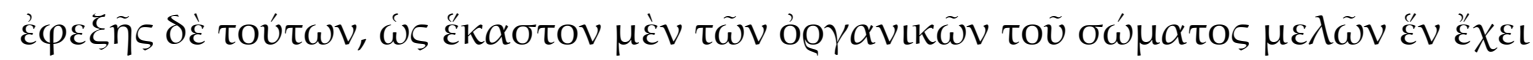

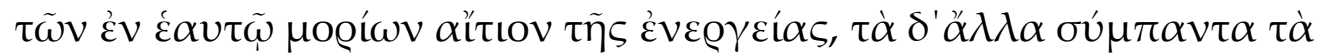

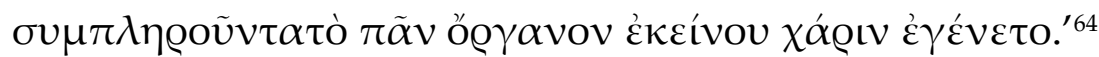

'And here the starting-point of our enquiry must be the investigation as to what is the constitution of the body at the time when our functioning is at its best. Now at this point we must make reference to matters which have been demonstrated previously in other works. First, that our bodies are a mixture of hot, cold, dry and wet. This was shown in our treatise on The elements according to Hippocrates. Secondly, that one must distinguish between the mixtures of different parts - as discussed in our work on Mixtures. The next point is that each of the organic parts of the body has one cause of activity from the parts that it has in itself; and everything else that goes to make up that organ as a whole comes into being in accordance with that purpose.' (tr. Singer, modified)

The cause of activity from the parts within the organ must refer to the homoeomerous bodies. We cannot assume that each organ as a whole has one activity - that would not make sense as most organs have many different activities according to Galen. So what must be meant here is, again, that each of the activities of the organ has a single cause deriving from the homoeomerous bodies the organ has within itself. Thus, this cause of activity, located 'in' the organs, is not a separate immaterial substance of any kind but rather the formal aspect of the most elemental level of composition, namely, the specific mixture of elemental qualities that forms the homoeomerous part, which is said to be primarily active. ${ }^{65}$

It is at this micro-level of composition that qualitative change is generated and the conditions for the activities of the soul, such as perception, are created, because Galen views the elemental qualities as a kind of primary agents of activity and change:

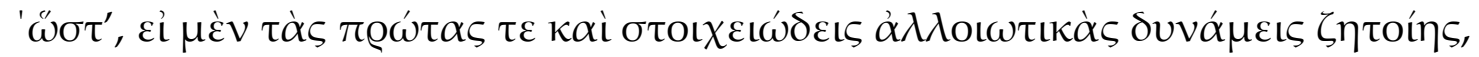

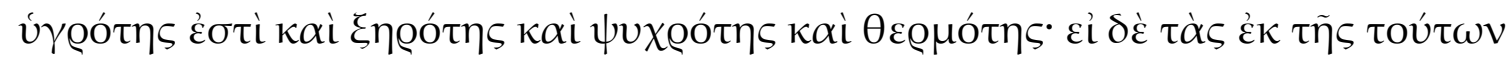

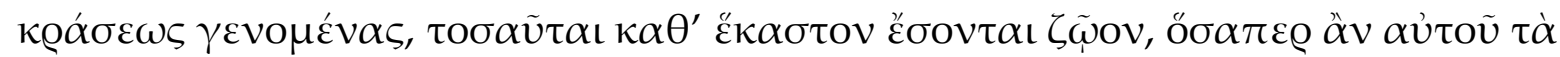

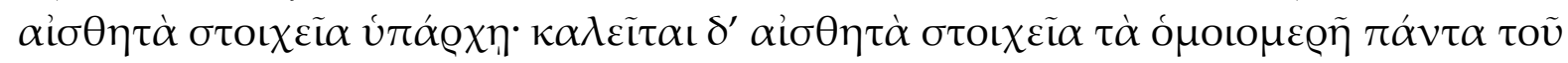

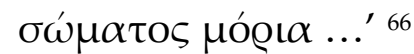

'Therefore, if you wish to inquire into which alterative powers are primary and elementary, these are moisture, dryness, coldness, and warmth, and if you wish to inquire into the things that arise from the mixture of these, there will be so many of these in each animal as it has perceptible elements. The name perceptible elements is given to all the homoeomerous parts of the body.' (tr. Brock, modified)

\footnotetext{
${ }^{64}$ Opt. Corp. Const. IV $741 \mathrm{~K}$

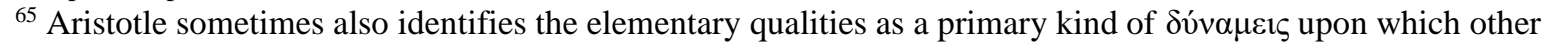
qualities are dependent, see Kupreeva (2014) 160 f. with reference to PA II,1 646a13-24 and GC 2,1-3

${ }^{66}$ Nat. Fac. II $12 \mathrm{~K}$
} 
The qualities are described here as $\delta v v \alpha \dot{\mu} \mu \varepsilon \varsigma$ in the primary sense, the primary and elementary forces of change. They act upon each other and constitute an interactive relation of mutual change that is the fundamental condition for all human functions. Another passage in which this notion comes to the fore can be found in Method of Medicine (MM), again in combination with the notion that each homoeomerous part exercises one activity:

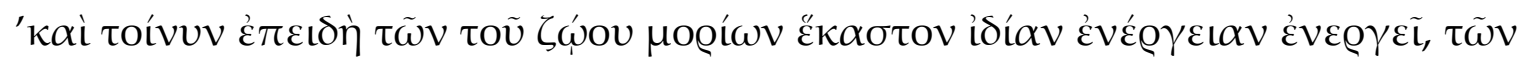

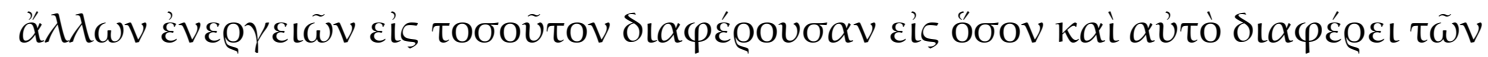

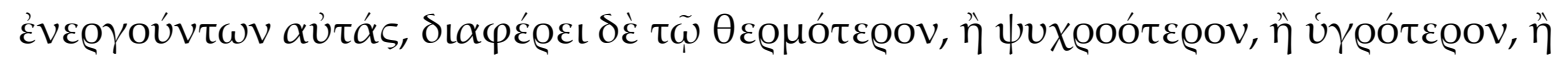

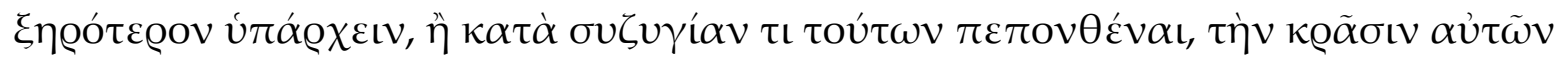

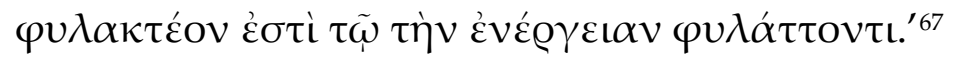

'Therefore, when each of the parts of the organism performs a particular activity, which differs from other activities to the extent that the part itself differs from those parts that perform those activities - that is, differs by being hotter, colder, moister, or drier, or by being affected in terms of a conjunction of these [qualities] - you must preserve their activity by preserving their mixture.' (tr. Johnston and Horsley, modified)

The parts Galen is referring to here are, again, homoeomerous parts, as is clear from the immediate context. Shortly before this passage, he states that he shall return to the discussion of the disease that befalls the homoeomerous parts, 'to which the

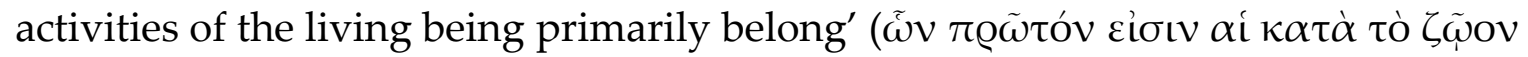
$\dot{\varepsilon} v \varepsilon \dot{Q} \gamma \varepsilon(\alpha \mathrm{l}) .{ }^{68}$ The activity of a given homoeomerous part of the body differs from the activity of other parts to the extent that the substances of these parts respectively differ, that is to say, to the extent that they differ in their mixture of the four elemental qualities. Again, we find that the at first suprising choice for the homoeomerous bodies as location of the soul in $Q A M$, based on the seemingly vague remark that 'the activities primarily belong there', has an extensive basis in Galen's other works. ${ }^{69}$

Galen grounds the very possibility of activity in this most fundamental level. In Hipp. Elem., he emphasizes that qualitative difference is a necessary condition for the functions of the soul, indeed for the very existence of the soul. There, he argues that perception can only arise in a body if we assume that the four elemental qualities that make up the body are 'changed and mixed and altered through and through'

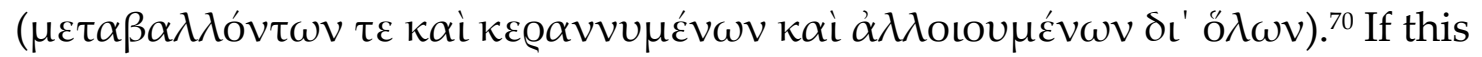
interaction of various qualities at the most micro-level would not take place, there would be a completely static situation, change and difference (such as there is

\footnotetext{
${ }^{67} M M \mathrm{X} 463 \mathrm{~K}$

${ }^{68} M M \mathrm{X} 459 \mathrm{~K}$, he returns to this in $464 \mathrm{~K}$ as well

${ }^{69}$ To sum up some of the passages referred to above: QAM 37,12-15 Müller (IV $774 \mathrm{~K}$ ); Loc. Aff. VIII $161 \mathrm{~K}$; Nat. Fac. II 12-4 K; MM X 459 and 463-4 K

${ }^{70}$ Hipp. Elem. 72,24 f. De Lacy (I 430-2 K)
} 
between all the various beings) would not be possible and therefore none of the capacities of the soul could exist. This is closely related to one of the objections Galen habitually makes to the atomists: if they assume only one kind of basic substance, they cannot explain perception and pain, because these are processes that assume qualitative difference. This qualitative difference is provided when we assume these four different elemental qualities that can interact with each other and change their substance. ${ }^{71}$

It seems that this most fundamental level of activity itself takes place beyond the realm of perception - or rather: before it, since it is more elementary. Both of the two

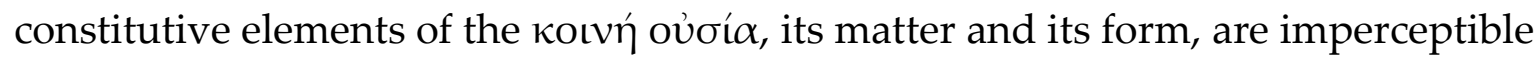
by themselves. So, according to Galen, often hailed for his empirical stance in philosophical matters, everything in the entire cosmos is made up of and even governed by these two principles that each cannot exist by themselves and for the individual existence of which there can be no direct empirical proof. ${ }^{72}$ The realm of perception is entered only after the combination of this primary form and matter into a homoeomerous body, therefore called a 'perceptible element' by Galen. ${ }^{73}$ However, Galen does give some empirical justification for his choice of these particular elemental qualities:

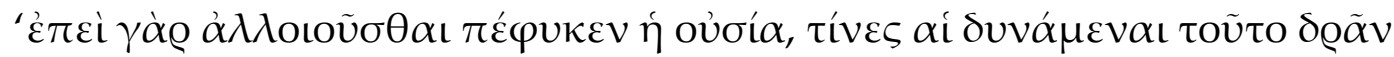

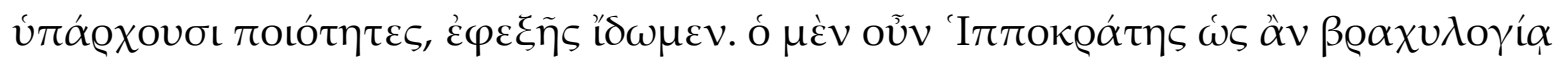

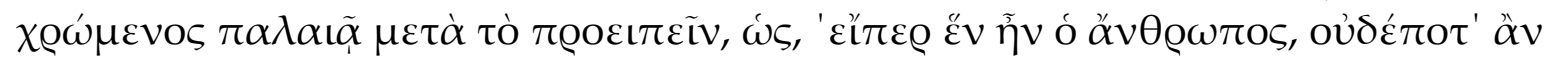

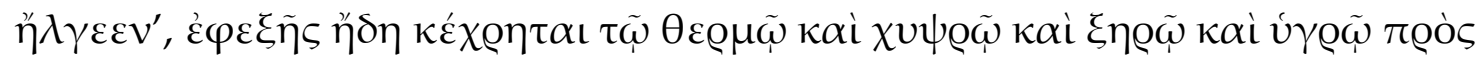

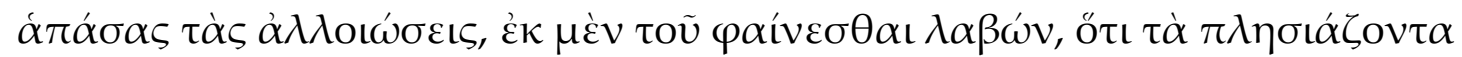

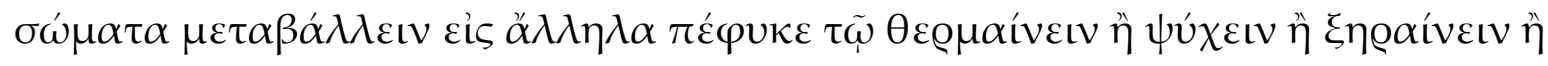

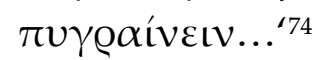

'Since it is the nature of substance to be altered, let us next see what the qualities are that can do this. Hippocrates, as one who employed the ancient brevity of expression, after first saying that 'if man were one he would never feel pain', immediately thereafter used hot, cold, dry, and wet for all the alterations; he took from observation the fact that it is the nature of neighboring bodies to undergo mutual change by heating, cooling, drying, or wetting.' (tr. De Lacy)

\footnotetext{
${ }^{71}$ See note 70 above, also 72,16: 'Shapes produce shapes and smaller magnitudes produce larger ones, but shapes do not produce magnitudes or magnitudes shapes, and for that reason it cannot be allowed that something different in kind is generated from elements that do not change their qualities; but it can be allowed from elements that do change them. For it is possible that in the course of many intervening changes what was formerly black may in turn become white and what was formerly white may in turn become black and what is now insentient may in turn become sentient.' (tr. De Lacy) Note here the correspondence in the examples of magnitude, shape and color with the previous passages which we quoted earlier. Cf. Hankinson (2014a) $967 \mathrm{f}$. ${ }^{72}$ Cf. PHP VIII 502,19-21 De Lacy (V 676 K): 'For the qualities are in the body potentially, not in actuality; in actuality are rather the things generated from the qualities by means of nutriment: blood, phlegm, yellow and black bile.' (tr. De Lacy)

${ }^{73}$ Besides the quotation above from Nat. Fac. II 12 K, cf. also Nat. Fac. II 213 K; Hipp. Elem. 126,1-2 (I 479 K)

${ }^{74}$ Hipp. Elem. 128,23-129,4 De Lacy (I 483 K)
} 
As Jim Hankinson observes, the reason for Galen to choose these elemental qualities is because they are the only ones 'which are such as to be capable of transmitting themselves from a body which possesses them in actuality to one which does not (but which is capable of receiving them) purely by contact. ${ }^{75}$

We have seen that the activities of the more complex parts of our constitution including the organs in which the various parts of the soul reside - are dependent on the activities of the more elemental ones, and that this is the reason why Galen could say that the most elemental bodies (the homoeomerous ones) are primarily active. We may add some further proof to this important notion. The dependence of all parts of the body on the mixture of the elementary qualities also becomes manifest in the case of the activities being damaged. If the mixture is of a bad quality, the organs are not able to perform their basic acitivities, while, if they are of good quality, their activities are performed well:

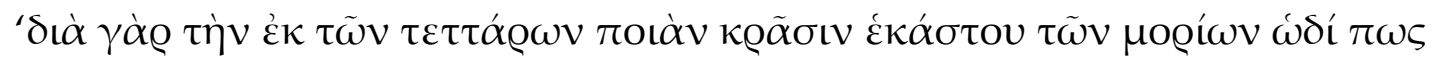

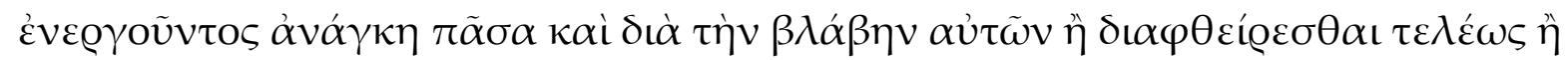

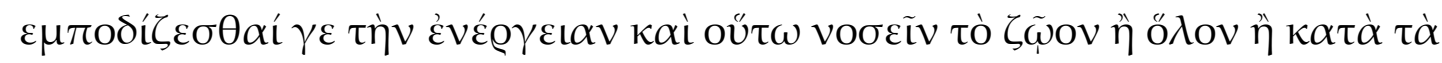
$\mu$ óot $\alpha .{ }^{76}$

'For, since each part functions such as it does because of the specific mixture of the four [qualities], it is absolutely necessary that through damage of these qualities the activity is either completely destroyed or at least impeded, and that this is how the animal becomes sick either as a whole or with respect to certain parts.'

All activities of living beings are eventually dependent on the mixture of the elemental qualities that form their most basic components. The capacities of the parts that exercise our functions and activities are decided on this micro-level, because that is where quality resides. Galen is quite clear that this goes for every part of the human body that fulfils any particular function:

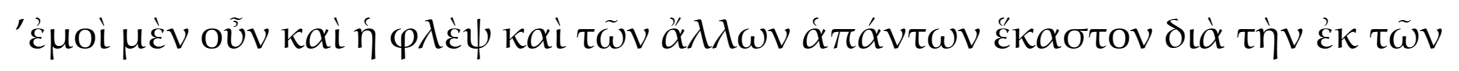

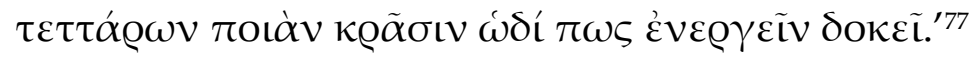

'Thus, it seems to me that the vein, and each of all the other [parts] as well, functions such as it does because of the specific mixture of the four [elemental qualities].'

Again, 'each of all the other parts' must include the three main organs in which the three parts of the soul reside and that are also made up of mixtures. That is to say, the functioning of the liver, heart and brain, 'in' which the respective parts of the soul

\footnotetext{
${ }^{75}$ Hankinson (2017)

${ }^{76}$ Nat. Fac. II $118 \mathrm{~K}$; cf. also, e.g., 126-7 K: the cause of the functioning of any organ is eukrasia, the activity

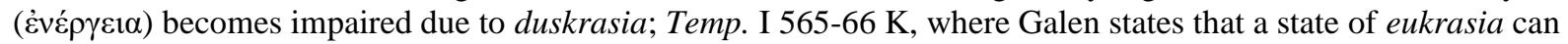
be inferred from the observation of optimal performance of activities, such as intelligence.

${ }^{77}$ Nat. Fac. II $7 \mathrm{~K}$
} 
reside, is determined by the specific mixture of its component homoeomerous parts, which are primarily active.

Another interesting passage in this regard can be found in the discussion of melancholy in Loc. Aff. book III, chapters 9 and $10 .{ }^{78}$ In the ninth chapter, Galen states

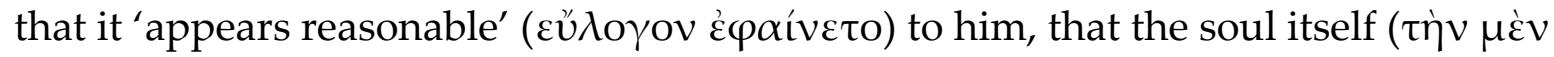

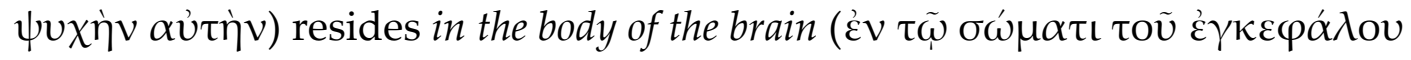
$\kappa \alpha \tau \omega \kappa \tilde{\eta} \sigma \theta \alpha \mathrm{\iota})$, where thinking and memory is located..$^{79}$ In the tenth chapter, when he discusses melancholy of the brain, he differentiates between the brain being affected

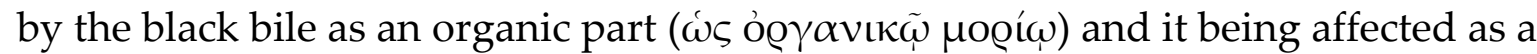
homoeomerous part ( $\omega \varsigma$ ó ${ }^{\prime}$ one presented in its title, and the stronger one of the soul actually being a mixture:

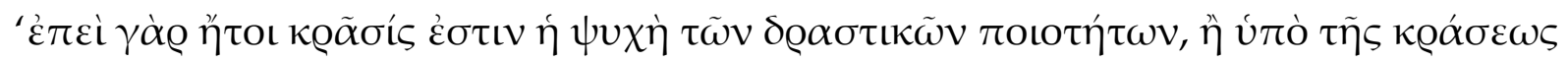

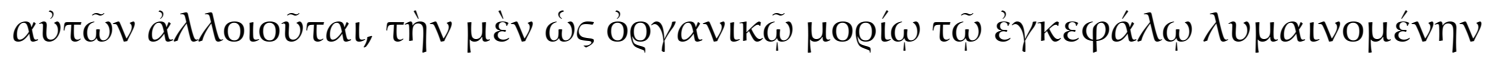

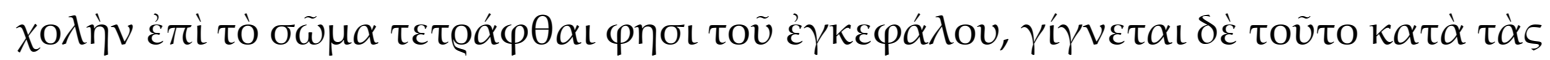

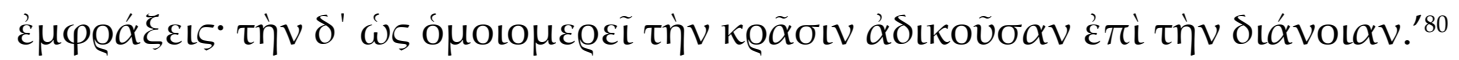
'Since the soul either is a mixture of the active qualities, or is altered by the mixture of these qualities, he [Hippocrates] says that the bile damaging the brain as an organic part affects the body of the brain, and this happens through stoppages; but the bile that damages the mixture as a homoeomerous part, affects the mind.'

The relation with $Q A M$ is clear, and at the end of chapter 10 Galen makes it explicit himself, saying that in that particular work he has demonstrated ( $\dot{\varepsilon} \mu$ oi $\alpha \dot{\pi} \pi \delta \varepsilon \dot{\delta} \delta \varepsilon \kappa \tau \alpha \iota)$ that the humours and generally the mixture of the body alters the activity of the soul. And here the division between organic and homoeomerous parts of the brain corresponds to the division of the body of the brain and the mind respectively. When the brain is damaged as a homoeomerous part, the rational soul itself ( $\left.\delta \iota^{\alpha} v o \iota \alpha\right)$ is affected, whereas, when the brain is affected as an organic part, the body of the brain

\footnotetext{
${ }^{78}$ Black bile and melancholy in Galen are the subject of CS IV, 199-288 infra

${ }^{79}$ De Loc. Aff. VIII $175 \mathrm{~K}$

${ }^{80}$ De Loc. Aff. VIII181 K; cf. Symp. Caus. VII $221 \mathrm{~K}$, where there is the same distinction between two kinds of affections and 'dyskrasia' is said to bring about a 'weakened capacity', while 'organic diseases' are said to 'narrow the passages'; note that Galen here adds the adiective ' $\delta \rho \alpha \sigma \tau ו \kappa \tilde{\omega} v$ ' to the qualities, which he does more

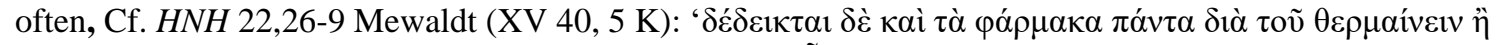

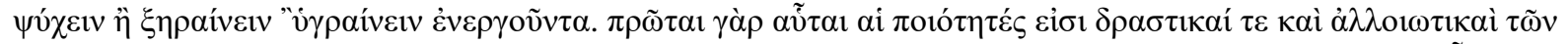

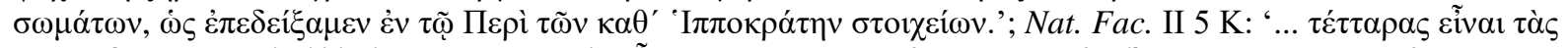

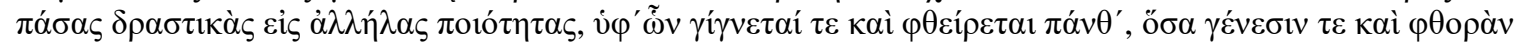

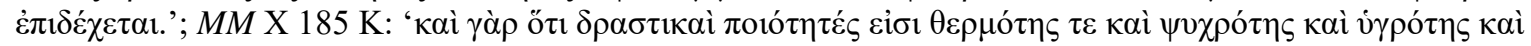

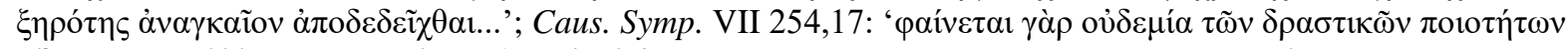

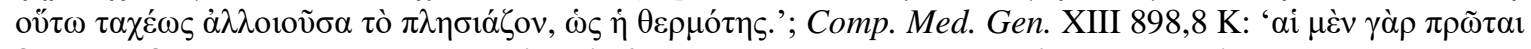

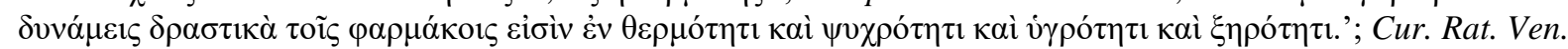

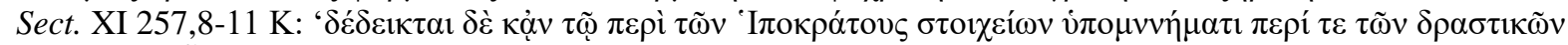

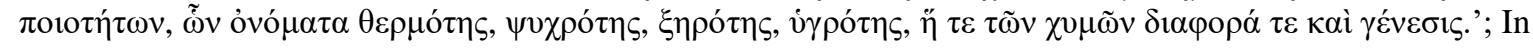
some cases, though (e.g. De Semine 184,9-11 De Lacy (IV $631 \mathrm{~K}$ ); MM X $470 \mathrm{~K}$ ), the adiective serves the purpose of singling out the qualities of warm and cold, rather than referring to all four; in this schema, moistness and dryness are considered the 'more material' (ì $\lambda \iota \omega \omega \tau \dot{\varepsilon} \rho \alpha \imath)$ qualities. In Fr II of Galen's Timaeus commentary (edition Schröder, 1934), he calls earth and water the more material of the elements, fire and pneuma the more active.
} 
is affected. Therefore, again, when Galen says in QAM that the soul resides in the organ, there is no need for us to assume that he is referring to anything other than the formal aspect of the homoeomerous part of the brain: its specific substance composed from the mixture of the elemental qualities that is inside the organic part that forms the 'body' of the brain.

In another passage earlier in Loc. Aff., Galen distinguishes two views on the soul and its relation to the body: some of the philosophers say that the soul is in its surrounding body as we are in a house; others say that the soul is the form of the body and as such inseparable from it. Galen, as often, is not too explicit on his preferences, but it is clear from this passage that he finds the latter view more appealing because it is better able to explain why the rational capacities are altered when the substance of the brain is altered. ${ }^{81}$ After all, what he proceeds to do in the following book of Loc. Aff., is to show how various affections of the rational soul, such as lethargy, phrenitis or melancholy, are caused by alterations in the mixture of the brain in terms of the humours and elemental qualities (or by alterations in another body part, in the case of an affection through sympathy). Likewise, at the beginning of $Q A M$, Galen states that the philosophers did not properly understand the notion of capacity ( $\delta \dot{v} v \alpha \mu \iota \varsigma$ ) in their discussions of the substance of the soul, since they apparently thought that these capacities are some kind of objects inhabiting their substances in the same way we inhabit houses. ${ }^{82}$

We can see now, how the capacities of the soul depend on the mixture of the body in the most fundamental sense possible: the kind of activity a living being can exercise is determined by the way the elemental qualities interact and form its homoeomerous bodies; these homoeomerous bodies exercise the activities in a primary sense and are, in turn, part of the organs as the locations from where these functions are exercised.

Now that we know why the activity must primarily ( $\pi \varrho \omega \tau \omega \varsigma)$ belong to the level of the homoeomerous bodies, we can take our findings back to the argument of $Q A M$. It is now much less surprising, I hope, to understand why Galen concludes that the soul as form of the body must be identified with the mixtures of elemental qualities, since these are the causes of the capacities, functions or activities of a specific living being.

\section{d. The substance of the soul as mixture}

After Galen decides that soul as form of the body must be located at the level of the homoeomerous bodies because these are primarily active, he concludes the following:

\footnotetext{
${ }^{81}$ Loc. Aff. VIII 127-8 K

${ }^{82}$ QAM 33,17 f. Müller (IV 769 K); cf. Hankinson (2006) 242 f. and (2014a) 965 f.
} 


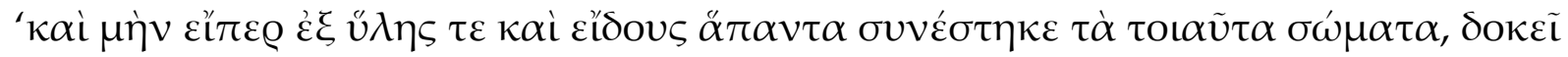

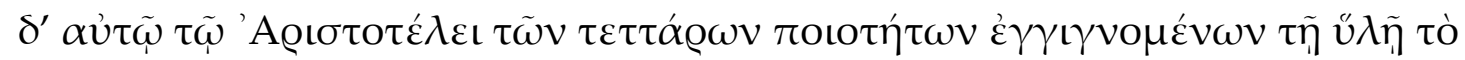

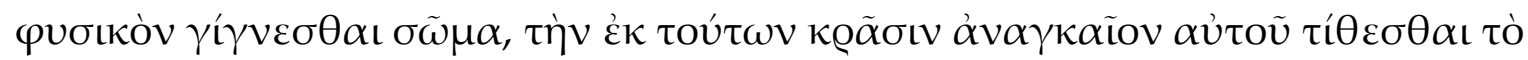

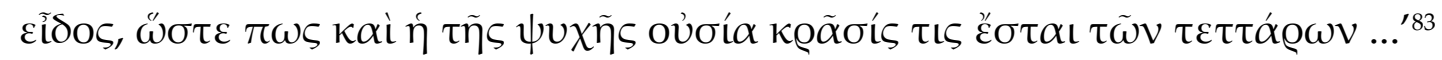
'And surely if all such bodies are composed of matter and form, but according to Aristotle himself the natural body comes to be because the four qualities come to be in the matter, it is necessary to posit the mixture of these as the form of it, so that the substance of the soul too will somehow be some mixture of the four ...'

Thus, through the hierarchical schema of the various levels of our constitution, his notion of the homoeomerous bodies as primarily acting and the linking of the parts of the soul to the main organs, Galen has now integrated Aristotelian hylomorphism into the Platonic-Hippocratic tripartition-trilocation he posited as axiomatic from the outset. ${ }^{84}$ The soul is the form of the body in the sense of a mixture of elemental qualities that comes to be in a prime matter and forms homoeomerous bodies that are primarily active and reside in the larger compositions that are the three main organs. The different soul parts reside in these organs, that is to say: as the formal aspect of a hylomorphic unity, they make up the micro-level of their constitution that is the primal cause of their specific activity. As we have seen, this notion of soul is prepared in other writings of Galen. Thus, it seems as if Galen, in $Q A M$, actually displays that audacity needed to make statements on the substance of the soul which he referred to in his Causes of Symptoms (Caus. Symp). ${ }^{85}$ In any case, as we shall see below, further on in $Q A M$ he does not only applaud Andronicus for defining the substance of the soul as a mixture, but also praises him for his audacity. ${ }^{86}$

Now, besides being audacious (for reasons that involve more than the overcoming of a sceptical or agnostic attitude, as will become clear below), this may also seem like a

\footnotetext{
${ }^{83}$ QAM 37,16-21 Müller (IV 774 K); I follow Müller and Bazou and do not take over Singer's reading $\alpha$ đò̀v for

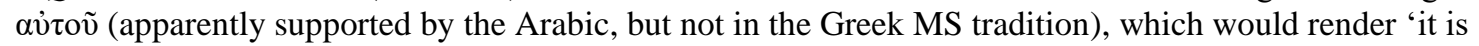
necessary for him' (i.e. Aristotle) and eliminate the 'of it' (referring to the matter) after form. Singer's reading supports his understanding of this argument as 'hypothetical'. He follows this interpretation throughout his translation of $Q A M$, arguing that Galen is merely presenting a conclusion (that the substance of the soul is a bodily mixture) that one should adhere to 'if one is an Aristotelian', not adhering to it himself. Although Singer's interpretation is ingenious, I think there are some serious difficulties for this view, as will become clear below.

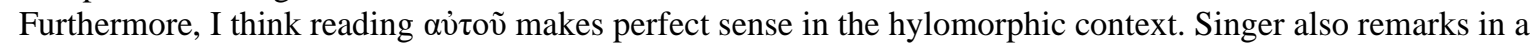
note to his translation (p. 381, note 38 ) that 'the adverb $[\pi \omega \varsigma]$ suggests that this is a surprising conclusion which is nonetheless drawn.' He translates $\pi \omega \varsigma$ as 'it seems as if' ('so that it seems as if the substance of the soul, too, will be some mixture of the four...') In my view, $\pi \omega \varsigma$ can be translated simply as 'somehow', referring to the immediately following remark, that this 'mixture of the four' can be understood in several ways, namely as a mixture of qualities ( $\pi$ oio $\tau$ í $\tau \nu$ ) or bodies ( $\sigma \omega \mu \alpha \dot{\tau} \tau \omega v)$. Cf. Moraux’s translation (1984), 780.

${ }^{84}$ Cf. Tieleman (2003), 150: 'In $Q A M$, as we have noticed (above, p. 143), Galen identifies the soul with the form ( $(\tilde{i} \delta \circ \zeta)$ of each of the three main organs, form being explained in terms of the mixture of bodily elements. What we have here is the marriage of the Platonic tripartition-cum-trilocation with the Aristotelian definition of the soul as the form of the body. this clearly supports Galen's main thesis that corporeal factors influence our mental functioning including character in a morally relevant sense.' Cf. Kovacic (2001) 174-9

${ }^{85}$ Caus. Symp. VII $191 \mathrm{~K}$ : 'Perhaps I shall have the audacity to give an opinion about the substance of the soul itself in some other work...' (tr. Johnston), more on this below. Cf. Hankinson (2003) 238, who remarks that 'it seems that he never did so.'

${ }^{86} Q A M 44,12$ f. Müller (IV $782 \mathrm{~K}$ ); see below, section 2, 54-5
} 
rather strong conclusion: the substance of the soul, the cause of our actions and affections, is nothing more than a particular mixture of the four elementary qualities? Is this not an extremely 'physicalist' position? And does this not amount to some kind of determinism, without room for free will? ${ }^{87}$ Indeed, many scholars have found it difficult to accept this conclusion as Galen's own, and have developed interpretations of $Q A M$ that weaken its status (see below, section 3).

So far we have left out two important general points, however, which, I think, add nuance and complexity to Galen's position. First, there is the question of the 'demiurge' of the mixture, which we briefly alluded to above. Even if it is so, that the specific mixture of the elemental qualities makes up the substance of the soul and therefore all capacities, affections and activities of the soul are dependent on this mixture, the exact ramifications of this view are utterly unclear as long as it remains unspecified what the specific formation of the mixture itself is dependent upon. Galen has some answers to this question of the 'demiurge' of the mixture and we shall treat those at the end of this section. Secondly, we have to qualify the extent of Galen's conclusion in the Aristotelian section in the following two ways. First, as in the example of small children at the beginning of QAM, we seem to be still in the context of an early or compositional phase of the body. As we saw in the quotation above, Galen states that 'the natural body comes to be because the four qualities come to be in the matter'. In other words, at least when it comes to this passage in $Q A M$, it is clear from the text that the focus here is on the initial formation of the soul through the mixture. As we shall see below (section 4), we can differentiate between an initial and natural formation of the mixture that accounts for the children's differences in natural character, and a later formative causality that springs from the rational part of the soul and that is apparently supposed to complete this initial formation. This brings us to the second qualification: this entire discussion (at this point in the text) still pertains only to the lower two of the three forms or parts of the soul. As we have seen, right before the beginning of the Aristotelian section, Galen remarked that Plato considered the rational form of the soul to be immortal, whereas he himself is unable to take position in the matter. ${ }^{88}$ This remark structured the discussion that followed, for it led to the division into the Aristotelian section on the lower two parts and the Platonic section on the rational part of the soul. Galen returns to this division between the mortal parts and (possibly immortal) rational part of the soul only after the Aristotelian section, which must mean that the conclusion proposed there, that the substance of the soul must be some mixture of the four elemental qualities, is not valid at this point for the rational part of the soul. Indeed, when Galen takes up the discussion of the rational part of the soul, he does so by asking whether it too (i.e. as the lower two parts) can be considered a particular mixture. ${ }^{89}$ As we shall see, Galen will eventually accept the same conclusion for the rational part of the soul as well,

\footnotetext{
${ }^{87} \mathrm{Cf}$. Donini (2008), 202: ' $\ldots$ the consequence is that a man is genuinely the product of a series of factors in which his own free will and voluntary initiative may play a very minor or even non-existent part...'

${ }^{88}$ QAM 36,15-6 Müller (IV $773 \mathrm{~K}$ )

${ }^{89}$ QAM 37,26 f. Müller (IV 774-5 K)
} 
but in a more tentative and careful manner and not without some preliminary discussion, which conveys the exceptional position of the rational part with regard to the mixture.${ }^{90}$ For now, it is sufficient to remember that Galen has postponed the discussion of the rational part of the soul, and that it takes place in the context of a discussion of the views not of Aristotle, but of Plato.

With these two general points in mind - the unanswered question of the 'demiurge' of the mixture and the restricted extent of Galen's conclusion so far - we should observe three things. First, nowhere in the remaining text of QAM does Galen distance himself from the conclusion that the ovoí $\alpha$ of the soul is a mixture of the four elemental qualities. Second, in several places the conclusion is almost literally repeated, exactly as if Galen takes it as proven within his own text. ${ }^{91}$ Finally, we have already noticed that Galen, right after the Aristotelian section, wonders if the rational part of the soul can be considered a particular mixture as well, that is to say, in the same way as the other two parts are a mixture. How could Galen make such a remark, if he did not think it established, at this point in the text, that the other two parts are a mixture?

A closer look at this sentence - from the section that we have referred to as the Platonic section (775-782) - also shows the close connection for Galen between the thesis that the substance of the soul is a mixture and the central thesis he presented at the beginning of $Q A M$, that the capacities of the soul follow the mixtures of the body:

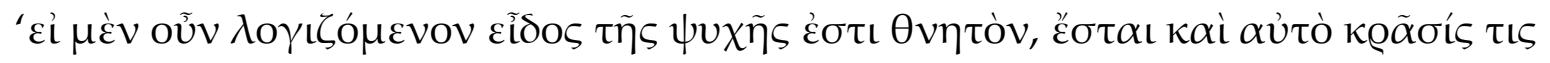

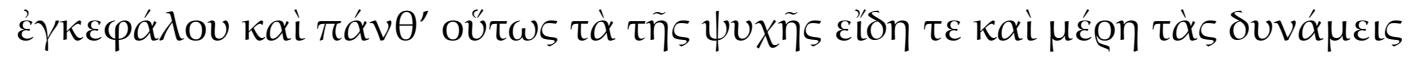

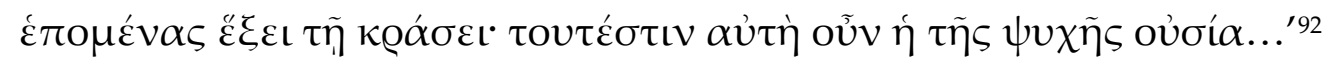
'If, then, the rational form of the soul is mortal, it too will be a particular mixture, [namely] of the brain, and thus all the forms and parts of the soul will have their capacities dependent on the mixture - that is, on the substance of the soul.' (tr. Singer, slightly modified)

\footnotetext{
${ }^{90} \mathrm{Cf}$. Donini (1996), who recognizes the importance of the separate treatment of the rational part of the soul, although he gives a different explanation for it than the one that will be suggested below. Apparently, Donini takes Galen's statement (in 38,18-23 Müller, IV 775-6 K) that he does not know 'what the essence of the soul might be if we suppose it to belong to the class of incorporeals' (Donini's translation) as an expression of Galen's agnosticism with regard to the ousia of the soul (Garcia-Ballester has done so as well; 2002, 130). But, I think the emphasis should be on 'if' here. In this passage, Galen is arguing against the Platonic doctrine of an independent soul, he does not declare his agnosticism with regard to the ousia of the soul as such, he remarks that he is unable to fathom the ousia of the soul if we take it to be incorporeal, as the Platonists do. Thus, this remark amounts to a discarding of the Platonic option, much rather than a general acknowledgement of agnosticism about the subject.

${ }^{91} \mathrm{Cf}$. The reference in Galen's discussion of the view of Andronicus, 44,6-9 Müller (IV $782 \mathrm{~K}$ ): '‘ُ $\delta \varepsilon i ́ \chi \theta \eta \gamma \grave{\alpha} \rho$

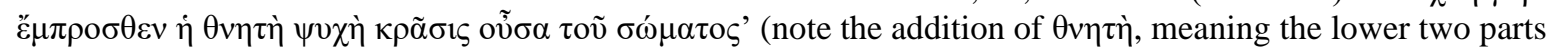
only). Müller omits this sentence (Bazou does not), but it makes perfect sense as a reference to the former discussion and is apparently also found in the Arabic (cf. Singer's textual note 4.19). Also, 38,3-4 Müller (IV $775 \mathrm{~K}$ ) right after the Aristotelian discussion, where the mixture is simply equated with the substance of the soul:

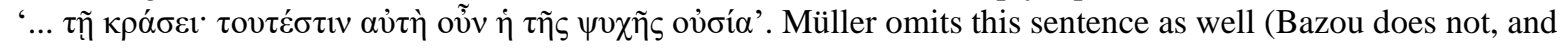
again, it is apparently found in the Arabic, cf. Singer (2013) textual note 4.14). Presumably, Müller simply found the conclusion too strong.

${ }^{92}$ QAM 37,26-38,4 Müller (IV 774-5 K)
} 
First of all, the substance of the soul is again equated with the mixture here, but this time it is suggested (for the first time) that this equation may be valid for all parts of the soul. The conclusion presented here in hypothetical form is the same as the one Galen approvingly ascribes to Andronicus right after the Platonic section in which he argues against the immortality and incorporeal existence of (the rational part of) the soul (see below). The structure of the text here is telling. Schematically, it has the following form: argument for the substance of the lower two parts of the soul being a mixture of the elemental qualities; introduction of a dilemma concerning the rational part: it is either mortal, and then it too (and thus the entire soul) will be a particular mixture, or it is separate and immortal, as the Platonists argue; arguments against one leg of the dilemma, i.e. the Platonic doctrine that the soul is a separate, immortal substance; introduction (and approval) of Andronicus' position that the substance of the whole soul is a mixture. This is particularly noteworthy because it has been argued that Galen, in the passage in which he introduces Andronicus' view, would merely be spelling out the consequences of an Aristotelian position, rather than giving his own doctrine on the substance of the soul..$^{93}$ What is more, he says that if it is the case that the rational form of the soul is also ( $\kappa \alpha i$, again, like the other two parts of the soul) a mixture, the central thesis of $Q A M$ - that the capacities of the soul are dependent on the mixture - is proven. If the rational part can also be shown to be a mixture, the central thesis has been proven for the entire soul. That shows the direct connection for Galen between the notion that the substance of the soul is a mixture of elemental qualities and the central thesis. ${ }^{94}$ In other words: to show that the substance of the soul is a mixture of elemental qualities is considered by Galen to be conducive to proving $Q A M^{\prime}$ 's main thesis that the capacities of the soul follow or depend upon the mixtures of the body. ${ }^{95}$ And that makes sense, considering the general way in which Galen defines the relation between substance and capacity in the passage before his discussion of the various parts of the soul (IV 769-771 K). We have briefly alluded to this above. It is a point that many of the philosophers do not understand correctly according to Galen: they conceive of a capacity as some kind of

\footnotetext{
${ }^{93}$ Cf. Singer (2013) introduction to QAM and notes ad locum, see also infra, section 3, 71-6.

${ }^{94}$ Singer states that we seem to need 'a way of linking (...) two models of explanation', namely those of either capacities or mixtures explaining the relationship between soul and body. But he already seems to provide the right way of linking (namely that the capacities are dependent upon the substance of the soul which is a bodily mixture and that therefore the capacities are dependent upon the mixture) in a footnote to this remark (referring to Praes. Puls. IX 305-306 K.): ' ... that Galen can now state that the ousia of a dunamis is a mixture of a

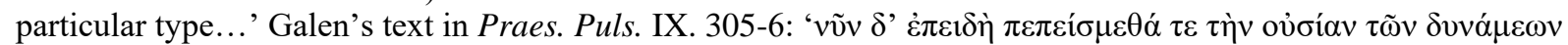

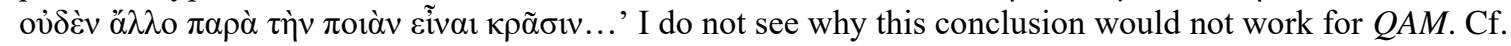
Tieleman (2003) $150 \mathrm{f}$.

${ }^{95}$ Caston (1997, 351-2) rather thinks the two theses are in conflict with each other, but that is because he apparently interprets the thesis of $Q A M$ wrongly. He states that Galen 'is not consistent' because 'Throughout most of the treatise, he argues for the position represented in its title, that the soul is actually a power that follows on the temperament of the body.' The position represented in the title is clear enough, and it does not say that the soul is a power (Caston is perhaps right in recognizing this as the main difference between Galen and Alexander), neither does Galen state anywhere else in the treatise that the soul is a power. It is typical for $Q A M$ 's fate in scholarship, I think, that Caston in an otherwise brilliant and acute work makes such a basic mistake in his reading of the very title of the work, and then proceeds to refer to Lloyd (1988) for an analysis of QAM's 'rhetoric' and 'poor arguments'.
} 
object inhabiting a substance. Instead, Galen explains,_a capacity is nothing but a appellation given in relation to a certain activity, which is also why we say that a substance necessarily has as many capacities as activities (we can only ascribe to a substance a capacity after it (or perhaps a being of similar nature) has exercised the activity of which we can then say it is capable). ${ }^{96}$ The agent of those activities is the substance (oú $\sigma^{\prime} \alpha$ ) itself, as his example of aloe makes clear. In retrospect the substance could be said to 'have' the capacity for doing that which it does, which merely expresses the relation between the cause, i.e. the substance, and its (observed) effect:

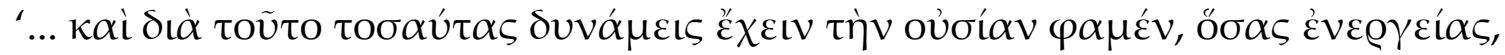

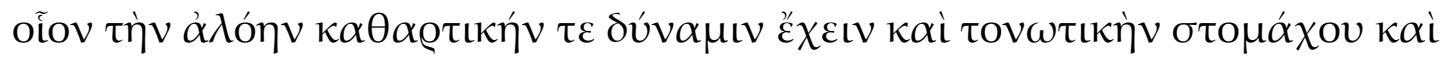

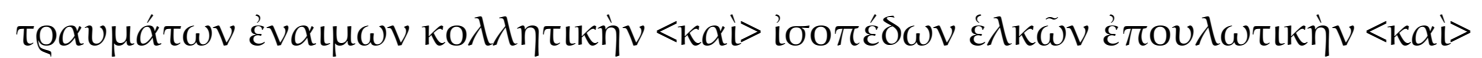

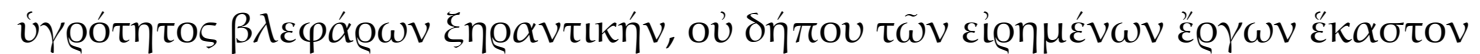

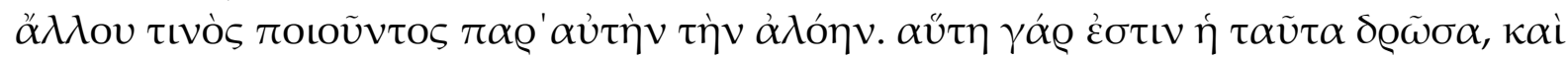

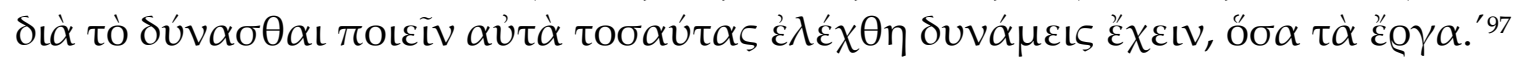
'... and therefore we say that the substance has as many capacities as activities; for example that aloe has a capacity of cleansing and toning the mouth of the stomach, of agglutinating bleeding wounds, of cicatrizing grazes, and of drying the wetness of the eyelids - without there being some other thing that performs each of these actions apart from the aloe itself. For it is the aloe that does these things; and it is because it can do these things that it is said of it that it has these 'capacities', as many as the actions.' (tr. Singer, slightly modified)

The substance, being the aloe, is itself active and does things. Therefore, we say that it has the capacity to do those things, recognizing that it can do the things it does. That does not mean that there is some thing that the aloe has besides the substance that it is, it is just a way of saying that this substance can do what we observe it doing. It is also clear from the example that a single substance could have several capacities. Galen states that we could say the same thing about the rational soul 'which is seated in the brain'. Once we recognize that it is a substance that is

\footnotetext{
${ }^{96}$ See Frede (2003) 94, with reference to Prop. Plac. 13, 7: 'We know that there is a soul, because the soul makes us do the things we as living beings do, like walk or run. But we do not know what it is, and hence also do not know what it does such that as a result of it we walk and run and do all the other things living beings do. Hence we introduce powers named after the observable effects of its activity, of its exercise of its power, for instance the natural powers...'; Hankinson (2003) 51, remarks that Galen's notion of capacity is a kind of 'placeholder for a proper, full-blooded causal explanation, a useful form of words to be employed when such an explanation is not yet available, but by no means a substitute for it'; see also Tieleman (2003) 144-51; Corcilius (2014) 20-58 on the notion of capacity from Plato to Galen; Chiaradonna (2019): 'Galen, however, further explains that it is not an empty term but a term that expresses the relation between cause and effect, i.e. the cause's capacity to produce an effect. Therefore, by using the term dunamis, Galen can offer a causal explanation of bodily activities without committing himself to any definite position regarding the factor that acts as a cause. Being a relational term, dunamis is not an absolute distinct factor, which, as Galen says in QAM IV.769 K., would inhabit substances in the same way as we inhabit our houses. The term dunamis expresses only the relation between cause and effect.'

${ }^{97}$ QAM 34,1-10 Müller (IV 769-70 K)
} 
primarily active and that does things, and that we attribute 'capacities' to this substance on the basis of its activity, it becomes evident that proving that the substance of the soul is a mixture of elemental qualities is more than conducive to proving the thesis that the capacities of the soul are dependent on the mixture of the body. This could be the very reason that Galen is so much more explicit on the substance of the soul here than in his other work - i.e. this notion of the substance of the soul serves his purpose of proving the central thesis of QAM. However, I think that we should be careful not to brush aside his account of the substance of the soul being a mixture as a mere tool to prove the main thesis expressed in the title, especially not since, as we have seen, it is coherent with some of his earlier writings. In any case, such an approach would also be reasoning in the wrong direction. I consider it both more fruitful and more elegant to employ the opposite perspective: Galen argues for the main thesis of QAM because he has what he thinks are good arguments for it, and one of those arguments is that it is plausible that the substance of the soul is actually a mixture of elemental qualities.

Finally, after the Platonic section (IV 775-782 K), Galen rhetorically asks whether it is not obvious that the mortal part of the soul is in every way a slave to the body, if even the rational part changes along with the mixture of the body, as he has just shown, and then repeats the earlier conclusion once more:

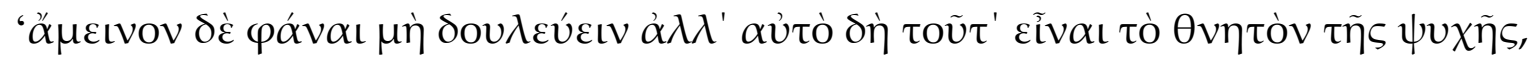

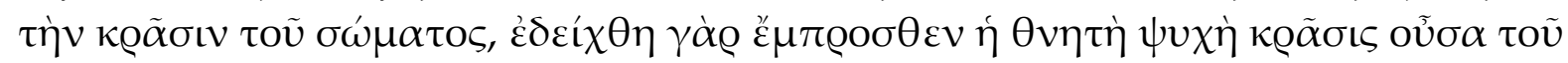
$\sigma \omega \dot{\mu} \alpha \tau \tau^{\prime}{ }^{\prime} 98$

'It is even better to state that the mortal part of the soul is not 'a slave to', but that it actually is precisely this, i.e. the mixture of the body, for it has been shown above that the mortal soul is a mixture of the body.' (tr. Singer, modified)

This is a very explicit repetition of the conclusion reached in the Aristotelian section. It is also an important passage because here Galen makes a clear distinction between the notion that the soul is merely dependent on or follows (i.e. is a slave to) the mixture of the body on the one hand, and the notion that the soul actually is the mixture on the other, and then proceeds to express his preference for the latter option.

At this point in the text Galen is ready to take the next step, and to commit himself to the view that the substance of the entire soul is nothing but a mixture of elemental qualities, which he introduces as the view of Andronicus the Peripatetic. We shall get to that passage below, after we have delved into the preceding discussion of the rational part of the soul, which takes place, as we have noted, in a Platonic context (section 2).

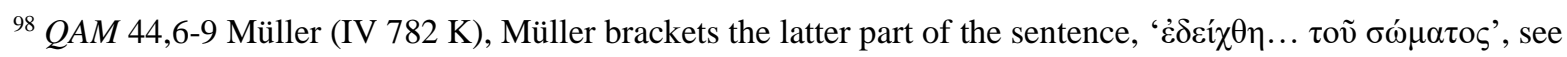
note 91 above
} 


\section{e. Soul and nature}

For now, what remains to be discussed in this paragraph, is the role of the 'demiurge' of the mixture. If the mixture is the substance of the soul and therefore causes the affections and activities of the soul, then we have to wonder what is responsible for the formation of the mixture itself. We have noticed that Galen, in $Q A M$, seems to attribute a 'demiurgic' or crafting activity to the elemental qualities themselves. He does so in the following passage in Hipp. Elem. as well:

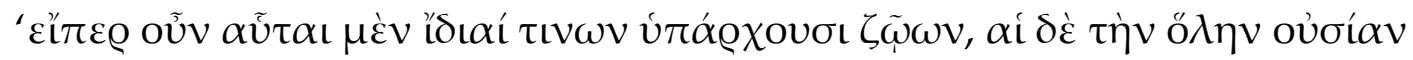

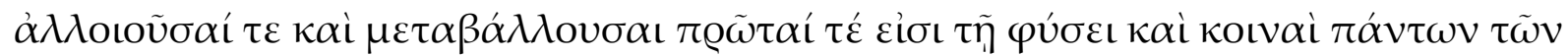

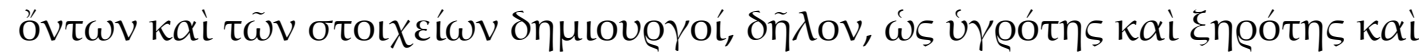

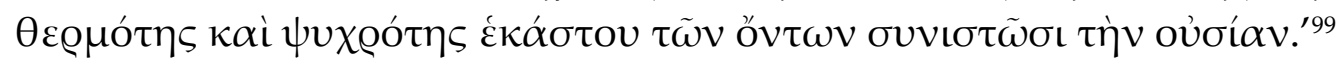

'Thus, if these [qualities] are peculiar to some animals, but those that alter and change the whole substance are primary in nature and common to all beings and crafters of the elements, it is clear that wetness, dryness, hotness and coldness form the substance of every being.' (tr. De Lacy, modified)

He also does so, here:

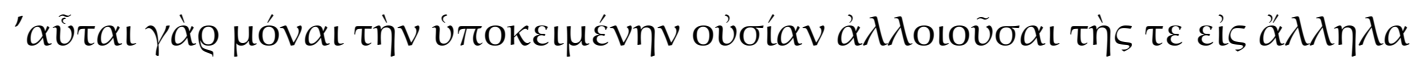

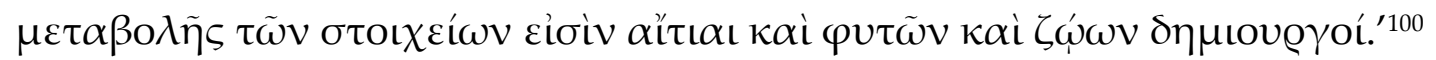
'... for they [the four elemental qualities] alone, by altering the underlying substance, are causes of the change of the elements into each other and crafters of plants and living beings.' (tr. De Lacy, modified)

We notice how the elemental qualities (primary in nature and common to all beings) are not only presented as the agents of change and constituents of the substance of all

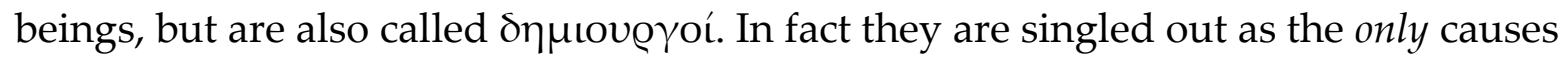
and crafters. What are we to make of this? It seems confusing, because we know that Galen often refers to 'nature' as the creator of man. In fact, the entire UP is presented as a work to prove the ingeniousness and wisdom of the demiurgic activity of nature. What this must imply, if we are to make any coherent sense of Galen's texts (and we can), is that nature is the 'demiurge' in a primary sense, mixing the elemental qualities in accordance with some intelligent plan that already presumes the ensouled being in its final state, while the elemental qualities also fulfil a role as crafters, but in a secondary sense, i.e. according to the plan of nature, as its instruments as it were. Such an interpretation would fit Galen's teleological outlook as he present it at the beginning of UP:

\footnotetext{
${ }^{99}$ Hipp. Elem. 132,9-13 De Lacy (I $485 \mathrm{~K}$ )
}

${ }^{100}$ Hipp. Elem. 128,11-3 De Lacy (I 482 K) 


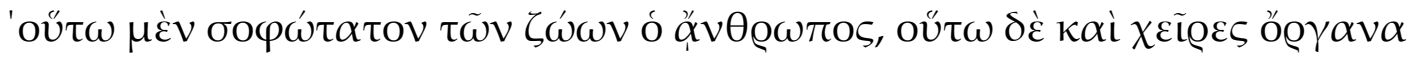

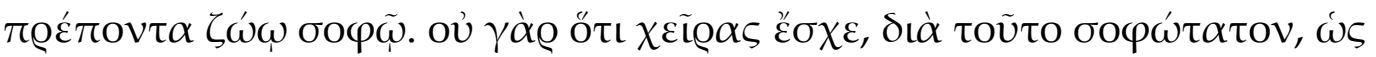

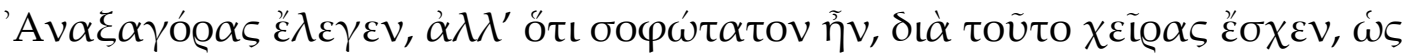

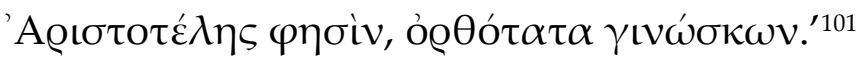

'Thus man is the most intelligent of living beings, and so, also, hands are the instruments suitable for an intelligent living being. For it is not because he has hands that man is the most intelligent, as Anaxagoras says, but rather it is because he is the most intelligent that he has hands, as Aristotle says, judging most correctly.' (tr. May, slightly modified)

In this reading, the natural teleology of functions would predetermine the mixture of the elemental qualities that determines the exercise of activities of anhomoeomerous parts such as the hand. The elemental qualities themselves then may be called

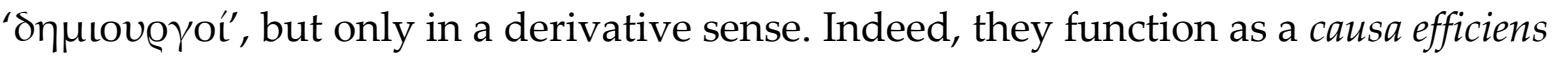
with regard to the activites of the anhomoeomerous organ or body-part and with regard to the activities of the soul. However, they have their own causa efficiens as well, which operates with skill and wisdom and which ensures that the activity of the qualities is not random because this cause is intelligent somehow. ${ }^{102}$ Such a distinction between a primary and derivative sense of the efficient cause has parallels in Galen's work:

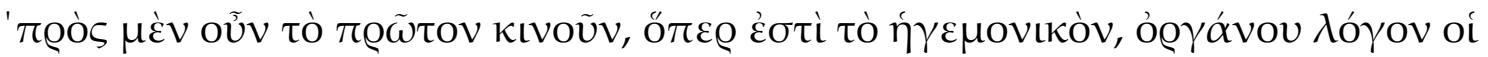

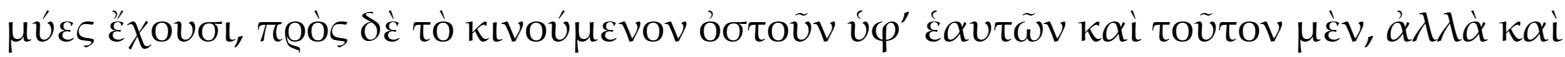

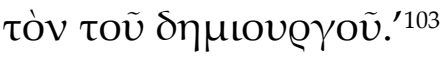

'Thus, with respect to that which moves first, which is the leading [part of the soul], the muscles have the status of instrument, but with respect to the bone moved by them, they have both the status of instrument and that of "demiurge".'

The meaning here is obvious: the muscles are an instrument (ö@ $\gamma \alpha v 0 v$ ) in relation to the rational part of the soul that moves them, but they are a 'demiurge' or efficient cause in relation to the bones, since they effectively move the bones. This passage on

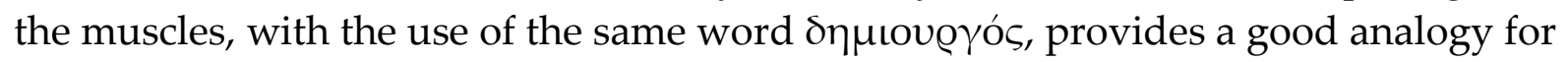
the sense in which nature and the elemental qualities can both be considered

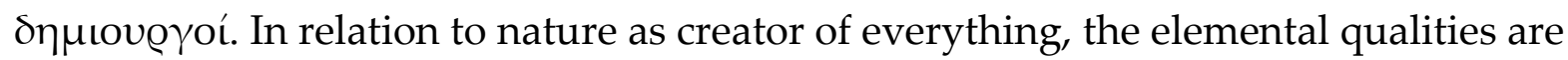
an instrument because they are mixed according to nature's systematic teleology. In relation to any more complex structure or activity that they effectively cause to be,

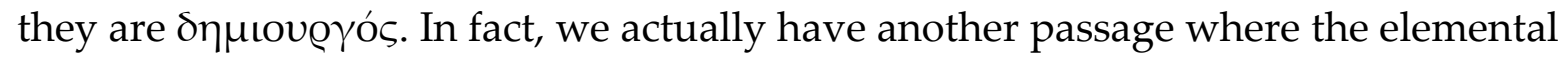

\footnotetext{
${ }^{101} U P$ I 3,25-4,5 Helmreich (III $5 \mathrm{~K}$ ); cf. Aristotle PA IV 10, 687a2 ff.

${ }^{102}$ Cf. UP I 338,20-22 Helmreich (III $464 \mathrm{~K}$ ) where Galen explains that the first cause for everything that comes

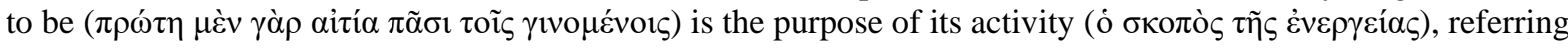
to Plato (perhaps Phaedo, 97B f.)

${ }^{103}$ UP II 437,18-21 Helmreich (IV 347 K)
} 
qualities are called instruments (ő $\gamma \alpha v \alpha$ ) in the same sense as the muscles above, and nature is designated as the true formative power:

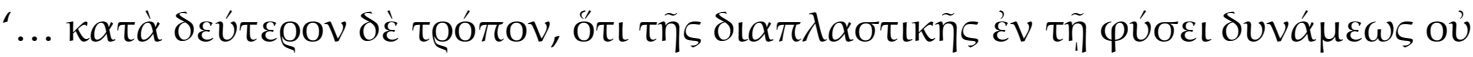

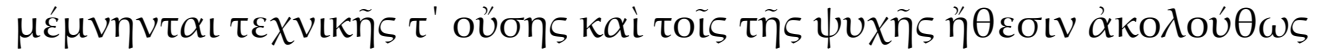

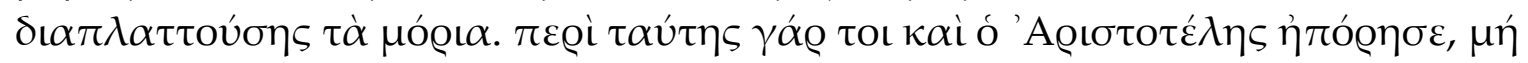

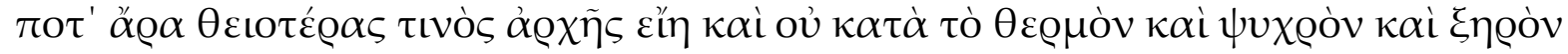

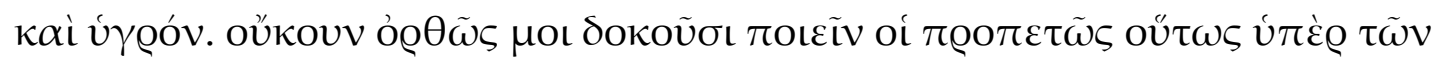

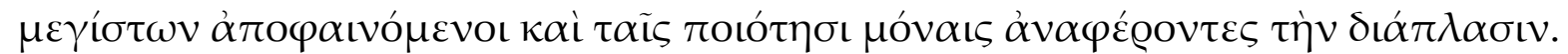

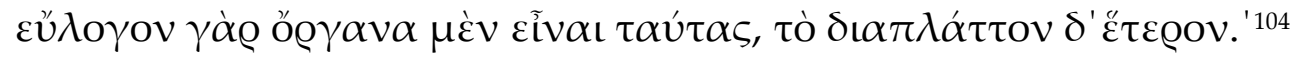
'A second mistake is that the forming capacity in nature is not regarded as being craftsmanlike and forming the parts in accordance with the character of our souls. For in regard to this capacity indeed even Aristotle was puzzled, whether it is not from some more divine cause rather than just in accord with the hot, cool, dry and wet. Therefore it seems to me that those who rashly make statements on the greatest matters in such a way, and refer the formative capacity solely to the qualities, certainly do not go about it correctly. For it is reasonable that these are only the instruments, while the actual former is something else.'

This formative power in a primary sense is nature, or Nature with a capital ' $N$ ', a divine cause. From this primary perspective, the elemental qualities and their mixture can be considered mere instruments, even though they function as (efficient) cause when they are related to the more complex structures or actions they form or cause, just like the muscles are instruments in relation to the brain and causes in relation to the moving of the bones.

It makes sense to interpret the demiurgic dimension of the mixture of elemental qualities in this way since, for Galen, there must be an intelligent cause behind this mixture that can account for the wonderful teleological order of the cosmos:

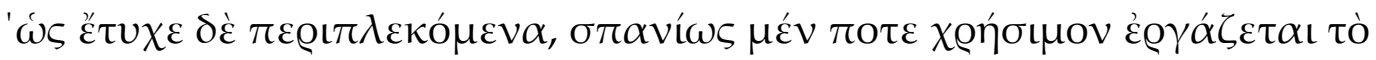

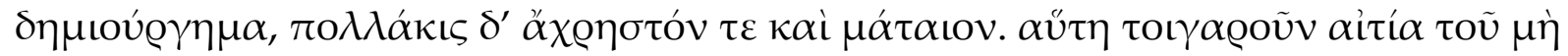

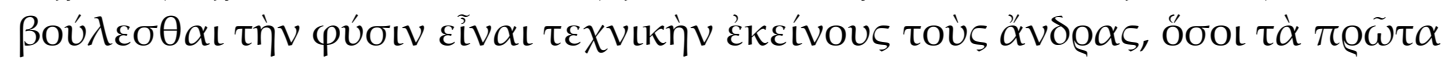

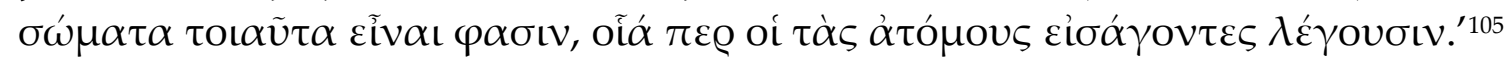
'But when they are interwoven in a random fashion, they rarely ever produce a useful work, rather often something useless and futile. This is exactly the reason why those men do not want nature to be skilful, I mean those that say that the primary bodies are such as those that propose the atoms say.'

So, we could say the specific mixture of elementary qualities forms the substance of the lower two parts of the soul, and these substances are themselves formed by nature, i.e., a divine, wise and skilful power. But, does this not imply that the lower

${ }^{104}$ Temp. I 635,16-636,8 K

${ }^{105}$ UP II 440,20-441,1 Helmreich (IV $351 \mathrm{~K}$ ) 
two parts of the soul are only effective causes in the derivative sense as well? What is primarily active in the lower parts of our soul, particularly in the desiderative or vegetative part seated in the liver, is nature. Therefore, in a way nature is eventually the true agent of the movement of which these parts are said to be the origin in a derivative sense. One beautiful consequence (if you like) of this line of thinking is that, because Galen considers nature itself as something divine and because it turns out to be the true effective cause of the actions and affections of our lower soul-parts, the actions and affections of our lower soul-parts - provided they have the right or 'natural' measure, of course - can be considered 'natural' in the sense of being divinely motivated much rather than random. We should keep in mind that the soul that is under discussion here, is something that is very closely associated, for Galen, to the rest of creation, and not something peculiar to human beings. In the sixth book of PHP for example, when Galen undertakes his investigation of the desiderative part of the soul, or the powers residing in the liver, he starts from an analysis of plants. This is because the power that is under investigation ( $\tau \eta \nu \zeta \eta \tau o u \mu \varepsilon ́ v \eta v \delta u ́ v \alpha \mu t v$ ) is present there by itself and thus easier to analyse. ${ }^{106}$ The crucial thing to grasp here is that it is the same power that is under investigation, whether we analyse the desiderative power of plants or the human soul, because it is eventually the power of nature and it does not 'belong' to an individual being in the sense that we might now be inclined to think of the soul of a specific person (this might be different for the higher parts of the soul, of course). Likewise, in Foet. Form., Galen suggests that 'enquiry into the formation of plants' could be used to 'learn exactly what needs the [human] embryo has during the period in which it is still managed by one soul in the same way as plants are.'107 We can see here how difficult it can be in Galen to disentangle 'soul' from 'nature': this (vegetative) part of the soul can even simply be termed 'nature', he says, as the followers of Chrysippus apparently term it, whereas Aristotle and Plato preferred the word soul. ${ }^{108}$ In UP, too, Galen decides to simply leave aside the question of whether this part of the soul should be called 'nature or nutritive soul', and in Nat. Fac. he states that it is only a matter of convention to call the nutritive capacity either 'natural' or 'psychic'. 109

And even though we have seen that, in $Q A M$, the role of nature is primarily associated with the context of the generation of a living being, we can learn from Nat. Fac. that the powers of nature that are manifested in the elemental mixture of the lower soul parts remain in function to guarantee the sustenance of these beings too:

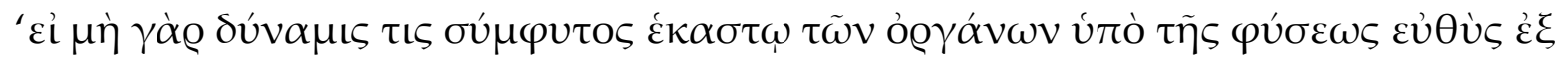

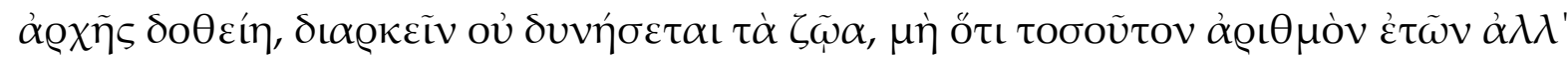

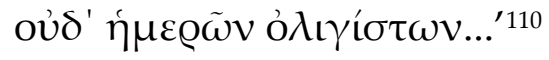

\footnotetext{
106 PHP VI 374,29-32 De Lacy (V $522 \mathrm{~K}$ )

${ }^{107}$ Foet. Form. 68,10 f. Nickel (V 665 K); translations Singer (1997)

${ }^{108}$ PHP VI 374,13-21 De Lacy (V 521-2 K)

${ }^{109}$ UP I 226,18-22 Helmreich (III 308-9 K). Cf. Nat. Fac. II 1-2 K. See also De Lacy (1988) 53 f.; Tieleman (1996) 158-9; Havrda (2017), 74

${ }^{110}$ Nat. Fac. II $80 \mathrm{~K}$
} 
'If there were not an inborn power given to each of the organs by nature immediately at the beginning, the animals would not be able to last even for a few days, let alone for so many years as they actually do.' (tr. Brock, modified)

Thus, nature is not only creator, but also maintainer. To a certain extent, at least, the functions of living beings, including functions that we would perhaps be inclined to think of as psychic, can be understood as capacities of nature:

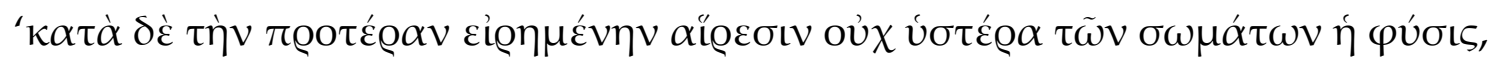

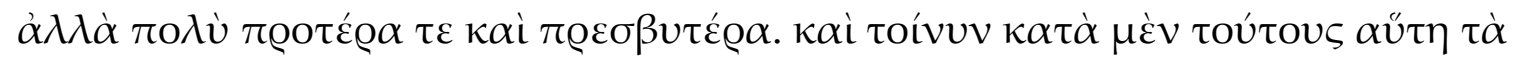

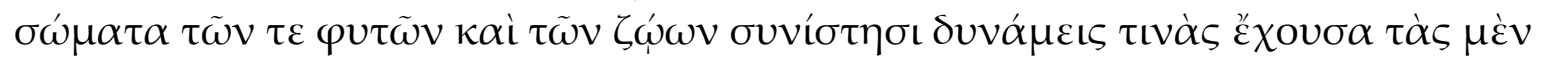

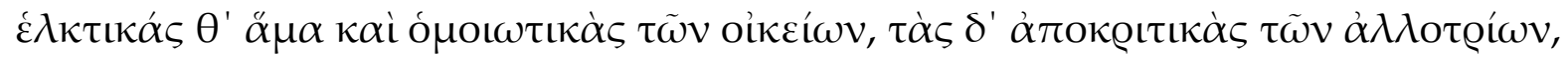

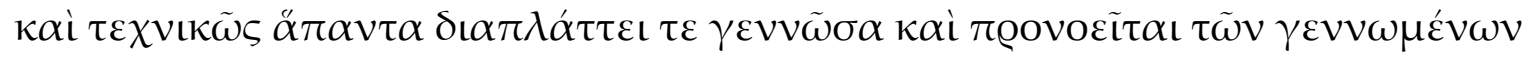

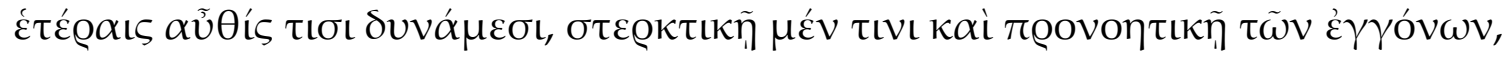

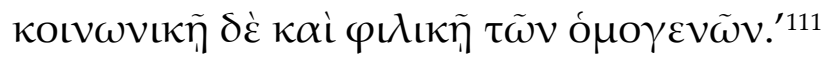

'According to the first-mentioned teaching, on the other hand, Nature is not posterior to the bodies, but is a long way prior to them and older than they are; and therefore in their view it is Nature that puts together the bodies of both plants and animals; and this she does by virtue of certain capacities which she possesses - these being, on the one hand, attractive and assimilative of what is appropriate, and, on the other, expulsive of what is foreign. Further, she skilfully moulds everything during the stage of genesis; and she also provides for the creatures after birth, employing here other capacities again, namely, one of affection and forethought for offspring, and one of sociability and friendship for kindred.' (tr. Brock, modified)

According to this view (to which Galen subscribes), nature, the skilful and wise artisan, does not leave its creatures alone after their generation. We can see here how Galen explains some basic emotional functions, such as affection for others, as a natural capacity. This seems to involve the part of the soul seated in the heart, although Galen is much less inclined to conflate this soul-part with nature as he is with the part in the liver. In general, we would do well to understand Galen's nature not as an external creator that makes autonomous beings other than itself, but as 'something' more immanent that is itself present in the living beings and continues to work its capacities in them, as the guardian of life ${ }^{112}$ :

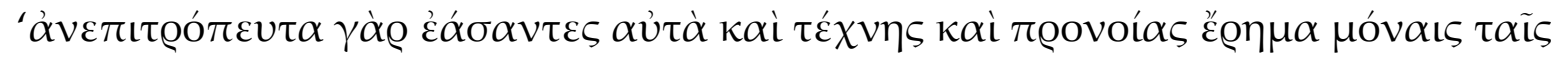

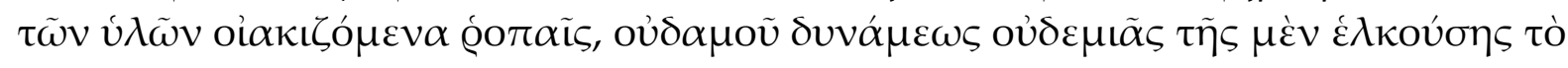

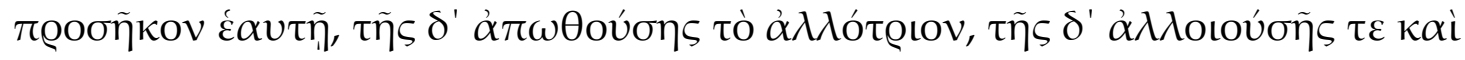

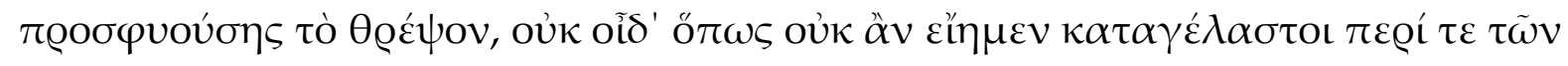

\footnotetext{
${ }^{111}$ Nat. Fac. II $28 \mathrm{~K}$

${ }^{112}$ See infra, CS II section 4, 117-30
} 


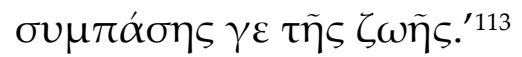

'For if it were conceded that they [the living beings] are without guardianship, devoid of artistry and foresight, governed only by the rule of matter and not by any power such as the attracting of what is appropriate to itself, the rejecting of what is foreign, the alteration and assimilation of that which shall nourish it, then I am sure we would make fools of ourselves discussing natural activities, and even more so discussing psychical activities and, in fact, life as a whole.'

It would be ridiculous to even discuss the activity of the soul without assuming that nature, in the form of the natural capacities that are innate in every living being, fulfils a governing and guarding function. We can take that quite literally, since the activities that are described here (and repeated throughout Nat. Fac.) as the activities of nature, are no different than the activities of the lowest part of the soul. Again, we notice that, at least when it comes to the parts of the soul that man shares with other living beings, and particularly the vegetative or desiderative soul seated in the liver, there is nothing about it that hinders an analysis in the same physical terms as the rest of creation. This is another way in which we need to modify the conclusion of the Aristotelian section in $Q A M$, namely that the substance of the soul is a mixture: the conclusion applies only to the lower two soul parts, which are in general considered to be the same as the souls of plants and animals and can to a large extent be understood as the workings of nature itself. This nature, furthermore, is intelligent. That is to say, it works according to a systematic teleology, including in its most primary activities of cooling, drying, heating and moistening.

\section{Conclusion}

To conclude this first paragraph and summarize the results of our analysis, we can extract the following views from the first part of $Q A M$ and the earlier work on which it relies.

The substance of the lower parts of the soul is a mixture of the elemental qualities. This mixture is the formal aspect of the smallest component parts (i.e. the homoeomerous bodies ${ }^{114}$ ) of their respective organs. It is the cause of the (psychic) functions exercised from these organs. This substance itself is formed, and to a large extent also governed by nature. Therefore, nature, in a strict sense, is the cause of those functions and that which is primarily active when these functions are exercised. However, since nature is conceived as skilful and wise, this governance should not be understood as a random determination of functions that we would otherwise understand as being in the control of individual beings, but rather as the manifestation of a divine and beautiful teleological order that is as it should be. Yet, there is something within this order that makes things more complex, because it

\footnotetext{
${ }^{113}$ Nat. Fac. II $80 \mathrm{~K}$

${ }^{114}$ See infra, CS II section 3, 112-6, for a discussion of the role of the elements in relation to the elemental qualities and homoeomerous bodies.
} 
shares some of the governing skill of nature without completely coinciding with it. This has been left out of consideration so far. We shall now turn to the next passage in $Q A M$, after the Aristotelian section discussed above, where Galen takes up the postponed discussion of the rational part of the soul. It will turn out that Galen partly explains this highest part of the soul, the only part that is peculiar to human beings (among mortal beings, that is), in the same terms as the other two parts. Galen argues that its substance is a mixture of elemental qualities as well. However, he also attributes to the rational part a rather exceptional status: it shares something with its maker.

\section{Plato and the rational part of the soul}

\section{a. The substance of the rational soul as mixture}

As we have seen, Galen considers the central thesis of $Q A M$ proven if it can be shown that the rational part of the soul is mortal and identical to the mixture that constitutes the brain, the highest of the three main organs. ${ }^{115}$ This conflicts with the doctrine of contemporary Platonists, who tend to view the rational part of the soul as immortal and capable of existing separately from the body. Thus, what Galen has to do from here on $(775-782 \mathrm{~K})$ to prove the proposed thesis, is to prove the impossibility of the immortality and separate existence of the soul. He gives various arguments to this end, most of them in some way showing the dependence of the state of the soul on the body and thus discrediting the idea of the soul's independent existence. The example of wine, for instance, is recurrent in showing how, upon consumption of it, the capacities of the soul are immediately affected by the change in the bodily mixture.

Galen proceeds to show that the hot, cold, dry and wet, so all four of the elementary qualities that make up the mixture of the brain, each modify the capacities of the rational soul and can even cause death or - as the Platonists would have it - the separation from the body. Now, it is important to note that Galen, by arguing against the immortality and separate existence of the rational part of the soul, i.e. against its independence of a specific bodily constitution, is actually arguing in favour of it being a mixture of the brain. This becomes clear from the disjunction he presents at the outset of the Platonic section:

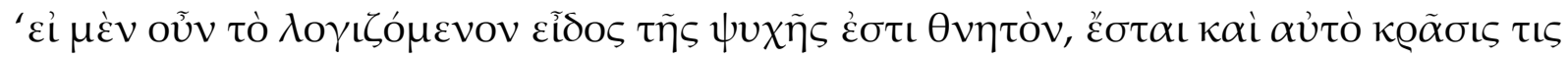

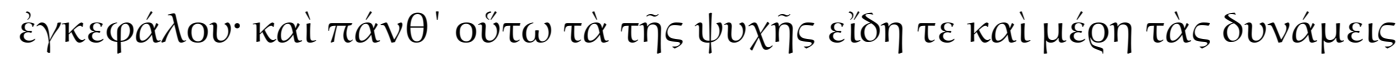

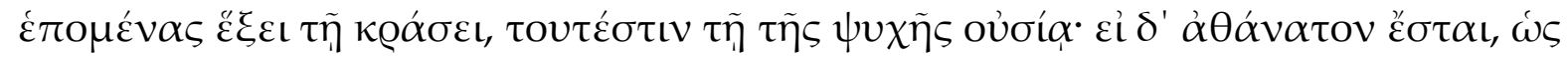

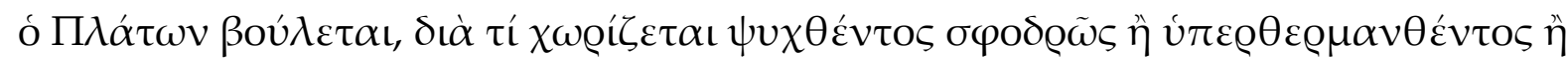

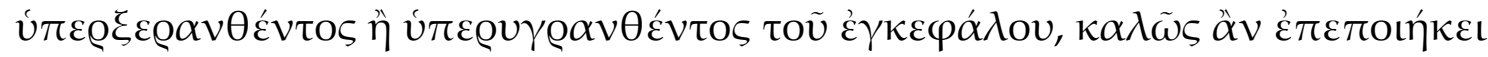

${ }^{115}$ See infra, section $1,38-9$ 


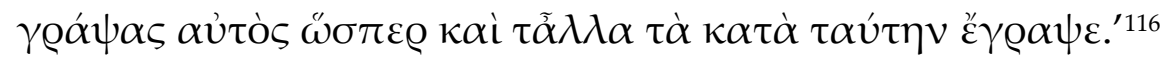

'Thus if the reasoning form of the soul is mortal, it too will be a particular mixture, [namely] of the brain, and then all the forms and parts of the soul will have their capacities dependent on the mixture - that is, on the substance of the soul; but if it turns out to be immortal, as Plato would have it, he would have done well to explain in writing himself why it is separated when the brain is excessively cooled, heated, dried or moistened, as he wrote about the other matters concerning it [i.e. the soul].' (tr. Singer, modified)

Clearly, we have a dilemmatic structure here: the rational part of the soul is either mortal or immortal. If it is mortal, it is a mixture, as the other two parts have been shown to be. If it is immortal, it should not be dependent for its existence on the condition of the mixture (since that, in any case, is not immortal). Galen is out to argue against the immortality of the soul in this passage, and given the form of the disjunction he presents at the outset, that means that he argues in favour of the rational soul being a mixture. ${ }^{117}$ And in fact he returns to this disjunction further on in the text $(787 \mathrm{~K})$, where he presents it again, saying that if the soul is the form of a homoeomerous body - this formulation should not surprise us anymore by now the thesis that the capacities of the soul follow the mixture of the body is proven beyond doubt. Again, the only other option is that of a Platonic immortal soul:

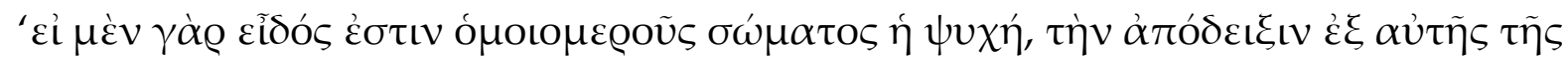

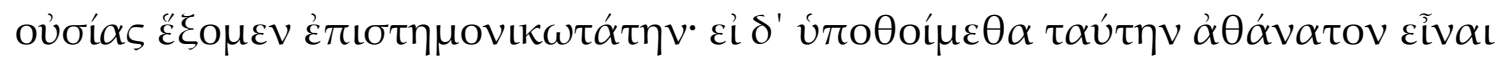

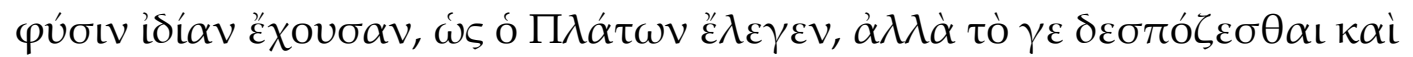

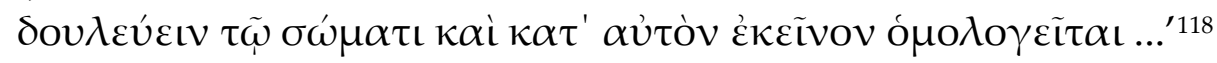

'For if, on the one hand, the soul is the form of a homoeomerous body, we shall have the demonstration based on its very substance, which is the most scientific demonstration possible. If, on the other hand, we would take it to be something immortal, having a nature of itself, as Plato said, even then he himself agrees that it is dominated by, and enslaved to, the body...'

'The demonstration' here refers to the demonstration of the central thesis of $Q A M$, as the preceding sentences make clear. The most scientific demonstration of this thesis is that proceeding from the very substance of the soul, namely the demonstration that shows that the substance of the soul must be the form of a homoeomerous body, i.e. the mixture of elemental qualities that constitutes this body. Again, such a

\footnotetext{
${ }^{116}$ QAM 37,1-38,8 Müller (IV 774-5 K), here I follow Bazou's text (except for her addition of $\alpha$ $\tau \eta$ after $\delta i \grave{\alpha} \tau i ́$ $\chi \omega \rho i \zeta \zeta \varepsilon \alpha 1$, which I agree with Singer seems unnecessary), cf. Singer (2013) notes 4,13-15

${ }_{117}$ Cf. Vinkesteijn (2019)

${ }^{118}$ QAM 48,3-8 Müller (IV $787 \mathrm{~K}$ ), I follow Singer and the MS tradition here, reading $\dot{\alpha} \theta \alpha \dot{v} \alpha \tau$ ov and not $\delta \sigma \omega ́ \mu \alpha \tau o v$ in Müller's line 5 (which Bazou also takes over), cf. Singer (2013) Textual Note 4.27, but for another reason: Galen here returns to the earlier disjunction between the soul being mortal (and thus a mixture) or immortal. Which also means that the difference between $\dot{\alpha} \theta \alpha \dot{v} \alpha \tau o v$ and $\dot{\alpha} \sigma \omega ́ \mu \alpha \tau o v$ is not as important as it might seem here, since they necessarily go together in Galen's dilemma.
} 
demonstration would logically imply that the capacities of the soul are dependent on the mixtures, since capacities are dependent on the substance of which they are said to be capacities. Again, this is the exact way Galen views the relation between the general thesis that the capacities of the soul follow the mixtures of the body and the stronger thesis that the substance of the soul is a mixture of elemental qualities: if the latter is true, that is the most scientific demonstration of the former, departing from the very substance of the subject under investigation. And it seems as if Galen takes that demonstration to have been given at this point in the text, after the other leg of the dilemma, the option of the Platonic immortal soul, has been rendered implausible by several objections. But, states Galen, even if we would take the soul to be something immortal (which would mean that the central thesis of $Q A M$ would not be directly proven from the substance of the soul itself, as it seems it has been now), then we could still prove the central thesis, even by means of what Plato himself has said (also supported by Aristotle and Hippocrates, as Galen goes on to show). Thus, in this part of $Q A M$, following the passage just quoted, he proceeds to take up the other side of the disjunction, although it seems to have already been repudiated. He argues that even if it would be accepted, $Q A M$ 's central thesis that the capacities of the soul follow the mixtures of the body remains true. Therefore, in the part after IV $787 \mathrm{~K}$, Galen does not argue for the substance of the soul being a mixture of elemental qualities anymore (although his previous arguing shows he considers this the most plausible position at least). From here on, he only argues for the thesis that the capacities of the soul follow the mixtures of the body, showing that this should be admitted even by those who do not agree with his previous argument that the substance of the soul is a mixture of elemental qualities.

However, in the Platonic section, Galen is concerned with disproving the possibility of the soul existing independent of a specific bodily mixture:

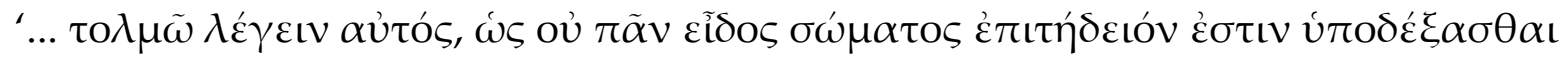

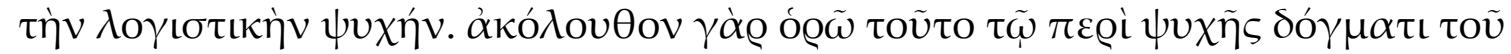

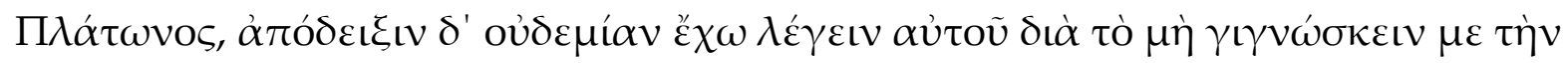

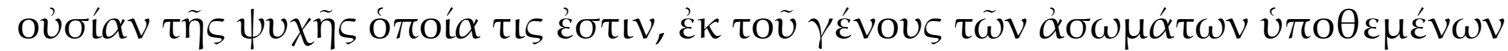

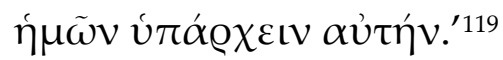

'... I dare to state myself that not every kind of body is suitable to receive the rational soul. For I see this as consequent upon Plato's doctrine of the soul, but I am not able to state any demonstration for it, because I would not know what kind of thing the substance of the soul is, as long as we assume that it belongs to the class of nonbodily things.' (tr. Singer, modified)

Interestingly, the 'daring' (forms of $\tau 0 \lambda \mu \alpha \alpha \omega)$ is a recurrent motif, as we shall see, when it comes to making statements on the substance of the soul that do away with

${ }^{119}$ QAM 38,16-23 Müller (IV 775-6 K) 
non-bodily options. ${ }^{120}$ For Galen, as we have seen, the soul comes to be when the elemental qualities mix in a certain way in the prime matter. That is to say, without that specific mixture of the qualities, the soul would not come to be. Therefore, he says, not every kind of body is capable of receiving ${ }^{121}$ the rational soul - and it is easy to see how this argument could just as well be extended to the other soul parts that are not under discussion here. But, according to Platonists (or Galen's reading of them), the soul exists independently of the particular form of the body it inhabits, and therefore does not require any specific mixture of the elemental qualities. A consequence of this view would be, according to Galen, that the soul could inhabit any kind of body, since the conditions of its existence do not include the constitutive properties of a particular kind of body. ${ }^{122}$

In Foet. Form., on the contrary, Galen describes how the higher part of the soul comes to be within an existent hylomorphic construct, depending on the food-distribution of the liver and the heat of the heart. The brain of the infant is constructed later than the two other main organs, and its powers - such as perception, voluntary movement and thinking - come to be only after the completion of the organ. Thus, Galen argues that the activity of the rational soul is dependent on a specific organ that in turn presumes other functions which have previously developed in the human body. Galen then remarks that 'this may also be learned from the book in which I show that the soul's faculties follow the mixture of the body.' ${ }^{123}$

To Galen, a soul that exists by itself without being an aspect somehow of a specific bodily construct, is unfathomable. If the soul is considered to be non-bodily, he declares himself unable to understand what it is, as we have seen.

This is not a mere declaration of agnosticism - as it has been taken to be - but much rather a reductio ad absurdum of one side of the previously presented disjunction, namely the Platonic view that the rational part of the soul is immortal and capable of an existence separate and independent of the body. ${ }^{124}$ Obviously, when Galen states that he is not able to fathom this possibility, even after inquiring into it carefully and considering it often, he does not mean to say that this is merely some lack of capacity on his part, so that maybe another, better qualified person could in the meantime

\footnotetext{
${ }^{120}$ See also Vinkesteijn (2019)

${ }^{121}$ Galen must be taking over the word 'receiving' from Aristotle's De Anima I 3 407b20-27, where Aristotle rebukes thinkers who try to state what the soul is, without also taking the body which receives it ( $\tau$ võ $\delta \varepsilon \xi o \mu \varepsilon ́ v o v$ $\sigma \omega ́ \mu \alpha \tau \zeta \varsigma$ ) into account, 'as if it were possible, in accordance with the Pythagorean stories, that any soul could enter into any body'. This argument is clearly aimed at Platonists in particular. Galen agrees with this critique and holds that the soul comes to be with the body, rather than that the body at any time 'receives' an already existent soul.

${ }^{122}$ Aristotle states the same in De anima 407b20-25, where he ascribes the view that the soul could find its way into any body to the Pythagoreans and seemingly also to the Platonists (depending on the way the context of this passage is read).

${ }^{123}$ Foet. Form. 76,10-78,11 Nickel (V 672-74 K); translation Singer (1997)

124 This passage has been taken as an expression of Galen's supposed agnosticism with regard to the substance of the (rational part of the) soul by Donini (1996), 198. I think that, as Singer's translation also brings out, the emphasis should be on if here, which means that this statement rather serves as a disqualification of one of the legs of the previously given dilemma than as a general expression of agnosticism with regard to the substance of the soul (although I certainly agree with Donini that Galen is less explicit on the rational part of the soul than on the other parts).
} 
have an adequately scientific notion of an immortal soul. We know enough about Galen's own estimation of himself and his contemporaries to conclude this much. Again, given the dilemmatic form of the argument, it is an argument for the mortality of the rational part of the soul and, since this was assumed as a consequence of its mortality, for the rational part of the soul being a mixture of elemental qualities. ${ }^{125}$ In fact, this becomes clearer in the sentences immediately following, where Galen suggests how much more plausible it is to understand the mixture to be the substance of the soul, since it can account for all the observable qualitative differences that he took to be the starting point of his argument at the beginning of the text:

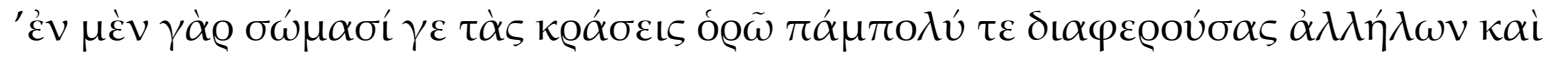

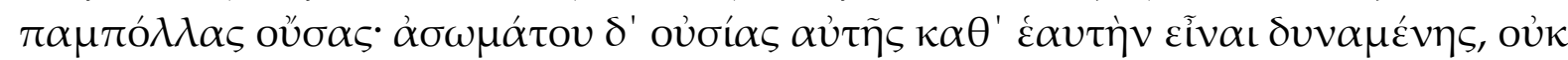

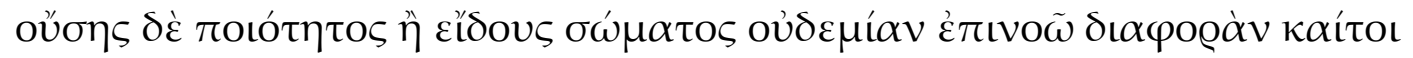

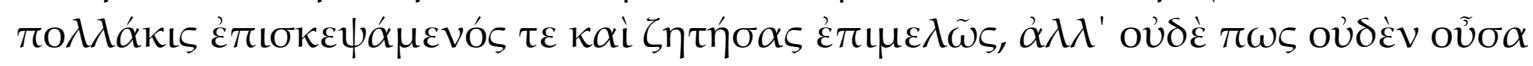

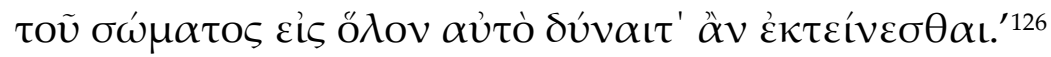

'For in the bodies, I see that the mixtures are completely different from each other and very many in number, but with a non-bodily substance able to exist by itself, not being a quality or form of the body, I do not discern any difference, even though I have often considered it and inquired into it carefully - nor, indeed, do I discern how, not being any part of the body, it would be able to extend through the whole of it.' (tr. Singer, modified)

Again, Galen states that if the soul is to be taken as something other than a form or quality of the body, such as he showed the mixture to be, he does not see a way to explain the observable diversity of individual souls and psychic functions. This clearly refers back to the starting point of the observable differences in the affections and actions of small children. ${ }^{127}$ The other option, the soul being the mixture of qualities, simply has superior explanatory value, which is one of the reasons why Galen is more sympathetically disposed towards it, besides it being better matched to his empirical findings. We can find this idea elsewhere in Galen, too, as in the following passage in which he expresses his own carefulness in accepting this (after all) speculative conclusion, as well as the fact that it does seem to be in agreement with his empirical findings:

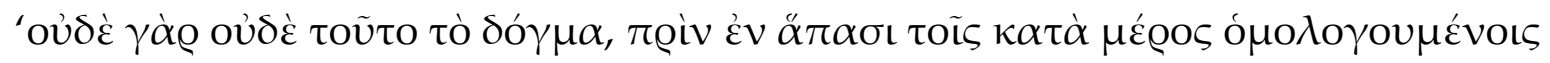

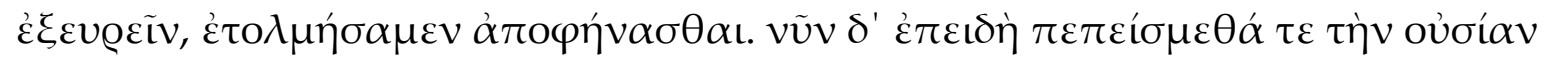

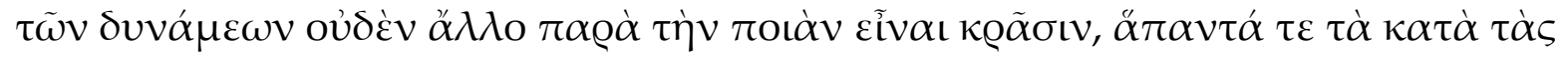

\footnotetext{
${ }^{125}$ Cf. also QAM 46,17-23 Müller (IV $785 \mathrm{~K}$ ), where Galen states that it has been shown that the substance of the soul is composed in accordance with the mixture that forms the homoeomerous bodies, unless one assumes that the soul can exist separately from the body, as Plato does.

${ }^{126}$ QAM 38,23-39,4 Müller (IV $776 \mathrm{~K}$ )

${ }^{127}$ QAM 32,14 f. Müller (IV $768 \mathrm{~K}$ ); see infra section 1, 16-7
} 


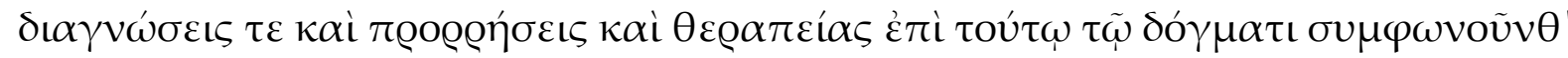

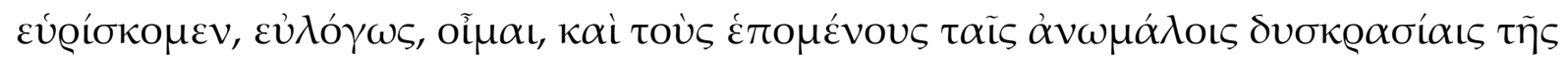

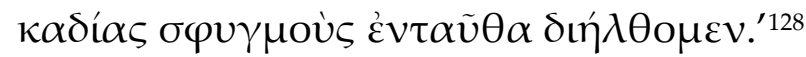

'This is because I did not dare to assert this doctrine before finding out if all particular [observations] are in agreement with it. But now, since we have already been convinced that the substance of capacities is nothing but a particular mixture, and, since we have found that all [observations] regarding diagnosis, prognosis and therapy are in agreement with this view, it was reasonable, I suppose, that we would also give an account on this occasion of pulses that follow the anomalous imbalances of mixture in the heart.' (tr. Havrda 2017, slightly modified)

Again, Galen writes about 'daring' to make the statement that the substance of capacities is a mixture, and relates it to the extent of agreement with his practice as a doctor: unlike the Platonic option of the soul as a separate substance, it is a speculative position that is in agreement with his empirical findings. This makes it a reasonable speculative position (we shall return to this use of عن่ $\lambda$ ó $\gamma \omega \varsigma$, also recurrent in this context together with $\pi \iota \theta \alpha$ vós, below). As we have briefly mentioned before, Galen announces in the (earlier) On the Causes of Symptoms that he might have the audacity to make a statement with regard to the substance of the soul in another work

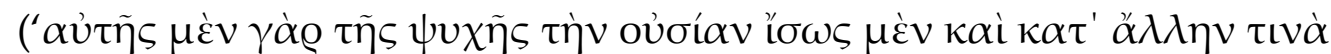

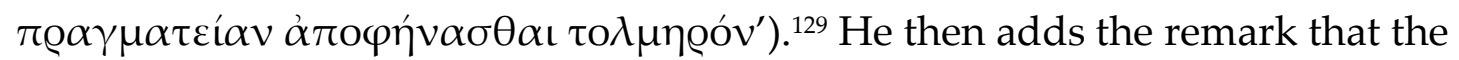
substance of the soul must be one of two things: either it is something that 'uses' the primary organs through pneuma or blood, or it is 'in' the primary organs themselves. That last option seems to be completely compatible with my proposed reading of QAM.

It appears as if Galen, after the Platonic section with its arguments against the immortality and supposed separate existence of the soul, indeed considers it proven that the entire soul is a mixture of the elementary qualities. The crucial passage in this respect is Galen's discussion of the view of Andronicus the Peripatetic (782-83 $\mathrm{K})$, right after the Platonic section. This is not a coincidental position in the text, as should be obvious by now, for Andronicus is credited with espousing the view that the entire soul is a mixture. ${ }^{130}$ Andronicus' position is a reflection of the position Galen's text is reaching at this point. We have already seen that Galen repeats the conclusion of the Aristotelian section - the lower two parts of the soul (or any parts that are mortal) are nothing else than a mixture of the qualities - right after the discussion of the rational part. ${ }^{131}$ At this point, however, Galen takes the discussion a

\footnotetext{
${ }^{128}$ Praes. Puls. IX 305,15-306,4 K

${ }^{129}$ Caus. Symp. VII 191,9-11 K; see infra, section 1, 36

${ }^{130}$ I agree with Singer (2013, note ad locum), that Galen presents Andronicus as speaking about the soul as a whole (ö $\lambda \omega \varsigma$ ): 'The sense that he is thus talking about all the soul, rather than just its 'mortal' parts, seems to be included.'

${ }^{131}$ Hankinson (2006) 250, on this passage: 'This text sees Galen at his most forthright, at least in regard to the lower two parts of the soul: he seems unequivocally to adopt an identity-theory regarding them. These parts of the soul really must be the appropriate (physical) mixtures, with the powers that result from them being attributes of the souls rather than the souls themselves.'
} 
step further and brings in Andronicus, who apparently stated that the substance of the entire soul is either a mixture or a capacity dependent on the mixture:

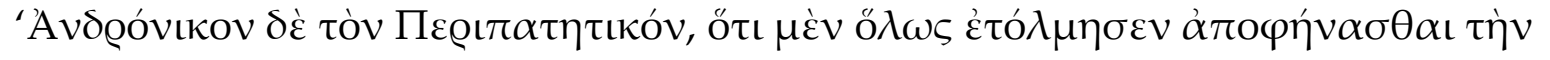

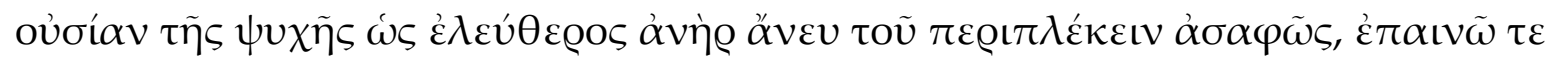

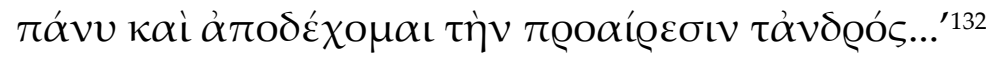

'... and as for Andronicus the Peripatetic, because he dared to speak out on the substance of the soul as a whole, as a free man without unclear complications, I praise him highly and I accept the position of the man...' (tr. Singer, modified)

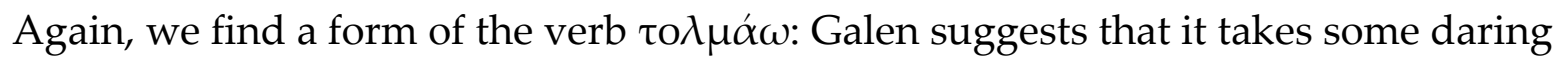
to express the view that the substance of the soul is a mixture. What is more, he applauds Andronicus not only for his bravery, but also for his position itself, and

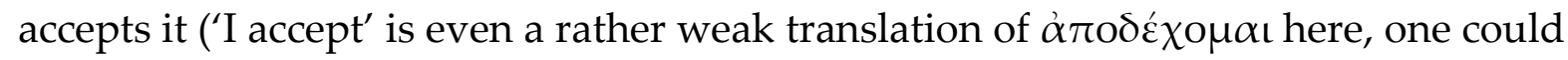
also think of 'I agree with', or 'I follow'). ${ }^{133}$ He agrees with Andronicus in as far as he states that the substance of the soul is a mixture, and merely disagrees with him in as far as Andronicus adds the possibility that it could rather be a capacity dependent on the mixture. ${ }^{134}$ Galen's problem here is with the confused equation of substance and capacity. ${ }^{135}$ That is why he immediately explains (with $\gamma \dot{\alpha} \varrho$ indicating that this is the reason for his disagreement with Andronicus) that the soul has many capacities and is itself a substance (and more specifically, as he adds, a certain mixture of the elemental qualities):

‘ő

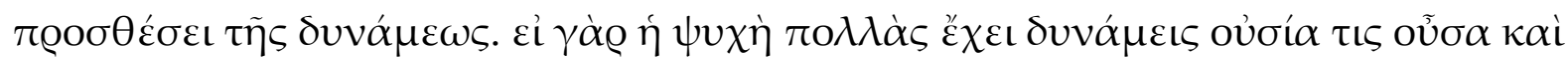

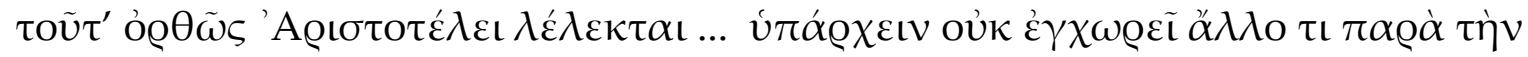

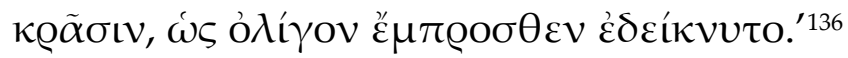

'... but surely when he says that it [the substance of the soul] is a mixture or a capacity dependent on the mixture, I disapprove of the addition of capacity. For if the soul has many capacities, while itself being some kind of substance, and this has been said correctly by Aristotle ... it is not possible for it to be anything else but the mixture, as has been demonstrated a little before.' (tr. Singer, modified)

\footnotetext{
${ }^{132}$ QAM 44,12-7 Müller (IV $782 \mathrm{~K}$ )

133 There might be some irony in Galen's words here, his praise of Andronicus could be considered somewhat excessive - why would it be so brave to speak on the substance of the soul as Andronicus does? On the other hand, we have seen how this 'daring' is a recurrent motive in Galen's talk of the substance of the soul. What is perhaps more striking, is that Galen first praises Andronicus for his clarity, to then proceed to point out that he confused the notions of substance and capacity, which must surely count as a very grave confusion for Galen. Perhaps, therefore, Galen ridicules Andronicus somewhat with his praise in this passage, even though he agrees with his final position (as Galen himself presents it).

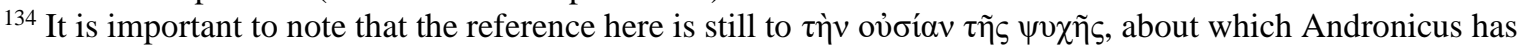
made these statements.

${ }^{135}$ Cf. Hankinson (2006) 244 f.; Sharples (2006) 178 on Andronicus' position

${ }^{136}$ QAM 44,18-45,3 Müller (IV $783 \mathrm{~K}$ ), following the suggestion to place vi $\alpha \propto \chi \varepsilon ı v$ after the parenthesis, which renders Müller's conjecture of $\lambda \dot{\varepsilon} \gamma \varepsilon ı v$ (followed by Bazou) unnecessary, Cf. Singer (2013) textual note 4.21 (Singer does take over the conjecture himself)
} 
Galen does not just recite Aristotelian doctrine here: Aristotle has 'correctly' (ỏ@ $\theta \tilde{\omega} \varsigma$ ) stated the difference between capacity and substance with regard to the soul. ${ }^{137} \mathrm{He}$ is accepting the doctrine of Andronicus (as he presents it) that the substance of the soul is a mixture and simply adds: 'as has been demonstrated a little before', clearly referring to the Aristotelian section on the substance of the soul being a certain mixture of the four qualities. Presumably, he here also refers back to the arguments against the Platonic position of the immortality and separate existence of the rational part of the soul, since Andronicus' position concerns the whole soul. ${ }^{138}$ After the discussion of all three parts of the soul, the lower two in an Aristotelian and the higher rational part in a Platonic context, we find Galen applauding the view that the entire soul is a mixture of the elementary qualities. He only corrects Andronicus in as far as he neglects the difference between substance and capacity, stating that he disapproves merely of the addition of the possibility that the substance of the soul may also be a capacity dependent on the mixture (perhaps also because this would be problematic for the soul's status as a primary cause of movement). The soul's capacities are dependent on the mixture, but the soul itself has to be a substance, not a capacity. Therefore, it has to be the mixture itself, as has been shown earlier. I see no other way here than to conclude that Galen, at least in this work, adheres to the thesis that the substance of the whole soul is a mixture of elemental qualities. That is to say, that the substance of each of the three parts is a specific mixture constituting homoeomerous parts that primarily exercise the activities of the soul from the respective organs.

\section{b. The mixture of the rational soul}

However, we have also noticed that Galen reserves a special position for the rational part of the soul. This is evident from the very structure of the text. In fact, with his arguments against the immortality and separate existence of the soul, Galen opens up a very Platonic-looking vertical perspective in which knowledge and the intelligence of the rational part of the soul are connected to the stars by virtue of their related dryness. ${ }^{139}$ Galen argues against the separate existence of the soul by showing that even its rational part is affected by the elementary qualities of dryness and wetness. Yet, at the same time and through the same argument, he connects the part of the soul that does the understanding to the heavenly realm of the stars. Thus,

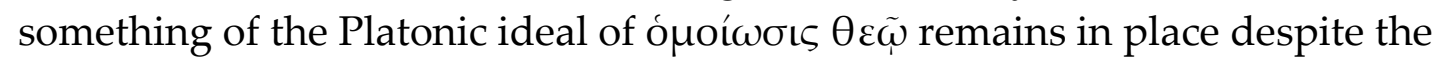

\footnotetext{
${ }^{137} \mathrm{Cf}$. Singer (2013), for the view that Galen refrains from presenting his own doctrine here and in many other places in $Q A M$, but is 'mainly concerned to prove what an Aristotelian ought to think.' (361) More on this reading below in section 3, 71-6.

138 Jouanna (2009a) has shown that, despite the traditional Latin title (with animi mores) there is actually a 'strong emphasis on the idea of the modification of the intellectual faculties' (199) in $Q A M$.

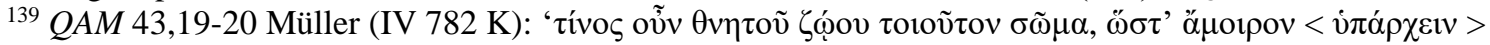

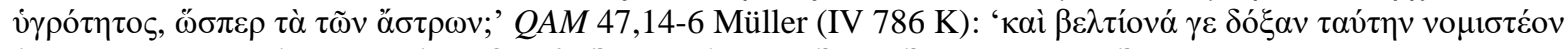

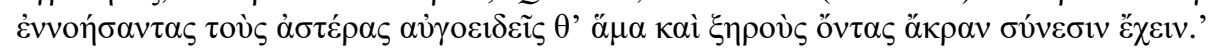


arguments against the immortal soul. In Galen's cosmos, though, where the traditional Platonic dualism is not affirmed, this ideal may perhaps rather be called a

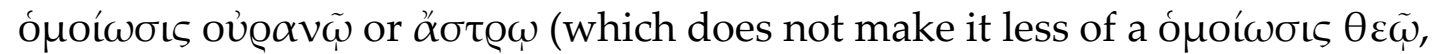
however). He reminds us that Plato stated that the soul, by being bound to the body, forgets what it used to know. Galen offers us a rather specific interpretation of this Platonic doctrine:

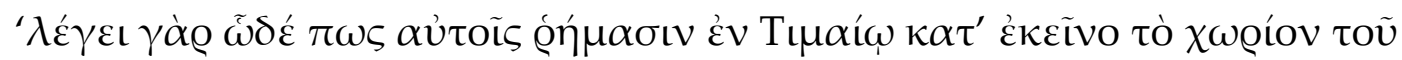

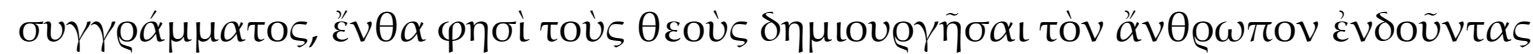

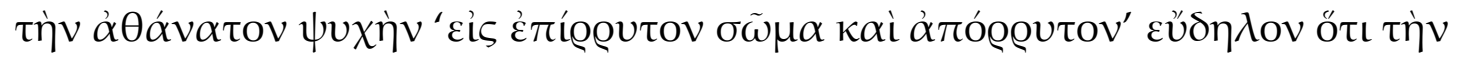

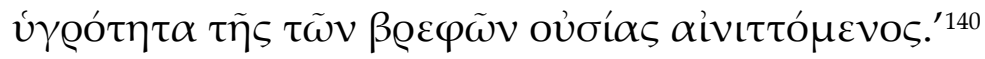

'For he [Plato] says something like this in these very words in the Timaeus, in that part of the work in which he states that the gods craft the human being by placing the immortal soul 'in a body subject to influx and outflow'. It is quite evident that this is an oblique reference to the wetness of the substance of infants.' (tr. Singer, modified)

The reference to the substance of infants reminds us of the starting-point of Galen's text, where he presented the observable differences between children as proof for our given difference in nature. ${ }^{141}$ The crafting of the gods concerns the original formation of the human being that would result, according to Galen, in a given nature in accordance with a certain mixture and also, as we now learn, in a (still) disabled state of the faculty of understanding due to predominant wetness. ${ }^{142}$

But Galen goes on to cite another passage from the Timaeus (44a8-9), which explains that our soul indeed 'becomes mindless at first' but is able to 'acquire a calm' and 'become intelligent' when the 'the stream of growth and nourishment' that comes upon it is reduced. As Galen explains, the reduction of this stream is to be understood as the change from the wet state of the substance of the infant to a more dried state of the mixture. Note the self-evident manner in which Galen can use the

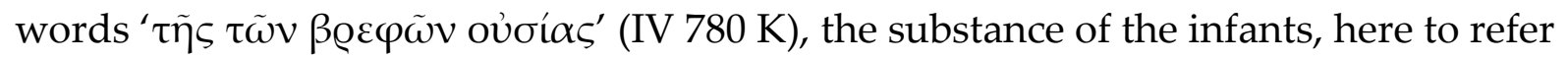
to the child's mixture of elemental qualities, being relatively wet or dry. Note also how obvious it is now in his text that the state of this mixture determines the capacities of the child, i.e. the rational capacity of understanding in this case. The Platonic 'recollection' ( $\dot{\alpha} v \alpha \dot{\alpha} \mu \nu \eta \sigma \iota)$ ) of the knowledge that the separate soul obtained in a former heavenly state is given a material (or rather, elemental) twist by Galen, for it is this increasing dryness that brings the soul into a state of understanding (and potentially even likens it to the stars). ${ }^{143}$

\footnotetext{
${ }^{140} Q A M$ 42,11-7 Müller (IV $780 \mathrm{~K}$ )

${ }^{141}$ QAM 32,14 f. Müller (IV $768 \mathrm{~K}$ )

${ }^{142} \mathrm{Cf}$. Temp I $578 \mathrm{f}$. K and San. Tu. VI 4-5 K, where the wetness of infants is more elaborately described; for more extensive discussion of Galen's interpretation of the Timaeus and the roles of the elemental qualities dryness and wetness therein, see infra, CS III, particularly section 3, 156-63.

${ }^{143}$ QAM 43,10-44,2 Müller (IV 781-2 K) and 47,9-18 Müller (IV 786 K)
} 
The role of the stars in $Q A M$ and the likening of the dryness of the intelligent soul to the dryness of the stars are not random and fit with the Platonic doctrine Galen cites from the Timaeus. There, the divine maker of the universe creates from the mixture of the soul of the universe the immortal parts of the human souls, a number equal to the stars, and assigns to each soul a star. If such a soul, after being incarnated, would succeed in mastering its emotions and living just, it would 'return again to the dwelling of its kindred star'. Particularly in the context of the Timaeus, presented as a follow-up on the Republic, both this mastering and justice are about the relation between the several parts of the soul and the extent to which the rational part is in control. ${ }^{144}$ In line with this, Galen states that the soul becomes more like a star, if it becomes more understanding and less occupied with the needs and desires of its lower parts. That is to say, in the end, when it lives what is considered a more philosophical life - remember the virtue that the Pythagoreans and Platonists achieved according to Galen, by taking good care of their mixture. ${ }^{145}$ Thus, when the causal forces that the different soul-parts exercise, are checked and controlled by the rational part in the end, the substance of the soul will become more like the substance of stars. This seems to me an adaptation of the general Platonic doctrine that we also find for example in the (probably near-contemporary) Handbook of Platonism presumably written by Alcinous. ${ }^{146}$ It is stated there that 'souls which achieved dominance over these affections [sensations, pleasure and pain, fear and anger] and were in no way constrained by them would live justly and return to their kindred star' ${ }^{147}$ Galen merely takes out the notion of the afterlife, which is in fact not needed if we assume that we can liken the substance of our rational soul to that of the stars to some extent during our life.

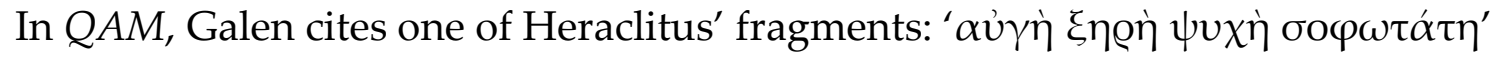

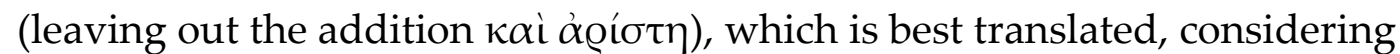
Heraclitus' other remarks on the 'moist soul': 'a ray of light is the dry soul, wisest'. ${ }^{148}$ Throughout the fragments of Heraclitus there is a basic opposition between the moist and dry soul to be found. The dry soul is associated with wisdom and the light of the heavenly bodies and the moist soul with drunkenness, those desires and acts that man has in common with animals, and even the death of the soul. ${ }^{149}$ In the same passage of $Q A M$ where he cites Heraclitus, Galen calls the stars 'of the nature of

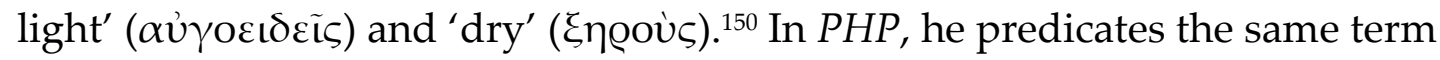

\footnotetext{
${ }^{144}$ Tim. 42b3-4

${ }^{145}$ QAM 32,9 ff. Müller (IV $768 \mathrm{~K}$ )

146 Dillon (1993)

${ }^{147}$ Alcinous Handbook of Platonism 16,2 (tr. Dillon)

${ }^{148}$ QAM 47,12 Müller (IV 786 K). Cf. Kahn's (1979) excellent commentary on fr. CIX (DK 118) in his edition of Heraclitus' fragments

${ }^{149}$ Kahn (1979) commentary on fr. CIX, gives references to the relevant fragments. Cf. also Theophrastus On sense perception 3-4, on Parmenides: 'Parmenides did not define anything at all except that, the elements being

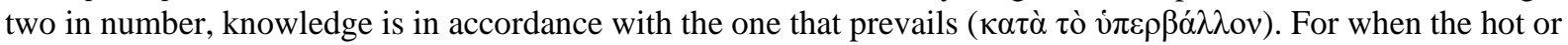
the cold dominates, the thought becomes different. The better and the purer one of two is the one produced by what is hot...' I thank Jaap Mansfeld for pointing out this passage.

${ }^{150}$ QAM 47,14-6 Müller (IV 786 K)
} 
$\alpha \dot{v} \gamma 0 \varepsilon\llcorner\delta \dot{\varepsilon} \varsigma$ of the $\pi v \varepsilon \tilde{v} \mu \alpha$ that comes from the brain - note that this pneuma has to be moving downwards to permeate and govern the rest of the body, like the intelligence of the heavenly bodies permeates the earthly bodies (see below) - and $\pi v \varepsilon \tilde{v} \mu \alpha$ is considered (and rejected) in PHP as one of the possible options for the substance of the soul (see below). ${ }^{151}$

This 'psychic' $\pi v \varepsilon \tilde{v} \mu \alpha$ fulfils an important role in the transmission of psychic functions throughout the body (especially that of vision, sensation in general and voluntary motion) because it moves from the brain through the nerves that connect the whole body (likewise the 'vital' $\pi v \varepsilon \tilde{v} \mu \alpha$ that stems from the heart moves through the arteries). ${ }^{152}$

We have seen how one of Galen's objections against the Platonic doctrine of the soul

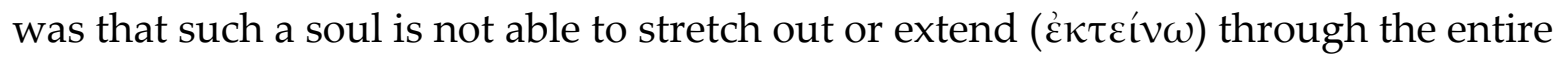
body because it is not anything bodily itself. ${ }^{153}$ But, accepting the thesis that the soul is a certain mixture of elemental qualities located in the three main organs, the extension of the soul's capacities through the rest of the body might still be considered a serious problem (even though the rest of the body is also formed of combinations of the same elemental qualities, the different parts are formed from different combinations and form separate organs). ${ }^{154}$ The $\pi v \varepsilon \tilde{v} \mu \alpha$ seems to play an important role here. Before we go on, it might be helpful to note that Galen's notion of (psychic and vital) $\pi v \varepsilon \tilde{v} \mu \alpha$ as presented in PHP and other works and the thesis proposed in $Q A M$ that the substance of the soul is a mixture of elemental qualities need not be at odds with each other in any way. Firstly, in $Q A M$, right after he has approved of the position of Andronicus that the whole soul is a mixture of elemental qualities, Galen states that the Stoics adhere to a similar kind of notion of the substance of the soul, since they believe it to be a kind of $\pi v \varepsilon \tilde{v} \mu \alpha$ that is composed of a specific combination of the elemental qualities. ${ }^{155}$ Thus, Galen seems to have no problem here in conflating the mixture and the $\pi v \varepsilon \tilde{v} \mu \alpha$ to get the Stoics on board. But secondly, and more importantly, Galen explicitly rejects the $\pi v \varepsilon \tilde{v} \mu \alpha$ as an option for being the substance of the soul already in PHP. First it is suggested that, on the basis of his previous findings, one might consider the $\pi v \varepsilon \tilde{v} \mu \alpha$ in the ventricles of the brain to be either the 'first home' of the soul (

\footnotetext{
${ }^{151}$ PHP VII 474,3-7 De Lacy (V 642 K). Cf. also Hipp. Epid. VI, XVIIB $214 \mathrm{~K}$, ‘ ... ஸ் $\alpha \hat{\gamma} \gamma o \varepsilon 1 \delta \dot{\varepsilon} \varsigma \pi v \varepsilon \tilde{v} \mu \alpha$

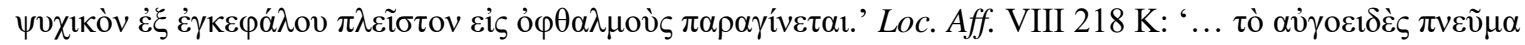

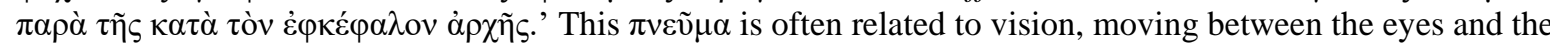
brain, Galen uses the term $\alpha$ ช่

${ }^{152}$ PHP VII 444,29-33 De Lacy (V $608 \mathrm{~K}$ ): 'Now the pneuma in the arteries is and is called vital, and that in the brain is called psychic, not in the sense that it is the substance, but rather the first instrument of the soul that resides in the brain, whatever its substance may be.' (De Lacy); Loc. Aff. VIII $175 \mathrm{~K}$ : 'The primary instrument of the soul for all sensory and voluntary [motor] activities is the pneuma in the cerebral cavities, and especially in the posterior ventricles.' (Siegel); Loc. Aff. VIII 233 K: 'As you know, I consider this pneuma as the first instrument of the soul, since the pneuma [psychikon], which is located in the cerebral cavities, has to transmit sensitivity and movement to all parts of the body.' See Trompeter (2018) on the relation between these different kinds of pneuma; Celkyte (forthcoming) for more extensive discussion on pneuma in Galen.

${ }^{153}$ QAM 39,3-4 Müller (IV $776 \mathrm{~K}$ )

${ }^{154}$ Cf. Tieleman (1996), 155

${ }^{155}$ QAM 45,4 f. Müller (IV 783-4 K)
} 
regarded as incorporeal, or otherwise to be the soul itself, if the soul is regarded as corporeal. But Galen then rejects both these options:

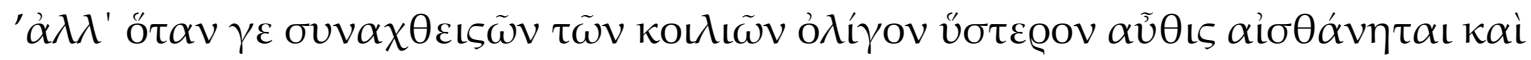

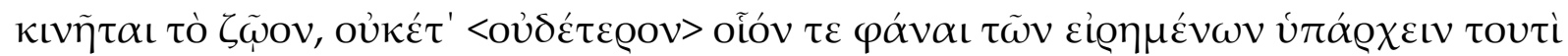

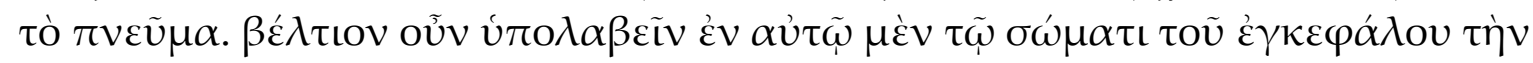

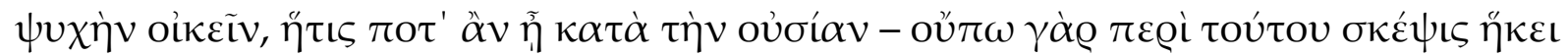

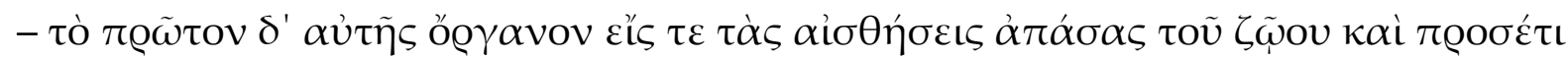

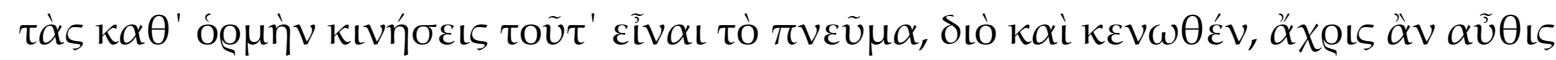

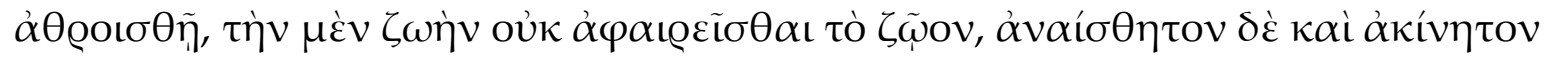

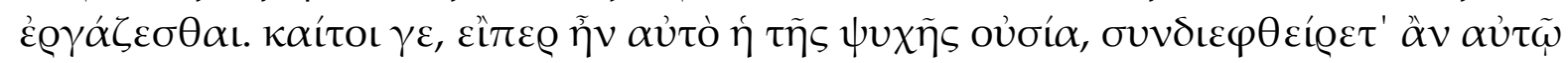

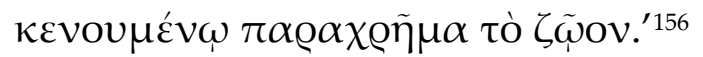

'But when presently, after the ventricles have been closed up, the animal regains sensation and motion, it is no longer possible to accept either alternative. It is better, then, to assume that the soul dwells in the actual body of the brain, whatever its substance may be - for the inquiry has not yet reached this question - and that the soul's first instrument for all the sensations of the animal and for its voluntary motions as well is this pneuma; and therefore, when the pneuma has escaped, and until it is collected again, it does not deprive the animal of its life but renders it incapable of sensation and motion. Yet if the pneuma were itself the substance of the soul, the animal would immediately die along with the escape of the pneuma.' (tr. De Lacy)

So the $\pi v \varepsilon \tilde{v} \mu \alpha$ is neither the 'first home' of the soul, nor the soul itself. What the soul itself is, remains unanswered here, although it is said to dwell in the body of the brain - which is perfectly compatible with our analysis of $Q A M .{ }^{157}$ The $\pi v \varepsilon \tilde{v} \mu \alpha$ is rather defined as the soul's first instrument for the sensations and voluntary motions. ${ }^{158}$ Since the function of the $\pi v \varepsilon \tilde{v} \mu \alpha$ is one of transmission, it is unsuitable to be identified with the soul itself or the substance of the soul, which is located in the three main organs, whereas it can be considered an instrument of the soul. ${ }^{159}$ It is the stuff through which the soul stretches itself out through the body, and which has its

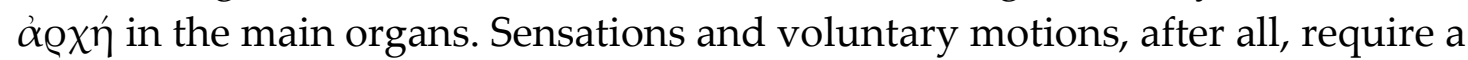
connection to all ends of the body. Thus, Galen's notion of the soul as $\pi v \varepsilon \tilde{v} \mu \alpha$ and of the substance of the soul as a mixture, are not only compatible but can even support each other. Questions remain on the precise relation of $\pi v \varepsilon \tilde{v} \mu \alpha$ and the mixture, particularly as regards to the stuff of the $\pi v \varepsilon \tilde{v} \mu \alpha$ : presumably, it must be very fine,

\footnotetext{
${ }^{156}$ PHP VII 444,2-11 De Lacy (V $606 \mathrm{~K}$ )

${ }^{157}$ Cf. Loc. Aff. VIII $75 \mathrm{~K}$, also referred to above, for the difference between the soul itself and 'the body of the brain' and the analogous difference between the brain affected as a homoeomerous and an organic part respectively.

${ }^{158}$ Cf. PHP VII 446, $11 \mathrm{f}$. De Lacy (IV 609 K): ‘... and we also learned that the psychic pneuma is neither the essence of the soul nor its dwelling, but its first instrument...' (tr. De Lacy)

${ }^{159} \mathrm{Cf}$. Hankinson (2006), 236: 'pneuma is thus a necesssary medium of transmission (like the fluid in a hydraulic system), and perhaps also a fuel for the movement, but not the source of the motion itself: and so it is not the substance of the soul.' Cf. Trompeter (2018) particularly $193 \mathrm{f}$.; Celkyte (forthcoming)
} 
as it travels quickly throughout the body, but must also have some resemblance to the mixtures that the organs are constituted of in order to fulfil its communicative and transmissive function. But these questions cannot be further pursued here. We have seen how the psychic $\pi v \varepsilon \tilde{v} \mu \alpha$ is said by Galen to have some resemblance to light, and how it moves from the brain, through the nerves, to the rest of the body. ${ }^{160}$

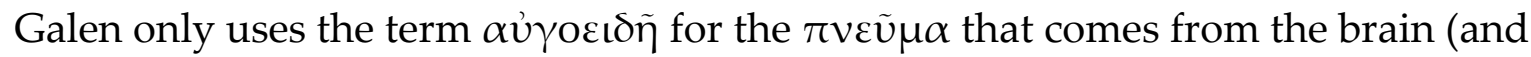
that forms the basis for the capacity of vision), and not for the 'vital' sort of $\pi v \varepsilon \tilde{v} \mu \alpha$ that comes from the heart, which is in line with the exclusive connection of the rational part of the soul to the heavenly bodies. In the epode of UP, Galen dwells on the amazing intelligence of the heavenly bodies, which permeates everything below:

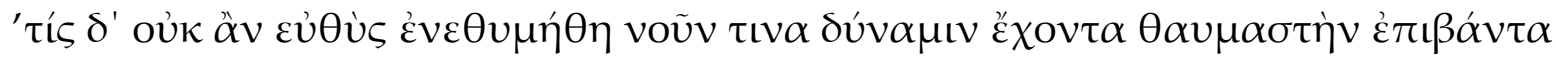

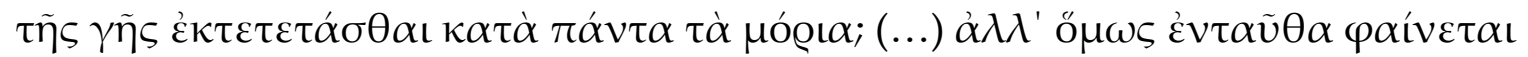

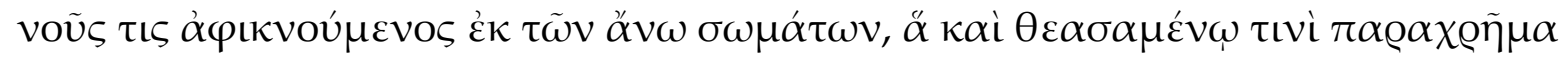

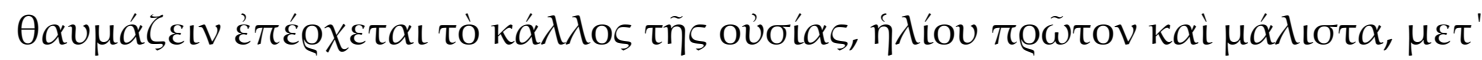

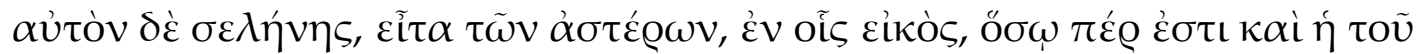

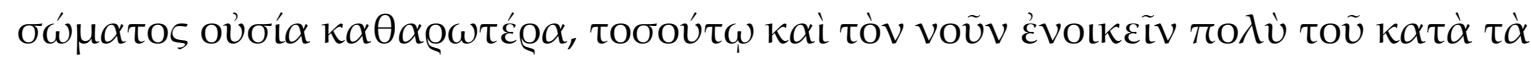

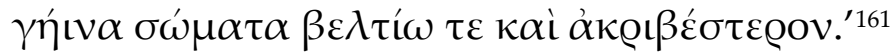

'Who would not immediately infer that some intelligence possessing amazing power treads the earth and extends through its every part? (...) But even here some intelligence appears to be reaching us from the bodies above, and the beauty of their substance forces anyone that sees them to be amazed at once, that of the sun first and foremost, that of the moon after that, and next that of the stars, and it is reasonable to suppose that the intelligence that dwells in them is exactly that much better and sharper than that [which dwells] in the earthly bodies as the substance of their body is purer.' (tr. May, slightly modified)

The marvellous usefulness of the parts that is praised throughout UP is grounded in an intelligence that primarily dwells in the heavens. In his Epode Galen both affirms the dependence of the observable teleological order on an intelligent principle, as well as the affinity of that principle with our rationality. Some kind of intelligent force reaches down from the heavenly bodies, apparently its primary location, and extends through every part of the earthly beings - as we observed, forming a beautiful analogy with the extension of the psychic pneuma from the brain downwards to the rest of the body. ${ }^{162}$

\footnotetext{
${ }^{160}$ See note 152 above; cf. Caus. Resp. 8 (IV 469 K); UP I 482 Helmreich (III 483 K), II 93 Helmreich (III 813K); in PHP VII, 448,4 ff. De Lacy (V $611 \mathrm{~K}$ ), Galen questions whether all nerves have pneuma in them. I thank Aiste Celkyte for some of these references, for a detailed discussion of these and other passages on pneuma in Galen, see her forthcoming The Unity of Galen's Physiology.

${ }^{161}$ UP II 446,7-19 Helmreich (IV 358-9 K)

${ }^{162}$ Cf. Sem. 136,7-9 (IV 584-5 K): ‘. . just as we see externally the distribution of sunlight to the circumambient, and within us (the distribution of quality) from heart to arteries and brain to nerves.' (tr. De Lacy); Loc. Aff. VIII 66,9-67,6 K; Plotinus, Enneads IV, 8, 4: 'So it is with the individual souls; the appetite for the divine Intellect urges them to return to their source, but they have, too, a power apt to administration in this lower sphere; they
} 
In this analogy between our brain and the heavenly bodies, the notion of a kotvi oú $\sigma i \alpha$ is operative, too, for the difference between our intelligence and that of the heavenly bodies is not essential but gradual. It is grounded in the difference in substance of their respective bodies: how intelligent must the heavenly bodies with their pure substances be, asks Galen, when we consider that the intelligence of men like Plato, Aristotle, Hipparchus and Archimedes came to be in something that moist

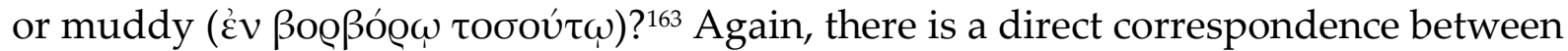
the purity of the bodily substance, or its relative dryness, and the quality of the intelligence of a given being. There is a vertical hierarchy in the cosmos, in which the higher realms have a greater degree of dryness and purity, and therefore of intelligence. Their superiority emanates and is communicated to the lower realm: the light and intelligence of the heavenly bodies reaches down, infusing the air and bodies below them. The human being, looking up and seeing the heavenly bodies, is brought into that state which Plato in his Theaetetus designated as the only possible beginning of philosophy - amazement $\left(\theta \alpha v \mu \alpha \dot{\zeta} \varepsilon \iota v\right.$ in the last quotation from UP). ${ }^{164}$ What we can gather from these quotations is that the state of a given substance, and thus the activities it can undertake, is strongly determined by the overall cosmic organization of qualities, in which some qualities predominate certain regions. Thus, because dryness predominates in the higher regions and wetness in the lower ones, a mixture with predominant dryness might be more apt to generate the activities of the higher regions. It seems as if Galen, in line with tradition, generally associates the qualities of hotness and dryness more with activity and the qualities of coldness and wetness with passivity: ${ }^{165}$

'Just as cold produces laziness, immobility and weakness, so heat produces energy, movement, and the strength to act. That is why the beginning of youth and wine arouse movement and power, while old age and chilling drugs produce laziness and weakness; they lead, in time, to the annihilation of actions and movements.'166

But this notion, that a specific mixture generates specific states and activities and that we can have knowledge of what kind of mixture causes what kind of state and activity, is where the possibility of a second formation of our mixture enters, after that of the first creation of nature: as soon as our rational faculty is functioning, we can and should develop our soul by adopting a way of life that further enhances our

may be compared to the light attached upwards to the sun, but not grudging its bounty to what lies beneath it.' (tr. MacKenna); cf. Frede (2003) particularly $115 \mathrm{ff}$.

${ }^{163}$ UP II 446,23-47,8 Helmreich (IV $359 \mathrm{~K}$ )

164 Theaetetus $155 \mathrm{~d}$ : 'Socrates: For this is an experience which is characteristic of a philosopher, this wondering ( $\tau$ ò $\theta \alpha \nu \mu \alpha ́ \zeta \varepsilon v v)$ : this is where philosophy begins and nowhere else. And the man who made Iris the child of Thaumas was perhaps no bad genealogist.' In Plato this is clearly also related to the heaven and heavenly bodies, compare from the same dialogue the passages on Thales staring at the sky and falling in the well (174a-b) and on the escaping from earth to heaven (176a-b), but also, e.g., Socrates staring at the sky before the Symposium.

165 See infra, CS III, particularly sections 3 and 4, 156-193, for more elaborate discussion of this point

${ }^{166}$ Character Traits tr. Davies in edition Singer (2013) 140 
mixture in such a way that we can become more virtuous and understanding. ${ }^{167}$ That is to say, after being given a certain mixture in the first place, by the gods or nature, we can continue this divine formation ourselves, because we have a rational soul. As Galen remarked at the very beginning of $Q A M$ :

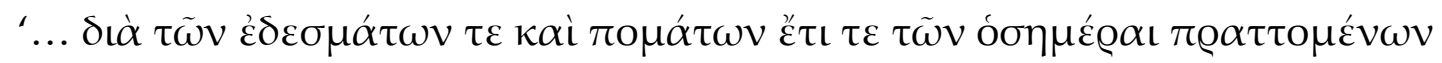

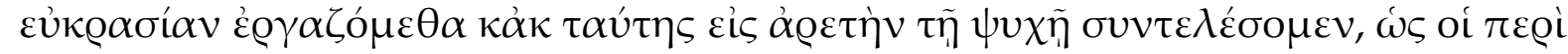

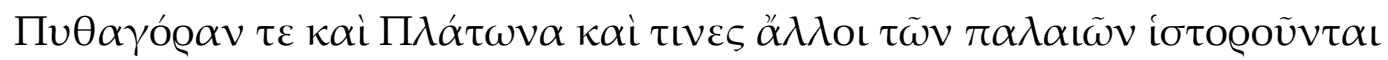
$\pi \varrho \alpha ́ \xi \alpha \nu \tau \varepsilon \varsigma^{\prime}{ }^{\prime 168}$

'... for through what we eat and drink and more generally through our daily practices, we bring about good mixture, and through this [good mixture] we shall achieve for the soul a state of virtue, as those around Pythagoras and Plato and some others among the ancients are reported to have done.'

This formative capacity of the rational part of the soul is crucial for Galen. It is not just what makes the difference between man and the other animals and guarantees the possibility of ethics. It also contains man's potential to reach his $\tau \varepsilon$ ćlos. The state of virtue that Galen refers to here is not an accidental attribute. Like most of the ancient thinkers, Galen's notion of man is that of an essentially unfinished being that has to play its own creative part before it can be said to have reached completion, thus continuing the role of its divine maker to which it always has some form of analogy. We will return to this theme below (section 4).

For now, what is important to observe for our purposes here, is that Galen retains the vertical connection, the kinship between the heavens and the rational part of the soul offered in Plato's Timaeus ${ }^{169}$, although he gives it a more material basis, namely that of relative dryness. This complies with his notion of the substance of the soul being a mixture of the four elemental qualities as well as with his association of the rational soul with the stars. ${ }^{170}$ Even though he argues against Platonists where it regards the separate existence and immortality of the soul, Galen retains the special connection of the rational part with the heavens that is fundamental for Platonic ethics. This must be the main reason why he treated the rational part of the soul in a discussion separate from the other two parts in a Platonic context.

\footnotetext{
${ }^{167}$ Cf. Hankinson (2014) 103: 'In other words, if the capacities of the soul are dependent upon the constitution of the body, no less, it seems, at least on occasion, can that constitution itself be affected by psychological dispositions.'

${ }^{168}$ QAM 32,9-13 Müller (IV $768 \mathrm{~K}$ )

${ }^{169}$ See Tim. 90a: 'Now we ought to think of the most sovereign part of our soul as god's gift to us, given to be our guiding spirit. This, of course, is the type of soul that, as we maintain, resides in the top part of our bodies. It raises us up away from the earth and toward what is akin to us in heaven, as though we are plants grown not from earth but from heaven. In saying this, we speak absolutely correctly. For it is from heaven, the place from which our souls were originally born, that the divine part suspends our head, i.e., our root and so keeps the whole body erect.' (tr. Zeyl)

${ }^{170}$ Galen's interpretation of Plato's Timaeus in various works is worked out more elaborately in CS III
} 


\section{Conclusion}

To conclude this section, I believe that on the basis of our discussion of the textual evidence, we have established the following things. Galen, in what I have called the Aristotelian section (773-5 K), argues that the substances of the non-rational parts of the soul are certain mixtures of the elementary qualities forming homeoemerous bodies, that is to say, they are the formal aspect in a hylomorphic composition with prime matter. He argues for the same conclusion for the rational part of the soul in what I have called the Platonic section (775-82 K). After both of these sections he applauds and accepts the view that the substance of the entire soul is a mixture (782$3 \mathrm{~K})$. Furthermore, he takes the proof that the substance of the soul is a mixture as the most scientific proof for his central thesis that the capacities of the soul follow the mixture of the body. However, the rational part of the soul has been assigned a somewhat exceptional position that retains something of a Platonic perspective, in line with Galen's classing of $Q A M$ as a work 'On Platonic philosophy'. As we shall see below (section 4), this kinship with the heavens of the rational part of the soul plays an important role in the possibility of ethical philosophy in the context of a work that emphasizes the determination of the soul's activities and affections by the bodily mixture and even identifies the substance of the soul with that mixture. But first, since the reading of $Q A M$ presented above differs from much of the preceding scholarly tradition and is not without problems, we shall discuss some of the possible objections to my view that Galen argues for the thesis that the substance of the soul is a mixture.

\section{Positioning in the scholarly debate}

\section{a. Preliminary remarks}

As we briefly mentioned before, several scholars have argued that the thesis of the substance of the soul being a certain mixture should somehow not be ascribed to Galen or not be viewed as an expression of his own doctrine. We shall critically discuss their views in this section. A few preliminary remarks are in order, however. It is certainly true that $Q A M$ is both a somewhat ambiguous work in itself and stands out in the Galenic corpus for its more speculative position. It is also true that Galen seems to firmly reject any knowledge of the substance of the soul in some of his other (partly later) work. On the other hand, as we have seen, Galen also refers to 'what has been shown' in QAM in other later works (such as HNH, Loc. Aff. and Foet. Form.), which are considered as works that reflect genuine Galenic doctrine. Thus, apparently Galen himself does take QAM to be consistent enough with these other works to refer to its arguments as support for them. Moreover, as we have also seen, the doctrine that the substance of the soul is a mixture is in line with, and based on, much of his earlier work that is presupposed in QAM. Also, QAM seems to be the only place in the Galenic corpus where Galen actually discusses the question of the 
substance of the soul at some length. Therefore, it might be a dubious strategy to dismiss what he states there merely on the basis of his reluctance to actually discuss the subject in other works. Finally, given that Galen classified the work as one concerning 'Platonic philosophy', it may make sense for him to enter somewhat more speculative or philosophical terrain in this treatise than in one, say, treating of the pulse or respiration. For these reasons, I think that characterizing $Q A M$ as vague, of lower quality than other Galenic work, or mere propaganda for the office of doctor, and using such evaluations to set the work aside and skip over its integration into the rest of the Galenic corpus, as has been done in some recent scholarship, will not do. The difficulty with Galen's speculative boldness in QAM goes back a long way in scholarship: a certain unease with $Q A M^{\prime}$ 's stronger thesis already becomes manifest through the editing work of Müller, who omits some of the evidence by bracketing the two sentences after the Aristotelian section that most clearly affirm it. ${ }^{171}$

Moraux seems to be an early exception in modern scholarship by taking the stronger thesis as the expression of Galen's view, albeit with a somewhat careful expression: 'In seinen letzten Jahren scheint er davon überzeugt, da $\beta$ die Zustände des Körpers das Psychische eben deswegen zu beeinflussen vermögen, weil die Seele nichts anderes ist, als eine besondere "Mischung" der elementaren Bestandteile des Körpers.' ${ }^{\prime 72}$ Moraux explains the difference with other, earlier works (UP and PHP) as a development towards 'Naturalismus'. The problem with a developmental view is obvious: as soon as we find another expression of scepticism or agnosticism after $Q A M$, the thesis of a linear development becomes difficult to maintain. Such has happened, of course, with the more recent discovery of Galen's On my own Opinions (Prop. Plac.).

A comparable but more careful position is found in Tieleman: 'In PHP Galen still clings to an agnostic position as to the substance of the soul. Nonetheless he already links psychic part and bodily part (PHP 6.2.5 [=V 515.12-516.1 K]). In the work of his late age, $Q A M$, he takes the next step of actually identifying the substance of the soul with the form of the three main bodily organs, taking form in the sense of the blend of elementary qualities distinctive of each organ. In effect he comes out in favour of the Peripatetic view of the substance of the soul as the form of the body, combining this with the Platonic tripartition-cum-location.' ${ }^{173}$ Mario Vegetti has argued among similar lines in an insightful chapter on Galen's interpretation of the Timaeus: 'Il confronto di Galeno con il Timeo riprende nel Quod Animi Mores (QAM) nel punto, si può dire, dove esso si era interrotto nel PHP. L'anima è divisa in tre parti, che hanno la loro localizzazione somatica in tre organi 'omeomeri', rispettivamente il cervello, il cuore e il fegato... L'anima non sta negli organi somatici come un inquilino in un appartamento. Sarà meglio parlare, seguendo un tesi affermatasi nella scuola di Aristotele, forse ad opera di Andronico di Rodi, dell'anima come 'temperamento' (krasis) o come facoltà (dynamis) derivante dal temperamento; anzi, Galeno ritiene sia

\footnotetext{
${ }^{171}$ See note 91 above

${ }^{172}$ Moraux (1984) 778

173 Tieleman (2003) 168
} 
meglio eliminare del tutto il riferimento alle facoltà e intendere l'anima soltanto come temperamento dell'organo, dando così una interpretazione molto restrittiva della definizione aristotelica dell' anima come forma del corpo. ${ }^{\prime 174}$

I think the analysis given in the first two paragraphs above supports the position of Moraux, Tieleman and Vegetti. However, rather than suggesting a one-way development as Moraux does, my conclusions are restricted to the content of $Q A M$ itself and its congruence with both earlier and later work. These conclusions can be taken as an elaboration of the suggestions made by Tieleman and Vegetti. Without trying to unify Galen's work into one coherent and consistent doctrine with respect to the substance of the soul, we can simply acknowledge that he chose to enter somewhat more speculative terrain in $Q A M$, consistent with the question he 'dares' to ask there. At the same time, we should acknowledge, based on the analyses offered above, that this speculation is in line with the rest of his work, which makes this particular speculative position, as we have noted above, a reasonable one for Galen.

On the other hand, Garcia-Ballester, Lloyd, Donini and Singer all seem to agree though, not all for the same reasons - that Galen does not actually argue for the thesis of the substance of the soul being a mixture in $Q A M$. What these scholars have in common with regard to their interpretation of $Q A M$ is the development of an interpretational strategy that enables them to avoid taking the thesis as a serious expression of Galenic doctrine. In other words, their agreement consists in the conviction that there has to be a reason for the presence of this conclusion in $Q A M$ other than it being an expression of Galen's own view. An important and legitimate motive behind the development of such a strategy for all of them seems to be the apparent incongruence of $Q A M$ 's stronger thesis with some of Galen's other work. Before discussing their views in more detail, I would like to briefly go into this general problem, first. The comparison is often made with $P H P$, which is dated much earlier and therefore not very compelling on its own (one could still argue for a developmental thesis in line with Moraux). But the comparison is also made with Prop. Plac., which is more interesting, because it is later than QAM and seems to advocate the same 'agnosticism' as expressed in PHP and other works. Because Prop. Plac. is a late work in which Galen looks back on his own writings, it would be the most problematic case in this regard. If he clearly expresses his agnosticism with regard to the substance of the soul in that work, should we then not conclude that he has always remained agnostic and that, indeed, we should not take the strong thesis of $Q A M$ too seriously? In the next paragraph we shall take a small detour to discuss the relation between $Q A M$ and Prop. Plac., before returning to the scholarly debate.

\footnotetext{
${ }^{174}$ Vegetti (2000) 80-1. On the possible Peripatetic precedents for Galen's position see Kupreeva (2014) and Chiaradonna (2019)
} 


\section{b. QAM and Prop. Plac.}

In Prop. Plac., Galen explicitly claims several times that he does not know what the substance of the soul is. ${ }^{175}$ Unfortunately, he does not refer to $Q A M$ at all. This is remarkable in itself, for several reasons: (1) he did refer to $Q A M$ in many of his other later works, (2) he frequently refers to many of his other works in Prop. Plac. and (3) it is obvious that the subject at hand in Prop. Plac. has strong affinities to QAM at some points. Whatever the reason for the absence of any explicit reference to QAM in Prop. Plac., I do not think it is legitimate to conclude from the apparent contradiction concerning what Galen has to say on the substance of the soul in both works, that what he has to say in $Q A M$ is not to be taken seriously. In this regard, it is important to note much rather the strategic aim of Prop. Plac. Galen, finding himself in a similar situation as the poet Parthenios, as he states, is defending himself against wrong interpretations of his works. He explicitly presents this predicament as the very reason for writing the work. In the apt words of Aileen Das: 'this work seems to be as much an apology as a career conspectus.' ${ }^{176}$ More specifically, Galen remarks that people have often misunderstood the status of some of the things he wrote. Thus, there has apparently been a mix-up of things he has claimed to know and things he has merely claimed to find plausible ( $\pi \imath \theta \alpha v$ ó $)$. It seems likely, considering the apologetic and careful tone of the whole text, that others have taken some views that Galen has presented as plausible as if they were presented by him as having the status of scientific knowledge. ${ }^{177}$ After these introductory remarks, Galen starts denying all knowledge with regard to ticklish subjects such as the creation and creator of the universe, the gods, the substance of the soul and the celestial bodies. As if he had never speculated on any of these subjects in his work (not only in QAM, but also in UP or his commentary on and summary of the Timaeus for example). Thus, Galen is here drawing a strict boundary between what he claims to have knowledge of, and what he could merely present as plausible, or as the most plausible position on a certain subject, on the basis of what he does know. ${ }^{178}$ Moreover, we can derive from $Q A M$ that Galen met with some kind of indignation over the views he presents there: they were apparently judged to be destructive of the beautiful fruits of philosophy (QAM IV $814 \mathrm{~K}$ ). One might think here of the well-known Stoic metaphor of philosophy as an orchard or garden, where logic is the protective fence around the

\footnotetext{
175 Prop. Plac. 3,1 (Lami and Garofalo 64); 7,1 (Lami and Garofalo 86); 15,1 (Lami and Garofalo 136-8), = 173,16-8, 179,28-9 and 188,27-30 Boudon-Pietrobelli

${ }^{176}$ Das (2014) 2

177 Prop. Plac. 1 (Lami and Garofalo 57-60 = 172,1-30 Boudon-Pietrobelli)

178 Cf. Frede (2003) 77: 'So Galen does distinguish between definitive answers, backed up by conclusive proof, and answers which, though not supported by proof, are supported by reasonable argument and are not ruled out by considerations to the contrary. Galen allows himself such plausible views, but is hesitant to express them.'; Chiaradonna (2009) 245 f. and (2014); Tieleman (2018); Vinkesteijn (2019); DeLacy, in his commentary on $P H P$ (p 623), lists instances in which Galen opposes plausibility and truth.
} 
orchard, physics the trees or plants and ethics the fruit or produce. ${ }^{179}$ Galen's physical doctrines were accused of being unfruitful in the field of ethics, so it seems. And it is not very difficult to see why, since in ancient and modern times alike more 'physicalist' doctrines on human nature often meet with some worry in this regard (everyone gets worried when our beloved free will and with it our notions of identity and responsibility are thought to be at stake). As we have noted, Galen himself frequently spoke of 'daring' to speak out on the substance of the soul, admitting that it is both a speculative and a sensitive subject and possibly also that his own thesis might be considered to have negative implications for the possibility of ethics. While Galen, in $Q A M$, might have merely wanted to float the speculative position that is most compatible with the knowledge he has of the human being, tradition shows that it is easy to forget about this distinction and to ascribe to this speculative position in a work on Platonic philosophy the same status as the more empirically verified knowledge that it has to match in order to be accepted as the most likely position on a speculative subject. ${ }^{180}$ I think it is crucial to recognize this difference in status, which Galen himself emphasizes in Prop. Plac. Surely this is preferable to dismissing his writing on the substance of the soul as simply incongruous with his 'agnosticism', or as serving some other function than an expression of his own thought.

Despite the fact that Galen does not explicitly refer to $Q A M$ in Prop. Plac., the views he elaborates in $Q A M$ certainly surface there. In paragraph 7, we find something quite reminiscent of what we read in $Q A M$. Interestingly, we find it right after Galen again remarks that he does not know what the substance of the soul is:

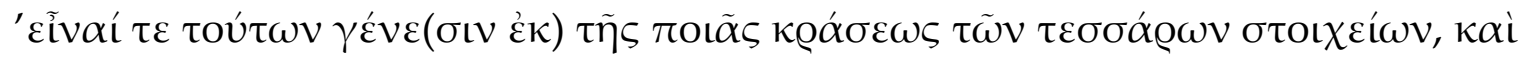

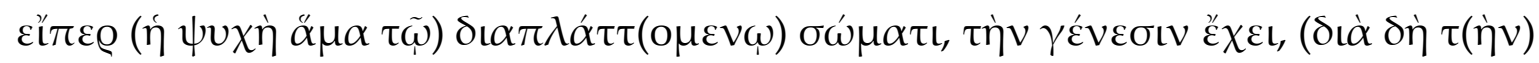

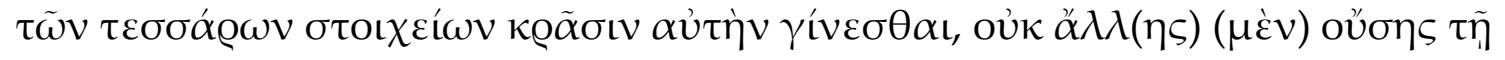

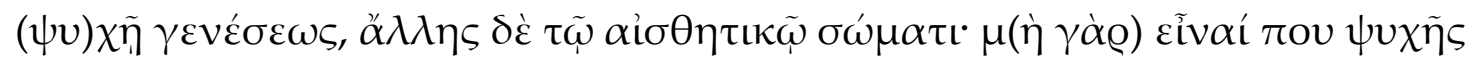

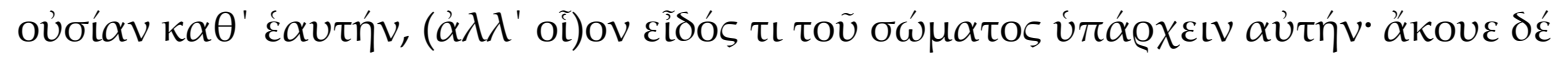

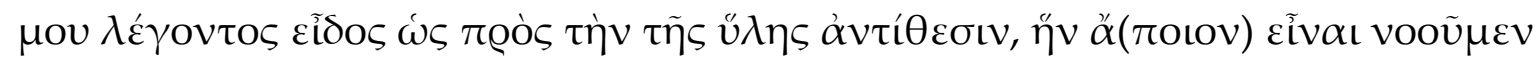

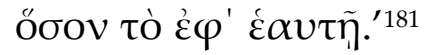

'And that the generation of them [the perceptive bodies] is from the specific mixture of the four elements, and if the soul has its generation together with the formation of

\footnotetext{
${ }^{179}$ Diogenes Laërtius 7,40; SVF 2.39, 2.40. For a discussion of the division of philosophy in Stoicism see Ierodiakonou (1993), who also concludes that the simile of the garden or orchard is likely to have originated outside of the Stoic school.

${ }^{180}$ Cf. e.g., Robert Burton, who simply states, as if self-evident: 'Galen supposeth the soul crasin esse, to be the temperature itself...' (Anatomy of Melancholy, 162). Nemesius was apparently more careful, see NH c. 2, p. 23.24-24.4 Morani: 'Galen has nothing to say on this point, and he bears witness in his works on demonstration that he had made no declaration about the soul. But, from what he says, he seems on the whole to consider that the soul is a mixture, since from this follows difference in character: his argument is based on those of Hippocrates.' (tr. van der Eijk)

${ }^{181}$ Prop. Plac. ed. Lami and Garofalo 86 (= Boudon-Pietrobelli 178,29-179,2). Lami and Garofalo are somewhat bolder in their editiorial choices and interventions than Boudon and Pietrobelli have been in their edition, particularly in filling in the gaps of the text, which has resulted in a more complete text. All quotations from Prop. Plac. are from their edition.
} 
the body, then it itself comes to be because of the mixture of the four elements, since there is not one generation of the soul, and another of the sense-perceiving body; and I suppose that there is not a substance of the soul existing by itself, but that it is a kind of form of the body; understand when I say form I mean the opposite of matter, which we understand to be without quality taken in itself.'

Here, almost immediately after saying that he does not know the substance of the soul, Galen proceeds to suggest that the soul - like the organs of perception - comes to be from the mixture of elements, that the soul does not have a generation separate from that of the body, that there is no separate substance of the soul, and that the substance of the soul is rather a kind of form of the body. Particularly his explaining remark at the end is reminiscent of $Q A M$ : the form he is referring to here is the opposite of a matter without quality. We have seen that for Galen the most basic building blocks of anything in the cosmos are this prime matter and the four qualities that mix in it. That implies that, like in $Q A M$, Galen is suggesting here that the mixture of qualities (and not the form of any more complex thing such as an organ, the matter of which can after all not be without quality) is the form of the body, i.e. the soul. How is it possible that Galen can say all this about (the substance of) the soul, while at the same time proclaiming that he does not know what the substance of the soul is? The answer to this question lies in the distinction he sets out at the beginning of Prop. Plac., between what he thinks he knows and what he thinks is plausible. The eĩv $\alpha$ c cited at the start of this passage is dependent on a previous

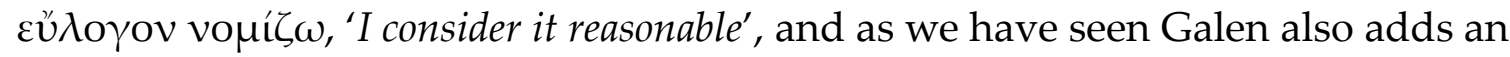
extra $\pi$ ov, 'I think/suppose', when he gives his take on the actual substance of the soul. By contrast, at the start of paragraph 7, and again after the passage cited above, where he denies knowledge of the substance of the soul, he expresses himself in a much stronger vocabulary, using forms of $\dot{\alpha} \gamma v 0 \varepsilon \tilde{\varepsilon} v$ and $\gamma \iota \gamma \nu \omega \sigma \kappa \omega$. Thus, Galen, in this late apologetic work, states that although he does not know what the substance of the soul is, he does consider it reasonable that it is a mixture of elemental qualities. This is completely in line with $Q A M$, where he presents us two options with regard to the substance of the rational part of the soul: either it has a separate, incorporeal existence, or it is the form of a homoeorous body. ${ }^{182}$ In $Q A M$ he then proceeds to show how the former view is more unlikely than the latter by enumerating problems with it.

Further on in Prop. Plac., we find another passage reminiscent of $Q A M$, particularly of the passage on the relation between substance, activities and capacities:

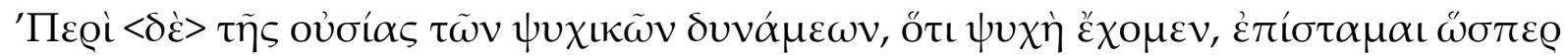

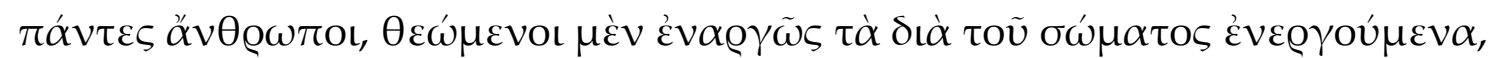

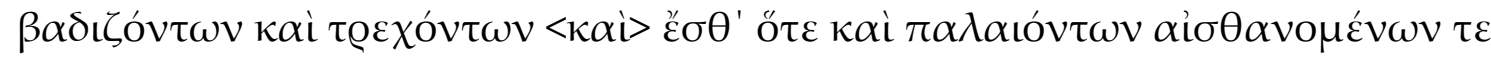

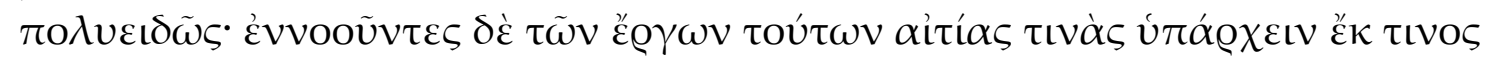

${ }^{182}$ Cf. Vinkesteijn (2019) 


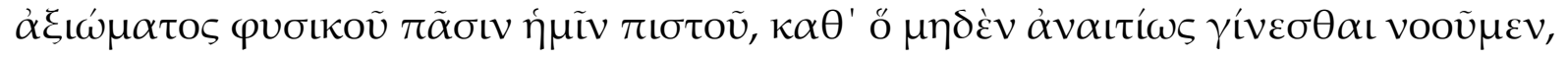

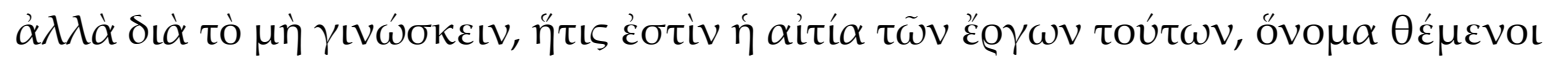

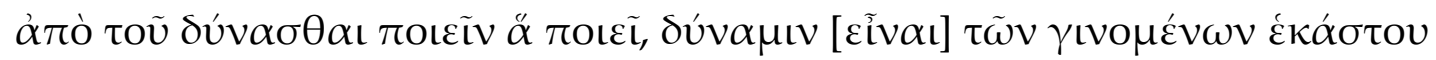

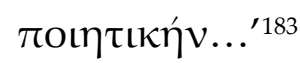

'With regard to the substance of the psychic capacities, that we have a soul, I know as all men do, because we clearly see the activities performed through the body, walking and running and sometimes also wrestling, and sense-perception of many kinds, and because we understand that there are certain causes of these actions, on the basis of a natural axioma trusted by all of us, according to which we consider nothing to happen without cause; but because we we do not know what the cause of these actions is, we postulate a name based on the being able to do the things that it does, a capacity as the efficient cause of each of the things that happen...'

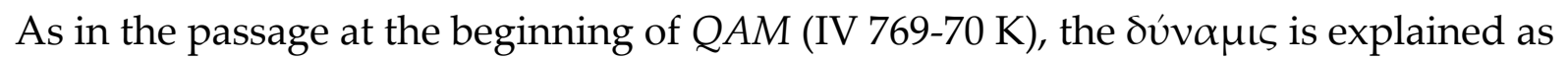
a mere appellation (óvo $\mu \alpha$ ) because the true efficient cause of the activities, the substance (oúí $\alpha$ ), is unknown. The fact that the activities are there prove that soul exists as their cause (just as the fact of well-designed creatures proves that an intelligent creator exists), but because we do not know what soul itself is, we name the causes of the activities in terms of capacities, while it is really the substance that is the cause, that is able to do what it is observed to do. ${ }^{184}$ As in $Q A M$, where it was aloe, Galen gives examples of the capacities of substances used for medical purposes, scammony and medlar in this case. He proceeds to enumerate two basic positions with regard to what the soul is, which we recognize from our previous discussion. First, there are those that state that incorporeal capacities 'inhabit' ( $\dot{\varepsilon} v o u \kappa \varepsilon \tilde{\imath} v$ ) the

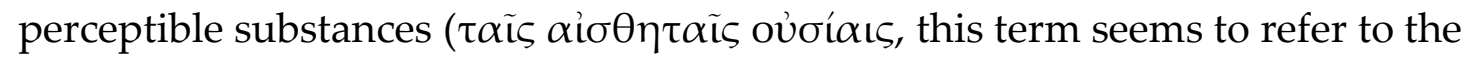
homoeomerous bodies, at least it does so for Galen). This is a view Galen obviously does not symphathize with. It is same view that is mentioned in $Q A M$ as the very reason to clarify the same matter just cited from Prop. Plac., namely that the actual cause is the substance itself and that the capacity is nothing other than an appellation based on the recognition that some substance can undertake a certain activity and cause a certain effect. In the second option, the substances themselves act according

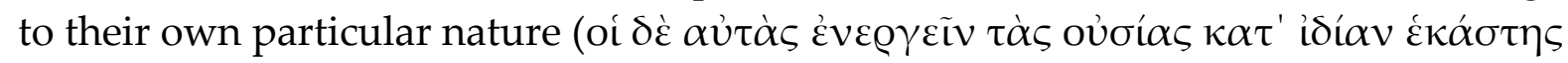
$\varphi v ́ \sigma v v)$. The latter view is in accordance with the notion that the substances themselves are the true efficient causes of activities, presented just a little earlier and argued for in $Q A M$. This view is again subdivided, according to the particular take on what the substance is: either a mixture of the four elements, or a non-mixed kind

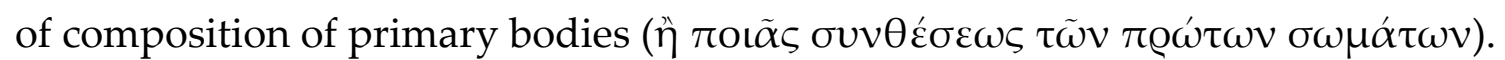
Within the latter category, there is another fourfold division. Some say that these primary bodies are indivisible ( $\alpha \dot{\tau} \mathrm{\mu} \alpha)$, others call them unlinked ( $\alpha \dot{\alpha} \alpha \varrho \mu \alpha)$, others say they are without parts ( $\not \alpha \mu \varepsilon @ \eta)$, and others, still, call them homoeomerous

\footnotetext{
${ }^{183}$ Prop. Plac. 14,1 ed. Lami and Garofalo 128 (187,14 f. Boudon-Pietrobelli)

${ }^{184}$ Cf. Frede (2003) 94; Tieleman (2003) 144-51; Hankinson (2014a) 965 f.
} 


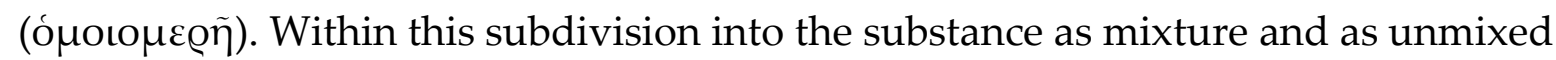
composition, it is obvious Galen sympathizes with the first option and not with any of the ones given after that. Those seem to represent various atomists ( $\ddot{\alpha} \tau о \mu \alpha$ and

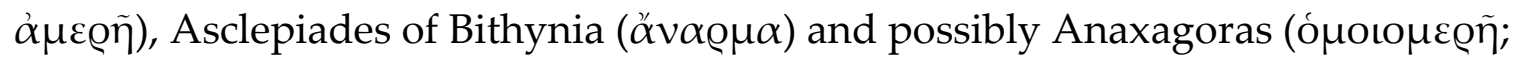
Galen's problem with this view is likely to be that the homoeomerous bodies are not unmixed but should rather be further subdivided (conceptually) in matter and mixture of the four qualities). ${ }^{185}$ Again, Galen states, some think the soul is an incorporeal substance (presumably the Platonists are meant here) and others think it is pneuma (the Stoics). Galen also clearly rejects both of these latter views, elsewhere. Finally, some others hold that the soul does not have some existence of its own $(\mu \eta \delta \dot{\varepsilon}$

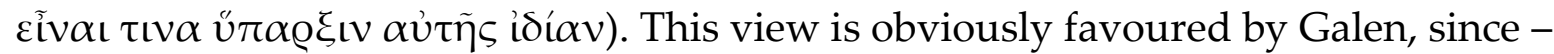
besides being much more compatible with the rest of Galen's work in general - in the passage we cited above, he had already stated that he thinks the soul does not exists on its own. ${ }^{186}$ He proceeds to specify this option as follows:

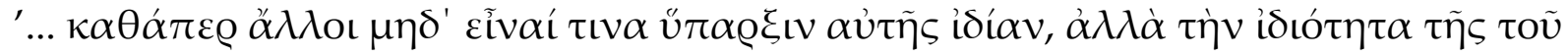

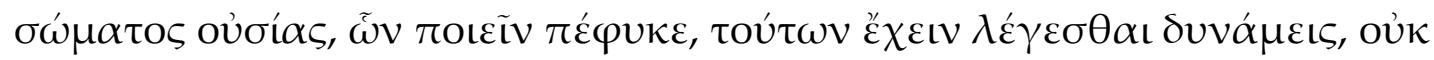

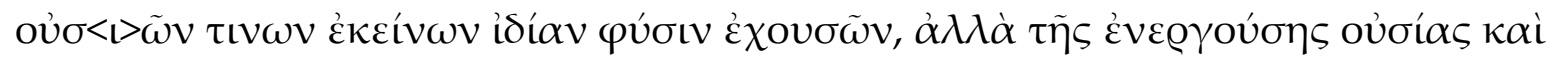

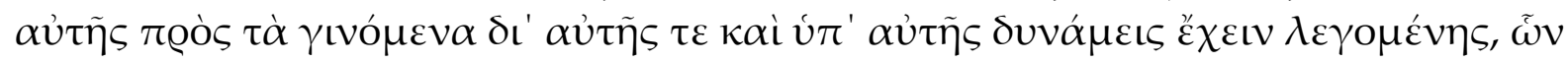

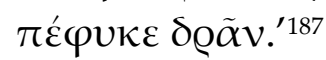

'... and according to others [the soul] does not have some existence of its own, but the specific nature of the substance of the body, is said to have capacities of those things which it does naturally; it is not the case that the capacities possess the particular nature of certain substances, but the substance that is acting, that is to say: it with regard to the things that happen through it and because of it, is said to have capacities, for the things which it does naturally.'

Again, we find the view that it is the bodily substance, and its peculiar nature, that is the cause of activity which we tend to attribute to a substance we call soul, while this very bodily substance is additionally said to have certain capacities for the things that it does. This seems to be the same view as the one that was contrasted with the notion of incorporeal capacities inhabiting the homoeomerous bodies before, namely that it is rather the substance itself (i.e. the homeomerous body through its constituent qualities) that is the cause of activity, and that it is merely said to have capacities because we observe that it does what it does without perceiving the substance itself as the cause of activity. Previously, several options were given as to

\footnotetext{
${ }^{185}$ See also Lami and Garofalo's notes ad locum. Cf. Hipp. Elem. 58,10-25 De Lacy (I 415-6 K): 'Quite obviously it is utterly absurd to say that what exists is one in number; that is truly the act of a man who has given no thought to any of the obvious facts. But a person might say that all things are one in form and power, as Epicurus and Democritus and their followers say of the atoms. And of the same chorus with them are those who postulate elements that are least and unattached [öv $\alpha \rho \mu \alpha]$ and without parts [ $\alpha \mu \varepsilon \rho \tilde{\eta}]$. Hippocrates, then, making a common answer to all such persons, proves that the element is not one in form and power...' (tr. De Lacy)

186 Prop. Plac. ed. Lami and Garofalo 86 (= Boudon-Pietrobelli 178,29-179,2). Cf. also Hankinson (2006) 248-9

${ }^{187}$ Prop. Plac. 14,3 ed. Lami and Garofalo 132 (188,1-6 Boudon-Pietrobelli)
} 
what this substance might be, among which was also the mixture of elemental qualities that forms a homoeomerous body, according to Galen. But now, unfortunately, it is not specified what the ones espousing this view hold to be the substance of the body. Galen proceeds to state that he has positioned himself somewhere midway in this discussion. On some other subjects he has spoken clearly, with regard to some of those he has known the truth and with regard to some others he did not know anything at all. In the discussion at hand, however, he goes as far as stating what is plausible $(\pi \mathrm{\imath} \theta \alpha v$ ov $)$. Although he thinks that it would be better to have a sure knowledge on this subject, as he has on some others on which he spoke out clearly, he also thinks it better not to be convinced that one has sure knowledge as long as a definitive demonstration is lacking. Finally, he characteristically adds that knowledge of these matters is not necessary for medicine and ethics. ${ }^{188}$ The 'middle position' that Galen says he has been taking, thus refers to the epistemological status of his position in this debate, rather than to a position in between the views of the soul being incorporeal or not having a separate substance. As to those views, it is clear enough, I think, where Galen's sympathies lie - namely with the view that the soul (i.e. the cause of activity) does not have a separate existence and is rather a bodily mixture - but he simply qualifies this subject as outside the current domain of matters that can be proven definitively and considers his views on the matter to be plausible rather than having the status of certain knowledge. ${ }^{189}$ That does not mean, however, that he does not find his position more plausible than that of someone who holds that the soul is a separate incorporeal substance inhabiting the body (which would be more at odds with the empirical evidence), or let alone that he does not have a view on the subject altogether. Aristotle ascribes to ethical philosophy a different status, another degree of certainty than he ascribes to the theoretical sciences. Yet that has not stopped us from writing libraries on 'Aristotle's ethics'. Is it curious for Galen, with his medical and empirical orientation, to deny to philosophical psychology the same kind of certainty as to the study of the human body and its workings and yet have some more or less definite thoughts about it because some of those thoughts may be more or less in congruence with our knowledge of the body?

\section{c. Critical discussion of some previous scholarship on $Q A M$}

In scholarship on Galen it has often been held that Galen does not really hold the view that the soul is a mixture or does not present this view as his own in QAM. Garcia-Ballester remarks that Galen in PHP and other works explicitly refuses to offer his opinion on the corporeality or incorporeality of he soul, and that in $Q A M$ he

\footnotetext{
${ }^{188}$ Prop. Plac. 14,4 ed. Lami and Garofalo 134 (= 188,6-17 Boudon-Pietrobelli)

${ }^{189}$ On this basis, I do not agree with Hankinson (2014) 89, that according to Galen we cannot even establish what the substance of the soul might be with plausibility, though I do agree with Hankinson (2003) $248 \mathrm{f}$., that Galen favours one of the options for the substance of the soul he discusses in Prop. Plac. (the one that corresponds to $Q A M$ 's thesis) and apparently finds it more plausible than the others. Cf. Vinkesteijn (2019)
} 
'maintains the same attitude surrounded by a certain vagueness' ${ }^{190}$ It seems that, according to Garcia-Ballester, the differences in content between PHP and QAM are to be understood as due to the latter's vagueness, as opposed to a development or the context of a different question or point of departure. This is a thought that finds ample resonance in later scholarship. ${ }^{191}$ The vagueness can again be accounted for in various ways, according to Garcia-Ballester. First, he states that 'The arguments used by Galen in Quod animi mores relating to the subject of the connection between body and soul are not aimed at expounding his personal position. They are hypothetical arguments concerning what Aristotle is committed to.' ${ }^{192}$ This fairly general line of interpretation (practically the whole text is about the connection between body and soul, including passages with arguments relying on Plato, the Stoics and Hippocrates) has been worked out in more detail and with much more nuance by Singer, who aims to explain 'some of the more extreme statements and some of the apparent inconsistencies' by arguing for the 'hypothetical nature' of Galen's arguments. ${ }^{193}$ According to Singer's reading of $Q A M$, we are to conjecture a 'conditional clause with the fundamental sense: 'if Aristotle is right', whenever Galen says or implies that the substance of the soul must be a mixture of the body. ${ }^{194}$ It is certainly the case that Galen's use of Aristotelian doctrine is crucial with regard to the thesis that the substance of the soul is a mixture. It is also the case that in $Q A M$ Galen uses, quotes from and interacts with various other authors in a way that can make it difficult to disentangle their views from his own. However, I think Singer stretches this strategy too far, perhaps in an attempt to neutralize the boldness of QAM somewhat, and to save Galen from being inconsistent with regard to his 'agnosticism'. The text-analysis offered above in the first two paragraphs, combined with the noted similarities in other works including Prop. Plac., suffices, I think, to prove that the view that Galen is merely presenting an Aristotelian position in $Q A M$ rather than his own, cannot be maintained. I think it is true, though, that Galen's own position on the matter is close to an Aristotelian one (though with some differences, as has been noted, particularly the emphasis on the primacy of the smallest units when it comes to the location of soul and the seemingly reductionist notion of capacities) and that, in $Q A M$, he is out to back his own position through the use of the authority of Aristotle, among others. ${ }^{195}$ We may rather conclude, I propose, that Galen's theses in QAM are Aristotelian to the extent that Galen's views on the soul are Aristotelian.

The second interpretational strategy that Garcia-Ballester suggests to account for $Q A M^{\prime}$ 's 'vagueness' is 'the involvement of socio-professional interests in motivating

\footnotetext{
${ }^{190}$ Garcia-Ballester (2002) 125

${ }^{191}$ Donini (1996) 201, speculates that 'Galen was fully conscious of the fact that in this treatise he was speaking at a different, indeed considerably lower, level than that of PHP'.

192 Garcia-Ballester (2002) 127

193 Singer (2013) 336

194 Singer (2013) 361

195 On the possible Peripatetic precedents for Galen's position see Kupreeva (2014) and Chiaradonna (2019)
} 
the formulation of such an extremely radical naturalism by Galen.' ${ }^{196}$ This again fairly general line of interpretation is worked out in more detail by both Donini and Lloyd. Besides being quite unelegant and methodologically problematic because it involves both speculating on the author's intentions and suggesting them to be somewhat dubious, there are other problems with this strategy as well. In Garcia-Ballester's case at least, it is based on a confused understanding of the relation between doctor and philosopher in QAM. Garcia-Ballester writes that Galen 'asserts that medicine is superior to philosophy for the total understanding of man.' ${ }^{197}$ To back this claim, he cites as evidence one passage, in which Galen states that those of the philosophers who think all humans are receptive to virtue and those who hold that no one chooses justice for its own sake both have a partial view of human nature. ${ }^{198}$ Garcia-Ballester then makes it seem as if there is a contrast here with the doctor (who is factually absent in the text), who would apparently be able to have a complete view. For one thing, this interpretation ignores Galen's repeated expressions of appreciation for the ancient philosophers, as he consistently presents them as paradigms of the possibility of ethical progress through the knowledge of his central thesis in QAM. In fact, Galen expresses such admiration shortly after the passage cited by Garcia-Ballester:

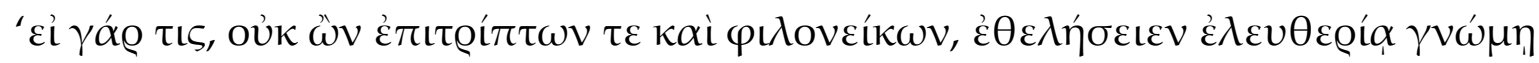

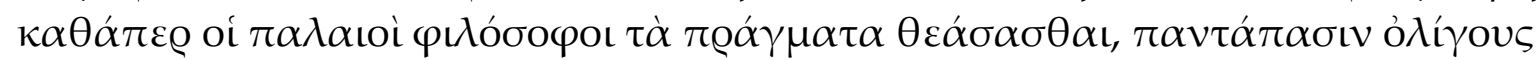

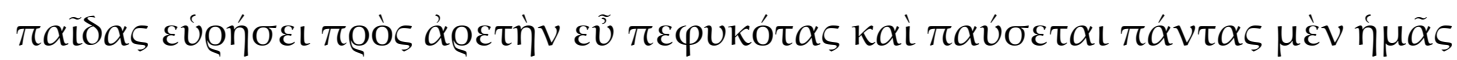

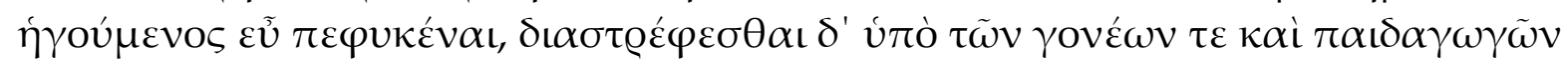

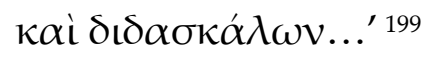

'For if someone, who is not one of those contentious rascals, would want to observe the matter with free judgement, as the ancient philosophers did, he shall find that there are exceedingly few children naturally well disposed for virtue and he shall cease to hold that we are naturally good but perverted by our parents, guides and teachers.' (tr. Singer, modified)

Note that what the ancient philosophers understand so well here, is exactly the natural difference in the characters (and thus souls) of children, i.e. the insight that was presented as the starting-point of the whole argument of QAM by Galen in the beginning. In general, it is helpful to note that when Galen writes of 'philosophers' in a derogatory sense, he is not referring to Plato or Aristotle. That is to say: he quite consistently employs a distinction between the contemporary types and the ancients,

\footnotetext{
196 Garcia Ballester (2002) 129

197 Garcia-Ballester (2002) 129

${ }^{198} Q A M 73,6$ f. Müller (IV $814 \mathrm{~K}$ )

${ }^{199}$ QAM 76,16-22 Müller (IV 818 K); cf. 76,1 f. Müller (IV 817 K) a few lines earlier, where 'the ancients' are praised for their virtue and wisdom (one could hardly think that Galen has only doctors in mind here); 32,11-3 Müller (IV $768 \mathrm{~K}$ ), right at the beginning of the text, where the followers of Plato and Pythagoras and certain other ancients are credited with knowledge of the views expounded in $Q A M$ (according to Garcia-Ballester, the reference to Pythagoreans and Platonists right at the beginning of $Q A M$ 'makes still vaguer ... his statement on the relationship between moral life and physiology.'); 79,21-4 Müller (IV $822 \mathrm{~K}$ ) at the very end of the text,

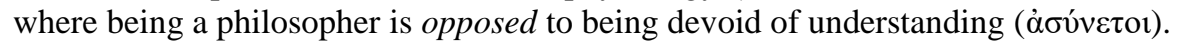


and while he wants to distinguish himself from the former, he often, and especially in $Q A M$, praises the latter and presents his own work as a continuation of theirs. ${ }^{200}$ Galen has no problem whatsoever with philosophy per se. On the contrary, his problem is with certain self-styled practitioners who do not meet the high standards the ancient philosophers have supposedly set, and who do not accept valid evidence when it is presented to them (for the soul's dependence on the body for example, or for the location of the rational soul in the brain as opposed to the heart). The fact that Galen likes to distinguish himself from the philosophers of his day simply does not mean in any way that he does not consider himself a philosopher.

Lloyd makes a point comparable to that of Garcia-Ballester, although he presents it rather more carefully as a 'suggestion': '... this would mean that his contributions to the debates on the relations between the soul and body, and to moral philosophical issues, are in places subordinated to a strategic concern with the prestige and power of the doctor. ${ }^{201}$ No scholar will deny that Galen's specific medical training, outlook and practice as well as his general concern with the status of medicine as a science, will deeply affect his philosophical work. However, if it turns out that all the relevant 'places' in which Galen supposedly subordinates his own philosophical aspirations to the 'prestige and power of the doctor' are those places in which he expresses what is considered too 'radical' a view on the causal role of the physical mixture, I think we have set out the contrast between medicine and philosophy too strongly and have denied Galen the possibility of an empirically and practically informed philosophy in which the body plays a crucial role. I would rather suggest that Galen works out a doctrine of the soul in which the care for the body has some ethical purport and that he presents 'the ancients' as proponents of this view (whether justifiedly so or not). Thus, he places himself in what he sees as the tradition of the ancient Pythagoreans and Platonists, rather than indicating a conflicting view of the value of philosophy and medicine for the health of the soul. Lloyd is only able to make this suggestion of a strategic concern with the prestige of the doctor, under the assumption that Galen works from an opposition between doctor and philosopher in $Q A M$ and affiliates himself solely with the former role. I think that Galen is not so much concerned with the power of the doctor here as with the power of the body. Lloyd also tends to make a sharp distinction between 'citation of authority' and

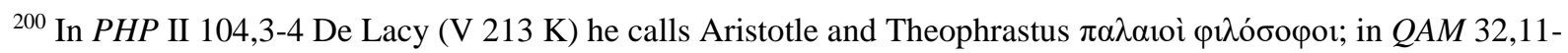
3 Müller (IV $768 \mathrm{~K}$ ) he calls the associates of Pythagoras and Plato simply $\pi \alpha \lambda \alpha$ ıoì; in $Q A M 76,1 \mathrm{f}$. Müller (IV 817-8 K) he speaks again simply of the $\pi \alpha \lambda \alpha$ เoì, but refers to these same 'ancients' as $\varphi 1 \lambda$ ó $\sigma 0 \varphi$ or in the next sentence (here particularly Plato and Aristotle, and possibly Hippocrates, must be intended, given that those are the ones cited before to corroborate his thesis); he refers to them again a few lines down and then ascribes to them 'free judgement' ( $\dot{\varepsilon} \lambda \varepsilon v \theta \varepsilon \dot{\varepsilon} \rho \alpha \gamma v \omega ́ \mu \eta)$; in Nat. Fac. II 178 K, Hippocrates, Plato, Aristotle, Diocles, Praxagoras and Philotimus are referred to simply as $\pi \alpha \lambda \alpha$ เoì, and credited with the right doctrine while having

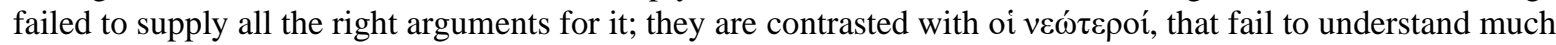
of what these ancients have put into writing (Galen puts himself on the side of the ancients, explaining to the philosophers and physicians of his own day what the ancients have put down before); cf. also Singer (2013) 248 note 58: 'When talking, always with approval, of 'the ancient philosophers', or 'the ancients' (hoi palaioi) Galen's reference is a fluid one, with, almost always, Plato and/or Hippocrates at its centre, but with a varying range of others sometimes added, in accordance with the details of the argument under discussion.'

${ }^{201}$ Lloyd (1988) 42
} 
Galen's 'own independent observation' and claims that the balance in $Q A M$ is 'weighted very heavily towards the former'. This is another way to neutralize the apparent radicalism of QAM (because it reduces its status), and it also one that is found in some of the other scholars mentioned. I think this is a seriously problematic general distinction, especially for a writer in Galen's age. How unusual is it for ancient writers, including Galen (in $P H P$, for example) to present their own views and observations under the veil of a specific and indeed sometimes rather unorthodox interpretation of more ancient authorities? Often, the whole point with this kind of writing is to blur the neat difference Lloyd is making. Besides, one might also infer that Galen, precisely because he knew his contemporaries might consider the views he expounded in $Q A M$ to be radical, purposely and emphatically tried to present them as being in line with traditional authority.

Donini follows Garcia-Ballester and Lloyd, in stating that Galen was mainly occupied with making propaganda for the office of doctor in this 'pamphlet', as he calls QAM ( $P H P$ on the other hand is a 'great treatise'). ${ }^{202}$ His general suggestion is that we should not take $Q A M$ as seriously as other work (Galen is speaking at a 'different, indeed considerably lower, level than that of $\left.P H P^{\prime}\right){ }^{203}$ As long as we consider $Q A M$ a 'more or less propagandizing manifesto devoted principally to promoting the image and the office of the doctor ... the threatened contradictions with respect to Galen's other works disappear'. This is a way for Donini to render 'the thesis of the corporeal nature of the soul itself ... more understandable' ${ }^{204}$ Here Donini, in my opinion, makes the same mistake as Garcia-Ballester and Lloyd. To back the hypothesis of $Q A M$ as a propagandizing pamphlet for the office of doctor, Donini also cites one single passage (IV 807-8 K), which is supposed to introduce 'a further thesis, apparently completely novel', namely, the thesis that one should 'look to doctors rather than philosophers' in order to develop one's soul. But in this passage, Galen merely states that he is able to help those people that do not believe in the power of nourishment to develop their souls. Again, the whole opposition between doctor and philosopher is completely projected into the text on the basis of the presupposition that Galen here should be considered solely as a doctor and as such as opposed to a philosopher (again, QAM was classed by Galen as a work treating of Platonic philosophy). Galen even goes on to state that by coming to him, these people 'will greatly enjoy the benefit of ethical philosophy' ${ }^{205}$ That is to say, he explicitly calls this care for the body philosophy. Again, right at the very beginning of $Q A M$, it is the followers of Pythagoras and Plato whom Galen mentions as having actually lived in accordance with the views he expounds in QAM. Rather than opposing medicine to philosophy and declaring the superiority of the former, Galen attempts to integrate both fields, as he does in other work as well. And that is not even such an exceptional activity in Galen's time, after all: Plutarch, for example, states at the beginning of

\footnotetext{
202 Donini (2006) 184

${ }^{203}$ Donini (2006) 201

${ }^{204}$ Donini (2006) 199

${ }^{205}$ QAM 67,9-12 Müller (IV $808 \mathrm{~K}$ )
} 
Advice about keeping well, that philosophers should 'make a single field, as it were, of all honourable studies', among which he mentions medicine as 'inferior to none' ${ }^{206}$ Again, the fact that Galen is a doctor and advocate of the medical science strongly and directly influences his thinking and writing to an extent that is not to be underestimated. However, to explain his supposedly 'extreme' or 'radical' views on the soul in terms of a kind of power-play between doctor and philosopher, seems to not do justice to Galen's self-understanding as both a doctor and philosopher and to his constructive relation towards philosophy.

What the above-mentioned scholars seem to have in common is that they oblige themselves to come up with some explanation for the conclusions Galen presents in QAM other than the one that seems to lie most at hand. Namely that they are, in the first place, expressions of Galen's own thought. I think part of the reason to desire such an explanation, besides the assumed contradictions with other work discussed above, is the supposition that these conclusions are 'radical' or 'extreme' (see the various citations throughout this section). I think it is a dubious interpretational strategy to judge an author's position as radical or extreme first, and then ask what could possibly be the reason for such radicalism, now assuming that the views, being radical, cannot simply be the author's views but came to be in his text for some other reason. Quite apart from that, the position presented in $Q A M$ does not strike me as radical at all. In any case, I think it may be worth our while to see what the implications of this position are according to Galen himself, when it comes to those beautiful fruits of philosophy. In the final section of this case-study, we shall work out some of these implications and see how $Q A M$ 's 'physicalist' notion of the soul bears on the possibility of ethics.

\section{The possible continuity in the divine and human formation of the bodily mixture}

In $Q A M$, Galen suggests that his conclusions may mislead people into accepting undesirable ethical implications: if a given mixture of elemental qualities determines the actions and affections of the soul, we cannot be praised or blamed for our actions or the state of our soul, it seems. ${ }^{207}$ After all, as Galen stated at the beginning of $Q A M$, if it were actually the case that the substances of the souls of children were the same, they would perform the same activities and suffer the same affections given the same causes. This implies that at the infant stage, at least, our actions and affections are completely determined by the naturally given mixture. ${ }^{208}$ But this is exactly the reason, I propose, why the rational part of the soul could not be identified with a particular mixture of qualities straightaway and why it was necessary to have a

\footnotetext{
206 Plutarch, Advice about keeping well, in Moralia, 122E, Loeb edition (2014); cf. Foucault (1984) $69 \mathrm{ff}$. ${ }^{207} Q A M$ 46,1-9 Müller (IV $784 \mathrm{~K}$ ) and 73,3 f. Müller (IV 814 f. K)

${ }^{208}$ QAM 33,10-4 Müller (IV $769 \mathrm{~K}$ )
} 
longer and separate discussion of it, which demonstrates that it shares something with its maker. I propose that the somewhat hasty conclusions that do away with ethical responsibility neglect the difference found in Galen's texts between the first stage of formation, by divine nature, and the second, by ourselves in virtue of our rational capacity. Arguing this way, in a quite literal sense, is to treat people like children. In this section, we will further elaborate the distinction between these two phases of the formation of the soul and the continuity between them, again by drawing on $Q A M$ and other Galenic texts.

After quoting a few passages from Aristotle's biological works, Galen concludes that according to Aristotle as well, 'the soul's character traits follow the mixture of the mother's blood' ${ }^{209}$ As we have seen, he seeks to prove that both Plato and Aristotle acknowledged the effects of the bodily mixture on the soul. In particular, in this

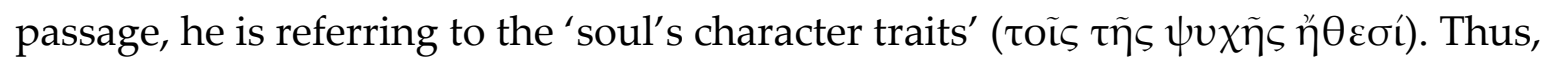
we get another affirmation of the influence of our original mixture on the state of our souls, more specifically in this case, on our characters. But in another small treatise that was probably written around the same time as $Q A M^{210}$ and that is titled Character traits ( $\pi \varepsilon \varrho i \eta j \theta \tilde{\omega} v)$, Galen emphasizes that we should reform our own soul (and finally those of others too) by shaping good character traits. Therefore, it seems that he both acknowledges an original and natural formation of character as well as the need for us to subsequently form our character ourselves. We have to be careful not to prematurely assume a contradiction here. Right at the beginning of $Q A M$, when Galen explains that we should follow the Pythagoreans and Platonists and bring about a good mixture in the body to cultivate the virtue of our soul, he refers to a text that might well be the Character traits. ${ }^{211}$ In this text, the formation of good character traits is presented in a rather Platonic manner as an activity of the rational part of the soul, which is supposed to discipline the desiderative part with the assistance of the spirited part. ${ }^{212}$ Galen argues here that it is possible and desirable to change our actions and affections by habituation. This implies that, after the initial natural

\footnotetext{
${ }^{209}$ QAM 54,23-4 Müler (IV 795 K)

${ }^{210}$ Ilberg (1974) 84, 90; Singer (2013) 39-40.

${ }^{211}$ Cf. Singer (2013) textual note 4.2. The Greek MS tradition has $\dot{\varepsilon} \theta \tilde{\omega} v$ (which would make it a reference to another work, De consuetudinibus, or Customary Practices), but the Latin and Arabic apparently translate $\dot{\eta} \theta \tilde{\omega} v$. I tend to agree with Singer that 'Neither text (in the form that we have it) provides a clear parallel for the precise proposition stated here.' But I also think that the text $\pi \varepsilon \rho i ̀ ~ \eta \theta \tilde{\omega} v$ could to some extent be read as a demonstration of this proposition and that it is closely connected to $Q A M$ with regard to Galen's notion of ethical philosophy as the potential of reciprocal causal influence between body and soul. When Galen, in another passage in $Q A M$ (IV $808 \mathrm{~K}$ ), illustrates the advantages people will enjoy when they adhere to his thesis and follow his advice on the

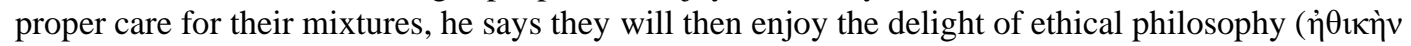
$\varphi \imath \lambda о \sigma о \varphi i \alpha v)$. We could say, perhaps, that Galen draws a connection here, as in the beginning of $Q A M$, between knowledge of his thesis and the philosophical activity of character formation, and that $\pi \varepsilon \rho i \grave{\eta} \theta \tilde{\omega} v$ is devoted to the latter subject.

${ }^{212}$ Character Traits $27 \mathrm{Kr}$ (= 139 tr. Davies) 'When pleasure passes [the bounds] of moderation it becomes harmful and it is the activity of the rational soul to reform it by regulating it and determining the times that may be devoted to it.'; also 140-41, the metaphors of dog and hunter, horse and rider; and particularly the passage from 40,10 onward (158) is well in line with the 'reducing of the stream of nourishment' and the becoming like a star that we saw earlier in $Q A M$ : 'Nevertheless, just as, if you could live without food or drink, you would be an angel, in the same way, if you restrict yourself to what is [absolutely] necessary for the life of the body, you will come near to being an angel.'
} 
formation, our bodily mixture and the actions and affections that follow from that given nature can (and should) be changed and improved through our own agency. Galen's imperative tone suggests that, despite all its divine genius in the creation of man, nature has left us essentially unfinished. What we can derive from this, it seems, is that the specific state of the elemental mixture in our main organs is at any point in time decisive for our actions and affections, but is simply never completed or definitive. Rather, the mixtures are naturally and continually changing, according to the myriad of factors that interact with them. Thus, their first natural formation is not the end of the story, but rather only the beginning:

'Both of these character traits come to be in the same way as all other traits, first by nature, then afterwards by habit; habit is an acquired nature, a second nature as it were. $^{213}$

This text most clearly expresses the continuity between the divine or natural and the subsequent human, rational formation of our selves: the results of the second can even literally be seen as a second nature. The character traits themselves are indeed a second nature in the sense that Galen defines them as non-rational, as 'unthinking motions of the soul'. ${ }^{214}$ Someone that is a coward will simply act cowardly. To this extent, the character traits show the same determinative quality as the mixture given to us by nature, but with the essential difference that we, by virtue of the authority of our rational part, are able to improve our character through continuous training and education. In fact, the potential of improvement is such that we can even, through relative neglect of the desires and needs of the lower part of our soul and through the acquisition of wisdom (both defined as activities of the rational part of the soul ${ }^{215}$ ), liken ourselves to a god:

'... there is no honour greater than that of imitating God, so far as is possible for a human being. This is achieved by treating immediate pleasures as of no importance and preferring the beautiful. ${ }^{216}$

As opposed to the immediate pleasures, the beautiful is presented as the proper object of the rational part of the soul in Character traits. Both here and in $Q A M$, where the relative abstention of the object desired by the lower part of the soul makes us drier and more intelligent, a discipline of formation of the self is proposed, which springs from the rational part of our soul and likens us to things that possess this rationality to an extreme extent; gods and stars, respectively. ${ }^{217}$ In fact, perhaps these latter two can even be identified: we have only an Arabic summary of Character Traits

${ }^{213}$ Character Traits tr. Davies in ed. Singer (2013) 167

${ }^{214}$ Character Traits tr. Davies in ed. Singer (2013) 136

${ }^{215}$ Character Traits tr. Davies in ed. Singer (2013) 139-140

${ }^{216}$ Character Traits tr. Davies in ed. Singer (2013) 158-9

${ }^{217} \mathrm{Cf}$. Temp. I 565,15-6 K, 'the peak of intelligence' is the natural goal of man, according to Galen, which he says in the context of answering the question what the best mixture for man is. 
and we know that Galen did not write about 'angels', of which there is frequent mention in the text. The idea in the text as we have it is that one could become like an angel, if one restricts one's bodily desires. ${ }^{218}$ It could be that there was a plural $\theta \varepsilon o$ in in Galen's text, rendered as 'angels' by the Arabic author, for obvious reasons. In $Q A M$ the stars are called $\theta \varepsilon$ có, and as we have seen, there is a kind of ideal of likening oneself to the stars there, through adjustment of one's mixture by reducing the 'stream of nourishment'. Likewise, in Character Traits, there is an ideal of likening oneself to the 'angels' by pursuing only the object of the highest part of the soul, and not those of the lower ones.

In any case, I propose that such formation of the self is not only an imitation of the divine because the self is improved and therefore becomes more similar (in as far as that is possible) to the perfection of the divine. It is also, on a more fundamental level, already an imitation of the divine as causa efficiens by virtue of the activity of formation itself, that is, as long as the formation is directed towards the good and the beautiful. Galen likens us to the divine by virtue of the potential of our rational soul, but the rationality of the divine is demonstrated through its ability to create perfectly designed creatures. Thus, rationality manifests itself primarily as creative and formative activity. By cultivating the state of our given bodily mixture with an eye to the improvement of our soul, we effectively continue the divine work through which we were initially formed. Galen is able to write an extensive ode of praise to the intelligence of our divine maker when it comes to the formation of the natural body $(U P)$, and he is able to prove and emphasize the causal influence of the bodily mixture on the soul, but when it comes to the perfection of our soul that is the goal of ethical philosophy and for which Galen venerates 'the ancients', we enter a second stage of formation. Nowhere is the supreme divine principle that is responsible for our initial formation credited for the wonderful state of the soul of man, even though it has been demonstrated that the soul is dependent on the bodily mixture, which is made by this divine principle. Galen states in another short treatise, which also concerns ethical philosophy and can probably be dated close to both QAM and Character traits ${ }^{219}$, the so-called Affections and Errors, that the initial formation by nature has left us unfinished to such an extent that we should spend practically our entire life trying to complete ourselves:

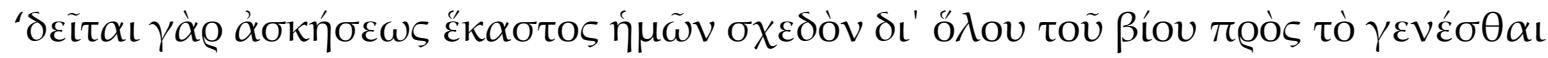

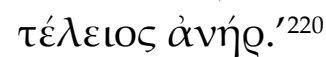

'For each of us requires training throughout practically the whole of his life in order to become a complete man.' (tr. Singer, slightly modified)

We may be determined by our given nature but that is not yet our complete form

\footnotetext{
${ }^{218}$ Character Traits tr. Davies in ed. Singer (2013) 158-9

${ }^{219}$ Singer (2013) 2

${ }^{220}$ Aff. Pecc. Dig. 11,15 De Boer (V 14 K)
} 


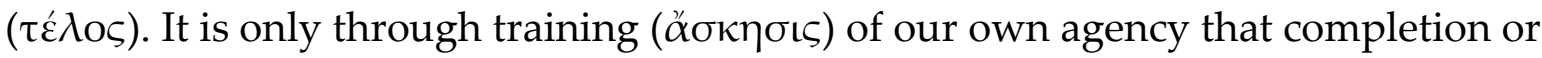
perfection can be attained. Completion or perfection, that is, as a human being. The perfection possessed by the divine itself is obviously out of reach - a logical consequence of the imperfect matter out of which we are made (as opposed to, again, the matter of the heavenly bodies). ${ }^{221}$ The words $\tau \dot{c} \lambda \varepsilon$ เos $\alpha v \eta \dot{\varrho}$ here should designate something like a man who has accomplished the best state possible for himself as human being or has fulfilled his potential as human being as much as possible. In the passage immediately following, Galen admits that such a state may not be feasible for everyone (although it remains a real possibility for some), but that we should at least make sure that our soul does not become 'utterly disgusting' ( $\pi \alpha \dot{\alpha} v \alpha \sigma \chi \varrho 0 \varsigma) .{ }^{222}$ That is to say, although the actual goal of completeness or accomplishment may only be achieved in a very limited number of cases, or perhaps never at all (particularly if we take $\tau \varepsilon \dot{\lambda} \lambda \varepsilon \iota \varsigma$ in the strong sense of 'perfection', one might think of the Stoic sage here), no one is exonerated from work. This is an important observation with regard to the supposed consequences of Galen's 'determinism' for human freedom and agency. In other instances, Galen gives the inspiring examples of the ancient philosophers, who trained and cultivated their virtue and who in this manner, to the extent to which that is possible, formed their own souls themselves. We cannot separate the 'material determinism' of QAM and the ethical ideal of the Character Traits by pointing out that we find them in two different works, since the same ideal is also emphatically present within $Q A M$ itself. ${ }^{223}$ As we have noticed, Galen presents this ideal right at the beginning of $Q A M$, when he states that we should alter our daily practices in order to improve our mixture and become virtuous as those around Pythagoras and Plato have done. He also comes back to it later:

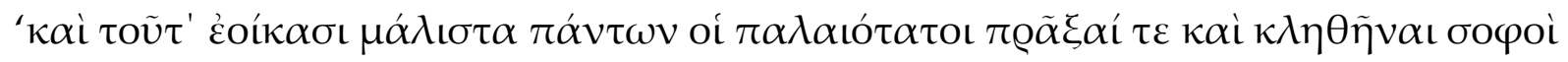

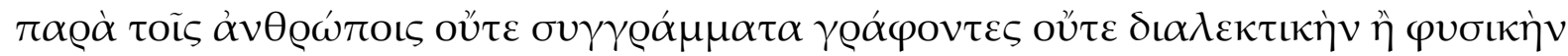

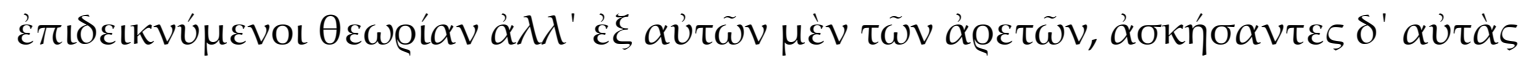

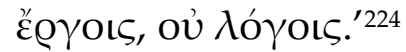

\footnotetext{
${ }^{221}$ See UP I 174,19-176,9 and II 446,7-447,21 Helmreich (III 238-40 and III 358-60 K)

${ }^{222}$ Cf. Hankinson (1993) $198 \mathrm{f}$. on this text and its emphasis on the necessity of training for moral development.

${ }^{223}$ There are many other similarities between these works as well: the repeated emphasis in Character Traits on the importance of the observation of small children as a point of departure for learning about the human soul (Character Traits p 136, 142, 143 in Davies' translation) which also formed the point of departure for Galen's argument in $Q A M$; the possibility of becoming like the divine to some extent by transformation of the self (149, $153,158-9)$; the importance of habituation and daily practices for achieving this kind of transformation and the emphasis on the need to subdue the desiderative soul.

${ }^{224} Q A M$ 76,1-6 Müller (IV 817-8 K), but Müller conjectures on the basis of the Latin edition: ' ... $\dot{\alpha} \lambda \lambda$ ' $\dot{\varepsilon} \xi \alpha v^{2} \tilde{\omega} v$

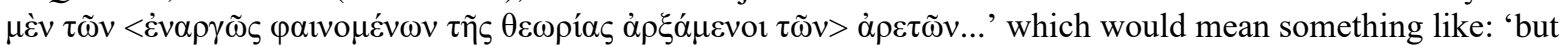
by taking the departure point for their theory of the virtues from the things that are evidently manifest...'. This conjecture is apparently also supported by the Arabic translation (see Singer (2013), textual note 4.53). It does make good sense in relation to Galen's repeated emphasis on the evident differences between children as the empirical point of departure, which the ancients supposedly have agreed with (also repeated a bit further in 76,15 Müller). On the other hand, as Singer remarks: 'If they were excised, an even more direct correspondence between philosophical intellect and practical virtue would perhaps be suggested.' It is exactly such a direct correspondence that makes up the ideal of the ancients as Galen often presents it. Also, the difference between
} 
'And it seems that the ancients have practised this most of everyone and have come to be called wise by people not by writing books or displaying dialectical or physical theory but from their own virtues, training themselves in deeds, not in words.'

If we take the thesis presented in $Q A M$ seriously (and even if we would take only the weaker thesis), all these statements on the cultivation of the soul must imply that Galen ascribes to philosophical training initiated by the rational part of the soul the potential to alter and form the bodily mixtures. So, indeed, the capacities of the soul depend on the mixtures of the body, but that does not mean the mixtures of the body do not depend on anything. As long as we have not established what the state of these mixtures themselves is dependent upon, we have no way of adequately assessing the consequences of the thesis that the actions and affections of the soul are dependent upon the mixtures. In fact, Galen always emphasizes that the mixtures do not come about in a random manner, but are dependent on something rational. First, they depend on a divine maker that creates according to some teleological plan. ${ }^{225}$ Second, human beings, resemble the divine with respect to their rationality and creative capacity. Therefore, they are able to exert influence over their bodily mixtures after their generation (and infantile stage) and able to continue and ideally complete (in as far as possible) the formation initially undertaken by the divine maker (and the better they realize this fact, the better they are able to do so). This is a very simple idea that can take its point of departure from the clear observation that the consumption of wine (to take an example beloved by the ancients) exerts influence on the state of the bodily mixture of our brain and, through it, on our rational capacities. Although some of us may naturally have a greater inclination to drink large amounts of it, we are all able to train our relative need for it through habituation and education. It is also easy to see how knowledge can lead to a change in our mixture here: if we learn that wine is bad for our rational capacities and thus our capacity for virtue, or if we rather learn that for our specific constitution it might be good to have moderate amounts of it on a daily basis because it makes us more gentle, we can decide to change our habits when it comes to wine-drinking, so as to make ourselves more virtuous. ${ }^{226}$ This is an easy example, of course. What seems more difficult to account for is how this knowledge itself could be understood as something that is a result of mixture. After all, it seems that Galen in QAM also proposes to understand the substance of the rational soul as mixture. Towards the end of $Q A M$ (in IV $821 \mathrm{~K}$ ), Galen seems to make a distinction between the causal influence of habituation and education on the one hand, and that of the bodily mixture on the other. That is to say, a distinction according to which they would both have causal influence, but on different aspects of the soul. The former would cause

this distinctive quality of the ancients is further brought to the fore with the oppositions between praxis and theôria and between ergon and logos. All of this comes out much clearer without the conjectures, which is why I chose to maintain the Greek MS reading here, although both readings seem like viable options to me.

${ }^{225}$ It is clear that the mixtures are always formed by the divine creator, if only because Galen states that it is only God or Nature that can make a complete mixture (Temp. I $563 \mathrm{~K})$.

${ }^{226}$ QAM 39,21 f. Müller (IV $777 \mathrm{~K}$ ) 


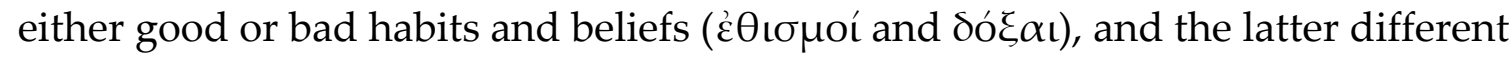

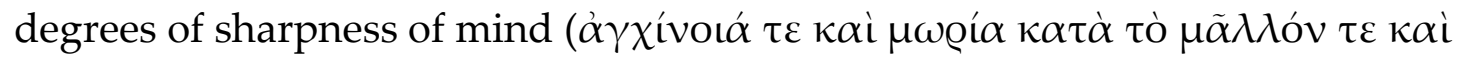
$\tilde{\eta} \tau \tau o v)$. It seems, then, that the latter would cause the state in the sense of the relative strength and sharpness of the powers of the soul, while the former would determine the 'content', the specific kind of habits or beliefs that are adhered to. However, this does not always apply to Galen's work in general. We know that he also holds that specific mixtures can determine the content of thought, for example, in the case of the darkness seen by the melancholic, which is caused by the black bile, or in the case of someone who thinks he is an earthen vessel because of his excessive dryness. ${ }^{227}$ In these cases, there is a clear determination of the content of thoughts and representations by the specific mixture of the substance of the rational soul. It does seem important, however, that Galen makes this distinction at the end of $Q A M$, allowing, for example, for a positive influence of education with regard to the formation of good and bad habits and beliefs, as well as, of course, for the opposite possibility of, for example, negative influences through bad examples. In any case, the passage just referred to is perhaps the clearest evidence in QAM that we can, to some extent, alter and form our own mixtures. For Galen proceeds to explain:

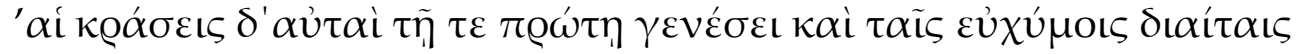

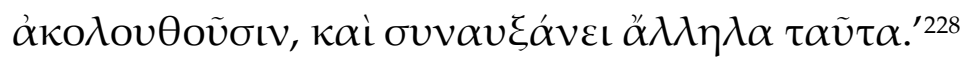

'But the mixtures themselves are consequent on the original formation and the regimens that are productive of healthy humours, and these things mutually increase each other.' (tr. Singer, slightly modified)

So, again we find the same two causal factors that decide on the state of our bodily mixture, that, in turn, determines the state of our soul: first, the primary creation of the mixture by nature or the divine creator, then the daily regimen we impose on ourselves. It should not come as a surprise that, according to Galen, a certain daily regimen has an effect on something like our relative sharpness of mind, even considered as a long-term capacity as opposed to common daily fluctuations of concentration and astuteness (depending, for example, on the amount of wine one has drunk). After all, as we have noticed, Galen is concerned with a second nature here, a change in substance. The regimens are productive of certain humours, but the humours are constituted by the four elemental qualities, as we have seen. Thus, the daily regimens could only form the humours if they change the mixture of the elemental qualities, which is exactly what happens when we drink and eat, for example. Thus, instead of some form of determinism, Galen rather ascribes a powerful transformative potency to regimens that we are able to impose on ourselves.

\footnotetext{
${ }^{227}$ See infra CS IV, section 3, 279-80

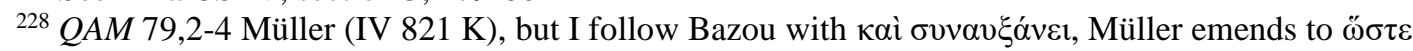

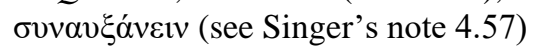


Here it is important to remember the notion of a кoเvì oú $\sigma i \alpha$ which we have mentioned earlier: everything in the cosmos is made of these four elemental qualities, so everything which we consume or even interact with in any way at all has some effect on our constitution made of these qualities (we also should remember here that Galen is a continuum theorist: we are always in contact with things that are not our own body). This implies that the substance of our soul is in a continuous state of change, with the change dependent on what we consume and interact with, in which we have a say. And in Galen's view it can make a major difference whether we have more or less yellow or black bile in our brain, for example. These can make us more or less active and intelligent, more or less sad, make us sleep more or less, etc. ${ }^{229}$ Moreover, these daily regimens are not restricted simply to things concerning climate and food, which might come to mind first:

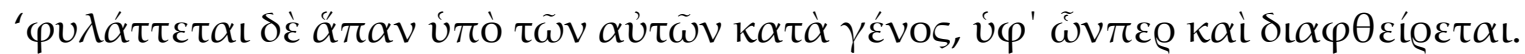

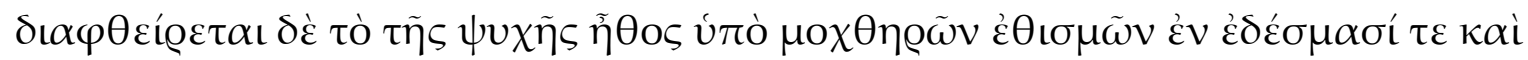

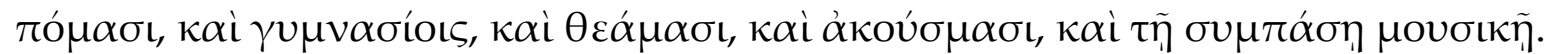

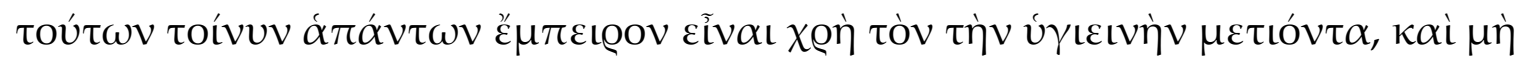

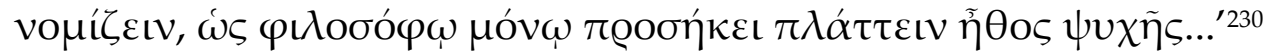

'For everything is maintained by the same kind of things as those by which it is also corrupted. The character of the soul is corrupted by bad habits in food and drink, and in exercises, and things seen and heard and the arts in general. Anyone that pursues health should be experienced in all of these things, and should not think that it befits the philosopher alone to shape the character of the soul.'

Interestingly, Galen here uses the word $\pi \lambda \alpha \dot{\tau} \tau \varepsilon \iota v$ for the shaping of the character of the soul, the same word he often uses for nature's shaping activity. It is also noteworthy that he mentions one should not think it only befits the philosopher to shape his soul in this manner, apparently implying that others would think this is the kind of thing that is typical of philosophers.

In the broader context of this passage, Galen explains how the shaping of the character of the soul is related to a healthy mixture. Both the shaping of health and that of character can be effected by regulating not only diet and exercise, but also by regulating that which is perceived. Perhaps Galen is thinking of theatre and music here, but possibly also of natural surroundings or perception in a broader sense. And, as becomes clear in the Character Traits, this transformative potency through training, education and regulation applies not only to character but to the rational part of the soul as well:

'We ought first to train that capacity of the soul by which we see that which is known by demonstration, so that it may grow; its training consists in geometry, the science

\footnotetext{
${ }^{229}$ See infra, CS IV section 2, 263-70

${ }^{230}$ San. Tu. VI $40 \mathrm{~K}$
} 
of numbers, mathematics, astronomy and the science of music. These sciences increase the capacity and perfection of the soul. ${ }^{231}$

The capacity and perfection of the rational soul is increased by adopting a certain discipline, namely, that of employing and developing it by learning the sciences. Again, if we take the thesis in QAM seriously, this would imply that the mixture on which the capacities are dependent, in this case mainly that of the brain, would be fundamentally changed by adopting a certain training that is, in turn, a consequence of the rational insight that we 'ought to train' ${ }^{232}$ In line with $Q A M$, we could say that the mixture of the brain changes (presumably becomes more dry, in this case) through intellectual activity and the rational soul therefore becomes more intelligent. ${ }^{233}$

Of course, one could point out how hard it would be to explain all the complexities of psychological functioning merely in terms of these four elemental qualities. And it seems a bit meagre indeed to state that drying the rational part of the soul will increase its intelligence. But then we first have to ask the following question: if one, in Galen's day, would be willing to speculate about the physiological nature of soul (as a principle of movement) on the basis of argument and observation, what basic elements would one choose to explain the soul's functioning, given that these would have to be the basic elements of the body or of the organs in which one is convinced that the soul resides? That is to say, Galen discards some other traditional options, such as that of atomism or that of an incorporeal soul, on the basis of reasoning and observation, but what other option could he have come up with? The elements were well established as basic building blocks of the human body and the entire cosmos. The interesting fact remains that Galen, in $Q A M$, might have been making an attempt at a physiological explanation of soul with the terms most suitable for it in his day. ${ }^{234}$ And it seems to me as though $Q A M$ is partly an attempt to think through the possibility of such a physiological approach, including its ethical consequences, while other ethical works, such as the Character Traits, devote less attention to the physiological aspect but do not seem to be at odds with it. In this particular passage of the Character Traits cited above, for instance, there is no reference to the mixture, but it does agree with $Q A M$ on the idea that the substance of the rational soul (on which the capacities must be dependent) can be altered through training. The

\footnotetext{
${ }^{231}$ Character Traits tr. Davies (ed. Singer, 2013) 163. Cf. also 161: 'The rational soul becomes strong by means of the demonstrative sciences, and ought to learn them step by step.'

${ }^{232}$ Cf. Hankinson (1993) 221: 'The sort of person one is directly depends upon one's physiological structure; hence one's dispositions, including one's dispositions to have certain types of thought, are at least a partial function of the structure.'

${ }^{233}$ There is a trope among the ancients (still in place with Ficino) of the dry philosopher, that becomes dry through excessive study, up until the point that he becomes a skeleton even, cf. Dunbabin (1986)

${ }^{234}$ I could not agree more with Jim Hankinson's remark on the risk of further specifying Galen's theory in modern terms (2014a, 967): 'So does then Galen's theory involve full reduction, emergence, or mere supervenience? The question is certainly anachronistic, and might also seem misplaced, since if Galen had been presented with such a range of options, he might well have said, characteristically, that he neither knew nor cared.'
} 
broader question here is: to what extent could Galen's views on training and development of the (rational) soul, elaborated in his works on psychology, be congruent with his more speculative stance in $Q A M$ on the substance of the soul, that is supported by his works on the human body?

It would seem, for example, that the rational insight that we 'ought to train' must itself again be to some extent dependent on a certain given elemental mixture: it would require someone of relative astuteness and philosophical ambition to have it, and those traits must depend on one's mixture, it would seem. The 'well-mixed man' that Galen writes about in Temp., can be recognized by his actions, because, due to the balance of his mixture, he is 'good-spirited, affectionate, generous and wise'. But for exactly the same reason, this man also follows a flawless regimen, which in turn balances his mixture again, presumably, in turn, maintaining or strengthening his intelligence. ${ }^{235}$ This is where Galen seems to differ from later Neo-Platonists that take up his work. Galen's reception by Neo-Platonists such as Proclus, Olympiodorus and Philoponus show that there was some acceptance of the views he worked out in $Q A M$, as long as the rational part of the soul remained exempted. Proclus discusses the view that the capacities of the soul follow the mixtures of the body in his commentary on Plato's Republic and remarks that this thesis only applies in the case

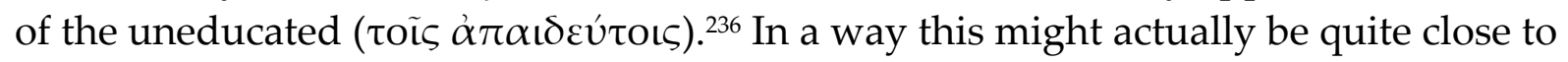
Galen's own position, as we shall see below. Olympiodorus, in his commentary on the Gorgias, refers to $Q A M$ 's claim that the powers of the soul follow the mixtures of the body, and then adds 'But they add 'unless one takes the preventive measures of philosophy'. ${ }^{237}$ It is clear from the context that this is important for Olympiodorus also in terms of the supposed consequences: the soul has an autonomous and immortal aspect as well, to which vice cannot be said to naturally belong, since otherwise vice itself would be immortal, which Olympiodorus considers absurd. Galen rather states in $Q A M$ that we do have 'a seed of vice within our selves'. ${ }^{238}$ Philoponus, in his commentary on Aristotle's De anima, also cites $Q A M^{\prime}$ 's title, and mentions that the doctors who hold that the capacities of the soul follow the mixtures of the body, 'even extend this to the higher cognitive faculties and claim that people whose brain has a drier mixture have better memories, but are slower in thinking...' He seems somewhat more agreeable to this thesis than Olympiodorus, as he adds: 'In general, people turn out to be better-talented and more sharp-witted or, on the contrary, dull-witted, according to the corresponding mixture. This, then, is the ground for the doctors' saying that the faculties of the soul follow the mixtures of the body. ${ }^{239}$ Again, however, he remarks that with regard to some people, it cannot be said that their impulses follow the mixture, because of 'the influence of philosophy'. $\mathrm{He}$, too, remarks that 'the doctors themselves' have admitted as much, because they

\footnotetext{
${ }^{235}$ Temp. I $576 \mathrm{~K}$ (tr. Singer)

236 Proclus In Rem. 222

${ }^{237}$ Olympiodorus Commentary on Plato's Gorgias, 49,6 on 524d5-6, tr. Jackson et al

${ }^{238}$ QAM 78,12 Müller (IV $820 \mathrm{~K}$ ), tr. Singer

${ }^{239}$ Philoponus On Aristotle's On the soul 50,32 f., translations van der Eijk (see also his notes ad locum)
} 
would have added to the title 'except for the occupations of philosophy'. This is perhaps a reference to Galen's Ars Medica, where he differentiates between character traits $(\grave{\eta} \theta \eta)$ that are naturally given ( $\dot{\varepsilon} \mu \varphi \dot{\tau} \tau o \varsigma)$ and those that are developed by philosophy. ${ }^{240}$ Whereas Galen seems to imply that philosophy can change one's mixture through insight and training, rather than that philosophizing is an activity that is somehow not dependent upon one's mixture in the first place because it is done by a part of the soul which is not subjected to it, Olympiodorus seems to interpret Galen in the latter manner. It seems that Philoponus also assumes that some forms of rationality are not dependent upon a mixture, since he maintains that when the soul controls the body, it does not follow the mixtures and that even though discursive thinking ( $\delta \iota^{\prime} \alpha \operatorname{vos} \alpha$ ) is dependent on the mixture, voũ $\zeta$ is not (in line, of course, with Aristotle's possible exception of voũ $\varsigma$ when it comes to existence separate from the body). ${ }^{241}$ It is noteworthy how far these Neoplatonist authors go in accepting the account of $Q A M$, though all agree that there needs to be room for some exception: philosophical or noetic activity should not be considered to be dependent upon the mixture. In a way, I think, Galen's position in QAM agrees with this, but in another way it does not. For Galen - in $Q A M$, at least - our rational capacity to engage in philosophical activity and effect a second stage of formation of the bodily mixture cannot be anything but a capacity dependent on that mixture itself, specifically, of course, of the mixture of the brain. In that sense, it seems that Galen would consider it highly unlikely that we would ever be able to undertake a thinking activity independent of a specific mixture. However, activities (for example, learning geometry, studying music) in turn change the mixture of the brain, sometimes as the consequence of a certain insight (I have to train my brain) and to that extent these activities rather form the mixture. Still, such activities themselves already require a specific mixture (remember that for Galen the homoeomerous bodies, i.e. their qualities, are primarily active). That means that the subject and the object of the philosophical training proposed by Galen, that which initiates the transformation and that which is transformed, are to some extent identical. Yet, this identical self is involved with itself in a continuous dynamic of transformation. ${ }^{242}$ This involves the paradox, as we shall see below, that we have to obtain something (wisdom, selfcontrol, a good state of the soul) we do not yet have, but that in order to obtain it, we must already have some of it, somehow.

The seemingly circular notion of the mixture philosophically forming itself, or the soul determining that by which it is determined, is best expressed in Galen's text through a joke:

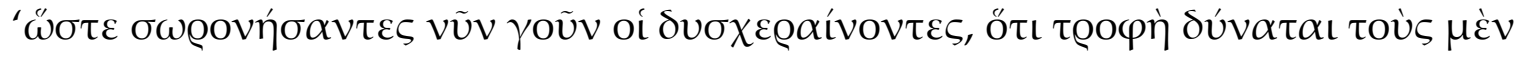

\footnotetext{
${ }^{240}$ Ars. Med. I 336-7 K; the distinction corresponds to the one in QAM 78,19-79,4 Müller (IV 820-1 K), but in the latter there is no specific reference to philosophy; cf. van der Eijk (2014) $131 \mathrm{ff}$

${ }^{241}$ Philoponus On Aristotle's On the soul 138,1-10, also van der Eijk's note 371 on the previous passage; 155,10 f.

${ }^{242}$ Cf. Hankinson (1993), 222: 'We have, effectively, a model in which the overall state S of some system generates outputs $\mathrm{O}$ which causally contribute to the creation of a new state $\mathrm{S}$ '.'
} 


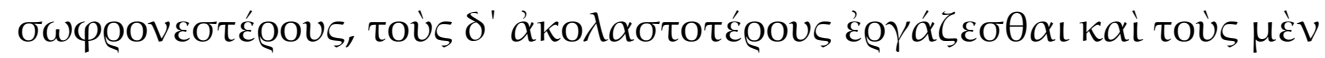

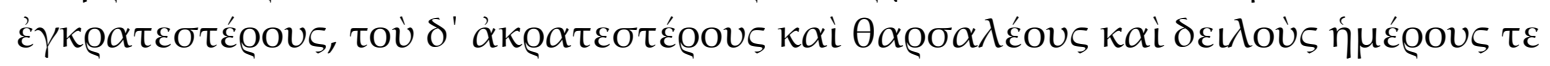

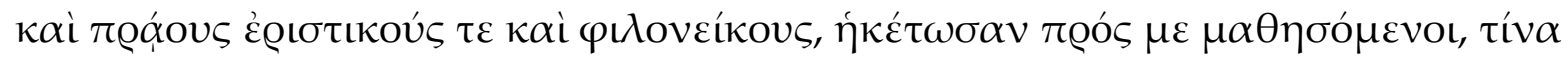

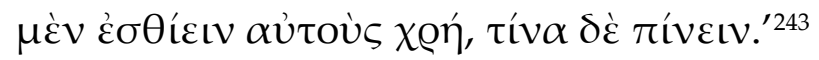

'So, then, let those who are unhappy with the notion that nourishment has the power to make some more self-controlled, some more undisciplined, some more restrained, some more unrestrained, as well as brave, timid, gentle, kind, quarrelsome and argumentative - let them now have some self-control, and come to me to learn what they should eat and drink.' (tr. Singer)

In this joke we find the reciprocity of the body-soul relation that is at the heart of Galen's ethical ideal in QAM. These people, who have not yet followed the example of those Pythagoreans, Platonists and other ancients to appropriate the thesis expressed in the title of $Q A M$, who have not yet taken it upon themselves to develop their self-control by regulating their mixture, should show some self-control and submit themselves to Galen's guidance, in order to develop their self-control by adapting their daily regimen and thus bodily mixture. ${ }^{244}$ In order to start developing they have to exhibit the very quality they wish to obtain. We find the same basic thought in Aristotle as well:

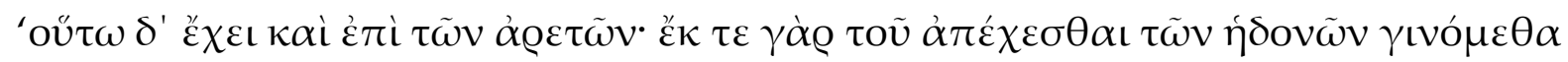

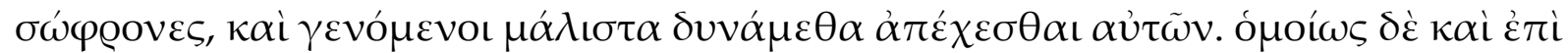

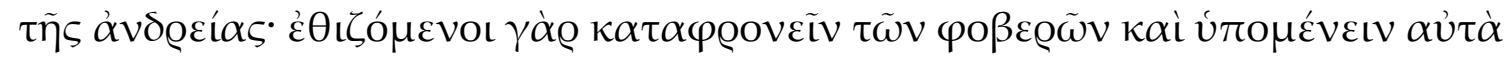

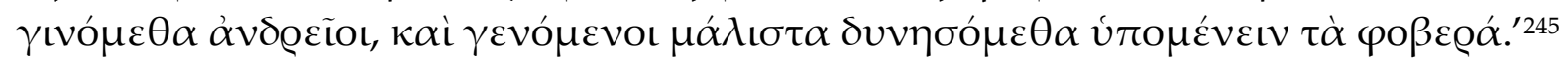
'The same holds good with the virtues. We become temperate by abstaining from pleasures, and at the same time we are best able to abstain from pleasures when we have become temperate. And so with courage: we become brave by training ourselves to despise and endure terrors, and we shall be best able to endure terrors when we have become brave.' (tr. Rackman)

This reasoning might appear circular, but (in my view, at least) it also does justice to our experience: the only way to develop character is by exhibiting it. Such a first display of self-control is the step that needs to be taken in order to continue the initial divine formation of our mixture and cultivate our soul. It is the beginning of ethical philosophy, as Galen explains in the sentence immediately following the one cited above:

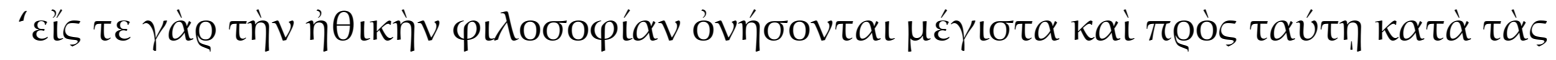

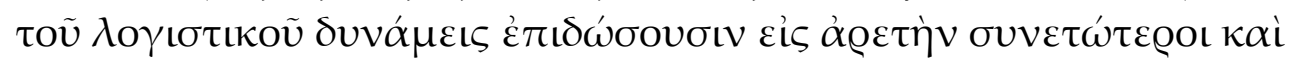

\footnotetext{
${ }^{243}$ QAM 67,2-9 Müller (IV 807-8 K)

${ }^{244}$ Cf. Singer (2013) 401-2 note 138: 'Galen is (if the text is correct) making a sort of joke here: one needs to sõphronein to some extent to realize the fact that bodily factors affect one's ability to sõphronein.'

${ }^{245}$ EN 1104a33-1104b3
} 


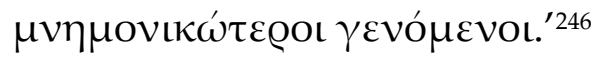

'For then they will greatly enjoy the delight of ethical philosophy and in addition to that they will devote themselves to virtue in accordance with their rational capacities and become more understanding and remember better.'

By taking this step, in which we undertake the activity to adapt the mixture that we are dependent on for our activities and affections, we can not only develop our characters, but also gain a better understanding and memory. Thus, Galen proposes an ethical programme of self-amelioration that includes the improvement of the rational capacities as well. This passage is reminiscent of his discussion of the

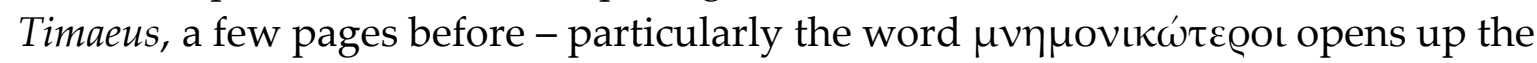
Platonic perspective again. ${ }^{247}$ In his previous discussion of the Timaeus, Galen stated that the soul reaches a state of forgetfulness when it becomes bound to the body Platonic doctrine that Galen took to refer to the wet state of the substance of infants. But, the soul can acquire a certain calm and subsequently develop its intelligence when the stream of nourishment towards the body becomes less. Galen explained this lessening of the stream of nourishment as a decrease of the wetness which causes

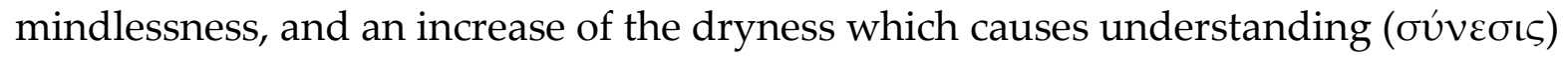
and makes us more like the heavenly bodies (among which we once had our place, according to Plato). Indeed, Galen states that he will teach his imagined students about nourishment, drink, winds, air or the mixture of the surrounding environment

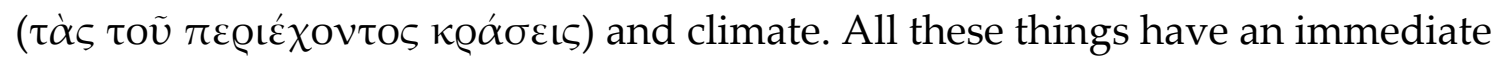
effect on the bodily mixture. Galen must have the passages about the dryness of the stars and the wetness of infants in mind here, when he is explaining the delight of ethical philosophy and the development of virtue and understanding. This is also clear from the next few sentences, where he states that Plato himself often wrote about these matters and goes on to give three examples. All of these examples are about the possible effects of nourishment on the state of the soul. Thus, they stress the importance of the care for the bodily mixture to make progress in the cultivation of the soul. Put differently, they demonstrate the necessity of understanding QAM's central thesis for the practice of ethical philosophy. After the three examples, Galen continues as follows:

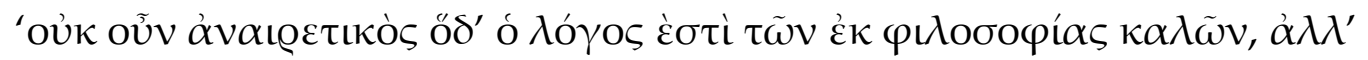
ú $\varphi$ iोoбó $\varphi \omega v . . .248$

'This argument, then, is not destructive of the fine things arising from philosophy, but rather is an argument useful for guidance and for teaching of a point within those things of which the philosophers are ignorant.' (tr. Singer)

\footnotetext{
${ }^{246}$ QAM 67,9-12 Müller (IV $808 \mathrm{~K}$ )

${ }^{247}$ QAM 42-3 Müller (IV 780-1 K)

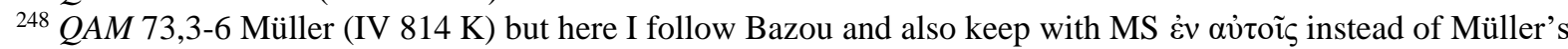
દ̇víors, follwing Singer $(2013$, note 4,48)
} 
That of which the philosophers - again, not Plato and Aristotle, but perhaps particularly the self-styled Platonists referred to earlier - are ignorant, is, as we know by now, the main thesis of $Q A M$ and its importance for the practice of ethical philosophy and cultivation of the soul. Apparently, however, there is a reason for the reluctance of other philosophers to appreciate the truth of this thesis: it is considered destructive of the fine fruits of philosophy. This is partly because, as soon becomes clear from Galen's text, the possibility of assigning responsibility for one's actions is considered to be at stake. After all, if it is the mixture that causes the state of one's soul, how are we to judge people for their being good or bad? Galen's initial answer is astonishingly simple and direct: it is in our nature to love the good and hate the bad, without asking questions about its origins. ${ }^{249}$ We simply destroy poisonous spiders, even though they have become what they are not by themselves but simply by nature. ${ }^{250}$ In other words, we should not care what the cause of someone's state of soul is when it comes to praising or blaming them. ${ }^{251}$ However, Galen does not say that we cannot be considered responsible for the state of our soul. For, although the mixture directly causes that state at any point in time, we do exert influence on the state of this mixture and it is possible for us to realize this and cultivate a mixture that conduces to a stronger character and increased understanding. Where other philosophers consider the thesis of $Q A M$ to be a danger, Galen argues rather that the realization of it is a condition for the practice of ethical philosophy and for acquiring freedom: yes, the soul is a slave to the mixture, but the mixture is partly dependent on how we decide to shape it, since this shaping capacity is also a capacity of that same mixture.

Partly, that is, for it is obvious to Galen that our given nature limits the possibilities of this second stage of formation. Our given mixture is not a piece of wax, the capacity for altering and forming our mixture already requires some natural predetermination, as we have seen. Moreover, Galen acknowledges that some people's souls are so corrupt that they are incurable, not capable to be taught by the Muses themselves or to be improved even by Socrates or Pythagoras. ${ }^{252}$ In this respect, Galen, perhaps partly due to his medical perspective, might be more realistic than many a philosopher. We should take responsibility for the state of our mixture, as we have seen, and it is our goal to cultivate our own soul and those of others, and liken ourselves to the divinity and perfection of the heavenly bodies. But most of us undeniably fall short of this ideal. Actually, we could conclude, following Galen, that as a kind we are quite hopeless in this respect: many people with a nature that does

\footnotetext{
${ }^{249}$ QAM 73-4 Müller (IV $815 \mathrm{~K}$ )

${ }^{250}$ Cf. Hankinson (1993) 219: 'The wicked are just like poisonous animals - no one would hold them responsible in the strong sense for what they are, but we do not destroy them because they are responsible for what they are, but simply because they are what they are.'

${ }^{251}$ Hankinson (1993) esp. 217 f. gives an extensive and nuanced overview of Galen's position here.

${ }^{252}$ QAM 74,20-2 Müller (IV 816 K); see also Aff. Pecc. Dig. 45,15-20 De Boer (V 65 K): 'It is utterly impossible for who was not born for truth, and who has also been brought up in bad, licentious ways, to hunger for truth, either on the basis of an internal impulse of that kind or through the encouragement of another. I myself have never claimed to be able to assist such a person.' (tr. Singer)
} 
provide potential hold the wrong beliefs and waste their time writing silly books on how everyone is naturally good, thereby preventing people from attaining the right insights that might lead them to take proper care of their own mixture (especially Stoics seem to act in such manner), and more importantly, most people do not even have the natural potential to become good in the first place. ${ }^{253}$ As Galen says, anyone who observes the matter with free judgement (and this is a significant qualification, with Galen using the same predicate, $\dot{\varepsilon} \lambda \varepsilon v \dot{\theta} \theta \varepsilon 0 \varsigma_{\text {, }}$ as he did for Andronicus, whom he praised for his insight that the substance of the whole soul is a mixture), will conclude that there are extremely few children that are naturally well-suited for the acquisition of virtue. ${ }^{254} Q A M$ and its thesis, should be considered useful, as Galen remarked at the very beginning of the text, 'to those who wish to improve their own souls', i.e. for those who want to practise ethical philosophy - there are just not too many of those, as everybody can tell. We should take this into account when we ask, for example, whether Galen advocates a position of 'material determinism': apparently, that depends on who we are talking about. In this sense, Proclus' reading makes sense: it is only those who both seek to improve themselves by their own nature and who find the right guidance to do so that can acquire what we would call freedom in this respect. For Galen, clearly, the potential which we have in our given bodily mixture to follow in the footsteps of our maker and to train and form ourselves, is not present to the same extent in everyone. It was not present to the same extent in Socrates and in one of those people that could not even have been cured from his bad ways by Socrates. Given that there are extremely few people who are naturally well suited to obtain virtue, most people will simply act according to their natural mixture, while only a few are inclined to undertake the ethical programme of self-amelioration and become like those 'ancients', and even less will actually do so. But, according to Galen, as we have seen, the ancients knew this.

\section{Conclusion}

We have seen how Galen, in $Q A M$, speculates on the substance of the soul, a subject he often avoided in other works. Through a discussion with the Aristotelian and Platonic traditions, guided by and based on his own previous work, he argued that the substance of the soul is a bodily mixture. He presented this argument as the best or most scientific proof for the central thesis of $Q A M$, that the capacities of the soul

\footnotetext{
${ }^{253}$ Cf. Hankinson (1993): 'In some systems, there will be a natural tendency to progress towards the better states; in others, the system will have become too corrupt to be self-ameliorating, and indeed even beyond external repair (just as diseases can progress to the stage where they are incurable).' I would only add that, according to Galen, some 'systems' do not just become too corrupt, but apparently lack the potential for self-amelioration in the first place (see next note); this is already a problem in Aristotle, cf. van der Eijk (2014) 94: '.. a cursory reading of Aristotle's works with a view to the various types of people he distinguishes makes one wonder whether the number of individuals who live up to these lofty ideals is higher than perhaps ten percent; and even that estimate may be on the optimistic side. This raises the question why nature, which supposedly arranges everything for the best, apparently does not manage to provide even the capacity to achieve such happiness and fulfilment in all members of the human species. This almost existential question is never directly addressed in Aristotle's works.'

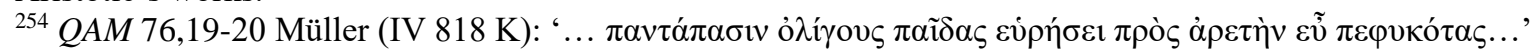


follow the mixtures of the body. Strictly speaking, the identification of the substance of the soul with a bodily mixture is not a materialist position. After all, as we have seen, Galen adopts a hylomorphic approach and considers soul to be the form of the body. As such, he considers it to be the form of the homoeomerous body rather than the organ in which soul resides, because it is the homoeomerous bodies, as the most primary bodies formed by the two principles of form (mixture of the four elemental qualities) and matter (as such without quality), which are primarily active, i.e. which should rightly be considered as principle of movement. More specifically, the homoeomerous bodies residing in the three main organs (liver, heart and brain) primarily carry out the (natural or psychic) functions Galen ascribes to these organs and on the basis of which he locates soul in them. In as far as these particular homoeomerous bodies (more precisely: their form) reside in the respective organs, to which they are entirely peculiar, it can be said that the soul resides in these organs. By locating soul at the micro-level of the body, as far as perception can go, Galen adheres to his general axiom formulated at the beginning of Hipp. Elem.: if we want to find out about the nature of something, we have to look for its smallest component parts that cannot be further divided. It seems that with $Q A M$, Galen applied this axiom to soul (as form of the body), as well.

Although this implies that the cause of our actions and affections are these particular bodily mixtures in the three main organs, as we have seen, this does not need to amount to a form of radical determinism. First of all, these mixtures are themselves subject to continuous change and we are able, to a certain extent, to form them in a way that will be beneficial for the development of our capacity for virtue and thinking. Second, we noted that habits and beliefs are not merely dependent on the mixture, but also on education and habituation, which we can also exercise some control over. Such self-amelioration is possible because, as rational beings, we share to some extent in the intelligence and creativity of our maker, though we do so by virtue of the specific mixture of our brain. This self-amelioration is necessary, in as far as it is a condition for human beings to fulfil their proper function, which is why it is also required from all of us, according to Galen. However, since the desire for such self-amelioration, the sharpness of one's mind and other characteristics of people's nature or soul vary across individuals depending on their naturally given mixture, and since, according to Galen, there are only few people equipped with a natural constitution that is well-suited to virtue, it would seem that, far from embracing determinism, Galen saw much work to be done. 


\section{Case-Study II: Galen on the Nature of Man}

\section{Introduction}

In this second case-study, we will have a closer look at the first book of Galen's commentary on the Hippocratic On the Nature of Man (Nat. Hom. is the abbreviation for the Hippocratic text itself, Galen's commentary is abbreviated as $H N H$ ). Presumably, this text was written by Polybus, Hippocrates' student and son-in-law, though Galen argues for it being an authentic Hippocratic text. ${ }^{255}$ It has been transmitted together with the so-called Regimen on Health, which Galen does ascribe to Polybus, and another text that came to bear the title of second book of On the Nature of Man. Galen ascribes this latter text to yet another unknown later author, suggesting that it might be the person who put together the first book of Nat. Hom. and the Regimen on Health into a single treatise in Hellenistic times. ${ }^{256}$ Galen's view on the text, and his threefold division, has influenced the editing of the Hippocratic text. There has been a division in two separate editions for the first (considered by Galen to be authentic) and second book (considered by Galen to be spurious) on the one hand, and for the third part under the title Regimen on Health on the other (thus, although seemingly inspired by Galen's division, the editing has not been faithful to it). However, Jouanna has made it clear that Galen's proposed threefold division and history of the text is unjustified, since the second part of the text, which Galen considers to have been written by an impostor from Hellenistic times, is already quoted by Aristotle, who ascribes it to Polybus..$^{257}$

In any case, this text, and Galen's commentary on it $(H N H)$, have become of pivotal importance for the tradition of humoural theory in particular. The Hippocratic text is the first clear expression we have of the notion that the nature of man consists of the now canonical four humours, i.e. blood, phleghm, yellow bile and black bile. Galen's commentary, in turn, has developed and systematized this notion. Together with other Galenic works it has laid the basis for a long-standing tradition in which the humours are considered to be the four basic constituents of human nature, consist themselves of the four elements or elemental qualities, and correspond to seasons, ages, specific temperaments and character-types. ${ }^{258}$

It is a particularly suitable text for studying Galen's notion of human nature, not only because it is actually the only text from the Galenic corpus explicitly on this subject, but also because it must have been written relatively late in Galen's life and seems to contain all of his elemental doctrine on human nature. Moreover, Galen introduces the work by saying it has the same subject as his The Elements According to Hippocrates (Hipp. Elem.), but set out in a manner that is more suitable for the reader who is not yet well versed in the subject. ${ }^{259}$ That is to say, the aim of this work, although it is a

\footnotetext{
255 Jouanna (2012) 335; cf. HNH 8,7 f. Mewaldt (XV 10-1 K)

${ }^{256}$ HNH 57,4 f. Mewaldt (XV $108 \mathrm{~K}$ )

${ }^{257}$ Jouanna (2012) 323 f.; cf. Kupreeva (2014) 154-5

258 Jouanna (2012) 336

${ }^{259}$ HNH 3,4-19 Mewaldt (XV 1-2 K)
} 
commentary on a Hippocratic text, is a non-specialist exposition of Galen's views on (human) nature, which amounts to a kind of hylomorphic elemental cosmology, as we shall see. This aim makes it particularly suitable for our purposes. ${ }^{260}$ Presumably, the work is also written later than $Q A M$, which was at the centre of our Case-Study I. Galen refers to $Q A M$ in $H N H$, and there are no references in $Q A M$ to $H N H$. This is in spite of the fact that it does contain a lot of useful material for the subject matter treated in $Q A M$ and also despite the fact that Galen seeks to emphasize the harmony between his own views and those of Hippocrates in $Q A M$ as well. In short, if $H N H$ would have in fact been written earlier than $Q A M$, and thus the reference to $Q A M$ would be a later insertion, it would have made sense for Galen to refer to it in $Q A M$. So even though we cannot be sure, it seems extremely likely that $H N H$ should be dated later than QAM..$^{261}$

In any case, regardless of the dating, there are many similarities between these two works, as well as some striking differences. QAM is about the relation between the soul and the body, and therefore about the substance or nature of the soul. However, the soul as such seems to be conspicuously absent in HNH. It is noteworthy in itself, that a $2^{\text {nd }}$ century AD Greek work on human nature barely mentions the soul at all. Not bringing in the soul as an explanatory factor in a book on human nature, or what is more - leaving the soul out of the discussion altogether, is, to say the least, highly remarkable for someone so steeped in the Greek philosophical tradition as Galen. In fact, Galen starts the whole treatise by placing himself into this philosophical tradition, in which the soul has been of such paramount importance. The mere fact that the work is a commentary on a much older treatise in which the notion of soul does not play much of a role, is not sufficient explanation for its notable absence in Galen's text, since Galen is usually comfortable enough in projecting his own thoughts upon Hippocrates' work. Moreover, Galen generally presents his explanation of Hippocrates as being in line with his own doctrines. This is exactly why his commentary can serve as an elaboration of what he wrote in Hipp. Elem., and elsewhere, in the first place. But in Galen's own works, as we know, the soul is far from absent. ${ }^{262}$ Finally, as we have seen in Case-Study I, Galen in other places identifies soul with the form of the body, identifying form, in turn, as the mixture of elemental qualities that, mixing in prime matter, form the homoeomerous bodies. In $H N H$, the distinction between elemental qualities and prime matter is assumed as elsewhere, and the notion that the elemental qualities are the form of the body is still in place as well. Yet, the notion of soul is almost entirely absent. Why would this be?

\footnotetext{
${ }^{260}$ Jouanna (2012) 288, calls the Hippocratic Nat. Hom. a 'reference point' for Galen, since Galen thought that Hippocrates used the word 'nature' in the most primary sense in that work.

${ }^{261} Q A M$ is dated after 193 by Ilberg (1896) and Bardong (1942), so rather late, which makes it seem likely that $H N H$ also postdates 193. Cf. Singer (2013) 335 ff. for a more problematizing view on the dating of $Q A M$, which, however, does not take into account the references to $Q A M$ from $H N H$ and Loc. Aff. and the similarity between the views espoused in $Q A M$ and the late Prop. Plac.

${ }^{262}$ Even in Hipp. Elem., HNH's predecessor, the relation between the elemental theory and psychic functions is repeatedly brought up, such as in Hipp. Elem. 76,12-18 De Lacy (I 433-4 K) and 134,9-14 De Lacy (I 487 K)
} 
We have already noticed in the previous case-study that for Galen nature and

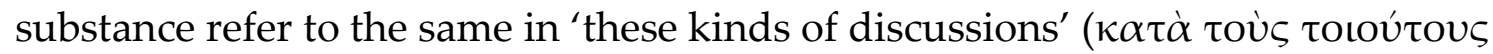

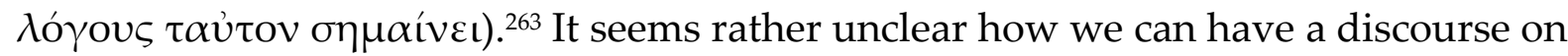
'our nature' or 'our substance' and leave out a discussion of the soul altogether. Particularly when this 'nature' or 'substance' is understood as the cause for our specific properties as well as our actions and affections, as Galen understands the terms in both $Q A M$ and $H N H .{ }^{264}$ In whatever way soul is usually explained in ancient Greek philosophy, it would seem to involve some notion of a causal power, which seems to make it a highly interesting subject for discussions of the causes of our actions and affections. But, if we were able to explain all of the functions that each of our organs (including brain, heart and liver) exercise in terms of a substance (i.e. that which exercises the causal power) that can be broken down into a mixture of elemental qualities and prime matter, what need is there still for some other causal power that we cannot understand in those hylomorphic terms? Perhaps this would not mean that we would dispense of the notion of soul; it would merely mean that the role of soul, i.e. the principle of movement, could be sufficiently played by the mixtures of the elemental qualities, so that we would not need something else besides it.

Philip van der Eijk has suggested that Galen, like Aristotle, when speaking of 'our nature', generally refers to our bodily nature. ${ }^{265}$ Indeed, in one or two passages Galen explicitly specifies that the treatise is about our bodily nature. ${ }^{266}$ Van der Eijk points out that there is a tradition of treatises titled 'On the nature of the human being', that had a focus on the 'physical, corporeal or natural constitution of human beings and the way this comes about and develops. ${ }^{267}$ Galen's commentary on the Hippocratic On the Nature of Man appears to stand in this tradition as well. Taken by itself, however, this is not a sufficient explanation for the absence of soul in Galen's treatise, since, as van der Eijk remarks, such a discussion of the nature of the human being 'would also include the soul, though primarily in its relationship to the body, the soul's embodiment, and the involvement of bodily factors in the soul's operation.'268 Typically it would exclude the rational soul, given its more precarious relationship with the body and its supposed divine provenance. In Galen's commentary, however, this distinction between rational and non-rational is not made, and there is nothing on the soul's 'embodiment' or the role of our 'bodily nature' with regard to

\footnotetext{
${ }^{263}$ See infra CS I, section 1, 16-7. Cf. QAM 33,9-10 Müller (IV 769 K); cf. Hipp. Elem. 136,1-3 De Lacy (I 488 $\mathrm{K})$, where Galen remarks that it does not matter whether the treatise is called 'On the elements', 'On nature' or 'On substance'; PHP VII 440,11-2 De Lacy (V $601 \mathrm{~K}$ )

${ }^{264}$ QAM 33,9-34,2; HNH 3,20 f. Mewaldt (XV 2 f. K)

${ }^{265}$ Van der Eijk (2014) 89 f.; see also Jouanna (2012)

${ }^{266}$ HNH 7,12-4 Mewaldt (XV $9 \mathrm{~K}$ ); in 53,17-8 (XV $102 \mathrm{~K}$ ) he states the nature of the body to be the subject in the Hippocratic treatise itself: 'Having set himself the task in this book of discovering the nature of our body

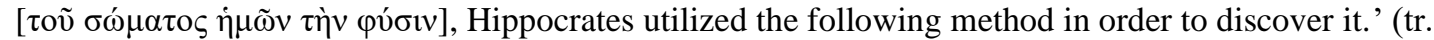
Hankinson - throughout this case-study I will be using Jim Hankinson's draft of his translation of $H N H$, which he has kindly provided to me and which has been of great use.)

${ }^{267}$ See van der Eijk (2014) 89

268 ibidem
} 
the functions of the soul (with the exception of one passage which refers to $Q A M$, as we shall see). These topics are not addressed at all and the soul remains almost entirely absent.

Furthermore, Galen also uses the phrase 'our nature' or 'human nature' in HNH to refer not to our bodily constitution but, rather, to refer to soul. ${ }^{269}$ This makes it problematic to assume that Galen, when writing about 'our nature', is thinking of the body from the perspective of a body-soul dualism. To give another simple example, in Trem. Palp., when explaining what he means by 'the natural heat in each animal'

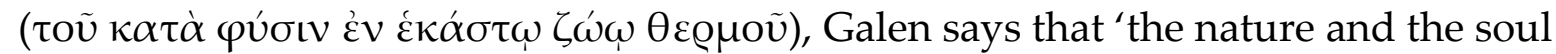

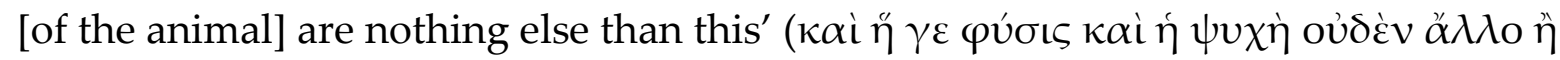
$\tau o \tilde{v} \tau$ ' ć $\sigma \tau \iota v) .^{270}$ So, here we have an apparently synonymous use of nature and soul, in which both amount to the same thing, namely the innate heat. Galen adds that this

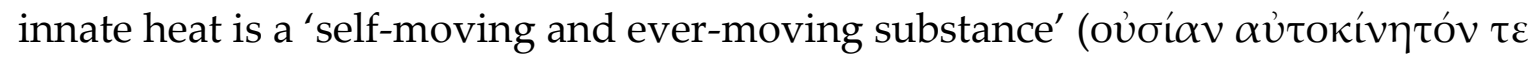

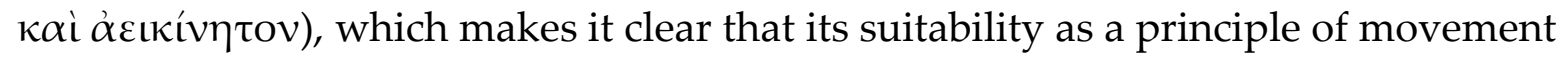
is the reason why Galen here considers heat as both soul and nature of living beings. Besides all this, it is generally difficult throughout Galen's work to make a clear-cut difference between the body and the soul. Basically, it is unclear where one stops and the other begins. For, what functions of the human being are not functions of the human body (e.g. the brain) according to Galen?

What is more, even if these matters were easier, and it would be unambiguous that Galen in all cases refers to our bodily (as opposed to psychic) nature when he speaks of 'our nature', then we should still ask: what does this mean - to treat the question of our nature in terms of our body? What consequences does this approach have for the classic notion of soul, with which Galen is thoroughly familiar? What does it mean that Galen refrains from discussing those consequences entirely in a work that supposedly functions as a basic exposition for his views on human nature?

Finally, Galen is also comfortable in, at least, asking about 'the nature of the soul' in $Q A M$ and other places (and even in HNH itself quotes from Plato's Phaedrus a passage on the nature of the soul), which indicates either, again, that the word 'nature' in itself does not have to imply, for Galen, something solely 'bodily' in the sense of 'something that is not soul', or that soul could be explained in terms of the body ('the bodily nature of the soul', which actually does seem to be the direction of $Q A M)$. Thus, even though Hippocrates' work was on the bodily nature of man, and Galen himself answers the question of the nature of man in what we could call predominantly bodily (although, importantly, hylomorphic) terms, all of this is not in any way self-evident. It remains remarkable that Galen is not only satisfied to discuss the question of our nature in these hylomorphic bodily terms, but that he does not even address the absence of soul at all in his treatise, despite repeatedly citing the Phaedrus (!) and despite the indubitable fact that the question of the soul itself is for him at least strongly related to the mixtures that he identifies as our nature in $H N H$

\footnotetext{
${ }^{269} \mathrm{HNH} 40,25-41,8 \mathrm{Mewaldt}$ (XV 76-7 K), we shall discuss this passage below, 134-6

${ }^{270}$ Trem. Palp. VII $616 \mathrm{~K}$
} 
and elsewhere. The very fact that Galen can talk about 'our nature' and refer in some cases to our bodily nature, while in other cases he refers to soul, reveals, if anything, the exceptional ambiguity of the difference between the two in Galen.

Instead of dismissing this ambiguity by taking it as sloppy terminology or laxity on Galen's part, I would like to see it as a sign for the general difficulty Galen has with distinguishing the soul from the body, and to find use for a notion of soul as something that is not bodily. This difficulty might rather be the consequence of his knowledge and appreciation of the body and his relative readiness to acknowledge it when he does not know something - for example, whatever soul might be if it is not understood as a form or quality of the body.

With help from the Phaedrus-passage, Galen presents it so that Hippocrates wrote on the nature of the body, while Plato stated that the same method used by Hippocrates should also be used for the inquiry into soul. At first sight, this might seem to entail that Galen himself is satisfied to discuss the nature of the body in his commentary, leaving the nature of soul to be discussed elsewhere, perhaps in an exchange with Plato, or leaving it for others to discuss altogether. However, as we shall see below, Galen seems to present his commentary not merely as a continuation of the Hippocratic text but rather - as he does more often - as the synthesis of the Hippocratic and the Platonic approach, which means, in this case, that he discusses the nature of man as a whole, as opposed to merely the nature of either man's body or soul. I will argue that this is what ultimately lies behind his repeated citation of the passage from Plato's Phaedrus in HNH and Galen's neglect of the notion of soul in this work, as becomes clear particularly at the end of his commentary. This approach comes down to an interpretation of the nature of man in hylomorphic terms, in which body and soul are inseparable and the mixture of elemental qualities provides the form that determines man's nature and functions as a principle of movement. In what follows, we shall first look at Galen's definition of nature, which he proposes at the outset of his commentary. He considers nature to be a kind of 'primary substance', which underlies the generation and destruction of all things, as well as the properties of these things. What this primary substance is, according to Galen, will be the subject of our first paragraph. Second, we shall look at the method Galen proposes to uncover this primary substance. As mentioned, Galen proposes what he presents as a Hippocratic-Platonic concord here; a method of division until no further division is possible, equally applicable to all beings subject to generation and destruction and equally applicable to body and soul. To gain some clarity about the primary substance that is to be uncovered through this method, I devote the third paragraph to a brief discussion of elements and qualities in Galen, since the distinction between these is important for his hylomorphic notion of human nature. Since the nature of the human being is constituted by the same two basic principles as the nature of anything else that is not eternal, namely a mixture of the four elemental qualites and prime matter, we shall discuss what nature in this more general sense is and how it relates to human nature, in the fourth paragraph. Finally, in the fifth paragraph, we shall come back to Galen's particular elaboration of the 
conceived Hippocratic-Platonic method and the division between the nature of the body and the nature of the soul, as well as their interrelation.

\section{The primary substance}

At the beginning of Galen's commentary, we find the same identification of nature and substance that we have seen in our discussion of QAM in Case-Study I: Galen here explains the term 'nature' in terms of substance (oúoí $\alpha$ ). ${ }^{271}$ After his introductory remarks on the relation of this treatise to his previous Hipp. Elem., he starts his commentary with a preliminary question of definition:

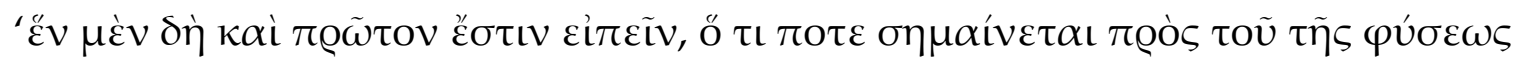

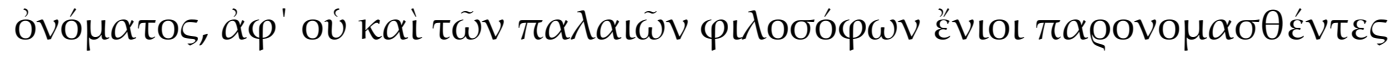

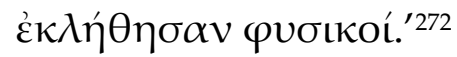

'There is one thing that needs to be discussed first: what, then, is signified by the term 'nature', because of which some of the ancient philosophers are called by derivation 'natural philosophers'.'

This is a good question, indeed. If some of the very first philosophers were called 'philosophers of nature', because 'nature' was their main subject of inquiry, and thus philosophy itself appears as something that is originally concerned with the question of 'nature', it makes sense to see if we can understand what is meant by this word. What is meant, at least as it appears to Galen from the works of those ancient natural

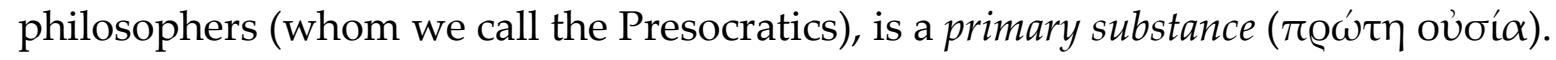
This primary substance underlies all bodies subject to generation and destruction, as well as all the properties that pertain to these bodies in accordance with their particular structure. ${ }^{273}$ As Galen remarks in HNH's predecessor, Hipp. Elem., it would not have mattered if, instead of 'On the elements' that work would have been titled 'On nature' ( $\pi \varepsilon \varrho i$ i $\varphi v ́ \sigma \varepsilon \omega \varsigma$ ) or 'On generation and destruction' ( $\pi \varepsilon \varrho i ̀ ~ \gamma \varepsilon v \varepsilon \dot{\sigma} \sigma \varsigma \kappa \alpha i$ $\varphi \theta$ o@ $\tilde{\alpha} \varsigma$ ) or 'On substance' ( $\pi \varepsilon \varrho i$ oúoí $\alpha \varsigma) .{ }^{274}$ These subjects apparently all amount to the same thing: that which underlies the continuous processes of change. Here, Galen rephrases the question of nature in terms of the question of substance, which has two fundamental aspects: it underlies the bodies as well as their elemental properties.

\footnotetext{
${ }^{271}$ See infra CS I, section 1, 16-7 and note 263 above

${ }^{272}$ HNH 3,20-2 Mewaldt (XV 2 K)

${ }^{273} \mathrm{Cf}$. Tieleman (forthcoming), who points out that this particular approach can be paralleled with some Middle Platonists, e.g. Alcinous Handbook of Platonism chapter V; Galen apparently also gave a definition of the word 'nature' in the Medical Names, which is unfortunately lost (see HNH 6,8-11 Mewaldt (XV 7 K)); cf. also Jouanna (2012) 288 on the primary meaning of nature being that of the mixture, and on the definition found in Galen's Hipp. Epid. VI (253,19-21 Wenkebach): 'by the word nature we should understand the ability residing in

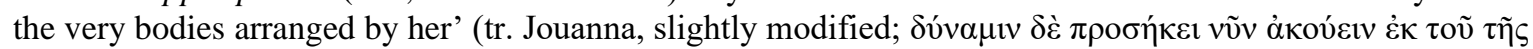

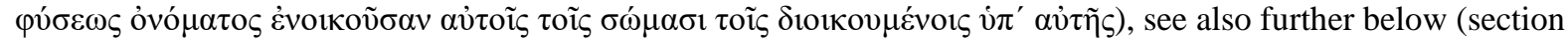
$4,119)$ for this latter passage

${ }^{274}$ Hipp. Elem. 136,1-3 De Lacy (I 488 K)
} 
Any knowledge of anything subject to becoming is dependent on knowledge of this primary substance:

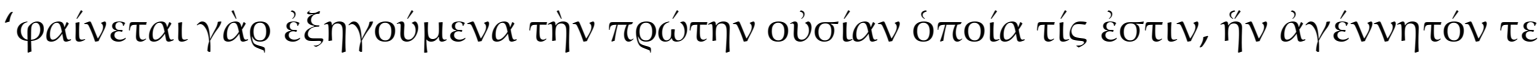

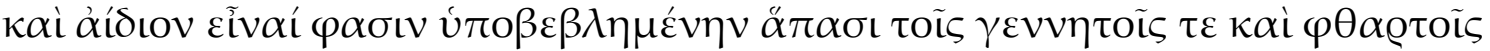

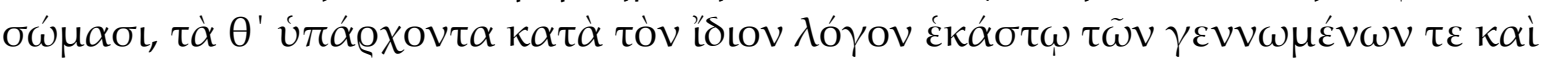

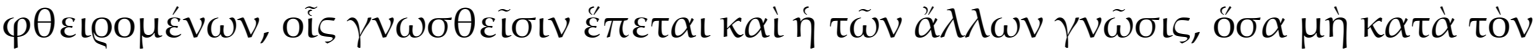

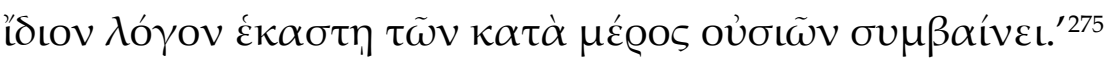

'For it is clear that they seek to give an account of what sort of thing is the primary substance which they say is ungenerated and eternal and which underlies all bodies that are subject to generation and destruction, as well as the properties which obtain for each of the generated and destructible things in virtue of their particular structure, upon a knowledge of which depends the knowledge of everything else which belongs to each individual substance not in virtue of its particular structure.' (tr. Hankinson ${ }^{276}$ )

This primary substance, or nature of things, underlies both the body of any given thing, as well as its essential properties. Here we recognize the Aristotelian perspective Galen also took up in $Q A M$ and elsewhere, as we saw in Case-Study I: the primary substance is one substance that can be viewed in either its material aspect (underlying subject) or its formal aspect (most basic properties which determine secondary properties). ${ }^{277}$ Furthermore, the knowledge of everything that belongs to an individual substance accidentally, or not by virtue of its particular structure, is also dependent on knowledge of this primary substance. That is to say, nothing can be known about anything, if it is not built upon knowledge of this primary substance. This is something we need to keep in mind, as it will be important for the interpretation of what comes later in this treatise. In any case, this must apply to the properties of our bodies and their organs as well, since our bodies are subject to generation and destruction. Thus, we need to know this primary substance underlying all of our properties and functions, if we are to know anything about ourselves. Now, again, what if we were to exclude soul from this discussion, but nonetheless would be able to have a complete analysis of all of the essential and accidental properties of our body, in terms of this primary substance underlying them? This would leave us with an obvious question: what, then, is soul supposed to account for? If we are able to account exhaustively for the causes of all of our bodily functions in terms of this substance, would it be the case that there is no role left for soul to play? Unless, of course, what is considered 'soul' is already taken into this account, as the formal aspect of a hylomorphic whole. This train of thought could perhaps be taken to explain the soul's absence in Galen's commentary, that is to say: perhaps this absence is merely an explicit absence because the role of soul is fulfilled

\footnotetext{
${ }^{275}$ HNH 3,24-4,5 Mewaldt (XV 3 K)

${ }^{276} \mathrm{Jim}$ Hankinson has been kind enough to let me use a draft-version of his forthcoming translation of $H N H$

${ }^{277}$ Cf. Kupreeva (2014) 191-2
} 
by the formal aspect of the hylomorphic whole. I think it might not be unreasonable, from Galen's perspective, to consider an explanation of our bodily functions in terms of the substance that underlies them as their cause, as a complete description of our nature, including that which is traditionally referred to as soul. Or at least, it would be a description of all we can know about soul. If soul, or a part of it, cannot be explained in these terms, we cannot know anything about it - not according to the epistemological criteria Galen has just proposed here. Could this not simply be the reason why Galen so often expresses his inability to answer the question for the substance of the soul? In this regard, the manner in which he states the problem in $Q A M$ might be telling: he does not know what the substance of the soul might be if we take it to be something incorporeal. ${ }^{278}$

The primary substance introduced by Galen at the beginning of his commentary, is

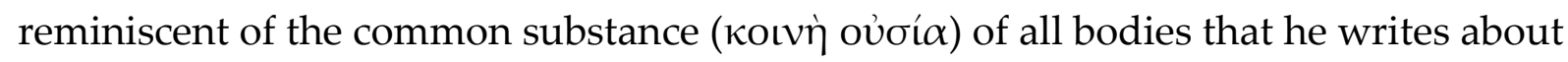
in QAM and elsewhere. ${ }^{279}$ There, the common substance of all bodies was described as hylomorphic, analysable into a matter without quality and a form consisting of a mixture of the four elemental qualities. With he distinction between the primary substance underlying all bodies (the function of matter as such) and the essential properties of these bodies (the function of elemental form), Galen seems to be framing the traditional endeavour of natural philosophy in his own (Aristotelian, hylomorphic) terms at the start of this treatise. Indeed, further on in $\mathrm{HNH}$, Galen

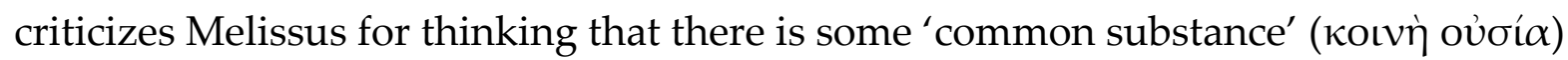
in the sense of a matter that is ungenerated and indestructible, and that underlies the four elements, while really this matter 'is not the only thing which is the principle of bodies in generation and decay, as Melissus supposed. In addition to it there are the four qualities, the extreme forms of cold, dryness, heat and moisture.'280 That is to say, in Galen's reading of Melissus, he was right to assume a common substance as a principle of all bodies subject to generation and decay, but he made the mistake of not seeing that this common substance is in fact hylomorphic and thus consists of two principles instead of merely an underlying matter. Moreover, as with the common substance in $Q A M$, we are concerned here - even though the title of the Hippocratic text refers specifically to the nature of man - with a nature of all things, or at least all things subject to generation and destruction. Notably, it is not only the case that we, as hylomorphic beings, certainly fall within this category, we would also expect our soul - if Galen were to discuss it as such - to at least partly and possibly completely fall into this category as well. After all, as we have noted in Case-Study I, Galen elsewhere assumes that the lower two soul-parts, residing in liver and heart, are mortal, and at least suggests that the rational part might be mortal as well. ${ }^{281}$ Again, this shows how, for Galen, a discussion of the nature or substance of man, does not need a point of departure that is fundamentally different

\footnotetext{
${ }^{278}$ See infra, CS I section 2, 50-2; QAM 38,16-23 Müller (IV 775-6 K)

${ }^{279}$ QAM 36,21 f. (IV $773 \mathrm{~K}$ ); cf. Hipp. Elem. 128,1 f. De Lacy (I 481-2 K)

${ }^{280} \mathrm{HNH}$ 17,20-30 Mewaldt (XV 29-30 K), translation Hankinson

${ }^{281}$ See infra CS I, sections 1 and 2, particularly 17, 37-9, 41, 48-55
} 
from that of a discussion about the nature or substance of any other thing in the cosmos. What man is can be explained in the same basic terms which we use to explain everything else. ${ }^{282}$

And, as we have seen, this explanation in basic terms is the only way to have knowledge of the explanandum. Therefore, Galen takes issue with people that seem to assume something's nature could be described by merely enumerating some of its accidental properties. He illustrates this point with an example from Homer's Odyssey, where Odysseus receives a drug from Hermes and relates how the god 'showed its nature [ $\varphi v ́ \sigma \iota \varsigma]$ to me'. In the immediately following sentence, however, it is said of the drug that 'It was black at the root and its flower resembled milk'. That is to say, Homer merely recites some of its qualities, as opposed to giving an actual description of its nature in the sense Galen intends. Galen wants to make a general point here, following upon and specifying his prior definition of nature:

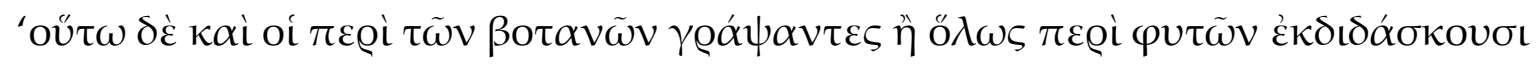

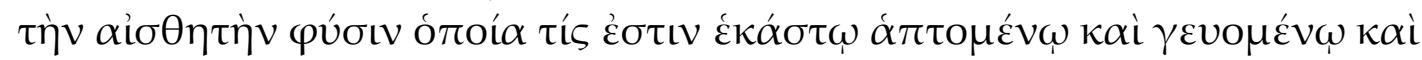

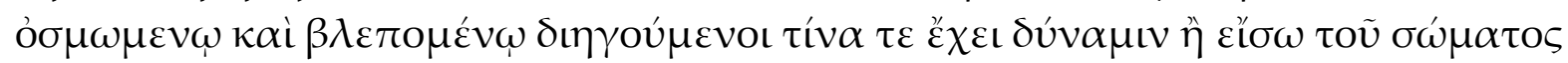

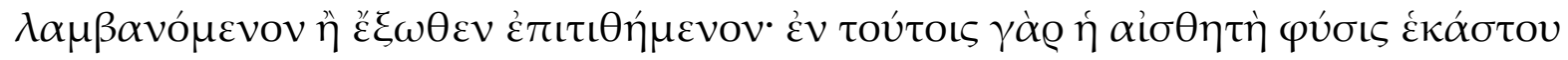

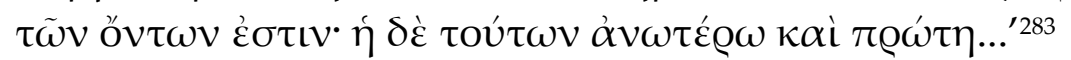

'In the same way too those who write about herbs, or plants in general, teach what the perceptible nature of each of these is when it is touched, tasted, smelled or seen, detailing what power each of them has, whether it is taken internally or applied to the body externally, since the perceptible nature of each thing consists in these things. But higher than these, and prior to it, is the kind of nature that I spoke of earlier...' (tr. Hankinson)

The nature that Homer was referring to, and that those herbalists refer to, is termed by Galen the perceptible nature of a thing. This is the nature of a thing according to our senses, it is what the thing is when it is 'touched, tasted, smelled or seen' and what we can observe it bringing about ('what power each of them has'). Galen carefully distinguishes this perceptible nature of a thing from the nature in the sense of primary substance, which he spoke of earlier. ${ }^{284}$ Apparently, this implies that nature in a primary sense, the higher kind of nature Galen is referring to, is not available to perception. This reminds us, again, of what he said about the elemental qualities and the prime matter that form the common substance of all bodies. Both matter and form of the most basic hylomorphic constructs making up all bodies in

\footnotetext{
${ }^{282}$ Cf. Kupreeva (2014) 177: 'Galen argues that proximate, i.e. organic, elemental qualities have the same nature as their inorganic counterparts: the principles of natural design and mixture are sufficient to account for a variety of properties manifest in the organic and inorganic elemental compounds throughout the cosmos.'

${ }^{283}$ HNH 4,14-9 Mewaldt (XV 3-4 K)

${ }^{284}$ And for good reason, since according to Galen the term púбıৎ is used in several senses. It can, for example,

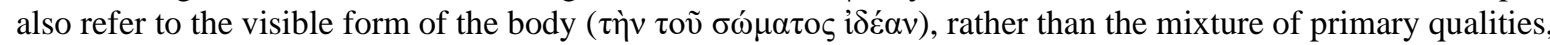
as we we can see in Hipp. Aph. XVII B 532 K. See Jouanna (2012) $288 \mathrm{f}$. on these two senses of nature, and Galen's tendency to call the mixture the primary or most important sense.
} 
our cosmos are not perceivable by themselves. Their joint construction is the first observable entity; this is the homoeomerous body. Such bodies can be 'touched, tasted, smelled or seen', and are therefore called by Galen the 'perceptible elements', i.e. the elements in terms of the realm of perception. ${ }^{285}$ This is clear from On the Natural Faculties (Nat. Fac.) as well:

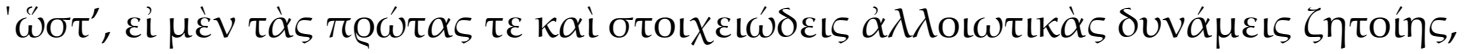

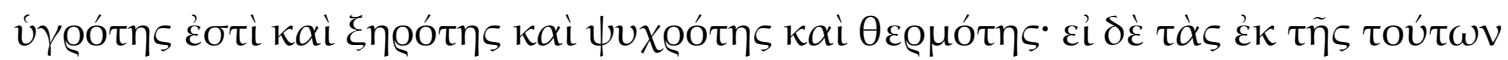

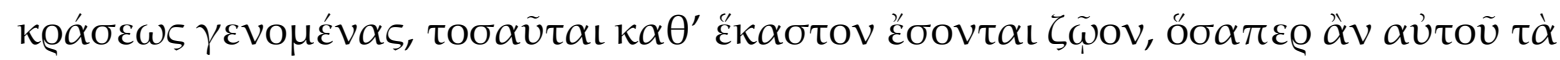

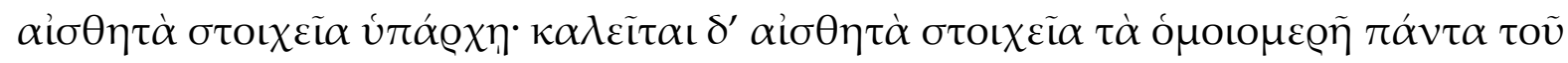

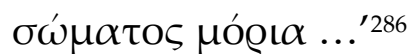

'Therefore, if you wish to inquire into which alterative powers are primary and elementary, these are wetness, dryness, coldness, and hotness, and if you wish to inquire into the things that arise from the mixture of these, there will be so many of these in each animal as it has perceptible elements. The name perceptible elements is given to all the homoeomerous parts of the body.'

And we find the same definition in Hipp. Elem., the predecessor of $\mathrm{HNH}$ :

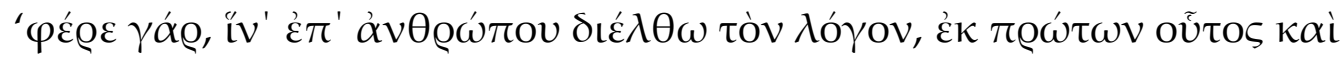

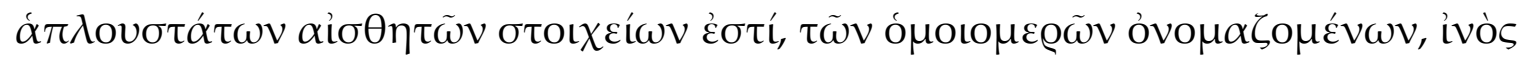

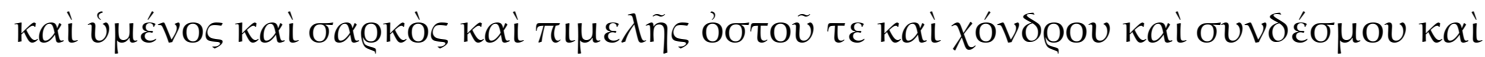

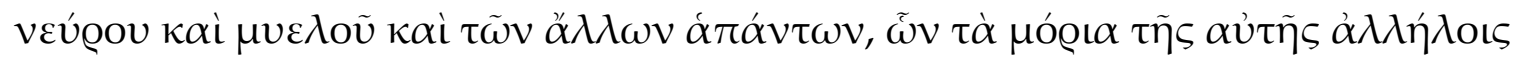

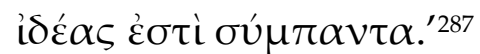

'Now let me go through the account as it applies to a human being: he is made of the primary and simplest perceptible elements, those called homoeomerous, namely fiber, membrane, flesh, fat, bone and cartilage, ligament, nerve, marrow, and all the other (bodies) whose parts all have the same form.' (tr. De Lacy, slightly modified)

These homoeomerous bodies are merely the elements of things in terms of what is perceptible, not the true elements of things in terms of their nature, as the herbalists seem to think. ${ }^{288}$ When it comes to finding out about the nature of a thing, we have to dig deeper than what the organs of perception tell us, according to Galen.

As he remarks at the beginning of Hipp. Elem.: 'let us try to find the parts that are first and simplest by nature and are no longer capable of being dissolved into other parts,

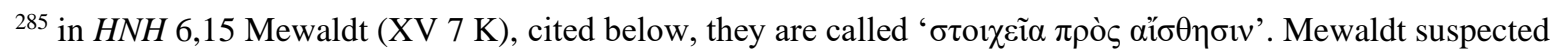
this part of the sentence (since the terminology is not Aristotelian, which might not be a good reason considering how common it would be for Galen to ascribe terminology to predecessors which they have not actually used either in the way he intends or at all).

${ }^{286}$ Nat. Fac. II 12 K; cf. also Nat. Fac. II 213 K

${ }^{287}$ Hipp. Elem. 126,1-5 De Lacy (I $479 \mathrm{~K}$ ); though from these latter two examples it may appear as if Galen only considers parts of animals to be homoeomerous bodies, this is not the case, see, e.g. QAM 37 Müller (IV 773-74 $\mathrm{K})$, where he mentiones also bronze, iron and gold as examples

${ }^{288}$ Cf. also Opt. Med. 6,14-9 Müller
} 
if we are going to obtain precise knowledge of the nature of man or of anything else.' 289

The nature of any given thing primarily resides at the level of its simplest component parts and manifests itself from there on out into the more complex parts. The simplest parts, however, are not available to our organs of perception, since the homoeomerous bodies, simplest in terms of perception, are composed of yet other elements (or strictly speaking: principles) themselves:

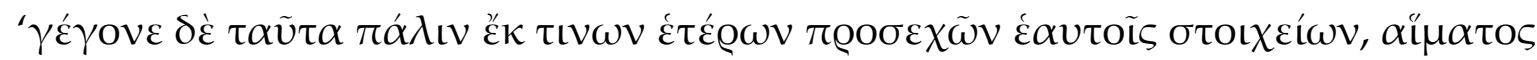

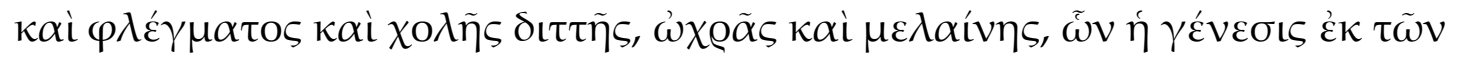

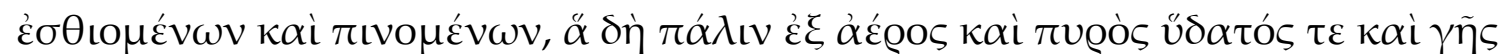

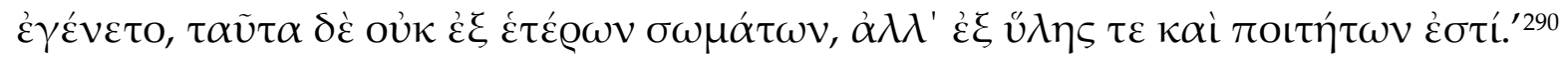
'These [the homoeomerous bodies] in turn have been generated from certain other elements closest to themselves, blood, phlegm, and the two kinds of bile, yellow and black; their genesis is from the things we eat and drink, which in turn were produced from air and fire, water, and earth; and these last are not from other bodies but from matter and qualities.' (tr. De Lacy)

Although the Hippocratic text on which Galen is commenting does not systematically connect the theory of the four humours to the four elements or the elemental qualities, Galen obviously does, in line with his own views in other works. ${ }^{291}$ On the basis of this and other passages, one could wonder why Galen does not consider the humours the perceptible elements, given that they are apparently simpler than the homoeomerous bodies and must be considered perceptible as well. On a general note, it seems to me as if the humours have a somewhat ambiguous status in the hierarchies of bodily construction Galen employs in the context of discussions of human nature. Even though the four humours are an intricate and established part of Galen's doctrines and explanatory schemas in many of his works, the four elementary qualities are more indispensable to his theories. It sometimes seems as if the humours do not really fit in well, or are perhaps considered less important. This seems to be the case particularly when Galen theorizes the general nature of the human being or human body in terms of these various levels of composition (prime matter and elemental qualities being the principles, homoeomerous bodies being the perceptible elements, organs being the unified structure of homoeomerous bodies, the human being as a whole being the unified structure of these organs and their interconnections). It could also be that this has something to do with the fact that the humoural theory has much less presence and importance in the philosophical tradition than it has in the medical one, while Galen prefers to take a philosophical and predominantly Aristotelian position in these

\footnotetext{
${ }^{289}$ Hipp. Elem. 58,2-5 De Lacy (I 414-5 K) tr. De Lacy, slightly modified

${ }^{290}$ Hipp. Elem. 126,5-9 De Lacy (I 479-80 K)

${ }^{291}$ See also Jouanna (2012) 336
} 
general discussions on nature and substance. ${ }^{292}$ Just to give an illustration, the following passage from Aristotle's Parts of Animals is basically a blueprint for Galen's physics, and we can see that the humours are not mentioned at all:

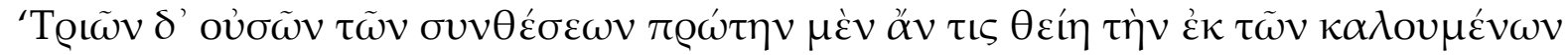

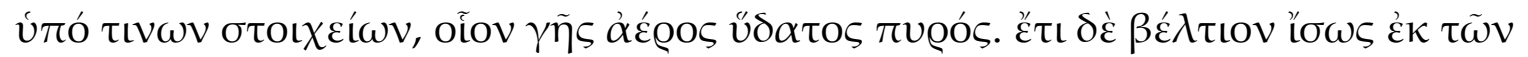

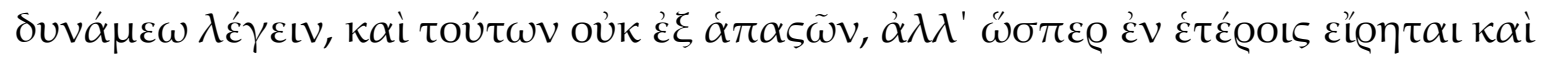

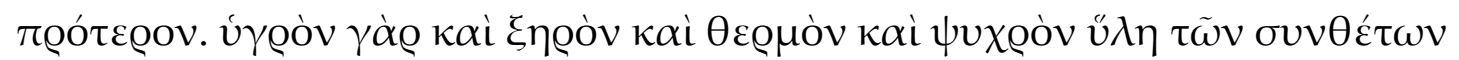

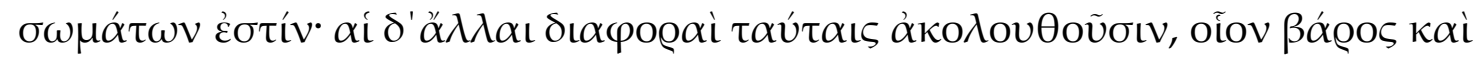

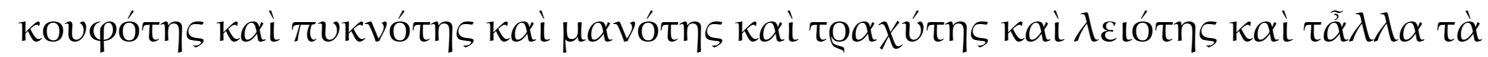

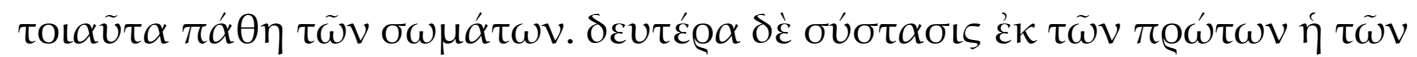

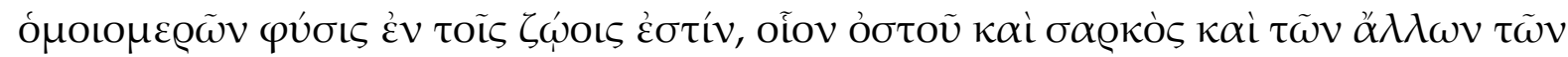

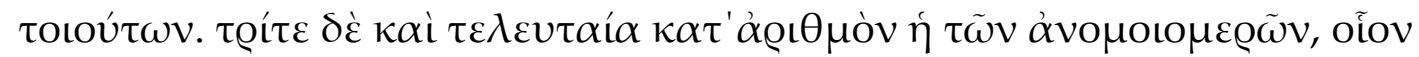

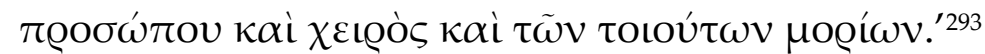

'Since there are three compositions, one might put first composition from what some people call the elements, e.g. earth, air, water, and fire. And yet, perhaps it is better to speak of composition from the powers, and not from all of them, but as stated previously in other places. That is, moist, dry, hot, and cold are matter of the composite bodies, while the other differences, e.g. heaviness and lightness, density and rarity, roughness and smoothness, and the other bodily affections of this sort, follow these. Second is the composition of the nature of the uniform parts within animals - e.g. of bone, flesh, and the other things of this sort - out of the primary things. Third and last in number is the composition of the nature of the non-uniform parts - e.g. of face, hand, and such parts.' (tr. Lennox, slightly modified)

The three compositional phases, the hylomorphic outlook, the difference between primary and secondary qualities, the terminology of homoeomerous and anhomoeomerous parts, even the examples given of both types... it is obvious that all basic physical doctrine Galen works out is already here and that this must have been a key passage for Galen. ${ }^{294}$ And yet, the humours are entirely absent. This might be a partial explanation for the odd status of the humours in Galen sometimes. However, I am unsure whether we should consider it sufficient. Another possible factor to take into account might be that, in Galen's schema, the humours are

\footnotetext{
292 Jouanna (2012) 337: ' $\ldots$ the theory [of the four humours] did not re-appear in the philosophical tradition of the fourth century, neither in Plato's Timaeus, where the nature of man is constituted of four elements (fire, water, earth and air), nor in Aristotle. The famous Problem 30.1, written in the Aristotelian tradition, concerning the melancholic's genius, i.e. those people in whom black bile is predominant, is not placed within a theory of the four humours.'. Also, Leith (2015) has shown how this Aristotelian compositional hierarchy does appear in the Hellenistic medical tradition of Erasistratus and Herophilus, but here the theory of the four humours also appears largely absent.

${ }^{293}$ Aristotle PA 646a12-24

${ }^{294}$ See QAM 37 Müller (IV 773-74 K); cf. HNH 6,10 f. Mewaldt (XV 7-8 K); PHP VIII,4 500,3 f. De Lacy (V 673 K); Part. Hom. 45 f. Strohmaier; Hipp. Elem. 126,1 f. De Lacy (I 479-81 K); Opt. Med. 6,14-9 Müller; cf. Kupreeva (2014); Hankinson (2017); Leith (2015) for the role of this passage in Hellenistic medicine and Galen's response to it.
} 
constituents of the nature of some beings (among which human beings) but not of other ones. So while the nature of everything is said to consist in the mixture of elemental qualities, the nature of blooded animals more specifically consists of the humours, both according to the Hippocratic text and Galen's commentary. ${ }^{295}$ But, saying man's nature consists of the humours clearly does not amount to saying man's nature does not consist of the mixture of elemental qualities, since the former come to be from the latter:

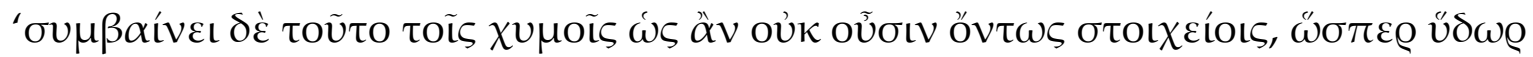

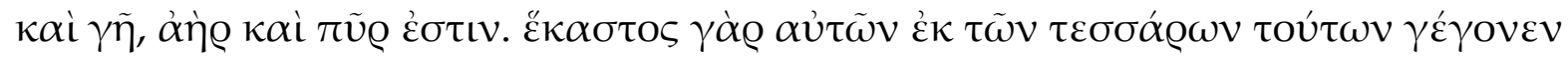

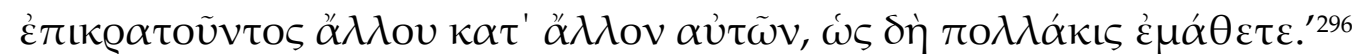

'And this happens to the humours since they are not really elements, as water and earth, air and fire are. For each of them comes to be from the four, when one of them gains mastery in respect of another, as you have learned on many occasions.' (tr. Hankinson)

Although everything's nature has something in common, there also has to be a difference, obviously. This difference has to be accounted for, in Galen's cosmology, in terms of the specific mixture of a given being. Thus, certain proportions of the qualities render a humour such as blood, others do not, as is clear from the passage quoted above. Therefore, Galen could say that the nature of man consists of the mixture of the four elemental qualities, and also say that the nature of man consists of the four humours - though in a more primary sense in the mixture, and in a more particular sense in the humours. This is also articulated in the following passage:

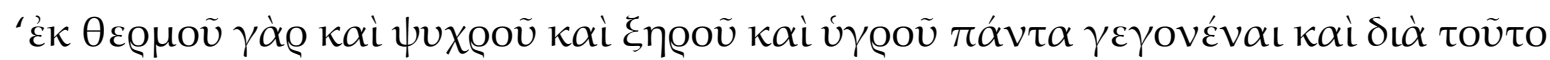

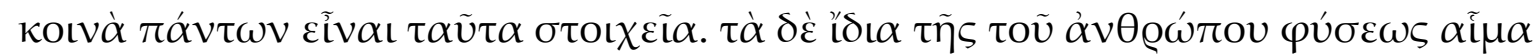

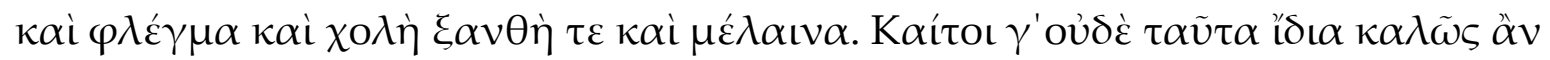

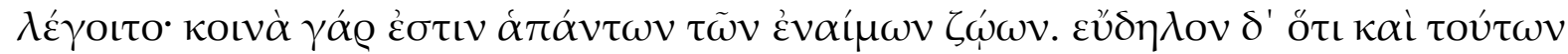

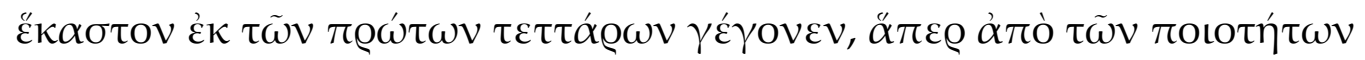

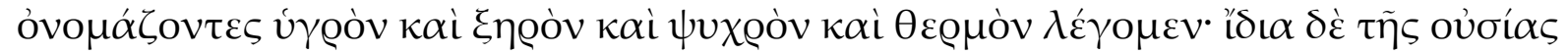

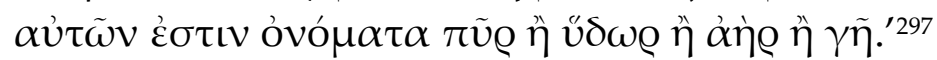

'For everything is generated from hot and cold and dry and wet, and for this reason these things are the common elements of everything. The particular ones of the nature of man are blood and phlegm and yellow and black bile, although not even these are properly called 'particular', since they are common to all blooded animals. And it is clear that each of these comes to be from the primary four, which we label wet and dry and cold and hot, naming them from their qualities; but the proper names of the substance of them are fire, water, earth and air.' (tr. Hankinson)

\footnotetext{
${ }^{295} H N H$ 32,10 f. Mewaldt (XV $59 \mathrm{~K}$ )

${ }^{296}$ HNH 36,8-12 Mewaldt (XV $67 \mathrm{~K}$ )

${ }^{297}$ HNH 28,12-19 Mewaldt (XV 51 K)
} 
Thus, the nature of a given being could be described on various levels of generality. The humours are constituent of the nature of any given sanguine animal, but they are so in a more particular and therefore less elemental sense than the elemental qualities that form the humours and that also form other things than humours. Perhaps this insight could partly account for the confused status of the humours in these hierarchies. Galen seems to switch very easily (and perhaps sometimes confusingly) between the analysis of the nature of man - where the humours have their place and the analysis of the common nature of any being subject to generation and destruction - where the humours should be left out to maintain the level of commonality.

But whatever the status of the humours, it is unambiguous that the final stage of this compositional hierarchy is a hylomorphic construct of prime matter and the four elemental qualities. This is not only so in the case of man, but in the case of everything that is not eternal. It implies that behind the nature that we can perceive for example that of a mixture of humours, that of something which is black in one part and white in another or perhaps even that of a being which has an organ capable of thought - there is another nature, that can not be perceived, and that it is the latter that is truly the nature of the thing under investigation, in this case man, as the endpoint of analysis. This endpoint is the conceptual division of the homoeomerous body in terms of its two principles of matter and form. Then we are at the level of the primary substance that Galen refers to in order to define what is meant by nature. This primary substance is continuously changing in quality, though it remains the same because of its underlying matter. It primarily manifests itself in the form of homoeomerous bodies, the simplest bodies forming the building-blocks for more complex structures.

\section{Divisio ad principes: a Hippocratic-Platonic method}

In $H N H$, Galen repeatedly articulates this same ideal of division until some indivisable point is reached, when it comes to the analysis of a beings' nature. He does so with reference to a passage from Plato's Phaedrus (270c-d), where Hippocrates is presented as having first proposed the right method for the examination of a thing's bodily nature: first, one has to find the simplest parts of it, then one has to determine what causal powers these simplest parts have. ${ }^{298}$ Galen quotes from the Phaedrus:

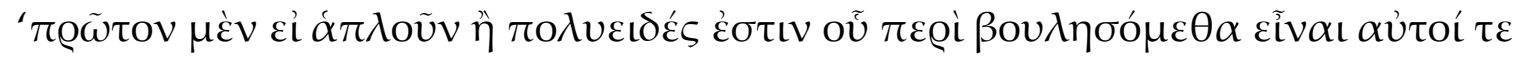

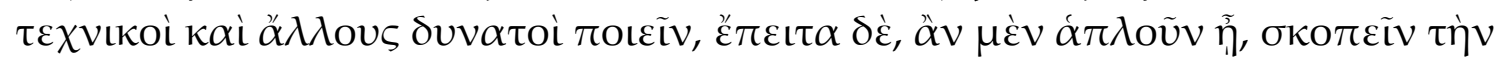

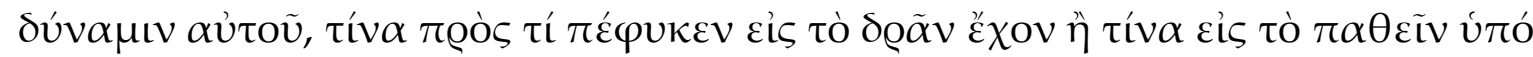

\footnotetext{
${ }^{298}$ Cf. Tieleman (forthcoming) on Galen's use of this Platonic passage; Corcilius (2014) 20-58 on the

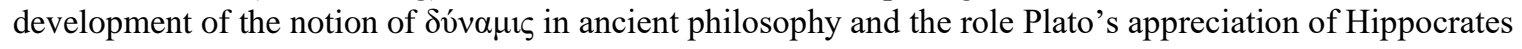
played therein.
} 


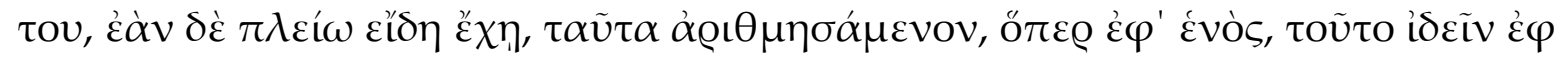

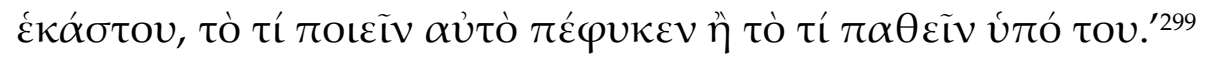

'Concerning anything in which we both want to be technically proficient ourselves and to be able to make others so too, we must first determine whether it is simple or complex, and then, if it turns out to be simple, to examine what power it has by nature for acting, and in respect of what, and what <power $>$ it has for being affected by something; while if it has many forms, we must enumerate them, and then do for each of them what we did in the case of the single one, namely what it by nature does to what, and how it is acted upon and by what.' (tr. Hankinson, slightly modified)

Galen obviously likes this passage a great deal, for several reasons. First of all, in what immediately precedes, the interlocutors credit Hippocrates for having described this as the proper method for investigating nature. It is also implied that the inquiry into soul needs to build on this. In The Therapeutic Method (MM) book I, Galen summarizes as follows: 'Plato thinks that the things concerning the soul are to be discovered by the same method Hippocrates used with regard to the body. ${ }^{300} \mathrm{~A}$ few lines further in the same treatise, he emphasizes the complete agreement between Plato and Hippocrates on the most important matters, as he does throughout PHP. However, beyond the apparent agreement of Hippocrates and Plato, with regard to their preferred method to investigate the body and soul respectively, the most important thing here is that the method now described, is the adequate method to understand the nature of anything, regardless of what we are talking about. Galen considers a being's nature to consist of its most primary active and passive causal powers. That is to say, the causal powers of its primary or smallest, most basic (in terms of quality) component parts to act upon something or be acted upon by something. ${ }^{301}$ For him, this is a description of the proper method of natural philosophy, which has been employed not only by his two great examples Hippocrates and Plato, but also by Empedocles, Parmenides, Melissus, Alcmaeon, Heraclitus and all those who wrote books entitled 'On Nature' ${ }^{302}$ Thus, according to Galen this is something philosophers have agreed upon throughout the tradition preceding him: to know a thing's nature we need to know its most basic elements and the powers of these elements. What these elements and their powers are, on the other hand, is something the philosophers have not agreed upon (which perhaps should not be surprising, from a Galenic perspective, considering that these elements cannot actually be perceived as such). Of course, Galen is not merely enumerating the previous tradition. He is attempting to insert himself into it by presenting this common method with various outcomes, and presenting his own thoughts (in the form of a commentary on Hippocrates with help of the repeated invocation of Plato)

\footnotetext{
${ }^{299}$ HNH 5,1-6 Mewaldt (XV 5 K)

${ }^{300} M M$ I.2 (X 13-4 K)

${ }^{301}$ Cf. also Hipp. Elem. 58,6 f. De Lacy (I $\left.415 \mathrm{~K}\right)$

${ }^{302}$ HNH 5,10 ff. Mewaldt (XV 5 K)
} 
on the nature of man as being the proper application of that common method. ${ }^{303}$ Towards the end of the first book of his commentary, Galen returns to his description of this general philosophical method (also citing the Phaedrus again) to remark that we can now conclude that Hippocrates followed this method in his work, and that Plato agreed that one must also apply this method for investigating into soul. ${ }^{304}$ The entire introductory passage, which we have been discussing so far, is what Galen considers the background to the discussion of nature that he omitted in Hipp. Elem., since, as he says, he assumed his audience to be familiar with it. ${ }^{305}$ All that we have discussed thus far is written by Galen at the beginning of his commentary - all before the first commentary on an actual Hippocratic passage - as the introduction to his writing on human nature that was lacking in Hipp. Elem. Whether or not the content of these two (and other) works are in complete agreement with regard to their notion of (human) nature and Galen is consistent in this regard, we can at least be sure that he tried his best to make it appear so with writing HNH. In line with this, Galen also remarks that his The Differences of Diseases and The Therapeutic Method as well as other works, 'presuppose the doctrine concerning the nature of our body, which is expounded in the present text'. 306 Thus, we can safely assume that the point of writing $H N H$, which must have been relatively late, Galen considered it feasible to present these writings as an elaboration of basic presuppositions he used throughout his earlier work.

Still within the introductory part of the commentary, Galen presents other familiar fundamental doctrine as well: the division of homoeomerous and organic parts we have seen also in Case-Study I:

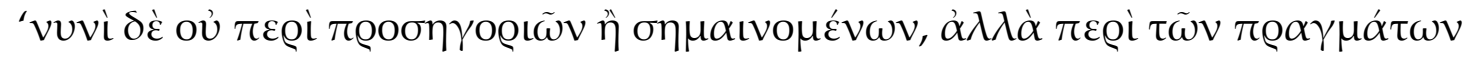

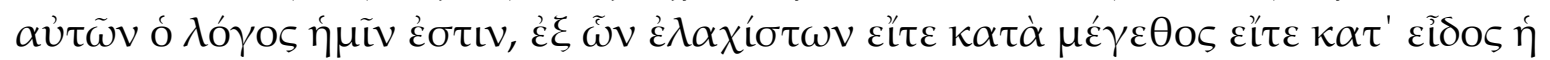

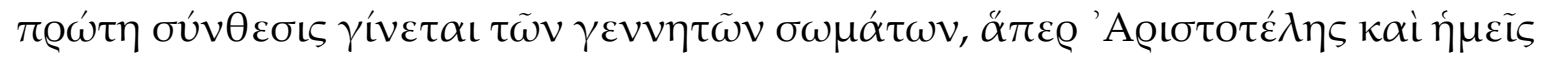

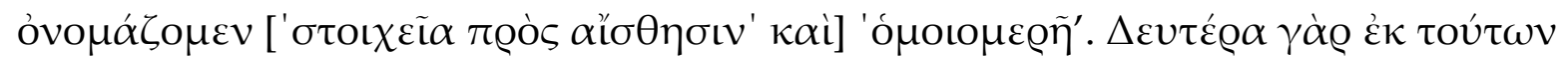

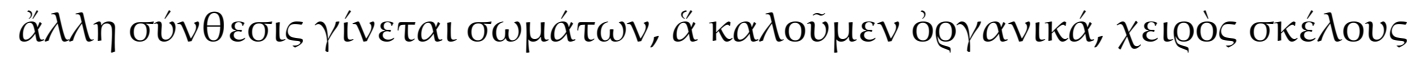

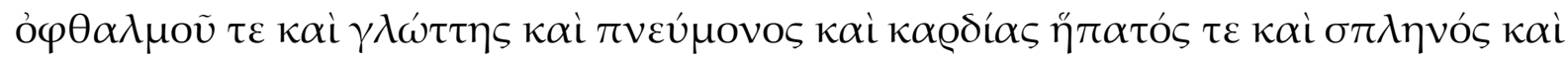

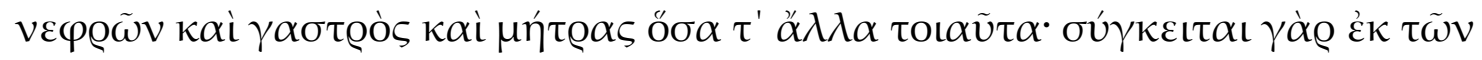

\footnotetext{
${ }^{303}$ Cf. Flemming (2008) on Galen's commentary practice in general, 347: 'Textual commentary, in Galen's world, played a key role in the development of ideas and understanding, in their articulation and elaboration, and in their transmission and dispersal. It allowed the exegete to define himself on an existing conceptual and ideological map, in an authoritative manner. The commentator was, after all, the student who had become the teacher. His commentary combined learning and teaching, announced his mastery of the subject, the sense in which he had absorbed, and could now contribute to, the tradition.'; Jouanna (2012) 313 ff. on this particular commentary.

${ }^{304}$ HNH 53,15 f. Mewaldt (XV 102 f. K)

${ }^{305}$ HNH 3,1-19 (XV 1-2 K), the introductory passage runs until 7,14 Mewaldt (XV $9 \mathrm{~K}$ ), after which Galen discusses the authenticity of the treatise; the actual commentary starts only at 11,7 Mewaldt (XV 16-7 K).

${ }^{306} \mathrm{HNH} 7,9-14$ (XV $9 \mathrm{~K}$ ), this is the passage referred to earlier, in which Galen states that his commentary concerns the nature of the body. It might be relevant that he does so in the context of referring to these two works, which are more practically oriented towards the treatment of illnesses of the body. It might perhaps also

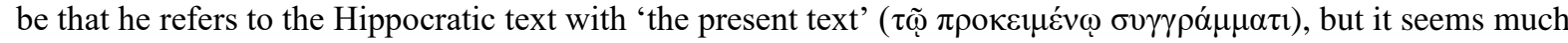
more plausible that it refers to the text the reader presently has in front of him, i.e. Galen's commentary itself.
} 


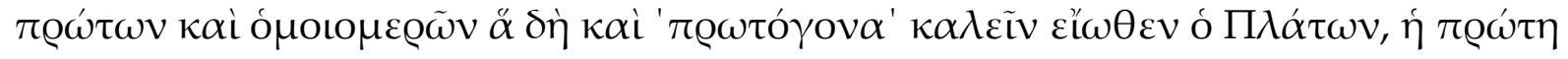

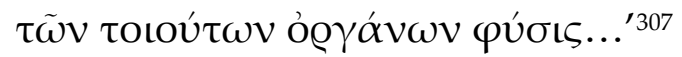

'But our present discourse is not concerned with appellations and meanings, but with the actual facts about the parts which are minimal, whether in respect of quantity or quality, from which are generated the first composition of generated bodies, which Aristotle and I call ['perceptible elements' and] 'homoeomerous bodies'. From these a second, distinct composition is generated, of the bodies we call 'organic': i.e. of the hand, leg, eye, tongue, lung, heart, liver, spleen, kidney, stomach, uterus and all the rest of them. For the proximate nature of this sort of organ is composed of the primary and homoeomerous ones, the ones which Plato was accustomed to call 'first-born'.' (tr. Hankinson, slightly modified)

This passage is reminiscent of QAM. There, Galen first explains how the common substance of everything consists of matter without quality and form as a mixture of the four elemental qualities, and then states that from the mixture the bodies come into being that are called 'first-born' by Plato and 'homoeomerous' by Aristotle. ${ }^{308}$ And while in $Q A M$ he chooses to locate soul at the level of the homoeomerous bodies rather than at the level of the organic bodies, here he explains the nature of the organs in terms of the homoeomerous bodies, which are primary and from which the organs are generated. But, as we have seen, the homoeomerous bodies cannot properly be understood as our nature in the primary sense distinguished earlier: they are themselves hylomorphic, and thus composite. They are rather the elements in terms of perception and in that sense the most primary body. Still, they are not entirely simple and therefore do not qualify as a description of nature in the sense of the primary substance. A further division is necessary, if only a conceptual one. But although the homoeomerous body is a composite, it is a composite only of form and matter and simple in terms of form itself. Galen calls the homoeomerous body 'form' of the body in PHP, when he draws an analogy with the parts or forms of the soul:

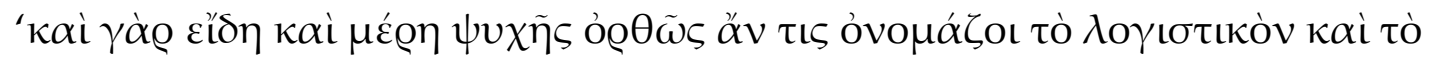

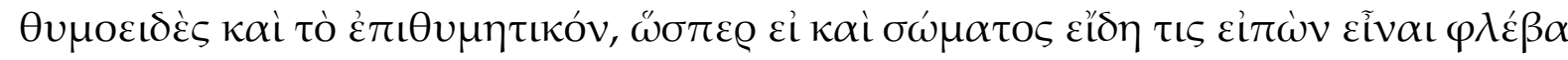

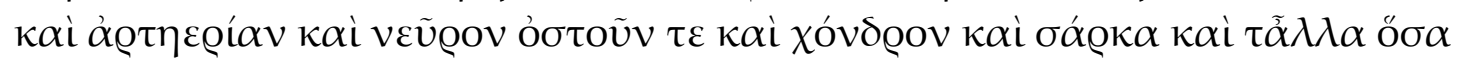

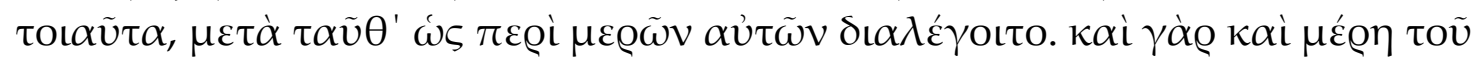

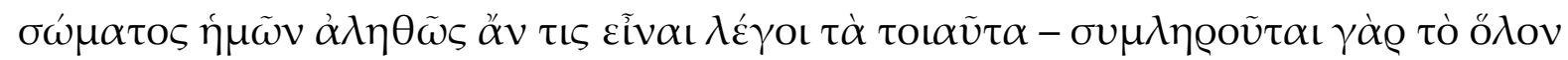

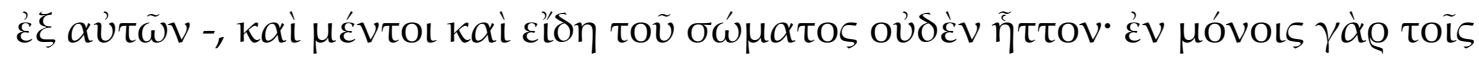

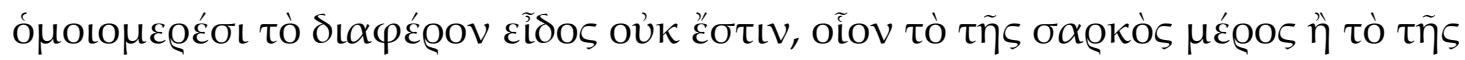

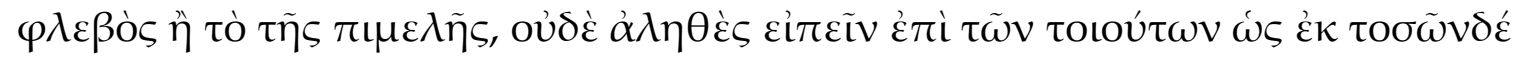

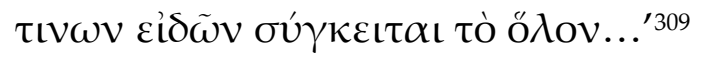

\footnotetext{
${ }^{307}$ HNH 6,11-20 Mewaldt (XV 7-8 K)

${ }^{308}$ QAM 36,21-37,5 Müller (IV 773 K). QAM 36,21-37,5 Müller (IV 773 K); cf. Singer (2014) note 32 ad locum: $\pi \rho \omega \tau$ ó ${ }^{\circ} \alpha \alpha$ is in fact not used in any of Plato's extant works, let alone in the meaning Galen attributes to it. The closest parallel is Politicus 288e and 289b, where Plato uses $\pi \rho \omega \tau$ o the least, towards Galen's meaning of basic bodies.

${ }^{309}$ PHP VI 370,3-12 DeLacy (V 514-5 K)
} 
'It would be correct to term the rational, the spirited and the desiderative both 'forms' and 'parts' of the soul, just as one might say that vein, artery, nerve, bone, cartilage, flesh and the like are forms of body, and then speak of them as parts. Indeed one could say of such things both that they are truly 'parts' of our body - for the whole is made up of them -, and again that they are no less truly 'forms' of the body. For it is only in homoeomerous structures that differences are not forms, for example, different parts of flesh or of a vein or of fat; and it is not correct to say of such things that the whole is composed of such and such forms.' (tr. De Lacy)

Here, already in PHP, Galen makes it clear that he thinks of the homoeomerous parts as being the (perceptible) elements of the body, not merely in terms of matter but also in terms of form. And, importantly, he refers to the impossibility to divide the form of homoeomerous parts further and presents this as the very reason to call them forms of the body. Thus, this passage also seems to indicate, as we saw previously in Case-Study I, that Galen thinks of form (and thus soul, if soul is understood as form of the body) primarily in terms of more basic constituent elements, rather than more complex ones. ${ }^{310}$ Therefore it matches with the passage from $Q A M$, where Galen chooses to locate soul - being the form of the body - at the compositional level of the homoeomerous substances rather than at that of the organs.

This notion of a compositional level where there is no more difference in terms of form, is brought up several times in $H N H$, sometimes with the metaphor of the letters: a syllable is composed of different letters, so the difference between its parts is a difference in terms of both quantity and form, but you cannot divide a single letter any further because 'its sound is single and indivisible, not in respect of simple quantity but rather in respect of form alone' ${ }^{311}$ The same applies to the homoeomerous body: it is not further divisible in terms of form, we cannot actually divide it into parts that differ from each other in terms of form. Therefore, taking Galen's earlier reference to the Phaedrus passage into account, it is the causal powers of the homoeomerous bodies that need to be analyzed in order to determine our nature. This is in accord with Galen's notion that the homoeomerous bodies are primarily active, as we have described it in Case-Study I. ${ }^{312}$

These causal powers in a primary sense, are the elemental qualities that constitute the most basic form by mixing with each other, by acting upon each other in matter and thus forming a homoeomerous body. For it is because of the causal powers of these qualities that everything else comes to be, as Galen explains on the basis of the Hippocratic text:

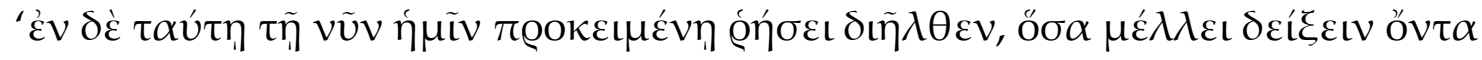

\footnotetext{
${ }^{310}$ See infra, CS I section 1, 20-35

${ }^{311}$ HNH 6,25-6 Mewaldt (XV $6 \mathrm{~K}$ ), translation Hankinson

${ }^{312}$ See infra, CS I section 1, 27-35
} 


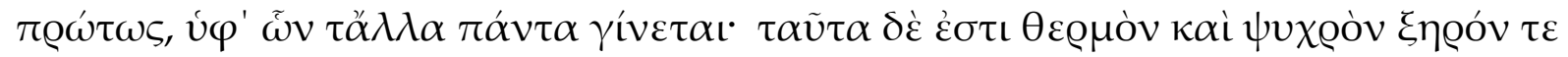

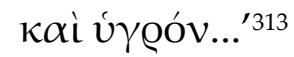

'In this passage which now concerns us, he enumerates the things which he is about to show to be primary, as a result of which everything else comes to be. These are the hot, cold, dry and wet...' (tr. Hankinson)

Again, Galen emphasizes that the four elemental qualities are primary ( $\pi \varrho \omega \tau \omega \varsigma)$, and that all other things come to be because of them. This may remind us, once more, of the passage in $Q A M^{314}$, where he decides to locate soul at the level of the homoeomerous bodies because the activities ( $\dot{v} v \dot{\varepsilon} \mathrm{\rho} \gamma \varepsilon\llcorner\alpha \iota)$ primarily ( $\pi \varrho \omega \tau \omega \varsigma$ ) belong there, particularly when we take into account these lines following shortly after the one quoted above:

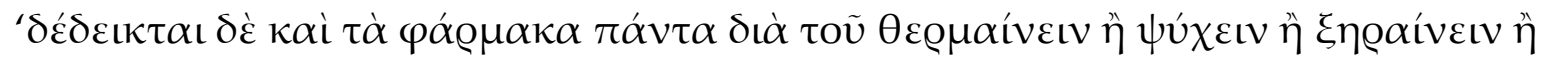

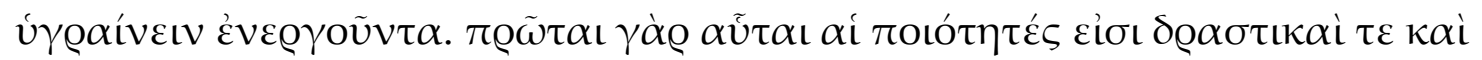

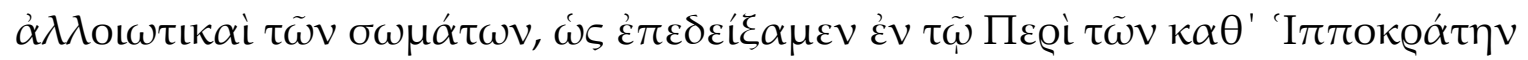

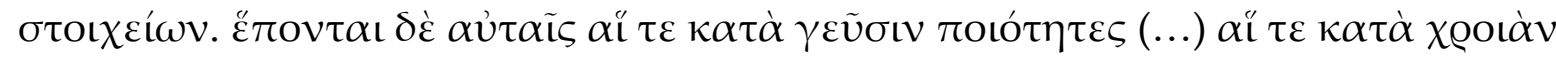

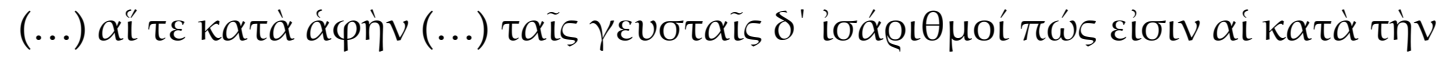

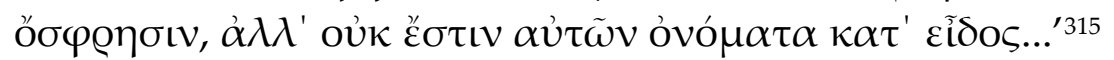

'It was also shown that all drugs act by heating or cooling, drying or moistening. For these are the primary active and alterative qualities in the body, as we showed in Elements according to Hippocrates. Derivative of these are the qualities of taste (...) and those of colour (...) and those of touch (...) The qualities of smell are more or less the same in number as those of taste, although they have no specific names.' (tr. Hankinson)

The four elemental qualities are primarily active and alterative, and therefore it is correct to say that all things come to be from them. Other qualities such as taste, colour, touch or smell, are secondary and derivative of those four elemental ones. It is these kinds of secondary qualities that Homer referred to in the passage quoted by Galen, qualities that relate to colour and to how the drug is perceived by the eye. This is the nature that 'those who write about herbs' teach, namely 'what the perceptible nature of each of these is when it is touched, tasted, smelled or seen' ${ }^{316}$ These derivative qualities make up what Galen has called the perceptible nature of a thing, but not its nature in a primary sense. They are already dependent on a more primary kind of qualities that generate the secondary ones through their activity. These qualities are not available to perception as such, since the perceptible bodies can only be divided further conceptually, into form and matter. Thus, Galen also

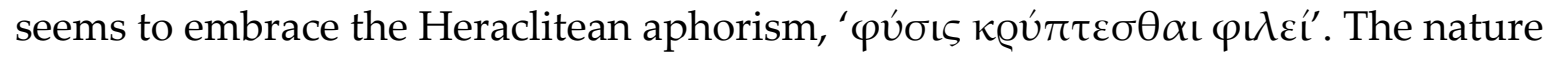

\footnotetext{
${ }^{313}$ HNH 22,4-6 Mewaldt (XV $38 \mathrm{~K}$ )

${ }^{314}$ QAM 37,12-5 Müller (IV $774 \mathrm{~K}$ ); see infra, CS I section 1, 27-35

${ }^{315}$ HNH 22,26-23,6 (XV 40 K); cf. Hipp. Elem. 118,16 f. De Lacy (I 473-4 K)

${ }^{316}$ HNH 4,14-6 Mewaldt (XV 3-4 K)
} 
of something is by definition never what it is first perceived to be. In fact, Galen emphasizes this axiom by making it the very starting-point, literally - the first sentence, of Hipp. Elem., the predecessor of $\mathrm{HNH}$ :

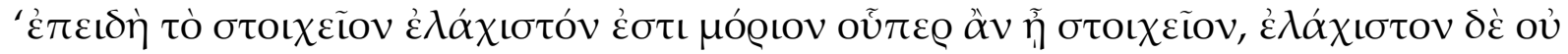

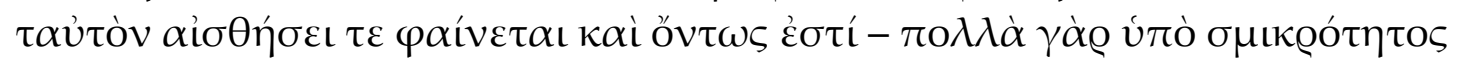

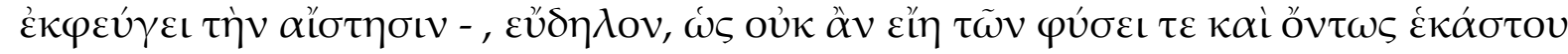

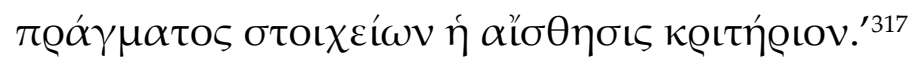

'Since an element is the least part of the thing of which it is an element, but what appears least to sense-perception and what is truly least are not the same - for many things go unperceived because of their small size -, it is evident that senseperception would not be the judge of each thing's natural and true elements.' (tr. De Lacy)

However, there is also an important difference between Galen and at least some of those of Heraclitean persuasion. One of the reasons why Galen wants to maintain this difference between a perceptible and a true nature, as he remarks right before the passage just cited, is to avoid a kind of perspectivism which potentially follows from taking the way a given being appears as the guide for determining its nature:

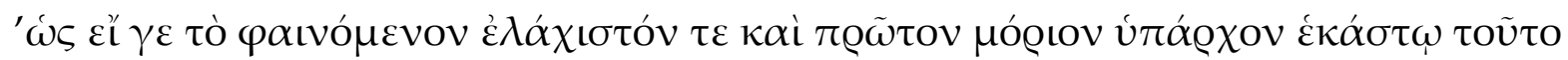

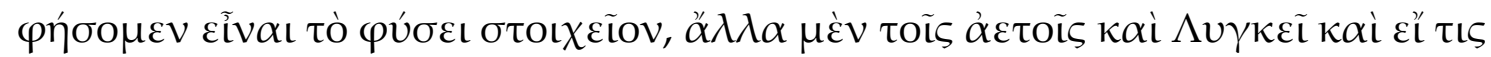

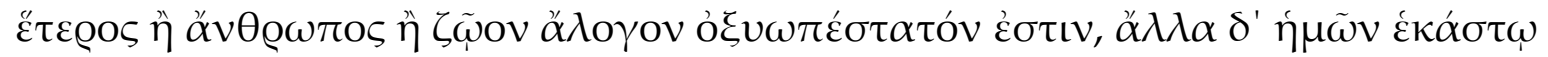
$\varphi \alpha v \varepsilon \tilde{\imath} \tau \alpha \iota \tau \dot{\alpha} \sigma \tau o \iota \chi \varepsilon \tilde{\imath} \alpha .^{318}$

'If we say that what appears to each one as the least and first part (of a thing) is its natural element, then the elements as they appear to eagles and to Lynceus and to any other man or irrational animal with very keen eyesight will be different from the elements as they appear to each of us.' (tr. De Lacy)

Thus, there would be no possibility of attaining knowledge, in the proper sense, of a thing's nature. Contrary to this, Galen holds that no perception of the qualities of a given being can be considered knowledge until it has been properly grounded in this nature behind perception. That is to say, we cannot know anything if we do not go deeper than the realm of perception and learn about the elemental qualities constituting the being we desire knowledge of.

Thus, according to Galen, presenting himself as following in the footsteps of Hippocrates and Plato, the general method for knowledge of the nature of any thing is that of division until no further division is possible, upon which follows analysis of the powers of the undividable elements. This analysis turns out to be an analysis of the elemental powers that constitute the homoeomerous bodies. These are no actual

\footnotetext{
${ }^{317}$ Hipp. Elem. 56,3-7 DeLacy (I $413 \mathrm{~K}$ )

${ }^{318}$ Hipp. Elem. 56,18-58,2 De Lacy (I 414 K)
} 
bodies themselves any longer, but conceptually distinguished from the matter in which they inhere.

Since Galen's talk of elements and of elemental qualities conceptually distinguishable from matter is not always consistent and can be confusing, we shall briefly discuss this issue a bit more extensively in the next section.

\section{Elements and Qualities}

Galen proposes that we go beyond the realm of perception, towards the metaphysical principles of prime matter and elemental qualities, in order to determine the nature of things. However, that does not mean that he does not give any empirical arguments for the thesis that the nature of everything consists of a mixture of the four elemental qualities. One of the most illustrative of such arguments is that of the fig tree. ${ }^{319}$ When a fig tree grows out from a fig tree seed that has been planted in the earth, it is unquestionable (considering its roots in the earth and its dependency on watering) that it has acquired its substance from earth and water. But it has to have a share in heat as well, considering that it is alive and remains so even through the harshest winters, and considering that the earth in which it is planted is of itself extremely cold. Likewise, it needs to have a share in air, since it is evidently lighter than the earth (on which it is standing) and than water (on which it can be seen to float) and it is air that makes things light. Therefore, the fig tree is made up of all four elements, which means that the fig, as a product of the fig tree, must be so as well. The same reasoning can be applied to all trees, and thus to all the fruits they bear. Because the humours in us and other animals are, in turn, generated from the nutriment of these fruits and plants, they will have these four elements as their principles as well. ${ }^{320}$

Though this example is illustrative as a form of empirical reasoning towards theoretical postulates that are as such not perceivable (we do not see earth and fire in the fruits we eat), it is also confusing because Galen here seems to neglect the difference between elements and principles which he posited before. In an earlier passage he was quite clear about maintaining this difference:

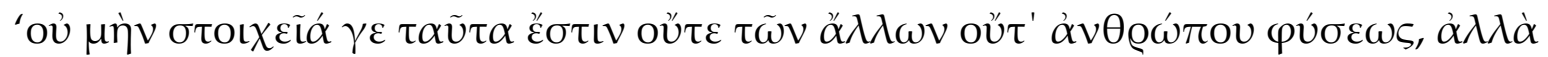

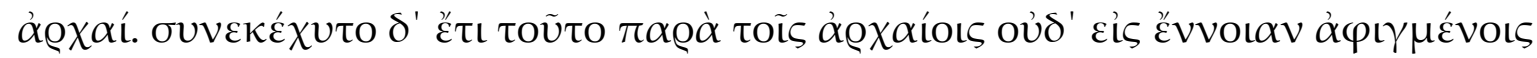

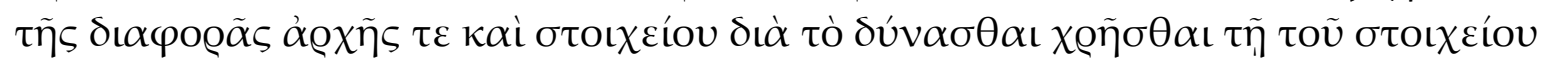

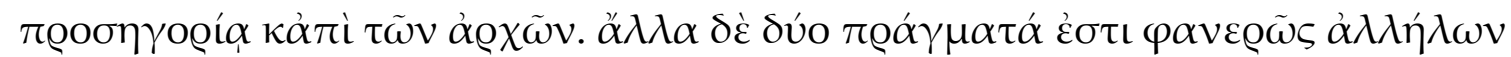

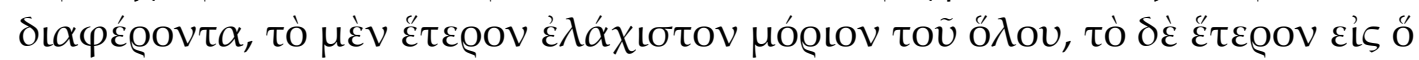

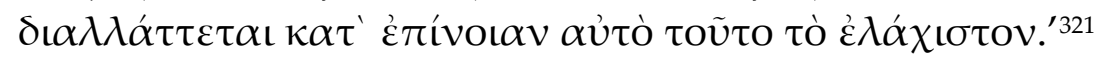

\footnotetext{
${ }^{319}$ HNH 30,29 f. Mewaldt (XV 55-6 K)

${ }^{320}$ Cf. Hipp. Elem. 100,2 f. De Lacy (I 455-7 K), where Galen employs the same reasoning

${ }^{321}$ HNH 17,30-18,5 Mewaldt (XV 30 K); cf. Kupreeva (2014) 190-2 on this passage
} 
'However, these [the four qualities] are not yet elements of the nature of man (or anything else), but rather its principles. This was confused already by the ancients, who did not arrive at the distinction between principle and element because they were able to use the term 'element' for principles as well. None the less, these two things are clearly distinct from each other, the one being the least part of the whole, the other that into which this least part itself can be divided conceptually.' (tr. Hankinson)

Galen, in line with tradition, justifies this conceptual difference in terms of the necessity to maintain the possibility of change of a given substance that nonetheless could be said to remain the same substance. The underlying matter accounts for that of which the change is predicated, while the changing form accounts for the change itself. Thus, the qualities are principles, while the elements consist already of two (metaphysical) principles, namely the underlying matter and the quality. ${ }^{322}$ Apparently a body could be called an element when the extreme of one of the qualities is present in the underlying matter, so that the element fire would be an underlying basic matter in which the quality of heat is extremely predominant. This is in line with what we find in Hipp. Elem.:

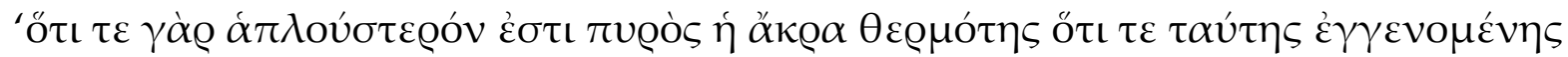

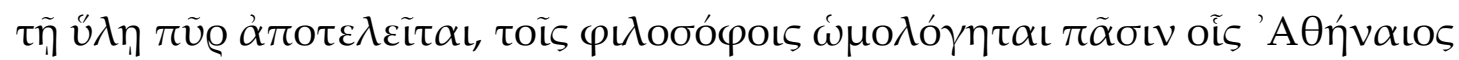

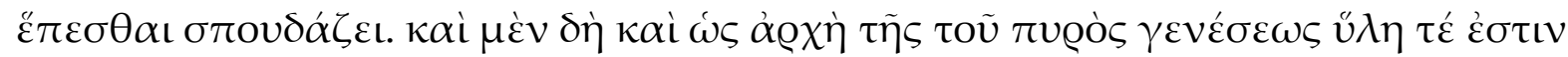

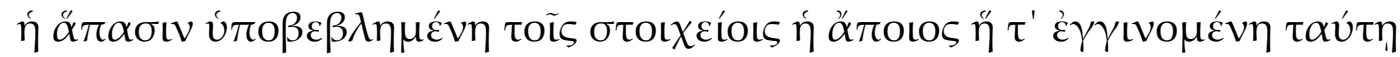

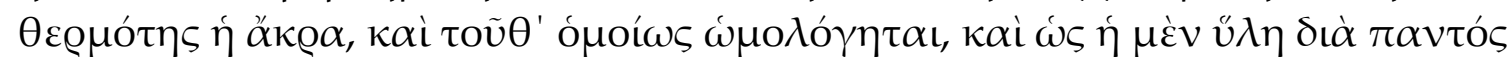

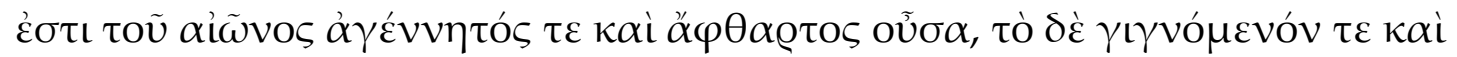

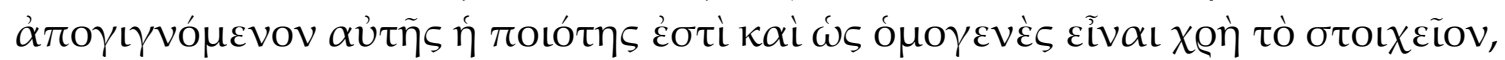

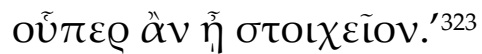

'That extreme heat is simpler than fire and that fire is produced when this heat has entered matter, this has been agreed to by all the philosophers whom Athenaeus is eager to follow. And indeed that the first principles of the generation of fire are the matter which underlies all the elements and is without qualities, and the extreme heat that enters into it, this too has been similarly agreed to, and also that the matter exists through all eternity, being ungenerated and undestroyed, and that what comes and goes in it is the quality, and that the element must be homogeneous with that of which it is an element.' (tr. De Lacy)

\footnotetext{
${ }^{322}$ Cf. Kovacic (2001) 96: 'In Galens Kosmologie stehen am Anfang die vier Elemente als Bausteine der Natur. Abstrakt gesehen sind diese vier Elemente nicht das Erste und Ursprüngliche. Denn es gebe eine eigenschaftslose Materie, die allen Elementen zugrunde gelegt sei. Diese Materie währe die ganze Ewigkeit hindurch, ungezeugt oder unerschaffen un unvergänglich; das, was an ihr aber entstehe und vergehe, sei die

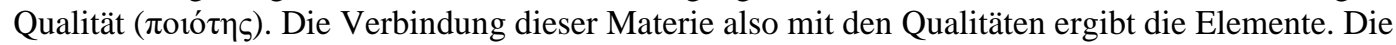
Grundqualitäten sind $\alpha \rho \chi \alpha i ́$, und Galen unterscheidet sie streng von den Elementen: Die Elemente müssen ganz und gar homogen sein mit den Dingen, deren Elemente sie sind; die Ursprünge (ả $\rho \chi \alpha i ́)$ sind nicht notwendigerweise homogen mit den Dingen, deren Ursprünge sie sind.'

${ }^{323}$ Hipp. Elem. 114,13-21 De Lacy (I 469-70 K). Cf. Hankinson (2008) 216 on this passage, also Kupreeva (2014) $187 \mathrm{ff}$.
} 
After this passage in Hipp. Elem., Galen distinguishes between three ways of speaking of hot, cold, dry and wet: as quality (conceptually distinct from being the quality of a specific matter), as unmixed body (e.g. the element fire, a body in which heat is unmixed with other qualities), and as mixed body (a body that is relatively hot, but consists of a mixture of heat with the other qualities). ${ }^{324}$ This threefold division seems helpful and clear, and could be applied to most of what Galen writes. However, he is not always consistent in the distinction between element and quality. Despite his emphasis on the need to distinguish element and principle (the principles being the qualities and the prime matter), he also calls the qualities the 'common elements of everything'. ${ }^{325}$ Perhaps this is a way to align his own notion of the common hylomorphic substance of everything, to the Hippocratic notions of the dry, wet, cold and hot, which Galen interprets as elements. But then again, the very fact that Galen interprets these as elements is in itself remarkable, especially since it is hard to see how the elements (as extreme instantiations of one of the qualities in matter) are indispensable to his own doctrines (since these extreme instantiations are never actually there - see below - and there is rather always a mixture of the various qualities in Galenic physics). It might be that he wishes to emphasize that Hippocrates did not merely write of qualities but also understood that there must be a combination of matter and quality, and that therefore Hippocrates must be taken to refer to elements, i.e. qualities instantiated in matter. Otherwise, Hippocrates would seem to be just the opposite of the Melissus portrayed by Galen earlier: he would have recognized only one of two principles. This seems to come to the fore in the following passage:

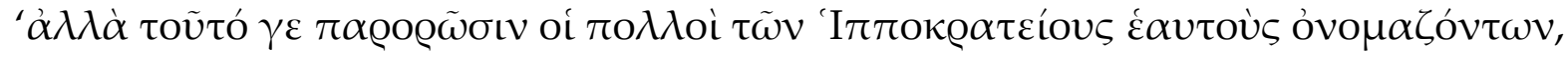

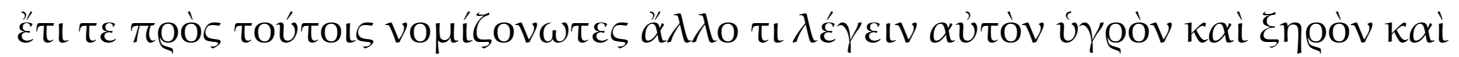

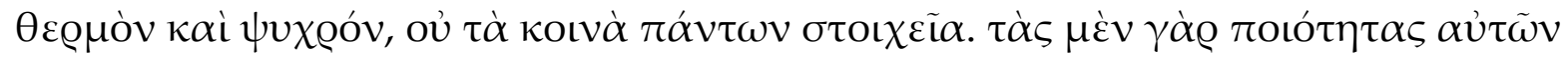

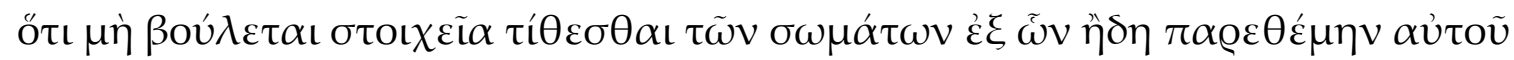

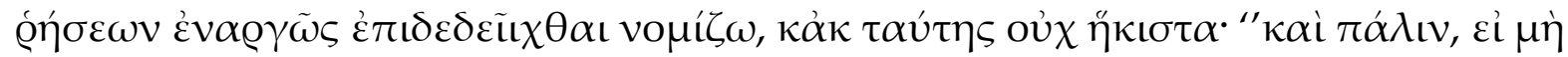

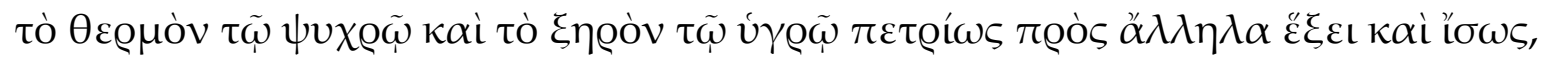

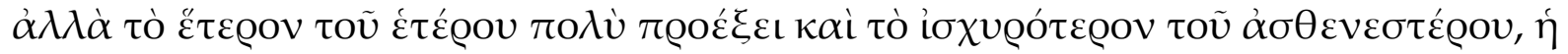

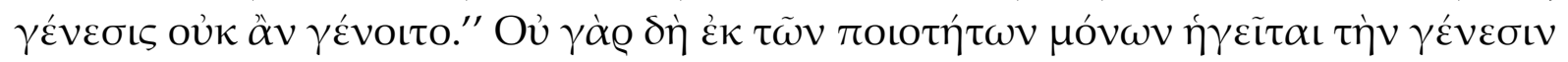

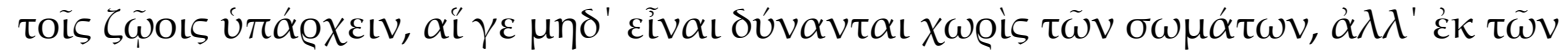

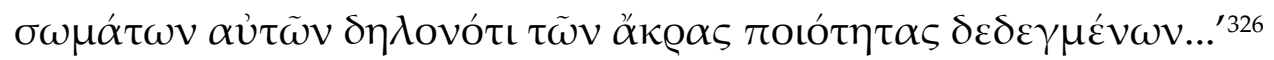

'But the majority of those who call themselves Hippocrateans overlook this, and in addition they think that by wet, dry, hot, and cold he refers to something else, not to the common elements of all things. For I think it has been clearly shown from the passages that I have already cited that he does not want to make the elements' qualities the elements of bodies, and not least from the following passage: "And again, if there is not a measured and balanced ratio of hot to cold and dry to wet, but

\footnotetext{
${ }^{324}$ Hipp. Elem. 114,25-116,5 De Lacy (I $470 \mathrm{~K}$ )

${ }^{325}$ HNH 28,16 Mewaldt (XV 51 K); 30,3-4 Mewaldt (XV 54 K)

${ }^{326}$ Hipp. Elem. 124,11-22 De Lacy (I 478-9 K)
} 
one greatly prevails over the other, the stronger over the weaker, birth would not take place." He does not believe that the birth of animals is from the qualities alone, which cannot even exist apart from bodies, but from the bodies themselves, obviously the bodies that have received the extreme qualities...' (tr. De Lacy)

Still, one could ask why it would have to be bodies that have received the extreme qualities and why Galen would not take Hippocrates here to simply say that the qualities need to mix with each other, and then remark that this needs to happen in a substance in which several qualities inhere, i.e. the matter. Given that Galen is out to maintain the notion of the elements, it makes some sense for him to see them as the extreme instantiation of the qualities: they have to be properly different from all other bodies that have the qualities in a mixed or even relatively predominant manner since otherwise there would be an infinite variety of elements (anything that is relatively hot could be said to be the element fire). ${ }^{327}$ But why Galen really needs to cling to this notion of the elements seems less evident. As Jim Hankinson puts it in an insightful paper teasing out this very difficulty: 'It is one thing to insist that generation cannot occur simply as a result of the qualities, since the qualities need physical vehicles for their instantiation; it is quite another to insist on the physical reality of the elements as such, conceived as the physical instantiations of those qualities in their extreme form.' ${ }^{\prime 28}$ We might grant that Galen takes the elements as the conceptually instantiated maxima of any of the four qualities, without insisting on their physical reality (which seems reasonable). However, it would still remain difficult to see why, on a mere conceptual level, he needs them. Again, in the words of Hankinson, Galen requires 'that the qualities need to be conceptualized in some sort of maximal manner, not that there be any maximal expression of them in bodies.' Therefore it remains difficult to see why Galen clings to this notion of the elements so much, except, perhaps that it might fit his positioning in the previous tradition of natural philosophy better. That is to say, the notion of element itself might just be assumed by Galen to require some meaningful content to be attributed to it, given that it is an important factor in the tradition Galen is placing himself in. From this perspective, perhaps this particular interpretation of the elements as the conceptually instantiated maxima of the respective elemental qualities in prime matter, is best, both in terms of not harming his own hylomorphic doctrine, as in giving a favourable explanation of Hippocrates. Obviously, this is not a very satisfying explanation.

In any case, within the threefold division Galen makes, the element is the unmixed body, so the elements in a proper sense are understood as prime matter formed only by an extreme of one of the primary qualities. However, these elements are not available to perception either, as Galen makes clear in Hipp. Elem.: you will not find

\footnotetext{
${ }^{327}$ Cf. Hipp. Elem. 104,24 f. De Lacy (I 461-2 K), where Galen puts this argument to Athenaeus; cf. also Hankinson (2006), (2008), and (2017); Kupreeva (2014), particularly 182-3

${ }^{328}$ Hankinson (2017) 2
} 
unmixed earth or fire. ${ }^{329}$ It seems as if Galen wants to maintain both the hylomorphic outlook that is more suitable for his central notion of mixture and his view on the relation between body and soul, as well as the traditional notion of element in the sense of a most basic body (partly already obsolete because of his notion of the homoeomerous body as the actual most elemental body). Therefore, perhaps, he fits the element in the hylomorphic schema as the most simple or extreme conceptual example of combinations of form and matter. Thus, fire as we encounter it, cannot strictly be considered an element, while the element fire in a strict sense cannot be encountered:

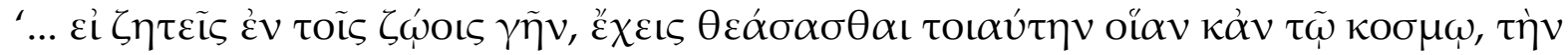

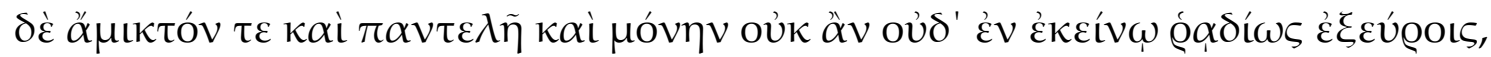

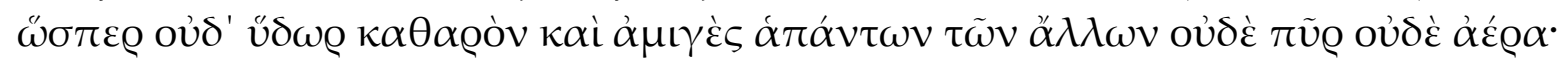

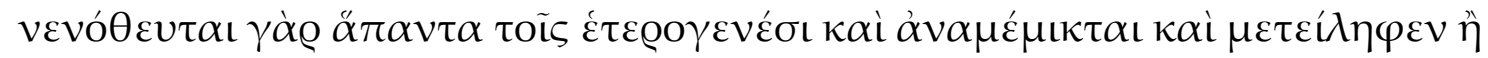

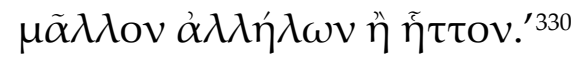

'...so if you are looking for earth in animals, you can see (in them) the kind of earth that you also see in the cosmos; but earth that is unmixed, complete, and by itself you would not easily find even in the cosmos; similarly you would not see water that is pure and not mixed with all the rest, and the same is true of fire and air; all have been adulterated by other kinds of things and mixed with them, and they have all received a larger or smaller share of each other.' (tr. De Lacy)

Still, even though these elements cannot be said to be visibly present in the human body, or any other body, and thus - similar to the principles of matter and form seem to function mainly as a conceptual tool for Galen, he does call them the actual elements of the human body. 'Actual' that is, apparently, as opposed to the perceptible elements: the perceptible elements are homoeomerous bodies, for example flesh, vein and bone. Those cannot be considered elements in a strict sense, because they cannot mix with each other to generate ever new substances, thus accounting for the possibility of continuous change:

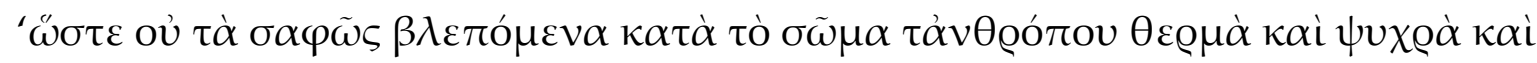

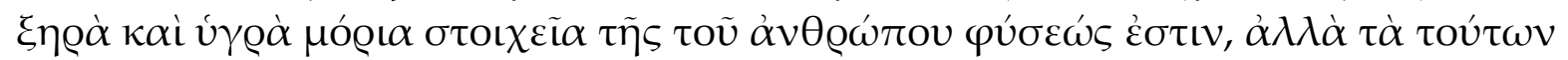

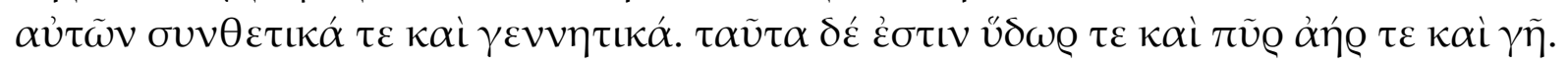

\footnotetext{
${ }^{329}$ Hipp. Elem. 98,2-11 De Lacy (I 453-4 K); cf. Hankinson (2008) 212: 'Speculative metaphysics cannot yield certain knowledge, since it is unsusceptible of empirical testing, peira, and the inquirer must sometimes remain content with plausibility rather than proof. Yet he expresses no such qualifications in the case of the elements, which can be known by inference to exist even though they cannot be directly perceived.'; Kupreeva (2014) 161: 161: 'There is indeed a whole list of philosophical questions which Galen himself considers to be of little importance for the medical doctor. The question about the nature of the elements is different. Galen takes it seriously, as lying within the doctor's professional remit. This has to do also with the question whether the elements constitutive of living bodies are the same as those that make up the rest of nature, which Galen answers in the affirmative. In this he differs from the Pneumatists, who seem reluctant to discuss this question. When they do discuss it, they aswer it in the negative.'

${ }^{330}$ Hipp. Elem. 98,6-11 De Lacy (I 453-4 K)
} 


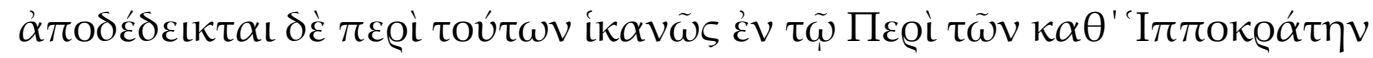

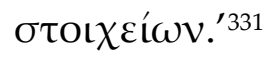

'Consequently it is not the clearly visible hot, cold, dry and wet parts of the human body which are the elements of the nature of man, but those which compose and produce them; and these are water and fire, air and earth. But this is amply demonstrated in Elements According to Hippocrates.' (tr. Hankinson)

The mistake made by some people who apparently think that the perceivable hotness, coldness, dryness and wetness are the elements of the human body, is comparable to that of the herbalists we saw earlier: it is to think nature is restricted to that which is directly accessible to the organs of perception. ${ }^{332}$ As in the case of the herbalists, Galen seems to be debating real contemporaries, who are apparently finding fault with Hippocrates' reasoning. These people would take the hot, cold, wet and dry to refer to some perceptible parts of the body that are relatively or predominantly hot, cold, wet or dry, and then point out the impossibility of these parts being the starting or ending point of cycles of generation and destruction: flesh is not generated from or dissolved into flesh. ${ }^{333}$ Besides, if we would stop at the perceptible level, there is no way we would have elements that are common to everything, since, as Galen says, a stone is not made of the four humours. ${ }^{334}$ I think this assumption of a common substance of everything is so necessary for Galen (and perhaps indeed some of his predecessors) that it might play an important role in his inclination to posit nature outside of the realm of the senses: how else could it be a primary substance of everything? After all there does not seem to be much that is perceivably common to everything, except for the mere fact that it is all there.

\section{Grades and shades of nature}

However, over and above this level of commonality, there is the specification of a being's nature in more particular terms. It is possible from a Galenic perspective to distinguish a scale of more general and more particular natures of a thing. The most particular nature in the end will be individual: individual human beings differ in nature from each other, as can be inferred, according to Galen, from observing their activities (here we have to bear in mind that the activities of a given being are determined by its substance or nature). ${ }^{335}$ The least particular nature will be common to everything and defined in general terms as a mixture of the four qualities in prime matter. At the same time, the most individual differences are eventually determined at the most general level. If we were to have the same mixture, we would have the same affections and activities given the same causes, i.e. we would not be

\footnotetext{
${ }^{331}$ HNH 30,11-16 Mewaldt (XV 54 K)

332 See infra, section $1,100-2$

${ }^{333}$ HNH 29,23-30,16 Mewaldt (XV 53-4 K)

${ }^{334}$ HNH 28,27-29,6 (XV $52 \mathrm{~K}$ )

${ }^{335}$ QAM 32,14-33,16 Müller (IV 768-9 K)
} 
distinguishable on any level. Thus, the governing principles of the activity of any given being are the elemental qualities, but their specific interaction - governed, in turn, by Nature as a divine ordering principle - determines the more particular nature of a being, e.g. a being that is made from four humours, a being that is capable of rational thought, a being that is prone to anger, a being that is melancholic, etc. In this way, each human being could have a different nature, while at the same time, at a more general level, the nature of all human beings has something in common. Moreover, at an even more general level it does not even differ from the nature of all other beings. As we have noted in Case-Study I, this commonality constitutes the unity of the cosmos, which is also expressed in the singularity of 'Nature' as a divine ordering principle operative in the generation, subsistence and destruction of all these beings. ${ }^{336}$ How, in Galen, 'Nature' as divine creator is exactly related to nature in the sense of this common substance and its elemental capacities, is a rather difficult question, it seems to me. ${ }^{337}$ Surely, there needs to be some difference between the two, though, since it is hard to see how the capacities of this common substance (heating, chilling, moistening, drying) could in themselves account for the complex teleological order they generate. However, a clear-cut separation between a nature as demiurge that steers generation on the one hand and the stuff (common substance) 'with which' the demiurge generates on the other, seems to be an injustice to the ambiguity of Galen's notion of nature and the way its teleological and immanent functions are bound up, especially considering the emphasis Galen puts on the activity of this 'stuff' itself when it comes to generation and destruction and, more in general, processes of change. For example, we noticed in Case-Study ${ }^{338}$ that Galen can say about nature as demiurge that it stays present in the living beings it creates, as a kind of guardian, in the form of the basic capacities these living beings have:

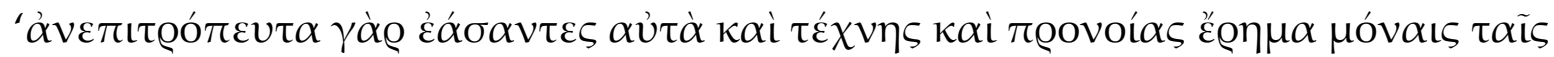

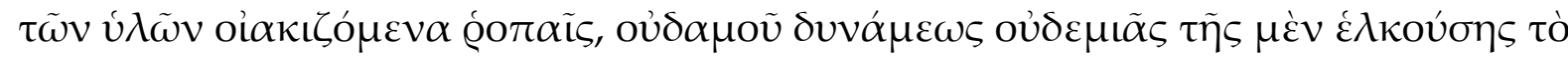

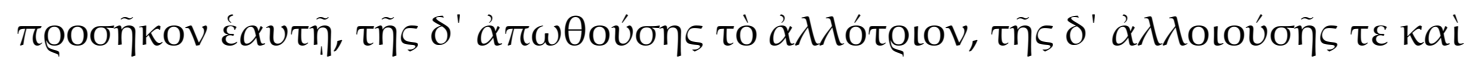

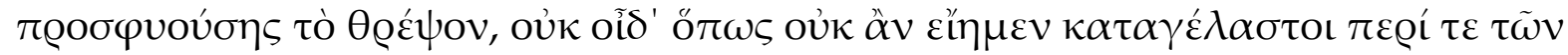

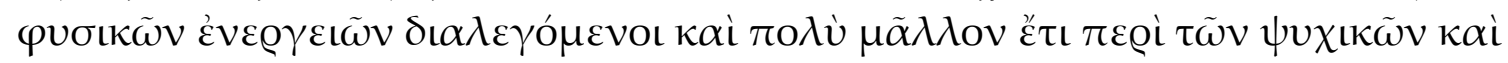

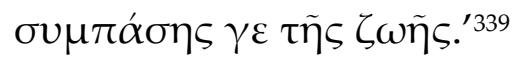

'For if it were conceded that they [the living beings] are without guardianship, devoid of artistry and foresight, governed only by the rule of matter and not by any power such as the attracting of what is appropriate to itself, the rejecting of what is

\footnotetext{
${ }^{336}$ See infra, CS I section 1, 21. Cf. Kupreeva (2014), 177: 'Galen argues that proximate, i.e. organic, elemental qualities have the same nature as their inorganic counterparts: the principles of natural design and mixture are sufficient to account for a variety of properties manifest in the organic and inorganic elemental compounds throughout the cosmos.'

${ }^{337}$ Kovacic (2001) seems to give the most comprehensive discussion of this question; cf. also Hankinson (2006); van der Eijk (2014)

338 See infra, CS I section 1, 45-7

${ }^{339}$ Nat. Fac. II $80 \mathrm{~K}$
} 
foreign, the alteration and assimilation of that which shall nourish it, then I am sure we would make fools of ourselves discussing natural activities, and even more so discussing psychical activities and, in fact, life as a whole.'

Besides an interesting ambiguity between the personal and the natural, or the individual and the universal, there is also an ambiguity here of nature as demiurge that generates an individual being, and nature as that which exercises these basic capacities of sustenance of that same being. Perhaps this is an ambiguity that is not to be solved when one does not want to make speculative commitments about the specific nature of a creator but also appreciates the complexity and capacity of body as well as the order to be found in nature and, at the same time, thinks that complexity cannot be explained in terms of non-intelligent causes. That is to say, I would not only say that we can find both a transcendent and immanent nature in Galen, but also that our analytical desire to distinguish between a transcendent and immanent nature might not have been shared by Galen to the same extent. This is, perhaps, not due to his lack of analytical desire but rather due to the empirical basis of his notion of a creative nature. We can also see this from a passage in his commentary on the Hippocratic Epidemics, to which Jouanna has called attention. There, Galen emphasizes both the artistry and providentiality of nature (nature is

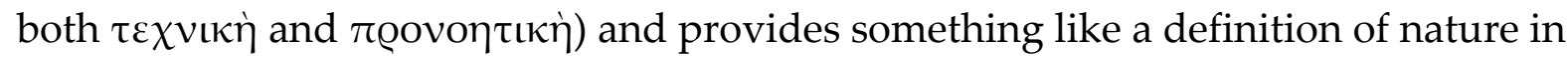
the following words:

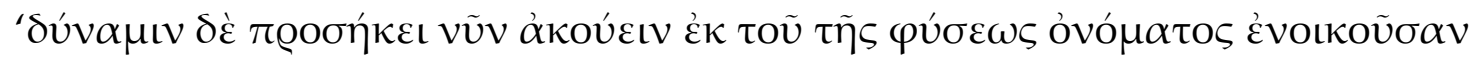

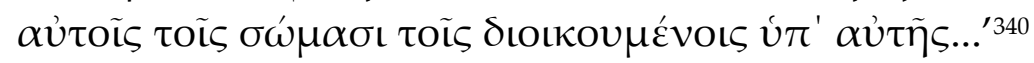

'By the word 'nature' we should understand the capacity residing in the very bodies arranged by her.' (tr. Jouanna, modified)

Here we can see how close nature as creator (the arranging aspect) and nature as guardian (the capacities then residing in the created body in order to maintain it) are for Galen. It seems here as if they are one, even, in concept.

In another passage in Nat. Fac., Galen dwells further on the powers that nature exercises in its beings as their guardian. He mentions 'affection and caring for

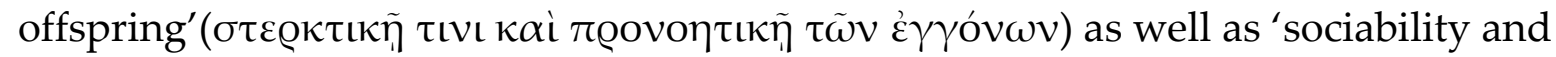

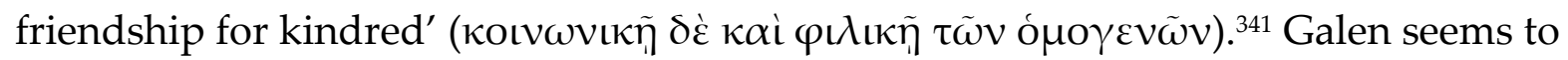
consider feelings such as love and friendship for family or others like us, as natural capacities as well. In what follows, he even suggests that certain concepts and notions of justice or beauty are natural. ${ }^{342}$ Is appreciation of beauty a natural

\footnotetext{
${ }^{340}$ Hipp. Epid. VI 253,19-21 Wenkebach (XVIIB 223 K); see Jouanna (2012) 290 ff.

${ }^{341}$ Nat. Fac. II $28 \mathrm{~K}$

${ }^{342}$ In this passage, Galen contrasts two schools of thought, one group basically consists of the atomists and followers of Asclepiades, the other is founded by Hippocrates, then continued by Plato and Aristotle, and of course finally - as the implication goes - represented by Galen. That is to say, we are in a polemical context of a discussion between schools, but it is safe to assume Galen agrees with the latter school, or rather positions himself as the continuation of this Hippocratic line, cf. Jouanna (2012) 307 and Kupreeva (2014) 160
} 
capacity? Galen seems to suggest it is, even though most of his work in On the Natural Capacities is not concerned with these kinds of capacities. ${ }^{343}$ Perhaps then, it is also nature acting in us when we appreciate beauty or justice. After all, such appreciation would likely be deemed 'according to nature' by Galen. ${ }^{344}$ From this perspective, the boundaries of nature are perhaps not entirely clear in Galen. With regard to the capacities that we share with plants, the capacities of the soul seated in the liver, Galen generally emphasizes that there is no point in distinguishing between the psychic and the natural at all. ${ }^{345}$ The passage just quoted from Nat. Fac. proves that it is unclear whether some capacities which belong to animals and do not belong to plants can also be included among the natural capacities. Furthermore, if more complex capacities follow the bodily mixture or are in the end primarily activities of the homoeomerous bodies, and if these mixtures are the result of nature operating through its most elemental qualities of heating, chilling, moistening and drying, how clear, then, is the boundary between our psychic and natural capacities? I would say that with regard to nature as our individual nature or soul on the one hand, and nature as a general or common teleological ordering principle on the other, the boundaries are at least ambiguous in Galen. In this respect it is important to realize that, first, the mixtures of elemental qualities that form our nature are always themselves generated by the same nature that is considered artistic by Galen, at least initially (since it is only God or nature that can generate a complete mixture (i.e. a homoeomerous body), as Galen emphasizes in Temp. I $563 \mathrm{~K}$ ). And second, that the basic powers exercised by the elemental qualities are considered by him as basic powers of nature itself. ${ }^{346}$ Given nature's artistry and foresight, this apparently must imply that the causality exercised by the mixtures cannot in any unambiguous sense be distinguished from the causality exercised by nature as an intelligent creator. There is the causality that we, by virtue of our rationality, can exercise on the mixtures, but this, again, is dependent on the present state of our mixture and on our original nature as well, which implies, again, that is difficult to determine in Galen where 'nature' stops and 'we' begin.

With regard to the difference between nature as a transcendent demiurge and nature as an immanent principle, we shall look at another passage in Nat. Fac. In it, Galen describes the role of semen and blood in generation. Here too, boundaries are ambiguous, as we shall see.

In a polemic against Erasistratus, Galen compares the artistry of nature to that of sculptors such as Praxiteles and Phidias. ${ }^{347}$ Whereas the sculptors merely change the outside appearance of their material and do not change the actual material itself ('Phidias could not turn wax into ivory and gold nor yet gold into wax'), nature is

\footnotetext{
${ }^{343}$ Cf. QAM 73,15 f. Müller (IV $815 \mathrm{~K}$ ), where Galen suggests that we all naturally love the good and hate the bad

${ }^{344}$ See Jouanna (2012) $291 \mathrm{ff}$. on Galen's use of this expression

${ }^{345}$ Cf. UP I 201,19-202,2 Helmreich; Nat. Fac. I 1, II 1-2 K; Meth. Med. IX 10, X 635 K; PHP VI 3, 374,18 De Lacy; De Lacy (1988) 53 f.; Tieleman (2003) 158-9

${ }^{346}$ See infra, CS I section 1, 24-6 (esp. note 50) and 42-7

${ }^{347}$ The passage starts around the beginning of the third chapter of book II (II $80 \mathrm{~K}$ )
} 
'extended throughout the whole substance' of the parts of the body and alters and shapes them through and through. ${ }^{348}$ If nature were to preserve 'the original

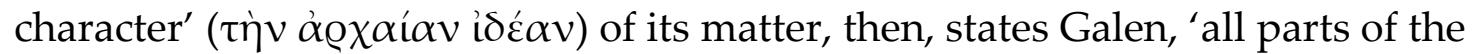
animal would be blood'. He compares blood to the wax of the sculptor, the basic material, which the sculptors embellish from the outside, whereas nature alters it completely to turn it into various other homoeomerous substances such as 'bone, artery, vein, nerve' etc. Now, Galen imagines asking Erasistratus what it would be that alters and fits together and shapes this material, in other words, what corresponds to the sculptor in the analogy. In Galen's imagination, Erasistratus would answer 'either nature or the semen' and would mean the same by it. He explains as follows:

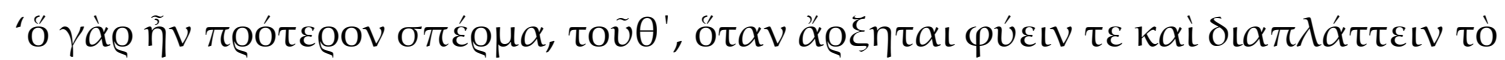

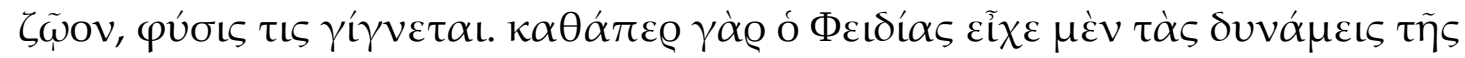

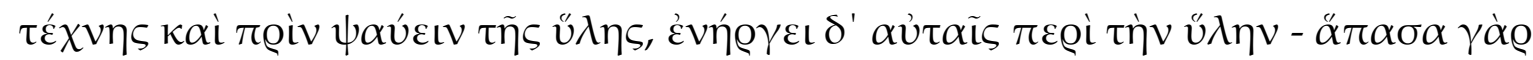

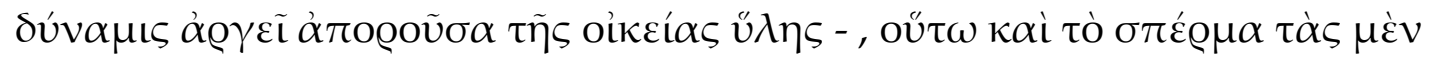

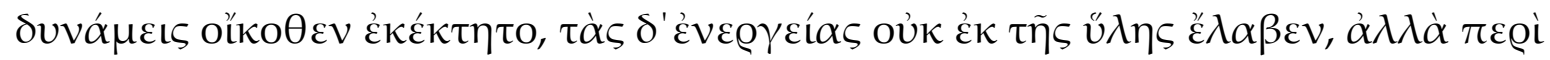

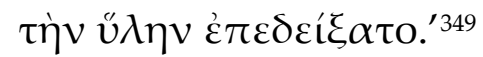

'For that which was previously semen, this, when it begins to bring forth and to shape the living being, becomes a kind of nature. For in the same way that Phidias possessed the powers of his art even before touching his material, and then actualized those in connection to his matter - for every power remains inoperative in the absence of its proper material -, in this way also the semen has its powers from the beginning, while it does not receive its activities from the matter but manifests them in connection with the matter.' (tr. Brock, modified)

We are here in the context of a polemic against Erasistratus and Galen seems to take a somewhat more Aristotelian position than elsewhere ${ }^{350}$ in order to show that the followers of Erasistratus are not proper Peripatetics. However, there is no reason to doubt that Galen is presenting his own views here. What is interesting, first of all, is that he ascribes the role of artificer to the semen, which he also does in other works. ${ }^{351}$ But whereas sometimes he speaks of the power in the seed as the natural power for shaping a living being, here he seems to identify the semen itself as artistic nature (which does, however, correspond to his general understanding of the relation between substances and capacities or powers, as we have seen ${ }^{352}$ ). It is said to bring

\footnotetext{
348 Translations Brock

${ }^{349}$ Nat. Fac. II 83-4 K

${ }^{350}$ Particularly with regard to the respective passive and active roles of blood and semen

${ }^{351}$ Cf. Foet. Form. 86,17-8 Nickel (V 682 K), where Galen says that the semen bears the 'formula of the creator'

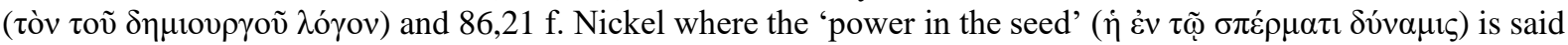
to 'shape' ( $\delta 1 \alpha \pi \lambda \alpha \dot{\tau} \tau \varepsilon \sigma \theta \alpha 1)$ the parts of the body and is used synonymously with 'the nature which shapes living

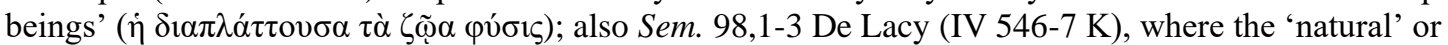

'vegetative principle' is said to 'create not from blood but from the semen itself artery and vein and nerve, bone and membrane' (tr. De Lacy), also Sem. 78,24 f. and 82,12 f. De Lacy

${ }^{352}$ See infra, CS I section 1, 39-41 and note 96
} 
forth and shape the animal and it is compared to the actual artificer in the analogy, namely Phidias. The semen becomes a nature when it has its appropriate material at hand. In the way Galen describes this becoming of a nature, the emphasis is on creative capacity. He continues to describe the necessity of the right amount of material, i.e. blood. If there would be too much blood, the semen would perish, while if there would be no blood at all, the semen would remain completely inoperative and 'would not become a nature' (oủk àv $\gamma \varepsilon$ ćvoıto $\varphi v ́ \sigma \iota \varsigma)$. As he said before, the semen becomes something else in the right circumstances, namely an artificer, creative nature. This is to be understood as a transformation in which it is no longer semen, it seems, since Galen says that when it does not perish, it can become nature instead of semen ( $\gamma \dot{\prime} \gamma \nu \eta \tau \alpha \iota$ that the right amount of blood is supplied and that the artificial capacities of the semen are unleashed so that it may become a creative nature? Here, the answer is again: the semen itself, which has the basic natural capacity of drawing to itself what it needs, i.e. a due proportion of blood. Galen gives us a more elaborate description of how this works:

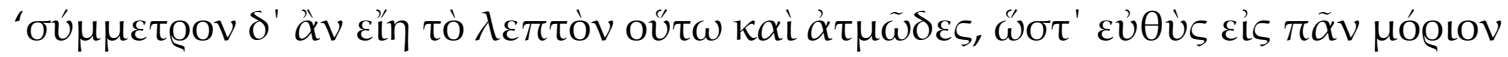

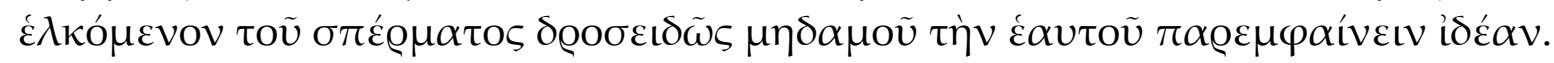

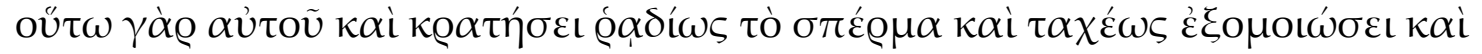

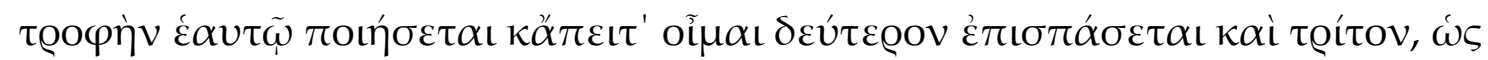

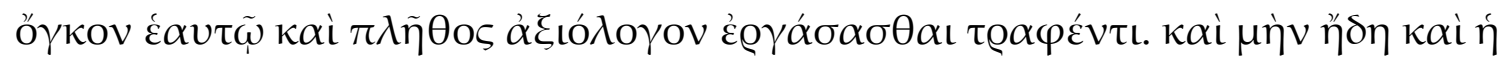

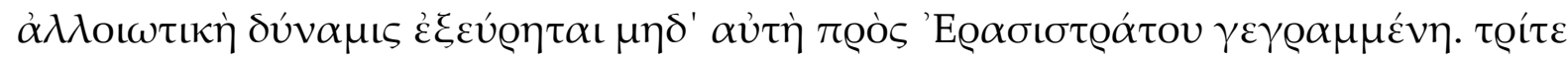

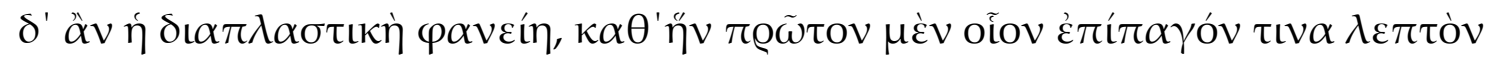

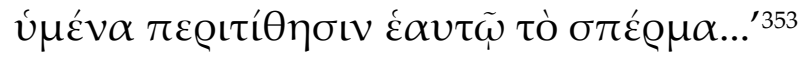

'Now, this fluid would be in due proportion if it were so thin and vaporous, that, as soon as it was drawn like dew into every part of the semen, it would everywhere cease to display its own particular character; for so the semen will easily dominate and quickly assimilate it and will use it as food, and then it will, I imagine, draw to itself a second and a third quantum, and thus by feeding it makes for itself a considerable bulk and quantity. In fact, the alterative power has now been discovered as well, although about this Erasistratus has not written a word. And, thirdly the shaping power will become evident, by virtue of which the semen firstly surrounds itself with a thin membrane like a kind of superficial condensation...' (tr. Brock, slightly modified)

The semen alters blood into other homoeomerous substances and shapes the embryo. These two capacities, the alterative and shaping power, are the same ones that Galen previously distinguished as the powers of nature by which it creates. ${ }^{354}$ So, what we

\footnotetext{
${ }^{353}$ Nat. Fac. II 85-6 K

${ }^{354}$ Nat. Fac. II 10-11 K: 'Genesis, however, is not a simple activity of Nature, but is compounded of alteration and of shaping. That is to say, in order that bone, nerve, veins, and each of the others may come into existence, the underlying substance from which the animal springs must be altered; and in order that the substance so
} 
can gather from all this, is that semen becomes creative nature when confronted with its proper material and then generates a living being by exercising the natural capacities of alteration and shaping. It seems then, that all the creative capacities of nature, in the case of human beings at least, are simply contained in the seed and in this way passed from one person to the next, i.e. from parent to child, so that it is unnecessary to postulate a transcendent nature. Now, however, Galen poses a caveat: we must take care to not attribute to the semen reason and intelligence. ${ }^{355}$ So on the one hand, the semen seems to have all the powers necessary for new generation given the right conditions, but on the other hand this provides Galen with a problem: if all of these powers can be accounted for with the semen itself, then what about the intelligent design of things? Galen seems to have remained puzzled by this problem, as the following passage from Foet. Form., a relatively late work, shows:

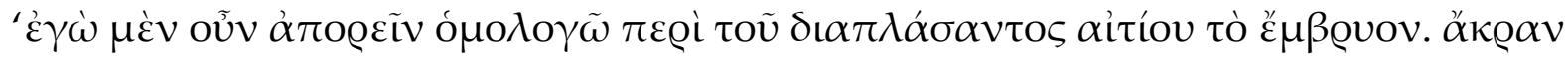

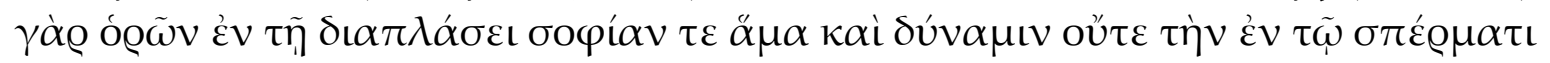

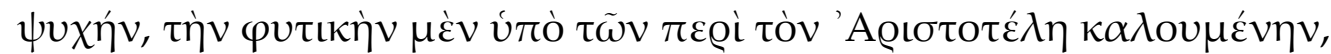

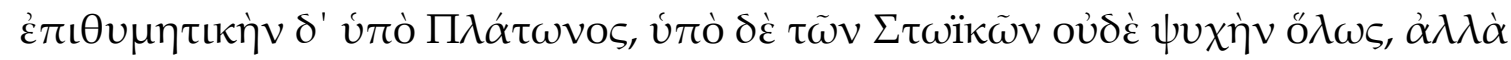

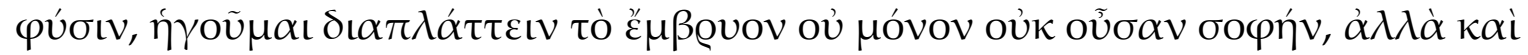

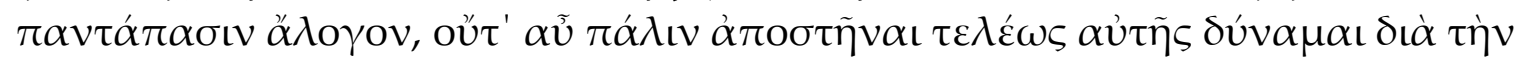

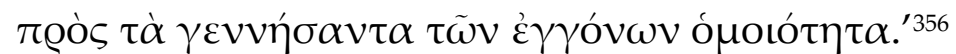

'And so I confess that I do not know the cause of construction of the foetus. For I observe in this construction the utmost intelligence and power, and I cannot allow that the soul in the seed, which Aristotle calls vegetative and Plato desiderative, and which the Stoics consider not to be soul at all, but nature, constructs the foetus, since this kind of soul is not only not intelligent, but entirely devoid of reason; nor, however, can I entirely distance myself from that opinion, in view of the similarity of the offspring to the parents...'(tr. Singer)

This question is decisive for the question about the relative immanence or transcendence of nature: were the natural powers of creation to be completely contained in the seed, nature would be immanent and passed on through time from one being to another. But if we rather think that this model cannot account for the apparent order of things, then we would perhaps be more inclined to think of a creative nature that transcends individual substances in a sense that is not merely chronological. In the end, apparently, Galen did not reach a final conclusion on this matter, and he seems to have remained caught in the tension between the explanatory power of mixture and the conviction of intelligent design. ${ }^{357}$ In this

altered may acquire its appropriate shape and position, its cavities, outgrowths, attachments, and so forth, it has to undergo a shaping or formative process. One would be justified in calling this substance which undergoes alteration the material of the animal, just as wood is the material of a ship, and wax of an image.' (tr. Brock, slightly modified)

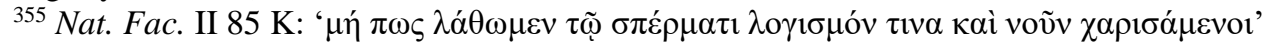

${ }^{356}$ Foet. Form. 104,15 Nickel (V 700 K)

${ }^{357}$ Cf. van der Eijk (2014) 89 ff. 
regard, Galen's work may puzzle our tendency to distinguish between 'top-down' and 'bottom-up' approaches in the study of human nature, as Philip van der Eijk has shown in an insightful chapter on the nature of human beings in Galen. ${ }^{358}$ Basing himself on an analysis of Galen's Mixtures, he phrases the problem as follows: 'On the one hand, we are told in Mixtures that human nature is to be defined as the 'whole being and mixture (ousia kai krasis) of the primary elements, hot and cold and dry and wet', and this is what the work is all about; yet on the other hand there are several intriguing passages in Mixtures hinting - but no more than that - at the possibility that a higher, indeed divine element, may be involved in the organization of human bodies.' ${ }^{359}$ This is a genuine problem, since, as van der Eijk points out, Galen repeatedly makes this distinction himself in Mixtures. The issue becomes more difficult when we consider the fact that for Galen the mixtures themselves must also have a divine cause, for several reasons: (1) nothing besides God or divine nature can produce a complete mixture of qualities (2) if we were to assume that the elemental qualities are mixed in a random manner, there is no way to account for the ordered nature of things (this general principle of intelligent design must also apply to the level of the homoeomerous bodies, especially considering their importance with regard to the activities of the soul) (3) the powers manifested by the elemental qualities in virtue of which they bring about alterations in matter are defined by Galen as powers of nature itself. ${ }^{360}$ Therefore, we cannot strictly distinguish between a 'mechanical' and 'teleological' aspect, but at best between a less and more directly divine or teleological aspect. That is to say, the 'higher, divine element', whatever it is (e.g. the so-called 'shaping capacity'), may be a more direct manifestation of the ordering power of divine nature, whereas the activity of the mixtures are a more indirect manifestation of the ordering power of divine nature, since they seem to manifest themselves as causes in themselves after their creation by nature. ${ }^{361}$ And indeed, Galen, as we have seen, considers the mixtures as a kind of instruments of divine nature, but at the same time as a kind of crafters. ${ }^{362}$ This difficulty, I think, is another way in which the ambiguity of nature as transcendent or immanent manifests itself in Galen's work and should, perhaps, remain unresolved to some extent.

\footnotetext{
${ }^{358}$ van der Eijk (2014)

${ }^{359}$ Van der Eijk (2014) 101-2

${ }^{360}$ For (1) Temp. I $563 \mathrm{~K}$; for (2) UP 440,20-441,1 Helmreich (IV $351 \mathrm{~K}$ ), see also infra CS I section, 42-5; for

(3) Nat. Fac. II 12-3 K, see also infra, CS I section 1, 24-6

${ }^{361}$ If I understand van der Eijk (2014) correctly, this is also his conclusion when he says the following, 123: 'To be sure, this is not a purely mechanical construction; but it is part of the 'immanent' nature, the phusis of human beings, rather than the result of some kind of external agency. Even the soul and its faculties, including the rational soul, arise 'from the bottom up'. True, they are not just there as a product of chance or mechanical causation: there is some good, some oikeion, here governing this process; which ensures that the mixtures of the body are such that they give rise to the appropriate faculties and dispositions of the soul, which in turn are tuned to the parts of the body through which they exercise their characteristic activities; and humans themselves have a role to play here in the management of their physical and psychological development. But this seems to be a different way of proceeding from the direct, causative influence of the divine that is present in the aristê diaplasis.'

${ }^{362}$ See infra CS I section 1, 42-5
} 
Another remarkable feature of Galen's notion of (human) nature that has so far remained unmentioned is its essential plurality. When thinking about the nature of the human being, Galen is not out to look for one thing, nor something that remains the same, but his assumption is rather that our nature, in its very core, needs to be a dynamic plurality, in order to account for our complexity and differences. On a more fundamental level, according to Galen, basic phenomena such as generation, pain and perception can only be explained when there is a plurality of qualitatively diverse and interacting stuff at the basis. ${ }^{363}$ This is a continuous thread in both Hipp. Elem. and $H N H$ alike. For example, Galen quotes the following passage from the Hippocratic text in his commentary:

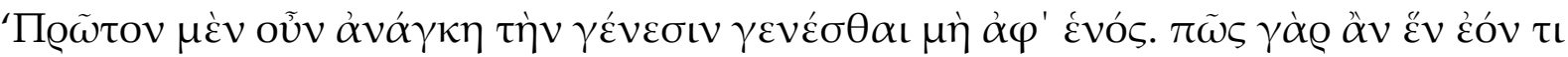

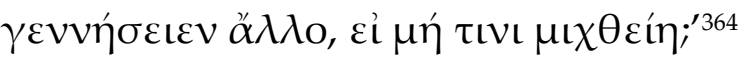

'First of all, then, it is necessary that generation not take place from a single thing; for how could something, being single, generate anything, if it is not mixed with something else?' (tr. Hankinson)

He then remarks that the author is here merely adhering to things that are clearly

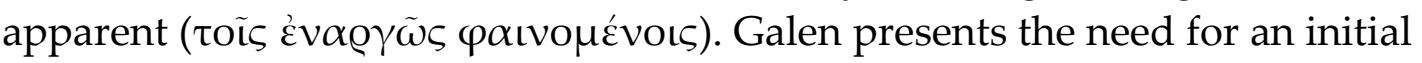
plurality for generation as utterly evident. One may think this is unsurprising, since we all know that 'it takes two to tango', and Galen tends to take an empirical point of departure for these questions. However, the matter is more interesting than that. After all, Galen extrapolates from this text, which seems to be primarily about the generation of living beings by other living beings, to general remarks on generation as such. This takes us back to the beginning of Galen's commentary, where he distinguished between the bodies that are subject to generation and destruction on the one hand, and the substance underlying all generation and destruction on the other. ${ }^{365}$ Thus, with the passage cited above, Galen takes an empirical departure point again, pointing to the necessity of two beings of different sex and the same species for procreation, as he did earlier with the necessity of water and earth for a seed to grow, to make a more general theoretical point that goes beyond empirical observation, namely that the primary substance underlying generation cannot be a unity in the fundamental sense that it has to be made up of essentially different constitutive elements that are not reducible to each other and that only through their constant interaction are able to establish the particular temporal unity which characterizes all individual beings as such. In this sense, Galen's emphasis is on plurality as a condition for unity, rather than the other way around.

We have already established that this primary substance (or nature), in Galen's view, is the mixture of elemental qualities in prime matter. Galen presents this specific application of the general philosophical method described in the Phaedrus as that of

\footnotetext{
${ }^{363}$ Cf. Hankinson (2008) $213 \mathrm{ff}$.

${ }^{364}$ HNH 24,16-8 Mewaldt (XV $43 \mathrm{~K}$ )

${ }^{365}$ HNH 3,24-4,5 Mewaldt (XV $3 \mathrm{~K}$ ); see infra section 1, 97-102
} 
Hippocrates, and repeatedly contrasts this Hippocratic-Galenic view with that of those who think that human nature consists of one of the elements (or one of the humours). This view is taken ad absurdum by Galen on several occasions, with several arguments, both in HNH and in Hipp. Elem. ${ }^{366}$ Remarkably, however, he does not so much argue against the impossibility of reducing the complexity of perceptible phenomena to some one particular element, but rather focuses on the supposed basic unity, as such, as the focal point of his attack. This shows that to Galen the main problem with these views is not so much empirical, i.e. about only taking one of the four elements or elemental qualities that exist and neglecting the others, but more fundamental, i.e. about not being able to explain the workings of the beings subject to generation and destruction if you take a unity as the nature of these beings. That applies to a unity of whatever kind, which is why, Melissus and the Atomists (Galen's argument is about unity in form), for example, can be included together in this group. ${ }^{367}$ As Galen cites the Hippocratic text:

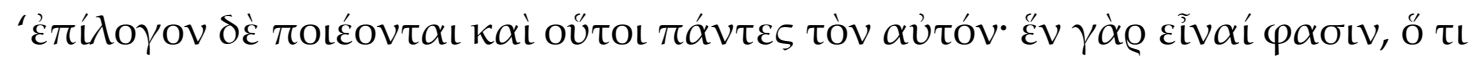

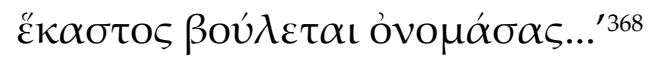

'All of them too employ the same reasoning: for they say man is one, whatever each of them wants to call it...' (tr. Hankinson)

One of the ridiculous consequences of taking the nature of man to be a unity is that then man would never suffer pain, which is, as we all know, evidently not the case. ${ }^{369}$ Again, Galen is following the text he is commenting upon:

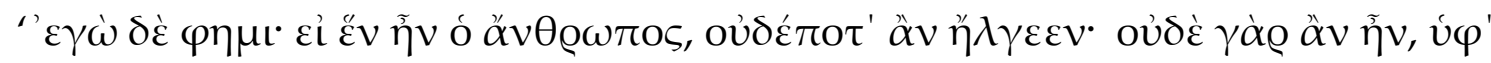

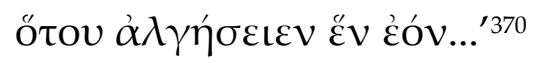

'I say rather that if man were one, he would never feel pain; for there would not be anything as a result of which he could feel pain if he were a single thing.' (tr.

Hankinson)

\footnotetext{
${ }^{366}$ HNH 13 Mewaldt (XV 20 K); 16 Mewaldt (XV 26 K); 19 Mewaldt (XV 33 K); cf. Hipp. Elem. 80- 86 De Lacy (I 438-42 K)

${ }^{367}$ Cf. Hipp. Elem. 58,10-25 De Lacy (I 415-6 K): 'Now Hippocrates gives the following proof that the first element from which our body and the bodies of all else came into being is not one thing; I think it is better (first) to quote his own words and then give my explanation of them: "I say that if man were one thing he would never feel pain, for there would be nothing that would cause him pain if he were one." He seems to me to give most excellently and at the same time in fewest possible words the essential point of his proof that the element cannot be one in form and power. Quite obviously it is utterly absurd to say that what exists is one in number; that is truly the act of a man who has given no thought to any of the obvious facts. But a person might say that all things are one in form and power, as Epicurus and Democritus and their followers say of the atoms. And of the same chorus with them are those who postulate elements that are least and unattached and without parts. Hippocrates, then, making a common answer to all such persons, proves that the element is not one in form and power...' (tr. De Lacy); cf. Kupreeva (2014), particularly $162 \mathrm{ff}$.

${ }^{368}$ HNH 19,26-8 Mewaldt (XV 34 K)

${ }^{369}$ HNH 13,9 f. Mewaldt (XV 20-1 K); cf. Hankinson (2008) $212 \mathrm{ff.}$

${ }^{370}$ HNH 20 Mewaldt (XV 35-6 K)
} 
In order to experience pain, a being must be affected by something. But, seems to be Galen's assumption, in order for things to be affected by something else, there has to be a difference in quality between those things. ${ }^{371}$ Then, if the nature of the being is eventually reducible to some one thing, this kind of affection could not possibly happen. Another assumption that comes to the fore here, is that affections in the end need to happen at the most fundamental level. For otherwise one might very well claim that differences which are accidental and which are dependent on a more complex level than that of the primary nature of a thing, could cause the affections, as an Atomist might do. This should not surprise us at this point, since we have already seen that, for Galen, the activities of a given being should also be traced to its activities at the most primary level (i.e. that of the interaction of the elementary qualities) and that it is the substance of a thing that determines its activities and affections, while Galen identifies the substance of any thing with its specific mixture. And indeed, not coincidentally, in the passage following this last quotation, Galen goes on to emphasize that the elemental qualities are primary, cause everything else to come to be, and are the primary active and alterative qualities in the body, of which all other qualities are derivative. ${ }^{372}$ Galen adds a less convincing argument by pointing out that even if something were able to be affected as a result of itself (i.e. by the same form which it itself has) and could thus experience pain, there would then only be one simple type of cure or one kind of therapy for this pain, which is, again, evidently not the case. ${ }^{373}$

It seems an essential assumption for Galen that the activities and affections of a given being must somehow (or in a primary sense) manifest themselves in the thing's primary nature itself and could not be merely generated by its primary nature. His argument against the Atomists, roughly, is: the atoms themselves are not capable of sensation or change, therefore, the physics based on atoms as the primary nature of things could not possibly account for sensation or change. ${ }^{374}$ Thus, the possibility of the atoms - incapable of being affected (according to Galen) and thus incapable of sensation or change - generating some more complex structure that is consequently capable of sensation or change is not considered viable at all by Galen ${ }^{375}$ :

\footnotetext{
${ }^{371}$ Cf. Hankinson's note ad locum: 'Here Galen appeals to a very general Greek (indeed Western) idea, namely that only things which are in the appropriate ways different in quality from one another can affect one another.'; cf. Kupreeva (2014)

${ }^{372}$ HNH Mewaldt 22,4-23,8 (XV 38-40 K)

${ }^{373}$ HNH. 21,20 f. Mewaldt (XV 38-9 K); cf. Hipp. Elem. 76,20 f. De Lacy (I 434 f. K)

${ }^{374}$ Hipp. Elem. De Lacy 62 f. (I 419-20 K)

${ }^{375}$ Cf. Hankinson (2008) 213: 'What is ruled out, Galen argues, is what one might call the supervenience of generically different properties: any supervenient properties must be similar in general type to properties actually disposed of by the elements they supervene upon. Thus, since sentience is a type of alteration, the elements in the aggregrate upon which sentience supervenes must be capable of alteration, although not necessarily of sentience itself...'; however, cf. Kupreeva (2014) 167 note 48, after quoting these sentences from Hankinson: 'I do not find in the text the argument stated in the second sentence. As for the analysis given in the first sentence, it does not sound right: Galen says that generically different properties cannot accrue to aggregates, but can do so in more complex structure, such as mixture. Therefore sentience cannot arise in an aggregrate, which is like a heap of grains, but can arise in a more unified structure, such as that of a living body.'
} 


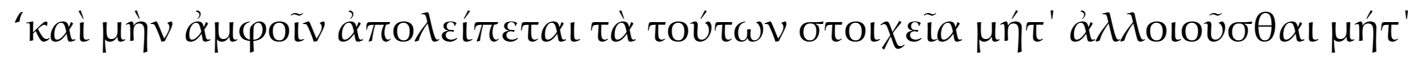

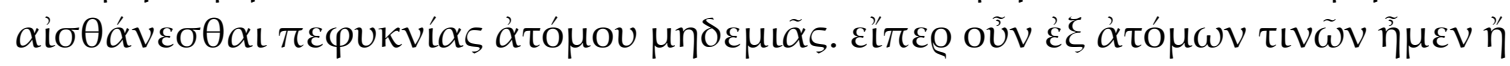

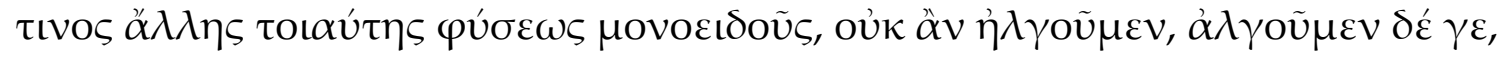

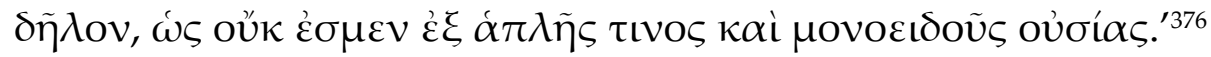

'And in fact these men's elements meet neither requirement; it is not in the nature of any atom to change or to have sensation. If then we were made of atoms of some sort or any other such nature that is of one kind only, we would not feel pain, but since we obviously do feel pain, it is clear that we are not made of a simple substance that is of one kind only.' (tr. De Lacy, slightly modified)

Galen is aware of his basic assumption and makes it explicit:

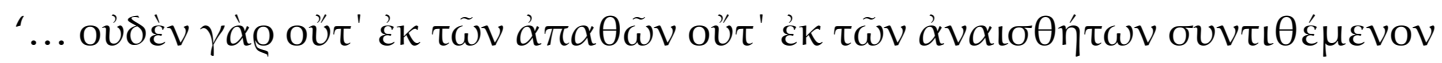

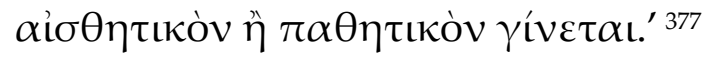

'... for nothing that is put together from things that are not affected or from things that lack sensation becomes sentient or affected.' (tr. De Lacy)

According to Galen, the elements of a sentient body must either be both sentient and affected, or at least affected. Also, as we have seen, in order for an element to be affected, there must be elements different in kind, affecting it. Hence, there must be a plurality of qualitatively different elements. Thus, now, we have the possibility of a plurality of insentient elements acting upon and affecting each other, consequently generating a sentient being 'in the course of many partial alterations' ${ }^{378}$ According to Galen, it is exactly the dynamic aspect of these elements, their continuous change due to their mutual interaction, that allows for the generation of capacities that are an attribute of their combined mixture, even though they are not an attribute of any of the original constituent parts of that mixture. ${ }^{379}$

Then again, we also have to remember that in a strict sense, for Galen, the elemental qualities or the prime matter in which they mix, are not elements, but (conceptual) principles. ${ }^{380}$ The first bodies, or unified structures, are already a mixture of various principles and therefore only simple to perception.

At the same time, it seems, Galen would have to say that these mixtures themselves, i.e. the homoeomerous bodies, even though they are the primary locus of activity and soul, are also not sentient (albeit affective and capable of change and alteration).

Sentience only comes in when they in turn form an (anhomoeomerous) organ, such as the eye or rather even the brain. This seems paradoxical: the functions that seem to determine what we are, are not yet to be found in what is identified as our nature. But that might be a general problem for anyone trying to explain complex functions

\footnotetext{
${ }^{376}$ Hipp. Elem. De Lacy 62,21-25 (I $420 \mathrm{~K}$ )

${ }^{377}$ Hipp. Elem. 64,24-5 De Lacy (I $422 \mathrm{~K}$ )

${ }^{378}$ Hipp. Elem. 70,17-18 De Lacy (I $428 \mathrm{~K}$ ), translation De Lacy

${ }^{379}$ Cf. Kupreeva (2014) particularly $165 \mathrm{ff}$.

${ }^{380}$ See infra, section 3, 112-7
} 
in terms of more simple ones. The absence of the complex function itself (that somehow defines the being exercising this function) in the cause of it (that is taken as the (primary) nature of that being), seems to suggest there is something missing, i.e. that the definition of this being does not correspond to the definition of its nature. What Galen seems to suggest, is that since the primary level determines the more complex level, what is happening at the more complex level is happening more truly at the primary level, even though the specific functions exercised at the more complex level are not to be found at the more primary level and even though these specific functions, for example rational thought, can be seen as defining for the specific kind of being it belongs to. In that sense, rational thinking could, perhaps, take place primarily in the mixtures of the brain, even though a homoeomerous body does not think. Again, it seems that we have to keep in mind that whatever soul is understood to be, it is primarily a principle of movement.

In any case, to get back to our previous line of reasoning, Galen argues that pain, pleasure and sense-perception - and with that also memory, reasoning and the soul itself' - will be done away with if it is not assumed that our substance is altered through and through. ${ }^{381}$ But, if we were to accept that, and accept that our nature has to consist of a plurality of elements (or principles) that are not reducible to each other, and that cause change through their mutual interaction, why would it have to consist of these four elemental qualities (hot, cold, dry and wet) exactly? We saw earlier that Galen does provide some empirical justification for his choice (in as far as it is his choice, clearly he is also following the previous tradition, and particularly his three main interlocutors Hippocrates, Plato and Aristotle). He also gives another argument for this choice in Hipp. Elem.:

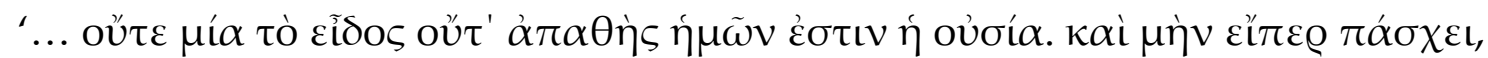

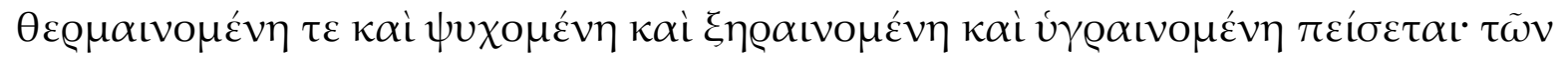

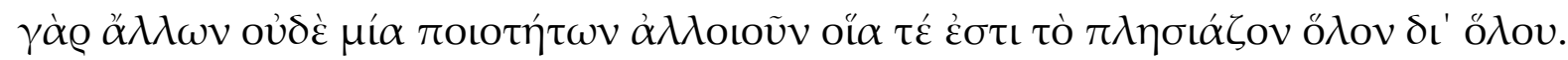

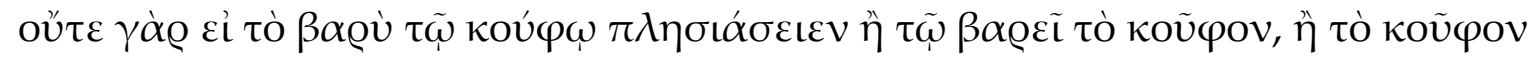

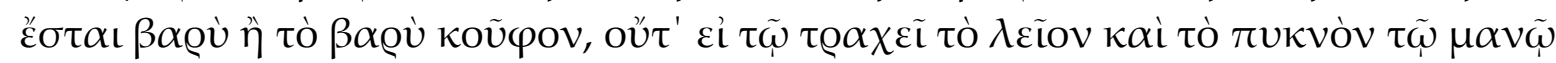

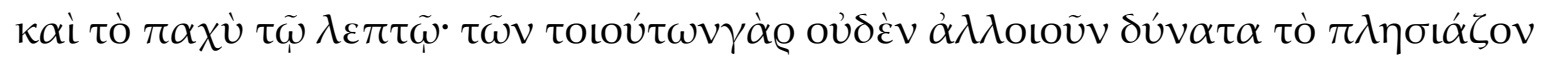

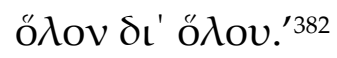

'... therefore our substance is neither one in kind nor unaffected. And if in fact it is affected, it will be affected when it is heated, cooled, dried and moistened; for not one of the other qualities is able to alter through and through (the body) that is close to it. It does not happen that if heavy is close to light or light to heavy, the light will be heavy or the heavy light, nor if smooth is close to rough, dense to rarefied, thick to thin, nothing of that kind can alter through and through the (body) close to it.' (tr. De Lacy)

\footnotetext{
${ }^{381}$ Hipp. Elem. 134,9-13 De Lacy (I $\left.487 \mathrm{~K}\right)$

${ }^{382}$ Hipp. Elem. 130-2 De Lacy (I 484-5 K)
} 
Apparently, Galen takes these four primary qualities as the only qualities that can be transferred from one body to another by mere contact and the only qualities that can alter a substance through and through. As Hankinson puts it: 'This, fundamentally, is how power is transmitted from one thing to another. ${ }^{383}$ Therefore, these four qualities are the only ones that can account for generation, destruction and change in general. That is to say, every other change in quality is already dependent on a change in these elemental qualities.

Since these elemental qualities determine the substance of everything, the human being has its nature in common with all other non-eternal beings. Since this nature is a plurality of qualitatively different aspects that interact with each other and alter their substance, it can, according to Galen, account for all further properties and qualities which we can observe and which differentiate all those beings. As such, this interaction must be governed by a divine and artful nature, since we can see from its generated effects that it causes an intelligible order. Since some of nature's capacities in generating this order are exercised by these elemental qualities, the border between a transcendent, intelligent nature and an immanent nature that passes on its inherent organization of elements through time, is ambiguous in Galen. The same seems to go for the differentiation between what, in a human being, is to be accounted for in terms of 'nature' and what in terms of 'soul'.

\section{Nature of the body, nature of the soul}

As we have seen earlier, both the essential and the accidental attributes of a given being are determined by its specific mixture of elemental qualities, according to Galen. ${ }^{384}$ This seems to imply that there is nothing about any being that cannot be explained in terms of these elemental qualities. That means that besides being merely a necessary part of the explanation of a thing's nature, an analysis of its specific mixture actually also suffices as a description of its nature.

It might be that one of the reasons why Galen is so fond of the passage from Plato's Phaedrus (270b-c) is that at its beginning, on one possible reading at least, there is an integration of the understanding of the nature of body and soul into the understanding of what is called in Plato's text 'the nature of the whole' ${ }^{385}$ There are different views as to how to interpret this notion of the whole ${ }^{386}$, but the most sensible reading for Galen may perhaps be 'the whole of body and soul', i.e. the whole human being as composite, hylomorphic being. This reading would integrate body and soul into a notion of a whole that would imply some kind of synthesis of Galen's

\footnotetext{
${ }^{383}$ Hankinson (2017) 10; see also Hankinson (2008), particularly 217

${ }^{384}$ See infra, section $1,98-9$

${ }^{385}$ On Galen's use of this passage and its importance for his self-understanding see also Tieleman (2015) and (forthcoming)

${ }^{386}$ Cf. Jouanna (1999) 59
} 
two great heroes, Hippocrates and Plato, who are then associated with the two respective parts of this whole:

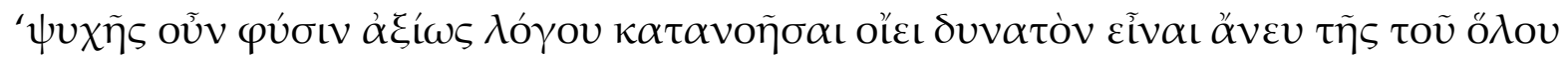

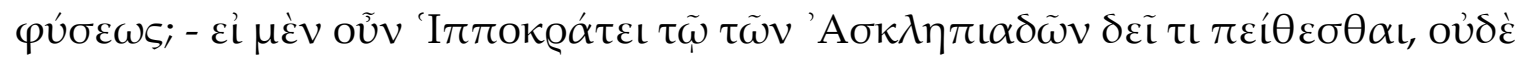

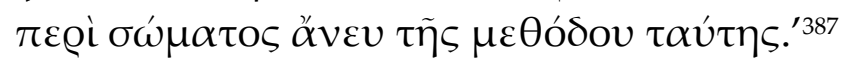

'So do you think it possible to understand the nature of the soul in a proper manner without understanding the nature of the whole?

If one should believe Hippocrates the Asclepiad, not even the body can be understood other than by this method.' (tr. Hankinson)

From this perspective, the passage fits very well with Galen's general hylomorphic approach of both $H N H$ and $Q A M$, in which body and soul as form of the body are explained in terms of a single hylomorphic substance. At the same time, he considers the Hippocratic treatise he comments upon to be about the nature of the body. ${ }^{388}$ That does not mean, however, that Galen's commentary should also be restricted to this part of the whole. The Hippocratic text does not have a hylomorphic outlook that ties in with the distinction between soul and body, as Galen does. It could not possibly arrive at the notion that soul is the form of the most elemental constitutive bodies of a given being. Galen can, however. Also, it is difficult to see how Galen would go about writing a similar kind of treatise (after $H N H$ ) about the nature of soul (being out to gain an understanding of the nature of man as a whole) and then proceed to integrate both into an understanding of the nature of the whole. Unless, of course, one would take $Q A M$ to be something like that (again, it was categorized by Galen as a work 'on Platonic philosophy'). After all, there, and nowhere else, Galen delves into the question of the nature of the soul. However, what comes to the fore in that treatise is that Galen does not have an answer to that question other than his answer to the question on the nature of man that is given in HNH. That is to say, it comes to the fore that for Galen, apparently, the questions for the nature of the body of man and the soul of man, treated by Hippocrates and Plato, respectively, are too intricately tied together to permit of separate treatment. ${ }^{389}$ The only viable answer Galen comes up with with regard to both of these questions goes as follows: a mixture of elemental qualities in prime matter. To me, it seems likely that, for Galen, an understanding of 'the nature of the whole' would consist in an account of the human being as a hylomorphic being consisting of mixtures of the elemental qualities that constitute all of its functions, some of which are traditionally called psychic. Again, this seems to me the most adequate explanation for the almost complete absence of soul in Galen's HNH.

\footnotetext{
${ }^{387}$ HNH 54,13-6 Mewaldt (XV 103-4 K)

${ }^{388}$ HNH Mewaldt 53,17-8 (XV $102 \mathrm{~K}$ ): 'Having set himself the task in this book of discovering the nature of our

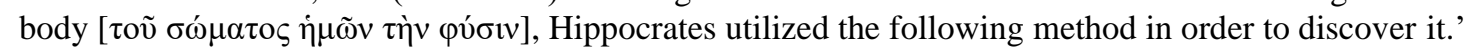

${ }^{389}$ I would argue that this seems to be the full extent to which Galen 'developed a synthesis between philosophy and medicine embodied by himself' (Tieleman, forthcoming), namely by an attempt to work out the nature of 'the whole' of which Hippocrates and Plato worked out a part.
} 
Almost, for it is not entirely absent. There is the repeated quotation of the Phaedrus, of course, in which soul is mentioned, and to which Galen refers back at the end of the first book of his commentary. It is precisely in the context of this quotation, with its contraposition of Plato and Hippocrates, that Galen says Hippocrates' writing was about 'the nature of our body'. First he describes how Plato replicated the method Hippocrates had used to examine the nature of the body:

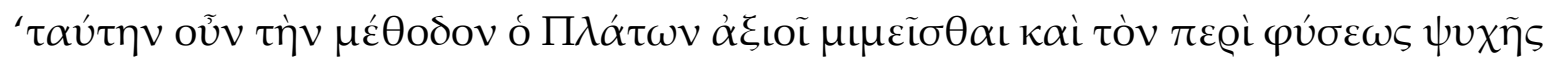

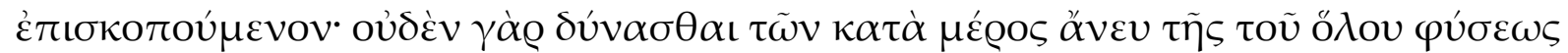
$\dot{\alpha} \kappa \varrho \iota \beta \tilde{\omega} \varsigma \gamma \nu \omega \sigma \theta \tilde{\eta} v \alpha \iota^{\prime 390}$

'Plato also thought it was right to replicate this method when considering the nature of the soul; for you cannot do this in individual cases without having a precise understanding of its nature as a whole.' (tr. Hankinson)

Then, after quoting the passage from the Phaedrus again, he summarizes the relation between Hippocrates and Plato in this regard once more, but now in a slightly different manner:

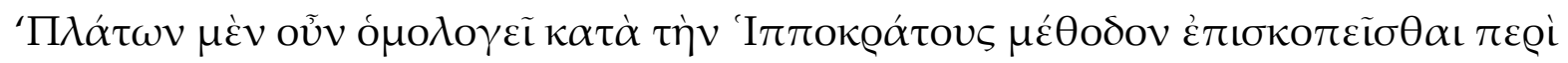

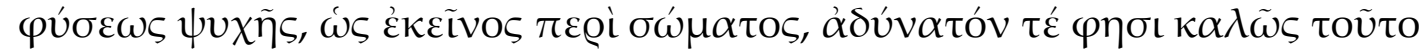

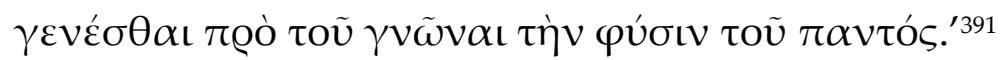

'So Plato agrees that one must investigate the nature of the soul according to the method that Hippocrates used in the case of the body, and says that this cannot be done properly, without knowing the nature of everything.' (tr. Hankinson)

The difference is clear: in the latter quotation, which is Galen's final remark on this subject, he does not merely claim Hippocrates and Plato had the same method to investigate two different subjects, namely taking them each as a whole and then analyzing them into elemental parts, as he started out by doing. Rather, he now claims that Plato held that in order to know the human soul, one needs to know the nature of everything. This is a statement altogether different than the maxim that in order to know the parts of something one needs to know this same thing as a whole. What the nature of everything is has been made abundantly clear in $H N H$ : the mixture of elemental qualities. Galen has been repeating what the nature of everything or all things is so often in his commentary, that I think it would be naïve to consider it a coincidence when he changes the quotation from the Phaedrus at the end, making Plato's remark about 'the nature of everything' rather than about 'the

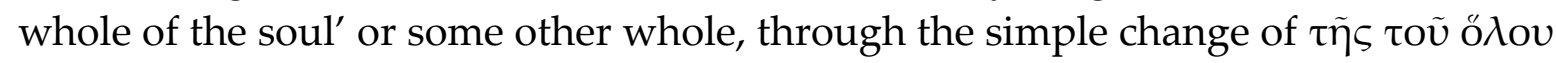

\footnotetext{
${ }^{390}$ HNH 54,9-12 Mewaldt (XV $103 \mathrm{~K}$ )

${ }^{391}$ HNH 55,14-6 Mewaldt (XV $105 \mathrm{~K}$ ), see also HNH Mewaldt 53,17-8 (XV $102 \mathrm{~K}$ ): 'Having set himself the

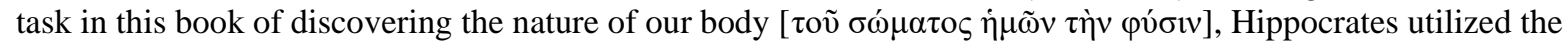
following method in order to discover it.'
} 


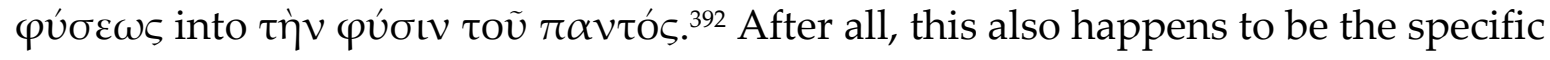
answer Galen comes up with when discussing both the question for the substance of the soul as well as the question for the substance of the body: their substance or nature is a specific mixture of elemental qualities, as is the nature of everything. I think this is why the Phaedrus passage appealed so much to Galen all along: the whole which Plato refers to is read by him as the whole of being as such, the nature of everything, which both the enquiries into soul and into body need to depart from if they are to result in knowledge at all. As Galen emphasized at the beginning of his treatise, without knowledge of this nature, there is no knowledge of anything.

Neither will there be any knowledge of the soul, as we now learn, which implies that according to Galen's reading of this passage, Plato said that one needs to know about the primary substance, the nature of all things, namely the mixture of the four elemental qualities, in order to understand anything about soul. This might appear strange as a reading of Plato, but it is not so strange as a Galenic reading of Plato. There is perhaps another Platonic subtext here that is not explicitly referred to by Galen, for good reason, but that was well-known to him. It is the following passage from Plato's Laws, where the Athenian says:

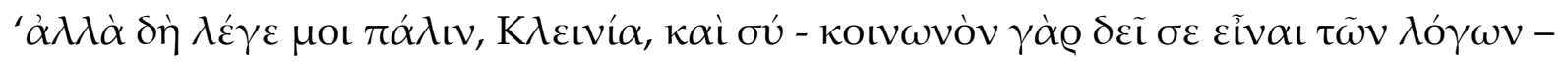

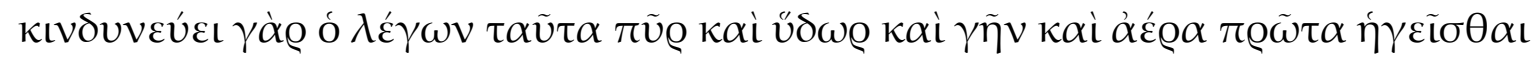

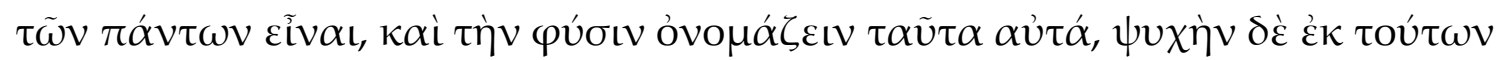
Uँ

'Now then, Clinias, you must take your share in the explanation, so tell me your opinion again. I assume the upholder of this doctrine thinks of fire and water, earth and air as being the first of all substances, and this is precisely what he means by the term 'nature'; soul, he thinks, was derived from them, at a later stage.' (tr. Saunders)

This view is considered impious and mistaken by the Athenian, since it is rather soul that is the cause of the alterations and transformations of all things. Clearly, Galen's work in $\mathrm{HNH}$ to some extent falls into the category rejected by the Athenian here, although the Athenian also ascribes to this position the view that the elements generate things by chance, which Galen obviously would not agree with. Galen knew the Laws well, it is certainly among the Platonic dialogues he wrote a summary of. ${ }^{394}$ Particularly considering the strong resemblances in terminology, it is extremely

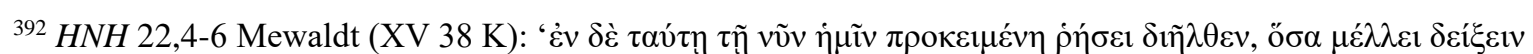

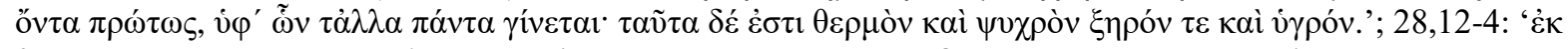

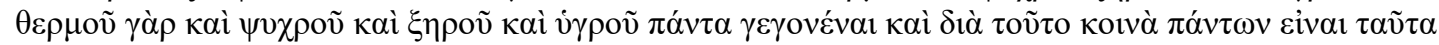

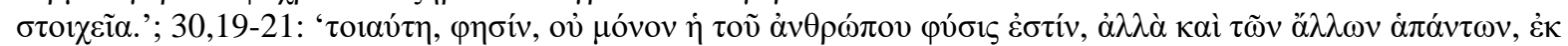

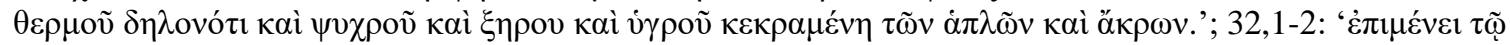

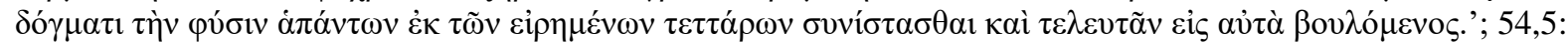

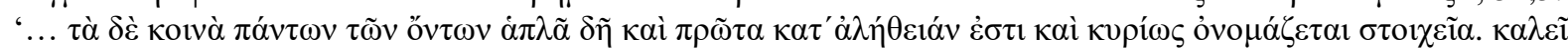

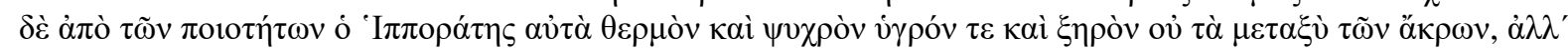

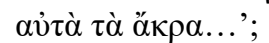

${ }^{393}$ Laws 891b8-c4 ed. Burnet

${ }^{394}$ See Arnzen (2002) 193 for the sources
} 
unlikely that Galen did not think of this passage when he introduced his notion of nature as a primary substance and then continued to explain this primary substance not in terms of the elements, but in hylomorphic terms with form dependent upon an intelligent creator much rather than chance. This passage makes it all the more remarkable that Galen did not discuss the soul in his commentary. But the Athenian's remark that soul is the primary cause of alteration and transformation in all things may remind us of Galen's descriptions of the elemental qualities as primary agents of alteration. Again, it is tempting to assume that Galen had this passage from the Laws in mind when writing $H N H$ and saw Peripatetic hylomorphism as a better approach than the alternative provided by the Athenian, who equated nature in this sense rather with soul. Therefore, it would not make sense to actually refer to this passage for Galen, since it would harm his portrayal of his work as the continuation of Plato's, whereas the Phaedrus passage, on the other hand, exquisitely lends itself to Galen's aims in $\mathrm{HNH}$ and provides a wonderful opening for a hylomorphic reading of nature. Of course, Galen is fully aware that Plato did not advocate hylomorphism in this passage, but he does not need to assume so for his reading. Rather, he can suffice with claiming that (1) Hippocrates developed the proper method of natural philosophy and applied it to the human body, (2) Plato saw that we need to apply this to the soul as well, (3) Plato claimed that we would not be able to understand either body or soul if we would not understand nature as a whole, (4) he was right about that, since body and soul form a hylomorphic whole based on the same principles as the rest of nature, (5) Plato, however, did not succeed in adequately analyzing nature as a whole and therefore did not meet his own demands for knowledge of body and soul, (6) with all of the previous steps made, what is required now is a proper analysis of nature as a whole, following the right method that has already been established, in order to gain knowledge of the whole of body and soul which we are. We will look more extensively at Galen's interpretation of Plato, particularly when it comes to the relation between the elemental qualities and the soul, in Case-Study III. We will then also go into the question of why Galen thought Plato did not succeed in his analysis of nature.

Besides the quotations of the Phaedrus, there is also a quotation from the Hippocratic work in which soul appears, namely the following:

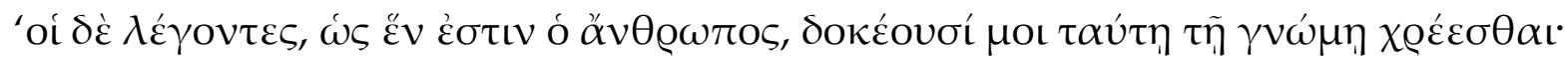

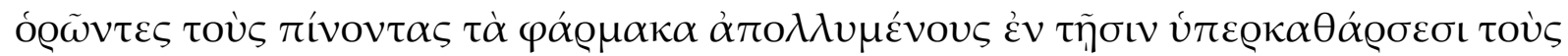

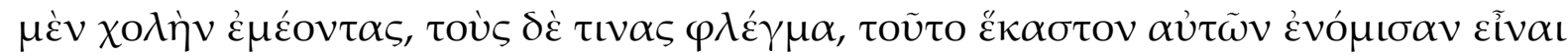

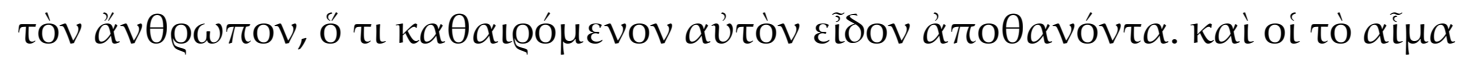

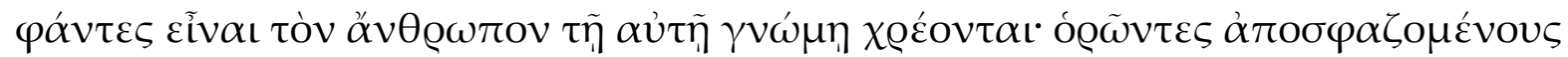

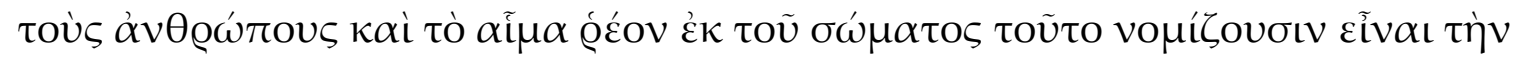

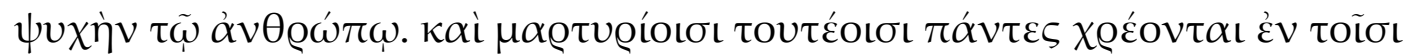
$\lambda$ ó́oเซเv. ${ }^{\prime 395}$

\footnotetext{
${ }^{395}$ HNH 40,25-34 Mewaldt (XV 76 K)
} 
'Those who say that man is one thing seem to me to be relying on the following thought. They see those who drink drugs and die as a result of superpurgation vomiting, some of them bile, others phlegm, and think that the man is whichever one of them as a result of the purging of which they saw him die. And those who say that man is blood rely on the same thought. They see men who have been mortally wounded, and blood flowing from the body, and so think that this is the soul of man. And all of them make use of the same type of evidence in their arguments.' (tr. Hankinson)

Interestingly, it is suggested here that blood could be the soul of man. We have noticed how in the previous text it has often been argued by Galen that man cannot be one but must be constituted from several basic elements or qualities. In all of the foregoing text this question of man being one or a plurality has consistently been about the nature of man. If man 'is one', then that means that his nature consists of one kind of thing. But in this passage, the Hippocratic author seems to equate the phrase 'man is blood' to the phrase 'blood is the soul of man'. What is more, Galen has no objections to this equation whatsoever, as appears from his explanatory comment:

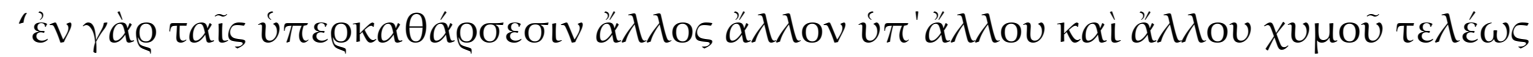

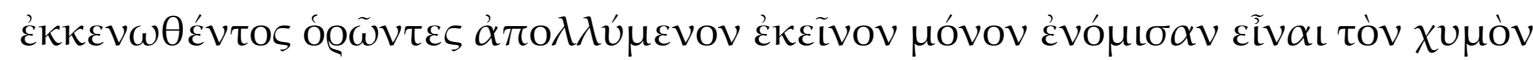

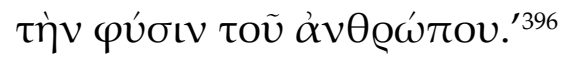

'For in the cases of superpurgation, where one sees someone die as a result of one humour finally being evacuated, and another sees another die as result of another, each of them thinks that humour alone is the nature of man.' (tr. Hankinson)

Galen simply paraphrases the Hippocratic author's 'soul of man' as 'nature of man'. The idea is completely the same: the one thing that is observed to abandon the body right before death is thought to be man's soul or nature. Galen criticizes this idea 'no one dies simply as a result of being purged of a single humour; they are always purged of the others along with it as well' - and argues that it is really a mixture of several kinds of things that forms the nature of man. But he does not criticize or take any issue with the apparent equation of soul and nature itself. ${ }^{397}$ These people are not wrong in thinking that the soul is flowing from the body when the humours are flowing from it, they are wrong in thinking that it is only one humour that is leaving the body, and that therefore man's soul (or nature) consists only of one humour rather than all four. Thus, though it might be true that we could sometimes take Galen to refer to the nature of the body specifically when using the term 'nature' in

\footnotetext{
${ }^{396}$ HNH 41,5-8 Mewaldt (XV 77 K)

${ }^{397}$ As we have observed earlier, Galen also equates the two in Trem. Palp. VII 616 K; in other places, he distinguishes 'soul' and 'nature', particularly in the context of the distinction between 'natural' and 'psychic' functions in Nat. Fac., in which the functions of the desiderative soul are considered natural and those of the other two souls are considered psychic. We have pointed out above (section 4, 119-20), however, that this distinction is not without ambiguity in Nat. Fac. itself.
} 
$\mathrm{HNH}$ and though it is certainly true that he in one place describes the subject of the treatise (i.e. his treatise, not merely the Hippocratic one) as 'the nature of our body'398, the passage quoted above shows that he has no difficulty with using 'our nature' synonymously for 'our soul' either. I think this proves how difficult it is to separate the two in Galen's work, and how, when he is writing about 'our nature', he has something in mind that resists being defined in the terms of this traditional dualism. The occurances of the word 'soul' in this text, as we have seen, are all either direct quotations from Plato or the Hippocratic author, or are part of Galen's immediate reaction to these quotations. Elsewhere, Galen simply seems to avoid using the word altogether. Actually, the only passage in which Galen himself does use the word 'soul' outside of the context of the citations from the Hippocratic author and Plato, is when he refers to $Q A M$, and precisely emphasizes the dependency of soul on mixture:

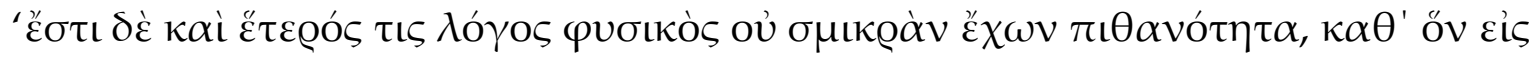

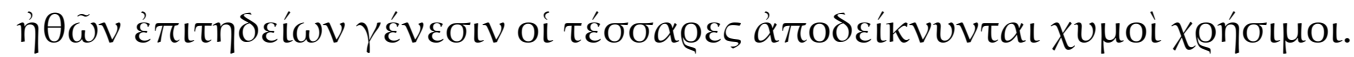

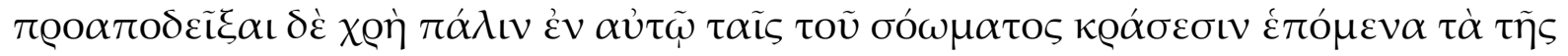

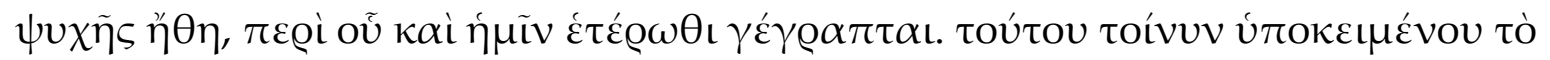

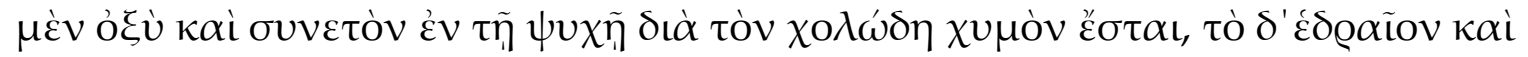

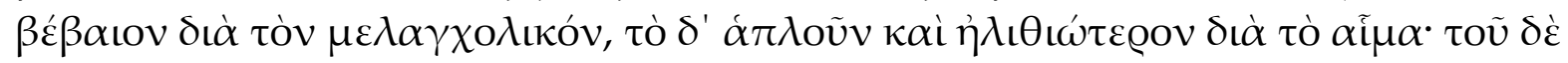

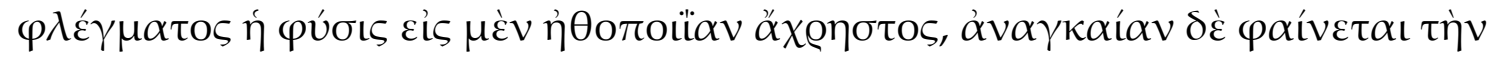

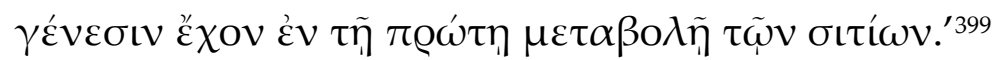

'There is also another physical account which has no little plausibility, according to which the four humours are proved to be effective in the generation of the states of character which are appropriate to them. In it we first need to establish that the states of character of the soul are consequent upon the mixtures of the body, about which we have written elsewhere. On this basis, sharpness and intelligence in the soul will exist as a result of the bilious humour, stability and firmness as a result of the melancholic, simplicity and artlessness as a result of the blood. The nature of phlegm is ineffective with regard to the prediction of character, having as it evidently does its necessary generation in the first alteration of the food.' (tr. Hankinson)

Note that Galen, here in the context of what he presents as his most basic work on human nature, remarks that the account advanced in $Q A M$ has no little plausibility, and proceeds to enumerate how each specific humour causes particular psychic capacities. ${ }^{400}$ Some (if not most) of the properties he enumerates seem to apply to our rational soul, which means that $\tau \dot{\alpha} \tau \tilde{\eta} \varsigma \psi v \chi \tilde{\eta} \varsigma \tilde{\eta} \theta \eta$ in this passage does not refer to character traits in the sense of qualities peculiar to the irrational parts of the soul, but rather has a much broader meaning, describing something like the habitual states of the entire soul, i.e. including all its parts. It is also noteworthy that Galen here calls

\footnotetext{
${ }^{398}$ HNH 7,12-4 (XV 9 K)

${ }^{399}$ HNH Mewaldt 51,9 (XV $97 \mathrm{~K}$ )

${ }^{400}$ With respect to the different roles of the specific humours, this passage will be discussed further in Case-

Study IV, as a part of the analysis of black bile in Galen (see esp. 269-70 below)
} 
the account of QAM $\varphi v \sigma i k o$ s. With this word he seems to put his account of the soul's dependence on the body in line with the writings of the natural philosophers he described in the introduction of HNH. Thus, the only time that Galen actually chooses to use the word 'soul' in this commentary beyond the context of his quotations, he refers to the potential for explaining psychic traits in terms of the humours or mixtures. This fact makes it all the more tempting to assume that Galen is not talking about soul in this treatise on human nature because he has nothing to say about it other than what he says in his discussion of the nature of the body.

\section{Conclusion}

We have seen how Galen, in his commentary on the Hippocratic On the Nature of Man, elaborates on his views on (human) nature. He works out a notion of nature as a primary hylomorphic substance underlying the bodies subject to generation and destruction both in the sense of underlying subject as well as in the sense of the basic form which determines secondary properties or qualities. This nature is the nature of human beings just as well as it is the nature of any other non-eternal being, for Galen. As such, he presents it as the main subject of the ancient quest for knowledge that came to be known as natural philosophy. The ancient philosophers - and Galen in their footsteps - have developed and employed a method of division for uncovering this nature that is always primarily hidden to our senses. Galen presents this method particularly as that of Hippocrates, who used it to inquire into the nature of the body, and as taken over by Plato, who proclaimed the same method should be followed for inquiring into soul. This same method is praised by Galen in other works as well, and consists of a division until no further division is possible, after which the indivisable last elements should be analyzed with regard to their active and passive causal powers.

According to Galen, this method of division reaches an endpoint with regard to the realm of perception in the homoeomerous bodies, but should be continued on a conceptual level to divide the homoeomerous bodies still in form and matter, matter being without quality and form being the mixture of elemental qualities. Thus, it turns out that the most basic active and passive causal powers that form the endpoint of the analysis are those of the four elemental qualities, namely heating, cooling, moistening and drying. Their specific mixture in the prime matter forms our nature, as well as that of anything else. Due to the qualitative variety of this mixture, however, it has the potential to generate all the various complex structures and capacities which we observe. In their generative role, these mixtures cannot be unambigously demarcated from nature as intelligent creator, which complicates the question of the transcendence or immanence of nature in Galen. Related to this problem is the ambiguity with regard to human nature; that is, in distinguishing the causality of 'nature' and that of 'soul', particularly when soul is understood as form of the body (i.e. a specific mixture of elemental qualities). 
With his definition of (human) nature in terms of the mixture, Galen does not merely adhere to the Hippocratic side of his Hippocratic-Platonic story. The way he quotes and discusses the passage from Plato's Phaedrus, betrays a synthesizing approach to the question of our nature, in which the hylomorphic nature of everything forms the adequate point of departure for both the body and soul of man, or rather, for the whole of man. 


\section{Case-Study III: Soul, Mixture and Galen's Timaeus}

\section{Introduction}

In this case-study, we shall have a look at Galen's interaction with Plato's Timaeus. Particularly, and in loose connection to the two previous case-studies, we will examine the way Galen uses the Timaeus to put forward a 'somatising' interpretation of the human soul and the relation between body and soul. That is to say, how he explains the distinction between body and soul in terms of a distinction between different elemental qualities.

In the previous case-study, we noticed how Galen drew Plato into his Galenic history of natural philosophy by depicting him and Hippocrates as his main predecessors with regard to the question of human nature. Particularly through his interpretation of Plato's Phaedrus 270c-d, he suggested that knowledge of the nature of everything is essential for knowing both body and soul. Galen explained this nature in terms of a primary substance common to everything, one consisting of the hylomorphic principles of a matter without quality and a mixture of the four elemental qualities as form. In this manner, it turns out that knowledge of the human soul, like knowledge of the human body, is dependent upon knowledge of this primary substance of mixture. This is in line with Galen's stronger thesis in $Q A M$, as we found in CaseStudy I, namely, that the substance of the soul is a specific mixture of elemental qualities. It is also in line with his interpretation of the Timaeus, as various texts and testimonies show. In his dealings with the Timaeus, as we shall see in the present case-study, Galen recasts the Platonic opposition between body and soul into an opposition of elemental qualities. In this way, the mixture of elemental qualities can account for man 'as a whole', that is, as a hylomorphic substance.

The Timaeus must have been one of Galen's favourite philosophical texts. Also, it is clear enough that, at least in his own explicit appreciation, Plato is Galen's favourite philosopher. One might argue that he is indebted to Aristotle and the Peripatetics to at least the same extent, but he often seems less willing to acknowledge this influence than that of Plato. ${ }^{401}$ At the same time, it seems that Galen has little use for some ideas that are central to Plato's work, most notably, his mythological and metaphysical speculations on the immortal, immaterial soul, and his theory of Forms. To put it in 'introduction to the history of philosophy' terms: we know Plato from his mind-body dualism and theory of Forms and we know Galen (if he is in the book at all) as a doctor and scientist with a thoroughly sceptical attitude towards metaphysical speculation. Now, introductions necessarily involve simplifications,

\footnotetext{
${ }^{401}$ Cf. Van der Eijk (2009) 261 f., 263: 'Plato, alongside Hippocrates, clearly stands on a higher pedestal for him than Aristotle and Theophrastus, let alone the older Stoics. Yet we should distinguish between overt and covert appropriation of an earlier thinker's ideas; and one of the points I intend to make in this paper is that Galen's implicit use of Aristotelian thought is much more profound and pervasive than his explicit acknowledgement of his debt to Aristotle might suggest.' See also DeLacy (1972); Singer (1991); Frede (2003) 75; Chiaradonna (2009) on Galen's relation to 'Middle Platonism' in particular. There are some themes around which Galen rather praises Aristotle instead of Plato as well, notably Aristotle's account of scientific demonstration and the theory of the elements.
} 
but there certainly is some justification for the worry that a Galenic Platonist might turn out to be a somewhat monstrous being (despite Ficino disagreeing) $\cdot{ }^{402}$ From the perspective of this difficulty, it is easy to see why Galen would love Plato's Timaeus in particular: it does not only explicitly emphasize the tentative nature of its speculative content, as Galen likes to point out, but it is also the most 'physical' of Plato's works. Furthermore, the elements play an important role in Timaeus' story (though the geometrical elements are problematic for Galen, as we shall see), there is a lot on subjects that pertain to the medical science, and Timaeus speaks extensively of the physiological constitution of the human body and the whole cosmos as well as their mutual relation. Besides, the Timaeus might also be the most teleological of Plato's works: the teleological design of the cosmos is a fundamental and structural aspect of Timaeus' narrative. In fact, as has been pointed out, Galen's own teleological outlook must have been strongly influenced by the tradition of the Timaeus, perhaps more so than by the Peripatetic tradition. ${ }^{403}$ Indeed, Galen draws on the Timaeus in various works, for example in $P H P$, where he aims to show the agreement of Plato with Hippocrates, in $Q A M$, where he is out to argue for the dependence of the psychological on the physical and in $U P$, where the goal is to show the unsurpassed grandeur of nature's inherent teleological design. Therefore, it should not surprise us that Galen did not only write a summary of the Timaeus, which he presumably did for all Platonic dialogues, but also produced a commentary (in four volumes), which he did not do for any of the other Platonic dialogues. ${ }^{404}$ Unfortunately, we do not have the Greek text of his summary of the Timaeus, but we do have the Arabic translation attributed to the workshop of Hunayn Ibn Ishaq. ${ }^{405}$ The Arabic edition was published by Kraus and Walzer in 1951, who conveniently included a Latin translation (Galeni Compendium Timaei Platonis). Kraus' Arabic edition is soon to appear in a new English translation by Das and Koetschet. ${ }^{406}$ Galen's summaries of Plato were very popular in the medieval Arabicspeaking world and must have been a major factor in the transmission of knowledge of Plato's works, as there seem to have been no direct Arabic translations of Plato's

\footnotetext{
${ }^{402}$ One significant simplification in this regard is the sceptic aspect of Plato's work, which Galen emphasizes particularly with regard to the Timaeus: he often points out that Plato presented his cosmology there as a 'likely account', i.e. as something which is not scientifically proven (cf. Tieleman (2018))

${ }^{403}$ Cf. Vegetti (1978) 37-41; Hankinson (1989) 211-18; Chiaradonna (2009) 245-47

${ }^{404}$ In Lib. Prop. XIII, Galen mentions the summaries of Plato's dialogues, in eight volumes, as well as the 'Commentary on the Medical Statements in the Timaeus, in four volumes. Cf. Arnzen (2012) $193 \mathrm{ff}$. , who has found Arabic references to Galenic summaries of eight different dialogues, among which the Timaeus; Flemming (2008) 327; Das and Koetschet (forthcoming)

${ }^{405}$ For an in-depth discussion of the authorship of this translation, see Das (2013) $41 \mathrm{f}$., who concludes (79): 'In absence of further comparative data, it is difficult to make a more specific assertion than the Arabic translation of the Synopsis likely belongs to the output of Hunayn's circle.' Das and Koetschet (forthcoming) conclude that 'the more general attribution of the extant Arabic version of Com. Tim. to Hunayn's workshop is fairly secure'. I am very grateful to Aileen Das and Pauline Koetschet for letting me use the drafts of their new translation of the Compendium as well as their introduction; since these drafts do not yet have a definite pagenumbering, I will simply refer to it in general when I refer to their introduction to the translation of the text. ${ }^{406}$ Das and Koetschet (forthcoming)
} 
work itself. ${ }^{407}$ Particularly in the case of the Timaeus, much of the Medieval Arabic knowledge of the text is dependent on Galen. According to Arnzen, it is likely that 'the entirety of Medieval Arabic references to various Platonic works entitled Timaeus can be reduced to exactly three works'. These are (1) a Middle or Neoplatonist 'paraphrase or epitome of the genuine Timaeus' translated by Yahya ibn al-Bitriq, (2) Galen's summary in the translation from Hunayn's workshop, and (3) the aforementioned Galenic commentary in four books, also translated by Hunayn and others. ${ }^{408}$

Besides the Arabic translation of Galen's summary, we also have fragments from his

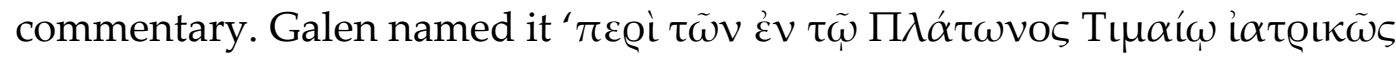

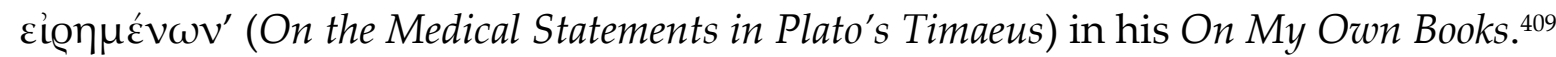
He anticipated this commentary in PHP book VIII, saying that his friends had requested him to write on the medical passages in the Timaeus, and that although many commentaries have been written on the Timaeus already, the medical passages in particular have not been sufficiently commented upon. ${ }^{410}$ We also find anticipatory references to it in Trem. Palp., from which it becomes clear that Galen intends the commentary to be critical of Plato instead of merely explanatory. ${ }^{411}$ In the fragments from Galen's commentary itself we find references to Nat. Fac. and the lost On Hippocrates' Anatomy. ${ }^{412}$ Based on these references, Schröder suggests that Galen wrote his Timaeus commentary shortly before 180, in the last years of Marcus Aurelius' rule. ${ }^{413}$

It is useful to keep in mind that Galen, both in PHP and Trem. Palp., brought up the need for this commentary in the context of a discussion of humoural theory and the way Plato and Hippocrates relate to it. In particular, he tells us that Plato did not have anything else to say on the subject than what Hippocrates had already said, except for the fact that Plato discussed the underlying causes of why a certain

\footnotetext{
${ }^{407}$ Arnzen (2012) 181-267, 185: ‘ . . in all likelihood no direct Medieval Arabic translation of the complete Greek text of any authentic Platonic work was ever made.' On Galen particularly 193 f.; see also Das and Koetschet (forthcoming)

${ }^{408}$ Arnzen (2012) 202-11; cf. Das (2013), for a more detailed discussion; see also Das and Koetschet (forthcoming)

${ }^{409}$ Lib. Prop. XIX $46 \mathrm{~K}$

${ }^{410}$ PHP VIII 508,6-9 De Lacy (V 682-3 K): 'These passages need not be quoted now, for it is better, as some of my friends request, that I comment elsewhere on the medical passages in the Timaeus. Many persons have written commentaries on the rest (of the Timaeus), some at greater length than was needed; but on these matters few have written, and they not well.' (tr. De Lacy); see also PHP VIII 522,34-6 De Lacy (V 702 K), referring back to the previous remark: 'I have decided that for the present this is enough about the humors if, as some of my friends ask, I am going to write a commentary on the medical passages in the Timaeus.' (tr. De Lacy)

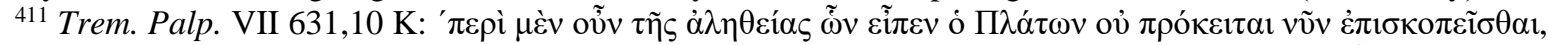

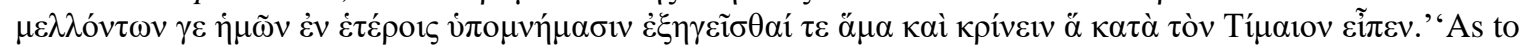
whether or not the things Plato said are true this is not now our task to consider. (I intend to write a critical commentary on the Timaeus).' (tr. Sider and McVaugh); see also a bit further Trem. Palp. VII 632,1 K: 'In the future, then, we shall examine the views of Plato in our commentary on the medical teachings of the Timaeus; now, however we are putting forward our own opinion, explaining what was said a little above according to the teaching of Hippocrates.' (tr. Sider and McVaugh)

${ }^{412}$ For Nat. Fac.: Fr II, 11,15 and Fr XIX, 25,26 Schröder; for the lost On Hippocrates' anatomy: Fr I, 10,3 Schröder.

${ }^{413}$ Schröder, Praefatio IX; cf. Das (2013) 12 f.
} 
humour is the way it is, e.g. why blood is red, bitter bile is yellow and sharp bile is black, whereas Hippocrates refrained from such inquiries, since they fall outside the scope of medical science. ${ }^{414}$ Interestingly, this implies that we can expect Galen in his commentary to also discuss things that lie outside the scope of medical science and were therefore not discussed by Hippocrates, despite his own suggestion that he merely comments on that which is relevant to the medical science. ${ }^{415}$ In fact, on the basis of these anticipatory remarks one would expect the commentary to explain how Plato's reasoning about the underlying causes of the humours is congruent or incongruent with Hippocratic humoural theory as Galen views it. In fact, this could be said to be the tendency of some of the fragments we have, particularly of those collected by Larrain; as we shall see, the author of those fragments is indeed very critical of the underlying causes Plato proposes.

This case-study will draw not only on PHP and QAM, but also on Galen's 'summary' of the Timaeus, the so-called Compendium, as well as the fragments of his commentary collected and edited by Daremberg and later republished by Schröder. Furthermore, we shall have a special focus on the contested fragments published by Carlos Larrain in 1992. These fragments are understudied, not to say almost completely neglected, presumably because Larrain's assertion that they are excerpts from Galen's Timaeus commentary has subsequently been questioned by Diethard Nickel (2002), who claimed they must have been written by someone deliberately imitating Galen. ${ }^{416}$ There is no doubt that these fragments show strong similarity with many attested Galenic writings and that their content generally fits well with Galen's interpretation of the Timaeus elsewhere, as Nickel also observed. But so far there has been no study that analyses the fragments in relation to the rest of Galen's work, except for the very brief critique by Nickel (based on only two of the thirty-four fragments) and Larrain's own work in his edition of the fragments. What is more, Aileen Das has recently argued that these fragments already circulated with those collected by Daremberg in the $9^{\text {th }}$ century Arabic tradition and that the question of their authenticity deserves a re-evaluation. ${ }^{417}$ Therefore, it may make sense to include a comparative discussion of Larrain's fragments, here, against the background of Galen's attested work. There is no need to attempt any definitive decision as to their authenticity, though our discussion of the fragments might have something to contribute to this debate as well. We will discuss and analyse some of the fragments, specifically those that lend themselves to comparison to Galen's somatising Timaeusinterpretation as we know it from his attested work.

It is noteworthy that almost all of Galen's works that particularly deal with the Timaeus are written around the same period: the final books of $P H P$, his Compendium and his commentary are probably all written between 169 and 180 . Only $Q A M$ is of later date, presumably after 193, but could be said to take up the earlier work on the

\footnotetext{
${ }^{414}$ PHP VIII 506, 25-508,5 f. De Lacy (V 681-2 K)

${ }^{415}$ Cf. Frede (2003) 80-1

416 Nickel (2002) 73-8

${ }^{417}$ Das (2014)
} 
Timaeus in the context of a more speculative treatment of the relation between body and soul. This suggests that Galen worked on the Timaeus for a prolonged period of time, which led to various kinds of texts that are closely interrelated (even though they seem to serve different purposes) and might therefore be conceived as a unified project to some extent. ${ }^{418}$ Nonetheless, with only a few notable exceptions, there are no studies that systematically look into Galen's dealings with the Timaeus, even though it must have been one of his most important philosophical source-texts. ${ }^{419}$ Since Galen's work on the Timaeus is relatively uncharted territory, some further introductory observations about the various editions of fragments and their relation to the Compendium and other sources are in order. Although the Timaeus must have been a profoundly important text for Galen and his writings on the Timaeus were crucial for the Arabic transmission, we now unfortunately have only scatters and testimonies, which can be found in various editions, later Arabic sources and a few small collections of scholia. Moreover, as we mentioned before, some of these scatters are contested, so it will be useful to first chart the sources we now have available. Following this survey of the sources (section 1), we shall proceed to a brief discussion of the scope of Galen's commentary, both in terms of his specific selection from the Timaeus, and in terms of its subject and status (section 2).

After these preliminaries, we shall discuss some general tendencies of Galen's Timaeus-interpretation (section 3), which we can then use for the subsequent comparative analysis of Larrain's fragments (section 4). This comparative analysis consists of four thematic subsections: (1) a discussion of the Aristotelianizing tendency of the author, (2) the somatisation of the soul, that is to say, the extent to which the soul is explained in terms of the elemental qualities, (3) the depiction of the soul as a dry and hot substance that exudes light, and (4) the role of the relation between substances and activities or movements in this reading of the Timaeus.

\section{Sources}

The most well known collection of fragments from Galen's commentary is that from the Paris manuscript BnF gr. 2383, first published by Daremberg in 1848, and republished in a new edition by Schröder in 1934. This collection presumably contains fragments from the third of Galen's four books only. Schröder republished the fragments collected by Daremberg with the addition of excerpts from the first and fourth book found in Al-Rhazi, Serapion and Maimonides, the Arabic excerpts translated into German by Kahle. These fragments have never been contested, as far as I know.

\footnotetext{
${ }^{418}$ Das (2013) 12-16, 16: 'These three texts [PHP, the commentary and the summary] constitute a period of Galen's career that is marked by sustained and varied engagement with the Timaeus.' See also Das and Koetschet (forthcoming)

${ }^{419}$ Vegetti (2000) devoted a chapter to this subject but does not take the commentary and compendium into account and focuses on PHP and QAM; Das (2013 and 2014) has made invaluable contributions to the study of both the commentary and Compendium as well as the subsequent Arabic reception.
} 
In addition, we have an edition of 34 possible excerpts published with a commentary by Carlos Larrain in 1992, under the title Galens Kommentar zu Platons Timaios. Larrain discovered these untitled and anonymous fragments in the $14^{\text {th }}$ century Escorial manuscript known under the name Scorialensis and has proposed that they are summaries of the first two books of Galen's commentary on the Timaeus. ${ }^{420}$ In his 1991 article on these fragments he suggested that they are 'ein zusammenfassendes Exzerpt aus den ersten beiden Büchern von Galens Timaioskommentar' ${ }^{421}$

Nickel's rejection of Larrain's view goes some way towards explaining the neglect subsequently his edition subsequently suffered, despite the potential importance of the material presented in it. ${ }^{422}$ Nickel argues that the fragments must be from an unknown author who has paraphrased several passages from original Galenic works, such as $P H P$ and $U P$, and that therefore the 'value of these texts for the study of Galen is very small.' ${ }^{\prime 23}$ A strongly formulated conclusion, perhaps deliberately chosen to counter Garofalo's earlier assessment in his review of Larrain's edition, which amounts to the exact opposite: 'La scoperta di Larrain di 34 nuovi estratti in un tardo manoscritto Scorialense gr. O III 11 (Revilla 230 del VI sec.) dunque del massimo interesse per gli studiosi di Galeno e del 'Timeo'.' 424

Nickel based his brief assessment on an analysis of only two of the thirty-four fragments (6 and 14). Fragment 6 is concerned with Platonists' responses to the question of how the communion of body and soul comes about (we shall discuss it below). Nickel states that 'The problem of ensoulment which is raised in this 'excerpt' did not interest Galen at all', but rightly adds that here the author might simply have been setting out the problem he sees with the Platonist position. This would indeed correspond to a rather common practice by Galen, i.e. setting out the possible (or actual) contemporary or earlier Platonists' answers to a problem related to their notion of soul, making their disagreement amongst themselves explicit, and pointing to the lack of clear answer in Plato's own text. ${ }^{425}$ Furthermore, it is not the case, as Nickel asserts, that this issue is raised nowhere else in Galen except for in

\footnotetext{
${ }^{420}$ Larrain (1992) 7 ff., 226; see also Larrain (1991)

${ }^{421}$ Larrain (1991) 10

${ }^{422}$ Before Nickel, Ferrari (1998, 16 note 8) has remarked that the differences between Larrain's fragments and those published by Schröder are so great that Larrain's attribution of them to the first two books is 'completely unfounded': '... a suo avviso, gli estratti deriverebbero dai primi due libri del Commento al Timeo di Galeno. In realtà, come mi riprometto di dimostrare in altra sede, si tratta di un'attribuzione del tutto infondata che non tiene conto delle notevoli differenze, sopratutto di natura formale, tra questi frammenti e quelli in nostro possesso derivati dal III libro del commentario galenico.' I know of no text in which Ferrari makes good on his promise, so are unable to assess his judgement; Flemming (2008) 349 note 21 follows Nickel in saying Larrain's edition 'does not add to our Galenic material'; Hankinson (2009) 150 note 20, regards some of Larrain's material as being 'of doubtful provenance'.

${ }^{423}$ Nickel (2002) 78

${ }^{424}$ Garofalo (1995)

${ }^{425} \mathrm{Cf}$. for instance $Q A M$ 38,9-18 Müller (IV $775 \mathrm{~K}$ ): 'For death takes place, according to Plato, when the soul is separated from the body. But why great voiding of blood, the drinking of hemlock, or a raging fever, causes this separation, I would have certainly have wanted to learn from him, if he were himself alive. But since he no longer is, and none of the Platonist teachers taught me any cause, on account of which the soul is compelled by those things that I have mentioned to be separated, I dare to state myself that not every form of body is suitable to receive the rational soul.' (tr. Singer)
} 
Prop. Plac., since the question of how a non-bodily soul could possibly acquire

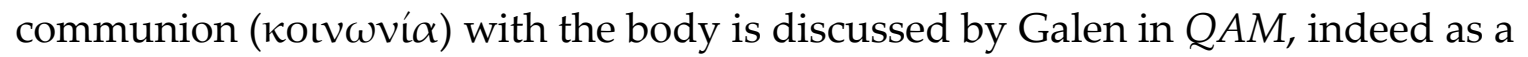
critique of the Platonist notion of an immaterial soul. ${ }^{426}$ Nickel's second argument for regarding Larrain's fragment 6 as inauthentic, i.e. not based upon Galen's actual Timaeus commentary, is the comparison made in the fragment between newborn babies and 'solidified cheeses'. In Nickel's opinion, the text of the fragment 'corresponds exactly with Galen's concepts and his style of expression' up until this comparison. He considers the comparison to be a 'deliberate imitation', since the metaphor would merely appear similar to the way Galen compares the constitution of babies to cheeses, while in truth it is used differently: 'while it does appear similarly expressed in genuine Galenic texts, [it] is used there to refer either to a different stage of development, or to specific component parts of the body.' However, Aileen Das, in her 're-evaluation' of the authenticity of these fragments published in 2014, has already shown that Nickel did not take into account some of these cheese-comparisons found in genuine Galenic texts and that the metaphor in Larrain's fragment 6 is 'entirely consistent with its application elsewhere in the Galenic corpus' ${ }^{427}$ Finally, Nickel proposes that the end of Larrain's fragment 6 presents the same material as a passage from Schröder's edition in a different manner, and concludes from this 'discrepancy in the mode of presentation' that the author of Larrain's fragment 'borrowed ideas from the work of Galen'. ${ }^{428}$ The two passages both state that man is composed of a mixture of opposing qualities and therefore loses part of his substance (fire burns up the substance or fire and air leave the substance), which is why the gods created another substance that could function as nourishment, making up for the continuous loss. However, Larrain's fragment 6 more specifically pertains to Tim. 43, while the passage in Schröder pertains to Tim. 76e-77c. In Larrain's fragment, the emphasis is on the introduction of innate heat, as a principle that orders and regulates. It is added to the stream of wetness that is considered to damage the rational soul, so that the rational soul can function properly as a balanced mixture of heat and wetness. The point of departure is the river-metaphor from the Timaeus, which the author presents as Plato's take on the communion of soul and body (for which we have a parallel in QAM IV $780 \mathrm{~K}$ ). The innate heat is presented as a contrasting force against the wetness that hinders rationality. As a consequence of the addition of the innate heat, however, as the

\footnotetext{
${ }^{426}$ QAM 48,20-5 Müller (IV $788 \mathrm{~K}$ ): 'Now, this point in itself casts great suspicion upon the question, whether the whole substance of the soul can really be non-bodily. For how could it be brought into the nature opposed to itself by communion with the body, if it is neither some quality of the body, nor a form, nor an affection, nor a

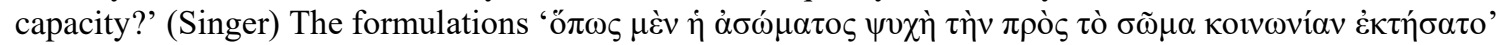

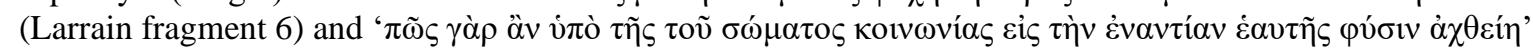
$(Q A M)$ seem rather close, and Nickel's assertion that Galen does not take an interest in this question anywhere else, seems to me too hastily made, especially considering that both passages are debating the Platonist notion of an immaterial soul.

${ }^{427}$ Das (2014) 4; Nickel gives De Sem.186,2-5 De Lacy (IV 632 K) and Temp. I 578-9 K; the additional parallels put forward by Das are: Praen. 114, II.8-9 ed. Nutton (1979); Hipp. Art. XVIIIA 597 K; Hipp. Off. Med. XVIIIb $842 \mathrm{~K}$

${ }^{428}$ Nickel (2002) 75-6; Larrain fr 6; Schröder book III fr II (p 11,4-9)
} 
author explains towards the end of the fragment, the body dissipates to some extent, which is why the gods have provided another substance to make up for this loss. In Schröder's fragment, relating much rather to $76 \mathrm{e}-77 \mathrm{c}$, the emphasis is more on this additional substance, which turns out to be that of the plants. As far as I can see, there is no contradiction between these two texts; rather, they seem to not only support each other, but also be in line with Galen's ideas in his attested work, as Nickel also observes. ${ }^{429}$ The 'discrepancy in the mode of presentation' might be explained as the consequence of these fragments pertaining to different parts of the Timaeus, instead of, as Nickel suggests, dealing with the same material. But, again, I think these two passages complement each other: because of the wetness the soul is hindered; this needs to be opposed by heat; because of the heat our substance dissipates; this dissipated substance needs to be replaced by another.

Nickel's discussion of Larrain's fragment 14, in turn, consists of a comparison of the fragment with parallels in PHP and UP. He argues that the fragment gives abbreviated and distorted versions of what is said there about the origin of the nerves. Certainly, Nickel is right about these parallels and also right in concluding that in Larrain's fragment we find, at least, less elaborated versions of the passages in PHP and UP. On the other hand, as Aileen Das has argued in her reply to Nickel, it is not 'uncharacteristic of Galen ... to reuse material from his own works' (this might even be somewhat of an understatement) and to rephrase more succinctly, and often with less clarity, what he has elsewhere worked out more elaborately. Das does not go into the particular distortions that Nickel observes, of which the ones relating to UP seem the most problematic to me (in PHP the differences observed by Nickel are slight changes in terminology amounting to less precise descriptions). However, here too, I think Nickel's account is debatable, and his comparison of the end of fragment 14 with UP VI 18 is open to criticism as well. For instance, in the UP-passage, in the context of a discussion of the origin of the nerves, Galen states that no nerves can be seen to branch from the heart itself, but that it can be observed that some thin nerves reach (from another source) the membrane around the heart. In large animals, he continues, these thin nerves can even be seen to go into the heart itself, i.e. through the membrane. However, Galen adds, it certainly remains impossible to observe them branching from the heart itself, i.e. having a common source in the heart and then getting divided into separate nerves, since in these larger animals they are still clearly separated when they go into the heart. ${ }^{430}$ The author of fragment 14 , on the

\footnotetext{
${ }^{429}$ Nickel refers to Foet. Form. 88,12-21 Nickel (V 684 K) and his note ad locum, which provides other parallels, particularly for the notion of the diminishing of our substance and subsequent need for nutrition.

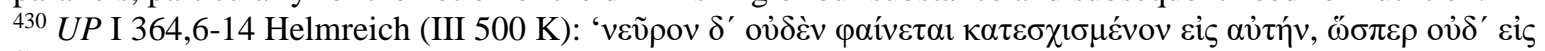

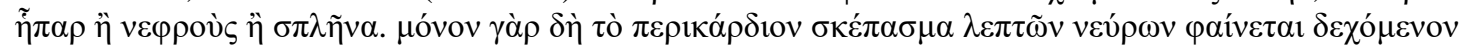

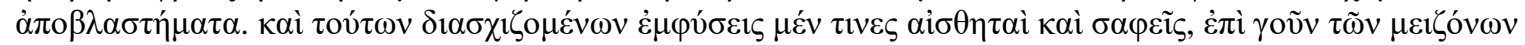

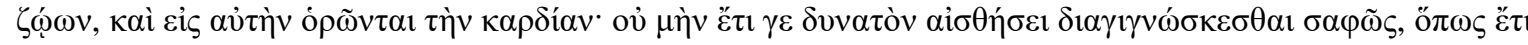

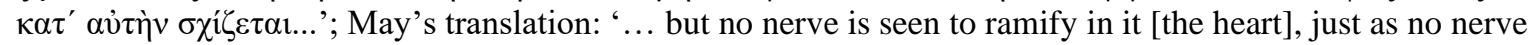
ramifies in the liver, kidneys, or spleen. Only its covering [membrane], the pericardium, is seen to receive branches of slender nerves, and when these ramify, there are to be seen some insertions even into the heart itself, perceptible and clear, at least in the larger animals. Certainly it is not possible to perceive by the senses how they branch in the heart...'
} 
other hand, remarks that these small nerves cannot even in the largest animals be seen to spring from the heart itself, presenting this as an argument against viewing the heart as source of the nerves. ${ }^{431}$ Nickel argues that this is a distortion of the text and proposes Larrain's fragment is a 'reversal' of what Galen says in UP, since Galen said there that the nerves can be seen to go into the heart in large animals (although, again, they cannot be seen branching from the heart). Once more, I think this might be too quick a conclusion, since it seems more reasonable to assume that the author of Larrain's fragment is presupposing the difference between observing that the the membrane around the heart receives the nerves and observing that these nerves cannot be seen to branch from the heart itself, and then simply remarks that even in the largest animals these nerves cannot be seen to stem from the heart itself (although they can be seen to go in it, from elsewhere), as an argument against the source of the nerves being in the heart. ${ }^{432}$ Again, I find the reading in which the two selected passages complement each other more plausible than the conclusion that one is a kind of deliberate but faulty imitation of the other. ${ }^{433}$

Having said this, I agree with Nickel that the text in Larrain's fragment 14 (and in some other fragments as well) is somewhat odd in places, and certainly less precise than the one in UP. In general, I think Larrain's fragments are more difficult to read and make sense of than most Galenic texts. In discussing Larrain's fragments, we shall encounter some of their textual oddities, which could in some cases cast doubt on their authenticity (as excerpts from Galen's commentary) as well. However, I agree with Aileen Das that Nickel's argument based on fragment 14 is not strong enough to ascribe the fragments to an imitator. There are many similarly odd passages in Galen's undisputed works as well, some of which have more precise parallels in other genuine works too. ${ }^{434}$

As mentioned before, the question of the heritage of these fragments took a new turn with the publication of an article by Aileen Das in 2014. She not only engages with Nickel's arguments, but also re-evaluates the matter in the light of the Arabic

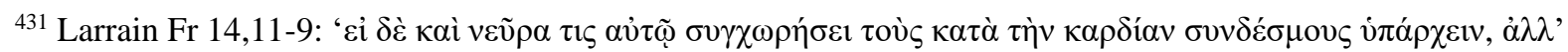

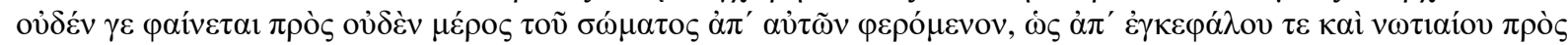

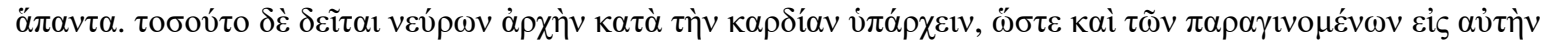

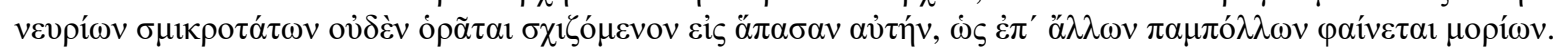

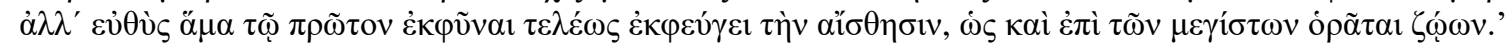

${ }^{432}$ Cf. Trompeter (2018) 188-90 on these two passages from UP and Larrain's fragment 14

${ }^{433}$ With regard to the fragments on the nerve-system and seat of the soul in general, namely Larrain's 13A and B, 14, 15 and 16: they could be part of a commentary on Tim. 44d (Fr 15 quotes from Tim. 44d), as Larrain observes (109 ff), since there Timaeus speaks of the head as the most divine part of the body, containing the imitation of the revolutions of the universe. It would make sense for Galen (or a Galenically-inclined other author) to use this passage to elaborate on one of his favourite subjects: the arguments for the tripartition of the soul and the leading part of the soul having its seat in the head, including the refutation of kardiocentric and Stoic views on the subject. It might also be, to follow Nickel's suggestion in a slightly different direction, that the author added parts from other works such as $P H P$ and $U P$ to his excerpts of Galen's actual commentary. But, once again, we do not need to resort to the assumption of several authors merely because Galen would otherwise be repeating his own work.

${ }^{434}$ An example is the passage from QAM that we discussed in Case-Study I (IV $774 \mathrm{~K}$; see infra, CS I section 1, 27-35), where Galen simply stated that the soul as form of the body should be located at the level of the homoeomerous bodies because 'the activities primarily belong there'. Within the direct context of $Q A M$ itself this does not make any sense and is left completely unexplained.
} 
tradition, which was not taken into account in Nickel's much briefer analysis. Das found that an Arabic translation of Galen's Timaeus commentary had been current as early as the $9^{\text {th }}$ century, and included both the fragments published by Schröder and Larrain together. She has shown that Larrain's fragments were likely a part of the Greek manuscript of Galen's commentary that was translated by Hunayn and others, and subsequently used by al-Rhazi, pseudo-Thabit and Maimonides. Her analysis is supported by and building on that of Arnzen (2012), who seems to presuppose the authenticity of the Larrain fragments, but was perhaps unaware of the controversy, since he does not refer to Nickel's article. Arnzen also gives a brief comparative analysis of Galen's Compendium and the fragments of both Schröder and Larrain, from which it appears that the Compendium and the commentary fragments contain some overlapping and similar passages, and that deletions or omissions occurring in the commentary correspond to those in the Compendium. I think all of this shows that Nickel's conclusions have been too rash. However, we still cannot be sure about the authenticity of Larrain's fragments, i.e. we still cannot be certain whether they are excerpts or paraphrased summaries of Galen's actual Timaeus commentary, as Larrain proposed. It is also noteworthy that in the $14^{\text {th }}$ century manuscript Larrain found, each of the fragments are marked with an obelus at their beginning. Larrain merely notes this fact in his introduction, without going into it any further. ${ }^{435}$ Presumably, the author of this manuscript indicated that he considered the complete text to be either not original or damaged.436 Then again, I do not know which of these options is meant, nor on what basis, nor how to assess the judgement of the responsible scribe. Larrain is certain that the writer of his manuscript was one Neophytos Prodromenos, a $14^{\text {th }}$ century monk and physician with an interest in the medical tradition, working in the monastery of Ioannes Prodromenos in Constantinople. ${ }^{437}$

It seems possible, though rather unlikely, that these fragments were interpolated into the Greek manuscript of the genuine commentary by an unknown pseudo-Galen, probably familiar with his Compendium, before they reached Hunayn. In the conclusion of her 2014 article, Das notes: '... the evidence presented above indicates that the fragments in Scorialensis graec. $\Phi$-III-11 circulated, at least by the ninthcentury, with the 'genuine' text of Galen's Timaeus commentary. On this basis, they have as good a claim to Galen's authorship as any of the other Greek fragments, whose provenance is widely accepted.' ${ }^{\prime 38}$ As we shall see below, there are a few other textual indications that may suggest that the author of these fragments wrote in a slightly later time period than Galen. That does not rule out the possibility of them being summaries of parts of Galen's authentic commentary, however, that as such may have found their way into the manuscript of the rest of his commentary early

\footnotetext{
${ }^{435}$ Cf. Larrain (1992) 12: 'Das Exzerpt ist in 35 Abschnitte untergliedert, deren Anfänge der Schreiber jeweils mit "† ǒ $\tau$ " markiert hat.'

${ }^{436}$ Larrain (1992) 12

${ }^{437}$ Larrain (1992) 226

${ }^{438}$ Das (2014) 11
} 
on. As long as we do not know the history of the transmission of these texts, it seems to me that we cannot determine with full certainty the extent to which they might be derived from Galen's actual commentary. Indeed, it seems to me that more research is needed on these fragments and that as things now stand, there is certainly not sufficient reason to discard them, with Nickel, as being 'of small value for the study of Galen' and leave it at that. Furthermore, even if it were proven beyond doubt that these fragments are not based on a lost part of Galen's commentary, they would still offer a valuable and interesting testimony of what is probably an ancient or at most late ancient form of 'Galenic Platonism', if we may call it that, and in particular, a Galenically inspired reading of the Timaeus.

Larrain, in his pioneering work with these fragments, might have been slightly overconfident in some of his conclusions and in some of the parallels he reports. This, perhaps, together with Nickel's article - which may have also stated its case in rather strong terms to counter Larrain's confident attitude and Garofalo's positive review - may have, unfortunately, condemned these fragments to near oblivion in scholarship. Future work on the Arabic reception in particular might still bring new insights as well. Meanwhile it is worth considering to what extent these fragments could be compared with Galen's treatment of the Timaeus in his genuine works, with a particular focus on the relation between body and soul.

Before we can do this, we should have a closer look at the relation between the Compendium and the commentary. Rashed has argued that the commentary is likely to have been written by Galen as a consequence of his epitomizing activity. ${ }^{439}$ As it appears from the medieval Arabic Liber Aneguemis, expertly analysed by Rashed, Galen found this particular part of the Timaeus to be in need of more than a descriptive summary given its exceptional value for the medical science. For this reason, and because it would benefit his intended audience, which supposedly required a more in-depth treatment, Galen would have decided not only to summarize the entire Platonic dialogue, but also to comment upon this particular section. The latter part of this reconstruction has come down to us, in the Liber Aneguemis, as a story about Galen's writings on Plato's Laws, but Rashed convincingly shows that it must have rather been the story of Galen's summary of and subsequent commentary on the Timaeus. ${ }^{40}$ This would imply that Galen initially simply summarized the Timaeus, and from there on, possibly with the further impetus of some of his friends' interest, decided to comment on part of it. ${ }^{441}$ I find Rashed's article convincing, but I do not agree with his suggestion that there would be anything enigmatic about Galen writing this kind of commentary on this specific section of the Timaeus, without an explanation of the kind he offers. ${ }^{442}$ Galen wrote so

\footnotetext{
${ }^{439}$ Rashed (2010)

${ }^{440}$ Das and Koetschet (forthcoming) in their new translation of the Compendium, have included this text as its preface

${ }^{441}$ Cf. Rashed (2010) 89; Ferrari (1998) 14-34.

${ }^{442}$ Rashed (2010) 89: 'Mais il pouvait se contenter d'une monographie pour établir ce point historique, qui ne lui aurait pas demandé de se confronter à chaque détail philologique d'un texte redoutable. Il n'est pas sûr que nous puissions un jour résoudre cette énigme.'
} 
many commentaries on so many different authors (Aristotle, Theophrastus, Eudemus, Chrysippus, Hippocrates, Erasistratus, Asclepiades of Bithynia etc.), including many commentaries on specific subjects within certain works or authors as well as commentaries that quote the commentated text, that it makes much more sense to me to consider this a common practice of his, rather than to look into particular reasons he might have had to write a commentary on a section of one his favourite works by one of his favourite authors. ${ }^{443}$ Besides, he used passages from this specific part of the Timaeus in other works as well, some of which are dated before the commentary, which indicates that he was already working with these parts of the Timaeus in any case. Finally, Galen frequently remarks that he wrote a certain work merely to gratify the needs of some friend or protégé. But it seems to me rather uncertain to what extent this is a rhetorical strategy to present himself in a certain manner (the modest figure that merely responds to the requests of others seeking to learn from him, rather than someone that is eager to produce writings and show off his knowledge) and to what extent such remarks refer to actual historical fact. ${ }^{444}$ That is to say, I think Rashed provides a convincing and sophisticated answer to a question that does not really need to be a question in the first place. This might simply be due to his point of departure, namely, asking the question 'why would Galen write a commentary on a part of the Timaeus?' and finding the answer in a kind of synthesis of the previous work on the matter. ${ }^{445}$ In any case, whatever the specific relation between the Compendium and the commentary, I think it makes complete sense from Galen's perspective on Plato, to engage intensively with the Timaeus, and particularly with this specific part of it. ${ }^{46}$ I hope this will become clearer when we look at Galen's use of the Timaeus in other works, below.

Das and Koetschet, in their important recent study of Galen's Compendium, conclude that it served not as a mere summary, but rather as an 'isagogic or mnemotechnical text' that was to prepare its reader for Galen's 'more detailed exegeses (such as his commentary)'. Such a practice which would find a parallel in that of contemporary Platonists, such as in the case of Alcinous' Didaskalikos. ${ }^{447}$ Indeed, in some concrete respects, the Compendium prepares the ground for a more elaborate Galenic interpretation of the Timaeus, as we shall see below.

\footnotetext{
${ }^{443}$ An astounding number of such commentaries can be found listed in Galen's On my own books.

${ }^{444}$ Cf. König (2009) 44; Das (2013) 3 f.

${ }^{445}$ Ferrari (1998) argues that the commentary came about in the context of a tradition of private (teacher and friends/disciples) discussion of texts of interest, and emphasizes the importance of the interests of Galen's friends, the first intended readership, as an impetus for the work to come about. Vegetti (2000) wrote on Galen's general approach to the Timaeus, and will be discussed below. Rashed (2010), 89: 'Quel était alors le but d'une telle entreprise? Deux réponses ont été proposées. Selon Franco Ferrari, Galien voudrait simplement rendre

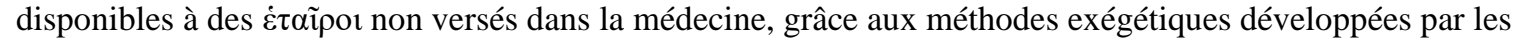
platoniciens des siècles précédents, les considérations médicales de Platon. Selon Mario Vegetti, il s'agirait aussi - et même surtout - de retrouver dans le Timée les précédents de la théorie (galénique) de trois âmes liées à trois organes essentiels du corps (cerveau, cœur, foie).'

${ }^{446}$ I think the same idea comes to the fore clearly in Vegetti's chapter (2000), although he focuses on PHP and $Q A M$ and leaves the commentary and summary out of his discussion.

${ }^{447}$ Das and Koetschet (forthcoming)
} 
Besides the Compendium, the commentary fragments collected by Schröder and the possible excerpts published by Larrain, we also have some fragments found in Galenic scholia by Moraux and by Lorusso. ${ }^{448}$ Paul Moraux has found two fragments among scholia to Hipp. Elem., which he published in the Zeitschrift für Papyrologie und Epigraphik (1977). The first corresponds exactly to the citation found by Daremberg in Paris. Gr. 2147 and included by Schröder as the start of the first book. ${ }^{449}$ It states that, in his commentary, Galen said that the demiurge shaped man out of the elements ${ }^{450}$ and must certainly pertain to Tim. 42e-43a, the place where both Schröder and Larrain thought Galen began his commentary (see below, on the scope of the commentary). In the second, we find a discussion on the elements being one or many in nature (Galen there equates Plato's i $\delta \varepsilon \dot{\alpha} \alpha$ with $\varphi v ́ \sigma ı \varsigma)$, in which Galen states that the elements are many (four) and proceeds to explain Plato's notion of the constitution of the elements in terms of geometrical shapes. ${ }^{451}$ It is reminiscent of the discussion in Hipp. Elem. and HNH on the elements being many not merely in number, but in form. ${ }^{452}$ The latter part of this passage can also be paralleled with $P H P$ book 8, where Galen argues that Hippocrates and Plato fundamentally agreed that the elements generate our body, but that Plato also proceeded to inquire what the cause of the generation of the elements themselves was, and therefore came up with the geometrical shapes, a subject purposely neglected by Hippocrates, since he was pursuing a practical rather than a theoretical science. ${ }^{453}$ These comments are lacking in Schröder and Larrain and must pertain to Tim. $54 \mathrm{D}$ and further, which means that, according to the proposed ordering of Schröder and Larrain (see below), they must have belonged to either the first or the second book. ${ }^{454}$ Moraux's finds can also be taken to affirm that there is overlap between the commentary and Galen's other writings on the Timaeus, for example the last books of PHP (which in turn again problematizes Nickel's conclusion that Larrain's fragments must be from an author imitating Galen's PHP and other works).

In addition, Vito Lorusso has discovered two new fragments in scholia to The Therapeutic Method. These fragments were also published in the Zeitschrift für Papyrologie und Epigraphik (2005), along with an Italian translation. The first is about vision and must pertain, according to Lorusso, to Tim. 45b-d. Lorusso also remarks that this fragment shows resemblance to Larrain's fragment 22 (on the same passage), particularly in its dependency on Aristotelian theory of vision. ${ }^{455}$ The

\footnotetext{
${ }^{448}$ Moraux (1977); Lorusso (2005)

${ }^{449}$ Cf. Daremberg (1848) 36; Schröder (1934) 1, note 2; Moraux (1977) considers Daremberg's Paris. gr. 2147 'ohne Zweifel eine Abschrift von $Y$ ', Y being Yalensis 234, from which his fragment is derived.

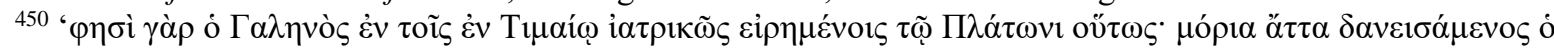

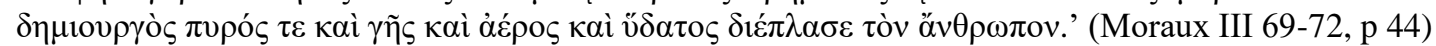

${ }^{451}$ Moraux (1977) III 212-227 p 49-50

${ }^{452}$ See infra, CS II section 2, 108-9 and section 4, 125-8

${ }^{453}$ PHP VIII, 494,26 ff. De Lacy

${ }^{454}$ Larrain relates this second fragment found by Moraux to his own fragment 2 (see below)

455 Lorusso (2005) 47: 'La dipendenza di Galeno dalla teoria aristotelica della visione è presupposta, del resto,

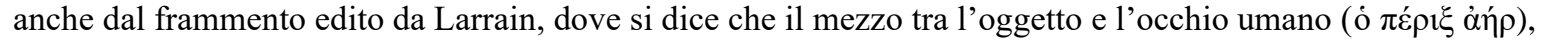

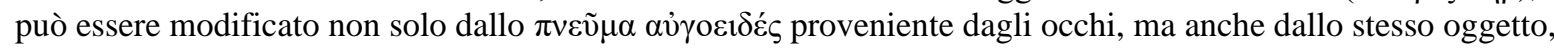


second fragment discusses the theory of the formation of the colour red, and is related by Lorusso to Tim. 67c-68d, a passage lacking in both Schröder's and Larrain's editions.

\section{Scope of the commentary}

As we have noticed, the title of his commentary (On the Medical Statements in Plato's Timaeus) seems to imply that Galen, perhaps unsurprisingly, was primarily interested in the content that he considered pertinent to the medical science. However, as is well known, Galen's notion of what is relevant to the medical science is quite broad - just think of his famous dictum that doctors need to be trained in philosophy in order to appropriately practice their art. ${ }^{456}$ Furthermore, we have also noticed that Galen thinks it typical of Plato to ask for the underlying causes that actually fall outside of the normal scope of the science of medicine, which might indicate that we could expect some of Galen's commentary to cross this boundary as well, if only as a discussion and interpretation of what Plato says. ${ }^{457}$ Aileen Das points out another good indication for this: Galen does not include his commentary on the Timaeus in the list of books that the doctor should read in On the Order of My Own Books, and what is more, in On My Own Books he classifies it not among his medical works but among those that pertain to Platonic philosophy. Das has shown that Galen included in his commentary material that had 'no clear application to medical practice or theory' but that was rather 'related to broader debates about the nature of the soul' and also that in his discussion of this material Galen 'draws on his own scientific or medical theories' ${ }^{458}$ In this sense, we could expect the commentary to show some overlap not with specifically medical works, but much rather with the more philosophical works on the soul in which Galen draws on the Timaeus as well, i.e. particularly $P H P$ and $Q A M$.

Finally, we learn from Mixtures (Temp.), HNH, Hipp. Elem. and other works of Galen, that medicine for largely consists of balancing nature. That is to say, it requires an understanding of the state of a particular individual in terms of the underlying principles behind generation and decay that rule nature in general. ${ }^{459}$ Therefore, the science of medicine cannot be mastered without some knowledge of the nature of man, and with that - since man is made of the same elements as everything else -

qualora la distanza che lo separa dall'osservatore non sia molto grande.' Cf. Ierodiakonou (2014) on Galen's theory of vision and its relation to various predecessors including Aristotle.

${ }^{456}$ Opt Med I $53 \mathrm{~K}$

${ }^{457}$ See infra $141-2$

${ }^{458}$ Das (2013) 37-9, all of this applies to the Greek fragments published by Schröder

${ }^{459}$ Cf. e.g., Temp. I 509-19 K, esp. 519: 'Nor can the healthy regime be discovered otherwise than by reference to this well-balanced state of nature; for the aim is to cool any body which is hotter than it should be, to heat any which is colder, and similarly to dry any which is wetter and moisten any which is drier. In each case the attempt is to remedy an excess by the introduction of what is missing, in order to bring about a state which may be described as well-balanced or median.' (tr. Singer) 
some knowledge of natural philosophy. ${ }^{460}$ If your doctor does not understand that your body-parts are made out of a mixture of the four elemental qualities, but rather thinks there are atoms underlying them, he will not be able to rationally infer the right cure based on the symptoms of your disease.

Despite all of Galen's remarks on not knowing the answers to speculative philosophical questions, he does fundamentally assume that the success of medical science is dependent upon adequate knowledge of human nature. ${ }^{461}$ It is useful to keep in mind this broad Galenic notion of the science of medicine and its relation to natural philosophy when studying his interaction with Plato's Timaeus. On the other hand, it is equally useful to keep in mind that Galen rather consistently makes a distinction between knowledge, in the sense of something that is or can be scientifically proved, and questions on which we can only find plausible or likely answers. ${ }^{462}$ This distinction is particularly relevant in the context of his reading of the Timaeus and some of the subjects discussed there, as Galen himself remarks in PHP IX:

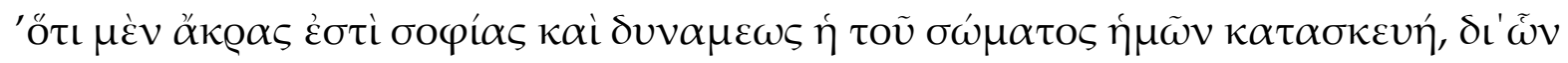

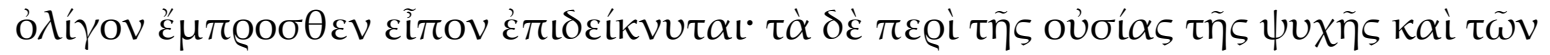

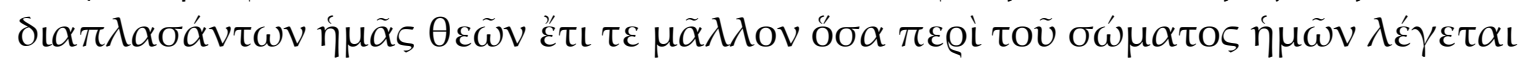

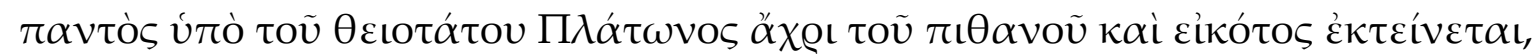

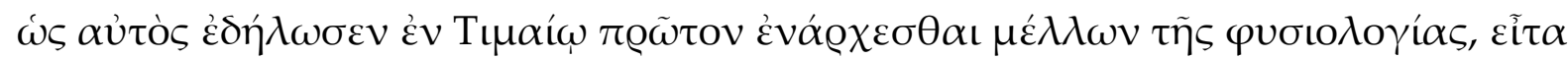

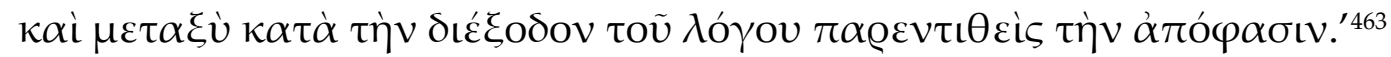

'My earlier remarks make it clear that the fashioning of our bodies is a work of the highest wisdom and power; but the statements of the most divine Plato about the substance of the soul and of the gods who formed us, and still more all that he says about our whole body, extend only to the point of being plausible and reasonable, as he himself pointed out in the Timaeus when first he was about to enter upon an account of the natural world, and again when he inserted the statement in the middle of the account.' (tr. De Lacy)

Galen gladly emphasizes that Plato made sure to repeatedly state the epistemological status of Timaeus' discourse and also states that, because of its status as merely plausible, Plato had Timaeus deliver it, rather than Socrates himself. ${ }^{464}$ We also find

\footnotetext{
${ }^{460}$ This is not a view entirely peculiar to Galen, cf. Longrigg (1993) 2-3 with reference to Aristotle's On Breath $480 \mathrm{~b} 24 \mathrm{ff}$. and Sense and Sensibilia $436 \mathrm{a} 8 \mathrm{ff}$.

${ }^{461}$ With emphasis on 'science'; there could be success in the sense of some kind of art of medicine completely based on empirical observation of symptoms, without knowledge of the human being (see Outline of Empiricism. 45 Frede and Walzer, 1985), but this is obviously not the art of medicine that Galen considers himself the advocate of, and not even in the strict sense a science as he sees it.

${ }^{462}$ See infra, CS I section 3, 66-71. Cf. Frede (2003) 77: 'So Galen does distinguish between definitive answers, backed up by conclusive proof, and answers which, though not supported by proof, are supported by reasonable argument and are not ruled out by considerations to the contrary. Galen allows himself such plausible views, but is hesitant to express them.' See also Chiaradonna (2009) $245 \mathrm{f}$.; Tieleman (2018); DeLacy, in his commentary on $P H P(98,12 ;$ p 623), lists instances in which Galen opposes plausibility and truth.

${ }^{463}$ PHP IX, 598,5-11 De Lacy (V 791-2 K); Cf. Vegetti (2000) 73-4 on this passage.

${ }^{464}$ PHP IX, 588,29-591,2 De Lacy (V 781-2 K); cf. Tim. 29c-d, 48d
} 
this notion in Larrain's fragment 17, though with more emphasis on difference in style. There, the author suggests that the poetical and elevated style of speculative cosmology better befits sophists than Socrates. ${ }^{465}$

In any case, the emphasis on the tentative nature of Timaeus' cosmology does not mean in the least that the discourse is uninteresting to Galen, or not worth extensive exegesis. Therefore, we should also not be surprised to see him make statements in his commentary about things that fall under the header of speculation, as long as we keep in mind that these statements should not be read as propositions that fall under the header of scientific knowledge. We can also see from this passage that Galen uses his qualification of what is 'plausible' ( $\pi \iota \theta \alpha v$ ó $)$ in different ways. The first subjects he mentions, the substance of the soul and the gods that made us, seem to be outside the scope of scientific knowledge altogether, whereas our bodies, clearly, are not. That Galen includes Plato's remarks on the body in this list of what is merely 'plausible', does not mean that the subject is outside the scope of scientific knowledge altogether, but that whatever Plato said about it in his Timaeus does not qualify as scientific knowledge and can thus be improved in favour of a different account that is perhaps more plausible or not merely 'plausible'.

This concludes the preliminary remarks about the scope of Galen's commentary in the sense of the subject-matter.

With respect to the actual part of Plato's text that Galen commented upon: both Larrain and Schröder (following Daremberg) propose a linking of their fragments to specific passages in Plato's Timaeus (for the Greek fragments in Schröder the lemmata were part of the transmission). Larrain has 42e8-46c6 (attributed to the first book of Galen's commentary) for his Fr 1-27, and 64a2-65a1 for his Fr 28-34 (attributed to the second book of Galen's commentary). Schröder has 42e8-46a2 (first book) and 59e566d 2 and 72e3-6 (second book) for the excerpts from Maimonides and Rhazi, 76d3$81 \mathrm{a} 2$ for his nineteen Greek fragments (book 3), and finally 84e2-91c7 for excerpts from Maimonides and Rhazi thought to belong to book 4.

Both Schröder and Larrain assume Galen started his commentary at Tim. 42e. If they are right, this would indeed make sense in terms of the title. That is, this part of the Timaeus is relevant to medical science in the broad Galenic sense, since it is where the nature of the human body comes into the picture. It would mean that Galen avoided commenting on the parts of Timaeus' story that would be particularly uninteresting or unsuitable for his purposes, leaving out not only the introduction, narrative setting and the story of Atlantis ${ }^{466}$, but also, more significantly, the beginning of Timaeus' speech containing: the creation of the gods, the address of the demiurge to the created gods in which they are ordained to create the three other kinds of beings, the making of the immortal part of the soul by the demiurge and the description of the process and hierarchy of reincarnation. And, in fact, these are all subjects that Galen generally seems to have limited use for. Even if the title of his commentary

${ }^{465}$ Cf. Larrain fr 17 and commentary 123-32; also Comp. Tim. I 11-16 p 34 Kraus-Walzer

${ }^{466}$ These topics are also left out almost entirely in Galen's Compendium, see Kraus-Walzer 33-5. Cf. Arnzen (2012) 215-20 
were different, what would we imagine him to comment on these passages? These subjects all involve some notion of the divine maker or the immortal soul he gave us, beings that cannot be sufficiently explained in Galenic terms, since they are essentially non-bodily. They belong to the category of subjects that Galen lists in PHP IX, as not susceptible to scientific demonstration. ${ }^{467}$ Besides, even if Galen were to interpret these passages as descriptions of what is likely or plausible as opposed to true, and simply discuss them as such, they would still evidently harm the continuity he insists upon between him and Plato. Since Plato took these subjects into a direction that Galen has no use for, there is no reason for Galen to include them in his commentary. 468

It is tempting to think that Galen started his commentary around the place where the body is introduced and the relation between body and soul becomes the subject at hand (42e). However, there is a relevant passage in Al-Biruni's Tahqiq ma li-l-Hind or India, which is a quotation from Galen's commentary according to Larrain, Arnzen and Das, and which reports on subjects that are definitely part of the immediately preceding passage in the Timaeus from $41 \mathrm{a} 6$ onwards. ${ }^{469}$ This passage was apparently unknown to Schröder, which explains why he assumed the commentary to start further on in the text. Larrain, however, knew of Al-Biruni's citation, but proposed that Galen merely wrote about these subjects as an explanation to go with the actual start of the commentary in 42e6, where it is about 'the children', i.e. the gods as children of the demiurge. Larrain's suggestion does not seem implausible to me, and I agree that it would be odd for Galen to start his commentary 'On the Medical Statements in Plato's Timaeus' with the demiurge speaking to the newly created gods about the immortal soul of man. It also makes sense that, given where he starts according to Larrain and Schröder, he would have to provide a short explanation to explain the term 'children' in terms of the foregoing, especially considering that he was citing the passages he commented upon from the Timaeus. Furthermore, the passage starting at $42 \mathrm{e}$, particularly the river-metaphor that is introduced to describe the state of the soul after its incarnation, is a passage for which Galen must have had a particular liking, since he comments upon it extensively in $Q A M$ as well. ${ }^{470}$ Although we cannot be sure whether Galen started commenting at $41 \mathrm{a} 6$ or $42 \mathrm{e} 6$, it seems reasonable enough to assume that it was around the introduction of the creation of the human body. With regard to the end of his commentary, we have testimonies from Rhazi that pertain to Tim. 91b-c (included in Schröder's edition), so it seems likely that Galen simply commented up until the end of the Timaeus (which perhaps makes it all the more pertinent that he skipped a large part of the beginning).

\footnotetext{
${ }^{467}$ PHP IX 588,7 ff. DeLacy (V $780 \mathrm{~K}$ )

${ }^{468}$ Cf. Baltussen (2003), who concludes that there was a 'trend' of 'partial use'of the Timaeus, before 'in the second to fifth century AD the Platonists came to write continuous and full-blown commentaries on the Timaeus'; he names Posidonius, Alcinuos and Galen, and for Galen refers to Larrain's fragments (69-70). ${ }^{469}$ Larrain (1992) 10-11; Arnzen (2012) 222-7; Das (2013) 10

${ }^{470}$ QAM 42-3 Müller (780-2 K)
} 


\section{Basic tendencies in Galen's interpretation of the Timaeus}

The river metaphor Plato introduces in Tim. 43a to describe the chaotic kinetics of the body by which the soul becomes disturbed, must have made a strong impression on Galen. He brings it up in QAM as well, using this metaphor to fit Plato closer into his notion of the nature of man as a specific mixture of the elemental qualities, in which, as we shall see, wetness in particular comes to take over the role that the body as a whole plays in Platonic cosmology. ${ }^{41}$ Even in the Compendium, which generally remains relatively faithful to Plato's text (although it is highly selective in the attention attributed to specific aspects), Galen distorts this metaphor so as to make it reflect his own doctrines. In Timaeus 43a, Plato describes how the gods made our bodies out of the elements and then bound the revolutions of the immortal soul into them, resulting in a perversion of the soul's movement:

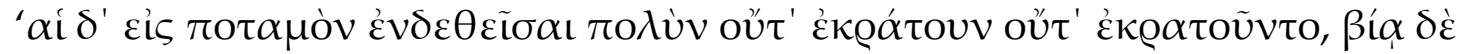

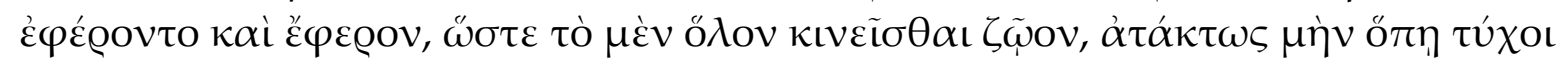

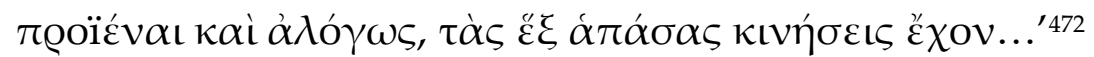

'These orbits, then, now bound within a mighty river, neither mastered that river nor were mastered by it, but tossed it violently and were violently tossed by it.

Consequently the living thing as a whole did indeed move, but it would proceed in a disorderly, random and irrational way that involved all six of the motions.' (tr. Zeyl)

Plato here describes the chaos that results when the proper movements of the soul are brought into contact with the elements through the body. He depicts the overwhelming multitude of impressions befalling the soul with the metaphor of being dragged along in a river. This causes the soul to become devoid of understanding:

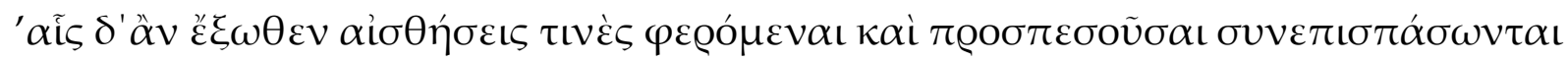

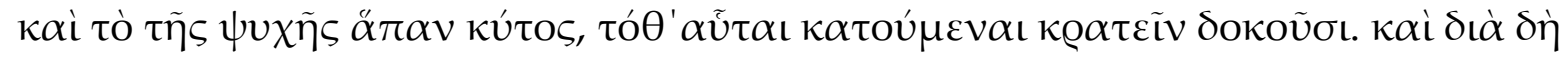

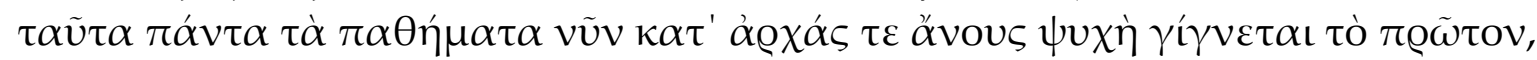

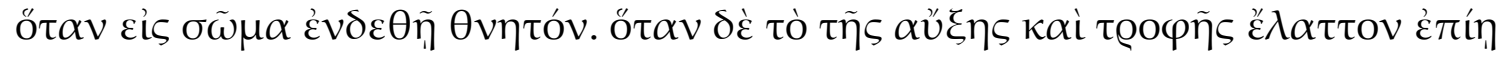

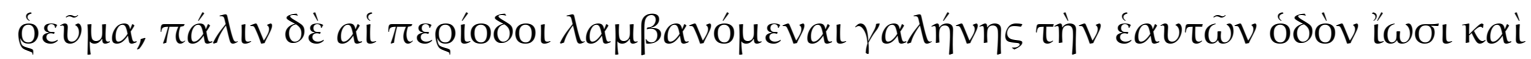

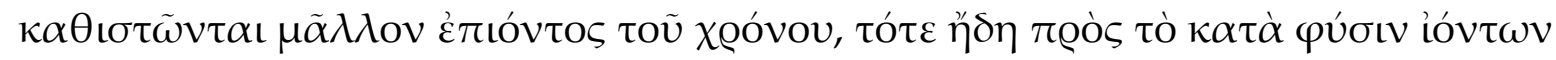

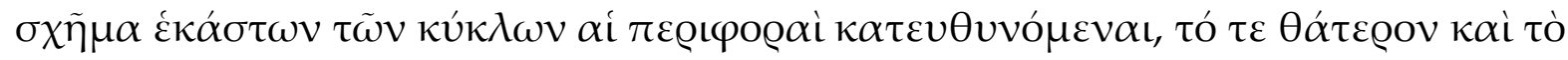

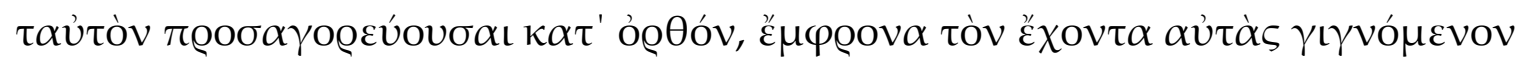

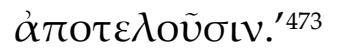

'And so when certain sensations come in from outside and attack them, they sweep the soul's entire vessel along with them. It is then that these revolutions, however

\footnotetext{
${ }^{471}$ Jouanna (2009a) 198: 'For Galen's reading of the Timaeus, the key point is that the excess of humidity in the body disturbs both intelligence and memory.'

${ }^{472}$ Tim. 43a6-b2 ed. Burnet

${ }^{473}$ Tim. 44a5-b7 ed. Burnet
} 
much in control they seem to be, are actually under their control. All these disturbances are no doubt the reason why even today and not only at the beginning, whenever a soul is bound within a mortal body, it at first lacks intelligence. But as the stream that brings growth and nourishment diminishes and the soul's orbits regain their composure, resume their proper courses and establish themselves more and more with the passage of time, their revolutions are set straight, to conform to the configuration each of the circles takes in its natural course. They then correctly identify what is the same and what is different, and render intelligent the person who possess them.' (tr. Zeyl)

Over time, when the bodily affections are less intense and more under control, the soul can stabilize in the body and regain its intelligence. Timaeus also stresses that education plays an important role here: the right educational training can reinforce this positive development of the soul. Conversely, a lack of such training could lead one to remain unaccomplished and devoid of understanding until the very end of

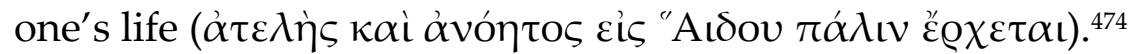

In his summary of this passage, however, Galen takes Plato's metaphor of the river rather literally, namely, in terms of an abundance of moistness. He even states that according to Timaeus the cause for the return of intellect is dryness:

'After this, he [sc. Plato] describes the things that happen to the soul necessarily because of its connection to the body: its mind is without intellect at the beginning of its connection with it [the body] and [this is] why intellect arises second to it after this. Then, He made the cause of the first state an abundance of moisture and the cause of the second state dryness.' 475

According to Galen's summary, the lack of intellect in the newborn is caused by an abundance of fluid or moisture: the cause of the ignorance of the newborn is not the binding to the bodily elements as such, but rather the abundance of one specific element or rather elemental quality, namely that of wetness. In Plato's text, the metaphor of the river clearly referred to all four elements and the incarnation of soul as such, rather than to water or wetness particularly:

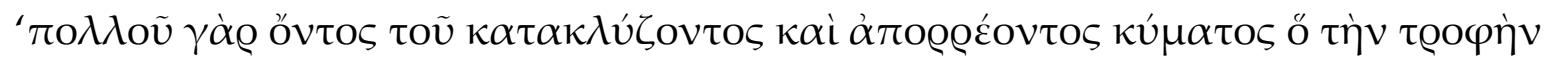

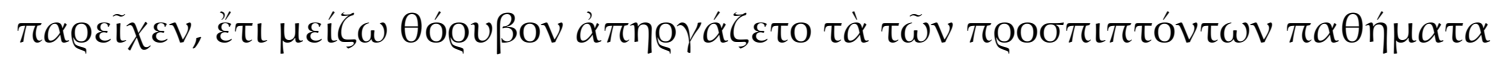

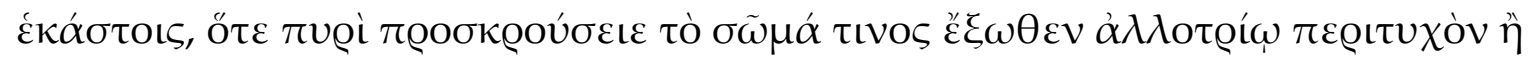

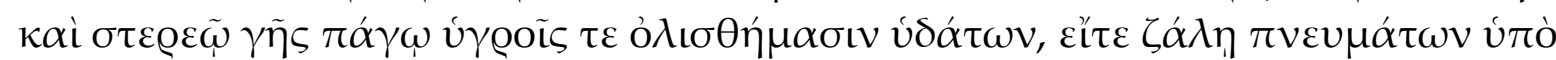

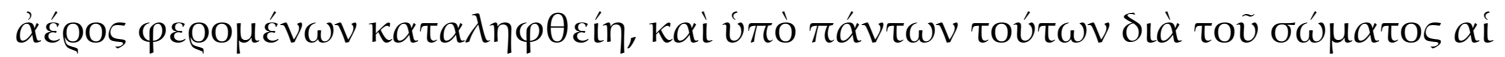

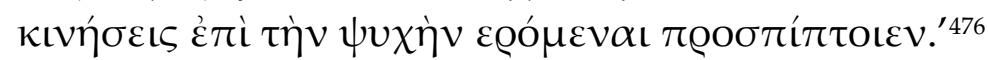

\footnotetext{
${ }^{474}$ Tim. $44 \mathrm{~b} 8$ f. ed. Burnet

${ }^{475}$ Das and Koetschet (forthcoming) paragraph 7

${ }^{476}$ Tim. 43b5-c5 ed. Burnet
} 
'For mighty as the nourishment-bearing billow was in its ebb and flow, mightier still was the turbulence produced by the disturbances caused by the things that struck against the living things. Such disturbances would occur when the body encountered and collided with external fire (i.e., fire other than the body's own) or for that matter with a hard lump of earth or with the flow of gliding waters, or when it was caught up by a surge of air-driven winds. The motions produced by all these encounters would then be conducted through the body to the soul, and strike against it.' (tr. Zeyl)

Galen here makes a crucial interpretative step - one that is rather remarkable in the context of this summary, which generally stays close to Plato's text and does not stand out for interpretative originality. Perhaps this indicates that this is truly how Galen reads the Timaeus, rather than it being a deliberate manipulation to fit his own agenda. Or perhaps it indicates that this is indeed such a crucial matter for him that he does not even want to leave it out in this generally more neutral summary. ${ }^{477}$ The next step, making dryness the cause for the coming to be of understanding, simply follows from the first step of making an abundance of wetness the cause of the lack of understanding. The notion that dryness or the decrease of the initial wetness of the newborn is the cause of understanding is completely absent from the text Galen is summarizing, and must be understood, I propose, as a way to rewrite the Platonic soul-body dynamics in terms of Galenic mixture and the predomination of specific qualities within it. As we have been able to gather from our previous two casestudies, this interpretation is in line with Galen's approach in $Q A M$ and $H N H$, where the nature of the soul and the nature of man respectively were understood in terms of the mixture of the elemental qualities. ${ }^{478}$ Indeed, we find the exact same interpretative movement in $Q A M$, where Galen uses the same passage from the Timaeus:

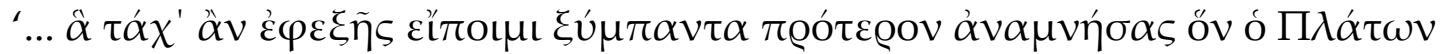

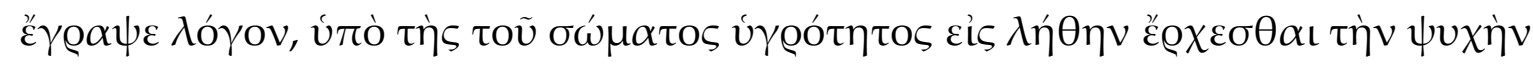

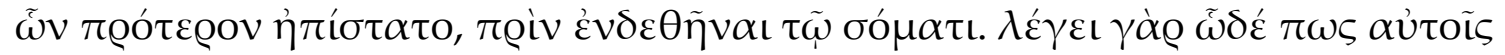

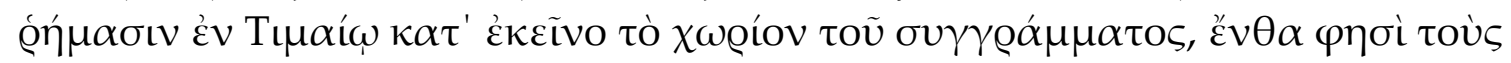

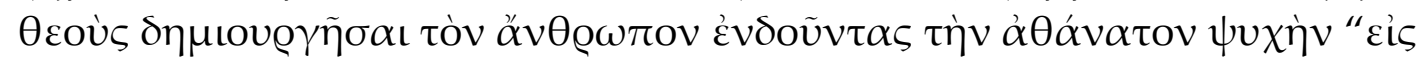

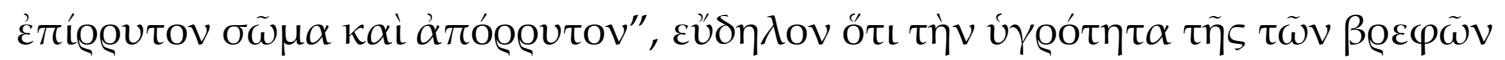

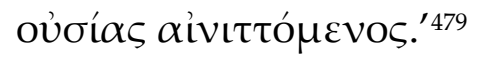

'Perhaps I should discuss these all next - after first giving a reminder of that statement of Plato's, that as a result of the wetness of the body the soul reaches a state of forgetfulness of what it knew before being bound into the body. For this basically is what he says - in these very words - in the Timaeus, in that part of the

\footnotetext{
${ }^{477}$ Again, see Jouanna (2009a) 198: 'For Galen's reading of the Timaeus, the key point is that the excess of humidity in the body disturbs both intelligence and memory.'

${ }^{478}$ See infra, CS I and II, 90-1 and 137-8 for the conclusions

${ }^{479}$ QAM 42,8-17 Müller (IV $780 \mathrm{~K}$ )
} 
work in which he states that the gods craft the human being by placing the immortal soul 'in a body replete with ebb and flow'. It is quite evident that this is an oblique reference to the wetness of the substance of infants.' (tr. Singer)

It is 'quite evident', according to Galen, that Plato here intended to refer to the relative wetness of the substance of newborns, but merely expressed it in a veiled or

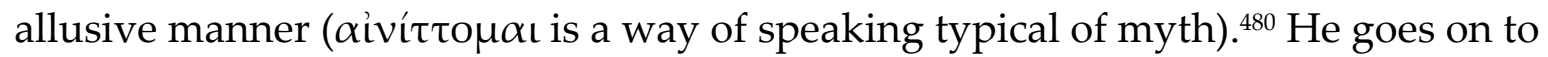
unambiguously state that this wetness is the cause of 'mindlessness in the soul' ( $\tau \tilde{\eta} \varsigma$

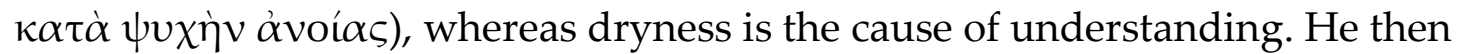
remarks that a body that does not have any share of wetness would be extremely intelligent, as the bodies of the stars are. The stars, of course, are associated with the rational soul already in the Timaeus, and Galen also refers to Heraclitus' aphorism comparing the dry soul to a 'ray of light'. ${ }^{481}$ There will be much more to say about all of this, but we will come back to Galen's peculiar use of this metaphor from the Timaeus when we discuss fragment 6 from Larrain's edition below. For now, let this be a preliminary illustration of what is exceptional about Galen's use of the Timaeus: he seems to come closer to a consistent somatisation of the soul (i.e. explaining soul and its functions in terms of bodily mixtures), including its rational part, than he does in other contexts. ${ }^{482}$ What happens in this passage in QAM, in the Compendium and some of the fragments from the commentary (in particular the ones that supposedly pertain to the first book), is a recasting of the dualistic Platonic view of man consisting of body and soul into terms of the (opposing) elemental qualities. Wetness is related to forgetfulness, ignorance, destruction, disorder, inactivity, sleep etc., that is, everything caused by the linking with the body in Platonic myth and cosmology. Dryness, on the other hand, is related to thinking, wisdom, orderly (circular) movement etc., that is, everything related to the Platonic (rational) soul. This is one of the main reasons why these fragments from the first part of Galen's commentary are particularly interesting in the context of our case-study: they cast light on the extent to which it is possible, from a Galenic perspective, to account for functions that are traditionally considered psychic in terms of the elemental qualities. As we have noticed in Case-Study II, there is a tension throughout Galen's work between what one could call the explanatory power of mixture on the one hand, and the intelligence of nature implied by the observable design of its individual beings on the other hand. ${ }^{483}$ We have seen how this tension still comes to the fore strongly in a late work such as Foet. Form.:

\footnotetext{
${ }^{480}$ Cf. Stroumsa (2005) 11-26

${ }^{481}$ QAM 47,11-6 Müller (IV 786 K); Tim. 41d-42b; for Heraclitus see Kahn fr CIX

${ }^{482}$ Vegetti (2000) 72, with regard to Galen's general use of the Timaeus, speaks of 'manipulation' of the dialogue in a 'strictly material sense': ‘. .. egli si sente libero dalle costrizioni di scuola, il che gli consente, da un lato, un atteggiamento francamente critico la dove questo gli sembra necessario, dall'altro un uso spregiudicato del dialogo, fino alla manipolazione ma non al tradimento, in senso nettamente materialistico.'

483 See infra, CS II section 4, 117-24
} 


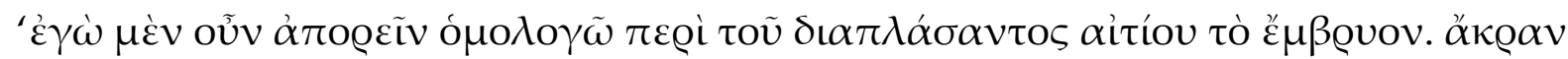

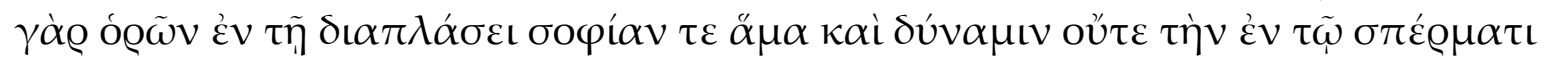

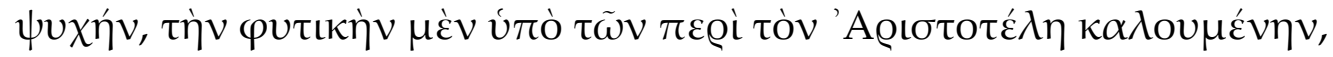

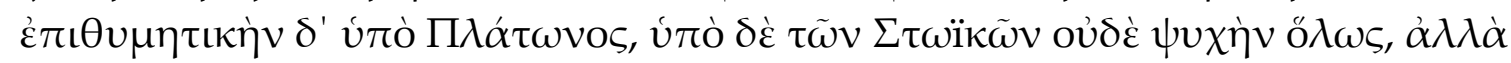

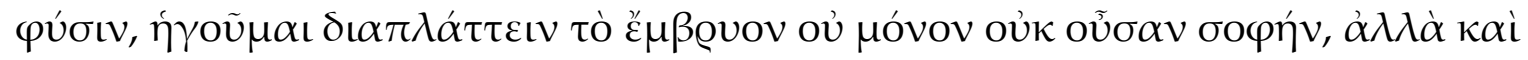

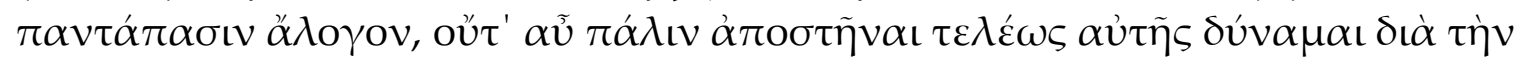

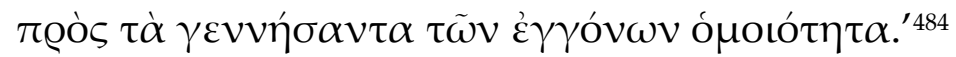

'And so I confess that I do not know the cause of construction of the foetus. For I observe in this construction the utmost intelligence and power, and I cannot allow that the soul in the seed, which Aristotle calls vegetative and Plato desiderative, and which the Stoics consider not to be soul at all, but nature, constructs the foetus, since this kind of soul is not only not intelligent, but entirely devoid of reason; nor, however, can I entirely distance myself from that opinion, in view of the similarity of the offspring to the parents...' (tr. Singer)

The seed is a substance consisting of a mixture of the four elemental qualities. In other places, Galen seems to suggest that it is the seed itself, or a 'power in the seed' that constructs the human being. ${ }^{485}$ Here, at the end of Foet. Form., we can see how he is still attracted to this view, but at the same time we see his inhibitions to fully commit to it. Lacking intelligence itself, a mixture of elemental qualities could not sufficiently explain the intelligent design Galen observes in nature's creations. In the end, Galen does not seem to solve this tension by choosing to commit fully to any of the two possible directions. One might view this as philosophical inadequacy or scientific integrity, according to one's own taste. In any case, this tension has been the subject of much discussion already ${ }^{486}$ and we will not pursue the problem further here. I simply note that while, for example, Galen's UP tilts more towards an emphasis on intelligent design and a wise artificer, his writings on the Timaeus rather seem to tilt towards the opposite aspect, which is striking, considering the prominence of the demiurge in Plato's Timaeus itself. This makes Galen's commentary on the Timaeus an interesting case to see to what extent the physiological explanation of the soul in terms of elementary qualities could be successful from a Galenic perspective. It has already been shown by Mario Vegetti that Galen displayed a tendency of somatisation of Plato's Timaues in PHP and QAM as well. Vegetti argues that, in PHP, the Timaeus has been particularly useful for Galen's central doctrine of the division of the soul in three separate parts ( $\varepsilon i \delta \eta$ ) or substances (oúrí $\alpha$ ) and their concomitant location in and attachment to three separate bodily organs, and that, in $Q A M$, this line is taken a step further towards identification of the three parts of the soul with the homoeomerous bodies that constitute these organs. ${ }^{487}$ Teun Tieleman has argued in a similar vein for

\footnotetext{
${ }^{484}$ Foet Form 104,15 Nickel (V $\left.700 \mathrm{~K}\right)$

${ }^{485}$ Foet. Form. 86,21-88,2 De Lacy (V 683 K); Sem. 98,1-3 De Lacy (IV 546-7 K); Nat. Fac. II 83-6 K

${ }^{486}$ See infra, CS II section 4. Cf. Hankinson (2008) and van der Eijk (2014)

${ }^{487}$ Vegetti (2000) $71 \mathrm{f.}$
} 
understanding $Q A M$ as an elaboration of Galen's interpretation of the Timaeus as presented in PHP: 'In PHP Books 1-6 Galen mounted an extensive vindication of the trilocation of the soul as presented by Plato in the Timaeus. The localization of reason, anger and appetite in three different organs committed him to the view that the soul consisted of three parts rather than powers... In PHP Galen suspends judgement as to its substance (corporeal/incorporeal, mortal/immortal) but in the work of his old age, $Q A M$, he explicates his position in this matter by adapting a Peripatetic theorem: form is to be understood as the blend of corporeal elements of the main organs.' ${ }^{488}$ Our analysis of $Q A M$ in Case-Study I supports these readings. Both Vegetti and Tieleman see continuity (rightly, I think) between PHP and QAM and the relationship of both to Galen's interpretation of Plato's Timaeus. In the fragments and testimonies of Galen's commentary on the Timaeus - particularly those supposedly belonging to the first book, including the contested excerpts found by Larrain - this specific line of interpretation (or 'manipulation' if you like ${ }^{489}$ ) of the Timaeus is continued. Again, this Galenic interpretation of the Platonic text, basically consists of a recasting of the traditional Platonic body-soul opposition into an opposition of elemental qualities, which fits Galen's notion of mixture as the nature of man. Thus, whereas Plato understands soul as a (self-moving) cause, Galen argues that soul is causally dependent on or even identical with bodily mixture in $Q A M$, after he has shown, already in $P H P$, how each of the three soul-parts is localized in a specific bodily organ from which it functions and without which it cannot function. In the excerpts collected by Larrain, be they excerpts from Galen's commentary or not, this line of interpretation is continued, as we can also see when we briefly look at one of the main cosmic structures explained in the Timaeus: that of the two kinds of movement. An important aspect of Timaeus' narrative is that there are essentially two kinds of movement in the cosmos, that of the same and that of the other, and that human beings can take part in both (which makes it so that we can partake both in being and in becoming). The movement of the same is fixed, circular and wise, while the movement of the other, in various linear directions, is irrational, inconsistent and variable. ${ }^{40}$ In the Timaeus these movements are prior to that which they actually move. ${ }^{491}$ However, as we have seen in our previous case-studies,

\footnotetext{
488 Tieleman (2003) 161

${ }^{489}$ Vegetti (2000) 76: 'Ma non è certamente questo l'aspetto principale del lavoro esegetico da Galeno sul testo del Timeo. Il suo nucleo centrale consiste nell'interpretazione della teoria dell'anima e del rapporto anima/corpo, che costituisce il tema maggiore di PHP: all'osservazione imparziale di sostituiscono qui operazioni assai più interessate alla fruizione e all manipolazione del testo platonico.'

${ }^{490}$ Tim. 33b-34a; 36c-d; 37a-c; 43b-c; cf. Laws 896e-898b, for what is in fact a clearer explanation than the one we get in the Timaeus.

${ }^{491}$ Cf. Tim. 34b-c: 'As for the world's soul ... it isn't the case that the god devised it to be younger than the body. for the god would not have united them and then allow the elder to be ruled by the younger... The god, however, gave priority and seniority to the soul, both in its coming to be and in the degree of its excellence, to be the body's mistress and to rule over it as her subject.' (tr. Zeyl); 36d8-e1: 'Once the whole soul had acquired a form that pleased him, he who formed it went on to fashion inside it all that is corporeal, and, joining center to center, he fitted the two together.' (tr. Zeyl); Cornford (1952) 93 on this latter passage: 'Nothing has yet been said about the bodies which display these motions and the additional motions of the seven circles. The intention
} 
Galen's approach is rather to explain whatever activity of any given thing in terms of its substance, which in itself - if it is assumed that the substance is a body - amounts to a somatisation. Galen also applies this principle with regard to his interpretation of the Timaeus: the type of movement undertaken by something depends on its constitution in terms of the elemental qualities - particularly its relative wetness or dryness. In this manner the movement of the same becomes related predominantly to dryness, the movement of the other to wetness. The explanation of these movements in terms of the elemental qualities is a fundamentally different point of departure, since for Plato the movements (i.e. soul) are primary and the bodies are fitted in later (at least in the narrative). For Galen and the author of Larrain's fragments, the causal explanation has to run the other way around: a substance that is relatively dry and fiery will, therefore, be wise.

There are a few other general tendencies in Galen's interpretation of the Timaeus, which will be less important for our analysis but can be briefly mentioned here. In accordance with Middle-Platonist predecessors and indeed with his own work, Galen, in his reading of the Timaeus, places all causality with the demiurge, or intelligent nature, and understands Plato's $\chi \tilde{\omega} \varrho \alpha$ as the (qualityless) matter unto which nature or the demiurge puts its form, which fits his hylomorphic outlook better. ${ }^{492}$ Das has shown that Galen, in his Compendium, too, downplays the notion of the eternal paradigm in his description of the creative activity of the demiurge. ${ }^{493}$ Again, this corresponds to a general Middle Platonist tendency to put greater emphasis on the role of the efficient cause, by reducing the autonomy of the Forms as cosmic paradigms and making them more inherent to the demiurge as creator. ${ }^{494}$ It also corresponds to Galen's UP, however, in which the beauty and order of the cosmos and its inhabitants is due to the providence and artistry of the demiurge, much rather than due to the perfection of eternal paradigms. ${ }^{495}$ Das has also argued that the 'distinctively mechanistic account of primordial chaos' that we find in Plato's Timaeus as description of the workings of necessity, would have been reason for Galen to diminish the role of necessity in his Compendium, given his obvious lack of appreciation for mechanistic accounts of nature. ${ }^{496}$ For what it is worth, these preferences are matched in Larrain's fragments, where we also do not find anything on necessity or eternal paradigms.

Finally, it might be good to keep in mind that it is likely that Galen wrote the last books of PHP, the Compendium and the commentary on the Timaeus, quite soon after one another. They were also all included, together with $Q A M$ as well, under the header 'Works concerning Platonic philosophy' in his On My Own Books. The many parallels, programmatic resemblance, and the fact that these works can be dated

is to emphasize the superior dignity of soul and the truth that the self-moving soul is the source of all physical motions.'

492 cf. Das (2013) 81-95

${ }^{493}$ Das (2013) 83-5

${ }^{494}$ See Das and Koetschet (forthcoming), notes on paragraph 2

${ }^{495}$ Das (2013) $82 \mathrm{f}$.

${ }^{496}$ Das (2013) 85 
closely to each other, suggests that Galen undertook some sort of Timaeus-project. Hence, it might be fruitful to interpret the several results of it together or at least in relation to each other. ${ }^{497}$ Some of the tendencies described above can be found in all of these works, and come to the fore in a particularly lucid manner in those fragments of Larrain's edition that are supposedly excerpted from the first book of Galen's commentary. We shall now discuss some of these fragments, and compare them to some of Galen's attested work on the Timaeus.

\section{Comparing Galen's Timaeus to the Larrain fragments}

\section{a. Aristotelianizing Plato}

One of the first things to notice, when looking at these fragments, is that even though they are supposed to be commenting on a Platonic dialogue, two of the first three fragments are about Aristotle. In the first fragment, the author expresses his appreciation of Aristotle's use of the so-called geometrical method in a book on vision and in the Problemata. ${ }^{498}$ As Larrain remarks, this is not unusual. Galen is wont to make methodological remarks at the beginning of his works, and he also specifically praises Aristotle's scientific methodology on several occasions, including another work in which he is in fact writing about Plato and the Timaeus, namely in PHP. ${ }^{499}$ It is therefore not untypical, but still significant, that the author - in either case well-versed in Galen's previous work - evokes Aristotle so prominently in what is likely to be an introductory passage at the very beginning of the commentary. In the second fragment, moreover, Plato's notion of the underlying nature of things is criticized and discarded. In the third, the compositional hierarchy of homoeomerous and organic bodies is brought in. As we have seen in the previous case-studies, this is standard Galenic doctrine hailing from Aristotle, who is again explicitly referred to. Let us have a brief look at these latter two fragments:

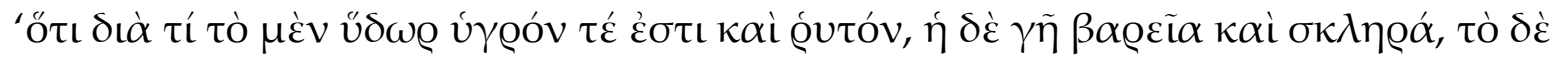

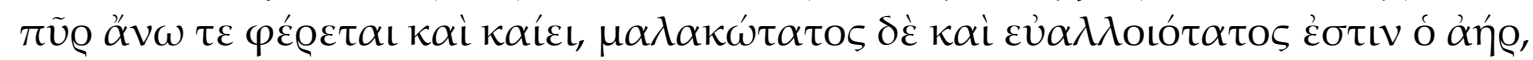

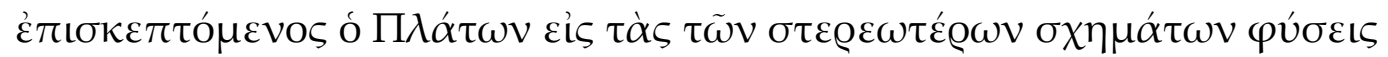

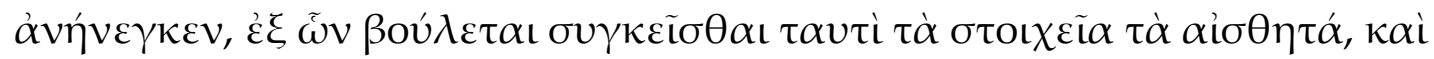

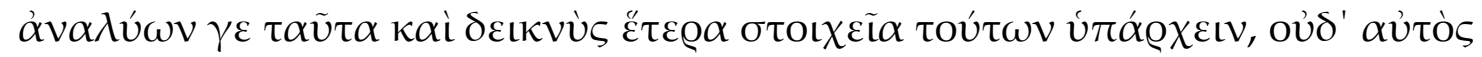

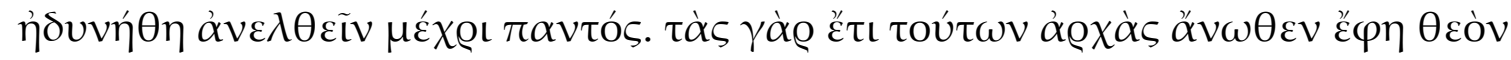

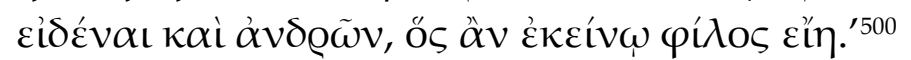

'That the reason why water is moist and fluid, earth is heavy and hard, fire is borne upwards and burns, and air is most soft and alterable, Plato, after examination,

\footnotetext{
${ }^{497}$ See Das and Koetschet (forthcoming)

${ }^{498}$ Larrain (1992) 21

${ }^{499}$ Cf. Larrain's comments on Fr 1, 21-6; PHP II 104,3-5 De Lacy (V 213 K)

${ }^{500}$ Larrain 27, fragment 2; the last sentence is a citation of Tim. 53d6-7, where it is about the principles that underlie the geometrical figures underlying the elements.
} 
referred to the natures of the solid figures, from which he thought those perceptible elements are composed, and even though he indeed analyzed them and showed that other elements underlie them, he himself was not able to go up to the whole. For he said that the principles still higher than those are known by God and by those men who are loved by God.'

The structure of this fragment is reminiscent of the general philosophical method described by Galen in HNH and Hipp. Elem. and discussed in Case-Study II: to analyze the elements available to perception, that is to say, to break them down into final principles that cannot be further analyzed and to determine the causal powers of these principles. ${ }^{501}$ We see the same terminology here as in those works $-\tau \dot{\alpha}$

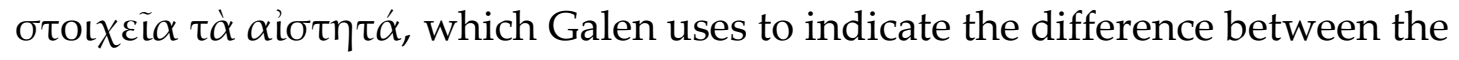
elements according to perception and the true elements (that in a strict sense are to be called principles, $\alpha \varrho \chi \alpha$ í). ${ }^{502}$ But, although Plato was right not to stop at the realm of perception and to further analyze these perceptible elements (Plato realized, at least, that there must be other principles underlying the perceivable ones), Galen does not deem his final analysis successful. Plato comes up with the geometric figures as the principles that underlie the perceptible elements, and we can safely assume that Galen considered this a mistake. This would be one of Galen's main problems with the Timaeus: as we have seen in the previous two case-studies, it is clear enough that Galen prefers a hylomorphic model in which the elements according to perception are conceptually broken down into the two principles of form and matter. ${ }^{503}$ From this perspective, this particular fragment fits well with Galen's attested work.

That Plato was mistaken must be the meaning of the somewhat odd sentence 'ou' $\delta$ '

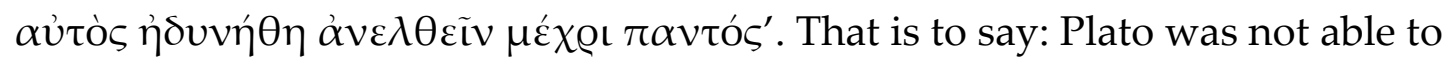
completely fulfil this method since his analysis did not bring him to the true

\footnotetext{
${ }^{501}$ See infra, CS II section 2, 105-112

${ }^{502}$ See infra, CS II section 1, 100-2; the Platonic difference between being and becoming could perhaps be understood by Galen in terms of his difference between perceptible elements and the true nature or primary substance of things in the sense of the two hylomorphic principles. In his Compendium, he remarks: 'He [sc. Plato] distinguishes between a substance that is apprehended by the intellect and is not a body and a sensible substance that Plato usually calls 'generated [being]', rather than substance.' (Das and Koetschet, paragraph 1) This sentence could be applied to what Galen does in $H N H$, since he differentiates between the two eternal principles making up the primary substance which underlies generation and destruction and which are only grasped conceptually, and the perceptible substances which they constitute and which are subject to generation and destruction. That is to say, the Platonic difference between the noetic and the aesthetic realms could well be interpretated by Galen in terms of the underlying hylomorphic substance and perceptible substance of things. ${ }^{503}$ Cf. Vegetti (2000) 72-3: 'In uno scritto breve ma di importanza strategica, il de elementis, Galeno avevo definito il punto centrale della sua filosofia della natura: la compatibilita, o meglio la reciproca implicazione, nella dottrina ippocratica dei quottro umori (sangue, flegma, bile gialla e nera), delineata nel De Natura Hominis, con quella aristotelica delle quattro qualita (dunameis) primarie della materia (caldo, freddo, secco, umido), come era formulata sopratutto nel secondo libro del De Partibus. A questo sistema compatto il Timeo opponeva resistenza. Esso parlava di aria, acua, terra e fuoco, ma non li definitiva neppure elementi, preferendo riservare questa espressione alle figure geometriche costitutive della materia corporea.'
} 
principles of things. ${ }^{504}$ This sentence might also be a play on the passage on dialectics from book VI of Plato's Republic (which is also full of references to the ideal of the geometrical method), where Socrates speaks of going up to the 'first principle of everything' that requires no further hypotheses itself. There, it is said that in this highest form of science, one uses the fundamental hypotheses of the other sciences not as first principles, but rather truly as hypotheses, so that they become a kind of stepping stones, so that one 'could go up to the unhypothetical first principle of

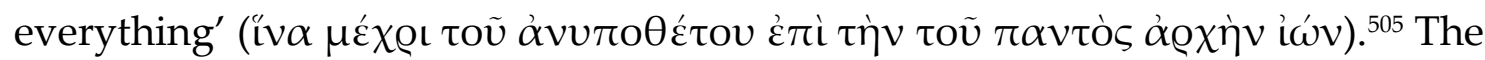
resemblance in choice of words is striking, and is reinforced by another sentence from the same passage in the Republic a few lines down, where it is said that those who study the objects of the other sciences, 'do not go back to a genuine first

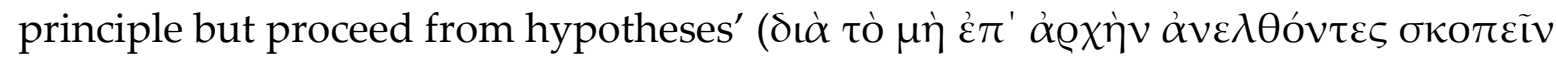
$\left.\dot{\alpha} \lambda \lambda^{\prime} \dot{\varepsilon} \xi \hat{v} \pi \sigma \theta \dot{\varepsilon} \sigma \varepsilon \omega \nu\right) .506$ If this was indeed done intentionally, it must be a joke on Plato (which would not be untypical of Galen), saying that even though he did examine the matter, he was not able to live up to his own ideal as he portrayed it in the Republic, since he did not in fact end up at the actual principles of everything. Plato, of course, is not talking about the principles of the bodily elements in that passage in the Republic, but that is not a requirement for the author's presumed joke to work, since Galen generally is talking about the principles underlying the mixtures when he talks about the principles of everything. ${ }^{507}$ Finally, this sentence may also remind us of Galen's interpretation of the passage from Plato's Phaedrus, discussed in Case-Study II. According to Galen, Plato suggested that a knowledge of 'the nature of everything' is required to arrive at knowledge of the nature of man, implying that knowledge of the mixture of elemental qualities - which Galen identified as the nature of man - is a prerequisite for knowledge of the whole of man, i.e. both body and soul. The 'whole' or 'all' that Plato was not able to uncover, despite using the right method, is the same 'whole' or 'all' that Galen analysed in his commentary on the Hippocratic On the Nature of Man; namely, a hylomorphic composite consisting of two principles, matter and the elemental qualities. This particular critique of Plato fits well with the strong presence of Aristotle in the first few fragments.

We saw how Galen in PHP brought up the need for a commentary on the Timaeus in the context of Plato's explanation of the human body (and its congruence with Hippocrates) and his reasoning on underlying causes for the humours being such as they are. ${ }^{508}$ In PHP, Galen still refrained from criticism on Plato's choice, declaring that 'the question whether Plato's opinions about these matters were correct or incorrect lies outside our present discussion'509. 'These matters' here refer to the

\footnotetext{
504 This is also how Larrain interprets this sentence: 'Platons Versuch, die Elemente auf die Figuren der stereometrischen Körper zurückzuführen, betrachtet Galen - in deutlicher Anlehnung an Aristoteles - als gescheitert.'

${ }^{505}$ Rep. $511 \mathrm{a} 6$, ed. Burnet

${ }^{506}$ Rep. 511c8, ed. Burnet

${ }^{507}$ See infra, CS II section 1, 97-100 and section 5, 130-7 (note 392 for references to $H N H$ )

${ }^{508}$ PHP VIII, 494,26 ff. De Lacy; VIII, 506,25 ff. DeLacy; VIII 6, 522,34 ff. De Lacy

${ }^{509}$ PHP VIII, 496,11-2 De Lacy (V $668 \mathrm{~K}$ )
} 
discourse on the principles of the elements, which apparently belongs to theoretical philosophy (that is not to say that Galen does not engage with this question himself; he often does, in fact). After this remark, Galen continues to simply sum up Plato's analysis of the elements in terms of the geometrical shapes, without criticizing it. In Larrain's fragment 2, however, Plato's reasoning about geometrical figures is quickly discarded. In that sense, this fragment would live up to Galen's anticipatory remarks on his Timaeus commentary in Trem. Palp., where he states that the commentary will be critical of Plato (rather, I take it, than merely explanatory or descriptive as in PHP). ${ }^{510}$ Finally, it is easy to see why Galen would have no use for Plato's geometrical shapes. They do not have any place or role to fulfil in the hylomorphic schema of primary matter and elementary qualities that Galen usually proposes, as we have seen in the previous two case-studies. Again, this is also one of the aspects of the Timaeus that is downplayed in Galen's Compendium. The analysis of the elements in terms of geometrical shapes is only briefly mentioned and the emphasis is then immediately turned towards the respective qualities of the elements rather than their constitution from specific geometrical structures. ${ }^{511}$ Section $52 \mathrm{~b}-55 \mathrm{~d}$ from the Timaeus, which discusses the geometrical figures, is left out of consideration entirely. ${ }^{512}$ As we mentioned briefly above, it is striking to note these similarities between the Compendium and the texts published by Larrain. Indeed, they could be taken as indications that the author of Larrain's fragments must have been familiar with Galen's Compendium, which in turn may make it more likely that the fragments are based on Galen's actual commentary (it is one thing to assume that the original text was written by someone familiar with PHP and UP, as Nickel does, another that the author was also familiar with Galen's summary of the Timaeus).

Thus, after what seems to be a fundamental critique of Plato's natural philosophy, which has been anticipated in Galen's attested works, in the next fragment Aristotle is brought up once more:

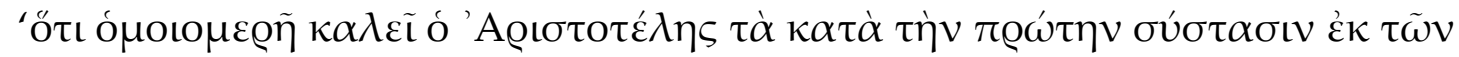

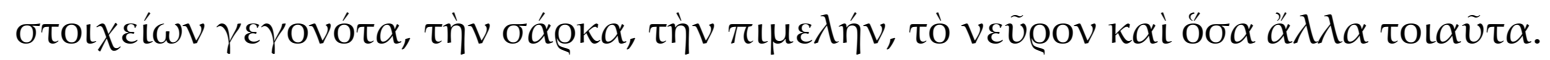

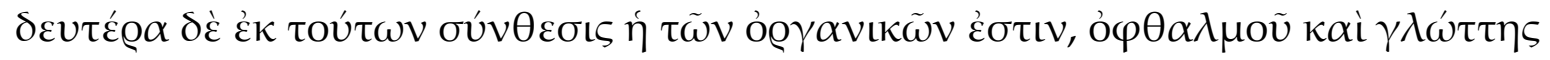

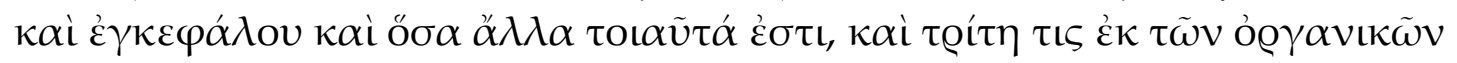

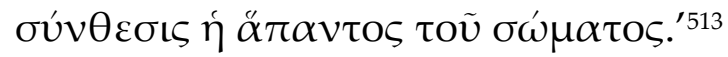

'That Aristotle calls 'homoeomerous' the things that have come about as the first composite from the elements, flesh, fat, sinew and all other things that are such. That from these there is a second composition, namely that of the organs, of the eye and the tongue and the brain and all other things that are such, and that from the organic parts there is some third composition, namely that of the body as a whole.'

\footnotetext{
${ }^{510}$ Trem. Palp. 631,10 K

${ }^{511}$ Kraus and Walzer (1951) 59-60

512 Cf. Arnzen (2012) 220-1; Das and Koetschet (forthcoming)

${ }^{513}$ Larrain 41, fragment 3
} 
The compositional hierarchy that Galen consistently employs is also presented at the outset here, in the Peripatetic terminology he is wont to use. ${ }^{514}$ Galen himself, at least, is well aware that Plato does not use this terminology. In both $Q A M$ and $H N H$, he remarks that Plato used the name $\pi \varrho \omega \tau o ́ \gamma o v \alpha$ for the most basic bodies, the 'first' bodies that come to be from a mixture of the elemental qualities in prime matter, while Aristotle calls them ó $\mu$ oเo $\mu \varepsilon @ \tilde{\eta} .{ }^{515}$ Galen seems to have been wrong about

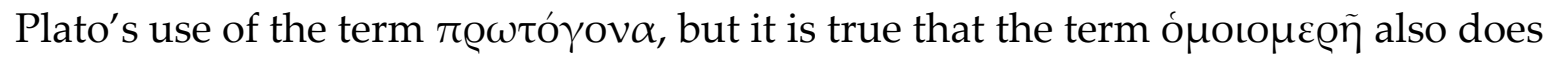
not occur in Plato. Hence, bringing up this terminology here, together with Galen's

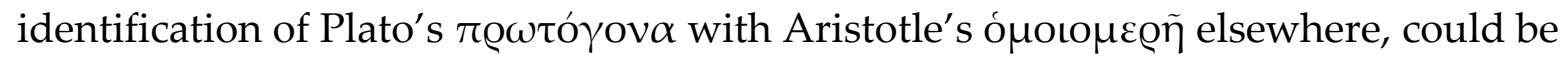
taken as a deliberate attempt by the author to steer the Timaeus into more Peripatic spheres, similarly to what Galen has done elsewhere. As Vito Lorusso has already pointed out, Larrain's fragments about vision (Fr 18-23) also mix Aristotelian (and Stoic) influences into the theory of vision that we find in the Timaeus, in a manner which is paralleled in Galen's attested writings. 516

In general, it is safe to conclude - given the praise for the Aristotelian method, and the rejection of Plato's notion of the underlying nature of things (presumably in favour of the hylomorphic scheme of the mixture of elemental qualities and prime matter) - that the author at least gives a Peripatetic twist to his reading of the Timaeus, not to say that he considers it necessary to introduce some basic Peripatetic conceptual apparatus at the very outset of his commentary to make what follows more understandable. As we know and as has been pointed out above, this Peripatetically inclined reading of the Timaeus - particularly the combination of emphasis on the distinction between homoemoerous bodies and organs with the tripartition and trilocation of the soul - can be considered typically Galenic. We also find a similar use of Aristotelian terminology to 'clarify' the Platonic text in the longest Greek fragment preserved of Galen's commentary in Schröder's edition, where he comments on the passage about plants. ${ }^{517}$ On the other hand, while this specific way of Aristotelianizing Plato might be typically Galenic, Aristotelianizing Plato is a general tendency shared widely among earlier and contemporary Platonists. Hence, both Galen and/or the author of Larrain's fragments might already have found themselves in a context in which Plato is an Aristotelianized Plato to some extent. ${ }^{518}$ However, it seems that the author of Larrain's fragments did not only Aristotelianize Plato as many so-called Middle-Platonists did, but that he Aristotelianized Plato in a distinctly Galenic manner, with his emphasis on the soundness of Aristotle's scientific method, the disapproval of Plato's analysis of the elements in terms of geometrical figures, the introduction of the distinction between

\footnotetext{
${ }^{514}$ See infra, CS I section 1, 19-27 and CS II section 3, 98-104

${ }^{515}$ QAM 36,21-37,5 Müller (IV 773 K); HNH 6,11-20 Mewaldt (XV 7-8 K). Cf. Singer (2014) note 32 ad locum: $\pi \rho \omega \tau$ ó $\gamma$ ov $\alpha$ is in fact not used in any of Plato's extant works, let alone in the meaning Galen attributes to it. The

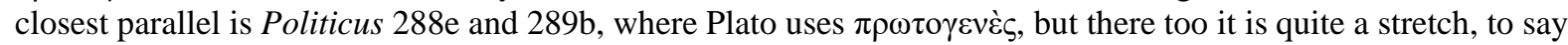
the least, towards Galen's meaning of basic bodies.

${ }^{516} \mathrm{Cf}$. note 452 above

${ }^{517}$ Ed. Schröder (1934) 10 f. Cf. Das (2013) 17-37 for an excellent and detailed discussion

${ }^{518}$ Cf. Chiaradonna (2014) on Galen and Middle Platonism
} 
homoemoerous and anhomoeomerous bodies or organs and the Aristotelian influences in his discussion of Plato's theory of vision.

\section{b. Somatising the soul}

Let us have a look at the next fragment in Larrain's edition, fragment 4, which happens to feature Galen's favourite Platonic doctrine, the tripartition of the soul:

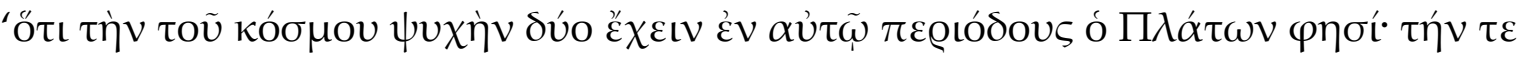

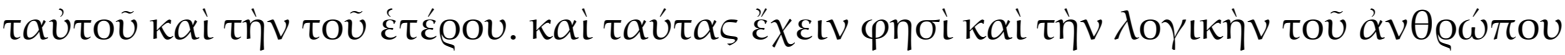

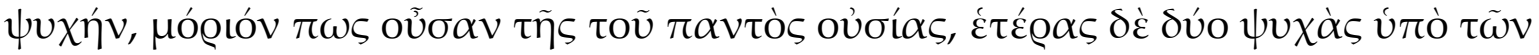

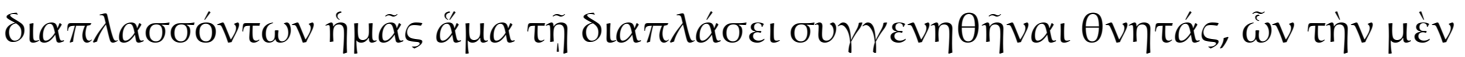

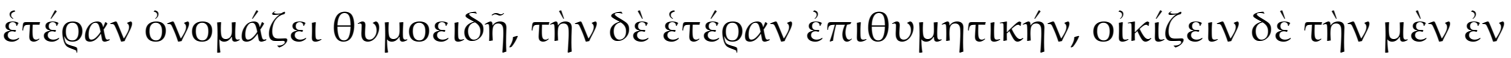

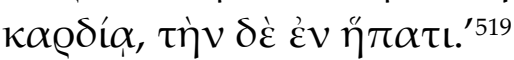

'That Plato says that the soul of the cosmos has two cycles in it: that of the same and that of the different. And he says that the rational soul of man also has these, it being in some way a portion of the substance of the all, but along with the formation of it two other souls, mortal ones, have been created by the ones that formed us, of which the one is called 'spirited part', and the other 'desiderative', and the first dwells in the heart, the second in the liver.'

As we have mentioned before, Galen appreciates the tripartition of the Timaeus better than that of the Republic and that of the Phaedrus with its horse and chariot metaphor, since in the Timaeus it is clear that there are not only three forms but also three

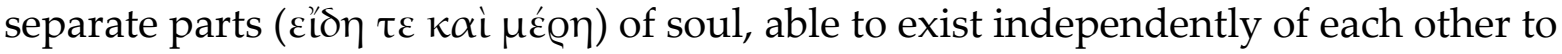
some extent (the vegetative soul exists in plants, the rational in gods or heavenly bodies) and located in three distinct organs, with all the required connections from the organ to the rest of the body.

Both the emphasis on the other two parts of the soul being mortal (without making any definitive statement on the mortality of the rational part), as well as the inclusion of their specific location, is typical for Galen. ${ }^{520}$ In that sense, this fragment too is at least very similar to Galen's attested work.

The two cycles of the same and the different return in some of the other fragments and are given a specific somatic or elemental twist by the author, as we briefly mentioned before. They bring out an interesting difference between Plato and the author, one that also applies well to Plato and Galen. In Plato, these cycles are prior to the body that follows their movement, since, in Platonic cosmological narrative, soul has to be prior to body:

\footnotetext{
${ }^{519}$ Larrain 50, Fr 4

${ }^{520}$ Cf. PHP VI 368,13 ff. DeLacy; QAM 44,2-12 Müller (IV 782 K); cf. Vegetti (2000)
} 


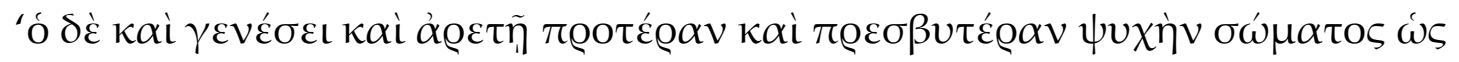

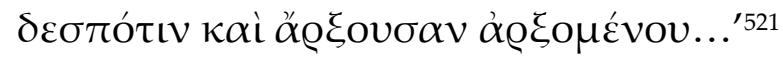

'The god, however, gave priority and seniority to the soul, both in its coming to be and in the degree of its excellence, to be the body's mistress and to rule over it as her subject.' (tr. Zeyl)

This applies to the world-soul as well as to our rational soul, which is fabricated out of its left-overs. However, that implies that, in a very fundamental sense, the movements of the world-soul are prior to the bodies that move in them, the bodies by which we can observe those very movements. Accordingly, Timaeus describes the movements and revolutions of the heavens before the creation of the heavenly bodies:

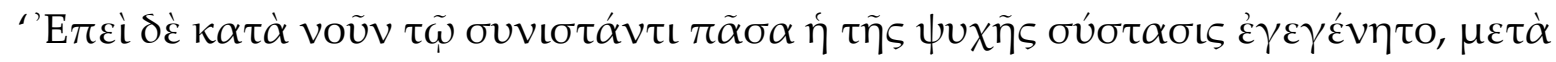

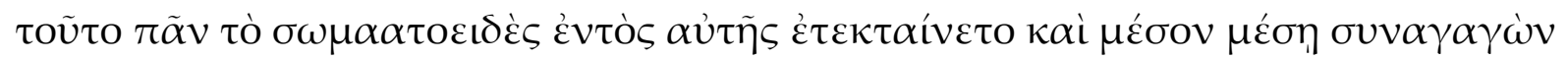

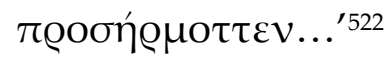

'Once the soul had acquired a form that pleased him, he who formed it went on to fashion inside it all that is corporeal, and, joining center to center, he fitted the two together.' (tr. Zeyl)

This is a central point in Plato's narrative, since it follows from the relation between soul and body as ruler and ruled, respectively. Soul, as ruler, has to be prior to body, as that which is ruled by soul. Galen, however, is wont to use an explanatory scheme that is quite different. For him, it is an axiom that the kind of activity a being undertakes is dependent on its specific bodily substance. ${ }^{523}$ This is a fundamental reversal of perspective. To Galen, the notion of movement apart from a bodily substance moving must have been completely foreign and in fact not understandable, as is the notion of soul apart from body. ${ }^{524}$ We can see this difficulty in Galen's dealings with Plato and we see the subsequent manipulation of Plato's text to fit Galenic preferences come to the fore in Larrain's fragments in exceptional clarity. Whereas Plato would do no such thing, the author of these fragments explains the type of movement that the heavenly bodies make in terms of their specific substance, particularly, again, their relative wetness or dryness. And through

\footnotetext{
${ }^{521}$ Tim. 34c4-5 ed. Burnet

522 Tim. 36d8-e1 ed. Burnet

${ }^{523}$ See infra, CS I section 1, 39-41

${ }^{524}$ Cf. QAM 38,20-3 Müller (IV $776 \mathrm{~K}$ ): ‘ ... I do not know what sort of thing the substance of the soul is if we take as our assumption that it belongs to the class of non-bodily things.' (tr. Singer); QAM 44,12-20 Müller (IV $783 \mathrm{~K}$ ): 'And as for Andronicus the Peripatetic, because he dared to make a declaration on the substance of the soul altogether, as a free man and without unclear verbal complications, I approve him highly, and accept the opinion of the man (and I find him similar in many other areas too). Where, however, he says that it is either a mixture or a capacity dependent on the mixture, I disapprove of the addition of 'capacity'.' (tr. Singer); 48,20-5 Müller (IV $788 \mathrm{~K}$ ): 'Now, this point in itself casts great suspicion upon the question, whether the whole substance of the soul can really be non-bodily. For how could it be brought into the nature opposed to itself by communion with the body, if it is neither some quality of the body, nor a form, nor an affection, nor a capacity?'(tr. Singer)
} 
the exact same reasoning, our own activities as human beings are determined by our relative dryness or wetness. This strong emphasis on the causal power of the mixtures of elemental qualities over soul has parallels in Galen's attested work. As we have found in Case-Study I, Galen argues in QAM that the activities of our souls are dependent on the interaction of the four elemental qualities taking place in the organ from which the respective psychic functions are exercised. ${ }^{525}$ In the Larrainfragments, this principle is extended to an analogy between the activities of human beings and heavenly bodies, which has its basis in an analogy between their respective bodily substances. This, too, is in line with several passages from genuine Galenic works, as we shall see below. Furthermore, it is notable that in his Compendium, Galen leaves out the remark we just quoted on the soul being prior to body, which forms a kind of apology by Timaeus for speaking of the body before the soul in his cosmogony. 526

The author of these fragments projects this Galenic doctrine of the soul being dependent upon the mixture onto Plato's Timaeus, taking as his point of departure the river metaphor used by Plato to describe the embodiment of soul. We have briefly discussed Galen's reading of this metaphor above, and noticed how he, both in his Compendium and in $Q A M$, steered the Platonic struggle of the soul with incarnation towards a struggle between elemental qualities, by taking the metaphor of the river to refer to the abundance of moisture in the substance of newborns, and adding to that the notion that dryness rather causes intelligence or understanding. ${ }^{527}$ In Larrain's fragment 6, the same passage from the Timaeus is cited and interpreted in the same manner, with some additions with respect to the citation in QAM. It may be useful to quote the fragment in full:

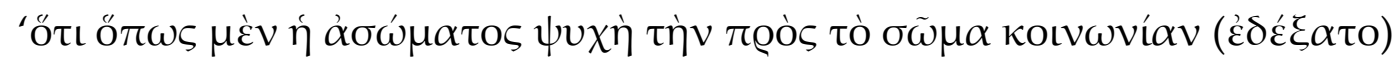

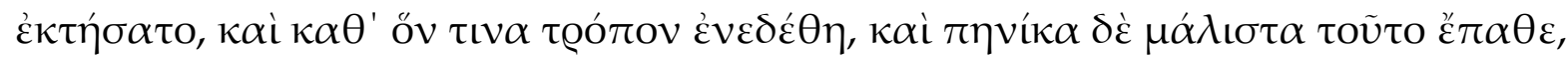

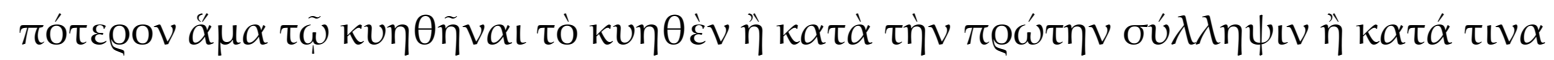

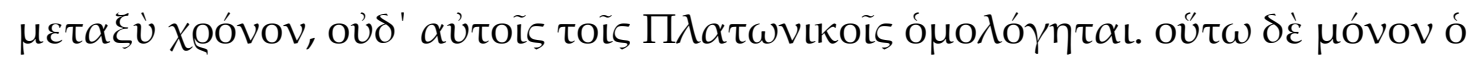

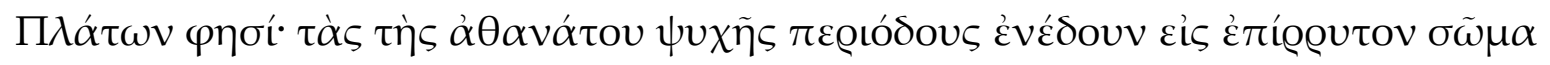

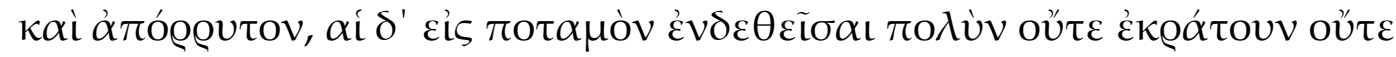

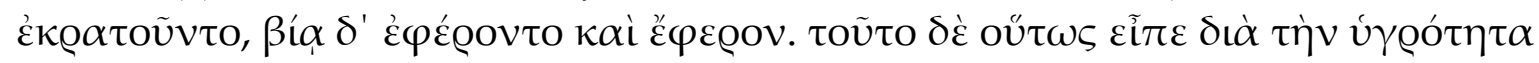

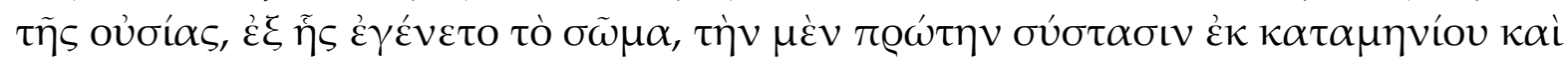

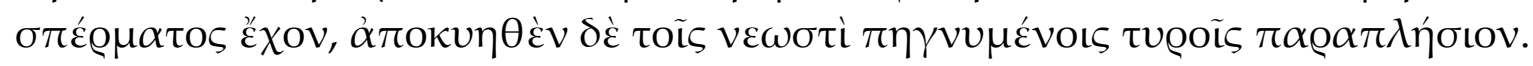

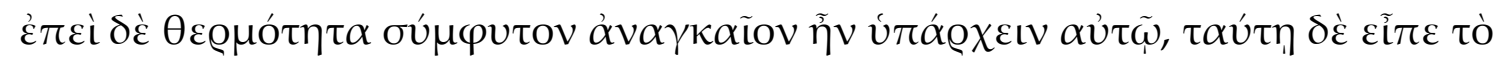

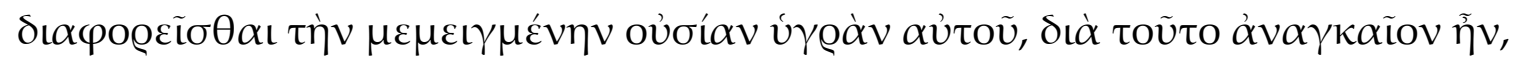

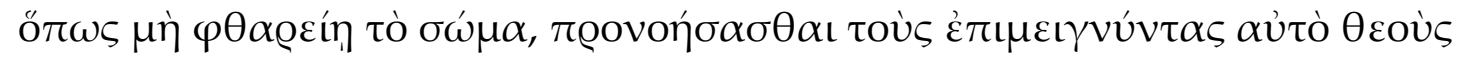

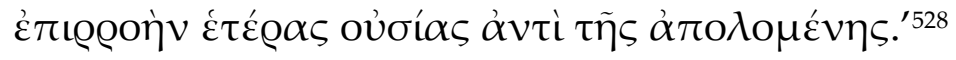

'That it is not even agreed upon among Platonists themselves how the incorporeal

\footnotetext{
525 See infra, CS I section 1 and 2

${ }^{526}$ See Das and Koetschet (forthcoming) notes on paragraph 4

${ }^{527}$ See infra, section 3, 156-63

${ }^{528}$ Fragment 6, ed. Larrain
} 
soul acquires the communion with the body and is bound to it in some way, and especially the exact time when this happens, either at the same time with being born or with the first conception or at some time in between. Plato speaks only in this manner: that the cycles of the immortal soul are bound to a body that is subject to influx and efflux, they are bound in a great river and they don't rule and are not ruled over, but they produce violence and suffer it. It is like that he says due to the wetness of the substance from which the body comes about, since its initial structure consists of menstrual blood and semen, after birth nearly resembling solidified cheeses. Therefore it is necessary that it also had an innate hotness, but because of this, he says, the wet substance mixed with it was dissipated by it, and therefore it was necessary that the gods who mixed it in provided an influx of another substance to compensate what is lost, so that the body is not destroyed.'

The first remarks of this fragment are again typically Galenic. The author points out that the doctrine of the incorporeal soul is so difficult to account for that even its adherents have not agreed upon how to do it, and then points towards the difference between what those Platonists hold and what Plato himself has actually said. The author emphasizes that Plato himself has not handed us anything to solve the

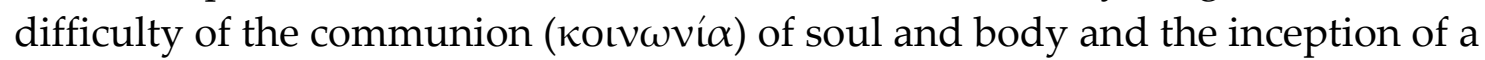
composite being, but merely introduced the metaphor of the river. ${ }^{529}$ This metaphor is related, through an odd literalist reading, to the substance from which the body comes about, which is relatively wet, as Galen also remarked in QAM. ${ }^{530}$ The wetness of this substance is specified here in a way which makes perfect sense from a Galenic perspective: it is a composite of blood and semen, two fluids, while in its state after birth it is likened to a solidified cheese because, like cheese, it has undergone a drying process which makes it more solid. As we have noted above, Galen ignores the fact that in the Timaeus the river-metaphor is about the bodily elements as such. Both in his Compendium as well as in $Q A M$, he takes it to refer only to one specific elemental quality of the four that constitute the body, namely its wetness. In this way, something else that is also an elemental quality, namely dryness or in the case of this fragment (as elsewhere in Galen's attested work) rather innate heat, can be posed as the counteracting antagonist, taking the place of what is usually called soul. ${ }^{531}$ Thus, this fragment fits with Galen's idiosyncratic interpretation of the metaphor of the river from the Timaeus. The innate heat, says the author, has been mixed in together with the wetness by the gods that formed us (presumably still the 'children' of the demiurge), to make it less moist by dissipating some of the wetness. As a consequence, there needed to be another addition, an influx of another

\footnotetext{
${ }^{529}$ This fragment is reminiscent in style and structure of what Galen says in $Q A M(38,4-16$ Müller, IV 774-5 K) in the context of the discussion of the possible immortality of the rational soul, namely that Plato did not provide an answer as to why death takes place when the body is disturbed by an excess of one of the elemental qualities, and the later Platonists aren't able to account for it either.

${ }^{530}$ QAM 42-3 Müller (IV 780-1 K)

${ }^{531}$ Cf. Trem. Palp. VII $616 \mathrm{~K}$, where the innate heat in each living being is identified as its nature or soul, being a principle of movement.
} 
substance to avoid complete dissipation and destruction of the body, so as to bring about a balance. It seems as if the author of this passage, completely in line with Galen's interpretation of the Timaeus, reconstructs the struggle that results from the incarnation of the soul as a struggle between two elementary forces, here designated as wetness and innate heat, mixed together by the gods to balance each other and to render possible the generation and growth of a human being. The addition necessary after the mixing in of the hotness, is that of nourishment, or, as it is described in Plato's Timaeus and the third book of Galen's commentary: the gods made the plants so that human beings can regain what they lose due to the continuous dissipation of their substance. ${ }^{532}$ The necessity of nourishment is explained here in terms of the basic human constitution being a precarious balance between the various elemental qualities.

According to this reconstruction, the reason for children's lack of rationality is not that the soul has just been embodied and needs some time to come to its senses, control its new vehicle and remember the knowledge it previously had, but it is rather that the body of children is exceptionally wet, whereas intelligent bodies are more dry (as we shall see below). The reason given for the wetness of the newborn is a simple reference to the stuff from which it is generated: blood and semen. Human beings are understood in these fragments as composites of two conflicting elementary forces, wetness and dryness, and at first, the one that renders us intelligent is predominated by its opposite due to the wetness of our initial substance. After we are born, our substance is still soft and malleable, like a solidified cheese. For Nickel, this cheese-analogy was one of the reasons to ascribe the text to an imitator, since he considered it to be motivated by, but not consistent with, other, similar comparisons in authentic Galenic works. ${ }^{533}$ Das, however, has added several other passages in which Galen makes similar comparisons, and concludes that 'Galen uses these metaphors to differentiate levels of moisture in the body. ${ }^{\prime 53}$ Here, too, Nickel's conclusion might have been somewhat rash. One of the passages Nickel refers to for comparison is from Galen's Mixtures. There, Galen also generalizes about the state of newborn animals that have their first composition from blood and sperm, 'substances which are hot and wet'. ${ }^{335}$ The context is that of blooded animals in general, although the prior discussion has been about man in particular. These two substances, blood and sperm, are said to enter into a continuous process of drying,

\footnotetext{
${ }^{532}$ Cf. Schröder book III fragment 2 (pp 10-1), on Tim. 76e7-77c5

${ }^{533}$ Nickel (2002) 75. The comparisons are with De Sem. II 5,29-30, CMG V 3,1, 186,2-5, where the embryo in its first stage of formation is compared to milk that is just beginning to curdle, and with De Temp. II 2, 44, 11-14 Helmreich, I 578-9 K, where the bones of young animals are compared to 'solidified cheese'. See also infra section 1, 144-9 for a discussion of the articles by Nickel and Das (2014)

${ }^{534}$ Das (2014), 4. The additional parallels put forward by Das are: Praen. 114, II.8-9 ed. Nutton (1979); Hipp. Art. XVIIIa $597 \mathrm{~K}$; Hipp. Off. Med. XVIIIb $842 \mathrm{~K}$. She also points out that it is important to note that 'set cheese and curdled milk are products of different stages of the cheese-making process', which clarifies the continuity of these different parallels, and points to a passage in Alim. Fac. (VI 695-99 K), where Galen 'goes into some detail in distinguishing ỏ $\xi v \gamma \alpha \lambda \alpha$, which seems to be a type of yoghurt or cottage cheese, from soft ( $\dot{\alpha} \rho \alpha$ ó $\varsigma$ ), spongy ( $\chi \alpha \tilde{v} v o \varsigma)$ young cheese, and other older varieties.' These products are used by Galen in the passages mentioned before, to describe 'the texture or consistency of parts of the body in various conditions'.

535 Temp. I 577,16 ff. K
} 
which evolves into the construction of all the various kinds of homoeomerous bodies and organs while the child is in its mother's womb. Even after the child has been born, it remains 'extremely wet', even in its driest parts, the bones. Galen proceeds now to give a concrete example of this: when you eat a young animal that has just been sacrificed, you find its flesh to be relatively moist and flabby, and you'll find that even its bones resemble 'solidified cheese'. ${ }^{536}$ Because of this excess of moisture, baby animals are not pleasant to eat. Clearly, Galen is using this particular example because in this case we can actually see and taste or chew the flesh and parts of the newborn animal and in this manner empirically verify the texture. That does not mean, as Nickel seems to think, the comparison does not equally apply to human newborns. Both the immediately preceding and following context is specifically about human beings and their relative dryness and wetness in relation to their age. Neither should the comparison be restricted to the bones (which rather serve as an extreme example, being the driest parts), as becomes clear when one reads a few pages further, where it is the skin that is compared to solidified cheese. ${ }^{537}$ Therefore, the whole passage should be read as treating of the substance of blooded animals as such. It shows how Galen's occasional remarks in QAM, UP and elsewhere on dryness and wetness in relation to the capacities of the (rational) soul, are rooted in his basic physiological ideas on the composition, formation and growth of human beings and indeed blooded animals in general.

In the fragments following Larrain's fragment 6, the role of relative wetness and dryness is further elaborated, particularly in its relation to our rational soul. In fragment 7 , it becomes clear that the predominance of wetness does not only trouble our soul around the time when we are born:

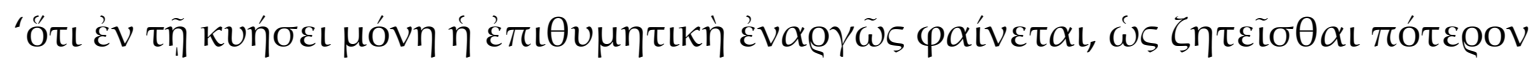

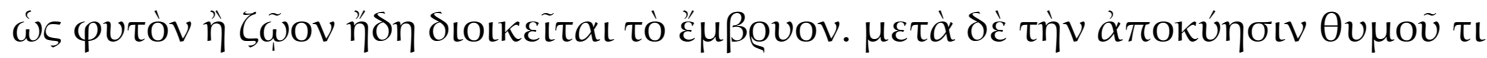

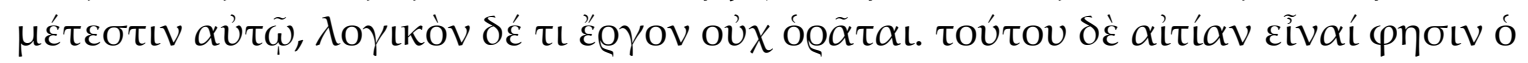

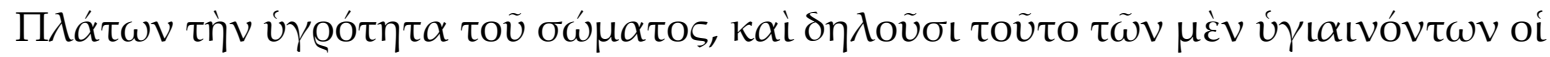

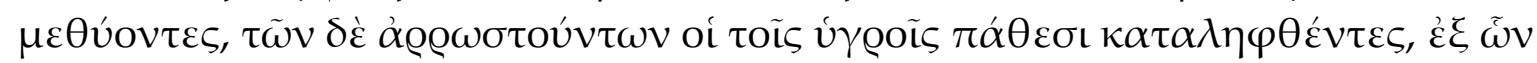

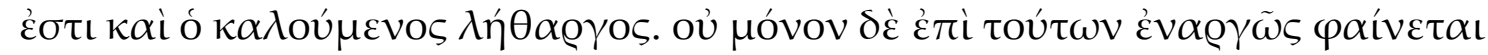

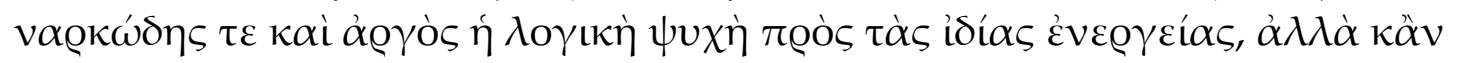

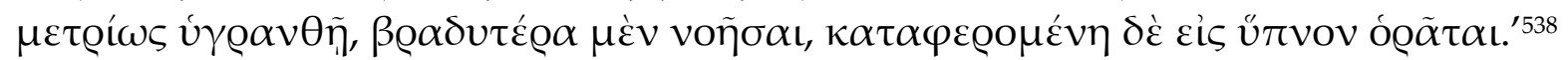
'That during pregnancy only the desiderative [soul] is clearly manifest, so that it needs to be inquired whether the embryo is governed like a plant or already like an animal. After birth something of the spirited soul is in it as well, but there is no sight of any rational activity. Plato says that the cause of this is the wetness of the body, and of the healthy people those that are drunk with wine testify to this, of the unhealthy those who are seized by wet affections, from which the so-called lethargy comes. But the rational soul clearly appears torpid and idle with regard to its proper

\footnotetext{
${ }^{536}$ Temp. I 579,1 ff. K

${ }^{537}$ Temp. I 614,9-10 K

${ }^{538} \operatorname{Fr} 7$, ed. Larrain
} 
activities not only with those people, but even when it is moderately moistened thinking becomes heavier, and it can be seen to descend into sleep.'

The first few lines of this fragment depict a gradual development of the three souls starting with the embryo. This schema, including the question whether the embryo, since it is governed by the desiderative soul only, should be considered a plant or an animal, is familiar from Galen's genuine work. We also find it in the Greek fragments of his Timaeus commentary published by Daremberg and Schröder. ${ }^{539}$ The idea that Plato ascribed the lack of rationality in newborns to the wetness of their substance is also familiar by now and can be found, as we have noted, in QAM and Galen's Compendium, as well as in some of the other fragments collected by Larrain (see below). Here, however, the author also takes another step, by going beyond the context of generation. First, the author claims that the lack of understanding due to predominant wetness can also be found in some extreme physical conditions, namely in the case of drunkenness or lethargy. Then, he continues to state that even a moderate increase in wetness can already hinder one's rational capacities and induces sleep. This is an important step; whereas Galen's Compendium merely used the river-metaphor to make relative wetness and dryness into the causes of understanding or lack thereof departing from the state of the newborn, this fragment also specifies how the strife between these elemental qualities of our substance determines our capacities for understanding throughout our life.

As we noted above, in QAM Galen also generalizes the causal role of dryness and wetness with respect to understanding, so that it has a wider application than the context of generation:

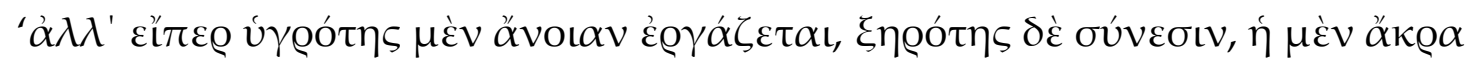

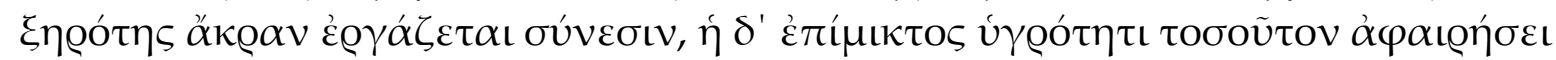

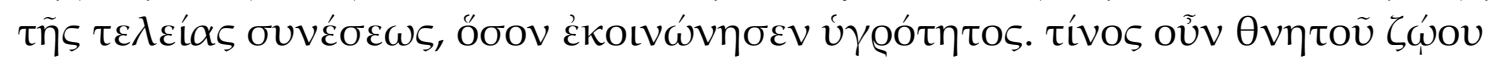

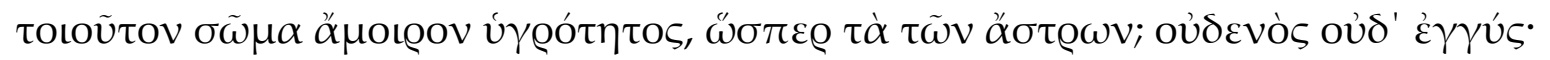

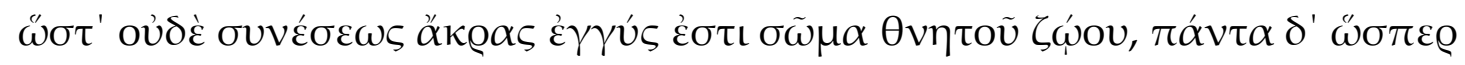

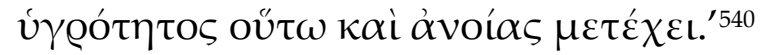

'If, then, wetness brings about mindlessness, and dryness understanding, then extreme dryness brings about extreme understanding, while a dryness mixed with wetness will take away from perfect understanding to precisely that extent to which it partakes of wetness. And indeed, which mortal animal's body is of such a sort as to be without any share of wetness - like the bodies of the stars? There is none which is even close to this. And so too there is no body of a mortal animal which is close to extreme understanding; but all partake of mindlessness too just as they partake of wetness.' (tr. Singer, slightly modified)

\footnotetext{
${ }^{539}$ Cf. Das (2013) 17 ff., Wilberding (2014) on Galen's views on this issue and interpretation of this particular passage; Long (1982), Tieleman (1991), Gourinat (2008) on this same issue in Stoicism.

${ }^{540}$ QAM 43,15-44,2 Müller (IV 781-2 K)
} 
Here, the degree to which a given body partakes of wetness is said to determine the degree to which it lacks 'perfect understanding'. Given the fact that no mortal animal is without any share in wetness, this kind of understanding is not to be found among them, though it is present in the stars, which are apparently completely devoid of wetness. In $U P$, too, we find this vertical hierarchy in which wetness predominates the substances on earth, hindering the development of their intellectual capacities, while it is inferred from the dryness of the heavenly bodies that they must be supremely intelligent. ${ }^{541}$ Although it is rather long, it is useful to quote the passage in full:

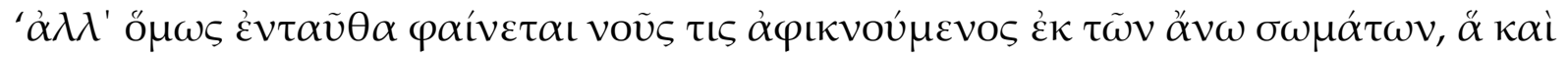

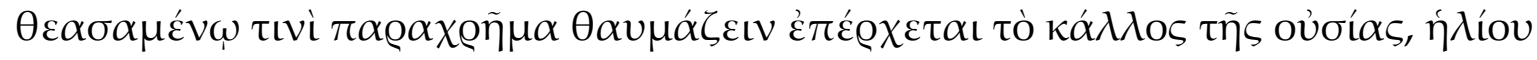

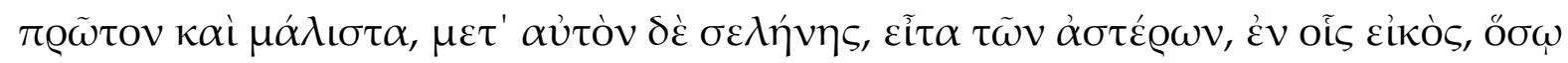

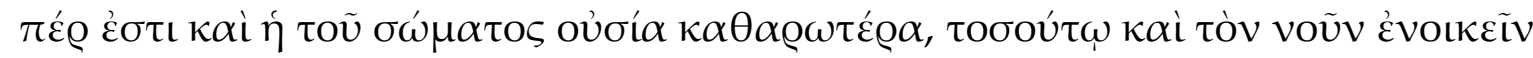

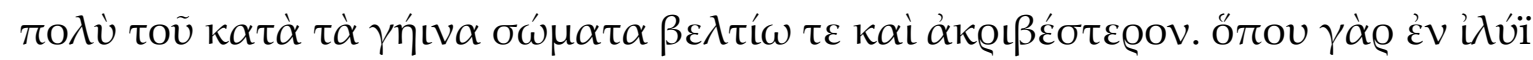

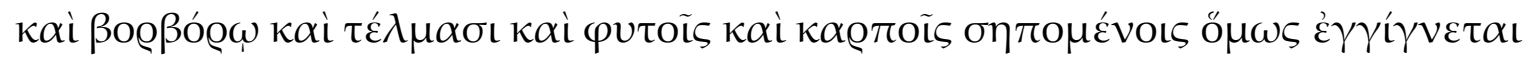

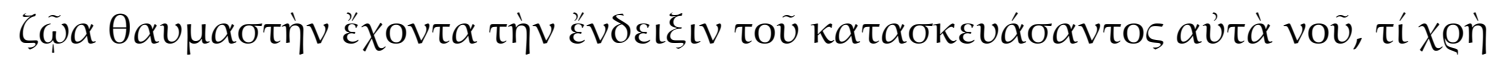

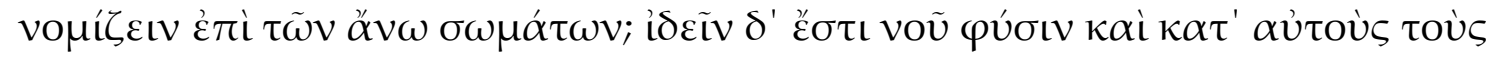

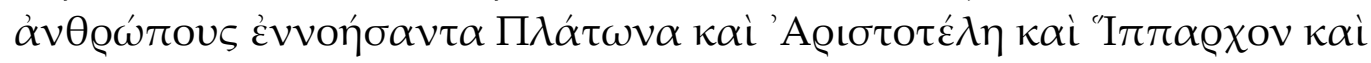

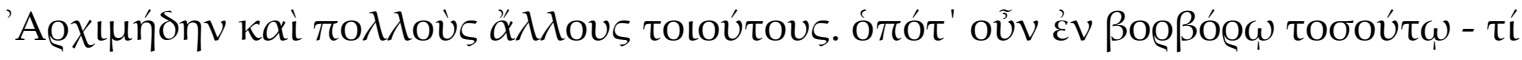

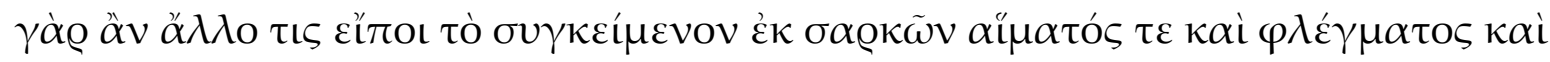

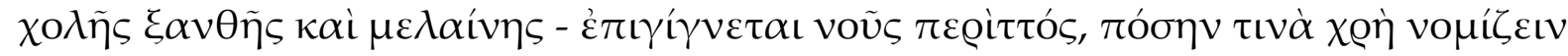

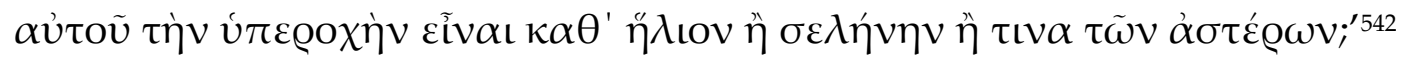

'But even here some intelligence appears to be reaching us from the bodies above, and the beauty of their substance forces anyone that sees them to be amazed at once, that of the sun first and foremost, that of the moon after that, and next that of the stars, and it is reasonable to suppose that the intelligence that dwells in them is exactly that much better and sharper than that in the earthly bodies as the substance of their body is purer. For when in mud and slime, in marshes, and in rotting plants and fruits animals are engendered which yet bear a marvelous indication of the intelligence constructing them, what must we think of the bodies above? But you can see the nature of the intelligence in man himself when you consider Plato, Aristotle, Hipparchus, Archimedes and many others like them. When a surpassing intelligence comes into being in such slime - for what else would one call a thing composed of fleshes, blood, phlegm, and yellow and black bile? - how great must we consider the pre-eminence of the intelligence in the sun, moon, and stars?' (tr. May)

Clearly, in this passage towards the end of $U P$, Galen points to the relative wetness of human beings as a hindrance to the development of their intellectual capacities. ${ }^{543}$

\footnotetext{
${ }^{541}$ Cf. Frede (2003) 116 ff., who also refers to the similarities with the Pseudo-Aristotelian De Mundo ${ }^{542}$ UP II 446,12-447,8 Helmreich (IV 358-9 K)

${ }^{543} \mathrm{Cf}$. Frede (2003) 118: 'Galen here is presupposing that the elements themselves ar ranked according to purity in the following order: fire, air, water, earth, and that accordingly bodies mixed from them are, depending on the
} 
Whereas in $Q A M$ he stated that a being is removed from perfect understanding to the degree that it partakes of wetness, now we read that the heavenly bodies are that much more intelligent as their substance is purer, i.e. more like fire. Given the recurrence of this idea in various works, it makes no sense to put passages such as these aside by appealing to the rhetorical context of the epode of UP or QAM in general. In these passages, Galen is re-establishing the physiological basis of the psychic over against - presumably mostly Platonist - opponents. One important difference between these passages from Galen's attested work and Larrain's fragment 7 , however, is that in the former the wetness and dryness are always attributed to the human body, whereas in the last sentence of Larrain's fragment it is predicated of the rational soul itself. In this sense, the author of Larrain's fragment seems to go a step further than Galen does in his attested works (as far as I can see), attributing specific elemental qualities to soul itself. We will come back to this issue in the discussion of some of Larrain's other fragments below.

We noticed how, in Galen's interpretation of the Timaeus, the causal role that relative dryness and wetness plays with regard to rational capacity, is rooted in the metaphor of the river that Plato uses for the description of the incarnation of the soul, or in more Galenic terms: for the phase of generation, of the embryo and the newborn. However, both in Larrain's fragment 7 and in some of Galen's attested works, as we have seen, this theme is taken beyond the context of generation alone. In fragment 7 , particularly, the state of the newborn is compared to a state of inebriation, the implication being that drinking wine wets the substance of the soul. Also, the predominance of wetness is said to cause sleep. Both of these points are paralleled by an important testimony found in Rhazi, supposedly pertaining to the first book of Galen's commentary on the Timaeus and added to the commentary fragments by Schröder as an excerpt from the first book. Let us have a look at the Latin translation provided in Schröder's edition:

'Dixit Timaeus in primo libro suo: constituerunt medici et physici certam dietam hominibus qua non multiplicetur sanguis in eis, quod multiplication humiditatum in corporibus administrat defectum in intellectu. Et signum ad hoc est, quod multotiens invenimus quod illi quorum humiditas multiplicatur sunt ebetes et lenti et somni profundi et melancholici et moventur in eis egritudines quibus deficit eorum ingenium, et quoniam cerebrum humectatur, deficit eorum ingenium sicut accidit in ebrietate. ${ }^{\prime 544}$

'In his first book Timaeus says: doctors and natural philosophers have set up a certain diet for men so that the amount of blood in them is not increased, because increase of wetness in bodies causes weakness in intellect. And an indication of this

proportion of the different elements in the mixture, more or less pure, terrestrial bodies being the most impure because of the large proportion of water and earth they contain. He may also assume that the elements themselves come in purer or less pure forms. In any case, the heavenly bodies will consist of particularly pure fire and hence will be the purest, first among them the sun. Thus the sun will be the most intelligent.'

544 Schröder (1934) 2-3 
is that, often we have found that those in whom wetness is increased are obtuse and sluggish and sleep immoderately and are melancholic and mental illnesses are troubling them that make their natural intellectual capacity fail, and since the brain is moistened, their natural intellectual capacity fails just as if they are inebriated.'

This text is particularly important because it is considered an excerpt from the first book of Galen's commentary and shows great resemblance to what is discussed in Larrain's fragments, particularly fragments 7-12, as Larrain has noted himself. ${ }^{545}$ As we see more often in the Arabic tradition, Galen's text is simply attributed to 'Timaeus'. ${ }^{546}$ Interestingly, it is said here that doctors and natural philosophers have established diets to regulate the predominance of wetness in the body, since wetness decreases intellectual capacity. Of course, these particular thoughts on diet are not found in Plato's Timaeus, but we do find them, notoriously, in Galen's $Q A M^{547}$, so it should not surprise us to find them in his Timaeus commentary as well. Schröder thought Rhazi's testimony pertains to Tim. 43a4-44b1, which is also where Galen's beloved river-metaphor is introduced. This makes sense if we compare the passages from $U P$ and $Q A M$ cited above ${ }^{548}$ : departing from this river-metaphor Galen develops an opposition between wetness and dryness that amounts to a rewriting of the Platonic struggle between soul and body. In this passage, the traditional themes of sleep and inebriation are added. It is also noted that mental illnesses causing damage to rational capacities can result from excessive moisture and that an increase of blood implies an increase in wetness. To all of this, again, there are parallels in Galen's work. The predominant wetness of blood is well attested throughout Galen's work. As we have seen in Case-Study II, in HNH Galen considers blood to be the cause of 'simplicity and artlessness', which corresponds to the correlation between the increase of blood and decrease of intellectual capacities here due to the wetness of blood. ${ }^{549}$ Schröder points to a passage in Galen's commentary on the Hippocratic Aphorisms (Hipp. Aph.), where it is said that those who are drunk with wine lisp because their brain becomes soaked by an excess of wetness, and that their brain is weighed down ( $\beta \alpha \varrho v v o \mu \varepsilon \varepsilon^{\prime}$ ov) because of this excess. ${ }^{550}$ The idea seems to be that the same symptom of lisping can be caused both by a natural local excess of moisture and an excess caused by temporal inebriation. Besides lisping, another symptom that inebriation and excessive wetness of the brain share, is the dysfunctioning of normal rational capacities.

We find a similar comparison between inebriation and mental illness based on an excess of wetness as their common aspect in Galen's commentary on the Hippocratic Epidemics (Hipp. Epid.), where he discusses an affliction called ' $\kappa \tilde{\omega} \mu \alpha$ ', which is a kind of lethargy. Both excess of wetness and coldness are said to cause this condition:

\footnotetext{
${ }^{545}$ Larrain (1992) 8

${ }^{546}$ Das (2013) 94-5

${ }^{547}$ QAM 67,2-16 (IV 807-8 K)

${ }^{548}$ See infra 174-5; QAM 43,15-44,2 Müller (IV 781-2 K); UP II 446,12-447,8 Helmreich (IV 358-9 K)

${ }^{549}$ HNH Mewaldt 51,9 (XV $97 \mathrm{~K}$ ); see infra CS II section 5, 136 and CS IV section 2, 269-70

${ }^{550}$ Hipp. Aph. XVIIIA $52 \mathrm{~K}$
} 


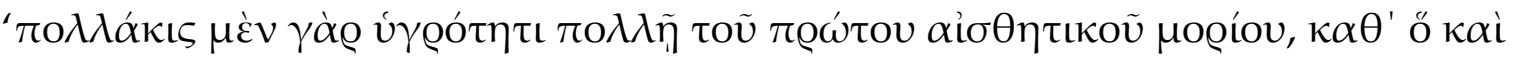

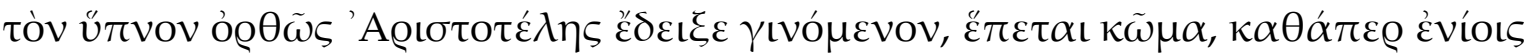

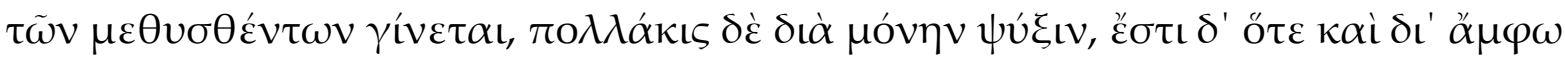

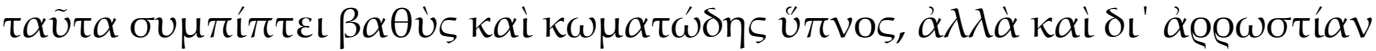

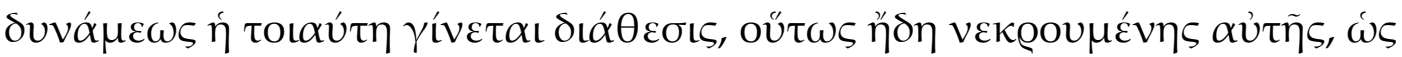

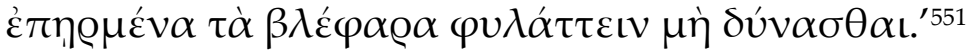

'For often coma follows upon an excess of moisture of the primary organ of perception, according to which Aristotle has correctly shown sleep also arises, just as it happens with some of those that are intoxicated, though often it comes about by coldness only; and when it is both of these, a heavy and lethargic sleep occurs, but such a state also arises becauses of a deficiency of power, such as when the power has already died out, so that it is not possible to keep the eyelids raised up.'

Thus, the association of predominant wetness with lack of intelligence and with sleep, as well as the examples of drunkenness and lethargy, both found in Larrain's fragment 7, are well attested in Galen's genuine works (we will return to the notion of lethargy below, in the discussion of fragment 9). In this last quotation, 'coldness only' was added as an alternative cause for the same symptoms. This is paralleled by, among many others, a passage in book III of Galen's The Affected Places (Loc. Aff.), where he goes into these matters somewhat more elaborately. There, damage in

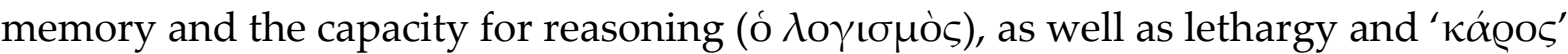
(an affection of deep sleep), are all associated with predominant coldness of the homoeomerous parts constituting the brain. ${ }^{552}$ In general, Galen remarks, 'one can see that cold weakens the mental activities'. Cooling of the head causes somnolence and purging phlegm, one of the wet humours, can relieve 'heaviness of the head'. Heating, on the other hand, leads to sleeplessness, and 'warm and biliary diseases' are said to cause lack of sleep and even delirium and phrenitis, the same condition mentioned in Larrain's fragment 8. We also find the notion that infants are 'drowsy' due to their predominant wetness and that the older become sleepless because of the predominant dryness of the mixture of their brain. Galen concludes that in 'rendering the soul inactive' moisture is the second strongest cause and coldness is the first. ${ }^{553}$ Of course, these two are related, since if heat is more predominant, the moisture will dissipate and a substance will become dry. Here we can see that the effect of wetness on the rational capacities attributed to newborns, is embedded in a larger physiological framework of which drunkenness and diseases such as lethargy are part. Ialso n Larrain's fragment 12, the author takes the notion of the river Lethê, the river of forgetfulness from which the souls drink before their reincarnation according to Plato, as an allegorical reference to the wetness of newborns in the same vein as Galen's reading of the river-metaphor from the Timaeus (using also the same

\footnotetext{
${ }^{551}$ Hipp. Epid. XVIIA $540 \mathrm{~K}$

${ }^{552}$ Loc. Aff. VIII $160 \mathrm{~K}$ ff.

${ }^{553}$ Loc. Aff. VIII 162,8-10 K
} 
verb $\alpha i v i ́ \tau \tau \varepsilon \sigma \theta \alpha \iota) .{ }^{554}$ The author relates the notions of lethargy and the mythical river Lethê to one another, while both are explained in terms of predominant wetness hindering rational capacities such as memory. ${ }^{555}$

All of this corresponds well to Galen's interpretation of the Timaeus in QAM, which we have discussed above. However, it is not simply the case that dryness and heat are beneficial to intellectual capacity per se, while wetness and coldness are detrimental per se. An excess in heat can, likewise, cause serious impairment of the intellectual capacities, but more in the sense of an overload that leads to a phrenetic or delirious state, i.e. a state characterized by a kind of overload of activity. In the words of Jouanna: 'So change to the mixtures of the brain towards an excess of either heat or cold produces contrasting effects on the intellectual faculties, either delirious excitement or the numbing of intelligence and memory. ${ }^{556}$ Jouanna has shown that Galen's descriptions of the effects of humoural mixture on the intellectual capacities in $Q A M$ are close to those of some Hippocratic writings. In The Sacred Disease, excess of bile (a dry humour) is said to cause an agitated madness, while excess of phlegm (a wet humour) causes a calm madness. In Regimen, the relative predominance of fire or water is said to increase or decrease intelligence respectively. ${ }^{557} \mathrm{He}$ has also argued that Galen draws on an extensive tradition for the idea that the intellectual capacities of our soul can and need to be improved through dietary regime, exercise and choice of climate - i.e. through influencing one's mixture. ${ }^{558}$ I would merely add to this that Galen (as well as the author of Larrain's fragments) through his somatising interpretation of Plato's Timaeus, is concerned to give this tradition a firmer physiological and philosophical grounding by anchoring it in his favourite philosophical authority.

We find another interesting passage in this regard in the so-called Character Traits (extant only in Arabic). At the outset of the work, Galen states that he will ignore the questions on what it is that makes thought, anger and desire come about, and whether these things are called different souls, parts of the soul or different capacities

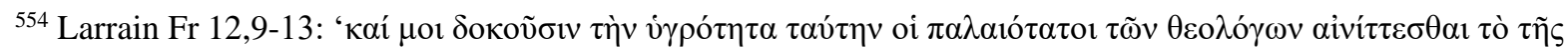

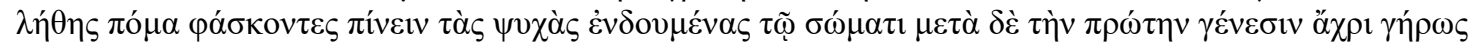

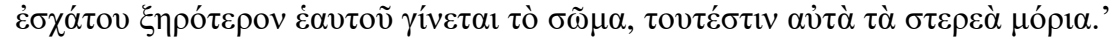

${ }^{555}$ See also on lethargy the testimony from Tabit Ibn Qurra, translated in Larrain's edition (188): 'Es sagte Galen im 'Timayus' bei seinem Kommentar zum Wort des Platon: 'Die beiden feuchten Mischungen sind das Blut und das Phlegma, die, wenn sie im Körper in großen Mengen vorhanden sind, den Betroffenen dumm, faul und schläfrig machen. Ebenso leidet der Betroffene, wenn sich die beiden Gallen im Körper vermehren, an Schaflosigkeit und körperlicher Unruhe. Mann nimmt ein Heilmittel gegen diese Schwäche zu Hilfe, unter Berücksichtigung des Heilmittels gegen 'LYTRGS' $<\lambda \eta \dot{\eta} \theta \alpha \rho \gamma o \varsigma>$, d.i. die kalte Hirnhautentzündung.'

556 Jouanna (2009a) 197

${ }^{557}$ Jouanna (2009a) 197 ff.; see, e.g. Regimen I, 35,50-60: 'If in any case fire receive a power inferior to that of water, such a soul is of necessity slower, and persons of this type are called silly.' (tr. Jones) 'Silly' translates $\grave{\eta} \lambda \dot{\theta} \theta$ ıo, the same word Galen uses in HNH Mewaldt 51 (XV $97 \mathrm{~K}$ ), discussed below, to describe the effect of blood on the soul; 35,70-80: ' . . f following such a regimen will make such men more healthy and intelligent. But if the fire should be mastered to a great extent by the water in the soul, we have then cases of what are called by some 'senseless' people, and by others 'grossly stupid'. Now the imbecility of such inclines to slowness...' (tr. Jones); in 35,80-90 the fire in the soul is also related to perception: 'But if the power of the water prove

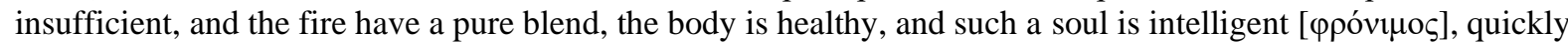
perceiving without frequent variations the objects that strike it.' (tr. Jones)

558 Jouanna (2009a) 203
} 
of a single substance. Typically, Galen wants to discuss more practical matters in this work and stay away from difficult theoretical issues discussed elsewhere (he refers to $P H P)$. Nonetheless, on the next page he proceeds to explain that, in his view, the essence of the strength of the spirited soul is identified as innate heat:

'The essence of this strength, which enables someone to act patiently and steadfastly is, as far as I can see, innate heat, for the more powerful the movement of the innate heat, the more someone moves. Just as cold produces laziness, immobility and weakness, so heat produces energy, movement, and the strength to act. That is why the beginning of youth and wine arouse movement and power, while old age and chilling drugs produce laziness and weakness; they lead, in time, to the annihilation of actions and movements.' 559

As in other works cited above, coldness and wetness (this time particularly coldness, but again, they are related) are associated with degeneration, weakness and immobility, while dryness and hotness are associated with the opposite. In all passages cited, this association clearly has a strong causal sense. Likewise, in $Q A M$ Galen states that a higher quantity of heat in the heart (the seat of the spirited soul) makes one more 'manic and sharp-spirited' while a higher quantity of coldness makes one lethargic, heavy and slow to move'. ${ }^{560}$ Thus, it seems that even in a work such as the Character Traits, which is emphatically about ethical philosophy and shuns the difficult theoretical discussion on what soul itself is, the same underlying schema that comes to the fore in QAM and Galen's interpretation of the Timaeus is also at work. In this underlying schema, the qualities that are associated with the lower realm of the cosmos, wetness and coldness, are considered to cause passivity of the soul, while the qualities that are associated with the heavenly bodies, dryness and hotness, are considered to cause activity of the soul.

In UP we also saw the humours associated with the wetness of the lower realms. ${ }^{561} \mathrm{In}$ Rhazi's testimony, however, it was blood in particular, apparently because of its predominant wetness. Since the various elementary qualities each have their specific relations to specific psychic capacities, it would make sense if the four humours too, being composed of different mixtures of the elementary qualities, accordingly relate differently to the exercise of psychic capacities. Indeed, an important passage from $H N H$, which we also cited in Case-Study $\mathrm{II}^{562}$, shows that Galen took this into account:

'

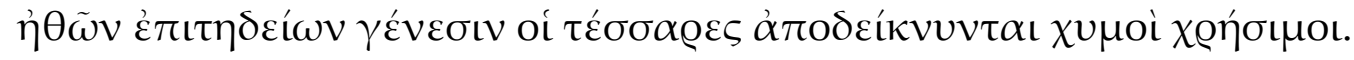

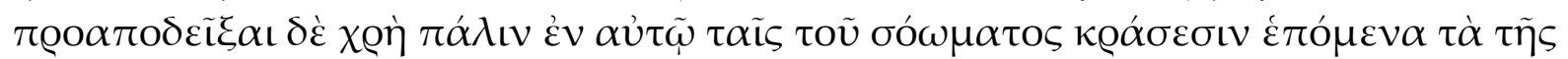

\footnotetext{
${ }^{559}$ Character Traits, ed. Singer (2013) 140 (27 Kraus), tr. Daniel Davies

${ }^{560}$ QAM 63,29-64,2 Müller (IV $804 \mathrm{~K}$ ) tr. Singer

${ }^{561}$ See the passage quoted above, UP II 446,12-447,8 Helmreich (IV 358-9 K), more particularly 447,4-6

${ }^{562}$ See infra, CS II section 5, 136-7
} 


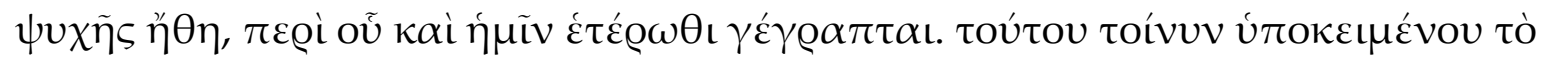

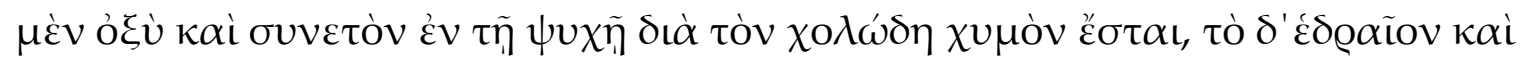

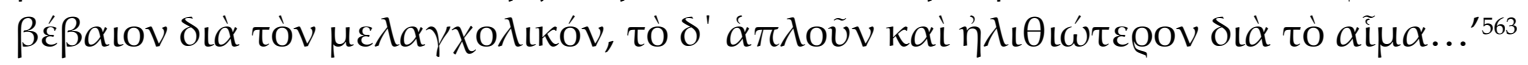
'There is also another physical account which has no little plausibility, according to which the four humours are proved to be effective in the generation of the dispositions which are appropriate to them. In it we first need to establish that the dispositions of the soul are consequent upon the mixtures of the body, about which we have written elsewhere. On this basis, sharpness and intelligence in the soul will exist as a result of the bilious humour, stability and firmness as a result of the melancholic, simplicity and artlessness as a result of the blood...'564

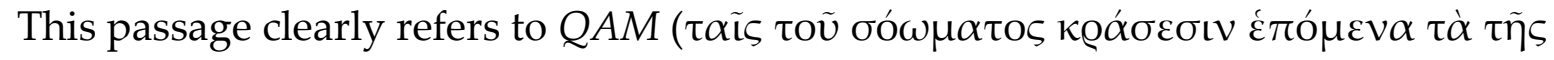

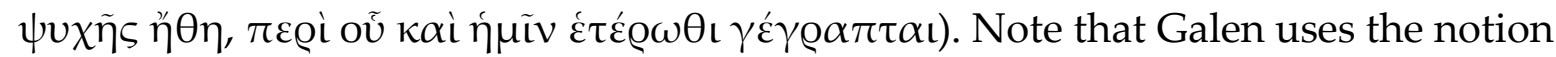
of the 'plausible' here again, which we have discussed above. ${ }^{565}$ The theory of the causal power of mixture over psychic activity is said to have more than a little plausibility. The bilious humours are considered the drier two of the four humours, while blood and phlegm are the wetter ones. Hence, the ordering in which the drier humour increases the intellectual capacity, and the wetter humour reduces it, corresponds to the passages cited above on the causal relation between relative dryness or wetness and intelligence. It is also noteworthy that the examples that Galen gives here seem to particularly relate to the rational capacities.

This passage from $H N H$ compares well to the next text-fragment in Larrain's edition, fragment 8:

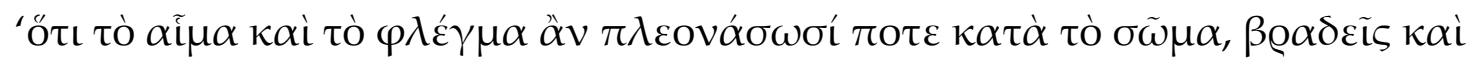

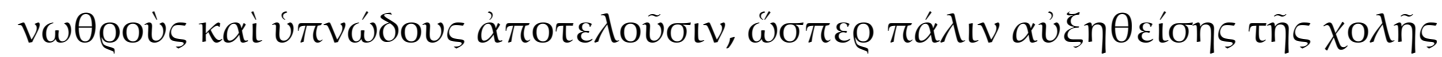

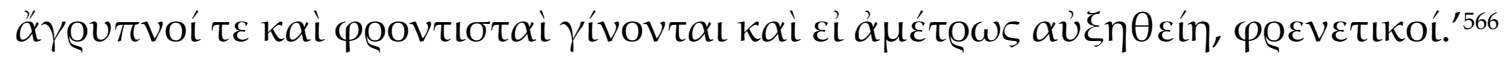
'That blood and phlegm, whenever they excessively increase throughout the body, bring about slowness and sluggishness and sleepiness, just as when the bile is increased, they become wakeful and deep thinkers again, and when it is increased excessively, [they become] phrenetic.'

Unfortunately, there seem to be some textual problems with this fragment. The word $\varphi \varrho \varepsilon v \varepsilon \tau$ เ ó $\varsigma$ is not attested for Galen and barely attested for any other texts.

However, forms of $\varphi \varrho \varepsilon v ı \tau \iota k o ́ s$, with iota instead of epsilon, are found rather

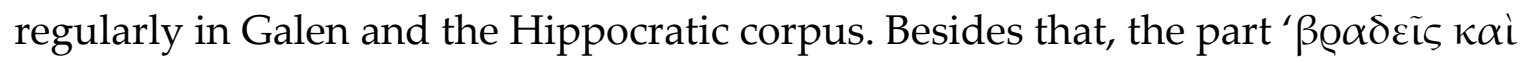

\footnotetext{
${ }^{563}$ HNH Mewaldt 51,9-16 (XV 97 K)

$564 \mathrm{Tr}$. Hankinson (forthcoming), modified. I think it is better to not translate $\tilde{\eta} \theta 0 \varsigma$ here as 'state of character', since the examples Galen gives cannot successfully be placed in the traditional category of 'character', i.e. in the lower part of the soul as opposed to the rational part (Galen also often uses the word this way). Rather, the examples include the functioning of the rational soul (in fact they relate most to this part), which is why I choose to translate with the more formal and general term 'dispositions'.

565 See infra, CS I section 3, 66-71

${ }^{566}$ Fr 8, ed. Larrain
} 


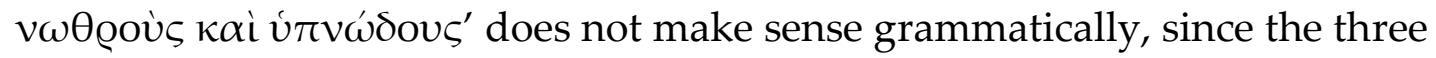
adjectives are not congruent with each other. Unfortunately, Larrain does not go into these problems and as we mentioned before, all of Larrain's fragments were marked with an obelus in the manuscript. Whether these issues can be explained in terms of errors or deviations by a scribe taking excerpts from Galen's actual commentary, or whether a different explanation is needed, I do not know. In this fragment too, however, the resemblance to Galen's attested works is obvious. Furthermore, Larrain found a translation of this fragment in Tabit Ibn Qurra's Al Dahira (9 ${ }^{\text {th }}$ century), where it is ascribed to Galen's commentary on Plato's Timaeus. 567

From our comparison of Larrain's fragments 4-8 with Galen's attested work, we can at least conclude the following: the somatising interpretation of the Timaeus, through the introduction of the causal relation between relative dryness or wetness and rational capacities, corresponds both to passages from Galen's work on humoural theory and to his notion that psychic capacities are dependent on the mixtures of elemental qualities. We find it supported by passages from works such as UP, QAM, Loc. Aff., Temp., HNH, as well as Galen's Compendium and the testimonies on the first book of his Timaeus commentary. It is unavoidable to conclude that the author of these fragments was, at least, thoroughly familiar with Galen's work and in strong agreement with it. Additionally, they discuss the same topics as Galen apparently discussed in the first book of his Timaeus commentary. As we have seen, the correspondences go much further than a resemblance to a few passages of major Galenic works such as PHP and UP (as it may appear from Nickel's article). Moreover, despite some textual oddities, I have so far not found anything speaking strongly against Larrain's conclusions, however confident they may have been in themselves.

\section{c. The soul as a dry and hot substance that exudes light}

Besides the Hippocratic tradition discussed by Jouanna and briefly referred to above, another clear precedent for these views on the relation between elemental qualities and rational capacity, is Heraclitus, who Galen also refers to in this context. ${ }^{568}$ In several of the extant fragments, Heraclitus associates a dry state of the soul with intelligence and a moist state with drunkenness, stupidity and death. Kahn says, in his commentary on the fragment in which Heraclitus calls the dry soul a ray or beam of light, wisest and best (CIX in his edition, $118 \mathrm{DK})$ : 'This gives a new dimension to Heraclitus' doctrine of the soul: just as moisture weakens the soul so that it may perish into water, so dryness strengthens and improves it to the point where it may be purified as light (not fire). ${ }^{\prime 569}$ Heraclitus relates the good state of the soul to the light of the heavenly bodies and Kahn points to the roots of this notion in preSocratic cosmology, which separates the upper and lower realms of the cosmos in

\footnotetext{
567 Larrain (1992) 79-80, 188; Arnzen (2012) 222-3; I quoted Larrain's translation above, note 555 ${ }^{568}$ QAM 47,9-18 Müller (IV $786 \mathrm{~K}$ )

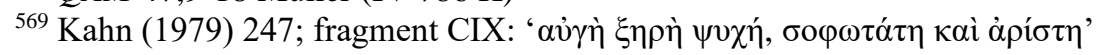


terms of their respective elemental qualities: 'This conception is deeply rooted both in the language of early Greek poetry and in the theories of pre-Socratic philosophy. In poetic terms CIX defines the best condition of the psyche as a kind of aither, not fire as such but the clear and luminous upper sky, as contrasted with the murky and moist lower aer, comprising haze, mist, and cloud. ${ }^{\prime 570}$ In another fragment, Heraclitus relates a wet soul to inebriation, youth and faulty perception, all themes we have encountered in Galen's interpretation of the Timaeus as well. ${ }^{571}$ In Larrain's fragment 9, the author also refers to Heraclitus' notion of the dry soul being wise, as we shall see below.

The river-metaphor of the Timaeus and its connotation of the flux of becoming is easily associated with Heraclitus. ${ }^{572}$ It is no coincidence that Galen refers to Heraclitus in $Q A M$ right after he has discussed it. Apparently, the idea of flux represented by the river is related by Galen to the notion of the wet soul and thereby contrasted to the soul that is dry and fiery. In a way, the contrast of flux and stability as we find it in Plato, is maintained in Larrain's fragments with the notion of the two kinds of movements, one of which is round and continuously the same, i.e. stable, while the other is linear and goes in all directions, i.e. more chaotic and never the same. As we shall see, these two motions are determined by the relative dryness or wetness of the moving substance, which makes them either more or less like divine movements.

The characterization of the upper and lower realms in terms of different elemental qualities and the association of soul and intelligence with the qualities of the heavenly bodies, is something we have seen before in several of Galen's works, and which we find also in the longest fragment we have of his commentary on the Timaeus. This is the second Greek fragment in Schröder's edition, supposedly pertaining to 76e7-77c5 of Plato's Timaeus, in which Galen divides the elements in more 'material' and more 'active' ones:

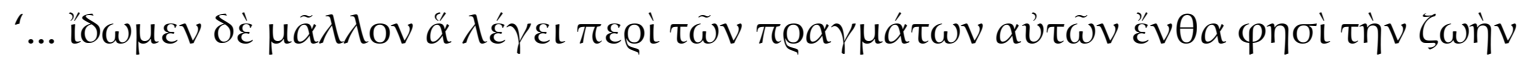

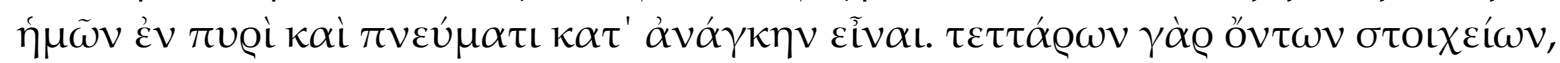

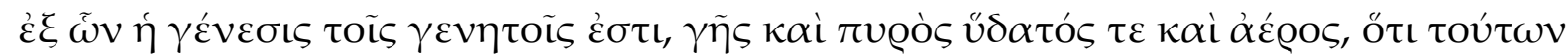

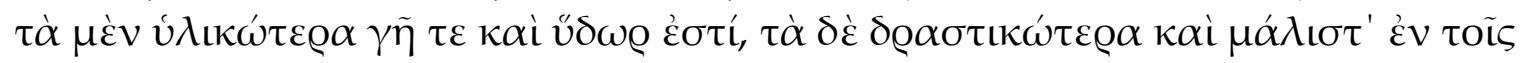

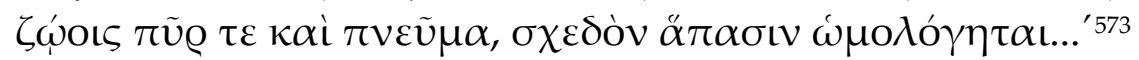

'... we see that he speaks more of the matters at hand themselves where he says that our life necessarily consists in fire and pneuma. For there are four elements, from which the coming-to-be of generated beings comes about, namely from earth, fire, water and air, and almost everybody agrees that of those earth and water are the more material, while fire and pneuma are the more active, particularly in the living beings...'

\footnotetext{
${ }^{570}$ Kahn (1979) 247

${ }^{571}$ Kahn (1979) fr CVI

572 Cf. Mansfeld (1967) $21 \mathrm{ff}$.

573 Schröder (1934) 10-11
} 
The extent to which Galen here stays true to the Platonic text is debatable. He quotes

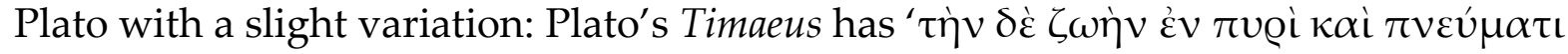

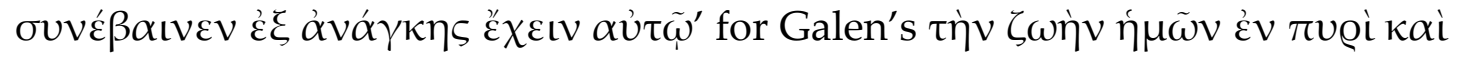

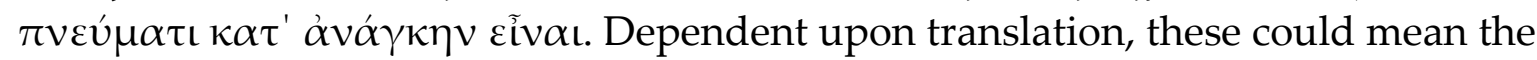
same. For example, Zeyl translates Plato's text as 'Of necessity, however, it came about that he [i.e. the newly created human being] lived his life surrounded by fire and air'. In that case, the fire and air that are wasting the human being away are not considered innate to the human being, but rather part of its surroundings. Because of the surroundings of the human being gnawing away at it, it must acquire nourishment to add new substance to itself. This is why the gods made plants. Galen seems to read this sentence differently than Zeyl does, saying rather that our life (itself) consists in fire and air. While both readings seem possible to me, dependent also on the wider interpretation of the text, it is also clear that the way Galen quotes Plato fits his general reading of the Timaeus, which emphasizes a schema of opposition between wetness and coldness or earth and water on the one hand, and dryness and hotness or air and fire on the other hand. Thus, this opposition is also what Galen proceeds to refer to as the explanation for Plato's words: earth and water are more material, while fire and air are more active. It is said in the Timaeus itself that fire is made up of the smallest particles and can therefore pass through the other elements. ${ }^{574}$ In that sense, as an interpreter of Plato one might be justified in calling fire less material than the other three. However, the strong opposition between active and material elements or qualities, with life belonging exclusively to one of the two opposites, is certainly Galen's own projection, familiar from what we have seen before. Again, this is also in line with Galen's humoural theory, in which the humour that is most like the heavenly bodies (i.e. most fiery) is also the humour that is most active or causes activity to the greatest extent. This is yellow bile, a humour that tends to move upwards and that Galen associates with intelligence. ${ }^{575}$ These thematics from the Timaeus also recur in a passage on innate heat in Galen's On Tremors, which we alluded to above. ${ }^{576}$ Notably, Galen also refers to Heraclitus in

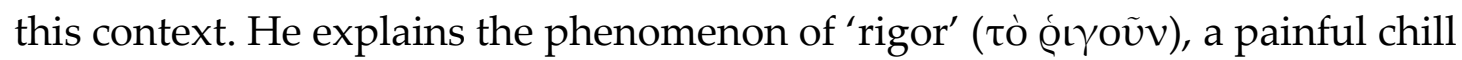
accompanied by irregular shock and agitation, as an affection of our 'natural heat'

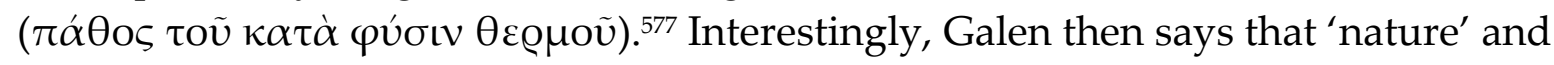

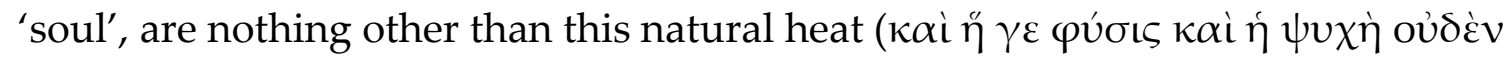

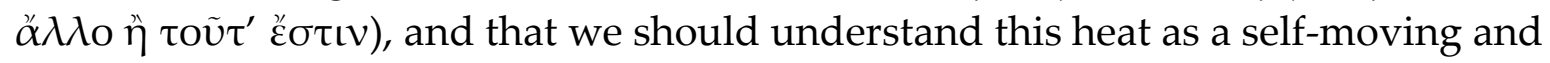

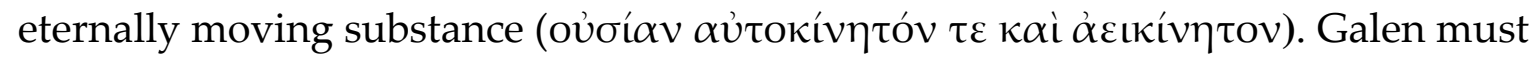
have the Platonic definition of the soul from the Phaedrus in mind here, which was

\footnotetext{
${ }^{574}$ Tim. 55e-56e, $78 \mathrm{a}$

${ }^{575}$ HNH 46,5 ff. Mewaldt (XV 35 K), 50,23-4 Mewaldt (XV 96 K), 51,9-18 Mewaldt (XV 97 K)

; Nat. Fac. II 9, II 135 K; Hipp. Elem. 154,5-6 De Lacy (I 506 K); PHP V, 502,23 De Lacy (V 676 K); Hipp. Aph. XVIIB 667 K. See also infra, CS IV section 2, 263-70

576 See infra, 171 note 531

577 Trem. Palp. VII 614
} 
very well known to him, as we have seen in Case-Study II. ${ }^{578}$ Here we have one of the elemental qualities - one that is specifically associated with the substances of the heavenly bodies - defined in the same terms as the Platonic soul. Moreoever, this occurs in the context of a rather practical discussion of a specific medical condition, not in a context of tentative speculating. This corresponds to the observed tendency of a somatisation of Plato's notion of soul that has a strong point of departure in the Timaeus. And indeed, in this passage from On Tremors, Galen brings up the same issue of the increase and decrease of heat, in terms that are reminiscent of the passage around 77a in the Timaeus (the same passage to which Galen's commentary from our last quotation pertains). He says that, since the innate heat continuously moves, there must be both an inward as well as an outward motion of innate heat that succeed each other, if a living being is to persist. Should the heat only move inward, the living being would become immobile; should it only move outward, the heat would become dispersed and the living being would perish as well. Therefore, it rather remains constantly in motion 'now quenched and now kindled, as Heraclitus said'579. Now we can see also how Galen reads the passage from the Timaeus and understand his commentary better:

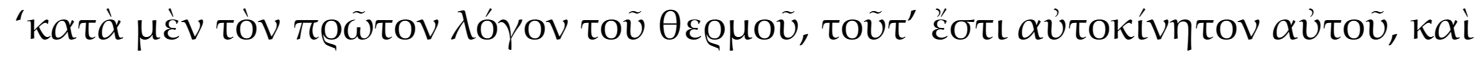

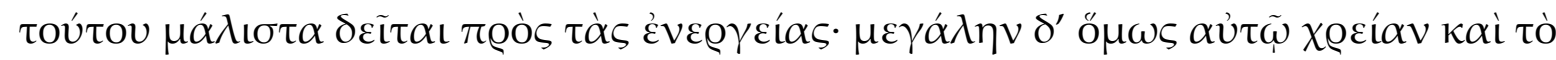

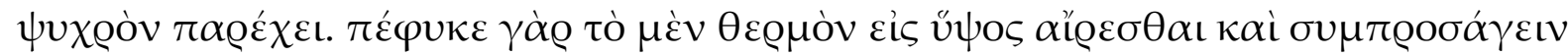

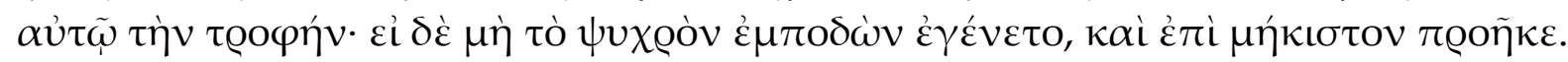

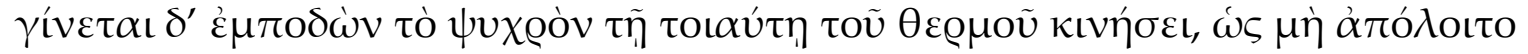

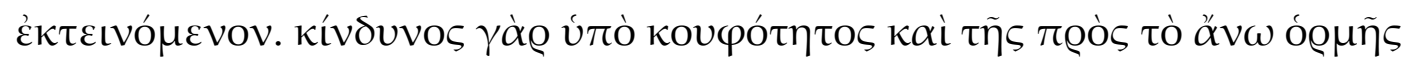

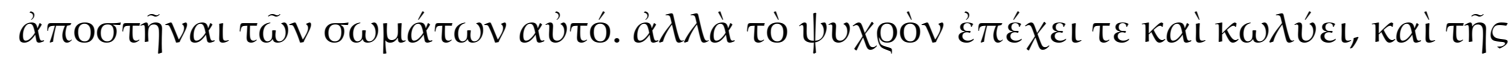

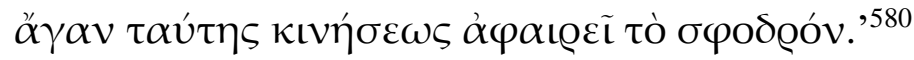

'By reason of its heat, it is self-moved, and very much needs this property in order to act. Yet cold too is very useful for it. For heat is accustomed to rise up and bring along its nourishment; if cold did not prevent this, it would proceed to the greatest heights. But cold does prevent heat from moving in this way, and thereby keeps it from dispersing and perishing. For there is danger that heat will leave the bodies because of its natural lightness and its tendency to move upwards. But the cold checks, hinders, and reduces the violence of this excessive motion.' (tr. Sider and McVaugh)

Heat naturally moves upward and our heat apparently would do so unhindered, and perhaps would add itself to the realm of the heavenly bodies, if it were not checked by the coldness that is mixed with it and that reduces it and keeps it down. Thus, the heat and air Galen mentions in his commentary on the Timaeus is our natural heat that is naturally constantly leaving us, moving upwards, and creating a constant

\footnotetext{
${ }^{578}$ Phdr. 245c ff.; see infra, CS II sections 2 and 5, 105-12 and 130-7; cf. Tieleman (forthcoming)

${ }^{579}$ Trem. Palp. VII 617, tr. Sider and McVaugh

${ }^{580}$ Trem. Palp. VII 617-8 K
} 
need for replenishment. This heat, as we saw, is itself identified by Galen with our 'nature' and 'soul'. Supposedly, the cold that checks it is something else then, something more 'material' or something that belongs more to the lower cosmic realm. In the same manner, wetness generally hinders our psychic activities while dryness makes us more intelligent. It is clear that there needs to be a balanced mixture of all four, for Galen, in order to have a properly functioning and subsisting human being. However, it is also clear that Galen rather often privileges the hot and dry by associating it with activity, intelligence and the heavens, while he often portrays the cold and wet as mere hindrances with respect to the exercise of our proper activities and associates them with passivity, lack of intelligence and the lower part of the cosmos. This is still the same paradox that we find so often in Greek philosophy: man finds his fulfilment in part of himself, while other parts hinder this same fulfilment. At the same time, man, as such, cannot be without any of these parts: were we fire like the sun, then we would move upwards and leave the earth; were we water like the river, we would not know of ourselves.

This general outlook is also displayed in Larrain's fragment 9, which shows a lot of similarity to the various passages from Galen's attested work discussed above. I shall quote it in several parts, since it is a bit longer and requires some explanation:

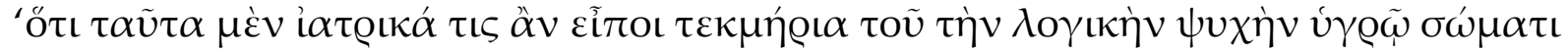

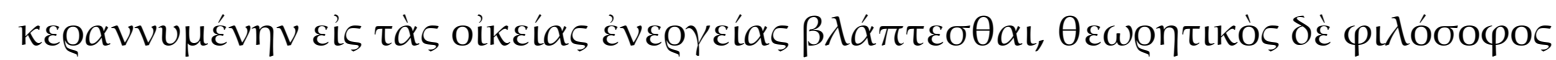

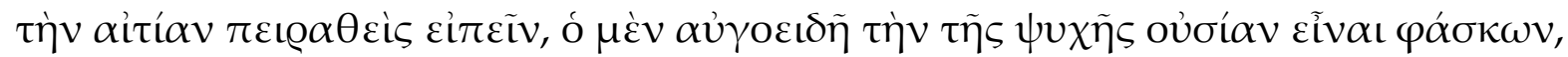

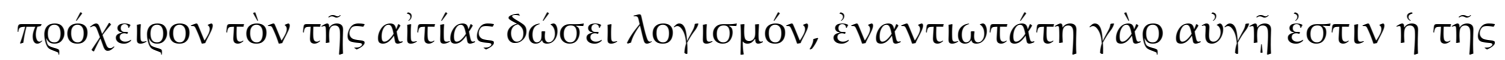

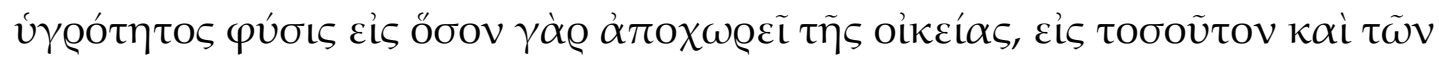

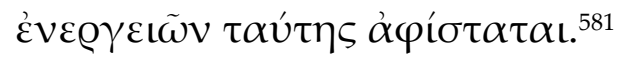

'That someone might say these medical observations are indications that the rational soul is damaged with regard to its proper activities when it is mixed with a wet body, and that when a theoretical philosopher is challenged to state the cause of this, he would say that the substance of the soul is of the nature of light and he shall give the common account for the cause, namely that, since the nature of wetness is utterly opposed to light, it shall be distanced from its activities to the extent that it is away from its proper nature.'

This fragment starts out with a challenge to philosophers, which we also find in Galen's attested work: how do you explain the fact that the activities of the (rational) soul are hindered due to specific changes in the body? ${ }^{582}$ The next part is more remarkable, because here the author comes up with a possible answer a 'theoretical philosopher' would give, and that the author of these fragments seems to adhere to as well. This is a somewhat more speculative move than what we usually get in Galen's works. It is not, however, in contradiction with it. After all, the answer

\footnotetext{
${ }^{581}$ Fr 9, ed. Larrain

${ }^{582}$ See particularly $Q A M$ 38-43 Müller (IV 775-783 K)
} 
consists simply in attributing a specific quality to the substance of the soul that is opposed to that of the one that hinders the soul's activity, i.e. wetness. Furthermore, this quality, being 'of the nature of light' ( $\alpha \hat{v} \gamma \mathrm{O}$ เ $\delta \tilde{\eta})$ is consistent with that of dryness and (innate) heat as well as with the characterization of the stars as supremely intelligent, which we have found both in Larrain's fragments and in Galen's attested work. Finally, it has a precedent in the Timaeus itself, where the souls were related to the stars as their original dwelling-places. ${ }^{583}$ In $Q A M$, Galen seems to have had this passage in mind as well, when he interprets wetness as the cause of mindlessness and predicates the extreme dryness that causes perfect understanding to the stars. ${ }^{584}$ As we noted, he then relates Heraclitus' aphorism, which he cites as 'a dry ray is the

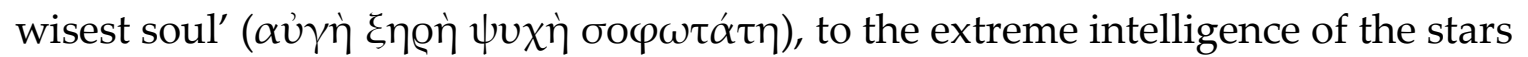
that are both dry and 'of the nature of light' ( $\alpha \dot{\gamma} \gamma 0 \varepsilon \iota \delta \varepsilon \tilde{\iota} \varsigma) .{ }^{585}$ There are also passages in Galen where he states that the intelligence of the heavenly bodies is transmitted through the light they exude. Frede has offered an excellent discussion of this subject, noting that 'Notoriously from Plato onwards down to late antiquity the $\alpha \dot{v} \gamma$ ' of the sun or of fire is referred to again and again in discussions of the soul and in particular of the cognitive powers of the soul. ${ }^{586}$ As Frede observes, Galen mostly

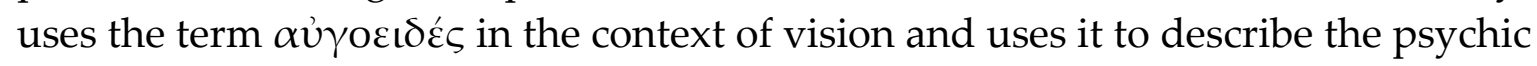
pneuma that is produced in the ventricles of the brain and moves between the brain and the eye. ${ }^{587}$ Katerina Ierodiakonou, in her insightful study of Galen's theory of vision, has shown how he 'collects elements from the Platonic, the Aristotelian, and the Stoic model, in order to form his own eclectic theory', in which the psychic pneuma functions as a kind of extension of our eye, assimilating the air into something similar to itself with the aid of sunlight and thus gathering data about perceived objects through the observation of colour. ${ }^{588}$ Galen considers this psychic pneuma to be of the same character as the light of the sun. ${ }^{589}$ Furthermore, in PHP book 7 , he suggests that either soul needs to be identified with this 'light-like and

\footnotetext{
${ }^{583}$ Tim. $41 \mathrm{~d}-42 \mathrm{~b}$

${ }^{584}$ QAM 43,10-44,2 Müller (IV 781-82 K)

${ }^{585}$ QAM 47,9-18 Müller (IV 786 K)

${ }^{586}$ Frede (2003) 120

${ }^{587}$ Frede (2003) 120

${ }^{588}$ Ierodiakonou (2014) $235 \mathrm{ff}$.

${ }^{589}$ Frede (2003) 121; Cf. Sem. 136,7-9 De Lacy (IV 584-5 K): ‘... just as we see externally the distribution of sunlight to the circumambient, and within us (the distribution of quality) from heart to arteries and brain to nerves.' (tr. De Lacy); Loc. Aff. VIII 66,9-67,6 K: 'And in this regard the natural organs differ completely from the psychic organs, because the power for activity has been shown to be innate for the natural organs, whereas for the psychic organs it flows from a source like the light of the sun... But since they [the muscles] do not have an innate principle for sensation and movement, they rely on the nerves to guide it [the psychic pneuma] to them, as the sun illuminates everything on which it shines.' (tr. Siegel, modified); PHP VII 474,3-7 De Lacy (V 642 $\mathrm{K})$ : 'Something similar happens also in the case of the air that surrounds us. When it has been illuminated by the sun, it is already an instrument of vision of the same description as the pneuma coming to it from the brain; but until it is illuminated it does not turn into a sympathetic instrument by virtue of the change effected in it by the outflow of the pneuma.' (tr. De Lacy); cf. also Plotinus, Enneads IV, 8, 4: 'So it is with the individual souls; the appetite for the divine Intellect urges them to return to their source, but they have, too, a power apt to administration in this lower sphere; they may be compared to the light attached upwards to the sun, but not grudging its bounty to what lies beneath it.' (tr. MacKenna). See infra, CS I section 2, 56-61
} 
ethereal pneuma' or the light-like pneuma is the vehicle (ó $\chi \eta \mu \alpha)$ of the soul. ${ }^{590}$ Typically, Galen does not reach any definite conclusion on this subject, except that the pneuma is not likely to be the substance of the soul, since the substance would rather dwell in the 'body of the brain itself', whereas the pneuma appears to be an instrument moving from and to the brain. ${ }^{591} \mathrm{It}$ is clear, though, that the psychic pneuma is related to the power of cognition and that both are related to the light exuded by the heavenly bodies.

The notion of a vehicle of the soul is also used in Plato's Timaeus, in two ways. First, Timaeus states that each soul is assigned to a star as its vehicle, and later on in the text the body, or more particularly the head, becomes the vehicle for the soul. ${ }^{592}$ These two Platonic characterizations of the vehicle correspond to Galen's location of the light-like pneuma in the head, eyes and heavenly bodies. Since the sun is not to be identified with the light it exudes, it might also make sense, given Galen's comparisons between the brain and the sun, that the psychic pneuma that is produced and distributed from the brain, is not identical to its source, which would rather be something like the sun, i.e. a body of such mixture that it exudes something light-like. Therefore, the psychic pneuma should not be considered the substance of the soul, which is seated in the brain and rather produces and exudes the pneuma, using it as its instrument to extend itself throughout the body and outside of it. ${ }^{593}$ In the context of his theory of vision, Galen holds that this psychic pneuma meets with the air in such a manner that the air 'forms one body' with it, or is 'assimilated' to it. ${ }^{594}$ The eye uses air as an instrument, in the same manner as the nerve is an instrument of the brain - as a medium for the psychic pneuma. ${ }^{595}$ In his Compendium, Galen gives the same abridged and altered version of the theory of vision from the Timaeus. 596

In Larrain's fragment 18, the author seems to build on this notion of psychic pneuma as a corporeal substance that is able, due to its fineness, to penetrate other bodies like fire does, but due to its mildness compared to fire, can do so without burning or damaging those bodies. ${ }^{597}$ The author cites from Timaeus 58c the passage on the different types of flames. As Larrain remarks, he also connects this passage to Timaeus $45 \mathrm{~b}$, where Timaeus describes the fire flowing through the eyes, which is milder, comparable to the light of day and therefore does not burn. ${ }^{598}$ In Larrain's

\footnotetext{
${ }^{590}$ PHP VII 474,22-9 De Lacy (V 643-4 K); cf. also PHP VII 442,36-443,2 De Lacy (V 606 K), where the second option is that the pneuma is the soul's 'first home' rather than its vehicle

${ }^{591}$ PHP VII 442,36-444,11 De Lacy (V 606 K); see infra, CS I section 2, 58-60

${ }^{592}$ Tim. 41d-e, 69c

${ }^{593}$ On pneuma see infra, CS I section 2, 56-61 with notes 152, 159-60 for further references

${ }^{594}$ PHP VII 460,28-33 De Lacy (V 627 K); Ierodiakonou (2014) esp. 14

${ }^{595}$ PHP VII 460,1-4 De Lacy (V 626 K), 474,3-7 De Lacy (V 642 K)

${ }^{596}$ See the discussion in Das and Koetschet (forthcoming): Galen omits both what could be seen as the 'atomistic elements' in the account of the Timaeus, such as the notion of the 'particles [that] emanate from visible objects and collide with visual rays (67d-e)', as well as the 'central comparison between vision and reflection in a mirror (46a-c)'

${ }^{597}$ Fr 18, ed. Larrain

${ }^{598}$ Larrain (1992) 134; Galen does the same in PHP VII 462,25 ff. De Lacy (V 629-30 K)
} 
fragments 19 and 20, likewise, the pneuma which flows through the eyes is called

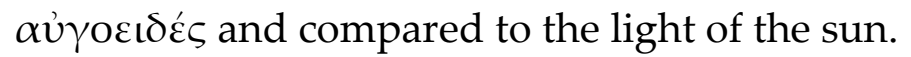

In fragment 21, the author emphasizes that, if according to Plato himself the worldsoul stretched itself out through everything, it surely must have been pre-eminently present in the sun. ${ }^{599}$ Since our rational soul has some likeness to the world-soul, and the world-soul is pre-eminently located in the sun, it would make sense that our rational soul is light-like as well and that its substance would show some likeness to the substance of a heavenly body like the sun. ${ }^{600}$ The passage from UP that we discussed earlier, on the pre-eminent intelligence of the heavenly bodies and the intelligence coming down through the air, seems to correspond well to this fragment. The author of Larrain's fragments connects this notion of the heavenly bodies - being supremely intelligent because of their fiery substance and communicating their intelligence through the light they exude - with the notion of the light-like pneuma that moves between the eyes and the brain and that is described as the primary instrument of soul in PHP book VII (a description repeated in Larrain's fragment 25,3-4). ${ }^{601}$ Thus, visual perception and intelligence are strongly linked, as in Plato, but with more emphasis on the physiological underpinnings of this connection in terms of the light-like substance. This corresponds to the Galenic appreciation of dryness and heat as the qualities that increase intelligence and that are found pre-eminently in the heavenly bodies. ${ }^{602}$ The same idea seems to come to the fore in Larrain's fragment 22 as well, where the interaction of the light of the sun and the light-like pneuma from the eyes explains visual perception. ${ }^{603}$

If the substance of soul is of the nature of light, then it has to be dry and warm, or have a substance that is fiery, like the stars. If the substance of the soul were then combined with something that is wet by nature, this combination would impede the activities of soul to the extent that its substance would not be as it should be in its 'natural' state, which seems similar to that of a star or heavenly body. Therefore, according to this fragment, the 'embodiment' of soul as it was depicted with the river-metaphor in the Timaeus, should be understood in terms of a kind of downward movement of a substance resembling the heavenly bodies towards the earth, including the changes it necessarily falls prey to on this journey. To step out of the Platonic cosmological frame a bit further, we might say: the generation of soul and intelligence on earth is dependent on the downward movement of intelligence from the heavenly bodies in the form of light, which forms the basis for our capacity of vision, cognition and understanding. ${ }^{604}$

\footnotetext{
${ }^{599}$ Fr 21, ed. Larrain

${ }^{600}$ And in fact we find such comparisons in Galen, see note 589 above

${ }^{601}$ PHP VII, 442,19-446,17 De Lacy (V 604-9 K)

${ }^{602}$ Cf. Frede (2003) 120: 'That Galen assumes a close connection between intelligence, or, more generally, cognition, and light, becomes clear if we look at the role light plays in Galen's doctrine of cognition.' Ierodiakonou (2014) 242: ' . . for it is exactly this luminous, light-like pneuma which, in line with the principle of like being perceptible by like, allows us to perceive and discriminate colours, to see objects, to have cognition, and to acquire some kind of understanding.'

${ }^{603}$ Fr 22, ed. Larrain

${ }^{604}$ Cf. Frede (2003) 118-9
} 
The underlying pattern of thought here seems to be something like the following. The heavenly bodies are divine and eternal. Soul bears some resemblance to them with respect to these qualities. Light is the quality that fiery heavenly bodies emanate and through which, perhaps, they order events down below (day and night, the seasons, growth and decay of living beings). Soul, originally a fiery substance that is dry and hot, is exuded from purely dry and hot heavenly bodies. It reaches down through the air in the form of light and mixes with an earthy substance that is wet and cold. That makes it lose some of its power. At the same time, however, it burns up the wet and cold substance. Therefore, there must be additions of substance in order to acquire a precarious and ephemeral balance between those two opposed qualities, temporally united in a single substance. However, even if this ephemeral balance is acquired, the activities of soul as something that is light-like, are still impeded to the extent that it is mixed with a substance opposite to itself, as becomes clear from the end of the last quotation: '...since the nature of wetness is utterly opposed to light, it shall be distanced from its activities to the extent that it is away from its proper nature.' ${ }^{605}$ In that sense at least, this schema seems to remain faithful to the Platonic notion of the composite of body and soul. In those last lines, we can also recognize a basic axiom of Galen's we have referred to earlier, namely that activity is determined by substance (or nature): when the substance changes, so does the activity it causes. The phrasing is similar to the passage in UP that we referred to above, where it was said that the intelligence of the heavenly bodies is 'that much better and sharper than that in the earthly bodies as the substance of their body is purer.' ${ }^{606}$

Interestingly, the author presents this account as common, or the one that is most at

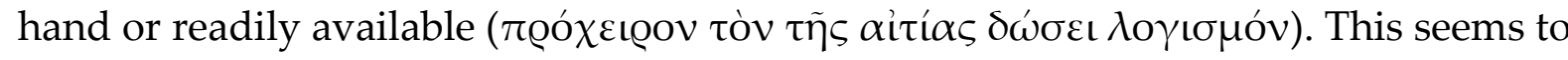
indicate that the notions of soul as something light-like and, therefore, that of wetness as something that is opposed to it and that hinders the proper activities of soul, were more commonly held or discussed.

In the next lines of the fragment, Heraclitus is brought in again:

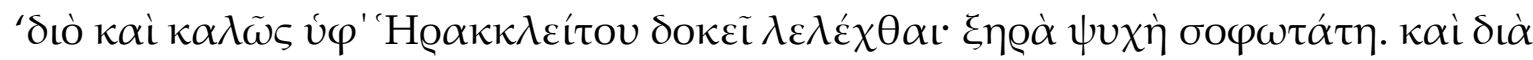

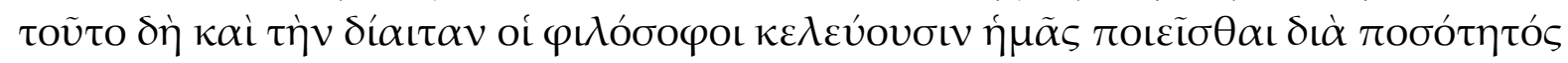

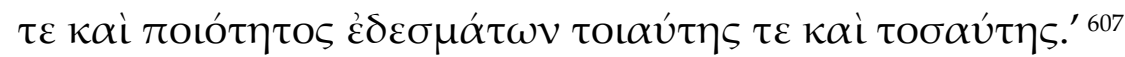

'And therefore it seems to have been stated also by Heraclitus rightfully: the dry soul is wisest. And for this reason also, the philosophers urge us to make a diet based on quantity and quality of foods that are such and so much.'

The way Heraclitus is quoted here is slightly different than in $Q A M$, but the meaning attributed to it is the same: the dry soul is wiser since the rational soul is naturally

\footnotetext{
${ }^{605} \operatorname{Fr} 9$, ed. Larrain

${ }^{606}$ UP II 446,16-9 Helmreich (IV $359 \mathrm{~K}$ )

${ }^{607}$ Fr 9,8-11, ed. Larrain
} 
dry ${ }^{608}$ We also find the notion of a specific diet that is conducive to changing one's substance for the better in order to improve intelligence. Rhazi also reports this in the passage we quoted earlier, which Schröder and Larrain considered to be on the first book of Galen's commentary. We also know it from $Q A M$, where Galen claims to be able to prescribe diets that increase intelligence and memory. ${ }^{609}$ To take a concrete and practical example: in Loc. Aff., Galen suggests that loss of memory is due to cold and wet affections of the head, and should be treated by prescribing substances that warm and dry the head. ${ }^{610}$ Under the assumption that the relative dryness of the substance of the rational soul determines its intellectual capacities, it seems reasonable for philosophers to try and change their substance to become drier. This would involve, as we have seen, the soul becoming more active, closer to its original nature, hot and dry, exuding light and intelligence like the heavenly bodies do. That is to say, once the idea is established that the activities of the rational soul are dependent upon its substance, and that its substance is something that can be analysed as some kind of mixture of the elemental qualities, while at the same time we know that these mixtures are subject to change and that we can influence them via the qualities we bring them in contact with, it seems perfectly reasonable to assume that specific diets could be more or less conducive to the pursuit of wisdom because of the changes they bring about to the substance of the rational soul, especially considering the assumption that there is a hierarchy of mixtures corresponding to the vertical cosmic hierarchy. After all, the very fact that the soul, or the stuff of soul, moves from its primary source, i.e. the heavenly realm, to the realm of the earth -this Platonic background seems to be still in place to some extent - with the corresponding change in elemental qualities that are found in these respective regions, apparently prompts a change in its substance that is so intense, that it loses the rationality that defined its nature, as Galen (and the author of Larrain's fragments) seems to interpret Plato. Thus, the struggle of soul with its newly acquired body is explained in terms of a struggle between elemental qualities predominantly found among the heavenly bodies and those predominating the lower realm.

Let us look at the next part of Larrain's fragment 9:

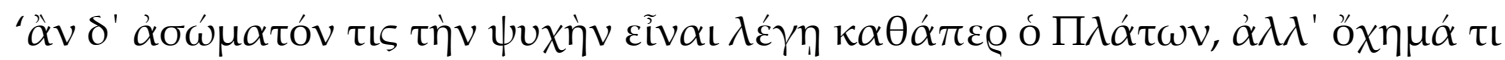

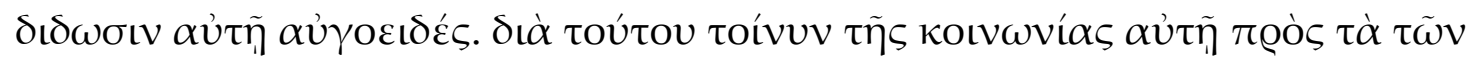

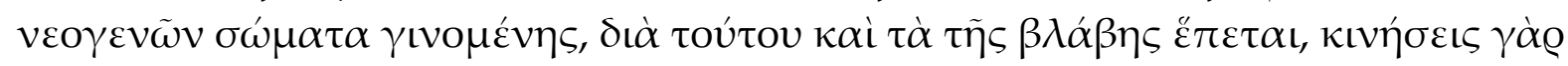

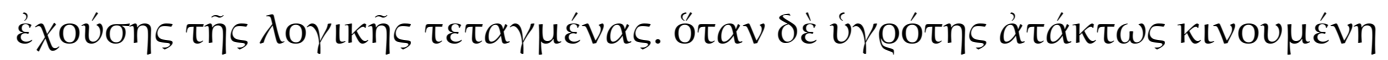

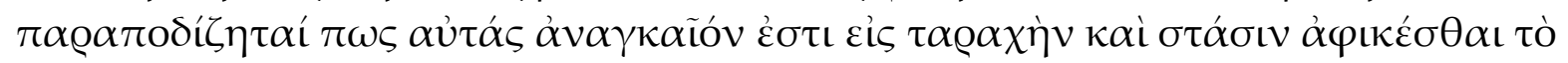

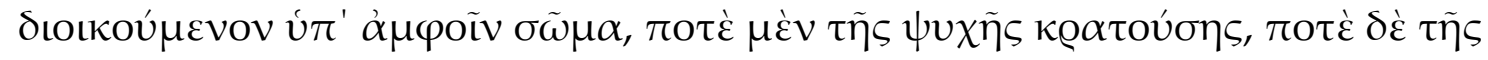

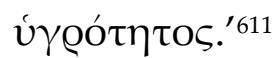

\footnotetext{
${ }^{608}$ We know there were different variations of this fragment circulating, see Kahn (1979) ad locum ${ }^{609}$ QAM 67,2-16 (IV 807-8 K)

${ }^{610}$ Loc. Aff. VIII 150-2 K

${ }^{611}$ Fr 9,11-19 ed. Larrain
} 
'Someone might say, like Plato, that the soul is something incorporeal, but he gave some kind of vehicle to her that is of the nature of light. This is why, accordingly, when the communion of her with the bodies of newborns comes to be, therefore also the indications of damage follow, for the rational has ordered movements. But when the soul is wet and is moved in a disorderly fashion, those are somehow hindered, and it is necessary that the body arranged by both comes to be in disorder and discord, where sometimes the soul wins, and sometimes the wetness.'

The author emphasizes that Plato gave a luminous vehicle to the soul. As we have seen, this may go back to the star assigned to each soul, or the head as the soul's abode. This remark seems to imply that even Plato himself did not strictly deny the soul all bodily qualities, or at least that he considered it necessary to give it a proper vehicle. Since the qualities of this vehicle, then, clash with the wetness of the body, the soul's movements are perturbed. In the fragment, however, the opposition in the end is simply between soul and wetness, not between two different kinds of bodies of which the soul naturally inhabits one (which would also, obviously, amount to further problems). The phrase ' $\tau \dot{\alpha} \tau \tilde{\eta} \varsigma \beta \lambda \alpha \dot{\alpha} \eta \varsigma^{\prime}$ must refer back to the medical observations ( $\tau \alpha \tilde{v} \tau \alpha$ i $\alpha \tau \varrho \iota \kappa \alpha)$ at the beginning of the fragment, that were called indications ( $\tau \varepsilon \kappa \mu \eta \dot{\varrho} \alpha)$ for the rational soul being damaged when mixed with a wet body. Thus, it seems as if the author here is trying to bring Plato closer to the notion of soul being a hot and dry substance originating from higher realms, by emphasizing that Plato thought it necessary to give soul a luminous vehicle. Next, the distinction between the soul itself and its vehicle is simply dropped again, and the struggle between body and soul is depicted as a struggle between soul and wetness. The harm that follows is not harm for a vehicle or a body, but for the rational soul itself, which becomes hindered in its proper movements. The author simply calls the soul itself wet. This clearly implies that he assumes that the soul itself can be described in terms of the elemental qualities. Again, the struggle is that of a continuous fight between the elemental qualities, rather than a fight between an incorporeal and corporeal substance. The only way to make sense of this text seems to be to assume that 'soul' here is equivalent to a substance that is relatively dry. In fact that is also what the fragment started out with when calling the substance of the soul $\alpha \dot{v} \gamma о \varepsilon \iota \delta \tilde{\eta}$, that is to say, something that is of such nature that it exudes light, i.e. fiery, warm and dry, opposed to wetness. The last part of fragment 9 is as follows:

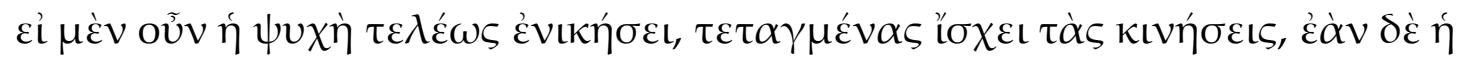

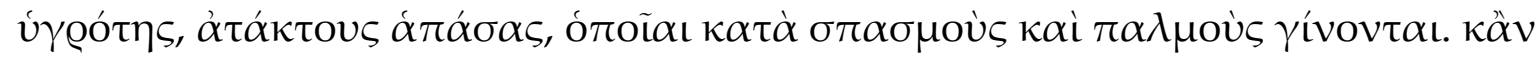

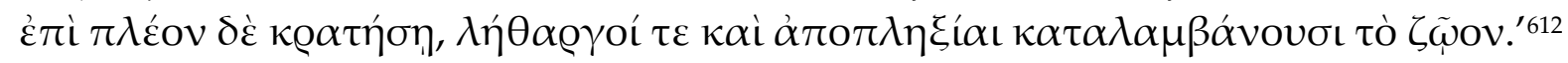
'Thus, if the soul wins completely, it holds ordered movements, but when the wetness wins, all movements are disordered, such as those that happen with spasms

${ }^{612}$ Fr 9,19-23 Larrain 
and quivers. And if it wins for the most part, lethargy and apoplexies take hold of the living being.'

Here we see clearly, once more, that the relative predominance of the elemental qualities of a substance determines the quality of its movements: if wetness wins, the movements are of the disordered, irrational kind; if 'soul' wins, the movements are of the ordered kind. This struggle between the qualities, which determines the relative intelligence of a substance, can also cause disease if wetness wins for the most part. The disorder caused by predominant wetness can cause extreme conditions such as lethargy. As we have seen, this relation of lethargy and predominant wetness (sometimes coldness), is found in attested Galenic works as well. The conception of soul as something that is luminous, or dry and hot, fits well with the explanation of psychic ailments, such as lethargy, in terms of mixture.

\section{d. Substance, activity and soul in Plato's and Galen's Timaeus}

The author of Larrain's fragments takes over the dualism of ordered and disordered movements from the Timaeus. However, its explanation in terms of the elemental qualities is dependent upon the assumption that substance determines activity and the accompanying assumption that the substance of any given thing, including the soul, must consist of a specific mixture of elemental qualities. In Larrain's fragment 10, these two kinds of movement are differentiated according to a hierarchy in which the circular motion is said to be the best. The other movements are considered inferior to it because they differ according to 'the more and less' ( $\kappa \alpha \tau \dot{\alpha}$ тò $\mu \tilde{\alpha} \lambda \lambda$ ov $\tau \varepsilon$

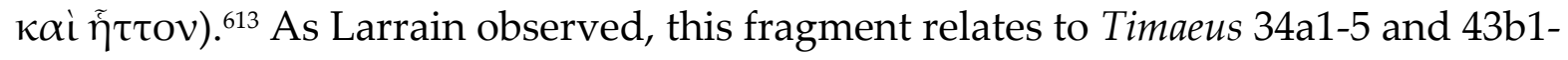
e8, where the two kinds of movement are described respectively. ${ }^{614}$ Opposed to the unordered and non-recurring movements, the circular motion is said to be the most

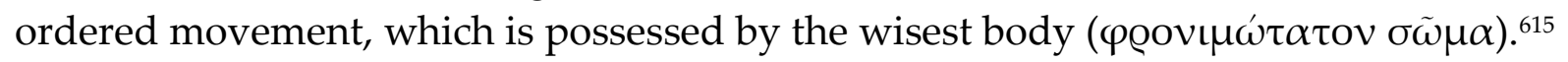
The author here uses the word $\kappa v \kappa \lambda$ оороє $\eta$, which is mostly found in Byzantine authors, but also in early Christian ones such as Eusebius and Basilius, and in Neoplatonists such as Olympiodorus, Philoponus and Syrianus. The word seems to have been used in this form from somewhere around the $4^{\text {th }}$ century only, although

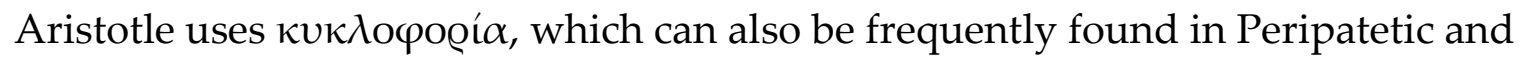
Neoplatonist authors after Aristotle. This could be taken as an indication that the text we are dealing with was not (strictly) based on Galen's own commentary. On the other hand, it is not uncommon to find exceptional forms of existing words in Galen that we hardly find anywhere else before his writings. Moreover, it would not be odd if an excerptor of Galen's actual commentary would use terminology from his own

\footnotetext{
${ }^{613}$ Fr 10,1-4 Larrain

${ }^{614}$ See Larrain's notes ad locum

${ }^{615}$ Fr 10,1-2 Larrain
} 
day to summarize its content. We also know that Neoplatonist scholars such as those just mentioned knew and discussed Galen's work, particularly QAM.616

In Plato's Timaeus, the other movements, apart from the circular and wise one, are six in number and are essentially distinct from the circular one because their movement is characterized by the different. This second kind of motion is quite opposed to the circular motion of the same. It is not motion in one place, not uniform or regular, not systematic, and does not relate to the same things. This is irrational motion, and the six rectilinear motions fall under this qualification. Specifically, this is the motion attributed by Timaeus to the primary bodies, when they are governed by necessity, 'before' or separated from the persuasion of reason. Everything within the cosmos is governed through some mix of these various kinds of motions, while those things that move more regularly and rationally have a larger share in the movement of the same. The circular movement that is always the same is the movement of the universe as such, which has no share in the other six, irrational movements. ${ }^{617}$ In Laws book $X$, the Athenian elaborates on this idea and distinguishes two basic kinds of motion. ${ }^{618}$ The first is motion that takes place in one place, and therefore round some centre, regularly and uniformly, in relation to the same things. This is the motion that

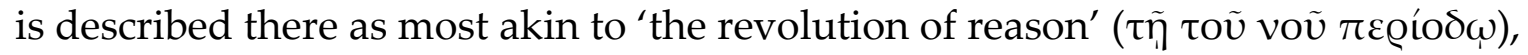
while in the Timaeus the motion of the same is attributed primarily to the universe as such (which is the most rational movement) and then also to the motion of the heavenly bodies, which, however, partake of the movement of the different as well. It is this motion that we need to adapt our own motion to, if we are to partake of the divine. ${ }^{619}$

The author of Larrain's fragments seems to transform this idea of becoming like the gods by adapting our movements to one of becoming like the gods through altering our mixture into a substance that is more luminous and dry. This idea comes to the fore clearly in Larrain's fragment 11, where the author states once more that the

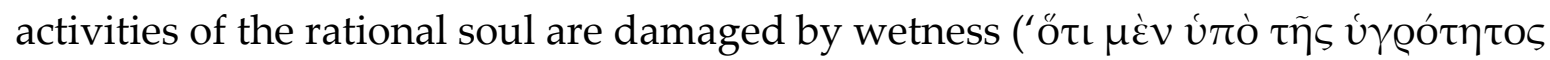

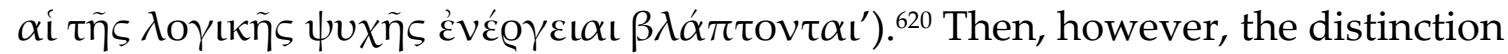

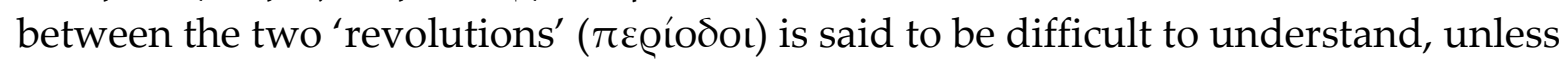
these revolutions are understood as substances rather than movements, to which the

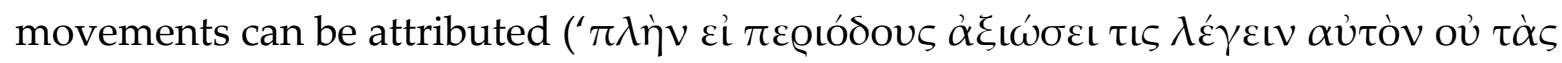

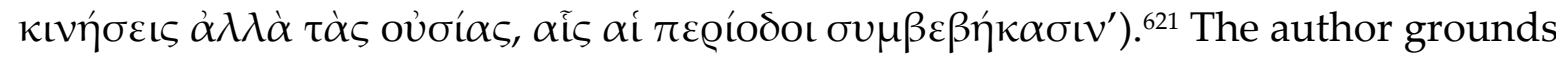
the resemblance of our soul to the heavens in a similarity of substance, rather than

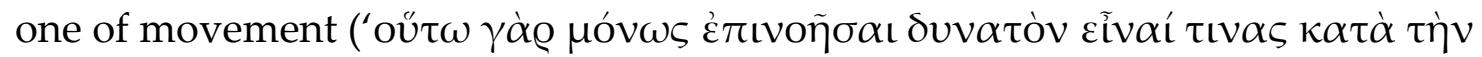

\footnotetext{
${ }^{616}$ Proclus, In Remp. i. 222 Kroll; Olympiodorus Commentary on Plato's Gorgias 49.6 Westerink (ad 524d5-6); Philoponus, On Aristotle's On the Soul 50.32 ff. Hayduck (and the notes ad loc. in van der Eijk 2006); I thank George Boys-Stones for some of these references. See infra, CS I section 4, 85-6

617 Tim. 34a, 37a-e, 52e

${ }^{618}$ Laws 896e-898b

${ }^{619}$ Tim. 90c-d

${ }^{620}$ Fr 11,1-2 Larrain

${ }^{621}$ Fr 11,2-6 Larrain
} 


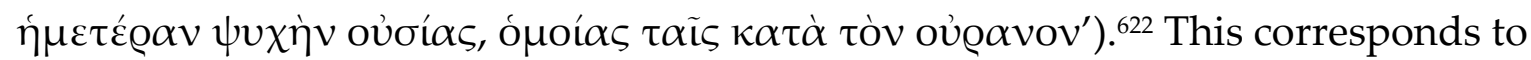
Galen's views on substance and intelligence in UP and QAM, as we have seen, as well as to his general views on the relation between substance and activity (i.e. the former is cause of the latter). Moreover, in his Compendium, he speaks of the 'natures' of the same and the different rather than the 'movements'. As Das and Koetschet indicate, 'nature' may be a vague term in this context, but it could be that this is 'an interpretative reworking of Plato's doctrine of soul rotations' by putting emphasis on a difference in nature rather than movement. ${ }^{623}$ I think that, indeed, especially given Galen's common equation of nature and substance, it is quite plausible that we have another parallel between the Compendium and Larrain's fragments here. Moreover, this interpretation of Galen's Compendium would also be in line with his general reading of the causal role of mixture with regard to intelligence. That is to say, one's movements would be more in accordance with the movements of the same if one's substance or nature would be more in accordance with the nature of things that display this movement, i.e. the heavenly bodies. The emphasis on substance as a cause of movement - as opposed to the distinction of different kinds of movement that are defined as the soul which is prior to body as in the Timaeus - corresponds to Galen's general appreciation of the causal role of the body with regard to the activities of the soul. The lack of rationality of newborns due to the wetness of their substance also recurs again in Larrain's fragment 12, and is particularly related again, as we also have seen in Galen, to the abundance of blood, which is required in greater amount in newborns because they need it for their growth. ${ }^{624}$

In QAM Galen does something similar to what the author of Larrain's fragments does, when he argues that our psychic capacities are dependent upon our mixture and that there are diets (in the broad sense of regimens) that could change mixture for the better, improving our capacity for memory and understanding by increasing the predominance of dryness, supposedly. ${ }^{625}$ In $Q A M$, Plato's ó $\mu$ oí $\omega \sigma \iota \varsigma \theta \varepsilon \tilde{\omega}$ becomes

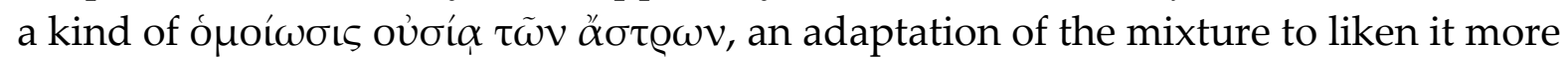
to the substance of the stars. ${ }^{626}$

The important differences with Plato are (1) that the change that needs to be made is a change primarily in substance, rather than in motion, upon which a change in motion follows since substance determines activity, and (2) that this change of substance consists in a change in the elemental qualities of the substance of the rational soul. According to Galen, at least, such a change is not only effected by diet. Besides the fact that for Galen one's mixture is affected by many other factors besides

\footnotetext{
${ }^{622}$ Fr 11,9-11 Larrain; see Larrain (1992) 97: ' Daß im logischen Seelenteil, oder besser: in den Substanzen, durch die dieser agiert, die Substanzen des Himmels anzutreffen sind, scheint Galen hier nahezulegen.

Zweifelsohne hat Galen dabei konkrete Elemente im Blick und zwar die leichten, nach oben strebenden, d.h. Feuer und Luft.' Larrain (pp 96-104) points to similarities with the Pseudo-Aristotelian De Mundo and Posidonius, which cannot be further pursued here.

${ }^{623}$ Das and Koetschet (forthcoming) notes on paragraph 4

${ }^{624}$ Fr 12,1-5 Larrain

${ }^{625}$ See particularly $Q A M$ 67,2-16 (IV 807-8 K)

${ }^{626}$ See infra, CS I section 2, 55-62
} 
food and drink ${ }^{627}$, it is not only the case that mixture determines activity, but also that activity determines mixture, as we can see, e.g., in the following passage from Temp.:

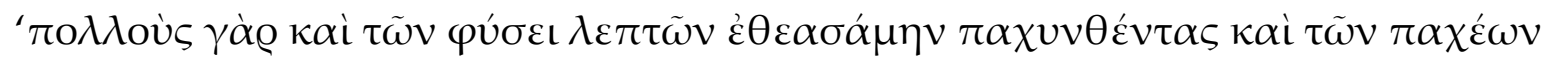

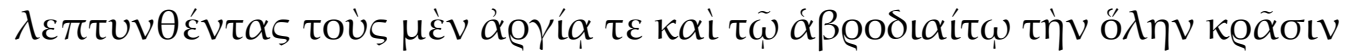

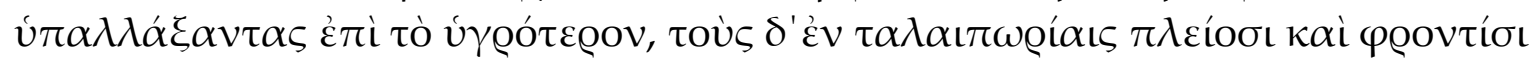

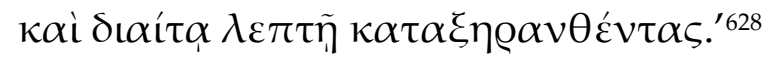

'I have observed many naturally thin people become thickened, and naturally thick people thinned, the former as a result of changing their entire mixture for the wet through idleness and self-indulgence, the latter as a result of drying-out process arising from excessive labour, worry and a thinning daily regime.' (tr. Singer)

Here, it is activity or a lack thereof that changes mixture: by being idle and selfindulgent, one's mixture becomes wetter, while through labour and worry it becomes drier. This corresponds to the specific way the causality functions when conceived the other way around: wetness makes the soul inactive and dryness or heat stimulates the activity of the (rational) soul. Here must also remember, however, that activity for Galen is always already activity of a specific substance and thus dependent on the condition of the substance prior to the activity that then alters that same substance. ${ }^{629}$ Perhaps we can infer from this passage that thinking, too, makes the mixture of one's brain drier, since $\varphi$ Qovtís can have a meaning much broader than 'worry' - as it is translated here - namely 'thought', 'care' or 'attention'. ${ }^{630}$ We do find in Plato's Timaeus the notion that certain bodies are proper to certain movements, ${ }^{631}$ but in no way should the substances of these bodies be taken to determine their movement, particularly not in case of the heavenly bodies. The reasoning in the Timaeus is rather the other way around: these substances were put there because they suit the movements that were already put there. ${ }^{632}$ Therefore, in Plato, it is essentially the movement or the mover (i.e. soul) that is wise, and not the body partaking of the wise movement, which is, rather, a hindrance. In the reading of Galen and the author of Larrain's fragments, however, a specific quality of bodies

\footnotetext{
${ }^{627}$ See San. Tu. VI $40 \mathrm{~K}$ : 'For everything is maintained by the same kind of things as those by which it is also corrupted. The character of the soul is corrupted by bad habits in food and drink, and in exercises, and things seen and heard, and in the cultural arts in general. Anyone that pursues health should be experienced in all of these things, and should not think that it befits the philosopher alone to shape the character of the soul.' See infra, CS I section 4, 83-90

${ }^{628}$ Temp. I. 604-5 K

${ }^{629}$ Cf. Hankinson (1993), 222: 'We have, effectively, a model in which the overall state S of some system generates outputs $O$ which causally contribute to the creation of a new state S'.' See infra, CS I section 4, 86-90 ${ }^{630}$ There is a trope among the ancients (still in place with Ficino) of the dry philosopher, that becomes dry through excessive study, up until the point that he becomes a skeleton even, see Dunbabin (1986).

${ }^{631} \mathrm{Cf}$. Tim. 34A: 'For he assigned to it the motion proper to its bodily form, namely that one of the seven which above all belongs to reason and intelligence...' (tr. Zeyl) In 34C, however, Timaeus hurries to state that this order is only due to the narrative, and that the god made soul prior to body and to rule over body, see the earlier quotation above. It is telling that Galen in his Compendium leaves out Timaeus' correction.

${ }^{632}$ Cf. Cornford (1952) 78: 'But Plato's rings symbolise motions and nothing else. The bodies which have the motions are not mentioned at all at this stage; they are fashioned later and set in the motions here provided...'
} 
becomes the hindrance, while another specific quality of bodies becomes the cause for the movement.

\section{Conclusion}

The question of the heritage of the fragments collected by Larrain must remain undecided for now. Yet, I think that this case-study shows that, at the least, Nickel's conclusions have been too rash and the fragments published by Larrain are valuable for the study of Galen. We have seen how specific and idiosyncratic interpretations of the Timaeus that we know from Galen's attested work can be found in these fragments as well; we have looked at testimonies that refer to the first book of Galen's commentary and discuss the same content and issues that we find in Larrain's fragments; we have not found any conclusive evidence that these fragments cannot be based on Galen's actual commentary on the Timaeus; and we know that scholars working on the Arabic tradition conclude that these fragments must have been part of the Greek manuscript of Galen's commentary before the $9^{\text {th }}$ century. Therefore, without reaching a definite conclusion, I think it is fair to say that Larrain's conviction that these fragments are 'summarizing excerpts' from Galen's commentary on the Timaeus, might well be the best explanation for the heritage of these texts so far.

We have found that the fragments propose a Galenic reading of Plato's Timaeus, in which the opposition between body and soul is recast into an opposition between the elemental qualities that make up our bodily mixture, viz. the cold and the wet versus the dry and the hot. This corresponds to Galen's project in $Q A M$, which, as we have seen in Case-Study I, has a strong basis in other Galenic works. Besides the resemblances to Galen's works on the Timaeus - his summary and commentary as well as PHP and QAM - we have also seen how the content of these fragments is not only consistent with, but shows parallels to, works such as HNH, UP, Temp., Loc. Aff. and Galen's commentaries on Hippocratic treatises.

The specifically Galenic Aristotelianizing tendencies, the arguments against the cardiocentric theory of the soul in favour of the encephalo-centric one based in the analysis of the nerve-system, the characterization of the substance of the rational soul resembling the fiery substance of the heavenly bodies, the relation of this resemblance in substance to the theory of vision and understanding through the psychic pneuma exuded by the brain and the psychic pneuma's similarity to the light of the heavenly bodies, the general characterization of dryness and heat as contributing causes to understanding and the characterization of wetness fulfilling the opposite role, the anchoring of this theory in the river-metaphor of the Timaeus, the application of this general theory to the different phases of human life from embryo to old age, to mental illnesses such as lethargy and to diet, the emphasis on bodily substance as cause of activity or movement - all of these themes are typically Galenic. It is true that the author of Larrain's fragments takes some of these issues a bit further than Galen does in (most of) his attested work. We have also noted, 
however, that Galen considered his commentary on the Timaeus a work on Platonic philosophy and not something indispensable to practicing physicians, that is to say: we can expect it to be somewhat more speculative. Besides this, the anticipatory references to the commentary Galen gives elsewhere suggest a critical form of commentary, in which matters that fall outside of the scope of the medical science are also discussed.

We have also seen how, in general, both Galen and the author of Larrain's fragments use the Timaeus to put forth a somatising interpretation of the soul and anchor it in Galen's favourite philosophical authority. This Galenic interpretation of the Timaeus is in line with our findings in Case-Study I and II and points to Galen's explorative inclination to try to understand man as a whole - including what is (in the Platonic tradition) considered psychic - in terms of the hylomorphic substance that he considers to be the substance of everything. 


\section{Case-Study IV: Galen on Black Bile and Melancholy}

\section{Introduction}

Melancholy has been making a comeback. Books on melancholy abound, there have been calls to reinstate melancholia within the classificatory system of mood disorders and the Lars von Trier's film Melancholia has been a cinematic success. ${ }^{633}$ As is well known, the term, as well its primary meaning and symptomatology hail from ancient Greek medicine. Melancholy has changed much through the ages, but a quick comparison between the modern diagnostic criteria of depression and the descriptions of melancholy in ancient medicine shows that there is much similarity between the two. ${ }^{634}$ Practically all the basic diagnostic criteria for the various forms of depression distinguished in the DSM were already associated with melancholy in antiquity, many of which ancient doctors and philosophers related to the qualities and activities of the black bile itself: depressed mood, changes in weight, loss of pleasure in activities, slowing down of thoughts and movement, psychomotor retardation, diminished ability to think, suicidal thoughts or inclinations, sleep problems (either oversleeping or insomnia), social isolation and anxiety, a heavy feeling in the body, inclination to substance-abuse... As Andrew Solomon, the author of the modern day bestseller The Noonday Demon, aptly remarks: 'The shape and detail of depression have gone through a thousand cartwheels, and the treatment of depression has alternated between the ridiculous and the sublime, but the excessive sleeping, inadequate eating, suicidality, withdrawal from social interaction, and relentless despair are all as old as the hill tribes, if not as old as the hills.' ${ }^{635}$ Besides these similarities in symptoms, many of the questions surrounding depression nowadays, can already be distilled from the ancient texts. Why does someone become melancholic? What is the cause for the excessive fear and sadness that melancholic people experience? How are bodily and psychic symptoms and causes related to one another? What is the classificatory boundary between the

\footnotetext{
${ }^{633}$ Some examples are the anthologies by Radden (2000), Dandrey (2005), Ter Borg (2005) Blamberger, Kellerer, Klemm and Söffner (2015); the works on melancholy with regard to specific authors such as Pensky on melancholy in Benjamin (1993), Ferguson on Kierkegaard and melancholy (1995), Ferber on Benjamin and melancholy (2013), Enderwitz on melancholy in Freud, Conrad and Ford (2015), Traverso on Marxism and melancholy (2016), Radden on Burton's classic Anatomy of Melancholy (2017); general or more specific histories of melancholy such as Toohey on melancholy and the sense of self in ancient literature (2004), Lund on melancholy in early modern England with focus on Burton (2010), Middeke and Wald on the history of melancholy from early modern times (2011), Dickson, Ingram and Sim on depression and melancholy 16601800 (2012), Feld on the history of melancholy and its role in philosophical and religious thinking (2013), Bell on the history of melancholy and self-consicousness (2014), Lertzman on environmental melancholia (2015), Bollas on melancholia and a modern loss of meaning (2018), Eng and Han on racial melancholia (2019), and of course Andrew Solomon's international bestseller on modern depression and its long history (2001); for the argument for reinstating melancholia in the classificatory system of mood disorders, see Fink and Taylor (2007, 2008), Taylor (2006); Lars von Trier's critically acclaimed Melancholia premiered in 2011

634 Jackson (1986) ix; Dandrey (2005) 13; Bell (2014) 3 f.

${ }^{635}$ Solomon (2002) 286
} 
normal and the abnormal or between health and disease? Can we say that someone is more or less melancholic? Indeed, to what extent does melancholy entail gradual divergence from normal phenomena, rather than an essential difference? And what are effective therapies for melancholy? From the perspective of these striking similarities, as well as from that of the immense suffering that depression currently causes for an enormous number of people, the current interest in the history of melancholy makes sense; we might learn something valuable from this history. Galen is known as the most influential medical writer of antiquity and perhaps we could say that in the period between his own life and somewhere around the end of the Middle Ages or early modern times, he was generally one of the most influential writers when it came to the subject of human afflictions and diseases. ${ }^{636}$ Yet, the subject of black bile and melancholy in Galen has been insufficiently studied. ${ }^{637}$ The general idea seems to be that Galen was not much interested in the subject of melancholy, or did not add substantially to its tradition. ${ }^{638}$ Galen, however, is almost unparalleled for his ability to synthesize his philosophical and medical predecessors into a new, relatively coherent whole, which subsequently often turns out to have an immense influence on the centuries to come. I hope to show that this could be said with regard to the subject of black bile and melancholy as well. In order to so, we shall have a look at Galen's main predecessors on the topic first and then turn to Galen himself. The development of the notions of black bile and melancholy had, until Galen, been elaborated through various preceding traditions. It is safe to say that with Galen the development of these notions culminates in a way that goes on to be unparalleled for more than a millennium to come. That is, until Ficino brings about a new focus on the Problemata's notion of melancholy genius, and until, almost two centuries later, Burton writes his encyclopaedic Anatomy of Melancholy. Much work has been done on the history of black bile and melancholy in ancient philosophy and medicine more generally. Therefore, it suffices to give brief overviews of the authors and texts that have influenced Galen the most: the Hippocratic Corpus, Aristotle and the Peripatetic Problemata XXX,1, and Rufus of

\footnotetext{
${ }^{636}$ Cf. Nutton (2008)

${ }^{637}$ Flashar (1966) 105-118 has provided a solid but basic introductory overview in his chapter on Galen as a part of his excellent general introduction to ancient theories of melancholy; Klibansky et al. (1964) have provided a wonderful work on the history of melancholy, but focus almost exclusively on the Problemata and its reception while Galen remains nearly completely undiscussed in their work; Jouanna has written a few insightful papers on melancholy in ancient Greek medicine, including Galen, as well as on the humoural theory which becomes established with the Hippocratic On the Nature of Man and Galen's commentary on it (these papers are collected in English in an edition by Philip van der Eijk, 2012); Stewart (2016) has recently produced a dissertation devoted to Galen's theory of black bile, to which much can be added, I think, and we shall relate to his work in our discussion of black bile in Galen ad locum. Other general histories of melancholy, such as some of the ones mentioned in previous notes, understandably do not provide any in-depth discussion of Galen's work, but base themselves on more specialized works such as those mentioned in this note.

${ }^{638}$ Bell (2014) 42, states that Galen had a 'relative lack of interest in melancholia'; cf. Pormann and van der Eijk (2008), Appendix 1, who see Galen's discussion of melancholy in Loc. Aff. as possibly 'little more than a Galenic summary of Rufus' ideas on the topic without proper acknowledgement.' and state that 'Galen appears to have added very little to Rufus' clinically as well as therapeutically impressive account of melancholy.' I think both are right to some extent, since Galen wrote more about other topics and Galen's account of melancholy leans heavily on Rufus, but as this case-study hopes to show, there is much more to be said.
} 
Ephesus' books on melancholy. With regard to other, less important predecessors some of which we shall discuss or refer to briefly in the course of our discussion there is often not much textual evidence and what there is has been adequately analysed elsewhere. ${ }^{639}$ We shall focus on aspects from these three main predecessors that surface in Galen, such as: the ambiguous status of black bile itself, which is sometimes defined as an exceptionally detrimental or unnatural substance that causes disease, sometimes as a useless by-product of digestion and sometimes as a normal part of our constitution; the elementary qualities of black bile, which are mostly cold and dry but sometimes also involve hotness or heating; the element and season of black bile, generally earth and autumn, but sometimes also spring; the relation of black bile to melancholy and other affections; the symptoms of melancholy and their particular relation to the properties of black bile; the primary associations that accompany black bile and melancholy and their relative normality; the psycho-somatic nature of melancholy.

There is excellent scholarship available on these particular texts with regard to the subject of black bile and melancholy specifically, notably including the work of Flashar, Jouanna, Klibansky, Panofsky and Saxl, Kudlien, Pormann and van der Eijk. Hence, there is no need to reinvent the wheel. Nevertheless, a few exceptions in this regard will arise as we proceed, one of which, e.g., is the role of Aristotle and the Problemata. I think the possible influence (direct or indirect) of these on Galen's writings have been downplayed too much in previous scholarship. ${ }^{640}$ In general, I think there has been a strong focus in scholarship on the differences between all these authors with regard to black bile and melancholy. This is perhaps because the astounding similarity in the basic symptoms of melancholy over the ages has acquired a kind of self-evidence of its own, and perhaps also because specialized scholars have been (over) wary of generalizing comparisons between ancient melancholy and modern experiences of depression. However, this is in itself, as is often the case with trends in scholarship, at least to some extent a reactive attitude.

\footnotetext{
${ }^{639}$ Diocles will be briefly discussed in the context of Galen's notion of the 'hypochondriac' melancholy, see infra, 277-8, and see van der Eijk (2001) for a collection, translation and commentary of his work; cf. Flashar (1966) on melancholy in Diocles, Celsus, Aretaeus and Soranus, 73: 'Wenn uns die Melancholie als Gegenstand medizinischen Denkens in der Folgezeit [i.e. after Diocles] nicht begegnet, so könnte man zunächst vermuten, dies liege daran, da $\beta$ uns die großen Werke der alexandrinischen Medizin verloren sind. Aber es spricht vieles dafür, daß in ihnen von der Melancholie gar nicht die Rede war.'; Klibansky et al (1964) 92-101; Jouanna (2012) 241 f.: 'A well-known problem of post-Hippocratic Greek medicine is posed by the great lacuna caused by the loss of the writings of the medical authors in the three centuries after him. Melancholy as an illness did not reappear in the direct tradition until Aretaeus of Cappadocia, a doctor from the first century AD, and Galen, a doctor from the second century AD. Between these two periods, we possess only indirect information. We know that Diocles of Carystus, in the fourth century, had discussed a form of melancholy, different from that of Hippocrates, affecting the stomach. Galen quotes fairly long extracts. However, the lacuna in the history of melancholy in Greek medicine from the Hellenistic period is not only accidental. It occurred because the humoral view of man was replaced in this period by a solidist view.' Stewart (2016) $27 \mathrm{f}$., particularly on the Anonymus Londinensis

${ }^{640}$ Flashar (1966) 68: 'In Galens eigener Darstellung der Melancholie bleibt die Konzeption der Problemata ebenso unberücksichtigt wie in den übrigen Spätantike, in denen es ausschließlich um die krankhaften Erscheinungsweisen der Melancholie geht.' Jouanna (2012) $237 \mathrm{f}$. strongly emphasizes the differences between the medical tradition and the Problemata XXX,1, and the continuation of the Hippocratic legacy (over against the Aristotelian one) by later medical authors such as Aretaeus and Galen.
} 
Hence, it may be valuable to bring back into focus some of the common threads, which we shall do in this case-study.

Another reason to study black bile and melancholy particularly in the context of this dissertation is the assumption that they might offer an interesting perspective on the relation between body and soul in Galen. Melancholy is a psychosomatic condition, in which the boundaries between body and soul can become rather ambiguous.

Although its main symptoms are psychic, its very name refers to a bodily substance. Black bile, in turn, is conceived of as a bodily substance, but does not have much empirical credibility and is strongly linked to mental illness from the start. Moreover, by focusing on a particular disease, we might see whether the philosophical framework that came to the fore in the previous case-studies, can be given a more concrete form.

The basic set-up of the case-study is simple and proceeds as follows: (1) discussion of black bile and melancholy in Galen's main precedents: a. the Hippocratic Corpus b. Aristotle and the Peripatetic Problemata c. Rufus of Ephesus; (2) discussion of black bile in Galen; (3) discussion of melancholy in Galen.

\section{Precedents}

\section{a. Hippocratic precedents}

As pointed out by Hellmut Flashar, the earliest instance of the word 'melancholy' is from the Hippocratic Airs, Waters, Places, which is dated among the oldest texts of the Corpus Hippocraticum. ${ }^{641}$ There, it is presented as a condition of illness that can be the consequence of very specific meteorological circumstances for people of a particular constitution. Among the many descriptions of variations in the qualities of seasons and winds that correspond to the manifestation of various diseases in people of particular constitutions, there is one that describes a dry autumn with a northerly wind, following upon a dry summer with a northerly wind:

'

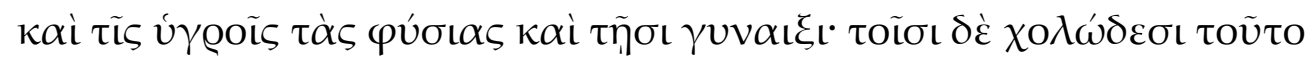

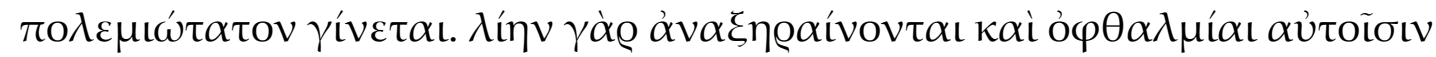

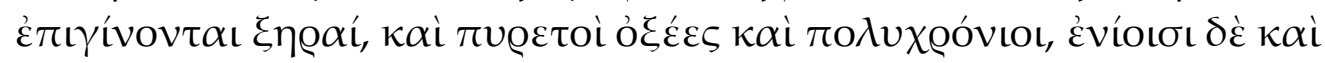
$\mu \varepsilon \lambda \alpha \gamma \chi \mathrm{o} \lambda \mathrm{i}_{\mathrm{i}} \mathrm{s}^{\prime} 642$

'But if the weather be northerly and dry ... it is very beneficial to those who have a phlegmatic or humid constitution, and to women, but it is very harmful for the bilious. For these dry up overmuch, and are attacked by ophthalmia and by acute, protracted fevers, in some cases too by melancholies.' (tr. Jones)

\footnotetext{
${ }^{641}$ Flashar (1966) 21; cf. Jouanna (2012) $232 \mathrm{f}$.
}

${ }^{642}$ Airs, Waters, Places, X, 80-90 ed. Heinemann 
Due to these specific circumstances, the bilious types become excessively dry and thick in autumn, which can lead to melancholy. The constitutions that are relatively moist benefit from these same circumstances, but since the bilious types are already dry, their dryness becomes excessive and cause of disease. ${ }^{633}$ All moisture in their bile and blood dries up, leaving behind only the thickest and most acrid parts of it. ${ }^{64}$ Notably, there is no mention of black bile ( $\mu \varepsilon \dot{\lambda} \lambda \alpha \mathrm{\imath} v \alpha \chi 0 \lambda \eta)$ as a separate humour or substance in this text yet, there is only the alteration of the substances bile and blood. Still, the two processes of drying and thickening as well as the timing of autumn, also occur in On the Nature of Man. They will become a standard part of the tradition on black bile as a humour and are fundamental for Galen, as we shall see. ${ }^{645}$ There is also no mention of a 'mental' illness here yet, the melancholy seems to be conceived only in physical terms. The designation of this condition as 'melancholy' appears to be based in the blackening of the bile, which is the result of its drying and thickening. As Flashar notes, melancholy at first probably indicated not a state in which a particular humour called 'black bile' predominates, but rather a disease that is characterized by a blackening of the bile, the latter being in itself a normal part of the constitution. ${ }^{646}$ Hence, melancholy results from the alteration of a substance that is not necessarily harmful in itself. This is a notion we also find in Galen, and so is a form of black bile that is the result of the burning of (yellow) bile. This particular understanding of melancholy and black bile will appear in Galen besides the one of black bile that is a substance in its own right. The latter seems to hail from the Hippocratic On the Nature of Man.

Melancholy quickly appears as a mental illness as well, one that is particularly related to the brain. In book III of the Epidemics, a patient's state of mind is characterized as 'melancholic' after a list of symptoms have been summed up, all of which will become traditionally associated with melancholy:

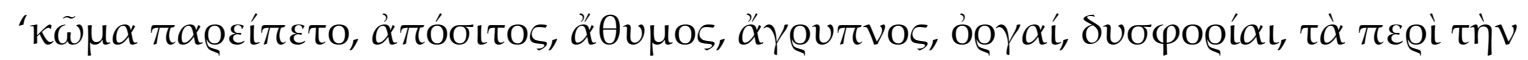
$\gamma \nu \omega ́ \mu \eta v \mu \varepsilon \lambda \alpha \gamma \chi \mathrm{o} \lambda \iota \kappa \alpha .{ }^{\prime}{ }^{647}$

'Coma was present, aversion to food, despondency, sleeplessness, irritability, restlessness, the state of mind was melancholic.' (tr. Jones)

Thus, we clearly find in the Hippocratic Corpus a notion of melancholy as a disease dependent upon specific meteorological and constitutional circumstances, a notion of melancholy as something that particularly disturbs the mind, and the relation of melancholy to a detrimental state of one's bile, that is characterized by excessive

\footnotetext{
${ }^{643}$ The bilious types are found in regions that are cold and dry, cf. chapter IV.

${ }^{644}$ Airs, Waters, Places X 91 f. ed. Heinemann

${ }^{645} \mathrm{Cf}$. for autumn as the season of melancholy: Epidemics VI, 1, 11; On the Nature of Man VIII, 186,17-9 Jouanna; Aphorisms III, 22

${ }^{646}$ Flashar (1966) 23: 'All diese Überlegungen legen den Schlu $\beta$ nahe, da $\beta$ das Wort Melancholie ursprünglich nicht, wie allgemein angenommen wird, heißt: Verfassung, in der der Saft 'schwarze Galle' vorherrscht, sondern: Krankheit, die charakterisiert ist durch die schwarze Verfärbung des Saftes 'Galle'.'

${ }^{647}$ Epidemics III XVII, case 2
} 
drying and blackening. But do we find a notion of black bile as a substance that causes the mental illness melancholy? According to Flashar, we do not. He concludes: 'Die Melancholie stellt sich zunächst dar als eine Krankheit, die ihre Ursache in einer schwarzen Verfarbung des Körpersaftes Galle hat.' ${ }^{648}$ Thus, it is rather the alteration of another substance that is seen as the cause of the disease called melancholy. However, Flashar also points to a development within the Hippocratic corpus, in which black bile evolves more and more into a substance in its own right, one that is part of our nature and that has the potential to cause melancholy.

Our previous quotation shows that in the Hippocratic Corpus the disease of melancholy has already assumed, in rudimentary form, the character by which it will be known for millennia to come. Its described symptoms are fear, despondency, sleeplessness, irritability, aversion to food, difficulty with speech or aphasia and possible derangement or delirium. ${ }^{649}$ Andrew Solomon seems to have been right about depression being as old as the hills. In the Hippocratic Corpus melancholy is also described as both manic and depressive, a feature that, as we shall see, will become established more strongly with the Peripatetic Problemata and that is at least to some extent comparable with present-day notions of the bipolar variety of depression. It is particularly related to the mind, more than other diseases, as also becomes clear from Epidemics VI, where it is said that there is some congruence or overlap between melancholy and epilepsy, but that those whose sickness tends more towards the body, become epileptics, while those whose sickness tends more

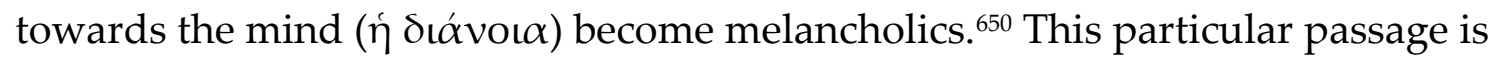
picked up by Galen in Loc. Aff., as we shall see below.

The most concise and well-known description of melancholy can be found in the Aphorisms, unfortunately completely without context:

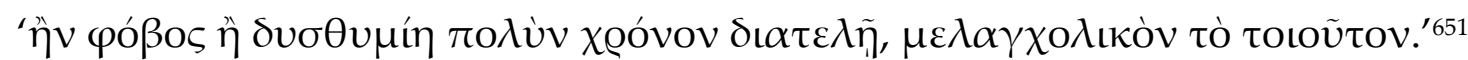
'If the fear or despondency lasts for a long time, this is a melancholic state.' 652

Galen cites this passage in various works and (partly due to Galen) these main symptoms will become an integral part of the tradition on melancholy, even still as descriptions of its modern successor, depression, as we have noted above. ${ }^{653}$ As a separate substance of its own, rather than a degenerated or detrimental version of the bile that is a normal part of our constitution, black bile seems to become

\footnotetext{
${ }^{648}$ Flashar (1966) 45, he mentions two possible exceptions in note 51 (Affections 36 and Diseases I 3); cf. Jouanna (2012) and also Müri (1953) $29 \mathrm{f}$.

${ }^{649}$ Epidemics III, 17 case 2; Aphorisms VI, 23 and VII, 40; Diseases I, 30; Prorrhetic I,14 I,18 and I 123; Regimen in acute diseases 16; Diseases I 30; Müri (1953) 33-4; Flashar (1966) 47; Jouanna (2012) 235

${ }^{650}$ Epidemics VI, 8, 31 ed. Smith

${ }^{651}$ Aphorisms VI, 23

652 Translation Jouanna (2012) 235

${ }^{653}$ For Galen's quotation: Loc. Aff. III, 10 (VIII 188-90 K) ); Symp. Caus. VII 202-3 K. See infra, introduction, 199
} 
established at first in the Hippocratic On the Nature of Man. ${ }^{654}$ There are some other passages in the Hippocratic Corpus where there is mention of a black bile, but it is unsure whether it is considered as a separate substance there or rather as a specific form of the 'normal' bile. It is generally considered a harmful substance that manifests itself in situations of extreme illness. One reason, perhaps, to assume that there was no concept of black bile as a separate substance in the earlier treatises of the Hippocratic Corpus until the On the Nature of Man, is that in other treatises we find enumerations including all of the canonical humours except black bile. ${ }^{65}$ In On the Nature of Man and Galen's commentary on it, we find a systematization of the humours into a fourfold schema integrated with the four elemental qualities and the four seasons in the following manner: phlegm is cold and wet and predominates in winter; blood is warm and wet and predominates in spring (but blood also has an exceptional position, as we shall see below); yellow bile is warm and dry and predominates in summer; black bile is cold and dry and predominates in autumn. Together, these four humours constitute our nature; when they are mixed in a proper balance, we are healthy, while the various diseases are explained in terms of their respective predominance. As is well known, this fourfold schema will become completely dominant after Galen and thus crucial for the history of black bile and melancholy in general. Galen will also extend the analogies with age: blood predominates during infancy, yellow bile predominates in youth, black bile predominates during the period after one's prime, phlegm predominates old age; as well as with taste: blood is sweet, yellow bile is bitter, black bile is sharp or acid, phlegm is salty; and the elements: yellow bile corresponds to fire, black bile to earth, phlegm to water and blood to a well-balanced mixture of the four ${ }^{656}$ :

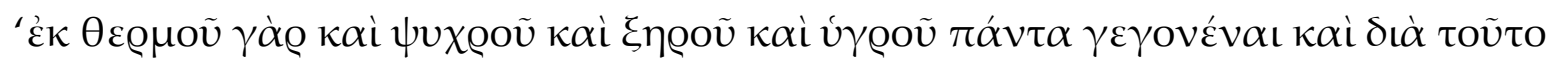

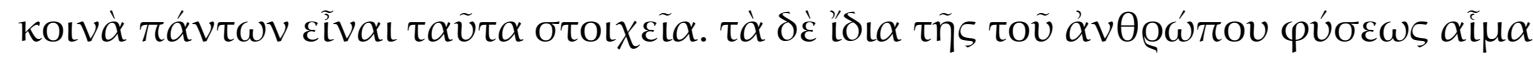

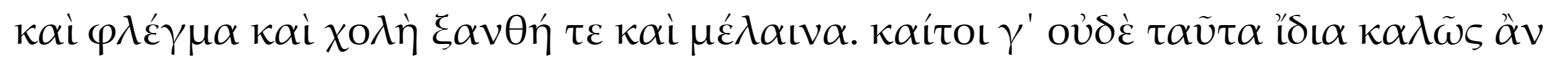

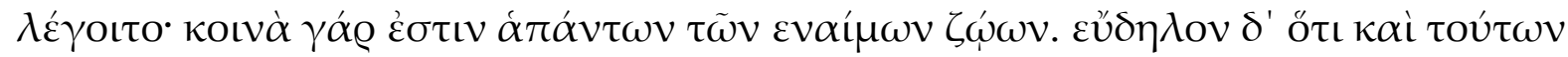

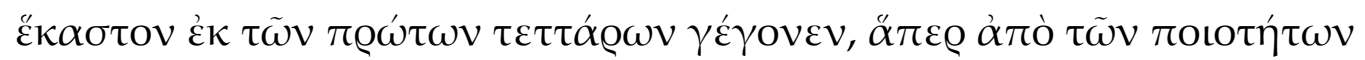

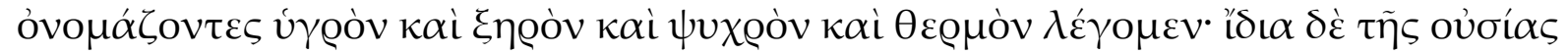

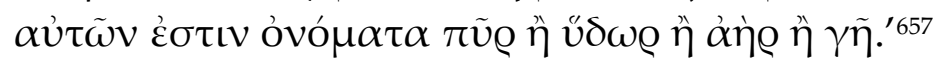

'For everything is generated from hot and cold and dry and wet, and for this reason these things are the common elements of everything. The particular ones of the nature of man are blood and phlegm and yellow and black bile, although not even these are properly called 'particular', since they are common to all blooded animals. And it is clear that each of these comes to be from the primary four, which we label

\footnotetext{
${ }^{654}$ Flashar (1966) 39 f.; Jouanna (2012) $335 \mathrm{f}$.

${ }^{655} \mathrm{Cf}$. Stewart (2016) $26 \mathrm{f}$. for more extensive discussion of these issues.

${ }^{656}$ Cf. PHP VIII 502,10-504,2 De Lacy (V 676-7 K) and VIII 512,25-516,17 De Lacy (V 689-93 K); HNH 42,23 Mewaldt (XV $80 \mathrm{~K}$ ); cf. Jouanna (2012) 339 f.

${ }^{657} \mathrm{HNH} 41,12-9$ (XV $\left.51 \mathrm{~K}\right)$
} 
wet and dry and cold and hot, naming them from their qualities, but the proper names of the substance of them are fire, water, earth and air.' (tr. Hankinson)

This schematization undertaken by the author of On the Nature of Man and further developed by Galen is fundamental for the history of black bile and melancholy, since black bile would otherwise not be considered a common part of our constitution. With the inclusion of black bile in this basic schema that describes our common nature, black bile and melancholy acquire the potential to become a normal part of our constitution in the centuries to come.

Müri and Flashar see the addition of black bile to the other humours, which were older and more commonly established notions, as 'Systemzwang' or 'Systemtrieb', that primarily served to integrate the schema of the humours with that of the four seasons and that of the four elemental qualities. ${ }^{658}$ That might seem a proper explanation, especially since it seems that previously there was no black bile in its own right, while the other fourfold divisions were already in place. But the question still remains: even if we assume it logical to add a fourth for the sake of systematization, why this one? After all, there were many recognized forms and shades of bile and other humours or bodily juices. Morever, there was little or no empirical evidence for black bile. ${ }^{659}$ As Jouanna has pointed out, the humoural theory of the Hippocratic On the Nature of Man was 'just one humoural theory amongst others'. He gives an example with the Hippocratic Diseases, in which water takes the place of the fourth humour, rather than black bile. ${ }^{660}$ The competing theories, however, did not leave a such a legacy as that of the On the Nature of Man. Stewart also emphasizes that the humoural system of the On the Nature of Man was not the 'dominant humoral theory' in ancient medicine, but that its uniqueness consisted in the constructed correspondence to the four seasons and the stages of life. However, he then simply adds: 'It is also important for the status of black bile, which is defined as an element of the body, as opposed to a pathogenetic residue that is produced

\footnotetext{
${ }^{658}$ Müri (1953) 27; 'Das physiologische Modell, das auf der Zuordnung von vier Säften zu vier Jahreszeiten und auf der paarweisen Verkoppelung der Qualitäten warm-kalt-feucht-trocken mit je einem Saft beruht, trägt die Spuren mühsamen Systemzwanges noch an sich. Die schwarze Galle ist wirklich 'faute de mieux', aus dem Willen zum System darin aufgenommen worden, weil ohne sie die Vierzahl nicht zu erreichen war.' Flashar (1966) 41: 'Die Einordnung der schwarzen Galle in den Kreis der anderen Säfte ist aber deutlich das Ergebnis eines Systemtriebes.' Cf. Klibansky et al (1990) 40-8 on the Pythagorean and Empedoclean precedents for this tetradic tendency.

659 The dubious empirical status of black bile has been widely recognized, see Kudlien (1967) 77: 'Jeder Medizinhistoriker wei $\beta$, da $\beta$ die berühmte 'schwarze Galle' nicht nur das faszinierendste, sondern auch das problematischste Glied der nicht minder berühmten, alten Viersäftelehre ist - unter anderem gibt es sie ja, als solche, gar nicht!'; Bennett (1978) 234 f.; Bell (2014) 50: 'It might make more sense to think of the humours as theoretical postulates that helped the ancient physicians to model the invisible processes underlying disease. But the difficulty still remains: the other three humours all had real, observable physiological correlates. Blood, bile, and phlegm are visible, tangible things - only black bile is not.'; Pormann (2008) 5: 'Scholars generally have no difficulty identifying the first three of these humours: blood is what we know as blood; phlegm is the mucus secreted from the nose and sometimes the mouth, especially when one has a common cold; yellow bile is the bile produced in the gallbladder and sometimes excreted during vomiting. But what is black bile, called mélaina cholé in Greek, whence we get the term for melancholy?'

${ }^{660}$ Jouanna (2012) 336; cf. Klibansky et al (1990) 45-6; Nutton (2005) 115 ff.; Stewart (2016) 22 f.
} 
from the alteration of another substance.' ${ }^{661}$ The importance of this systematization for the status of black bile is undeniable, but the question still remains: why was it, then, that the humoural theory that added black bile became so successful? Why was the choice for black bile such a success? Why would the blackened bile, which was previously considered a cause of disease rather than a normal part of our nature or constitution, be a suitable candidate to expand the humoural schema in the first place? It had negative associations from the start, why incorporate this detrimental dark substance into the nature of healthy human beings? Stewart's work is mostly concerned with the historical importance of Galen's interpretation of black bile and his manipulation of the previous history into something that aligns with his own theory. Galen, in his commentary on On the Nature of Man (HNH), argues that the text was the foundation of Hippocrates' work and with his own authority ensured its legacy - that much is sure. He emphasizes its importance and attributes it to a host of other prominent physicians and philosophers without proper justification, to portray the theory as universally adopted, as Stewart notes. ${ }^{662}$ Thus, we have noted that Galen played a crucial role in the installation of this humoural theory, which was to play such a dominant role in later history. But, that is not an answer to our previous question: why could this humoural theory, the one that included the black bile, have been so attractive in the first place, for Galen and the later tradition alike? ${ }^{663}$ It seems insufficient to answer this question merely in terms of Galen's authority and his apparent liking for Hippocrates in general or the On the Nature of Man in particular, especially considering the interest that melancholy as a disease (by then related to black bile) already had well before Galen, as we can observe for instance in the Problemata and in Rufus' work (with which Galen was thoroughly familiar). On this question, I think, Kudlien's study still provides a more useful point of departure. ${ }^{664}$ Kudlien points to a general appreciation in ancient Greek culture for something dark that causes madness, something that is associated with anger ( $\chi$ ó $\lambda \circ \varsigma$ ), spilled blood, earth and the diaphragm. He argues that this appreciation existed prior to the establishment of black bile as a proper substance in itself and facilitated its conception. ${ }^{665}$ According to Kudlien, these pre-Hippocratic, non-medical precedents need to be taken into account, since the more technical medical notion of black bile builds on them. As he sees it, these precedents leave an 'inherited conglomerate' - as

\footnotetext{
${ }^{661}$ Stewart (2016) 28. Cf. Jouanna (2012) 338, who suggests that Galen's use of the Hippocratic treatise was 'one of the important historical factors behind the survival of Hippocrates and the fortune of the theory of the four humours.'

${ }^{662}$ Stewart (2016) 29 f. Cf. Nutton (2005) 115 ff.

${ }^{663}$ It seems that the Hippocratic humoural theory was already in antiquity particularly defined as the one that includes the black bile (which was less common than the other three humours), since we can gather from Galen's $A d v$. Jul. that the followers of this humoural theory (including Galen) were jokingly called melancholics - or perhaps in a more broader sense 'people that have lost their minds' - by Julian because of their supposed preoccupation with the black bile ( $A d v$. Jul. $291 \mathrm{~K})$ : 'We are bound to marvel, first, at what is said at the beginning - that we 'ought not to act entirely on black bile'. For clearly Julian implies that we, the supporters of Hippocrates, are mad (melancholein).' (Tecusan 2004)

${ }^{664}$ Kudlien (1967); see also Kudlien (1973)

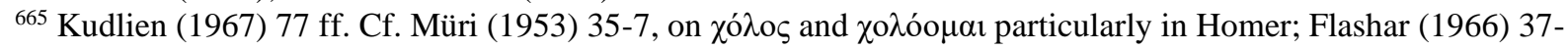
8; Bennett (1978) 234-6; Pigeaud (1981) $122 \mathrm{f}$.
} 
he calls it, after a notion developed by Dodds - that paves the way for the later inclusion of black bile among the canonical constituents of the human body. Likewise, Klibansky, Panofsky and Saxl, in their Saturn und Melancholie point to these kinds of pre-scientific associations with black bile, which 'schon durch seinen Namen ( $\mu \varepsilon \dot{\lambda} \lambda \alpha \varsigma=$ schwarz) mit allen bösen und nächtlichen Vorstellungen verknüpft war.' They remark, rightly so in my opinion, that the scope of meaning of the word $\mu \varepsilon \dot{\lambda} \lambda \varsigma$ in Greek, as in most other languages, is far wider than a mere designation of colour, and that this is a fact of relevance for the study of the history of black bile and melancholy. ${ }^{666}$ In Aretaeus of Kappadocia, we find an explicit connection of black bile to the Homeric $\chi 0$ ó $о \varsigma$, in which the addition of blackness would express a more vehement or violent anger than the normal bile. ${ }^{667}$

Besides having an obvious methodological advantage, namely that Kudlien is able to explain to some extent why black bile was an attractive option to include into the basic human constitution beyond a mere reference to Galen's authority and his liking of Hippocrates, Kudlien also makes a solid point about the precedents. In fact, people have remained fascinated by the substance of black bile as a part of our constitution for hundreds and almost thousands of years after Galen - does an appeal to Galen's authority suffice to explain this, or should we look further into what might make the notion of black bile so appealing? In the chapter on black bile in Galen below, we shall further delve into the primary associations that black bile evokes in Galen's work in order to better understand its attractiveness. For now, I would merely make the general suggestion that there was something interesting and attractive about the incorporation of black bile into our constitution, because it effected a physiological integration of a darker side of the life of human beings into the medical and philosophical conceptual framework, a side that was associated with death, madness, heaviness and the dark depths of the earth. This is not an anachronistic projection of more modern notions of melancholy unto Galen, as we shall see, since all of these associations can already be found in Galen's own work. When he cites the Hippocratic passage that identifies fear and despondency as the two main symptoms of melancholy, he explains these symptoms in terms of the darkness of the black bile. He even compares the person afflicted by melancholy to a child wandering in external darkness. ${ }^{668}$ There is, then, a clear association in Galen of melancholy with the dangers of night and death and the experience of these dangers has been fundamental for human beings from time immemorial.

We shall continue this line of thought in the section on black bile in Galen. To conclude this section, we find in the Hippocratic Corpus two possible causes of melancholy: the drying and thickening of bile that becomes black as a consequence of excessive heating of another humour, and the excess or isolation (i.e. not being mixed with other humours) of black bile as one of the four humours that need to be balanced in order for there to be health. These two options seem to be the

\footnotetext{
${ }^{666}$ Klibansky et al. (1964) $55 \mathrm{f}$.

${ }^{667}$ Aretaeus, On the Causes and Symptoms of Chronic Disease I, 5 ed. Adams. Cf. Flashar (1966) 76-7

${ }^{668}$ Loc. Aff. 284 Van der Eijk and Pormann (III 190-1 K)
} 
consequence of black bile first appearing as a degeneration of normal bile and then becoming integrated into a more systematic humoural theory, to some extent already in the Hippocratic Corpus. They remain in tension in the tradition building on the Hippocratic Corpus, as we shall see, and will also resurface as the tension between an extremely harmful and more normal version of black bile. We have also seen in this section how melancholy is specifically associated with the mind and with the symptoms of fear and despondency from its inception. Finally, we have had a brief discussion on the possible underlying reasons for the attractiveness of black bile as a normal part of our constitution, which will be continued later.

\section{b. Aristotle and the Problemata XXX,1}

The so-called Problemata Physica have had a profound impact on the history of black bile and melancholy with its bipolar-like description of a melancholy genius exemplified by various poets, heroes and philosophers. It was commonly attributed to Aristotle until $20^{\text {th }}$ century scholars have made a convincing case that it is in all probability not a work by Aristotle himself but more likely by his successor Theophrastus or another Peripatetic. ${ }^{669}$ It contains a single chapter (XXX.1) devoted to melancholy, which was to exercise a major influence, particularly on the Renaissance association of melancholy with genius and the subsequent romanticisation of melancholy. ${ }^{670}$ The theory of melancholy in the Problemata has recently been compared to Aristotle's genuine work in a seminal study by Philip van der Eijk, showing that it depends on Aristotle's notion of the melancholic in some aspects, and could be a continuation of Aristotle's own work or thoughts in this regard. ${ }^{671}$ In the following section on Aristotelian precedents for Galen's theory of black bile and melancholy, we shall build on van der Eijk's work in order to provide a brief overview of both, starting with Aristotle's genuine work and then proceeding to a discussion of the Problemata chapter XXX,1.

\footnotetext{
${ }^{669}$ Müri (1953) 21; Flashar (1962) 711 f. See also van der Eijk (2005) 139 including note 2 and 3

${ }^{670}$ Cf. Flashar (1962) 715 ff. for a brief overview of the text's 'Nachwirkung'; Klibansky et al (1990, first published in 1964)) still remains the standard work for this subject; a great early modern source is Richard Burton's Anatomy of Melancholy (1621)

${ }^{671}$ Van der Eijk (2005) 139-68. Cf. Schütrumpf (2015) 357 f., 369, on van der Eijk (2005): 'However, this focus seems too narrow, and what is missing in this strategy is a complementary approach as we just undertook it, that is of examining whether the specifics of the working of black bile and the theoretical framework in which this is presented can be reconciled with Aristotle's views on the causes of human behavior, and it will be this strategy I will pursue here.' It seems that while van der Eijk sought to compare Aristotle's writings on melancholy to the Problemata 30,1, in order to see whether the latter can be seen as a continuation of the former, Schütrumpf sought to compare the Problemata 30,1 to Aristotle's writings, in order to determine the extent to which the former can be reconciled with the latter (Schütrumpf concludes that the 'the views of Aristotle and Pr. 30,1 cannot be reconciled'). However, it seems clear to me that, the conclusion that the author of the Problemata builds on Aristotle's thoughts on melancholy is not contradicted by showing that the Problemata contain aspects which cannot be reconciled with Aristotle's views. For our study it is enough to note the similarities between Aristotle and the Problemata and there is no need to further dwell on the extent to which the author of the Problemata is faithful to Aristotelian doctrine.
} 


\section{Aristotle}

One important aspect of Aristotle's notion of the melancholic, as van der Eijk has noted, is that it is underpinned by the recognition of black bile as a distinct fluid that is, moreover, characterized as a residue $(\pi \varepsilon$ Qí $\tau \omega \mu \alpha) \cdot{ }^{672}$ In fact, both biles as well as phlegm, are characterized by Aristotle as residues that do not have a purpose but are rather the by-product of something that does have a purpose. This is a notable change from the late Hippocratic tradition, in which the four humours form our basic constitution and there is no mention of the humours as residues or by-products. Van der Eijk suggests that the notion of black bile as a residue might, in fact, have been introduced by Aristotle or someone in his school. ${ }^{673}$ This is interesting for our casestudy, since Galen also often defines black bile (as well as yellow bile and phlegm) as a residue, a point to which we shall return in due course. It is noteworthy that Aristotle says that bile comes into being as a residue when there is something off with the blood, and that as such this residue is opposite to nutrition (blood is the substance that nourishes). ${ }^{674}$ As we shall see, according to Galen black bile is a kind of aberration that results from a surplus of innate heat in the digestive process. This process should normally or ideally lead to the production of blood to nourish the various parts of the body. Van der Eijk also suggests that the notion of 'the melancholic' as a person with a specific physiological constitution that is related to the substance of black bile, is an originally Aristotelian idea as well. From van der Eijk's survey and discussion of all passages in Aristotle on the subject, we can summarize a few findings. First of all, the melancholic usually enters Aristotle's writings in the context of discussions of the physiology that underpins certain psychic processes and then serves as an example of a deviation from the norm. That is to say: there is something extraordinary about the functioning of melancholics, the cause of which is their particular nature in the sense of their physiological constitution.

In a discussion of sleep, Aristotle says that melancholics are great eaters and do not sleep much. ${ }^{675}$ Sleep, according to Aristotle, is a consequence of the process of digestion, which causes hot exhalations to first move upwards and then, after having reached the upper parts of the body, return again downwards in a mass that causes sleep. In the case of melancholics, however, the quantity of these exhalations is small, since they do not derive much benefit from what they eat. Despite their large appetite, they remain thin, since their digestive process is apparently suboptimal. The reason for this, says Aristotle, is the coldness of the black bile, which cools the process of digestion. Several things are noticeable here: first of all, the elemental quality of coldness corresponds to the previous Hippocratic and later Galenic tradition; secondly, the melancholic's condition is associated with a flawed digestive

\footnotetext{
${ }^{672}$ Van der Eijk (2005) $143 \mathrm{f}$.

673 Van der Eijk (2005) 153

${ }^{674}$ Somn. Vig. 456a33: ‘ ... and in all cases food in its ultimate form is, in sanguineous animals, the natural substance blood...' (tr. Barnes); Part. An. 677a27: 'But, when animals are formed of blood less pure in composition, the bile is the residue left by this.' (tr. Barnes)

${ }^{675}$ Somn. Vig. $457 \mathrm{a} 27 \mathrm{f}$.
} 
system, which, in different terms, is a fundamental aspect of Galen's notion of black bile and melancholy; finally, as we have mentioned, black bile is defined here as a residue $(\pi \varepsilon$ Qí $\tau \tau \omega \mu \alpha)$, which is also a pivotal aspect of black bile in Galen.

One of the things Aristotle considers extraordinary about melancholics and which does not surface as such in Galen - although it will become an important part of the broader tradition on melancholy - is their intense imagination. However, Klibansky, Panosky and Saxl have rightly pointed out that the delusions of melancholics, which medical writers such as Rufus and Galen describe, can very well be seen as a related to, or a more specific continuation of, this theme of intense imagination. ${ }^{676}$ In the context of a discussion of the corporeal nature of recollection and possible problems with it, Aristotle states that melancholics are most powerfully moved by images ( $\varphi \alpha \nu \tau \alpha \dot{\alpha} \sigma \mu \alpha \tau \alpha \kappa \iota v \varepsilon \tilde{\imath} \mu \alpha \dot{\alpha} \lambda \iota \sigma \tau \alpha)$, which makes it harder for them to control their processes of recollection. ${ }^{677}$ Related to this, melancholics are exceptional with regard to their dreaming. In On Divination in Sleep, Aristotle explains their alleged prophetic dreams with reference to their intense imagination, which causes them to experience so many movements: given the sheer amount of images that occur to them, the images must sometimes chance to correspond to actual affairs. Also, the intensity of their imagination makes it somewhat mono-manic: the movements of their imagination are not hindered by other movements. ${ }^{678}$ Aristotle uses the melancholic inclination toward alleged prophetic dreaming to prove that dreams must not have been godsend. After all, should they have been godsend, they would have been sent to the wise in broad daylight. It is implied in these passages that melancholics have a powerful imaginative capacity but that their rational capacity is not above average or even exceptionally weak. ${ }^{679}$ Likewise, in On Dreams, the melancholics are used as an example of people that dream in a confused and incoherent manner, like people that are feverish or drunk. ${ }^{680}$ In the Eudemian Ethics, we find a remarkable passage that is concerned with the starting-point of thinking and a kind of direct relation to the divine that sidesteps reasoning. In it, the melancholics, 'the dreamers of what is true', are again presented as examples. ${ }^{611}$ It seems that the melancholic is portrayed here as someone with exceptional access to the divine and to truth, exactly because of an intense immediacy that is (at least partly) the consequence of a lack of reasoning power. ${ }^{682}$ In the Nicomachean Ethics too, melancholics are said to follow their imagination due to its intensity, without thinking or deliberating, which makes them

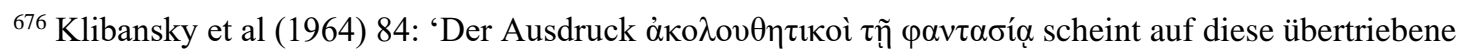
Erregbarkeit der 'vis imaginativa' abzuzielen, die spatter für den Halluzinationszwang oder aber für eine besondere Kraft des anschaulichen Vorstellungsvermögens verantwortlich gemacht wurde.'

${ }^{677}$ Mem. 453a14-19

${ }^{678}$ Div. Somn. 463 b17 f., 464a31-2

${ }^{679}$ Div. Somn. 464a20 f.

${ }^{680}$ Insom. $461 \mathrm{a} 20 \mathrm{f}$; f for a more in-depth discussion of these passages from Div. Somn. and Insomn., as well as their interrelation, see van der Eijk (2005) 143-8

${ }^{681}$ EE 1248a20 f.

682 The idea that the melancholic has an exceptional relation to truth frequently recurs in the subsequent tradition and we find it still in Freud, who stated that melancholics 'have a keener eye for the truth.' (Standard Edition of Complete Psychological Works 14, 246) as well as in Walter Benjamin's work, cf. Ferber (2013) $41 \mathrm{ff}$.; it also appears in the modern 'depressive realism' hypothesis, cf. Bell (2014) $156 \mathrm{ff}$.
} 
impulsive. ${ }^{683}$ Thus, from Aristotle's writings we can obtain a relatively coherent picture of the melancholic, as someone that has a certain intensity of imagination that can lead to exceptional capacities, even though it is, at the same time, associated with a lack of reason.

One further passage from the Nicomachean Ethics deserves more extensive discussion because it invites comparison with the role of black bile in Galen and because it remains somewhat underused in van der Eijk's otherwise full treatment.

At the end of book VII of the Nicomachean Ethics, Aristotle discusses pleasure (†்oví), or more specifically, physical pleasure. He asks why it is that physical pleasure appears to be highly desirable, whereas people do not believe it to really be desirable, as opposed to the more noble type of pleasure. Aristotle gives a twofold answer to this question. First, the bodily pleasures are a remedy against pain. Particularly those who experience excessive pain will seek out excessive pleasure to counteract it, and the bodily pleasures have a potential for excess. Second, they are sought out, again, for their intensity, by those who are not able to enjoy anything else:

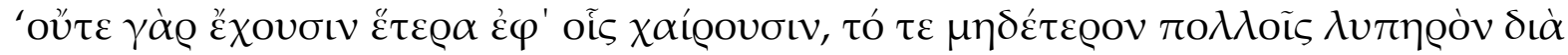

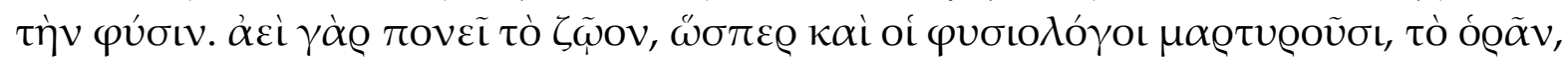

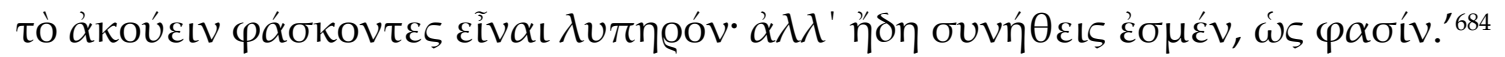
'For they have no other things which they enjoy, and for many people a neutral state is painful because of their nature. For the living being always suffers, as the natural scientists also testify, who say that seeing and hearing are painful, but we have come to be accustomed to that [pain], as they say.'

It is remarkable that Aristotle here starts out his discussion with what appears to be a few people who are not able to enjoy anything but intense bodily pleasures, but then proceeds to explain this lack of capacity in much more general terms: for many people a neutral state is painful. The explanation that he gives for this experience of pain appeals to a more universal truth again: a living being always suffers. Aristotle must mean here that a living being suffers as such, i.e. qua living being, considering the examples he gives of ordinary sense-perception being painful. These clarifying examples imply that we are actually always in a state of pain, to which we are simply accustomed. What started out as a description of people who need excessive bodily pleasure because they do not enjoy other things has now culminated in a remarkable description of a general 'pain of living', as Joachim calls it in his commentary. ${ }^{685}$ Apparently, Aristotle's point is that this 'pain of living' demands a kind of permanent cure, which is why an apparently neutral state is actually painful to many

\footnotetext{
${ }^{683}$ EN 1150 b19 ff., also $1152 \mathrm{a} 19$ and $1152 \mathrm{a} 27$

${ }^{684}$ EN 1154 b5-9

685 Joachim (1951) ad locum. We cannot neutralize this remarkable statement by translating $\pi$ óvo $\varsigma$ with something milder such as 'strain', as becomes clear from the fact that the hearing and seeing are described as $\lambda v \pi \eta \rho$ óv, which unambiguously means 'painful', as well as from the fact that we are still in the context of the traditional opposition with pleasure (ं்oví).
} 
people and why we often seek bodily pleasure to counteract the pain. Aristotle's own account of the Pythagorean 'harmony of the spheres' might be a useful analogy here: since we have been hearing the sounds of divine harmony from birth, so the Pythagoreans argue, we have no notion of a contrary silence to contrast the sound with, and thus we never notice perceiving the sounds. ${ }^{686}$ In the same way, we could say, the living being does not notice his normal state of suffering while engaging in common activities such as seeing and hearing, because the suffering has been there since birth and there is no state of the absence of this suffering to contrast it with. Aristotle even goes as far as to compare this blissful ignorance of our normal state of suffering to a state of intoxication:

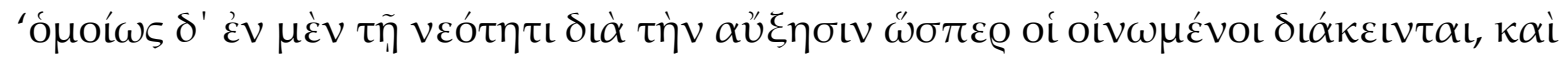

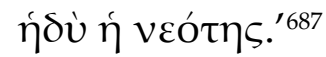

'In a similar manner, during their youth people are in a state resembling drunkenness because they are growing, and therefore youth is pleasant.' (tr. Rowe, modified)

This comparison with the growth of youth and with drunkenness makes it clear that Aristotle considers the accustoming to our state of suffering as something that impedes accurate perception, however desirable and normal it may be in itself. As with the harmony of the spheres, the suffering is actually there, but it is not perceived as such. At this point the melancholic enters the scene:

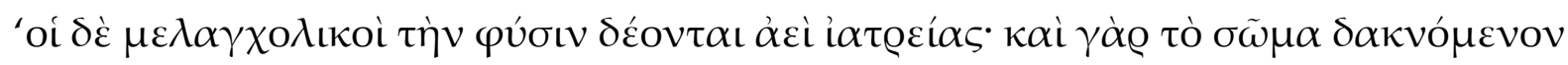

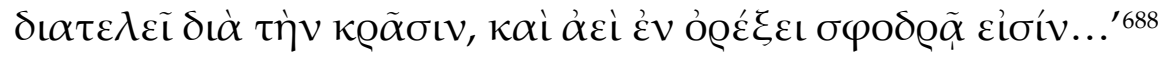

'The melancholics, on the other hand, are in permanent need of a remedy due to their nature, since their bodies too, because of their mixture, are constantly stinging, and they are always in a state of intense desire...'

Remarkably, Aristotle contrasts the melancholics with those who are youthful or intoxicated (notice the $\mu \dot{\varepsilon} v$, $\delta \dot{\varepsilon}$ construction). In contrast, melancholics do not experience pleasure, but they are rather in permanent need of remedy because their body is constantly stinging. This stinging causes an insatiable need for pleasure, which makes them become 'licentious and bad'. What Aristotle seems to be saying here is that, as opposed to the young and the intoxicated, the melancholic perceives his or her 'pain of living' and is stung by it constantly. The choice for the verb $\delta \alpha \kappa v \omega$ seems to suggest an immediate physical pain that is perhaps related to the acidity of black bile, which we already found in the Hippocratic tradition. ${ }^{699}$ The question now

\footnotetext{
${ }^{686}$ De Caelo II 9, 290b12-29

${ }^{687}$ EN 1154b9-11

${ }^{688}$ EN 1154b11-13

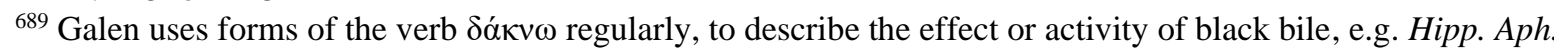
VI XVIIB 688,1-3
} 
is: why is it that these melancholics are so stung? Clearly it has to do with their particular nature or physiological constitution, their particular $\kappa \varrho \tilde{\alpha} \sigma \iota \varsigma$ is indicated to be the cause. It might also be that Aristotle here implies that the general 'pain of living' he was just referring to is experienced to a greater extent by melancholics, since their nature (i.e. their specific constitution) does not lend itself to the kind of habituation that makes the painful state appear neutral or even pleasurable, as in the case of youthful or intoxicated people or those who have become accustomed to the normal pain of sense-perception. This would fit well with the exceptional susceptibility to truth that Aristotle ascribed to the melancholics in the Eudemian Ethics. Another thing to take into account in this regard is the fact that Aristotle, immediately after this passage, presents an opposition between the pleasure of God as a single being, and the pleasure and pain of perishable, composite beings such as we are. God is in a state of continuous pleasure, due to his unity and simplicity. We cannot be in such a state, because our nature is a composite one: besides the divine

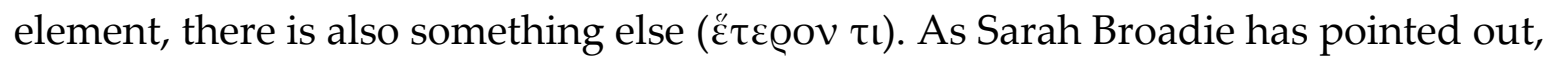
this 'element of a different sort', has to mean 'different from the divine element in us'. Aristotle presents the flight into excessive pleasure 'as a sort of reaction against physical embodiment' ${ }^{\prime}{ }^{60}$ It is the very fact that we are not god, or not only our divine part, that causes the need for pleasure to counteract the pain that necessarily accompanies the division into parts, the fragmentation of a composite being that would not have been there if our being would have been confined to the divine element. Aristotle seems to suggest in this passage that it is this pain that melancholic natures are overly sensitive to: the pain of not being god. Again, this seems to be in line with the passage from the Eudemian Ethics, in which the melancholics are presented as an example of people who are moved by a divine principle of movement that is prior to intellect. This is how Aristotle there explained the capacity of melancholics to have prophetic dreams, there: they do not need deliberation to arrive at truth, because what moves them is prior to and better than intellect, it is god itself. ${ }^{691}$ Perhaps the same affinity to the divine makes it so difficult for the melancholic to get used to the pain of physical embodiment.

\section{Conclusion}

Some of the things that come to the fore from the scattered remarks on black bile and melancholy in Aristotle lend themselves well to comparison with Galen; others do not. The topic of the melancholic's exceptional imaginative capacity, which seems to in fact be the most well-established characteristic of the melancholic in Aristotle's genuine work, seems absent in Galen. However, there might be a thin line between this irrational capacity of compulsively generating images and certain forms of delusion Rufus and Galen associate with melancholy, especially considering the mono-manic tendency that Aristotle ascribes to the melancholic's imagination and

\footnotetext{
${ }^{690}$ Broadie (2002) 406

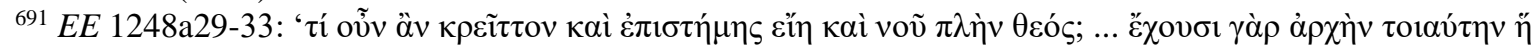

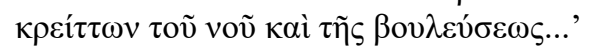


the emphasis on delusions with regard to one particular object that we find in Rufus and Galen. ${ }^{692}$ The most important issues to take along from our brief discussion of Aristotle are the following: the notion of black bile as a residue related to the digestive process as a by-product that does not have a purpose in itself; the notion of the melancholic as a type of person that is exceptional in certain regards due to their specific constitution; the relation of this melancholic type to a feeling of pain that is related to the mortality and imperfection that characterizes human beings compared to the divine. These themes, all of which seem to be Aristotelian innovations, return in Galen, sometimes mediated by Rufus or others.

\section{Problemata XXX,1}

It seems that in chapter $X X X, 1$ of the Problemata, we find, for the first time, a strong association of melancholy with philosophy and with excellence. In Aristotle, the melancholic is often ascribed an exceptional capacity, as we have seen. But this relates to their intensive imagination and is accompanied by a lack in rational prowess. The Problemata, by contrast, starts out by asking why all the men who stand

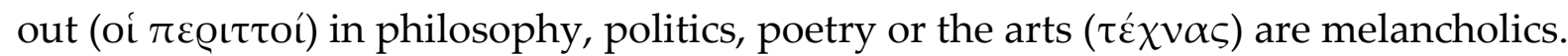
It seems to me that this description is so broad as to include anybody with any exceptional capacity, as is also confirmed by the subsequent inclusion of the heroes. Again, there is excellent scholarship on this text already, so it suffices to point out a few tendencies that are of particular relevance for our discussion of black bile and melancholy in Galen. ${ }^{693}$ The text gives a physiological explanation for the question posed at its beginning. It appears that, due to the variability of black bile, people who naturally contain much of it are receptive to inexplicable despondency that can lead to suicide on the one hand, but cheerfulness and frenzy on the other. The first arises in them when their black bile is cold, the second when it is overheated. Thus, they have a kind of natural bipolar inclination since they seem to be able to hit both extremes in an exceptionally intense manner. Yet, when they manage to strike the rightly balanced mixture of hot and cold - here we recognize Aristotle's celebration of the right mean - they become outstanding. ${ }^{694}$ It has been noted that this particular

\footnotetext{
${ }^{692}$ See for Rufus F13, for Galen Loc. Aff. VIII 190 K. Cf. Klibansky et al (1964) 84: 'Der Ausdruck

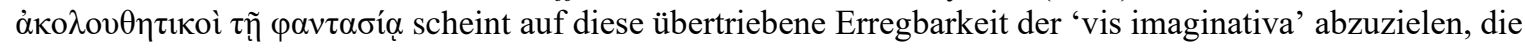
spatter für den Halluzinationszwang oder aber für eine besondere Kraft des anschaulichen Vorstellungsvermögens verantwortlich gemacht wurde.' also 100 and 109 on Rufus specifically. ${ }^{693}$ For previous scholarship on the Problemata XXX: Müri (1953) 21-38; Flashar (1962) provided a German translation (250-61) and a rich commentary (711-22) that has laid the groundwork for later studies; Flashar (1966) 60-73; Klibansky et al (1964) 55 ff.; van der Eijk (2005) 139 ff.; Schütrumpf (2015)

${ }^{694}$ Problemata XXX 954b10-28. Cf. Müri (1953) 24-6; Klibansky et al (1964) 82; van der Eijk (2005) 161. I do not agree with Schütrumpf (2015) that 'One cannot find in Pr. 30.1 the conceptual framework of a mean that controls Aristotle's ethical and political philosophy.' With regard to the people with a melancholic constitution themselves, it clearly is a mean which they ought to aspire to, i.e. a mean between the hotness and coldness of their black bile, which both lead to extremes when they are not moderated (955a27-36). This is still the case, even if these people themselves are not a mean compared to others because they are excellent when they strike the right middle with regard to their mixture; one does not need to resort to 'making the middle the center of the argument' in order to accept this, let alone assume that black bile plays some part in Aristotle's notions of the
} 
theory of melancholy builds on Plato's notion of mania as we find it in the Phaedrus, and can be seen as a secularization of that notion by means of Aristotelian-based philosophy of nature. ${ }^{695}$

How does this curious little text relate to the other authors that we are discussing here? With regard to Aristotle, Philip van der Eijk has convincingly argued that it 'corresponds quite well to the Aristotelian concept of melancholy' and has suggested that it may go back to 'a treatise on melancholy that may have been part of Aristotle's lost Problemata' or that it may have been the attempt of a 'later Peripatetic (perhaps Theophrastus) to systematize the scattered statements of the Master'. He concludes that 'in any event ... the theory of Pr. 30.1 has proved to depend strongly on Aristotle's own statements on melancholics' ${ }^{696}$ Most of the tendencies we found in Aristotle's notion of the melancholic, notably the intensive imagination, impulsive nature and strong desire for bodily pleasures, show resemblance to the described effect of heat on black bile in the Problemata (so to one side of the bipolar whole). With regard to Galen, there are obviously some important differences, particularly the positive associations with genius and with exceptional joy that are simply absent in Galen, and for example also the air-like nature of black bile that makes it comparable to wine. ${ }^{697}$ These differences have been adequately described. ${ }^{698}$ There are also, however, important similarities that might be overlooked at first - particularly when one focuses on the differences - which may then result in the view that the theory of melancholy developed in the Problemata does not bear any relation to Galen's writing on black bile and melancholy. ${ }^{699}$ As Flashar has noted, Galen refers to the Problemata in his commentary on the Hippocratic Epidemics, although not particularly to chapter $X X X, 1$. However, he does refer to it in the context of melancholy, since his reference concerns the issue of the lustful nature of the melancholic (Problemata IV, 30). ${ }^{700}$ As we have seen, the question on the melancholic's

mean in order for Aristotle's mean to play a role in the Problemata XXX,1 (see Schütrumpf's note 33 against Klibansky's reading)

${ }^{695}$ Müri (1953) 24; Flashar (1966) 62; Klibansky et al (1964) 55 ff., 90: 'Gerade dies Aufgabe stellt und löst nun aber das Problem XXX,1. Der mythische Begriff des Wahnsinns ( $\mu \alpha v i ́ \alpha)$ wurde durch den naturwissenschaftlichen Begriff der Melancholie ersetzt, was um so leichter geschehen konnte, als

'melancholisch' und 'verrückt' in rein pathologischem Sinne seit langem Synonyme waren und als die auch dem krankhaften Melancholiker eignende Gabe der Wahrträume und Prophezeiungen der Platonischen Gleichsetzung von Mantik und Manik entsprach.'

${ }^{696}$ Van der Eijk (2005) 160-8. See earlier Müri (1953) 38; Flashar (1962) 712 f.; Klibansky et al (1964) 81 f.; see also Schütrumpf (2015) for a different perspective (see notes 671 and 694 above) which I think makes van der Eijk's first suggestion, that it was part of a text written by Aristotle himself, less likely, though I do not think it weakens the suggestion that the author of the Problemata might be taking up Aristotle's writing on melancholy. ${ }^{697}$ Problemata XXX,1 953b22 ff.

${ }^{698}$ Most recently by Jouanna (2012) $237 \mathrm{ff}$.

${ }^{699}$ Flashar (1966) 68: 'In Galens eigener Darstellung der Melancholie bleibt die Konzeption der Problemata ebenso unberücksichtigt wie in den übrigen Spätantike, in denen es ausschließlich um die krankhaften Erscheinungsweisen der Melancholie geht.' Jouanna (2012) $237 \mathrm{ff}$. strongly emphasizes the differences between the medical tradition and the Problemata XXX,1, and the continuation of the Hippocratic legacy (over against the Aristotelian) by later medical authors such as Aretaeus and Galen.

${ }^{700}$ Hipp. Epid. VI, XVIIB 29 K, Galen remarks that Aristotle explains this lustful nature in terms of the black bile being full of air (as it is also described in chapter XXX,1)) and relates it to Diocles' notion of hyponchondriac melancholy. 
lustful nature fits with Aristotle's characterization of the melancholic as someone with a strong desire for bodily pleasure. In fact, Galen ascribes the Problemata to Aristotle, as has been common for centuries by then. ${ }^{701}$ This indicates that besides knowing it and therefore presumably also knowing the chapter on melancholy, Galen had reason to seriously study it, considering his general knowledge and appraisal of Aristotle and more particularly his tendency to portray Aristotle as one of his fore-runners with regard to the theory of the four humours. ${ }^{702}$ In the same passage, Galen places the Problemata, Hippocrates and Rufus in one tradition of writing on melancholy. ${ }^{703}$

As it might appear, another important difference between the Problemata and Galen consists of the association of black bile with both heating and cooling in the former and the association of coldness alone in the latter. Indeed, at first sight it might seem as if only the cold aspect of the bipolar melancholy of the Problemata corresponds to Galen's notion of black bile, while the hot aspect remains absent. But in fact that is incorrect, since Galen tends to understand the black bile as a substance that used to be hot and is now cooled down. Galen associates intense intellectual activity (associated with the hot aspect of the bipolar melancholy in the Problemata) with hotness and yellow bile, not coincidentally the humour that is abundant in the period preceding the season in which black bile predominates. The predominance of black bile in autumn, as well as the concomitant danger of melancholy, is a direct consequence of the cooling down of hot yellow bile, which prevails in summer. ${ }^{704}$ It is a fact that Galen works with four elemental qualities and four humours, while in the Problemata there seem to be only two elemental qualities, hotness and coldness, and there is no theory of the four humours to be found there. ${ }^{705}$ However, this amounts merely to a general difference in the underlying physiological framework, which can be partly reconciled. For example, attributing to yellow bile the symptoms and qualities that are caused by heating of black bile and attributing to black bile proper the symptoms and qualities that are caused by the cooling of black bile (that is now cold but that used to be hot), might be a good way to go about interpreting the Problemata if one wants to maintain its general description of symptoms, while also keeping to an underlying theory of four humours and four elemental qualities. That is to say, taking into account the division of bile into yellow and black bile, Galen's account might be much closer to that of the Problemata than it may appear at first sight. ${ }^{706}$ But we shall return to this subject below, in our discussion of Galen.

\footnotetext{
${ }^{701}$ Cf. Klibansky et al (1964) 81

702 Stewart (2016) $29 \mathrm{f}$.

${ }^{703}$ Specifically, he claims Rufus chose to write $\varphi$ óßos ('fear') instead of $\psi$ ó $\varphi$ os ('noise') for the passage from the Problemata (IV, 30), since this fits the symptomatology from the Hippocratic Corpus (XVIIB 29,16 K f.)

${ }^{704}$ In the Hippocratic On the Nature of Man itself, in a passage quoted by Galen in $H N H 44,25-45,1 \mathrm{Mewaldt}$ ( $\mathrm{XV} 84 \mathrm{~K}$ ), it is even said that it is the same bile that persists through summer and autumn: 'The bile of summer also dominates the body in autumn.' (tr. Hankinson)

705 Cf. Van der Eijk (2005) 159

${ }^{706}$ In this regard, it is also relevant to note that, as Walter Müri has observed, there is a parallel between on the one hand, the development of black bile as a separate substance - that is to say, the division of 'bile' into yellow
} 
There are also other notable features on the cold side or the depressed variant in the Problemata that show continuity with the previous Hippocratic or later Galenic tradition: the emphasis on despondency and fear as the main symptoms that potentially lead to the desire to commit suicide (954a20 f.; $964 b 34$ f.; 955a10) ${ }^{707}$; the taciturn tendencies of the melancholic $(953 \mathrm{~b} 13-4)^{708}$; the notion of a sadness without a cause (954b15) 709 ; the distinction between acquiring an excess of black bile because of one's diet and having it naturally as a part of one's original constitution (954a2530) ${ }^{710}$; the dinstinction between a normal and harmful amount and state of black bile with its accompanying ambiguity (953a10-14; 954b18 f.) $)^{711}$. To these we can add the association of melancholics with stuttering, lisping or other problems with speech from Problemata XI,38 $38^{72}$ and the association of melancholics with the need for release of sexual desire in Problemata IV,30. ${ }^{713}$ These parallels have been overlooked, perhaps because of a focus on the notion of melancholic genius, which was to become so important in later tradition from Ficino onwards, and which is absent in Hippocrates and Galen. Given the common ground between Galen and this text from the Problemata, it seems likely that Galen was, directly or indirectly influenced by the discussion of melancholy in the Problemata. Something else to take into account here, is the fact that Rufus leans heavily on the Peripatetic discussion of melancholy and refers to it explicitly as well ${ }^{714}$, while Galen in turn refers to Rufus as his main predecessor - besides Hippocrates - on the subject. Besides the explicit reference Galen makes to Rufus in At. Bil., van der Eijk and Pormann have shown that Galen's writings on melancholy in Loc. Aff. also lean heavily on Rufus' work, to say the least. ${ }^{715}$

and black - and on the other, the addition of autumn to the three other seasons by a division of summer (see below) into two separate seasons.

${ }^{707}$ Hippocrates: Epidemics III XVII, case 2; Aphorisms VI, 23; Galen: Loc. Aff. III, 10 (VIII 188-90 K); Symp. Caus. VII 202-3 K

${ }^{708}$ Hipp. Epid. III XVIIA 789,13-14 K, where Galen explains the change from not speaking ( $\sigma \gamma \tilde{\tilde{\omega} \sigma \alpha)}$ to excessive speaking ( $\lambda$ ó $\gamma_{0} \pi \mathrm{o} \lambda \lambda \mathrm{oi}$ ) in terms of the difference between a melancholic and phrenitic condition respectively, also Hipp. Epid. III XVIIA 785,5-786 K, where Galen explains the silence and gloominess of a patient in terms of her having a more atrabilious blood.

${ }^{709}$ Galen: Symp. Caus. VII 203,4-7 K; Plen. VII 576,10-13 K; Loc. Aff. VIII 418 K

${ }^{710}$ Galen: Loc. Aff. VIII $177 \mathrm{~K}$

${ }^{711}$ See our discussion of black bile in Galen below. Cf. Klibansky et al (1964) 80: 'Freilich ist es den Nachfolgern des Aristoteles nicht immer leichtgefallen, eine scharfe Grenzlinie zwischen der natürlichen Melancholie und der krankhaften Melancholie zu ziehen, denn es bedarf keiner Erörterung, da $\beta$ selbst eine wohltemperierte Melancholie stets in Gefahr ist, durch eine vorübergehende Steigerung der Gallenmenge oder, und vor allem, durch eine erhitzende oder erkältende Beeinflussung der Gallentemperatur in eine akute Krankheit umzuschlagen.'

${ }^{712}$ See note 708 above

${ }^{713}$ Also Problemata XXX,1 953b32. See Galen's Loc. Aff. VI,5 (V 418 K), where he compares the sad and hopeless facial expression of people that repress their sexual needs with the appearance of melancholics.

${ }^{714}$ See Pormann (2008) 7 for a brief enumeration of parallels and van der Eijk's essay in the same edition, 160-6 for more extensive discussion.

715 Pormann (2008) 4-9, 178 and 265 


\section{c. Rufus of Ephesus}

The physician Rufus of Ephesus, whose work is mostly dated to around the turn of the $1^{\text {st }}$ century AD, was perhaps Galen's most important predecessor on the subject of black bile and melancholy. ${ }^{716}$ Galen mentions him as the best of 'the more recent writers' on the subject at the start of his own On Black Bile, and even remarks that for those willing to listen there is nothing missing from Rufus' treatise. ${ }^{717}$ Coming from Galen, this is certainly exceptional praise for someone who is not Hippocrates or Plato. Rufus wrote two books on melancholy, of which we now only have fragments, mostly in Arabic. These fragments have been collected in an excellent edition with translation and commentary by Peter Pormann, which also includes additional essays by other scholars on Rufus and melancholy. ${ }^{718}$ According to Pormann and van der Eijk, Galen's writings on melancholy in Loc. Aff. rely on Rufus' work to a large extent, and might indeed be 'little more than a Galenic summary of Rufus' ideas on the topic without proper acknowledgement' ${ }^{719}$ Hence, it will be useful, to say the least, to discuss Rufus' work before we turn to Galen himself.

\section{Basic distinctions}

In line with the ambiguity we have already found in the Hippocratic Corpus between a black bile that is inherently harmful and related to disease and the black bile that is a regular part of our constitution, Rufus also seems to distinguish two kinds of black bile: the natural black bile that is mixed in with the blood and only becomes harmful under specific circumstances, and the black bile that is a result of burning and cooling of other substances, most notably yellow bile and blood. ${ }^{720}$ The first kind of black bile can be a normal part of our constitution without being harmful, as long as it has settled down, like a sediment in the blood. When it is stirred, however, it can become harmful. As long as it is regularly evacuated or piled up in the spleen, however, it does not cause melancholy. ${ }^{721}$ This notion of black bile as a sediment of the blood is to become an integral part of Galen's theory of black bile, as we shall see below. The other black bile is the result of burning and cooling: when yellow bile is burned, it turns into black bile and causes madness; when it is cooled it leads to depression. The latter kind clearly shows affinity to the discussion in the Problemata. It also leaves its print on Galen's work, since Galen considers the black bile that is the consequence of the burning of another humour, mostly yellow bile, as the most dangerous kind of black bile and as the kind that always leads to delirium. ${ }^{722}$ Furthermore, the division into three distinct types of melancholy that we find in Galen seems to go back to Rufus as well, though Rufus seems to have focused his

\footnotetext{
${ }^{716}$ For his dates see Pormann (2008) 4, $115 \mathrm{f}$. and $139 \mathrm{f}$.

717 At. Bil. V $105 \mathrm{~K}$

718 Pormann (2008)

719 Pormann (2008) 265

${ }^{720} \operatorname{Fr} 7,1,11,21,68,1,71,7$

${ }^{721}$ Fr 21,7 f., Fr 28-31

${ }^{722}$ Loc. Aff. VIII 176-77 K; Nat. Fac. II 136 K; At. Bil. 147-8 K
} 
analysis on one of these types, the so-called hypochondriac type. ${ }^{723}$ There is mention of two other types in Ishaq ibn Imran's rendering of Rufus' work, but there they are not further specified. ${ }^{724}$ Galen differentiated between a hypochondriac, encephalic and general type of melancholy in Loc. Aff., so it seems likely that this distinction essentially goes back to Rufus too, as Pormann and van der Eijk suggest. ${ }^{725}$ Another distinction we find in Rufus's work is that between an acquired melancholy that is the consequence of bad diet, and a melancholy that comes with one's nature and original mixture ( $\left.\dot{\kappa} \kappa \varphi v ́ \sigma \varepsilon \omega \varsigma \kappa \alpha \alpha^{\prime} \tilde{\eta} \varsigma \dot{\varepsilon} \xi \dot{\alpha} \varrho \chi \tilde{\eta} \varsigma \kappa \varrho \alpha ́ \sigma \varepsilon \omega \varsigma\right)$. However, this distinction occurs only once in the extant fragments. ${ }^{726}$ The description of the acquired kind of melancholy is also reminiscent of that of the bipolar-like description we found in the Problemata: at first, when the yellow bile is excessively heated, the melancholic becomes extremely active, bold and delirious; but then, when 'the bile is burnt up, they become downcast, sad and fearful'.$^{727}$

All of these basic distinctions - the two kinds of black bile, the three types of melancholy and the difference between an acquired and natural melancholy structure Galen's discussion of black bile and melancholy, as we shall see below. ${ }^{728}$

\section{Hypochondriac melancholy and digestion}

The hypochondriac type of melancholy derives its name from its location of origin: it

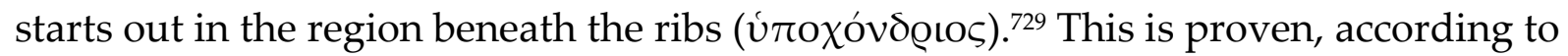
Rufus, by the observation that pain diminishes when the belly is relieved or when patients vomit, and that the disease often occurs through indigestion. ${ }^{730}$ The hypochondriac type of melancholy is also repeatedly associated with flatulence and constipation, which fits well with some of Galen's notions on the evacuation of black bile, as we shall see. ${ }^{731}$

We have previously noted that Aristotle ascribed to the melancholic type a flawed digestive system, ${ }^{732}$ and we find melancholy to be strongly linked with food and digestion in Rufus as well. Melancholy is often explained as a consequence of the body's inability to get rid of a superfluous residue - the black bile - and often arises in the stomach. Rufus associates the black bile, or the 'melancholic humour', with bad digestion and characterizes it as a residue, as did Aristotle. ${ }^{733}$ The emphasis on

\footnotetext{
${ }^{723}$ Pormann (2008) Introduction 5, Fragments 4, 5 and 38; for Galen, see Loc. Aff. chapters 9 and 10 from book III, also rendered in Pormann 265 ff., with translation

${ }^{724} \operatorname{Fr} 5$

${ }^{725}$ Pormann (2008) 82 and van der Eijk (2008) 172 f. See also Flashar (1966) 92-4

${ }^{726}$ Fr 11, 22 f.; on the other hand, van der Eijk (2008) 173, notes parallels for the difference between a natural melancholy and one that is the consequence of habit in Plato's Rep. IX 573c7-9 and Aristotle's Nic. Eth. 1152a27-33.

${ }^{727}$ Fr $11,23-5$

${ }^{728}$ Cf. Pormann (2008) 8

${ }^{729} \operatorname{Fr} 6,7$

${ }^{730}$ Fr 6, also 40,25-33

${ }^{731} \operatorname{Fr} 7,11$

${ }^{732}$ See infra, 210

${ }^{733}$ Fr 11,10: 'Why do they constantly suffer from indigestion? Because their body is turbid and full of superfluities, and the belly is therefore bad-tempered throughout owing to the melancholic humour.' (tr. Pormann)
} 
the stomach that we find in his fragments might be partly because Rufus supposedly only discusses the hypochondriac melancholy that arises in the region under the ribs by definition. Vomiting and purging through medication are generally proposed as a remedy. That is to say, the way to deal with the melancholic condition consists chiefly in the evacuation of the residue that does not seem to serve a purpose in the first place, so that the body is not completely dominated by its qualities, notably its dryness. ${ }^{734}$ Although, under specific circumstances, Galen does find a purpose for black bile (for instance, after it is has undergone a certain alteration, it can serve as nutriment for the spleen), the idea that black bile comes to be as a by-product of the digestive process and needs to be evacuated subsequently is central in his work as well. Rufus also suggests some other treatments that seem to be mostly physiological in nature, many of which suggest a direct countering of the quality of dryness: exercise, ${ }^{735}$ numerous suggestions on diet and drugs, ${ }^{736}$ wine, ${ }^{737}$ and bathing. ${ }^{738}$ Although most of his discussion is centred on the digestive system and the stomach, it is important to note that Rufus considers the stomach to have a direct relation to the head. As such, complaints in our stomach can have a strong effect on our brain or mind and vice versa, and diseases of the head can often also be treated by vomiting and purging. In Loc. Aff., Galen works out this notion of the stomach affecting the brain in terms of his more technical notion of sympatheia, as we shall see below. ${ }^{739} \mathrm{In}$ Rufus, we find an association with the spleen as well, as an organ that can cause melancholy when it is in a bad state and that shows symptoms of pain in patients suffering from melancholy. ${ }^{740}$ These associations will be further systematized by Galen, as we shall see, who reserves a crucial role for the spleen as the organ continually cleansing the body of black bile.

\section{The physiology of the melancholic}

Rufus considers the melancholic humour to be 'cold and dry', as did the Hippocratic On the Nature of Man. ${ }^{741}$ With regard to the described delusions, it is interesting that they are connected to the qualities that characterize the black bile itself: some patients think they are an earthen vessel or that their skin is dry parchment due to the dryness and coldness of black bile. ${ }^{742} \mathrm{~A}$ recurrent motif is also the patient who thinks

\footnotetext{
${ }^{734} \operatorname{Fr} 6, \operatorname{Fr} 7, \operatorname{Fr} 8, \operatorname{Fr} 42,1, \operatorname{Fr} 53, \operatorname{Fr} 55, \operatorname{Fr} 56, \operatorname{Fr} 67,14-15:$ 'I nourished him with spelt juice, rock fish, and broth made with beans for approximately thirty days. The more his body became moist, the more the symptoms of melancholy subsided, until he was completely cured.' (tr. Pormann); Fr 67,22, Fr 69,2-3, Fr 71

${ }^{735} \operatorname{Fr} 17,13$ and 40,5

${ }^{736}$ Fr 40,8-18, Fr 42,2-6, Fr 45, Fr 46, Fr 51, Fr 54

${ }^{737} \mathrm{Fr}$ 40,18, Fr 61, Fr 63, Fr 64, Fr 65; Galen, in $Q A M$ (IV $779 \mathrm{~K}$ ) notes that 'one who drinks wine in

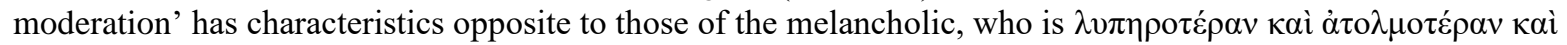
$\dot{\alpha} \theta v \mu$ o $\varepsilon \dot{\rho} \alpha v$; earlier, in IV $777 \mathrm{~K}$, he mentioned how the daily consumption of wine relieves us of all sorrow and

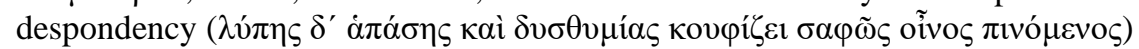

${ }^{738}$ Fr 40,7, Fr 61,2-4, Fr 62

${ }^{739}$ Fr 8, Fr 37, Fr 38, Fr 39,1; Fr 40,1-4; in Fr 67,5-7 we find a concrete example of this relationship, Rufus fearing that the patient's condition will spread from the hypochondriac area to the eyes and the brain; see Holmes (2013) for a seminal discussion of sympathy in Galen

${ }^{740} \operatorname{Fr} 66$

${ }^{741} \mathrm{Fr} 11$, also in $\mathrm{Fr} 68$ it is said that black bile is caused by bad mixture

${ }^{742}$ Fr 11,3-4
} 
that he lacks a head. Rufus relates this symptom to a pneuma rising upwards and making the head light, which must be a continuation of the idea that there is something air-like about the black bile, as we also found it in the Problemata. ${ }^{743}$ Indeed, when Galen refers to the passage in the Problemata on the question of why melancholics have excessive desire for sex, which is explained in terms of the airy nature of black bile, he involves Rufus in the discussion as well. ${ }^{744}$ Besides sex, the melancholics can also have excessive cravings for food and alcohol because their stomach is cold and they desire to warm it. ${ }^{745}$ The theme of excessive desire for bodily pleasures corresponds to Aristotle's characterization of the melancholic in the Nicomachean Ethics. ${ }^{746}$ It is notable that these examples testify to a strong and direct relation between the qualities of the physical substance black bile and the symptoms of the (mental) illness melancholy.

Rufus describes the physical appearance of the melancholic in considerable detail, relating many features to the physiological constitution of the black bile itself: 'They generally blink their eyes, and have prominent eyes and thick lips because of the thick pneuma. Their skin turns black owing to the [melancholic] humour being poured out. Many of them are hairy because of the great amount of thick superfluities. They generally speak fast, they lisp, and stammer since they cannot control their tongue. For the intensity of movement comes about through the pneuma. Everything which moves intensely decays quickly.' ${ }^{747}$

We shall find most of these outward characteristics in Galen as well. Also, the prominence of the eyes, their quick movements and the intensity recall Aristotle's emphasis on the melancholic's capacity for vision and dreaming due to their intense imagination, which they do not rationally control (the lisping is also mentioned in the Problemata XI, 38 903b19). Other, more dreadful outward manifestations of excessive black bile that we find in Rufus and that recur in Galen are: ulcers, haemorrhoids and varicose veins as well as black substance in vomit, stools and urine. ${ }^{748}$

As we noted, the elemental qualities of hotness and coldness play an important role in Rufus' notion of black bile. In fact, one fragment explains how the humour itself becomes black because of a combination of excessive heating and subsequent cooling down. Rufus makes a comparison with pieces of coal that are radiant when they burn but then blacken when they cool down. ${ }^{79}$ This process of heating and subsequent

\footnotetext{
${ }^{743} \mathrm{Fr} 11,12$; for the association of black bile with air in Rufus see also F 29,5 'For black bile is accompanied by wind, as all cold things are...' (tr. Pormann) and the repeated association with flatulence in many of the fragments; cf. Fr 60 'Their desire for sexual intercourse is also a proof that the black bile contains a lot of wind.' (tr. Pormann)

${ }^{744} \mathrm{Fr} 73$, which is the passage from Galen's commentary on the Epidemics referred to earlier (Hipp. Epid. VI, 138,19 f. Wenkebach (XVIIB 29 K)); also Fr 58-60, see Pormann's commentary 103 and van der Eijk's essay in the same edition, 165

745 Fr 11

746 See infra, 212-4

${ }^{747}$ Fr 11,14-16 (translation Pormann); cf. Fr 14,6-7

${ }^{748}$ Fr 21,4, also $17,1-3$

${ }^{749}$ Fr $11,18 \mathrm{f}$.
} 
cooling down changes the colour of the blood from bright to black. Rufus also notes that either of the two qualities can have the same or a similar effect by themselves. He points to 'some external bodies', which can become black from an excess of cold, and states that the humours can be rendered black by extreme heat that dries them out by consuming their moisture, 'just as the sun blackens fruits and human bodies' ${ }^{750}$

Rufus relates melancholy to old age in particular, since 'the old are naturally depressed, little inclined to merriment, and moody' ${ }^{751} \mathrm{He}$ also relates it to spring, because this is the time when the blood is stirred, which means that the black bile does not settle as a sediment but moves throughout the blood. ${ }^{752}$ We shall see how Galen works out a more systematic association of black bile with autumn, based on the Hippocratic On the Nature of Man.

\section{Symptomatology and 'psychological' therapy}

The 'psychic' state of someone afflicted by melancholy according to Rufus, is unambiguous and as we would expect: excessive fear and (social) anxiety, delusion, despondency, suicidal inclinations. ${ }^{753}$ Melancholics are also said to have various difficulties with speech, ${ }^{754}$ and can be prone to excessive eating and alcoholism. ${ }^{755}$ In one fragment, Rufus is cited as saying that 'the beginning of melancholy is indicated by fear, anxiety and suspicion aimed at one particular thing, whilst no disease is present in any other respect.' 756 This seems to take up both the Hippocratic designation of fear and despondency as the main symptoms of melancholy as well as the intense and mono-manic imagination ascribed to the melancholic by Aristotle. ${ }^{757}$ Interestingly, Rufus also takes up the association of melancholy with excellence or strong intellectual activity, which is, as we have seen, a prominent feature of the account of the Problemata. He particularly relates it to the intensity of movement that marks the melancholic: 'People of excellent nature are predisposed to melancholy, since excellent natures move quickly and think a lot. ${ }^{\prime 758}$ As has been observed by Pormann and others, however, Rufus seems to construct the causality the other way around: people of excellent nature tend to become melancholic, as opposed to melancholics being of excellent nature. ${ }^{759}$ This is clearly expressed in Miskawaih's

\footnotetext{
${ }^{750}$ Fr 11,21, translation Pormann

${ }^{751}$ Fr 17,8, also Fr 18,4-5, Fr 68,4-5, Fr 71,7

${ }^{752} \operatorname{Fr} 28-31$, also Fr 67,1-3

${ }^{753}$ Fr 11, Fr 13,2, Fr 14, Fr 15,2, Fr 67,16, Fr 68,2, Fr 71,5-6

${ }^{754}$ Fr 11,14-16, also 72,2; cf. Pormann's commentary 86, which provides parallels for both Galen and the Problemata

${ }^{755} \mathrm{Fr} 11$

${ }^{756}$ Fr 13, see also Fr 14,4, Fr 15,2, Fr 17,8

${ }^{757}$ Cf. also Fr 35 and Fr 68,6 on dreaming and delusional images; Rufus' symptomatology might also be compared to that of Aretaeus of Cappadocia, who has a strong emphasis on the threat of complete passivity, which compares well to modern-day depression, see On the Causes and Symptoms of Chronic Disease I, 5 ed. Adams and Flashar (1966) 78

${ }^{758}$ Fr 33 (translation Pormann), also Fr 34

${ }^{759}$ Cf. Pormann's commentary 93-94; Van der Eijk 164-5 and Toohey (2008) $222 \mathrm{f}$. in the same edition; we find this notion also in Diogenes Laertius' depiction of Chrysippus (SVF III, 237 = Diogenes Laertius VII 127), who supposedly has said that the wise man could lose his virtue because of melancholy (or alcoholism, which is an
} 
testimony, which states that Rufus said that 'no one who devotes too much effort to thinking about a certain science can avoid ending up with melancholy' ${ }^{760}$ Toohey has pointed to another difference with the Problemata, namely that Rufus' notion of melancholy does not seem bipolar-like (although, as we have seen, we do find echos of this bipolar-like melancholy in Rufus' description of the acquired kind of melancholy in Fr 11, 22-25). ${ }^{761}$ It is one thing to point out these differences, another to recognize the similarity that remains. It is not in any way necessary to associate melancholy with intellectual activity in the first place, and we know that the Problemata and Rufus made this association an important part of their views on melancholy, while apparently not doing such a thing for other afflictions. We also know that Rufus knew the Problemata XXX,1 and that there are many other similarities between Rufus' notion of melancholy and that of the Problemata. ${ }^{762}$ The association between melancholy and intelligence or an active intellect, important in both the Problemata and Rufus, will also reappear in Galen in a different form. As we shall see below, it will be tied to the specific properties of the substances of yellow and black bile and their interrelation. We see it also in the therapies that Rufus proposes. One of the things he suggests is for the patient to undertake long journeys, as they are not only beneficial for one's mixture and digestion, but also 'distract them from thinking, and amuse them'. ${ }^{763}$ Likewise, we might find in Rufus an early notion of what has come to be known as 'rumination', as Matthew Bell has observed. When confronted with a patient, the doctor should avoid having them believe that they are suffering from melancholy. Rather, he must pretend they merely suffer from bad digestion, so that the patient will refrain from reflecting on his condition and thereby make it worse. ${ }^{764}$ Bell has suggested that this implies that for Rufus there is a relation between self-consciousness and melancholy. Another means of distraction,

\footnotetext{
interesting pairing as well), while Zeno is portrayed as a melancholic type that needed moderate amounts of wine to soften his temper (SVF I 285-7), cf. Tieleman (2003) 163-66 on Chrysippus and Zeno; cf. Klibansky et al (1964) 95: 'Andererseits aber behandeln die Stoiker diese Erkrankung durchgängig als ein negatives Privileg des Weisen. Melancholie als Disposition hat zwar aufgehört, die wesentliche Bedingung der überragenden Begabung zu sein, aber sie ist als Krankheit die wesentliche Gefahr des überragend Begabten geblieben.'

${ }^{760}$ Fr 36 (translation Pormann), also in Fr 68, one of the case histories, the example is about somebody that became melancholic due to 'constant contemplation of the geometrical sciences'. In Fr 35, 'violent thoughts and worries' are said to potentially provoke melancholy

761 Toohey (2008) $222 \mathrm{f}$., I do not agree with Toohey that the association of melancholy with intellectual activity is 'but a minor element in his two-book text, On Melancholy.' In 8 of the 78 fragments collected by Pormann we find a direct linking of (scientific) thinking and/or excellence to melancholy as either cause or symptom (14,1, $33,34,35,36,40,19$ and 40,37-8, 58,2, 68,3), in other fragments we find the notion that melancholy damages the intellectual capacity $(70,2$ and 71,11), and then we also have all the associations between stomach and brain, that testify to the notion that melancholy, even if it comes to be as a problem of digestion, damages the brain. Cf. van der Eijk (2008) 163-5 for an overview of similarities between Rufus and Aristotle and the Problemata; Bell (2014), particularly 69-70 for the possible relation between self-consciousness and melancholy in Rufus.

${ }^{762}$ Again, see van der Eijk (2008) 163-5 for a brief overview

${ }^{763}$ Fr 40,19; likewise, Fr 67,16: 'The symptoms of melancholy from which he suffered were sadness and fear of death. I therefore ordered amusement and music. After eighty days he was saved.'; cf. Celsus De Medicina III, $18,17 \mathrm{f}$, in which entertainment is recommended as a remedy. Celsus also advises to praise the patient's work and change his mental attitude towards the things that trouble him.

${ }^{764} \mathrm{Fr} 40$ and 37. Cf. Bell (2014) 70
} 
particularly when one is preoccupied by a love-melancholy of sorts, is to have sex, which can 'bring back intelligence' and calm the melancholic. ${ }^{765}$

There is a strong psycho-somatic reciprocity in Rufus' writing on melancholy, where thinking can cause melancholy and excessive black bile can cause impairments of the rational capacity, where long and distracting journeys can improve our mixture and sex can bring back our intellectual capacity through the release of pneuma. To give another example, in one of Rufus' case-histories, we find the following description: 'When it [the melancholic superfluity] finally reached the brain, it had become extremely weak; there, however, it did encounter dry and burnt humours due to the sadness and sleeplessness which befell him. Therefore, the remainder had a yeastlike effect on them [these humours], turned them into black bile, and caused melancholy. ${ }^{766}$ In this case, a patient had a melancholic fluid in his arteries, making him sad and fearful. He underwent venesection and purging several times and Rufus cauterised the area between the ribs. Therefore, the melancholic fluid was greatly reduced, but there was still a small remainder flowing towards the patient's brain, though a very weak and seemingly harmless remainder. Then, however, this small remainder is brought in contact with dry and burnt humours in the brain, that are themselves a consequence of his sadness and sleeplessness, that is to say, of the symptoms that the melancholic fluid caused in the first place. This triggered a reaction that led to melancholy again, after which the patient needed new treatment. This is a clear example of the aforementioned reciprocity, in which there is a kind of circular effect going on: one becomes sad and fearful due to a specific matter in the blood; the sadness and fear cause the humours in the brain to dry and burn; the dried and burned humours make one susceptible to fear and sadness, once again!

In Galen too, as we shall see, this ambiguous psycho-somatic nature of melancholy already expressed in its very name $e^{767}-$ will come to the fore.

\section{Conclusion}

Much, if not most, of what Galen writes on melancholy (particularly in Loc. Aff.) is at least prefigured in Rufus. Galen seems to inherit from Rufus his main distinction between two different kinds of black bile: one that is like a sediment in the blood and one that is caused by burning. He also seems to take over the distinction between three different kinds of melancholy, namely, hypochondriac, encephalic and general. Rufus strongly emphasizes the association with digestion, which we previously found in Aristotle as well, and also associates it with the spleen. ${ }^{768}$ The apparent reciprocity between physiological and psychic states will also recur in Galen. The

\footnotetext{
${ }^{765} \operatorname{Fr} 58$, Fr 59, Fr 73 (from Galen); see also Aretaeus, On the Causes and Symptoms of Chronic Disease I, 5 ed. Adams, for an anecdote on a person who seemed incurably melancholic, but turned out to be merely suffering because of his love for a girl, as his symptoms immediately abated (and he 'became restored to understanding') as soon as he united with her, 'love being his physician'; cf. also Flashar (1966) 79 on Celsus: 'Mit diesem 'Fall' ist zum ersten Male in der Literatur der Liebeskummer als Form der Melancholie gedeutet.'

${ }^{766}$ Fr 67,20 (translation Pormann)

${ }^{767} \mathrm{Cf} . M M$ II $2, \mathrm{X} 82 \mathrm{~K}$, where Galen remarks that the disease melancholy is named from its cause, the black bile

${ }^{768}$ Fr 21,7 f., Fr 28-31
} 
association of melancholy with thinking will recur in a slightly different form. It is more dependent upon a broader schema of the relation between elemental qualities and humours on the one hand and psychic capacities on the other, and it differs from Rufus because the thinking is less particularly associated with scientific thinking. As far as I can tell on the basis of the extant fragments collected by Pormann, there are a few aspects in which Galen changes, systematizes and adds to the Rufian fundament, which certainly must have formed his point of departure. Some of these aspects have to do with Galen using a more systematically developed humoural theory, in which black bile is not only dry and cold, but also belongs to autumn, is ill-tempered, earthy and obstinate. As such, it is opposed to blood and spring, which are considered beneficial, and opposed to yellow bile, which stimulates activity and thinking. This allows Galen to further integrate black bile into a microcosmic schema, in which it is a regular part of us, while it is at the same time opposed to the most useful or beneficial parts of us. As we shall see, in Galen, black bile acquires a regular place among the qualities, elements and time-periods in which the order of the cosmos consists. This also extends to the role of the spleen, which, as it seems for the first time, becomes the organ specifically attributed to us in order to purify our blood from black bile. Galen also seems more successful than Rufus in explaining the cause of melancholy in terms of the darkness of its substance. He achieves this partly by further developing the hypochondriac kind of melancholy on the basis of Diocles and Rufus' work. Through a comparison with the external darkness that we all experience, Galen achieves a normalization of melancholy that we did not find in the extant fragments of Rufus yet. But we may be getting ahead of ourselves now. It is time to analyse the notions of black bile and melancholy in Galen's work, first. After brief discussions of black bile and melancholy in the Hippocratic Corpus, the Peripatetic tradition and Rufus, we are now sufficiently equipped to look at Galen's writing on black bile and melancholy. Many of the themes and distinctions that we have pointed out before shall recur in our discussion of Galen, whose work with regard to this subject, too, can be seen as a synthesis of the preceding tradition.

\section{Galen on black bile}

\section{Introduction}

We have seen, in the brief overview of Galen's main precedents, that the black bile had become an ambiguous substance. On the one hand it is a dangerous substance that is primarily associated with serious disease; on the other hand - especially under the influence of the late Hippocratic On the Nature of Man - it is also one of the four humours and as such a normal part of our constitution, healthy or otherwise. This is a tension that culminates in Galen's work, in which black bile is essentially both of these things. 
It has been observed that the theory of the four humours as it has come down to us via On the Nature of Man, was one humoural theory among many and did not have a dominant role until Galen. ${ }^{769}$ Galen argued in his commentary on the treatise and elsewhere that it was the foundation of Hippocratic medicine and he contributed greatly to the ensurance of its legacy through both a further systematization and a consistent depiction of the theory as something widely shared by all previous philosophers and physicians held by him in high regard. ${ }^{770}$ As in many other cases, Galen managed to successfully present his own theories - that often synthesize various previous ones into a more or less original Galenic whole - as the right continuation of previous authorities, ensuring their canonization in centuries to come. ${ }^{771}$

Thus, however many competing humoural theories existed and whatever they consisted of - we will not discuss them here - they all became obscure, while Galen's humoural theory became the humoural theory. As we have noted, this particular historical contingency was conditional for the systematic inclusion of black bile into our body. It was likely also conditional for the notion of melancholy as something that is a part of human nature, and as something that is to a certain extent a regular and normal part of our lives as opposed to merely a dangerous disease that arises in exceptional circumstances. The identification of fear and despondency as the main and basic symptoms in the Hippocratic Corpus, taken up by others such as the author of the Problemata and Rufus, certainly must have helped in this regard: everybody is fearful and despondent at times. But, despite the existence of melancholy as a particular affection that is not necessarily dependent on a systematic humoural theory, I think it is safe to say that without Galen's canonizing incorporation of these symptoms into an enigmatic black substance that we always carry around, much of the later history of melancholy, including its romanticized forms, becomes much harder to conceive of.

In this chapter, we shall discuss Galen's notion of black bile and his attempted synthesis of the various forms of black bile that we have encountered among his main predecessors. Several aspects of black bile seem to run through Galen's work and they cannot always be distinguished in a straightforward manner. There is the black bile that is one of the four humours, associated like the others with its own season and stage of life. We find it in Galen's more systematic works such as his commentary on On the Nature of Man $(H N H)$ and his On the Elements According to Hippocrates (Hipp. Elem.) and it goes back to the Hippocratic On the Nature of Man. But there is also the black bile that is a kind of residue of digestion and that is distributed from the liver to the spleen as a side-effect of the production of blood, which we have found, in more rudimentary form, in both the Peripatetic tradition and Rufus. ${ }^{772}$

\footnotetext{
769 Jouanna (2012) 336; Stewart (2016) 22 f.; see infra, 205-9

${ }^{770}$ Stewart (2016)

${ }^{771}$ Cf. Nutton (2008)

${ }^{772}$ See infra, 209-10 and 219
} 
There is a black bile that Galen describes as a kind of 'sediment' of the blood that is only harmful in large quantities, which corresponds to the way Rufus describes one of the two kinds of black bile. But there is also a black bile that is a result of the burning of yellow bile, or a black bile that is completely unmixed. The latter two are deadly even in small amounts. The black bile that results from heating is something that we have also encountered before, both in Rufus and in the Problemata. In the latter it could have significantly positive effects. How do all of these black biles relate to each other? Is there anything common about all of them? How can black bile be both so harmful and so common? What role do the qualities of hotness and coldness play in Galen's writings on black bile? What role do the various seasons play? How is black bile related to digestion and the spleen? These are questions that we shall discuss in the first part of this chapter. Galen is, if anything, a great synthesizer of various previous traditions, medical and philosophical. He knew all of the discussed precedents well and despite his relatively scarce writings on the subject, nobody except perhaps Ficino or Burton has had such a lasting influence on the history of black bile and melancholy as Galen.

It will turn out that the types of black bile found in Galen, all of which we have by now seen prefigurations of, can be usefully distinguished along the line of the 'normal' and the 'harmful', or what Galen himself sometimes calls $\kappa \alpha \tau \alpha$ $\varphi v ́ \sigma ı$ and $\pi \alpha \varrho \alpha ́$ $\varphi v ́ \sigma \iota v .{ }^{773}$ Although Galen distinguishes the harmful and normal variants of black bile, they show much common ground as well. As we shall see, both can be designated either as black bile or as a melancholic humour, that is, by the same name. What is perhaps most striking in Galen's treatment of black bile is both the extent to which black bile is a normal substance that is potentially harmful, as well as the extent to which the harmful potentiality of black bile is a normal part of our constitution. This is what makes black bile exceptional compared to the other humours, particularly in its opposition to blood, an opposition which becomes more important in Galen.

After discussing the varieties of black bile, we shall devote a separate paragraph to the spleen, further systematized in Galen as the organ that draws the black bile to itself and cleanses the blood from it, to prevent it from dominating the body. Though Galen apparently deems the production of a pernicious substance such as black bile necessary, he also observes that Nature - in accordance with her providential character - made up for it to some extent by supplying us with an organ that cleanses our body of it. In this manner, the integration into our nature of an essentially harmful substance that does not seem to do us much good by itself, is reconciled with Galen's teleological framework through the synchronic introduction of its own cleansing instrument - the spleen. The association of black bile with the spleen, too, becomes a completely canonical element of the subsequent tradition. Again, there are precedents, as we have seen in Rufus, but the canonization of the relation between

\footnotetext{
${ }^{773}$ Cf. Stewart (2016) 160-6 for this distinction.
} 
spleen and black bile and between spleen and melancholy, is hard to conceive of without Galen.

Finally, after having laid the physiological basis, we shall look into the more or less symbolic associations that black bile evokes, its field of meaning, so to speak, departing from the associations of black bile with a specific season and stage of life, as well as its relation to the other humours and its peculiar qualities of coldness, dryness and thickness. It will become clear that black bile has an exceptional position in Galen's humoural theory as the humour opposed to blood, which is identified as the most important, beneficial and useful humour. As a normal part of our constitution it is associated not only with darkness and earth, but also with death. In our analysis, black bile appears as the remnants of a fire that has been quenched, as that which remains after summer ends - the stubborn and static remnants of excessive sun that now hinder the flow of the substance that gives us life by weighing it down. It is, as it were, the physiological substantiation of our finitude, of the mortality that is a continuous part of our life as its limit and opposite, and which requires continuous care so as not to become definite.

\section{a. The normal and the harmful I: the normal}

Galen devoted a short treatise to the subject of black bile, in which he focuses almost exclusively on the substance itself and its various detrimental effects. A discussion of melancholy is absent here. The work is called On Black Bile ( $\pi \varepsilon @ i \mu \varepsilon \lambda \alpha i ́ v \eta \varsigma \chi 0 \lambda \tilde{\eta} \varsigma$; abbreviated after the Latin as At. Bil.) and is included in the Kühn edition (V 104-48). A later edition by de Boer appeared in the CMG and there is also a French translation by Barras, Birchler and Morand, as well as an English one by Grant. ${ }^{774}$ The question of the authenticity of this treatise has recently been raised and answered favourably by Jouanna in an insightful article, the main proof for its authenticity being Galen's own reference to it in Prop. Plac. ${ }^{775}$

What comes to the fore most prominently in this short treatise is the ambiguity between black bile as a common and necessary part of our constitution, and black bile as a destructive and malignant substance that causes disease and death, the same ambiguity that we have referred to earlier.

At the beginning of At. Bil., Galen singles out his predecessors: Rufus, as one of 'the more recent writers' and, unsurprisingly, Hippocrates himself as well as some of his alleged pupils. He then immediately integrates the subject of his treatise in his general humoural theory, which he developed in $H N H$, by first describing the outward appearance ( $i \delta \varepsilon \dot{\varepsilon} \alpha$ ) of each of the four humours with descriptions that are congruent with those of $H N H$. This is an important step, since such a humoural theory was absent in the Peripatetic tradition on melancholy and we find merely a few scarce allusions in the fragments that we have of Rufus.

\footnotetext{
774 ed. de Boer, CMG V 4,1,1 (1937); Barras, Birchler, Morand (1998); Grant (2000)

775 Jouanna (2009)
} 
Blood has an exceptional position in Galen's humoural theory. In At. Bil., he starts with the description of blood, since it is the 'best known to everyone'. It is generally red, but can also appear somewhat more yellowish or black. Its taste is generally sweet while its thickness also varies. In fact, 'whatever pours out of the veins and the arteries', says Galen, 'however it might look', is simply called blood. ${ }^{776}$ Further on in the same treatise, however, Galen remarks that 'from the diversity of colour and consistency it is revealed that all the humours are contained within the veins and arteries $^{\prime 777}$. That might seem like a contradiction: on the one hand, everything that pours out of the veins and arteries is blood, while on the other hand all the humours are contained in the veins and arteries. However, it simply implies that there are two kinds of blood, or that the word 'blood' can designate two kinds of things: 1 . blood in a strict sense, as unmixed with the other humours; 2 . blood in a broader sense, as the mixture of four humours of which blood is the most important.

This also corresponds to the picture we find in $H N H$, where Galen more explicitly distinguishes these two kinds of blood. First, when he refutes the notion that man consists of only one humour, he remarks that the ones who claim that blood is the only humour are more difficult to refute than those who choose whichever one of the other humours. ${ }^{778}$ The main empirical argument against the view that there is by nature only one humour in the human being and that this humour is blood, is based on the observed results of purgative drugs: if people are given certain drugs, it can be observed that they evacuate phlegm or bile, whatever their age or the season. ${ }^{779}$ That means that these fluids must be contained in the body at all time. However, that does not mean that they have the same status as blood:

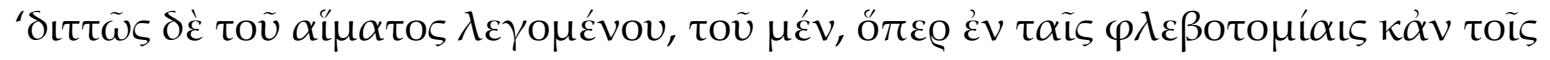

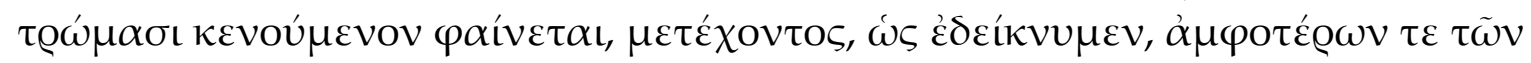

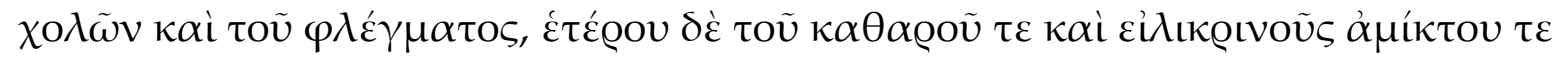
$\tau \tilde{\omega} \nu \not \ddot{\lambda} \lambda \omega \nu \chi v \mu \tilde{\omega} \nu . . .^{\prime 780}$

'But we talk of two types of blood: one which is manifestly evacuated as a result of phlebotomy and wounds, and which contains a portion, as we have indicated, of both types of bile and of phlegm; while the other is pure, unadulterated, and unmixed with the humours.' (tr. Hankinson)

The first type of blood, which is what we commonly know as blood, is only called 'blood' because it is, as Galen remarks, 'predominantly' blood. That is to say, it is a mixture of all four humours in which blood, in the purer sense, predominates. ${ }^{781}$ The

\footnotetext{
${ }^{776}$ At. Bil. V 107-9 K, translations Grant

777 At. Bil. V $119 \mathrm{~K}$, translations Grant

${ }^{778}$ HNH 38,5 Mewaldt (XV 70-1 K)

${ }^{779}$ HNH 38,1 f. Mewaldt (XV 70 K); cf. Nat. Fac. II 40-1 K

${ }^{780}$ HNH 39,23-6 Mewaldt (XV 73-4 K)

${ }^{781} \mathrm{HNH} 40,5-10$ Mewaldt (XV $74 \mathrm{~K}$ ): 'And to the extent that the semen is generated from blood, someone who says that the generation of the foetus comes about from blood might appear to be telling the truth: but not from pure blood, unmixed with any of the other humours, but from what is called 'blood', because it is so predominantly.' (tr. Hankinson)
} 
blood of a living being, however, will never merely consist of this pure form of blood and it is from blood in the mixed sense, states Galen, that the foetus is likely to be formed. ${ }^{782}$ That is to say: the other humours are always already mixed in the blood of a human being and their distinction is dependent on the empirical data of the purging. So the solution of the potential contradiction that we find in At. Bil. consists of the discovery of a homonymy, but not a mere homonymy. The mixture of all humours is also called blood, after one of the elements of the mixture itself, because blood is the most important humour:

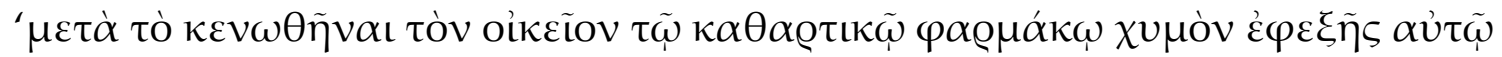

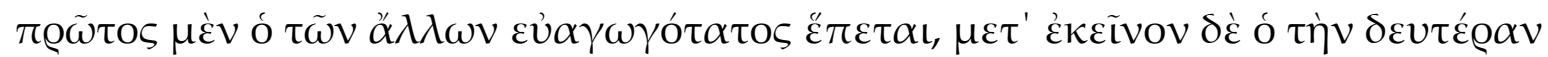

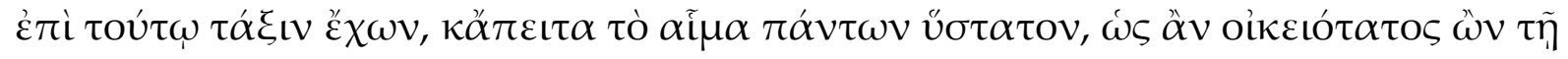

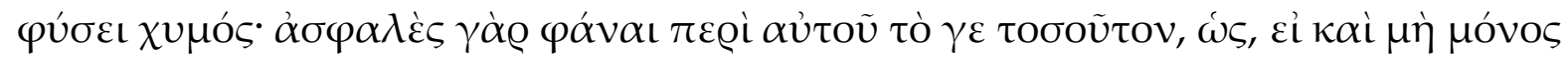

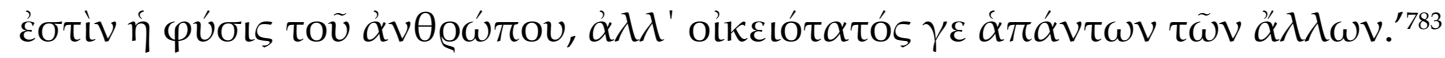
'After evacuating the humour which is most closely affiliated to the purgative drug, next in order there follows first the one humour among the others which is most easily attracted by it, and after that the second after it in this ordering, and then blood last of all, since it is the humour most closely affiliated to the nature (of man). For it is at any rate safe to say about this one, that it is, if not the sole constituent of the nature of man, then at least the most closely affiliated to it of all the others.' (tr. Hankinson)

The mixture of the humours derives its name, blood, from its predominant substance, blood in a stricter sense. There are other things in the blood besides blood in a strict sense and there is empirical evidence of those things due to the possibility of evacuation of phlegm and bile with purgative drugs, but these things are clearly not on a par with the blood. They fulfil a less important role than the blood itself. ${ }^{784}$ Unsurprisingly, Galen does not always distinguish between these two notions of blood as neatly as in the texts just quoted. Elsewhere in $\mathrm{HNH}$, when he enumerates the respective elemental qualities of each of the humours and arrives at those of blood, he remarks that since blood is the most well-tempered, none of the elemental qualities in it predominates greatly relative to the others. A little earlier, however, he simply attributed to blood the elemental qualities of hot and wet (this may be explained in terms of the difference between Galen's interpretation and the Hippocratic text, which does attribute to blood the qualities of hotness and

\footnotetext{
${ }^{782}$ HNH. 39,26 f. Mewaldt; also 32,20 (XV $59 \mathrm{~K}$ ), where it is said that all parts are generated from the menstrual fluid, which is blood in the mixed sense, containing the other humours; likewise in 50,13-14 (XV $94 \mathrm{~K}$ )

${ }^{783} \mathrm{HNH} 41,24$ Mewaldt (XV $78 \mathrm{~K}$ ). Galen also uses the same Hippocratic passage and gives similar comments in SMT, XI 616 K; In Hipp. Elem. 154,11 f. De Lacy (I $506 \mathrm{~K}$ ) he shows some appreciation for those predecessors that considered blood to be the only humour, even though he, of course, prefers the theory of the four humours in the end.

${ }^{784}$ Clearly, there are also differences in quantity: there is less black bile than there is yellow bile and phlegm, for example (UP 270,4-6 Helmreich (III 368 K)
} 
wetness). ${ }^{785}$ In fact, Galen says, since blood requires all four qualities in a certain balance, the most well-tempered blood must also contain the other humours. ${ }^{786}$ The reasoning in this latter passage is not entirely clear, but it is clear enough that the role of blood is ambiguous in Galen, because it is a humour among others on the one hand, but that which contains the other humours on the other. It is also clear enough that its latter role is explained not merely in empirical terms of a measured quantity, but rather in terms of its exceptional importance and well-tempered nature. There are also other ways in which blood is different from all three other humours: the other three are said not to congeal and they are often described as $\pi \varepsilon \varrho \iota \tau \tau \omega \mu \alpha \tau \alpha$, residues of the process of digestion, which is actually aimed towards the production of blood. This is something that we need to keep in mind, as it will become relevant for our analysis of black bile in Galen as well, since he opposes black bile to blood. ${ }^{787}$ Next to be described in At. Bil. is phlegm. It is said to have no particular taste of itself but to be able to take on a variety of tastes. Regardless of the particular taste it displays it can be called phlegm as long as 'it is white'. ${ }^{788}$ As opposed to blood, it does not congeal, which is, as we have just noted, actually a property that distinguishes all other humours from blood. The description of phlegm too, corresponds to that in $H N H$, where phlegm is also simply described as 'white' and where its variety in taste is emphasized as well. ${ }^{789}$ It is also characterized in terms of the elemental qualities and seasons as being particularly cold and wet and predominant in winter. ${ }^{790}$

Yellow bile is described as bitter and, like blood, displays some variety in colour and thickness. It becomes paler in colour and softer in consistency, less thick, to the extent that it contains more moisture. Eventually it could become as white and soft as the yolk of an egg. It is particularly related to the bladder, which is the organ that seems to take in the yellow bile after its generation in the digestive process. ${ }^{791}$ Again, this seems consistent with what we find in $H N H$, where yellow bile is also described as bitter, and comparable remarks about its variation in colour and thickness can be found as well. ${ }^{792}$ Its season is summer, and its elemental qualities are dry and hot. ${ }^{793}$

\footnotetext{
${ }^{785} H N H 46,25-47,5$ Mewaldt (XV 88-9 K); Cf. HNH 44,4 Mewaldt (XV $83 \mathrm{~K}$ ), where the same is predicated of spring, making it exceptional among seasons; in Temp. I 524-7 K, Galen provides a more elaborate discussion of this topic

${ }^{786}$ HNH 51,5-9 Mewaldt (XV $\left.97 \mathrm{~K}\right)$

${ }^{787}$ Cf. Klibansky et al (1990) 51-3: 'Daneben aber brachte die Systematisierung der Vier-Säfte-Lehre die weitere Komplikation mit sich, da $\beta$ zwei der vier Säfte, das Blut und die schwarze Galle, eine deutliche Sonderstellung einnehmen, die in der Entstehungsgeschichte des Systems begründet ist... Was zunächst das Blut angeht, so war es von vornherein gewissermaßen nur durch die Hintertür in das System gelangt, denn es ist nicht nur kein überschüssiger Saft, sondern sogar der unentbehrlichste und edelste Körperbestandteil... Die schwarze Galle hingegen war schon früh als eine böse Entartung der gelben Galle oder auch des Bluts aufgefaßt werden.'

${ }^{788}$ At. Bil. V 108-9 K

${ }^{789}$ HNH 20,17 Mewaldt (XV $35 \mathrm{~K}$ ) and $H N H 42,20$ Mewaldt (XV $80 \mathrm{~K}$ )

${ }^{790} \mathrm{HNH} 46,5$ f. Mewaldt (XV $87 \mathrm{~K}$ )

${ }^{791}$ Cf. At. Bil. V 147 where it is said that the bladder is the organ holding yellow bile; Caus. Symp. 222 K: 'The bladder on the liver (gall bladder) purifies the bitter bile, the spleen the black bile, the kidneys the serum.' (translation Johnston)

${ }^{792}$ HNH 20,17 Mewaldt (XV 35 K), 35,30 Mewaldt (XV 66 K; cf. Nat. Fac. II 9 (II 135 K), where the egg-yolk comparison also recurs
} 
Yellow bile has a peculiar relation to black bile, as we shall see below. It can become black by excessive heating, which must not be considered a rare phenomenon, it seems, given its abundant presence in summer, which also happens to be the season preceding autumn, the season of black bile. We shall pursue this peculiar relation further below.

So far, except perhaps for the ambiguous nature of blood, Galen's descriptions of the humours have been fairly straightforward and in line with his other works, not providing us with much interpretative difficulty. When it comes to the black bile itself, however, the matter seems to become somewhat more complicated.

In $H N H$ it is simply described as black, sour or sharp (ỏ $\xi u)$ and as having a thicker consistency than yellow bile. ${ }^{794}$ Its season is autumn and its qualities are cold and dry, while it is also said to be 'earthy' ( $\gamma \varepsilon \tilde{\omega} \delta \varepsilon \varsigma) .{ }^{795}$ Although it has its specific season in which it predominates and is more abundantly present - as do each of the other humours - it is a regular part of the human constitution in every age and season as well - as are each of the other humours. ${ }^{796}$ In Galen's commentary on the Hippocratic On the Nature of Man, each humour has its own combination of elemental qualities and seasons, creating an elegant whole by each providing an equal portion. There is at least a hint of a schematic association with the elements, as well, which seems to be based on the congruent descriptions of elemental qualities. Black bile is said to be earth-like, as we just mentioned. In PHP Galen is more explicit about this and completes the entire schema: yellow bile is analogous to fire, and phlegm to water, while blood has an exceptional role here as elsewhere and is said to consist of a balanced mixture of all four elements. ${ }^{797}$ This understanding of the humours is not restricted to $H N H$. We find it in many Galenic works, also sometimes extended to an analogy with the stages of life. ${ }^{798}$ In this schema, the four humours together constitute our nature (although, as we saw, there is an exceptional role for blood). When they are mixed in a balanced manner, we are healthy. Disease is the consequence of a relative imbalance or an isolation of one of the humours. Thus, in the Hippocratic treatise black bile simply appears as one among four and Galen, in his commentary, mostly seems content to leave it this way. There seems to be nothing to suggest that black bile is particularly dangerous or malignant compared to the other humours. Galen even remarks that a complete absence of any one of the humours, including black bile, would cause a human being to die. ${ }^{799}$ Black bile appears as a necessary

\footnotetext{
${ }^{793} \mathrm{HNH} 46,5$ f. Mewaldt (XV $87 \mathrm{~K}$ )

${ }^{794}$ HNH 20,17 Mewaldt (XV $35 \mathrm{~K}$ ), 42,20 f. (XV $80 \mathrm{~K}$ ) and 36,4 f. (XV $66 \mathrm{~K}$ )

${ }^{795}$ HNH 46,5 f. Mewaldt (XV 87 K), 50,25 (XV 96 K); cf. Nat. Fac. II, 9, II 135 K and 139 K; UP 232,14 f.

Helmreich (III 316 K); Hipp. Prog. XVIIIB 175,14-176,1 K

${ }^{796} \mathrm{HNH} 38,1$ Mewaldt (XV $70 \mathrm{~K}$ )

${ }^{797} H N H$ 50,25 Mewaldt (XV $96 \mathrm{~K}$ ) where black bile is called earthy; cf. HNH 28 Mewaldt (XV 50-1 K); PHP VIII 502,20 f. De Lacy; see also Flashar (1966) 108-9; Schöner (1964) 86-9 for a nice schematic overview ${ }^{798}$ PHP VIII 516,11-4 De Lacy; Adv. Jul. XVIIA 292,8-13; Hipp. Prog. XVIIIB 282,10-1, the stage of life which matches black bile is $\dot{\eta} \pi \alpha \rho \alpha \kappa \mu \eta$, the time after one's prime (the word also means decay), see also Temp. I 641,4-7 K; Jouanna (2012) 339

${ }^{799}$ HNH 40,20 f. Mewaldt (XV 75 K); cf. Hipp. Elem. 150,20-152,4 De Lacy; PHP 510,29-512,4 De Lacy

(Galen quoting from the Hippocratic On the Nature of Man); PHP 514,32-37 De Lacy
} 
constituent of our nature that is always present to some extent and without which we could not live.

In At. Bil. on the other hand - and this is where the complexity enters - Galen distinguishes between a black bile that is common to everybody, including healthy people, and black bile in a stricter sense, which is extremely detrimental. There is still a notion of a black bile that is always present as a normal part of our constitution Galen even cites from On the Nature of Man and uses the same Hippocratic argument of purgation, which shows that each of the humours is present in us at all times. ${ }^{800}$ But, there is also a black bile that is so utterly harmful and destructive that it can be considered as something opposed to life itself, comparable to the Dead Sea. ${ }^{801}$ In his conclusion, at the end of the treatise, Galen still maintains that both of them - the normal and the harmful black bile - can be called by the same name, despite these profound differences:

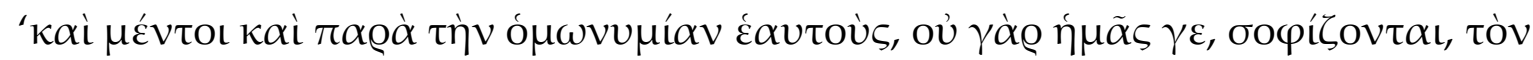

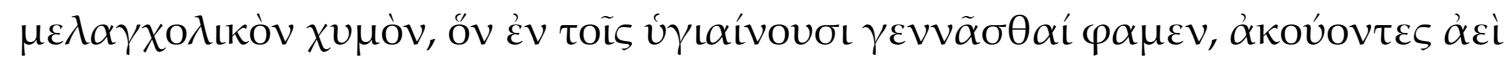

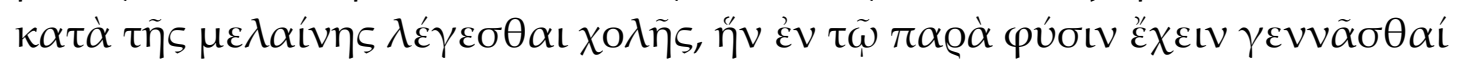

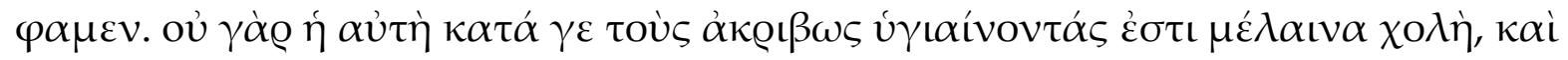

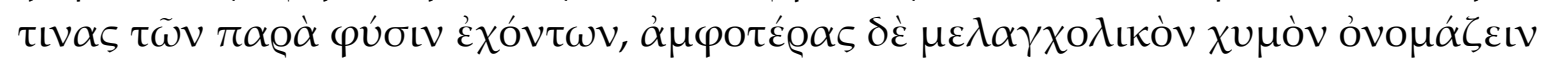

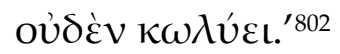

'And through homonymy they play tricks on themselves, but not on me, with regard to the melancholy humour, which we say is produced in the healthy, since they always understand what is said in relation to the black bile, which we say is produced in those that are in an unnatural state. For it is not the same black bile in those who are perfectly healthy and in some of those who are in an unnatural state, but nothing prevents us from naming both of them melancholy humour.'

The solution is, again, as it was in the case of blood, one of homonymy: the detrimental substance that is unnatural ( $\pi \alpha \varrho \dot{\alpha} \varphi v ́ \sigma v)$ and the regular humour that is always a part of our nature, can be called by the same name, even though they are so different. ${ }^{803}$ In this manner, both the systematic humoural theory of On the Nature of Man and the tradition of black bile as something causing disease - melancholy in particular - can remain in place. We can already see here how this particular synthesis has the potential to normalize melancholy. But let us first look at how Galen further defines these two kinds of black bile in At. Bil. It will turn out that in the case of black bile too, as in the case of blood, the homonymy that allows the different types to be called by the same name, is far from a mere homonymy between two things that have nothing else in common.

\footnotetext{
${ }^{800}$ At. Bil. V $128 \mathrm{~K}$

${ }^{801}$ At. Bil. V 111-2 K; cf. Caus. Symp. VII 245,15-7 where black bile is compared to the 'asphalt of the Dead Sea'; $M M$ X $973 \mathrm{~K}$, where it is said that 'no animal, not even mice, would taste it'.

${ }^{802}$ At. Bil. V 147-8

${ }^{803}$ See also Stewart (2016), particularly 160 ff., who focuses more on the differences in Galen's notion of black bile in the (polemical) context of different works.
} 


\section{b. The normal and the harmful II: the normal that is potentially harmful}

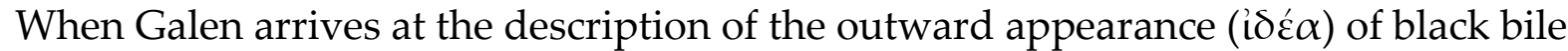
in At. Bil., he first notes that it must be distinguished from dark blood. ${ }^{804}$ This is interesting, since we noted before that blood changes its colour and, in particular, can become more yellowish or black. Since blood is a mixture of the four humours in which pure blood predominates, it would make sense for the blood in this broader sense to become darker when black bile predominates. ${ }^{805}$ Darkened blood, however, might point to an atrabilious condition or a relatively large amount of black bile in the blood, but is not to be identified with the black bile itself. ${ }^{806}$ Also, other black substances that frequently appear in vomit and faeces are to be distinguished from black bile proper, as can be seen not only from their specific powers, but also their observable qualities:

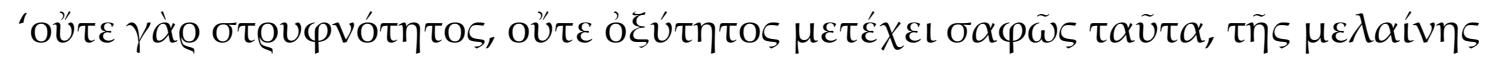

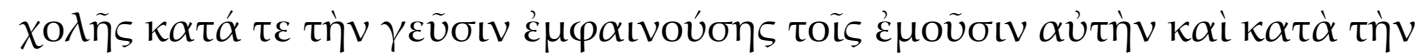

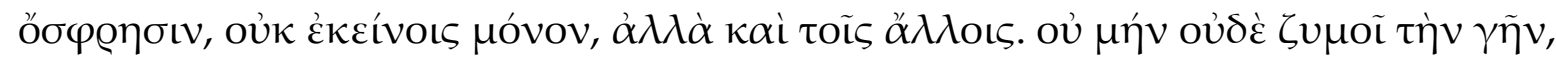

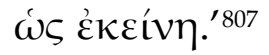

'They certainly do not have any sourness or sharpness, whilst black bile exhibits these qualities through two senses: taste, for those who vomit it up, and smell, for the same people and those around. But it does not react with the earth to produce effervescence, as black bile does.' (tr. Grant)

Black bile is described here as sour and sharp or acid, descriptions that we also find in $\mathrm{HNH}$ and other works. Furthermore, it is said to produce some kind of peculiar

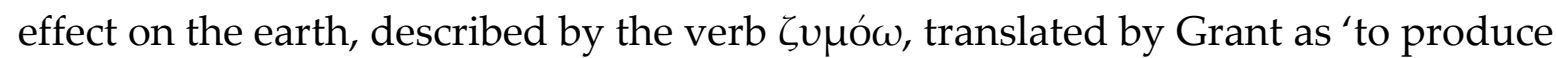
effervescence', meaning 'to leaven' or 'ferment' ${ }^{\text {' }} 808$ In the Hippocratic Diseases II, a similarly odd effect of black bile (or another black substance) on earth is mentioned: there it is said that the earth is raised by black material that is vomited ( $\tau$ co $\varepsilon \mu \varepsilon \sigma \mu \alpha$ $\tau \dot{\eta} v \gamma \tilde{\eta} v \alpha{ }^{\prime}\left(\varepsilon_{1)}{ }^{809}\right.$ The verb is also used in the Hippocratic Regimen in Acute Diseases LXI, where it is said that those who suffer from black bile are not benefited by the acidity of vinegar - as opposed to those who suffer from bitter bile - because it will

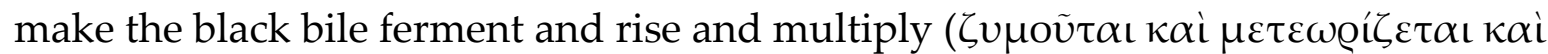
$\pi \mathrm{o} \lambda \lambda \alpha \pi \lambda \alpha \sigma\llcorner\mathrm{v} \tau \alpha \mathrm{\iota}) .{ }^{810}$ In Plato's Timaeus we find it as well: certain vessels of air that are of earthy nature can cause a kind of boiling and fermenting because of their acidity. ${ }^{811}$ Apparently the general idea is that the acidity of the black bile has some

\footnotetext{
${ }^{804}$ At. Bil. V 110-1 K

${ }^{805}$ Cf. Hipp. Elem. 144,8-18 De Lacy

${ }^{806}$ At. Bil. V 110-1 ; cf. Symp. Caus. VII 245-6 K; see note 801 above

${ }^{807}$ At. Bil. V $111 \mathrm{~K}$

${ }^{808}$ Cf. Hipp. Prorrh. XVI 661,4-7; Hipp. Aph. VI XVIIB 688,1-3; MM X 973-4 K

${ }^{809}$ Diseases II, 73

${ }^{810}$ Regimen in Acute Diseases LXI

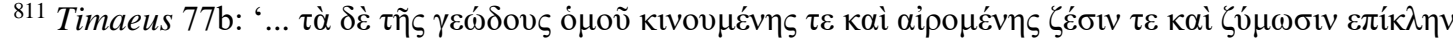

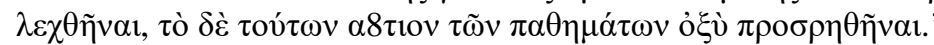


kind of corrosive effect on earth, which may also be associated with the acid that can rise from the stomach and be vomited out. We find the same description of the effect of black bile on earth in Nat. Fac. as well, including the comparison with vinegar. Finally we see it again in Loc. Aff., in a passage we shall discuss below. In At. Bil., Galen now also compares black bile to a very sharp vinegar, noting its difference from it in terms of thickness. Black bile is a more dense substance, which causes it to settle in the body, whereas vinegar would pass through. Clearly, we are talking about the detrimental and harmful form of black bile here. But the thickness is, again, a quality that we also encountered in $H N H$. That is to say: besides the blackness and the sourness or acidity, this is another aspect that shows that the normal and the harmful black bile share more than merely a name. Since the black bile, as opposed to vinegar, settles because of its thickness, it can completely consume those parts of the body that it associates with in an unmixed state. The depiction of unmixed black bile that Galen gives now is one of an utterly deadly substance, one that no living creature would go near. In this respect he compares it with the Dead Sea, a water so salty that no living being survives in it. ${ }^{812}$ Galen now seems to realize that some further explanation is needed. Is it not curious, that a substance of such description is part of the common constitution of all human beings? This is where he clearly distinguishes between two different kinds of black bile:

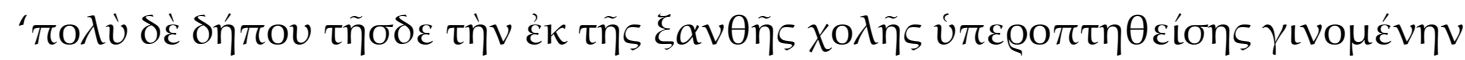

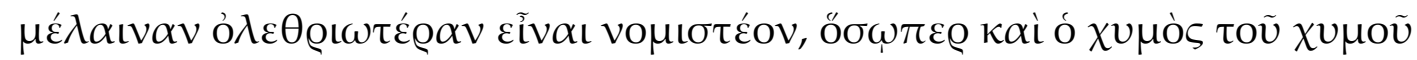

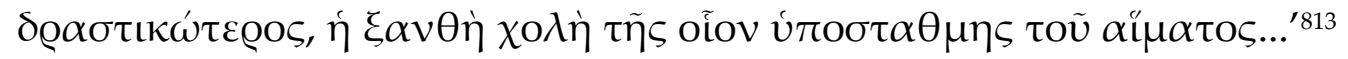

'You must remember, of course, that black bile which results from an excessive heating of yellow bile is more destructive than the black bile I mentioned before, just as one humour is more drastic in its action compared with another fluid, by which I mean yellow bile compared with a fluid that looks like the sediment of blood.' (tr. Grant)

This utterly destructive kind of black bile Galen just described is actually the result of excessively heated yellow bile. This is what Galen seems to designate as black bile in the proper sense. Its destructive power is related to the active power of yellow bile: since it is a kind of degenerated form of yellow bile, one that has become overheated, it becomes malignant; but it becomes powerfully malignant since yellow bile is the most active humour. This is important to note, since the hot aspect in the bipolar-like descriptions of black bile in the Problemata and Rufus were related to quick and intense movement, as well as to intellectual activity, as we have seen. The black bile that Galen distinguishes here as the most dangerous one, is a degenerated form of a humour that is pre-eminently active. The yellow bile is defined as particularly active

\footnotetext{
${ }^{812}$ At. Bil. V 111-2 K; cf. Caus. Symp. VII 245,15-7 where black bile is compared to the 'asphalt of the Dead Sea'; MM X $973 \mathrm{~K}$, where it is said that 'no animal, not even mice, would taste it'.

${ }^{813}$ At. Bil. V $112 \mathrm{~K}$
} 
compared to the black bile that Galen 'mentioned before', as he says here. This black bile must be the one that appears as black bile, although it is not strictly speaking black bile: the black substance that appears similar to thick dark blood and sometimes appears in vomit and faeces, sometimes affording a sharp and sour sensation. ${ }^{814}$ Galen now calls this more common substance a kind of 'sediment in blood' and contrasts it to the genuine black bile that is extremely detrimental. Here we have the same distinction that we previously found in Rufus: between a black bile that is like a sediment and becomes harmful only in particular circumstances; and a black bile that is the result of burning and that is harmful per se. For most of the rest of the treatise, Galen will continue to discuss the more common version of black bile rather than the harmful result of the overheating of yellow bile. What is this substance and how does it relate to the black bile of $H N H$, the black, sour, thick, dry and cold substance that forms a normal part of the healthy human constitution and predominates in autumn?

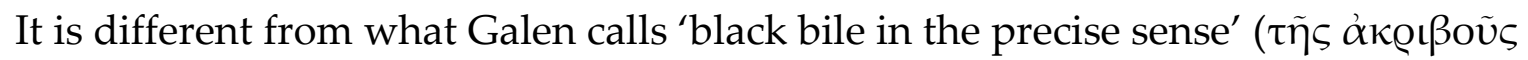
$\mu \varepsilon \lambda \alpha i ́ v \eta \varsigma \chi 0 \lambda \tilde{\eta} \varsigma)$, which is always fatal, as he emphasizes. ${ }^{815}$ This distinction is common throughout Galen's work. The black bile that is like the sediment of the blood is often compared by him to the lees of wine. It is a residue and a by-product of the production of something essential, namely blood, or wine in the metaphor, and it is contrasted with what he calls black bile in the precise or proper sense $(\dot{\alpha} \kappa \varrho \iota \beta \eta ่ \varsigma) .{ }^{816}$ If this sediment comes to be in excess, however, it can cause all kinds of serious afflictions. When it is isolated (from the other humours) it can cause a 'dark tumour' that can grow into a cancer, since isolated from the others it is 'very harsh and malignant' ${ }^{\prime 817}$ So this black bile, even though it is a normal part of our constitution, is, indeed, potentially extremely dangerous. We previously noticed that, in $H N H$, an imbalance of the humours is the cause of disease. What we learn from At. Bil. about the black bile that is like the sediment of blood seems to be congruent with that theory. It is notable, however, just how extremely detrimental the black bile can become when it is in excess or isolation. Also, there seem to be no particularly beneficial aspects to this black bile, even though it is considered a normal part of our

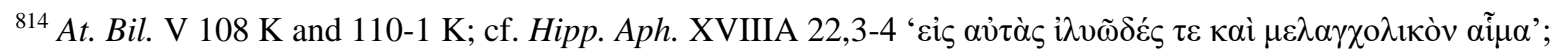
other parallels below

${ }^{815}$ At. Bil. V $116 \mathrm{~K}$ : 'Everyone who excreted genuine black bile died...' (tr. Grant); cf. Hipp. Aph. VI XVIIB 683,17-684,1; cf. Rufus’ fragments 25-6 (ed. Pormann, 2008)

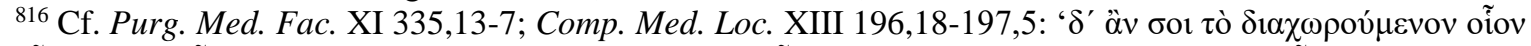

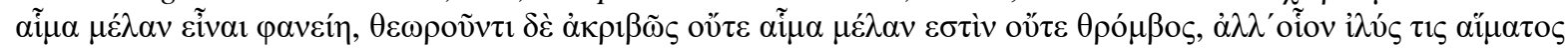

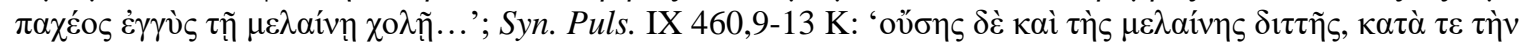

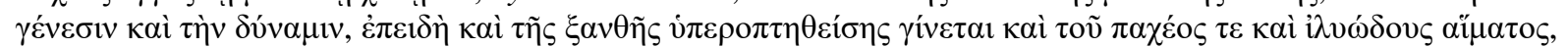

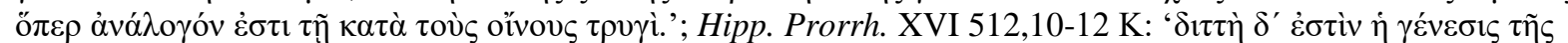

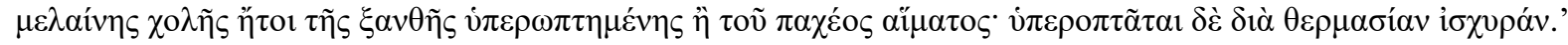

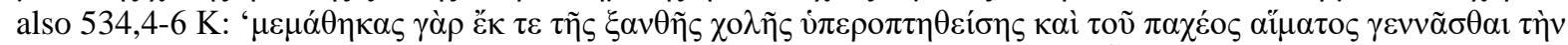

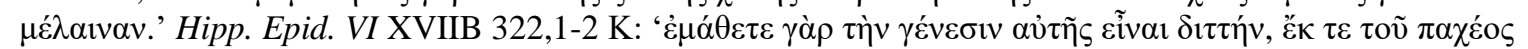

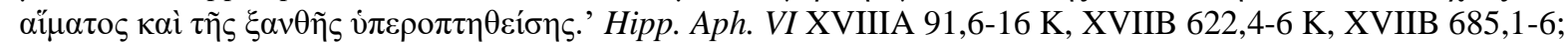
Hipp. Prog. XVIIIB 278,3-10 K; MM X 974,14-8 K;

${ }^{817}$ At. Bil. V $117 \mathrm{~K}$; cf. PHP VIII, 4, 32, 504,24-6 De Lacy
} 
constitution. ${ }^{818}$ The general impression we get of this substance in At. Bil. is that of something very dangerous and detrimental that should be managed carefully by experts when it manifests itself, and that seems to have absolutely no beneficial qualities or purpose in itself. This corresponds to the notion of black bile as a potentially dangerous residue that we have found both in the Peripatetic tradition and in Rufus. ${ }^{819}$ It is also at least congruent with the humoural theory of $H N H$, since that also does not mention any particular beneficial aspect of black bile mentioned, while it does, on the other hand, presents the aforementioned notion of disease as a consequence of imbalance or isolation of any particular humour. Indeed, Galen also cites from the Hippocratic On the Nature of Man in his description of the black bile that is like a sediment of the blood. He quotes the passage that states that health is achieved through a balance of the humours, while excess, lack or isolation of one particular humour causes pain and disease. Besides melancholy, excess or isolation of black bile can apparently cause cancer, ulcers, elephantiasis, phrenitis, varicoceles and haemorrhoids. ${ }^{820}$ Clearly, Galen is implying that these diseases are the consequence of a humoural imbalance in terms of an excess or isolation of the black bile that is discussed in $H N H$.

Still, despite all of its potential danger, Galen simply considers this black bile a necessary part of our body that is particularly related to digestion and the transformation of food into blood ${ }^{821}$ Nature does its best to deal with this substance in the human body, in order to preserve life, but that seems to entail only getting rid of it as much as possible. This sediment is a normal part of our constitution as long as it is regularly evacuated. ${ }^{822}$ Our body gets rid of black bile through evacuation, sometimes even forcing excess black bile towards the surface of the body in an attempt to get it out, which can cause the skin to thicken and dry. As we saw before, thickness and dryness are qualities peculiar to black bile in the humoural theory of $H N H$ as well. Likewise, the doctor's main concern seems to be for evacuation of the black bile, as well as for the development of a diet that produces better humours, which was also the main approach in Rufus' writings. ${ }^{823}$ However, it is not possible, according to Galen, to completely get rid of black bile; its production is necessary. ${ }^{824}$ What is possible, though, is to make sure that as little as possible of it is produced by

\footnotetext{
${ }^{818}$ In other works, notably Nat. Fac. and UP, we do find suggestions that black bile can be useful in certain ways after it has gone alteration in the spleen, see below.

${ }^{819}$ See infra, 209-10 and 218-25

${ }^{820}$ These can be found in At. Bil. and paralleled in other works, e.g. Symp. Caus. VII 224 K; Hipp. Elem. 146,5-7 De Lacy; Hipp. Epid. VI XVIIB 286 K; Tum. Pr. Nat. VII 719-20; Alim. Fac. VI 661,15-662,2; Hipp. Prorrh. XVI 795,1-2 K

${ }^{821}$ Galen also refers to $H N H$ in At. Bil. V $128 \mathrm{~K}$, after his description of the black bile that is cleansed from the blood by the spleen and repeats that Hippocrates has shown that all the four humours are always in the human body (also At. Bil. V $135 \mathrm{~K}, 144-5 \mathrm{~K}$ )

${ }^{822}$ At. Bil. V 115-6 K;

${ }^{823}$ E.g. Alim. Fac. VI 526, 632 and 661-2 state that lentils and beef respectively increase the amount of black bile in the body; Bon. Mal. Suc. VI 798,8-10, those whose blood is more melancholic need foods that are wet and warm in mixture

${ }^{824}$ At. Bil. V $124 \mathrm{~K}$
} 
regulating diet, since it is through processing food and drink that we obtain black bile in the first place. ${ }^{825}$

It is interesting that Galen brings up the impossibility of the complete absence of black bile in this manner, and then suggests reducing production of it. There have been predecessors, notably Erasistratus, who, according to Galen, did not consider black bile at all. Galen finds fault with them, obviously, but seems to agree that a complete absence of black bile appears like an appealing idea, given the description he just provided of its detrimental effects. We shall return to this suggestion later. In any case, there are also limits to the extent that the production of black bile can be regulated. Besides diet, people's specific constitution, the season, climate, and, notably, one's mental state, all have an influence on it. Interestingly, people with a

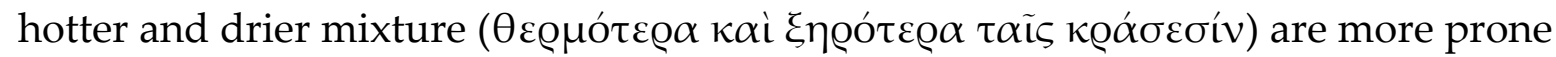
to produce black bile. Also, production goes up in hotter and drier times of the year. This fits with the connection of black bile to autumn that was made in On the Nature of Man, since autumn comes right after summer, the season that is hot and dry and that, thus, increases the amount of black bile, which would make the season immediately following summer the period in which black bile is most abundant. ${ }^{826}$ Finally, hotter and drier places also increase the production of black bile, as do dry foods that consist of thick particles. ${ }^{827}$ Clearly, the elemental qualities of hotness and dryness, and their predominance, are related to the production and possible excess of black bile in At. Bil. This might seem remarkable, since, as has been pointed out by Jouanna, in other Galenic works it is rather the qualities of coldness and dryness that are ascribed to the black bile. ${ }^{828}$ However, there is no need to posit inconsistencies here. We simply have to note that the quality of hotness is associated with the production of black bile, while that of coldness is used to describe the state of black bile itself. Black bile is a substance that is cold and dry because it was formerly very hot, lost all of its moisture because of that hotness, and then cooled down. It is abundant in autumn because it is a remnant of summer. As we saw before, Rufus compares it with pieces of coal that have cooled down. ${ }^{829}$ Galen does not attribute the quality of hotness to the black bile itself, but rather attributes the quality of bein burned to it. This already involves a receding of the hotness, leaving a remnant that cooled down to some extent or other. This comes to the fore clearly in the following passage from On the Causes of Symptoms (Caus. Symp.):

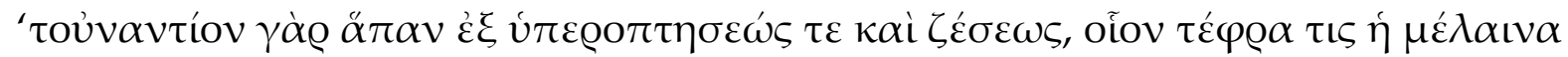

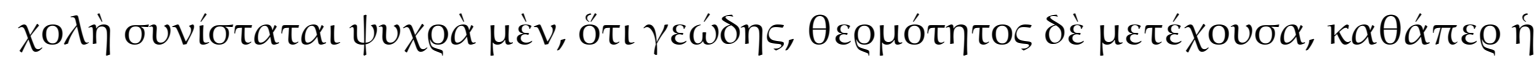

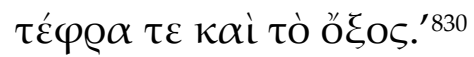

\footnotetext{
${ }^{825}$ At. Bil. V $124 \mathrm{~K}$

${ }^{826}$ See below, 257-60

${ }^{827}$ At. Bil. V $126 \mathrm{~K}$; cf. Alim. Fac. VI 526-8 K

${ }^{828}$ Jouanna (2009) $235 \mathrm{f}$.

${ }^{829}$ Rufus, Fr 11,18 f ed. Pormann; also Problemata 954a13-20

${ }^{830}$ Caus. Symp. VII 246,3-6 K
} 
'On the contrary, black bile like ash arises entirely from overheating and boiling. It is cold in that it is earth-like, but partakes of heat just as do ash and vinegar.' (tr. Johnston)

Like ashes, black bile comes to be as a result of the overheating of something that then subsequently cools down. ${ }^{831}$ This is how Galen also defines the black bile in $H N H$, as Jouanna points out as well:

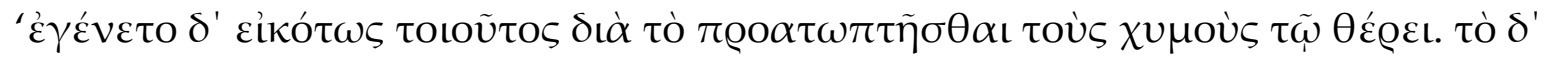

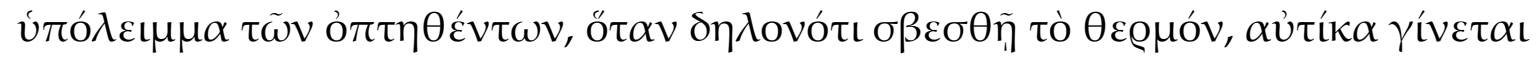

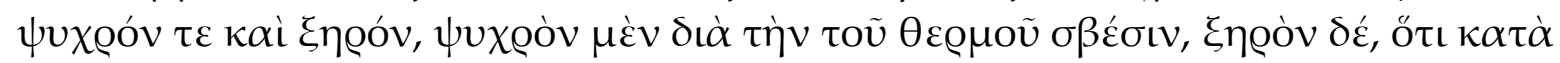

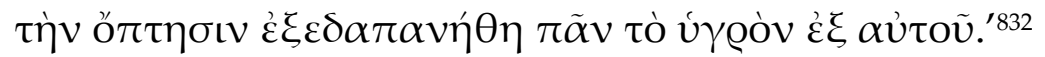

'And it is reasonable that such a humour arises as a result of the cooking of the humours during the summer. The residue of this cooking, when the hot has been thoroughly quenched, then becomes both cold and dry, cold as a result of the quenching of the heat, dry because the process of cooking drives out all of the moisture from it.' (tr. Hankinson)

Both of these passages are reminiscent of the metaphor of the coals, and show that the qualities of black bile are not just to be cold and dry by itself, but rather to be cold and dry as the consequence of a previous heating that has now receded. This is brought to the fore even more clearly in a passage from On Mixtures (Temp.):

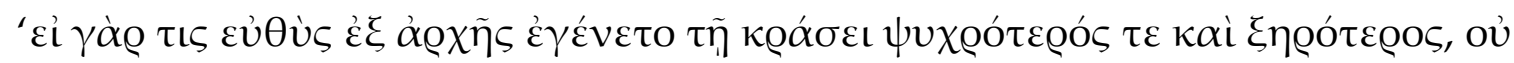

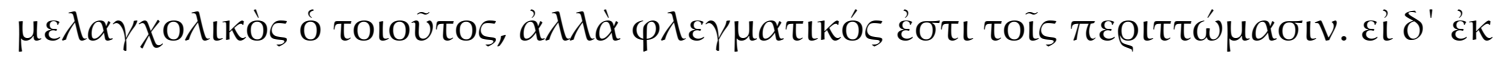

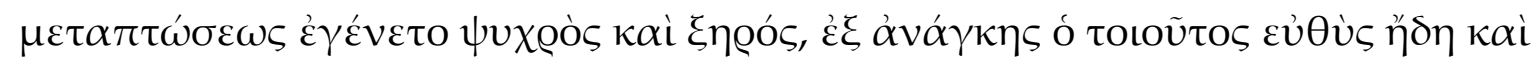

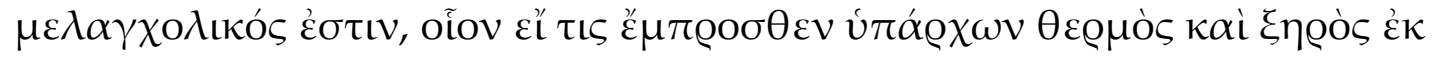

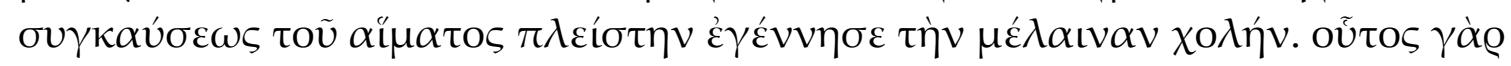

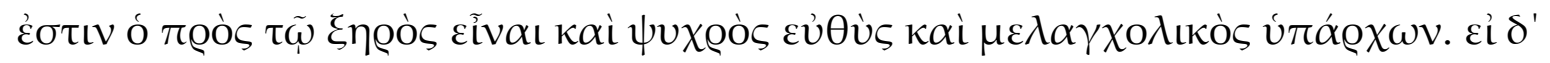

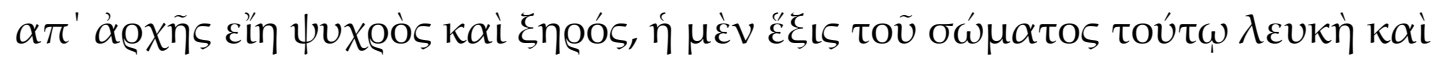

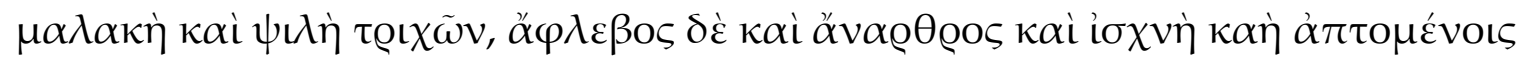

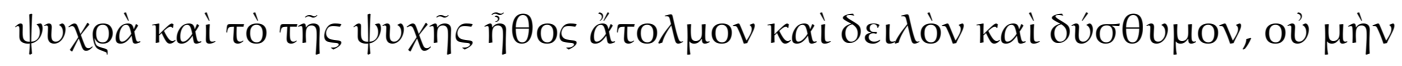
$\mu \varepsilon \lambda \alpha \gamma \chi \mathrm{O} \lambda \iota \alpha \dot{\alpha} \gamma \varepsilon \tau \dot{\alpha} \pi \varepsilon \varrho \iota \tau \tau \omega \dot{\mu} \alpha \tau \alpha .^{\prime 833}$

'Someone whose original nature is on the cold, dry side will not be melancholic, but will be phlegmatic in his excretions. But someone who is cold and dry because of some change he has undergone will necessarily also be melancholic, just as one who was previously hot and dry has produced a very great quantity of black bile from the burning of his blood. Such a man will automatically be melancholic, in addition to

\footnotetext{
${ }^{831}$ Cf. Tum. Pr. Nat. VII 719 for the comparison to ashes of an ulcer caused by black bile

${ }^{832}$ HNH 45,25-30 Mewaldt (XV $86 \mathrm{~K}$ ); cf. Temp. I $641 \mathrm{~K}$ : 'For melancholic mixtures come about as a result of the burning of the blood; but when this process has just began, the roasting effect is not yet a complete one.' (translation Singer)

${ }^{833}$ Temp. I 642-3 K
} 
being dry and cold. The state of body of the man who was cold and dry from the outset will be white, soft, bare, lacking in veins and articulation, thin, and cold to the touch; and the character of his soul will be lacking in resolve, cowardly, easily dispirited; yet his excretions will not be melancholic.' (tr. Singer)

The same notion is also found in The Art of Medicine, with emphasis on the stage of life rather than the season. There, Galen remarks that when a mixture that is dry and hot changes after the prime of life into one that is dry and cold, it will have become melancholic. ${ }^{834}$ This is completely in line with the description of the transition between summer and autumn, and both passages show, in accordance with the descriptions from HNH and Caus. Symp., that black bile is not merely dry and cold of itself but rather a remnant of excessive heat that has cooled down.

Jouanna restricts his discussion more to $H N H$, and regards the passage from $H N H$ quoted above as establishing a bridge between two different notions of black bile in Nat. Fac. and At. Bil., which associate it with coldness and hotness respectively. ${ }^{835} \mathrm{In}$ this manner, as Jouanna argues, Galen reconciles the theory of black bile as a result of the burning of other humours, particularly yellow bile, with the previous

Hippocratic theory on black bile that did not consider it as the result of an alteration of another humour. Jouanna follows this distinction, as we find it in Galen, back through Rufus and the Hippocratic corpus. ${ }^{836}$ Thus, Galen seems to connect the different kinds of black bile distinguished by Rufus: the sediment-like black bile that is related to digestion becomes associated with the quality of being burnt that was reserved for the other kind of black bile. This makes sense, since digestion is a process that involves heating. Again, by this association Galen normalizes the production of black bile and obscures the difference between normal and dangerous versions of it. ${ }^{837}$

While I generally agree with Jouanna's interpretation - even though I would also note that the connective function that he attributes to $\mathrm{HNH}$ is more broadly attested in Galen's work, as we have seen - there is one aspect of it that I find confusing. This is his distinction between a black bile that is 'innée', innate, and one that is not. In his view, the black bile of the Hippocratic On the Nature of Man should be innate, as opposed to the black bile that is a result of the burning of another humour. I find this a somewhat confusing perspective, since all the humours, including blood, are always already the result of a productive process within the body. At the same time, we always have these humours in our body, already from when we are still an embryo, before we are actually born. To give an example: I see no reason why an embryo, from Galen's perspective, could not have the kind of black bile that is the result of burning, if, for example, its mother has this kind in her body. Then, when

\footnotetext{
${ }^{834}$ Ars Med. I 345,17-346, K

835 Jouanna (2009) particularly 252-3

${ }^{836}$ Jouanna (2009) 254-5

${ }^{837}$ See Stewart (2016) 166-75 for a different response to the issue Jouanna raises, which criticizes Jouanna's view of $H N H$ fulfilling a kind of bridging function and explains the supposed contradiction in terms of Galen uses different notions of black bile to fit the respective polemical aims in his different works.
} 
the baby is born, is this humour innate to it but not to another baby? It does not make sense to me, therefore, to primarily distinguish the different kinds of black biles in Galen as either innate or not innate. Both are produced, even though one is more of an aberration that the other. It seems to me rather that, for Galen, black bile is a necessary part of our constitution in as far as digestion is, as a necessary by-product of it. As such, it can be present in the body either in a way that is according to nature or in a way that is unnatural and causes disease, as becomes clear from $\mathrm{HNH}$, Nat. Fac. and At. Bil. alike. Whether it is present in a normal or a harmful way, can depend on several circumstances: it is harmful when it is present in excess or isolation (i.e. unmixed) in various parts of the body or when it is the result of a severe heating. Likewise, Stewart also distinguishes between what he calls an 'ideal natural black bile', which he also calls 'innate', a 'non-ideal natural black bile', and an 'altered black bile'. ${ }^{838}$ The latter is the dangerous black bile that is the remnant of overheating of (other) humours. The distinction between the former two kinds, however, is a distinction that Stewart introduces between the black bile that we find in $H N H$, and the black bile that is described as a sediment of the blood and that is associated with digestion, as we find it in At. Bil. and Nat. Fac., among other works. This distinction seems to me to be Stewart's own fabrication and to be without basis in Galen's texts. It seems to rest on the assumption that the black bile of $H N H$ should be beneficial, for which I have not found textual warrant. ${ }^{839}$ The only passage that Stewart cites to justify the distinction between these two is actually from Loc. Aff. and will be discussed in the next paragraph, in which we shall discuss the harmful variation of black bile that is either the result of overheating, excess or isolation. We shall find that in Loc. Aff. too, Galen distinguishes between two kinds of black bile. One is normal (though potentially always harmful) and the other is extremely harmful. The latter is, in fact, the only variation that can be called black bile in a strict sense according to Galen, as we saw before. The former can function as a normal part of our constitution and is potentially harmful, as we have just discussed, when it is present in excessive amount or when it is isolated.

\section{c. The normal and the harmful III: the harmful that used to be normal}

Let us look at the relevant passage from Loc. Aff. It is a quite long so I shall cite it in parts. Galen starts with making a distinction between different kinds of black bile or melancholic humour, as he did just before this passage with different kinds of phlegm:

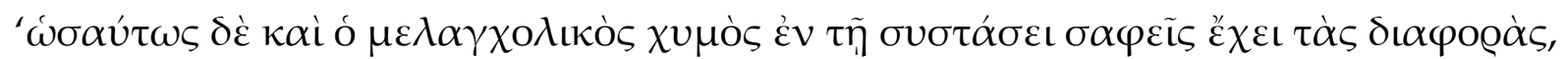

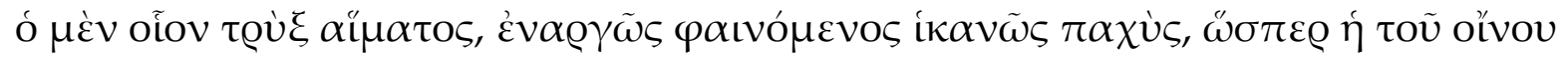

\footnotetext{
${ }^{838}$ Stewart (2016) 155-190

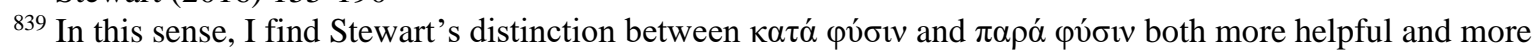
true to Galen's text, see Stewart (2016) 160-6
} 


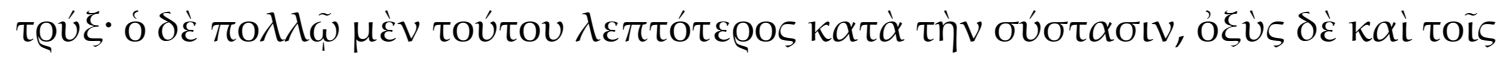

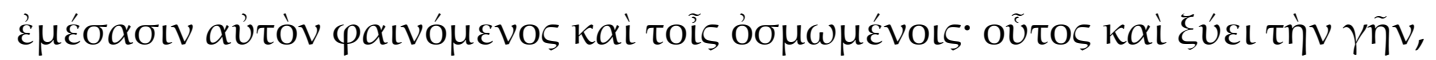

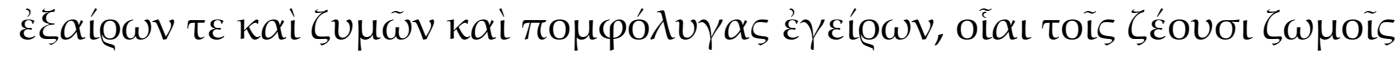
$\dot{\varepsilon} \varphi \dot{i} \sigma \tau \alpha \nu \tau \alpha$ l. $^{\prime}{ }^{840}$

'In the same manner also the melancholic humour has clear differences in its composition, one kind being like the sediment of blood, clearly appearing very thick, just like the lees of wine; the other is much finer in composition than that, and it appears acidic both to those that vomit it as well as to those who smell it; this one also corrodes the earth, raising it up and causing it to effervesce and arousing bubbles, as those that surface in boiling soups.'

Galen here distinguishes between two kinds of melancholic humour, a distinction that corresponds to the one we found in At. Bil. The first is the one that is like the sediment of blood, the second is a much more acidic and dangerous one. At the beginning of the discussion of black bile in At. Bil. he makes the same distinction between the acidity manifesting itself only to the person that vomits or to the bystanders as well. ${ }^{841}$ There, Galen distinguishes black bile in the strict sense ( $\tau$ òv $\tau \tilde{\eta} \varsigma$

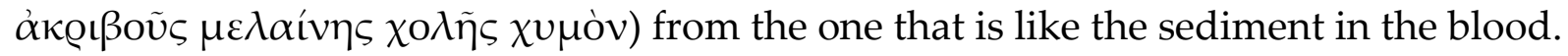
Only the acidity of the black bile in the strict sense, the one that is extremely harmful and has a corroding effect on the earth, is not only perceived by the person vomiting it up but also by the bystanders, through smell. Galen now proceeds to further specify the black bile that is like a sediment of the blood, and remarks that this is not black bile in a strict sense in Loc. Aff. as well:

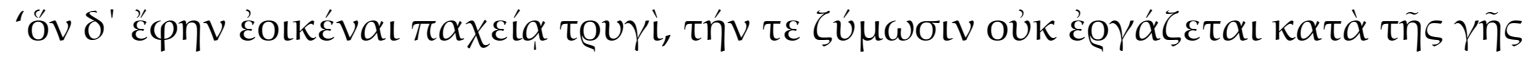

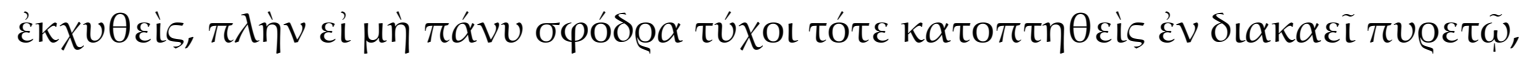

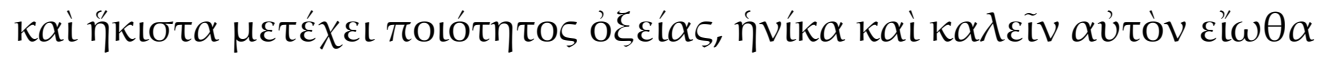

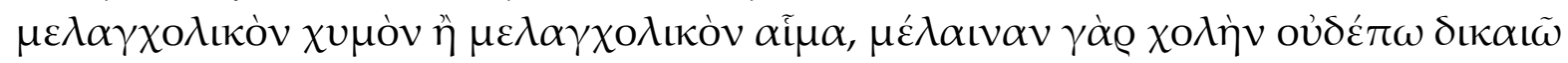

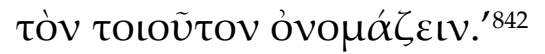

'The one which I said resembles thick sediment, does not produce the fermentation when it is poured out over the earth, unless it happens to have been burnt very intensely during a state of burning fever, and it only has very little share in the quality of acidity. Hence I'm used to calling it melancholic humour or melancholic blood, for I think that is not yet proper to call it black bile.' (tr. Van der Eijk)

Apparently, both of these kinds of black bile possess the quality of acidity to some extent, but the one that is like a sediment of the blood possesses only very little of it, which renders it much less dangerous. However, it can become much more acidic when it is excessively heated due to a fever. Here, again, we see that we have to be careful to apply all too neatly developed distinctions on the different kinds of black

\footnotetext{
${ }^{840}$ Loc. Aff. Van der Eijk and Pormann 266 (VIII 176-77 K)

${ }^{841}$ At. Bil. V 110-1 K

${ }^{842}$ Loc. Aff. Van der Eijk and Pormann 266 (V 177 K)
} 
bile that Galen discusses. The one that is like a thick sediment is a normal part of our constitution, unlike the one that is the result of an overheating of yellow bile, but it can become extremely harmful as well, when combined with fever, for example. Nonetheless, Galen does not consider it black bile in the strict sense and, therefore, as he says, also calls it melancholic humour or melancholic blood. But at the outset of this passage, as we have seen, he called both of these kinds of black bile 'melancholic humour'. What are we to make of this? Stewart sees Galen making a distinction between three different types of black bile here, one of which is the 'innate' black bile that Stewart considers as the only one that is properly speaking black bile - despite the contradiction that would generate with At. Bil. and other works, apparently, where it is only the acidic and malignant black bile that is properly speaking black bile - while the other two are the two defined above, which would then both be melancholic humours. ${ }^{843}$ However, in Stewart's reading, both of the two 'melancholic humours' would then not, properly speaking, be black bile, while it is clear from the text as cited and discussed above that Galen only says of the sediment-like black bile that it is not strictly speaking black bile, implying much rather that the highly acidic version is strictly speaking black bile. This also corresponds to the distinction between the two kinds of black bile as we find it in At. Bil. and elsewhere. ${ }^{844}$ Stewart's reading is not tenable in this light. How, then, are we to make sense of the fact that Galen first calls both of these types 'melancholic humours', and then says that only one of them is strictly speaking black bile, while the other one can be called a 'melancholic humour'? To solve this problem, we can have another look at At. Bil., where Galen makes the same distinction at the very end of the treatise:

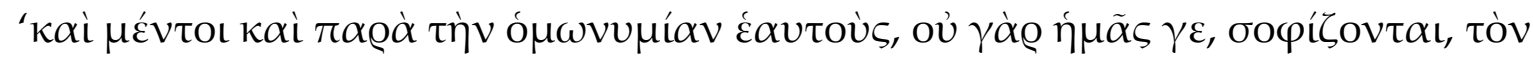

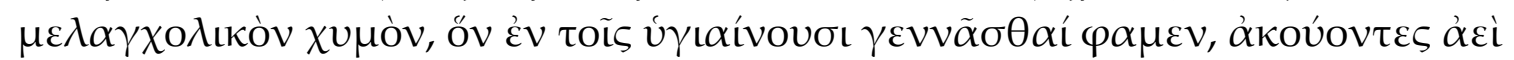

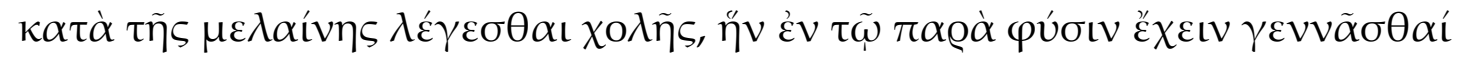

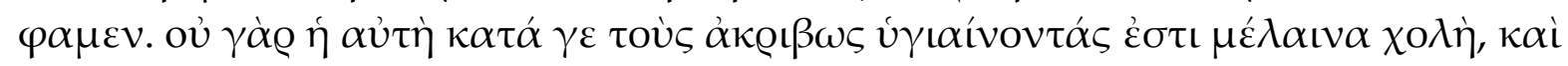

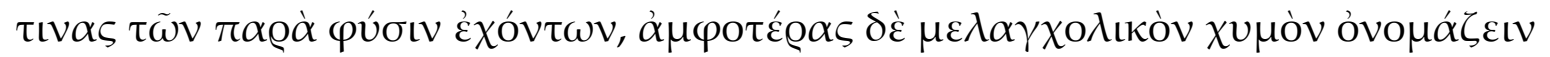
oủঠ่่̀ $\kappa \omega \lambda \hat{\varepsilon} \varepsilon$ l. $^{845}$

'And through homonymy they play tricks on themselves, but not on me, with regard to the melancholic humour, which we say is produced in the healthy, since they always understand what is said in relation to the black bile, which we say is produced in those that are in an unnatural state. For it is not the same black bile in

\footnotetext{
${ }^{843}$ Stewart (2016) 155-190, Stewart's threefold distinction is completely based on this passage, as it is the only textual evidence he cites for the distinction between three types by Galen himself.

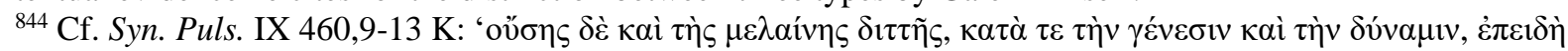

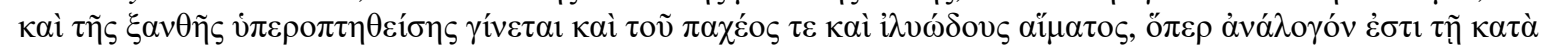

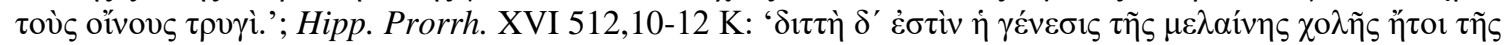

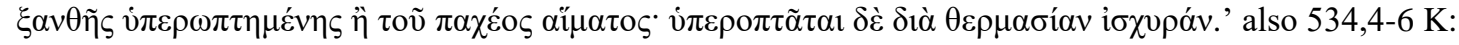

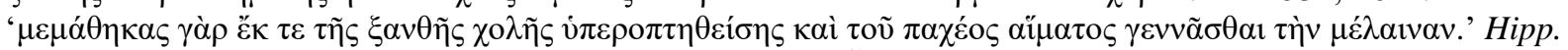

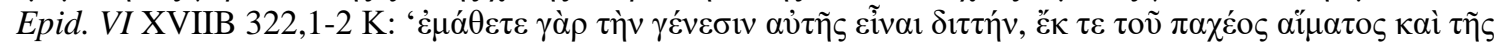

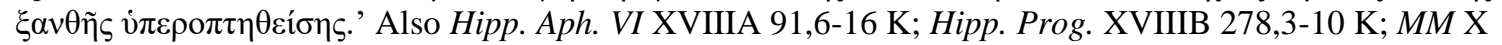
974,14-8 K; Diff. Feb. VII 376,15-6 K; Plen. VII 577,12-6 K ${ }^{845}$ At. Bil. V 147-8 K
} 
those who are perfectly healthy and in some of those who are in an unnatural state, but nothing prevents us from naming both of them melancholic humour.' (tr. Grant, modified)

Here we find, first of all, the same basic distinction: the melancholic humour is also part of a healthy constitution, whereas black bile is produced in an unnatural state the former is normal and the latter is harmful. But then, in the very next sentence, Galen simply proceeds to call both of them black bile: 'it is not the same black bile' in both of these types. What is more, he continues even to state that nothing prevents him from calling both 'melancholic humour'!

Thus, what we find is that, strictly speaking, the sediment-like kind of black bile should be called a melancholic humour and the highly acidic harmful black bile that is the result of the burning of yellow bile (or sometimes another humour ${ }^{846}$ ) should be called black bile proper. ${ }^{847}$ At the same time, however, both can be called black bile and both can be called melancholic humour according to Galen, and he even says explicitly that there is no need to get hung up on these names. The reason for this, I propose, is that even though it is certainly important to distinguish between the two, especially with regard to therapeutic practice (as we notice in At. Bil.), there are also important similarities between the two. We have already noticed above that the normal black bile, the sediment-like kind, is potentially harmful. In the next sentences from Loc. Aff., following the previous quotation above, this is affirmed:

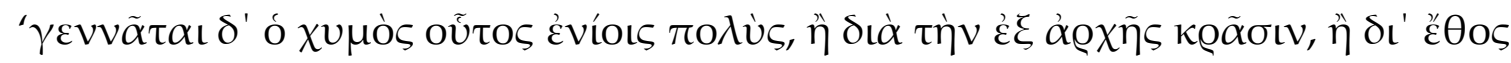

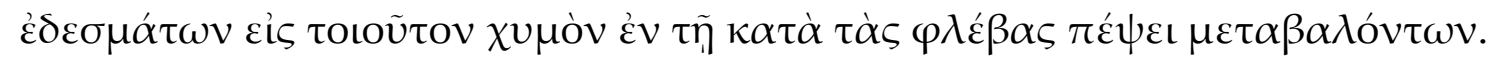


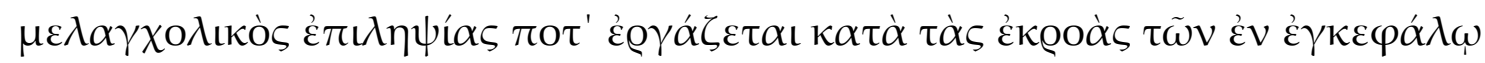

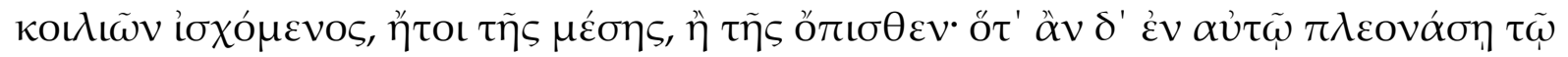

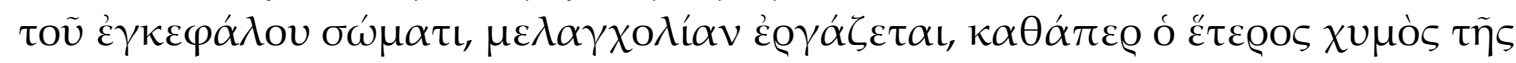

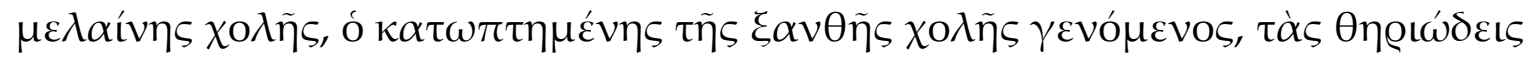

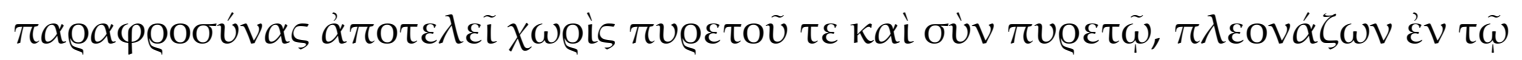

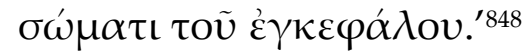

'For that humour is generated in some people in large quantity either as a result of their initial mixture or by a habit of eating foods that changes into this during the digestion within the blood vessels. Just like the thick phlegmatic humour, this thick melancholic humour likewise sometimes causes instances of epilepsy, because it is contained in the places where the cavities of the brain, whether the middle or the posterior cavity, have their exit channels. But when it is present in excess in the very body of the brain, it causes melancholy, just as the other kind of humour of black

\footnotetext{
${ }^{846}$ Cf. e.g. Diff. Feb. VII 376,9-14 K, for a description of thick blood changing into black bile when heated ${ }^{847} \mathrm{Cf}$. MM XIII, 16, X $916 \mathrm{~K}$, where we also find a clear distinction between the terms - a thick blood is drawn

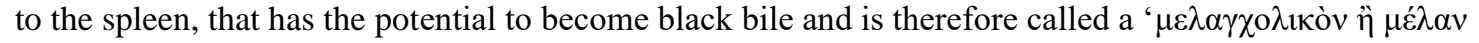
$\pi \varepsilon \rho i ́ \tau \tau \omega \mu \alpha$ ', a melancholic or black residue; Hipp. Aph. VI XVIII 91,12-6 K

${ }^{848}$ Loc. Aff. VIII $177-8 \mathrm{~K}$
} 
bile, the one that has arisen as a result of the burning of yellow bile, results in violent deliria, both without fever and with fever, when it fills the brain excessively.' (tr. Van der Eijk, modified)

In the first sentence of this quotation we can clearly recognize the distinction we found in Rufus previously, ${ }^{849}$ but here it is applied to the sediment-like black bile, of which some people, apparently, naturally have a higher quantity, whereas others have increased its quantity through overheating of particular food-substances in the blood vessels. ${ }^{850}$ Presumably, in more excessive quantity, it becomes more harmful. It can also become harmful when it obstructs ventricles, or when it abounds in the brain itself. In the latter case, it can even act as the same kind of cause as the harmful, highly acidic black bile that is the result of the burning of yellow bile. Thus, what is striking here, is that while Galen clearly distinguishes these two types of black bile, both are at least potentially harmful and can cause melancholy. The normal, sediment-like form can do so in particular circumstances, and the residue of the burning of yellow bile seems to do so without further qualification.

In the following passage from Nat. Fac. we find the same distinction between the normal and the harmful kinds of black bile, again phrased as being in accordance or against nature respectively:

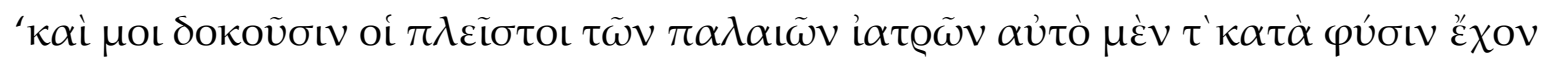

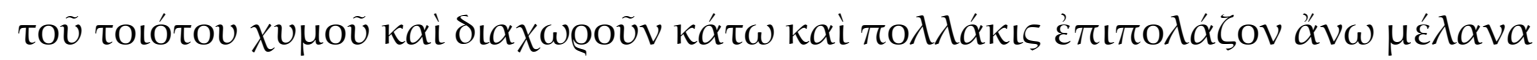

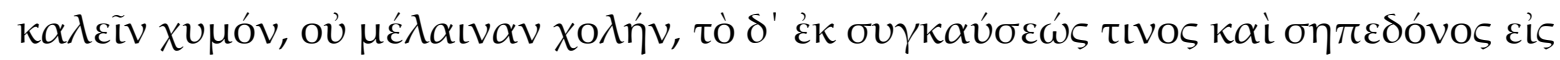

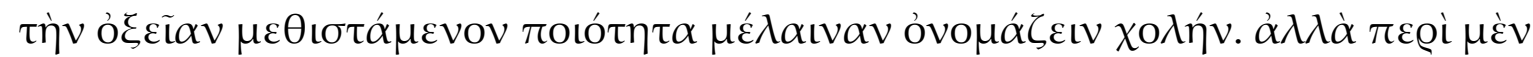

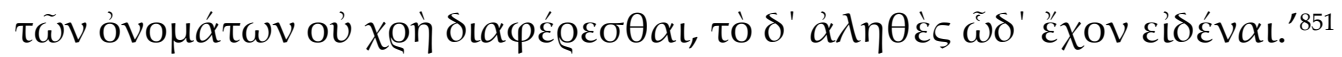

'It seems to me also that most of the ancient physicians call 'melancholic humour' the portion which we have naturally of this humour and which is discharged from the bowel and frequently rises up to the surface as well; but they call 'black bile' that which has been altered into a more acidic quality through a kind of burning and putrefaction. There is no need, however, to dispute about names, but we must realise the facts, which are as follows.' (tr. Brock, modified)

Here, Galen projects his distinction between black bile in a strict sense - the harmful acidic one that is the result of a burning of humours - and black bile in a loose sense that is rather a melancholic humour - the one that is a normal consequence of the natural processes of digestion - unto the work of his precedents, as he does more often. ${ }^{852}$ Again, he emphasizes that it is not so important to be precise about these names. After this passage he uses the property of causing the earth to effervesce

\footnotetext{
${ }^{849}$ See infra, 219-20

${ }^{850}$ This distinction is parallelled in At. Bil. V $124-5 \mathrm{~K}$

${ }^{851}$ Nat. Fac. II, 9 (II 136 K)

${ }^{852}$ Cf. Stewart (2016) 29-47
} 
again as a criterion for distinguishing the black bile in a strict sense, which is unnatural, from the melancholic humour, which is natural.

It is noteworthy that, in this passage, Galen distinguishes the two by saying that the melancholic humour that is in accordance with nature has not yet undergone the burning process that causes it to become highly acid. He repeatedly formulates the difference in this manner:

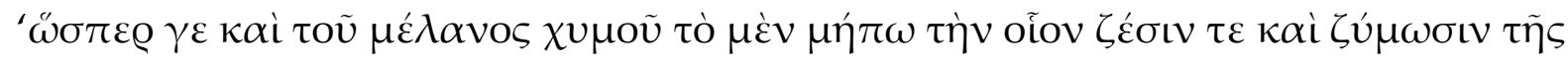

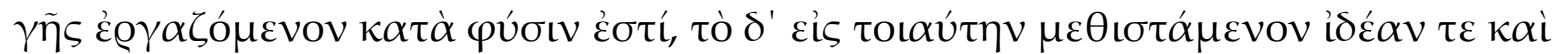

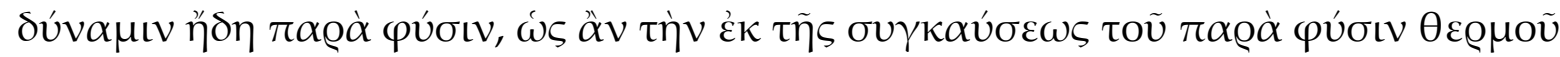

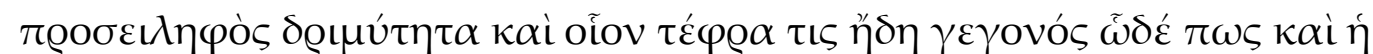

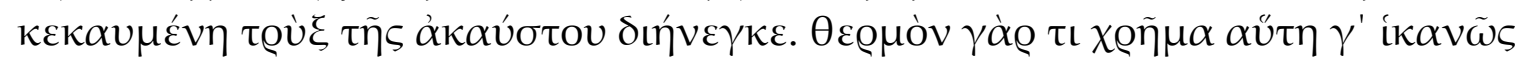

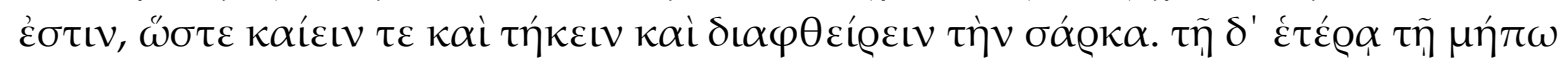

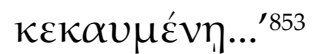

'Similarly with the black humour: that which does not yet produce this cooking and fermentation of the ground, is natural, while that which has been altered towards such an appearance and capacity, is already unnatural, as it has taken on an acidic character from the burning by unnatural heat and has already become transformed into ashes, as it were, in the same manner as lees that have been burned differ from unburned ones. For the former is a warm substance, able to burn, dissolve, and destroy the flesh. The other kind, which has not yet undergone burning...' (tr. Brock, modified)

Here we see that it is the normal, natural black bile (that should strictly be called 'melancholic humour') itself that can become the acidic, detrimental and unnatural black bile. ${ }^{854}$ The two kinds of black are closely related: the one can transform into the other. The harmful black bile that is here called unnatural, previously was a natural melancholic humour. It does not need to be black bile that is burned, but it can also be the yellow bile, as Galen adds right after the passage just quoted, and as we have seen before.

It appears that what Galen calls black bile in the strict sense is a degeneration of a humour (mostly yellow bile, but also black bile and blood ${ }^{855}$ ) that is in itself a normal part of a healthy constitution. At the same time, though, not all the humours are equally a normal part of our constitution. Even the normal black bile is described by Galen as a necessary by-product of digestion that is potentially dangerous and the production of which should be carefully managed and ideally reduced. ${ }^{856}$ Galen

\footnotetext{
${ }^{853}$ Nat. Fac. II 9, II $137 \mathrm{~K}$

${ }^{854}$ Cf. also Comp. Med. Loc. XIII 236,15-237,1 K, where Galen says that the black bile comes to be from the

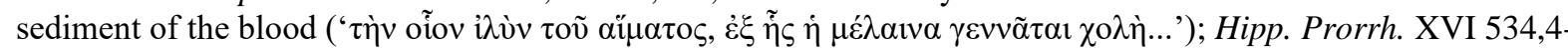

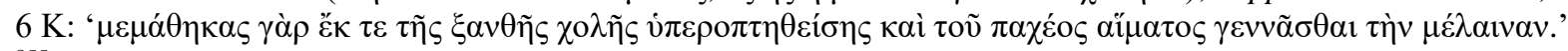
${ }^{855}$ Temp. II 6, 83,4 Helmreich (I 641 K) and Hipp. Prorrh. XVI 613,9-11 K, e.g., for the latter

${ }^{856}$ Cf. also Loc. Aff. V $359 \mathrm{~K}$, where Galen discusses a liver disease that, at first, causes a serous and bloody discharge, then a thick and melancholic blood, and finally black bile itself. There is clearly a gradual build-up there, not an essential difference; cf. MM X 916,16 f. K
} 
might have attempted to reconcile the Hippocratic notion of black bile as one of the four humours that constitute our nature with the Aristotelian notion of black bile as a residue, resulting in a theory of black bile that is a necessary by-product of our digestive system and that is, as such, a normal part of our constitution as long as it is properly managed. For this management, we are equipped by nature with an organ to dispose of black bile: the spleen. In the next paragraph, we shall discuss the role of the spleen, which shall shed more light on the role of black bile in the human body in Galen.

\section{d. Spleen}

As Galen seems to suggest in At. Bil., it might perhaps have been better if there were no need for us to produce black bile, but there is. ${ }^{857}$ Given our nature as mortal beings subject to continuous change, it is necessary for us to consume food and drink, which we need to digest and transform into blood, a by-product of which process is black bile. It is not uncommon for Galen to dwell on this necessity. In his commentary on the Timaeus, he notes that the gods made plants as nourishment for us since we would otherwise, given our elemental constitution, disperse our substance without sufficient restoration being possible. ${ }^{858}$ That is to say, the need for digestion, as such, is the direct result of an initially imperfect balance in our body. This is important to realize in our evaluation of black bile and the question of its usefulness. Perhaps black bile can to a certain extent be useful to thicken blood that would otherwise be too thin. It is, after all, the thickest of the humours. Some of it, upon thorough alteration by the spleen, can be useful as a nutriment for the spleen itself. Some of it, again upon alteration by the spleen, is disposed in the stomach, and can be beneficial to the stomach by tightening it and drawing it together so that it holds the food closer, which is good for digestion. ${ }^{859}$ Other than these functions, that already depend on the alteration by the spleen, I see no positive function of the stuff in Galen. In any case, the proper thickness of blood could have presumably been effected in another manner than adding a dark substance which one then needs to get rid of as much as possible, and which has horrible side-effects in various circumstances. The nourishment for the spleen itself is only necessary because the spleen is necessary, which is in turn only necessary for the breaking down of black bile in the first place. How, then, can the presence of black bile in the human constitution be reconciled with Galen's teleological framework, in which nature, that wise artisan, excels in making finely attuned products such as ourselves?

\footnotetext{
${ }^{857}$ At. Bil. V $124 \mathrm{~K}$

${ }^{858}$ Schröder Fr II - 76e7-77c5; cf. Hipp. Elem. 118,16 f. De Lacy (I 473-4 K), where he says that the substances of all things that come to be and pass away undergo two kinds of changes, namely alteration and depletion, which require 'a double correction, one that curbs excess in the qualities, the other that refills the place of that which was lost.' (tr. De Lacy)

${ }^{859}$ These functions are described in UP I 233 and I 264-5 Helmreich respectively (III 317 and 361-2 K respectively); cf. UP 273,15-20 (III 373 K); Hipp. Aph. VI XVIIB 681,15 f. K; MM X 920 K
} 
The answer has already been given: nature also gave us the spleen so that we can get rid of the black bile, instead of letting that pernicious substance wander around in our bodies:

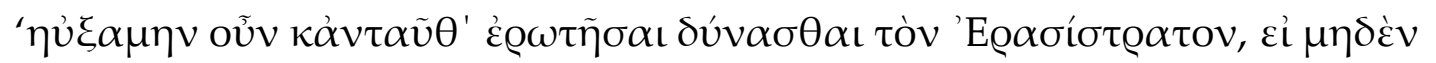

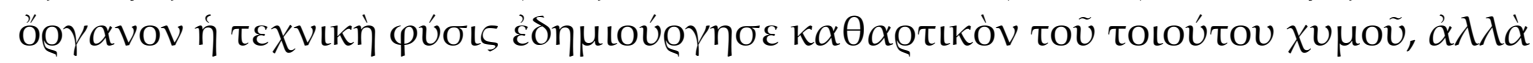

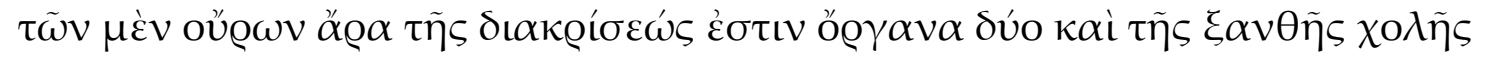

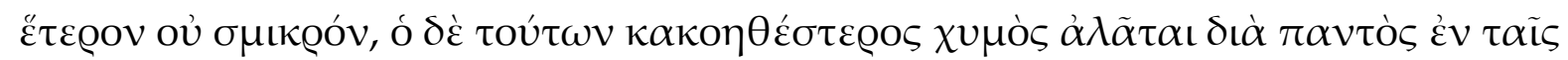
$\varphi \lambda \varepsilon \psi i v \dot{\alpha} v \alpha \mu \varepsilon \mu \iota \gamma \mu \varepsilon \dot{v} \cos \tau \tilde{\omega} \alpha i ́ \mu \alpha \tau$ l. $^{\prime 260}$

'At this point, also, I would gladly have been able to ask Erasistratus whether his artistic nature has not constructed any organ for clearing away a humour such as this. For whilst there are two organs for the excretion of urine, and another of considerable size for that of yellow bile, does the humour which is more pernicious than these wander about persistently in the veins mingled with the blood?' (tr. Brock)

Notice that Galen calls black bile a more pernicious humour than the others, while the subject is simply the normal black bile that is routinely separated out by the liver and then distributed to the spleen, as opposed to the highly acidic black bile that is the result of excessive burning and that is fatal. This pernicious substance comes to be as a kind of by-product or remnant of the normal digestive process of the liver, which transforms food into blood, and is then processed by the spleen. The black bile undergoes a long process of alteration in the spleen, which is powered by a flow of innate heat from the heart. In this process, some of it is changed into something else, namely a kind of thin, dark blood that can serve as nutriment for the spleen itself. The rest of it is discharged into the stomach, where it is normally not harmful, and is even beneficial for digestion by virtue of its capacity for drawing the stomach together. ${ }^{861}$

If the spleen functions properly, the dangers of black bile are averted: most of the black bile is altered and subsequently separated off, and it seems that perhaps, indeed, a small quantity, which also needs to be most moderate in quality, can be useful to give the blood sufficient thickness:

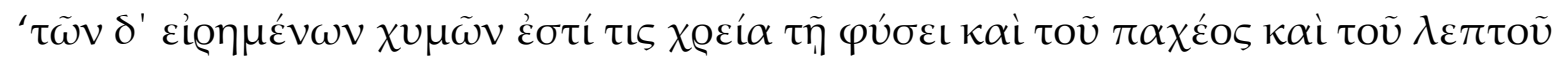

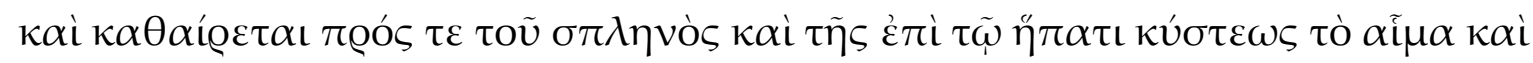

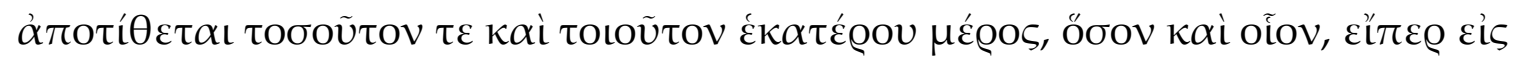

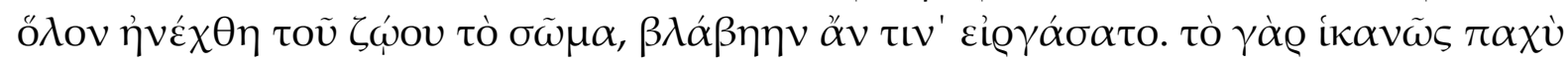

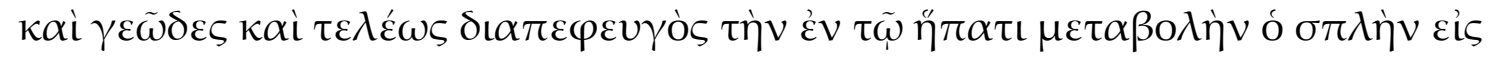

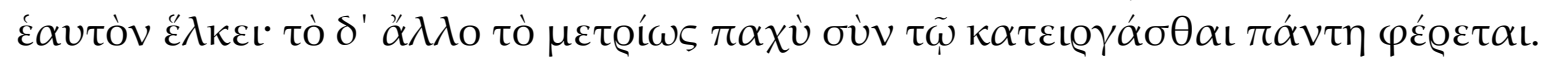

\footnotetext{
${ }^{860}$ Nat. Fac. II 9, II $131 \mathrm{~K}$; cf. At. Bil. V $136 \mathrm{~K}$ : 'Thus the system which formed animals did not neglect to form an organ which attracted the waste which belongs to black bile. But you cannot invent another part of the body which is capable of attracting this humour and ignore the spleen.' (tr. Grant)

${ }^{861}$ UP I 233, I 235 and I 264-5 Helmreich (III 317, 319-20 and 361-2 K)
} 


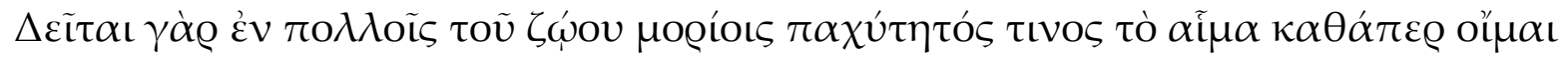

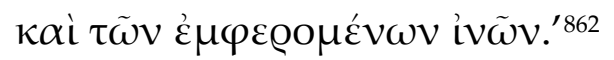

'There is, however, a natural use for the humours first mentioned, both thick and thin; the blood is purified both by the spleen and by the bladder beside the liver, and a part of each of the two humours is put away, of such quantity and quality that, if it were carried all over the body, it would do a certain amount of harm. For that which is decidedly thick and earthy in nature, and has entirely escaped alteration in the liver, is drawn by the spleen into itself; the other part which is only moderately thick, after being elaborated [in the liver], is carried all over the body. For the blood in many parts of the body has need of a certain amount of thickening, as also, I take it, of the fibres which it contains.' (tr. Brock)

This passage seems to imply that we can use a small amount of the more moderate parts of the black bile, in order to provide certain parts of the body with the proper degree of solidity. ${ }^{863}$ It seems that the black bile, though pernicious in nature, can also be useful as long as it is adequately managed by the spleen. That is to say, as long as the bulk of it is separated off and evacuated, and the mildest bits are used for a moderate thickening of the blood.

The spleen has an especially apt composition for drawing black bile into itself, as becomes clear from UP, and as we would expect of the wise artisan that Galen believes nature to be. ${ }^{864}$ The spleen is particularly porous and has a loose texture, like a sponge, so that it can attract and take into itself the thickness of the black bile. The part that does this is called the parenchyma ( $\pi \alpha \varrho \varepsilon \dot{\gamma} \chi \cup \mu \alpha)$, a name that Galen seems to have taken over from Erasistratus. It is full of large arteries that break up and alter the thick melancholic humour by virtue of their incessant motion (which is opposed to the static nature of the black bile itself, as we shall see) and a strong innate heat that comes down from the heart. ${ }^{865}$ Some of these compositional characteristics are also found in Plato's description of the spleen in the Timaeus. There, Timaeus describes the spleen as an organ of loose texture constructed out of hollow and bloodless material, which takes into itself the impurities and cleanses them, while, in turn, it also needs to be cleansed itself, since it will otherwise grow out of proportion. ${ }^{866}$ The description is quite similar to Galen's in terms of general function and constitution, but in Plato the kind of stuff that is attracted by the spleen is less specific and is certainly not defined as the dark bilious residue of digestion. But, as we have noticed, the spleen is associated with black bile and melancholy in Rufus. Galen knew both Rufus and Plato, of course, and it might have been logical for him to combine both of these descriptions. Its sponge-like nature could cause the spleen to grow when it takes in much residue, both in Plato and Galen, which in turn can

\footnotetext{
${ }^{862}$ Nat. Fac. II 9, 138-9 K

${ }^{863}$ Cf. Sem. 106,1-7 (IV 554 K), where Galen remarks that different body-parts require a different degree of thickness of the blood so that some need more black bile in it

${ }^{864}$ UP I 234 ff. and 273 Helmreich (III 319 f. and 373 K)

${ }^{865}$ UP I 232-3 Helmreich (III 316-7 K)

${ }^{866}$ Timaeus 72c-d
} 
again be counteracted, according to Galen, by a so-called 'thinning diet'. This diet is supposed to help against enlargement of the spleen and hardening of the liver, that is to say, it is supposed to reduce the production of black bile in the body. ${ }^{867}$ Diet logically plays an important role in the production of black bile, since it is through processing food that we produce the stuff in the first place - this is a theme that we have also found in Rufus before. ${ }^{868}$ Thus, Galen also distinguishes between excess of black bile that is the result of weakness of the capacity of the spleen (see below) and excess that is the result of an abnormal diet. ${ }^{869}$ In normal circumstances, the spleen deals with the consequences of the necessary intake of food that produces black bile. But this normal situation is relatively precarious: when the spleen does not function well, or when our diet is such that we put too much burden on it, there will be an excess of the pernicious substance. With regard to the composition of the spleen itself, we also find a similar notion of the basic composition of the spleen in the Hippocratic Ancient Medicine, where the structure of the spleen is described as

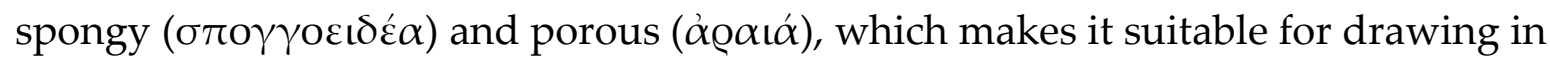
fluids. ${ }^{870}$ With regard to other possible precedents and antagonists for Galen's depiction of the role of the spleen, Stewart has provided an extensive and useful overview. ${ }^{871}$

As we noticed, thankfully, nature in all her wisdom has equipped the spleen with the proper constitution for neutralizing the dangerous potential of black bile, given the fact that she could not have entirely prevented its production. As soon as the spleen does not function properly, however, there is disaster in the making:

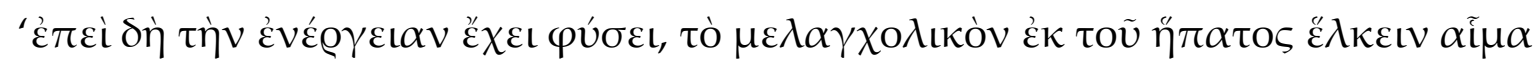

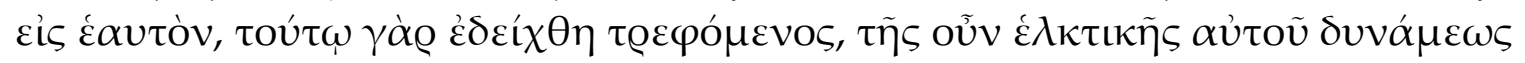

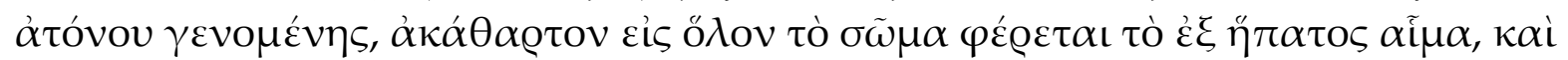

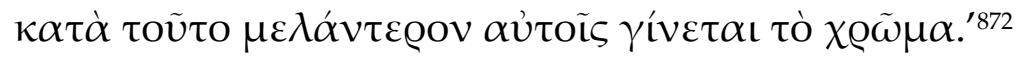

'Since [the spleen] indeed by nature has the function to draw the melancholic blood from the liver to itself - for it has been shown that it is nourished by that melancholic blood - the blood from the liver is borne through the entire body uncleansed when this attractive power has come to be weak, and for that reason the colour of those people becomes darker.'

If the spleen fails, the blood maintains the level of black bile that it had after its production by the liver, and carries this black bile through the entire body, causing

\footnotetext{
867 ed. Singer (1997) 305

${ }^{868}$ See infra, 220-1

${ }^{869}$ Symp. Caus. VII $223 \mathrm{~K}$

870 cf. Nat. Fac. II 9, II 132 K, where Galen names Hippocrates and Plato as having said that the spleen cleans the blood

${ }^{871}$ Stewart (2016) $199 \mathrm{f}$.

${ }^{872}$ Loc. Aff. VIII $377-8 \mathrm{~K}$
} 
the whole body to become darker. ${ }^{873}$ The process of digestion produces a substance that subsequently needs to be neutralized because its darkness will otherwise dominate the entire body. This neutralization is essentially the function of the spleen. ${ }^{874}$ Stewart interprets this passage in a different manner and translates the part after the first comma as 'blood draws the melancholic humour from the liver to itself, for it was shown that it receives its nourishment by this humour' ${ }^{875}$ The idea that blood (rather than the spleen) draws the black bile to itself and is nourished by it seems to fit Stewart's notion of an essentially beneficial kind of black bile, as one of the three types he distinguishes. As an interpretation of this text it does not seem tenable, though. First of all, the blood itself is also produced in the liver and is actually containing the black bile already. Second, the context here is clearly a description of the natural function of the spleen, for which we also have many parallels, some of which we discuss in this paragraph. Finally, there are other places in which Galen unambiguously states that it is the spleen itself that is nourished by the black bile (that is to say, after the black bile has undergone a certain transformation through being processed by the spleen). ${ }^{876}$

In At. Bil., Galen also stated that the whole body becomes darker when the spleen is diseased. According to Galen, the greatest doctors and philosophers have therefore held that the liver is cleansed by the spleen, drawing into itself that residual part of the blood that is comparable to the lees of wine. ${ }^{877}$ Interestingly, in these passages Galen presents us with an empirical basis for his conception of the function of the spleen, namely, that we become darker all over our body when the spleen is not functioning properly. The darkness of the black bile then becomes predominant and also manifests itself on the outside. In Nat. Fac., too, the spleen is said to draw the melancholic humour to itself when it is properly functioning; when it is weak, the blood will become thicker and darker because it has not been cleansed of black bile well enough, which again causes the whole body to take on a darker colour. ${ }^{878}$ In this particular passage, both yellow and black bile are depicted as residues $(\pi \varepsilon \varrho \iota \tau \tau \omega \mu \alpha \tau \alpha)$. They are natural results of the alteration that our innate heat effects on the foodstuff that we consume, and need to subsequently be broken down by the bladder and spleen respectively:

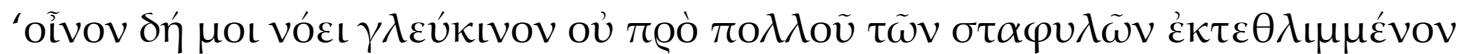

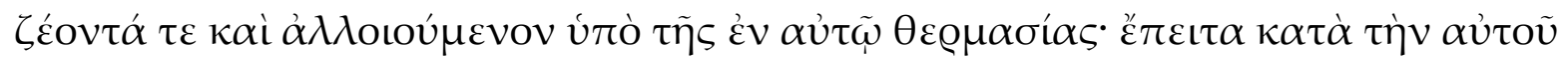

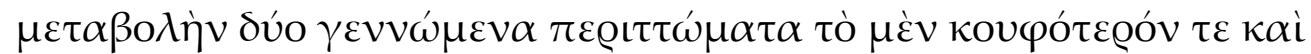

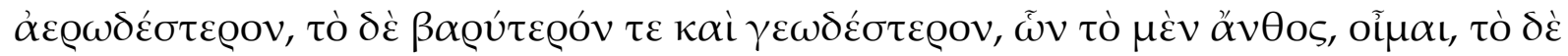

\footnotetext{
${ }^{873}$ Cf. Hipp. Elem. 144,9-12 De Lacy; San. Tu. VI 254,12-14; San. Tu. IV,4 (VI 254 K): ‘ ... while a change to a greater darkness shows black bile to be in excess...' (tr. Johnston); also Plen. VII 574,1-8 K and Comp. Med. Loc.XII 1003,14-1004,1 K for descriptions of all humours changing the body to their respective colours ${ }^{874} \mathrm{Cf}$. the description in UP I 232,14 f. Helmreich (III $316 \mathrm{~K}$ )

875 Stewart (2016) 191-2

${ }^{876}$ E.g. UP I 233,6-7 Helmreich (III 317 K); MM XIII, 17 (X $920 \mathrm{~K}$ )

${ }^{877}$ At. Bil. V $127 \mathrm{~K}$

${ }^{878}$ Nat. Fac. II 9 (II 133 K); see also note 873 above
} 


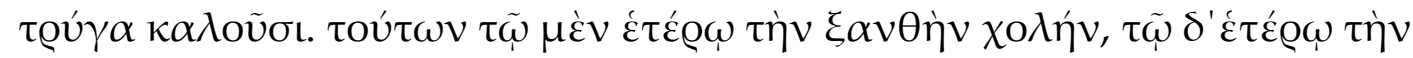

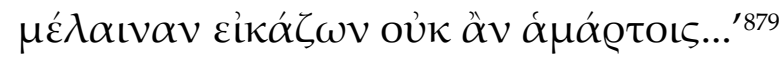

'Imagine, then, some new wine which has been not long ago pressed from the grape, and which is fermenting and undergoing alteration through the agency of its contained heat. Imagine next two residual substances produced during this process of alteration, the one tending to be light and air-like and the other to be heavy and more of the nature of earth; the one, as I understand, they call the flower and the other the lees. Now you may correctly compare yellow bile to the first of these, and black bile to the latter...' (tr. Brock)

It is a tiresome job, that of being a mortal being. First of all, one has to continually consume food in order to survive - for a short while, that is. Second of all, the consumption of food requires all kinds of secondary processes, which deal with the necessary by-products of the alteration of food into nourishing blood, and which in turn require their specific organs and processes, with which again all kinds of things could go wrong, leading to a fatal disease or disorder!

Galen, in this passage, distinguishes two of these necessary by-products, each with their own distinguishing characteristics. The comparison of black bile with the lees of wine is familiar from At. Bil. Here too, its production is clearly depicted as a byproduct of the digestive system similar to those by-products produced with fermentation. These metaphors or analogies that Galen repeatedly gives, that of the lees of wine, but also that of the watery part that runs out of olives when they are pressed, make it clear that black bile is understood as a by-product of a process that is aimed towards making something different. What is essential in these processes, is the oil, the wine or the blood. These simply happen to be hard to get. First, the watery, yeasty, slimy residue needs to be evacuated from these useful substances. Indeed, as we saw, the providence of the demiurge helps us out here:

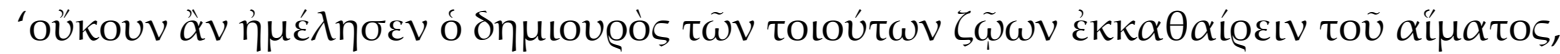

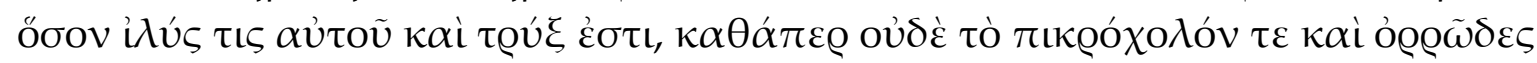
$\pi \varepsilon \varrho i ́ \tau \tau \omega \mu \alpha .^{\prime 880}$

'The crafter of these animals, just as it did not neglect to cleanse out of the blood all the sediment and dreg, just so it did with its bilious and serous residue.'

This process, to get rid of the residues caused by the digestive process, already starts from the very inception of the human being. Even when we are still a foetus, not yet in possession of our own functional system of evacuation in the form of a fully

\footnotetext{
${ }^{879}$ Nat. Fac. II 9 (II 135 K); cf. Foet. Form. IV 686 K; Symp. Caus. VII 222 K, where Galen distinguishes three

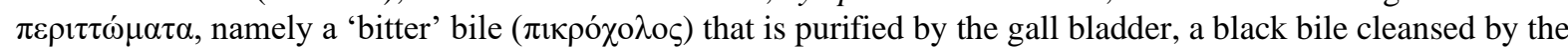
spleen and one that is watery (ó $\rho \omega \dot{\delta} \eta \varsigma)$ that is cleansed by the kidneys.

${ }^{880}$ At. Bil. V $135 \mathrm{~K}$; cf. PHP VI, 386,12-4 De Lacy (V 536 K): 'For nature, treating the production of the nutritive fluid as completed and as having its proper form, provided organs for removing the wastes: kidneys, spleen, and gall-bladder.' (tr. De Lacy)
} 
operational spleen, nature is already getting rid of the bilious residue of the blood for us:

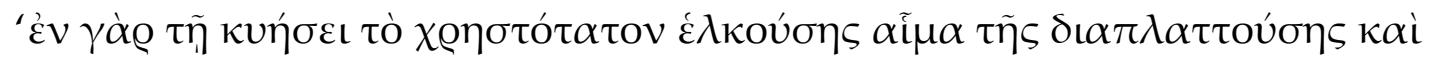

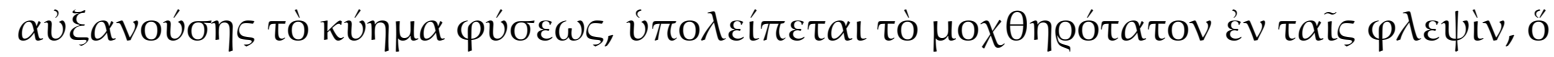

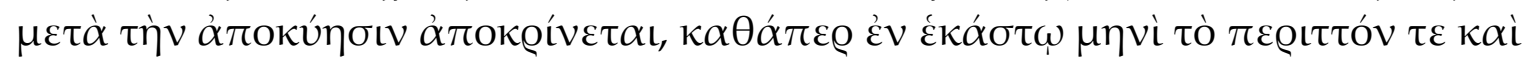

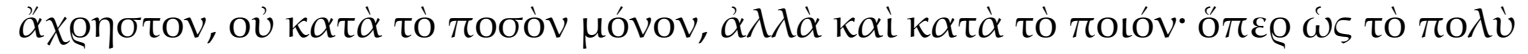

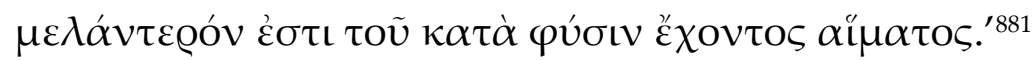

'The nature that shapes and augments the embryo during pregnancy draws the most useful blood and leaves behind in the veins the worst blood, which is secreted after birth like each month the superfluous and obsolete blood, not only with respect to quantity but also with respect to quality; this blood indeed is much darker than the blood we naturally have.'

Even while still in the womb, black bile is separated out of the blood that is used to shape the foetus, and left behind in the body of the mother, who takes care of its evacuation. Before we are born, our mothers deal with the consequences of our need for nourishment. This indicates that there is no moment for a human being in which black bile is not produced as a by-product or residue of the processes that ensure its survival. And this by-product is always dangerous. As Galen remarks in $U P$, nature made sure that the organs involved in digestion have small nerves that perceive causes of pain, so that these can be disposed of. He then says that if these organs were not able to perceive in such a way, 'they would all, I think, be easily ulcerated, eaten away, and putrefied by the daily supply of residues flowing into them', since even now, with this capacity in function and the organs equipped to get rid of acrid and pungent residues straight away, they are still 'ulcerated, abraded, eroded and putrefied by pure bile, either yellow or black.' 882 It is a finely balanced organism, our body, and in its very own depths continuously lurk detrimental substances out to destroy it.

Galen mentions yellow and black bile together here, as dangerous residues. In Nat. $F a c$., as we have seen, the yellow bile is also defined as another residue besides the black bile, but analogous to what is called the 'flower' in wine-production. The two residues are described in opposite terms. The yellow bile is light and air-like. That is to say, of such quality that it would tend upward towards the heavens. The black bile is, as usual, described rather as heavy and earth-like, that is to say, of such nature that it would tend downward towards the earth. Thus, in the production of these residues, the digestive system displays a kind of vertical cosmological schema, a reproduction of the entire elemental gamut, to which we shall return in the next paragraph. For now, let us also recall that blood, the production of which is the

\footnotetext{
${ }^{881}$ At. Bil. V 137-8. Cf. HNH 32,20 (XV 59 K) and 50,10-16 Mewaldt (XV 94 K); PHP 510,29-512,4 De Lacy (V 686-7 K), where Galen approvingly cites from the Hippocratic On the Nature of Man a passage that states that man was born with all four of the humours ${ }^{882}$ UP 274,14-279,5 Helmreich (translations May)
} 
essential aim of the digestive system, has an exceptional position among the humours and is considered to be 'well-mixed' or a mixture of all the humours, that is to say: a mean. ${ }^{883}$ In fact, in one passage in Nat. Fac., Galen defines the other humours as the result of a disproportionate amount of innate heat in the veins:

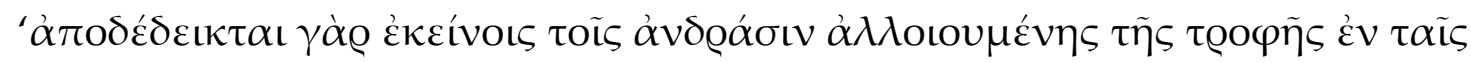

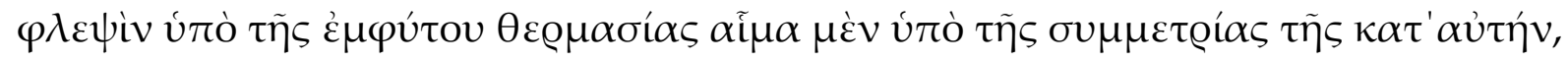

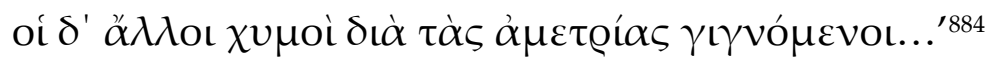

'It has been demonstrated by these men that when the nutriment in the veins is altered by the innate heat in the right proportion, blood comes to be, while the other humours come to be because of disproportion.'

Here, the humours as such seem to be the result of something gone wrong. This might seem paradoxical, given that Galen also repeatedly emphasizes that we contain all humours at all times. However, Galen expresses this notion in other works as well, and it might simply be taken to imply that there is always something going wrong, which does not seem implausible to me at all. ${ }^{885}$ On the contrary, it seems likely that the amount or intensity of innate heat is normally not perfect. The right amount would vary according to a myriad of factors, such as the type of food that is digested, one's individual constitution, the season, one's share of exercise, one's mental state, the climate etc. Would it always be completely proportionate, this passage seems to suggest, then we would produce only blood and not the other humours. ${ }^{886}$ There is some precedent for this notion of the humours in Aristotle, as we have seen, ${ }^{887}$ but also in Plato's Timaeus. There is a passage in the Timaeus - again, which Galen knew intimately, having written a commentary on it - in which Timaeus speaks of a blood that has 'a multitude of colors and bitter aspects', and that will contain 'bile and serum and phlegm of every sort'. This is a specific kind of blood in the story of Timaeus: it has received waste from flesh that is in a bad shape. Its description, however, might be close to Galen's notion of blood as a mixture of the humours (it has a multitude of colors and aspects). The description in the Timaeus of

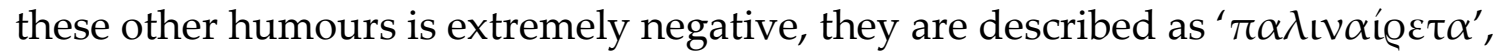

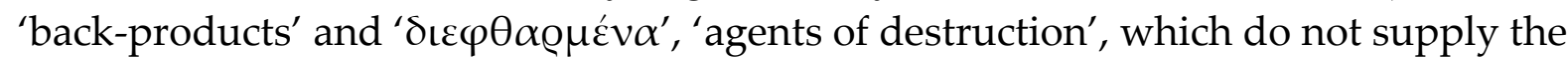
body with any nourishment. They are 'hostile to one another' and 'wage a destructive and devastating war' against the parts of the body that are properly functioning. ${ }^{888}$ Elsewhere, Galen approvingly quotes the passage from the Timaeus in

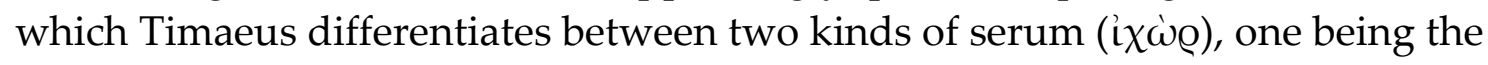

\footnotetext{
${ }^{883}$ HNH 46,31-47,3 Mewaldt (XV $88 \mathrm{~K}$ ), more on this below

${ }^{884}$ Nat. Fac. II 8 (II $117 \mathrm{~K}$ ), Galen agrees with 'these men', as is clear from the context.

${ }^{885}$ Cf. San. Tu. IV, 4 (VI 255-7 K), where the three other humours are explained as a kind of deviations from the mean of concoction, the result of which is blood; cf. Klibansky et al (1964) 50: 'Die völlige Gesundheit war ein Ideal, dem man sich annähern, das man jedoch niemals tatsächlich erreichen konnte.', see also their note 27

${ }^{886}$ Cf. PHP VIII, 504,1-2 De Lacy (V 677 K): 'The balanced mixture of all four elements generates blood in the precise sense.'

${ }^{887}$ See infra, 209-10

${ }^{888}$ Timaeus $82 \mathrm{e}-83 \mathrm{a}$, translations Zeyl
} 


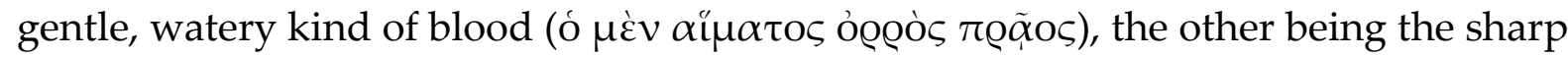

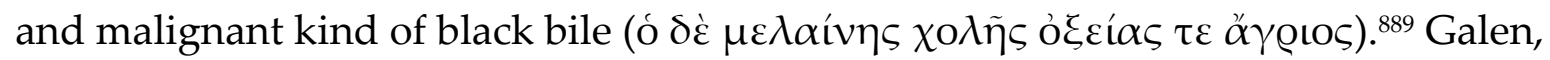
of course, systematizes Plato's remarks somewhat to fit his humoural theory: what Plato said here, is that black bile is the most harsh ( $\chi \alpha \lambda \varepsilon \pi \omega \tau \alpha \tau o \varsigma)$ of the humours,

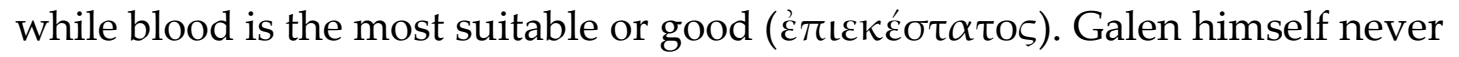
describes the three other humours in such negative terms in such a general way as in the Timaeus, but this particular passage fits very well with his opposition between blood and black bile, his notion of a pure and a mixed blood, and with the exceptionally beneficial nature of blood compared to the other humours. In fact, he also sets out the distinction between these two ways in which the word blood is used in his explanation of the passage from the Timaeus: one is separate from the other humours and the other is mixed with it. ${ }^{890}$ Certainly, passages such as the one from Nat. Fac. quoted above, do seem to suggest that according to Galen these other humours are produced because it just cannot be helped, rather than because they are so beneficial in themselves. Better beings than ourselves, such as the stars, do not have our humours since they do not need to continuously nourish their constitution in a way that causes by-products. It might well be, in our case, that these humours serve a function within the (digestive) system of our bodies, but that is only already assuming the fundamental imperfection (the continuous need for nourishment) that made their generation necessary in the first place.

But is this idea of something going wrong all the time with our body, as such, not terribly incongruent with Galen's general teleological framework in which nature produces well-designed beings? Let us have a look at the following passage from UP, Galen's teleological work par excellence:

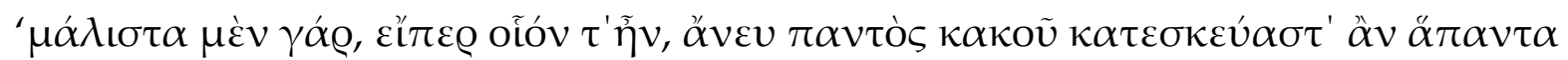

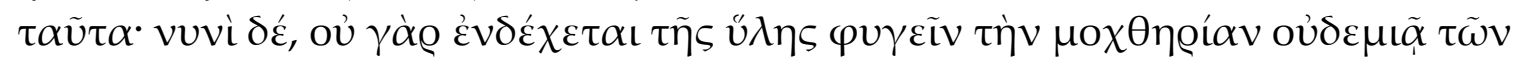

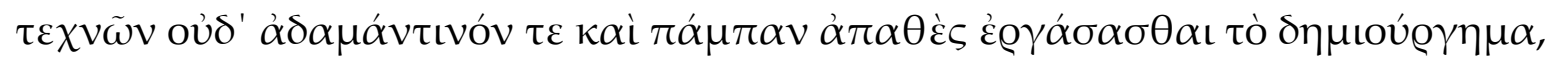

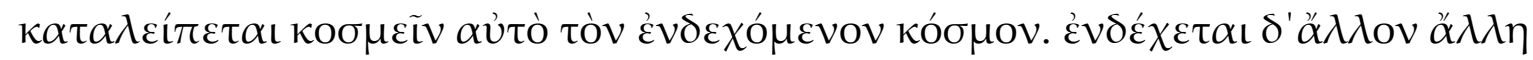

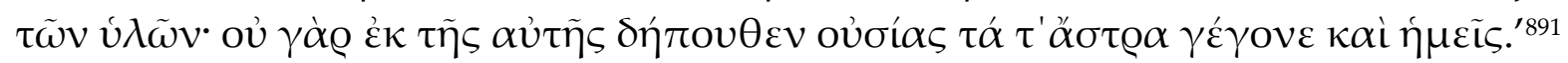
'Surely if it had been possible, she [nature] would have arranged all these matters with no drawbacks at all, but as it is, since it is impossible with all her arts to avoid the inadequacies of her material and to make her creations of adamant, entirely invulnerable, it remains for her to arrange them as best as she can. Different materials

\footnotetext{
${ }^{889}$ Timaeus 83c, Galen quotes and discusses it in Hipp. Epid. VI XVIIA 983,6 f. K; he also quotes and discusses the broader passage in $A d v$. Jul. VIIIA $260,7 \mathrm{f}$. K

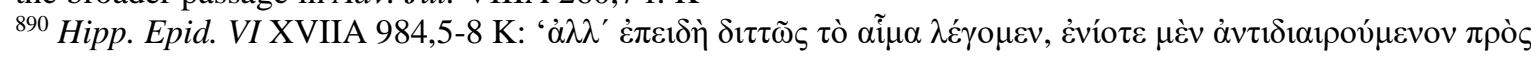

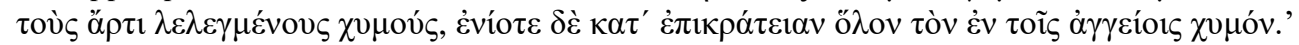

${ }^{891}$ UP I 260,5-13 Helmreich (III $355 \mathrm{~K}$ ). Cf. Hankinson (2008) 228; see also UP I 174-5 Helmreich: 'Then do not wonder so greatly at the beautiful arrangement of the sun, moon, and the whole chorus of stars, and do not be so struck with amazement at the size of them, their beauty, ceaseless motion, and ordered revolutions that things here on earth will seem trivial and disorganized in comparison; for here too you wil find displayed the same wisdom, power, and foresight. Consider well the material of which a thing is made, and cherish no idle hope that you could put together from the catamenia and semen an animal that would be deathless, exempt from pain, endowed with never-ending motion, and as radiantly beautiful as the sun.' (tr. May)
} 
admit of different arrangements; for certainly we are not made of the same substance as the stars.' (tr. May)

Indeed, immediately following this passage, Galen elaborates upon some of these drawbacks. Galen proceeds to discuss the use, necessity, and manners of alteration and evacuation of the various humours (except for blood, since it is not a $\pi \varepsilon Q i ́ \tau \tau \omega \mu \alpha)$. The humours are there because we are not like the stars. ${ }^{892}$

This notion of not being like the stars is far from uncommon in Galen, and we shall return to it in the next section. For now, let us focus again on the spleen.

Once the melancholic blood has been drawn to the spleen, the potential danger of black bile is not yet resolved. After all, were this the end of it, most of the black bile would just pile up in the spleen itself, presumably leading to a giant cancer and other unspeakable horrors. As we have mentioned above, some of it is altered into nutriment for the spleen itself. The rest is disposed of in the stomach after which it has to be discharged, partly through the vomiting that accompanies nausea and partly through the stools. ${ }^{893}$ This process of discharge is the normal course of events, it is not merely a description for those that are already affected by an excess of black bile. There needs to be a continuous evacuation of the stuff. Presumably, this entails that our stools normally contain black bile that has been drawn from the blood by the spleen, and has then been evacuated to the stomach after a process of alteration. ${ }^{894}$ When these evacuations are not properly performed and the black bile piles up, melancholy is the result:

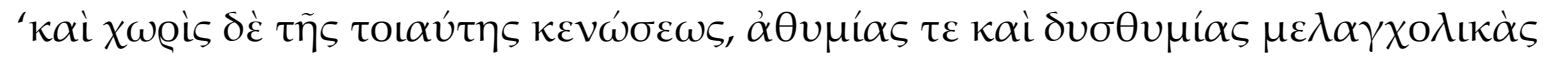

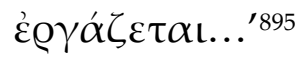

'And without this evacuation, despondency and melancholic depression arise.'

Melancholy can be a direct result of the inability to neutralize the potentially dangerous side-effects of normal digestive processes due to a weakness of the spleen. That is to say: if it were not for the continuous cleansing activity of our spleen, ceteris paribus, we would be naturally in a state of melancholy. In other words, the spleen is making up for the tragic fact that we are not like the stars.

Before we turn to discuss Galen's analysis of the condition of melancholy itself, we shall have a final look into the dark substance of its cause, now with less focus on its physiological reality, and more attention for the specific associations that it evokes, for what we could call its spectrum of meaning.

\footnotetext{
${ }^{892}$ In the Timaeus, of course, the rational part of the soul is made of similar stuff as the heavenly bodies and is designated a star, while the rest of the body is made of lesser ingredients.

${ }^{893}$ Loc. Aff. VIII 378,5-9 K

${ }^{894}$ Cf. MM XIII,17, X $921 \mathrm{~K}$, where Galen mentions that the purging of superfluities from the spleen happens

'via the stomach alone', which corresponds to the two normal processes of purgation through stools and vomiting in the case of nausea.

${ }^{895}$ Loc. Aff. VIII $378 \mathrm{~K}$
} 


\section{e. The end of summer}

The season of black bile, the time when it is most predominant, is autumn. Its abundance is prepared in the period before that, in summer, when the days are longest and the sun shines most vigorously, drying and heating everything beneath it. In the summer, blood is still strong in the body, since it is the season following spring, but the bile increases:

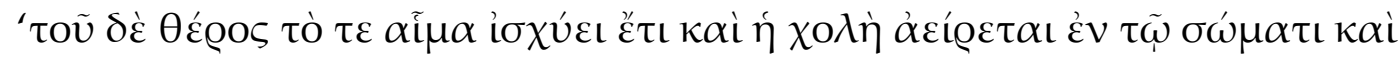

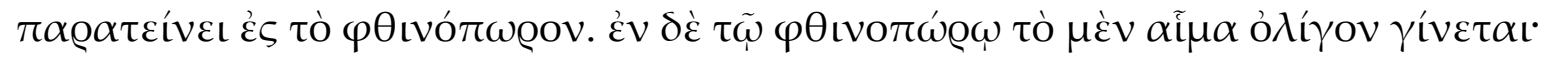

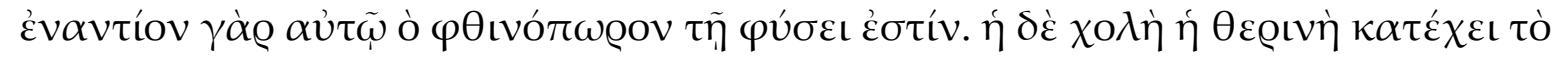

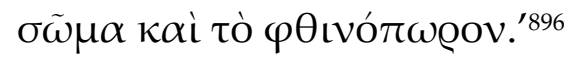

'In summer blood is still strong, and bile increases in the body and lasts until autumn. In the autumn, the blood becomes small in quantity, since autumn is opposite to it by nature. The bile of summer also dominates the body in the autumn.' (tr. Hankinson)

The bile remains in autumn, after the heat recedes. As autumn approaches, the amount of blood decreases. The moisture has been driven out because of the heat, and what remains is the abundance of a substance that is dry and has now become cold:

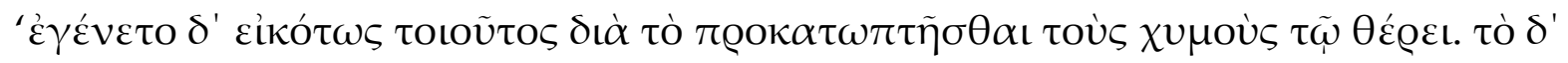

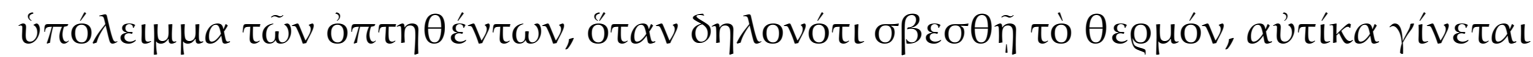

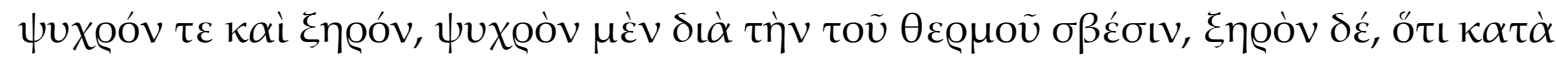

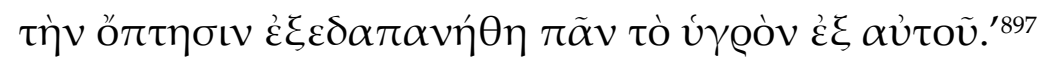

'And it is reasonable that such a humour arises as a result of the cooking of the humours during the summer. The residue of this cooking, when the hot has been thoroughly quenched, then becomes cold and dry, cold as a result of the quenching of the heat, dry because the process of cooking has driven out all of the moisture from it.' (tr. Hankinson, slightly modified)

What we have in autumn, is a kind of remainder of summer, the bile that persists after the sun has departed. In fact, autumn is literally described as the end of summer

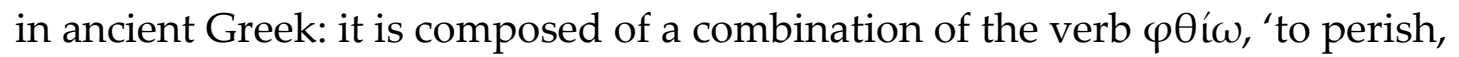
decline, decay, die' and the word ỏ $\pi \omega \mathrm{\rho} \alpha$, 'summer' (for which $\theta \dot{\varepsilon} \mathrm{Q}$ 's is more common) or 'the latter part of summer' and also 'fruit'. The combination of these two words designate autumn as a kind of death of summer, or the time when the fruits of summer decay. One might recall Rufus' words here, saying that excess of heat 'renders the humours black, just as the sun blackens fruits and human bodies' ${ }^{898}$ The

\footnotetext{
${ }^{896} \mathrm{HNH} 44,25 \mathrm{Mewaldt}$ (XV $84 \mathrm{~K}$ ) - Galen quotes this from the Hippocratic text

${ }^{897}$ HNH 45,27-30 Mewaldt (XV 86 K)

${ }^{898}$ On Melancholy Fr 11,21 Pormann (2008), see also Fr 75,3
} 
notion of excessive heating is already developed in Rufus, but he mostly relates melancholy to spring, rather than the period after summer, which might make more sense in this context of overheating and then cooling down. ${ }^{899}$ Galen's rendering of yellow bile being dominant in summer, while black bile already increases then and becomes dominant after summer, seems to have a parallel in the schema presented in a text from the Medical Excerpts by Paul of Aegina, that is there presented as a letter from Diocles (whose work Galen was familiar with) to a king Antigonus. The authenticity of this text is subject to debate, so we cannot be sure if it hails from Diocles himself. ${ }^{900}$ In this letter, it is noted that after the rising of the Pleiads, which would be around the end of April or early May, yellow bile increases until the summer solstice. The summer solstice, in turn, would have been around the $22^{\text {nd }}$ or $23^{\text {rd }}$ of June, and it is said that after this period the black bile starts to increase until the autumn equinox, which would be around the end of September. ${ }^{901}$ This corresponds well to the notion that black bile is produced in the latter part of summer so that it is predominant in autumn.

Walter Müri has noted that there is a parallel between the development of black bile as a separate substance - that is to say, the division of 'bile' into a yellow and black bile - and an expansion of the number of seasons from three to four - that is to say, the division of summer into summer and autumn. Somewhere in the $6^{\text {th }}$ century, autumn ( $\varphi \theta$ เvó $\pi \omega \varrho O \nu)$ was added to the already existent $\chi \varepsilon \iota \mu \omega \nu$, winter, $\varepsilon \alpha \varrho$, spring and $\theta \dot{\varepsilon} \mathrm{QO} \varsigma$, summer, as the latter part or end of summer. ${ }^{902}$ This is an interesting parallel indeed, especially considering that yellow and black bile remain so closely related in Galen, and considering that Galen repeatedly remarks that the Greeks, when they speak of $\chi 0 \lambda \eta$, 'bile', simply, refer to the yellow bile, whereas if they want to indicate the black bile, the word for bile needs to be further specified with the additional $\mu \varepsilon^{\prime} \lambda \alpha \mathrm{\iota v} \alpha$, 'black'. ${ }^{903}$ That is to say, just as there previously was only a summer and there is now a summer and an end or decay of summer, there previously was only bile, while there now is also a degenerated bile that is a remnant of an excess of heat.

One notices that there is something negative or privative about the description of autumn: it is primarily understood as a negation of what precedes it. ${ }^{904}$ The description of its coming to be is remarkably similar to the production of black bile itself, which comes to be when, during digestion, there is too much innate heat so that instead of blood, black bile is produced. Likewise, in summer, there is excessive heat so that the amount of blood diminishes and that of black bile increases. Clearly, since fruits and summers are generally good things, this description implies a

\footnotetext{
${ }^{899}$ In the Hippocratic Aphorisms, quoted by Galen in PHP VIII 516,24-5 De Lacy, melancholy is also said to abound in spring, although it is again said to abound in autumn as well.

${ }^{900} \mathrm{Cf}$. for text, translation and commentary of the text, van der Eijk (2001) fr 183A, specifically lines $107 \mathrm{ff}$.

${ }^{901}$ Ibidem, also for the dating of these periods

902 Müri (1953) 28

${ }^{903}$ SMT XII 275,13-8 K; HVA XV 637,8-10 K; Hipp. Epid. VI XVIIB 271,6-7 K; Hipp. Aph. XVIIIA 132,12-5

$\mathrm{K} ; \mathrm{HNH} 40,10-5$ Mewaldt (XV $75 \mathrm{~K}$ )

904 The exact same point applies to the stage of life which is associated with the black bile: $\dot{\eta} \pi \alpha \rho \alpha \kappa \mu \eta \dot{~ l i t e r a l l y ~}$ the time past the prime, also indicating a time of decay (cf. Hipp. Prog. XVIIIB 282,10-1, Temp. I 641,4-7 K)
} 
negative characterization of autumn, just as Galen sees the production of black bile as a deviation from the production of blood. The mere fact that this production is common, does not make it less of a deviation in this sense.

Another thing to note in this regard is that the qualities of black bile and of autumn are coldness and dryness. These are - in this specific combination - the qualities of death as well, since that is what we become when we die, or better: it is what the remainder of us becomes, after the life has flowed from our bodies. This is, in fact, a point that is noted by Galen in the context of a presentation of the position of followers of Athenaeus. They apparently claim that one of the four pairings of elemental qualities, hot and wet, is superior to the others, does not cause any illness, and is as such the best mixture and the mixture of life. ${ }^{905}$ They conclude this on the basis of the characteristics of death, which are the exact opposite:

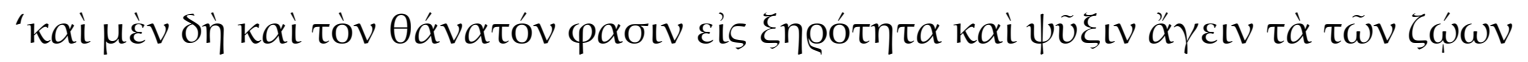

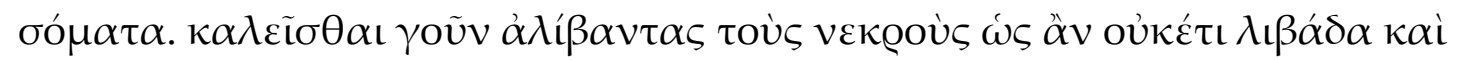

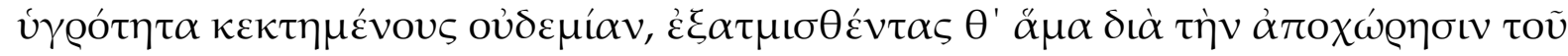

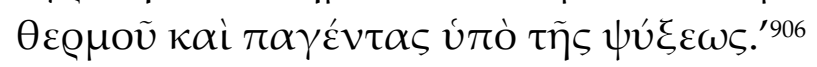

'They also make the point that death causes dryness and cold in animal bodies; corpses are referred to as alibas, on the grounds that they no longer possess any libas or moisture. For they have simultaneously lost their vapors at the departure of heat and been solidified by cooling.' (tr. Singer)

If death is characterized by the qualities of dryness and coldness, then life must be characterized by their opposites, wetness and hotness. Thus, spring is well-tempered, because it 'consists in nothing other than the domination of these two qualities', as Galen presents the position of these followers of Athenaeus. Galen himself takes issue with this argument, since spring, according to him, is not characterized by a predominance of hot and wet in the same way in which winter, for example, is characterized by wet and cold. Rather, spring does not possess any of its qualities in a disproportionate sense - this, according to Galen, is what it means to be wellbalanced. Galen defines spring rather as a precise middle with regard to all extremes. ${ }^{907}$ He approvingly quotes from the Hippocratic Aphorisms the saying that 'Spring is most healthy and least fatal'. But whereas he takes issue with the way spring is characterized by the followers of Athenaeus in terms of the predominance of wetness and hotness, he does not take any issue with their opposition of spring and autumn and their accompanying associations of life and death or health and disease respectively. In fact, he notes a particular problem with autumn - it is most conducive to illness, due to its irregularity of mixture:

\footnotetext{
905 Temp. I 522-3 K

${ }^{906}$ Tетр. I 522,15-523,2 K

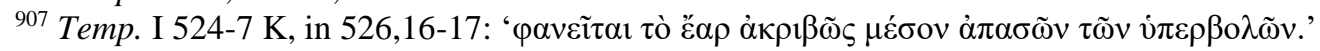




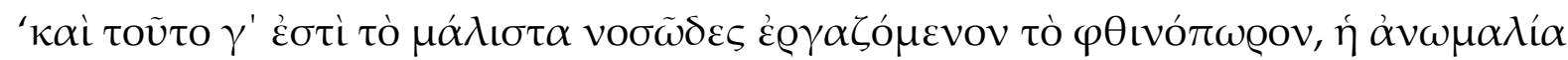

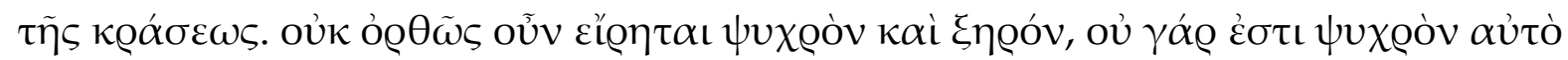

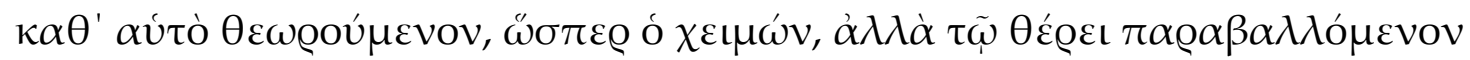

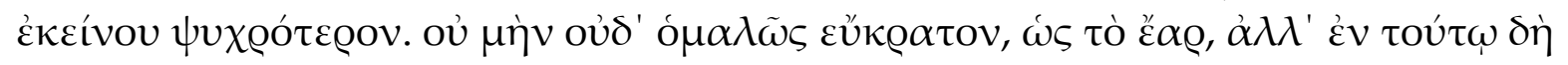

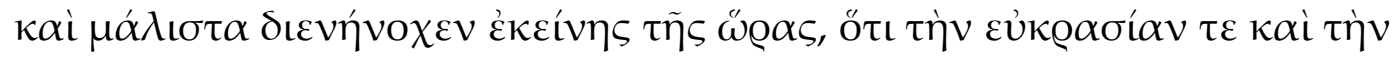

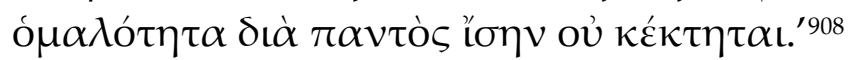

'And this irregularity of mixture is the factor that makes autumn most conducive to illness. It is not correct to term it cold and dry; for it is not cold in itself, like winter, but only by comparison with summer. And yet it is not possessed of an even state of good balance, like spring, its chief difference from that season in fact consisting in the lack of this evenness.' (tr. Singer)

Again, we find autumn defined in opposition to spring, in clearly negative terms. Whereas spring is well-tempered and evenly balanced, autumn is defined by the absence of these very qualities. Also, it is again defined negatively in terms of its precedent, summer: it is not cold in itself but only compared to summer.

This opposition between spring and autumn is the same opposition as the one between blood and black bile, both pairs are opposed because of their respective mixture. ${ }^{909}$

We noticed earlier that the amount of blood decreases as the amount of bile increases, and that the amount of blood is least in autumn, since 'autumn is opposite to it by nature'. This was a text that Galen quoted from the Hippocratic On the Nature of Man itself. In his commentary on the Hippocratic text, Galen adds the following:

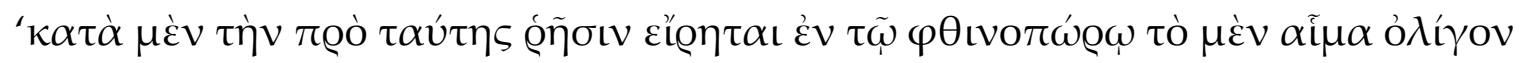

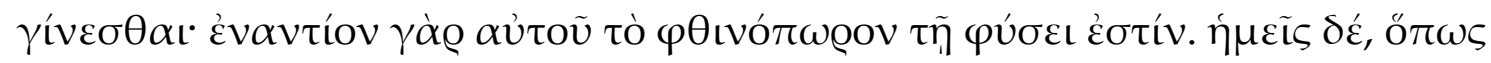

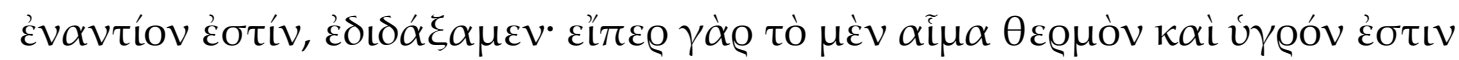

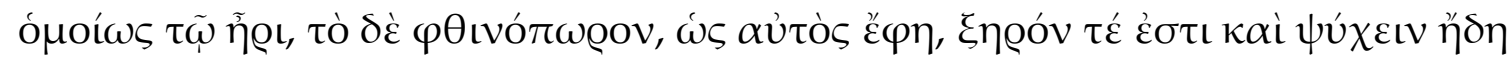

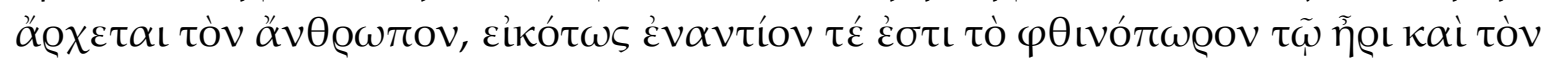

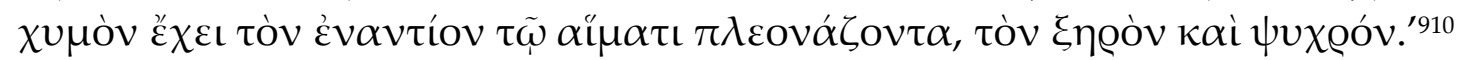
'In the preceding passage he said that 'In the autumn, the blood becomes small in quantity, since autumn is opposite to it by nature;' and we will explain in what way it is opposite. For if indeed blood is hot and wet in the same way as spring, then autumn, as he said, is dry, 'and man already begins to cool down', and it is reasonable both that autumn is opposite to spring, and involves an excess of the humour opposite to blood, namely one that is dry and cold.' (tr. Hankinson, slightly modified)

Autumn is opposite to spring and black bile is opposite to blood, by virtue of their respective pairs of elemental qualities being opposites. We noticed earlier, however,

\footnotetext{
${ }^{908}$ Temp. I 527,13-528,5 K

${ }^{909}$ Cf. also PHP 514,16-31 De Lacy

${ }^{910} \mathrm{HNH} 45,15$ Mewaldt (XV $86 \mathrm{~K}$ )
} 
that blood has quite an exceptional status among the humours. We saw how Galen considers blood, if not the 'sole constituent' of human nature, then at least 'most closely affiliated to it' (oikeı́ó $\alpha \tau 0 \varsigma$ ). ${ }^{911}$ We also noticed how blood is produced when the ideal amount of innate heat is used in the process of digestion, whereas the other humours are produced as by-products when the amount is too great or too small. ${ }^{912}$ Indeed, blood and spring are attributed by Galen the same exceptional status:

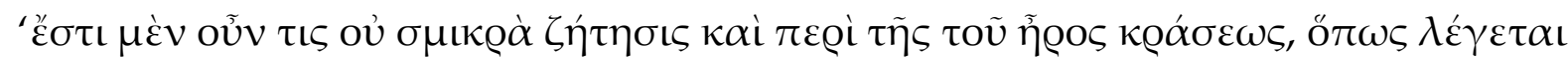

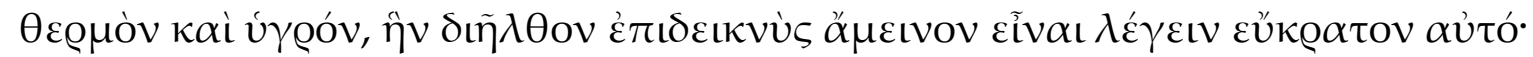

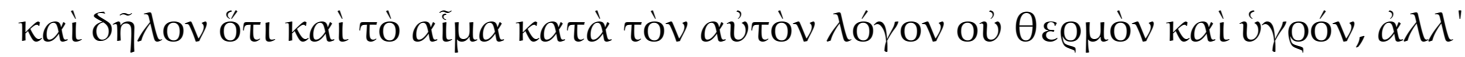

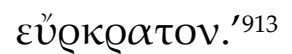

'Yet the investigation concerning the mixture of spring - in what way it is hot and wet - is no trivial one, which I have already covered when I indicated that it is better to call it 'well-tempered'. And clearly by the same argument, blood too will not be really hot and wet, but well-tempered.' (tr. Hankinson)

Instead of having a pair of qualities that predominate, like in each of the other humours and seasons, blood and spring are rather described as 'well-tempered'. In another passage in $H N H$, Galen makes a comparison between spring and autumn in which he calls spring 'the best of seasons' and 'the only one properly natural, as opposed to the one contrary to nature'. ${ }^{914}$ How odd, that one of the four seasons, which do seem to form a balanced natural order together, is said to be contrary to nature. What does it mean for the black bile itself, that blood and spring are the humour and season that black bile and its season are opposed to? Blood and spring are both defined as exceptionally beneficial, useful, healthy, moderate and close to our nature. If black bile and autumn are opposed to them, their characteristics must, to some extent at least, be opposed to those as well. ${ }^{115}$ Galen's commentary on the Hippocratic On the Nature of Man is one of the main texts in which we find this opposition between black bile and autumn on the one hand, and blood and spring on the other. This means that in Galen's most systematic continuation of Hippocratic humoural theory, black bile is not simply one humour among others. It is the worst of the humours, whereas blood is the best. Moreover, it appears to even be contrary to nature somehow, while at the same time being a part of it. Could it be, that black bile is both part of our nature and simultaneously contrary to it?

As we have noticed, black bile is often described by Galen as the sediment of the blood, as the nasty by-product that one needs to get rid of, like with the lees of wine

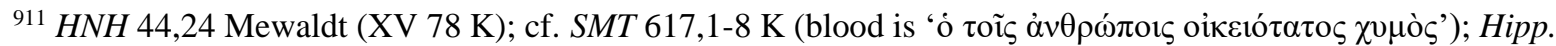

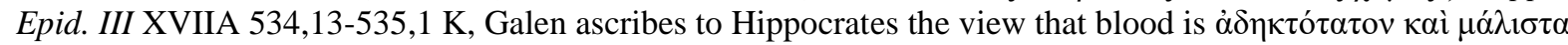
oikeĩov $\dot{\eta} \mu \mathrm{i} v$, least biting and most natural to us.

${ }^{912}$ Nat. Fac. II 8 (II $117 \mathrm{~K}$ ) and San. Tu. IV 4 (VI 255-7 K)

${ }^{913}$ HNH 46,31-47,3 Mewaldt (XV 88 K)

${ }^{914}$ HNH 44,9 ff. Mewaldt (XV $83 \mathrm{~K}$ ), translation Hankinson

${ }^{915}$ Cf. Klibansky et al. (1990) 51-3 on the opposition of blood and black bile and their exceptional position in the fourfold humoural theory
} 
or the watery part of olives: we are just stuck with those and have to remove them if we want those fine products of wine and olive oil. In the following passage these two opposites are also clearly brought together:

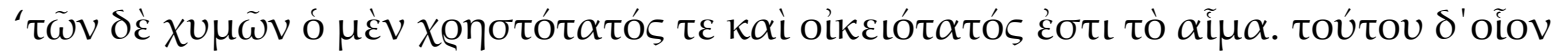

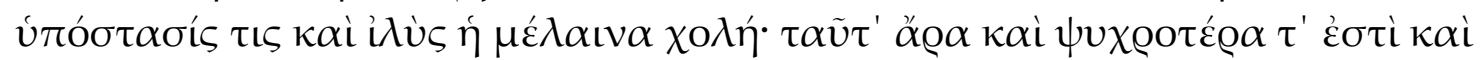

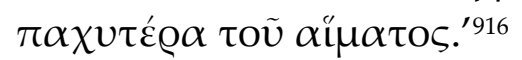

'Of humours the most useful and natural is the blood. Black bile is a kind of sediment or dreg of this; it is thus colder and thicker than blood.' (tr. Singer, modified)

Again, blood is the most useful of the humours and the one that is most congenial to us, while black bile is merely a dreg that is carried along by the blood and that needs to be evacuated from it. ${ }^{917}$ As we have seen above, yellow bile can also be understood as a by-product of the production of blood, and was involved in the same winemetaphor as black bile. Black bile has much in common with yellow bile and can even be seen as an altered continuation of the same substance, as became clear in the context of the discussion of the seasons and their respective humours, as well as in the context of the dangerous black bile that is a burned yellow bile. However, black bile is in some ways opposed to yellow bile as well. Let us have another look at the passage from Nat. Fac. that we quoted earlier:

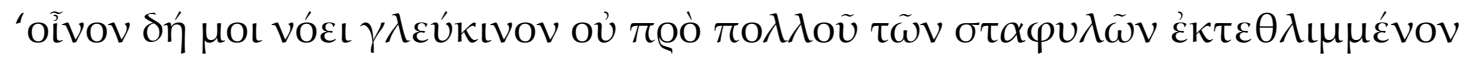

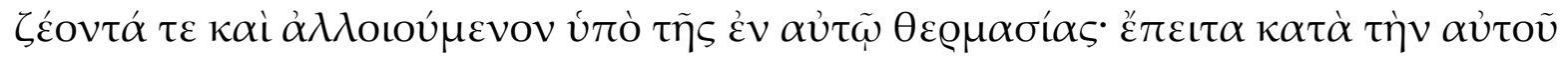

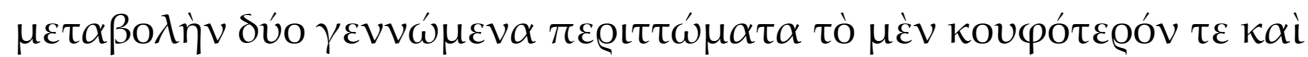

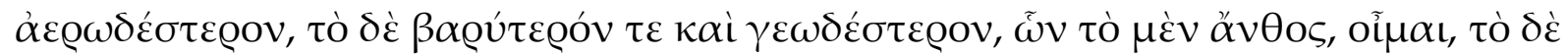

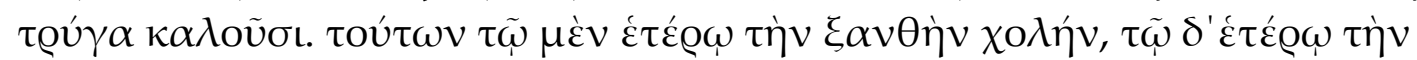

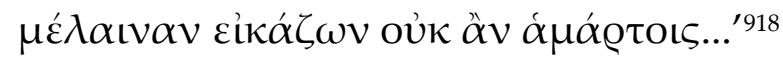

'Imagine, then, some new wine which has been not long ago pressed from the grape, and which is fermenting and undergoing alteration through the agency of its contained heat. Imagine next two residual substances produced during this process of alteration, the one tending to be light and air-like and the other to be heavy and more of the nature of earth; the one, as I understand, they call the flower and the other the lees. Now you may correctly compare yellow bile to the first of these, and black bile to the latter...' (tr. Brock)

\footnotetext{
${ }^{916}$ Temp. I 603,8-11 K; cf. Comp. Med. Gen. XIII 667,15-8 K, where a red and useful blood is contrasted to a

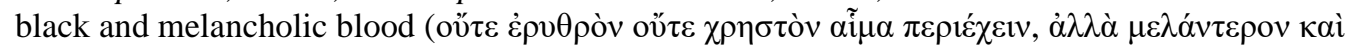
$\mu \varepsilon \lambda \alpha \gamma \chi 0 \lambda \iota \kappa \omega ́ \tau \varepsilon \rho o v)$

${ }_{917}$ As we have seen before, the term for dreg, ì $\hat{\nu}_{\zeta}$, is also used by Galen in At. Bil. to describe black bile; in $M M$, the adiectives $\imath \lambda \nu \tilde{\omega} \delta \varepsilon \varsigma$ and $\mu \varepsilon \lambda \alpha \gamma \chi 0 \lambda$ เкóv are used together to describe the part of the blood that is cleansed by the spleen, MM XIII, 17 (X $920 \mathrm{~K})$

${ }^{918}$ Nat. Fac. II 9 (II 135 K); cf. Foet. Form. IV 686 K; Symp. Caus. VII 222 K, where Galen distinguishes three $\pi \varepsilon \rho ı \tau \omega \dot{\mu} \mu \tau \alpha$, namely a 'bitter' bile ( $\pi \iota \kappa \rho o ́ \chi 0 \lambda \circ \varsigma)$ that is purified by the gall bladder, a black bile cleansed by the

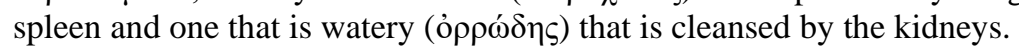


The descriptions of these residual substances are opposed to each other: yellow bile tends to be light and air-like, whereas back bile is heavy and earthy. Here we have the traditional opposition between heaven and earth associated with the two biles, understood as the two by-products of digestion. What would be the role of the wine itself in this analogy? Obviously, the wine is the essential product, it is what the entire process is about. In the process of digestion, this is the blood. Blood, as we saw, is defined as the well-mixed mean and that which is closest to our nature. Blood holds a perfect middle position between the extremes. In this respect it is interesting to note that Galen on several occasions names wine as a remedy to melancholy. In $Q A M$, he states that the daily consumption of wine relieves us of all sorrow and

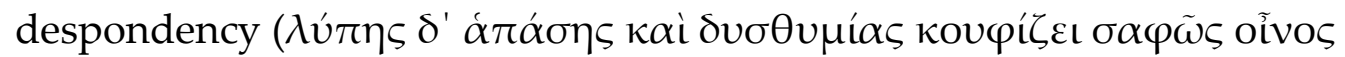
$\pi$ เvó $\mu \varepsilon v 0 \varsigma) .{ }^{919}$ Indeed, Galen says this in a context in which he has just given melancholy as an example of the body (i.e. the brain particularly) causing damage to the rational capacities, and he also proceeds to present Zeno of Citium as an example of the beneficial effects of daily wine-drinking (alluding to his reportedly melancholic behaviour when sober). ${ }^{920}$ It seems there is more to the metaphor than black bile and yellow bile being comparable to the two by-products of the lees and the flower. The essential product, the wine itself, also has the tendency to produce affections in us that are opposed to the ones that black bile produces. Indeed, in another passage, Galen compares the end-product, the wine, to useful blood. ${ }^{921}$ Clearly, there is a double opposition here, between black bile and blood on the one hand, and between black bile and yellow bile on the other.

Blood, as the mean between those extremes, suits us. Human beings, in the Greek philosophical tradition, are defined as being in between heaven and earth: we are intelligent, like the heavenly bodies, but we do not have a substance as pure as those bodies, since we also consist of water and earth. ${ }^{922}$ Black bile is the earthy humour, the sediment in the blood, the heavy humour that weighs us down and binds us to the earth - it literally makes us depressed when it predominates. Yellow bile, on the other hand, is associated with the heavenly bodies, it is described as fiery and light, naturally tending in the opposite direction of the black bile, it is dry and hot like the

\footnotetext{
${ }^{919}$ Galen, in $Q A M$ IV $777 \mathrm{~K}$, cf. $779 \mathrm{~K}$, where he notes that 'one who drinks wine in moderation' has

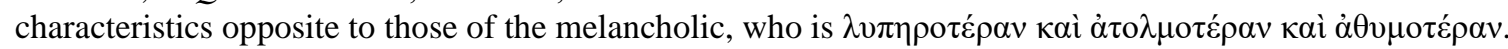
${ }^{920}$ See infra, note 759

${ }^{921}$ Cf. also UP 197,18-198,10 Helmreich (III 270 K): 'Let us, then, compare the chyle to wine just pressed from the grapes and poured into casks, and still working, settling, fermenting, and bubbling with innate heat. The heavy, earthy part of its residues, which I think is called the dregs, is sinking to the bottom of the vessels and the other, light, airy part floats. This latter part is called the flower and forms on the top of light wines in particular, whereas the dregs are more abundant in heavy wines. In making this comparison, think of the chyle sent up from the stomach to the liver as bubbling and fermenting like new wine from the heat of the viscus and beginning to change into useful blood; consider too that in this effervescence the thick, muddy residue is being carried downward and the fine, thin residue is coming like foam to the top and floating on the surface of the blood.' (tr. May)

${ }_{922}$ We find this general idea in Plato's Timaeus, of course, but also in Galen, see UP II 446-7 Helmreich (IV 359 $\mathrm{K})$ : 'It is reasonable to suppose that the intelligence dwelling in them [the sun, the moon and the stars] is as much better and more perfect than that in earthly bodies as their bodily substance is the purer. For when in mud and slime, in marshes, and in rotting plants and fruits animals are engendered which yet bear a marvelous indication of the intelligence constructing them, what must we think of the bodies above?' (tr. May)
} 
stars. ${ }^{923}$ Galen also states that it causes intelligence, in a passage in $H N H$ that refers to $Q A M$, where intelligence was said to be caused by dryness, the quality that the stars possess to the extreme..$^{924}$

Black bile is also dry, of course, but its dryness is nothing but a remainder of the heat of summer, as we have seen. ${ }^{925}$ It is there when the fire dies out. I think there is no doubt that we here have a link to the traditional relation between thinking and melancholy that we found in Rufus and the Peripatetic tradition as well. ${ }^{926}$ Intelligence is at its peak during summer since it is caused by yellow bile, which predominates in summer. But after this peak of activity of the intellect, a low point follows: the heat that inspired intelligence cools and a dark substance that is the cause of melancholy perseveres. Indeed, one might think here of the bipolar-like descriptions of melancholy from the Problemata. The only essential difference is that the cooling and heating of black bile is now further divided over two substances, the dry and hot yellow bile that increases intellectual activity, and the dry and cold black bile that increases sadness. But it might perhaps be more useful to have a somewhat broader association: what is depicted with these different substances is not so much a recurrent bipolar-like disorder that befalls exceptional people, but rather simply the fact that we, as human beings, are beings that relate ourselves in fundamental ways to both heaven and earth. Naturally, both of these extremes would have a place in our physical constitution, naturally we would swing from one to the other regularly, and naturally we would be most at ease when we rather produce that which essentially fits us and is closest to our nature: the mean, i.e. blood. With the transition from summer to autumn, from yellow bile to black bile, our substances change from something that is more similar to the heavenly bodies to something that is more similar to earth, as if portraying the course of a falling star which loses its heat as it descends. As we have seen, Galen considers black bile as one of the 'drawbacks' of the fact that nature needs to work with a matter that makes it impossible to make us like the stars, which are predominantly dry and hot. Likewise, we have argued how Aristotle attributed to the melancholic's constitution a particular sensitivity for the

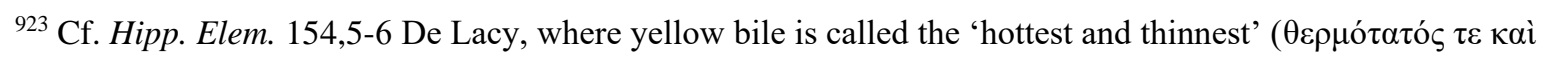

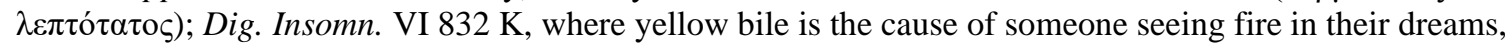
black bile of someone seeing mist, smoke and a deep darkness; Trem. Palp. VII 633,11-14 K, where Galen remarks that rigor can cause both quartan and tertian fevers, even though these arise from humours that are

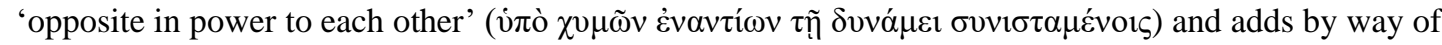
explanation: 'for the melancholic humour is cold, but the yellow bile is hot'; PHP 502,21-22 De Lacy, where yellow bile is said to be analogous to fire, black bile to earth; Hipp. Aph. XVIIB 667,-6 K, where black bile is said to move downwards, yellow bile upwards, due to their respective constitutions (black bile being thick,

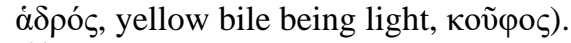

${ }^{924}$ HNH 51,9-18 Mewaldt (XV $97 \mathrm{~K}$ ), cited and discussed below; QAM 780-82 and $786 \mathrm{~K}$; see infra, CS II section 5, 136 and CS III section 4, 181-2; in the same vein (linguistic capacities being related to intelligence), black bile causes one to become more silent, yellow bile (as the cause of phrenitis) to become more talkative, cf. Hipp. Epid. III XVIIA 789,13-14 K, where Galen explains the change from not speaking ( $\sigma \gamma \tilde{\sigma} \sigma \alpha)$ to excessive speaking ( $\lambda$ ó $\gamma_{0} \mathrm{r} \pi \lambda \lambda \mathrm{o}$ ) in terms of the differece between a melancholic and phrenitic condition respectively; Hipp. Epid. III XVIIA 785,5-786 K, where Galen explains the silence and gloominess of a patient in terms of her having a more atrabilious blood

925 See infra, 239-41 and 257-60

${ }^{926}$ See infra, 209-26, esp. 215-8 and 223-4
} 
fact that we are not divine but composite beings. ${ }^{927}$ Both in Aristotle and in Galen the heavenly bodies serve as the embodiment of the divine par excellence, and in Galen black bile is the substance that is most opposed to the stars. In fact, it has the qualities of a star that has fallen to earth: it used to be hot, and therefore it is dry, but then it cooled down and therefore it blackened and now resembles thick earth. Galen links the very presence of residues such as black bile in our body to a necessary constraint presented to creative nature by matter. The fact of this matter implied certain drawbacks: it made it so that divine nature could not make us like the stars, as he remarks. ${ }^{928}$ That is to say, the fact that we are not capable of a divine life and are in a state of pain qua living beings - again, an idea that we previously found in Aristotle in the context of his discussion of melancholy ${ }^{929}$ - could be related in Galen to the fact that our matter determines that we cannot not be like the heavenly bodies. Indeed, this is what Galen says in UP:

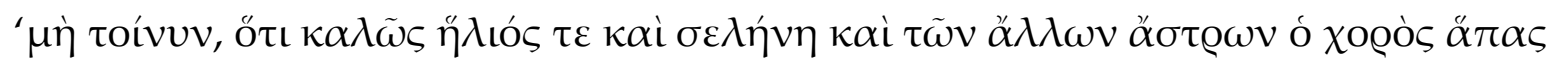

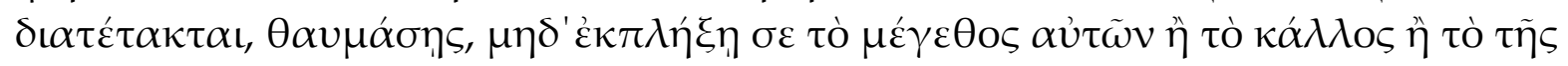

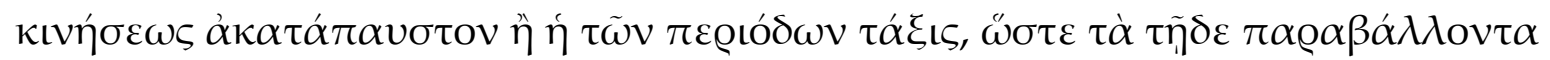

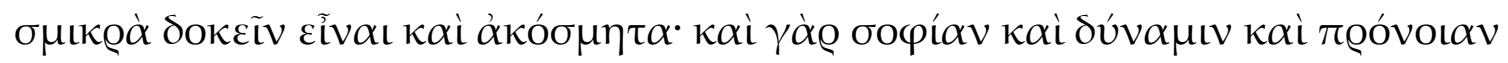

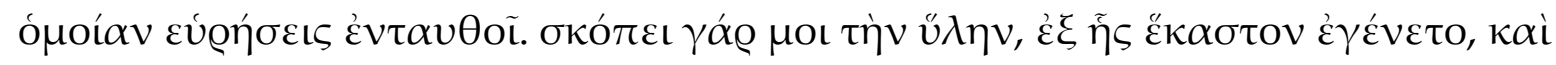

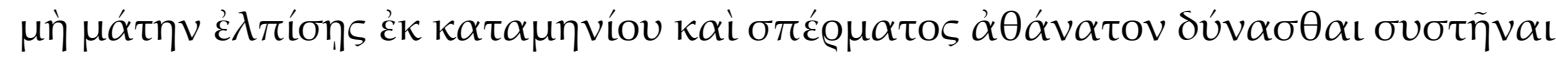

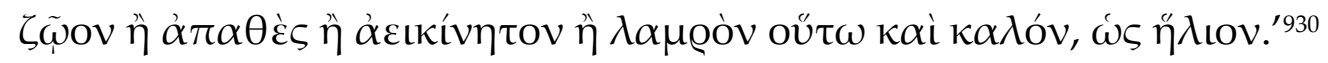

'Then do not wonder so greatly at the beautiful arrangement of the sun, moon, and the whole chorus of stars, and do not be so struck with amazement at the size of them, their beauty, ceaseless motion, and ordered revolutions that things here on earth will seem trivial and disorganized in comparison; for here too you wil find displayed the same wisdom, power, and foresight. Consider well the material of which a thing is made, and cherish no idle hope that you could put together from the catamenia and semen an animal that would be deathless, exempt from pain, endowed with never-ending motion, and as radiantly beautiful as the sun.' (tr. May)

Here, the limitations of the human being compared to the heavenly bodies are explained in terms of the stuff we are made of: blood and semen. From these materials nature can only create a being in need of nourishment, which suffers pain and death, a being which lacks the light of the heavenly bodies and their unceasing motion. Black bile is one of the necessary residues of this nourishment, and seems to embody this fact of human life with its particular characteristics. It is the most heavy and earthlike humour, the one most opposed to the the heavens; it is the darkest substance, lacking the light of the heavenly bodies more than anything else; it is the substance associated with death and mortality because of its qualities of coldness and

\footnotetext{
927 See infra, 212-4

${ }^{928}$ UP I 260,5-13 Helmreich (III $355 \mathrm{~K}$ )

${ }^{929}$ See infra, 212-4

${ }^{930}$ UP I 174,19-175,7 Helmreich (III $238 \mathrm{~K}$ )
} 
dryness; and it is the most obstinate and immovable of the humours (as we shall see below). ${ }^{931}$

Both in Aristotle and Galen man is understood as a being that is essentially imperfect in contrast to the divine, which, in turn, is embodied by the stars. Moreover, this imperfection is associated with the addition of 'another element', which the melancholics and the black bile seem to have a special relationship with, and which is rather opposed to the substance of the divine embodied in the heavenly bodies. ${ }^{932}$ Since we are not entirely divine, not of a star-like substance only, we suffer from the tension of being suspended between heaven and earth.

The transition from yellow bile to black bile, at the end of summer, embodies the course of this suspension, and gives its vertical hierarchy a place in the natural and regular passing of time. Therefore, this is also the time when blood, as the ideal mean, needs to be most absent. This transition from the predominance of a more heavenly substance to the predominance of the earthy black bile, happens in the time after which blood was predominant, and derails when blood recedes more and more. Then we come down, as it were, from resembling the substance of the stars closest when yellow bile is most predominant, being dry and hot, fiery and having our intellect at its peak, until we have reached the bottom of dark, cold, thick earth, risking sadness and despondency. According to the same analogy, black bile is

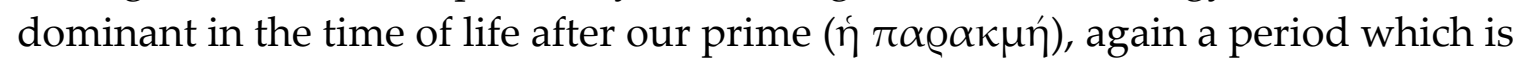
literally defined negatively with regard to the preceding period, which is also the best period. ${ }^{933}$ Black bile is the residue of our ceaseless but natural attempts to

\footnotetext{
${ }^{931}$ Cf. UP I 175,26-176,9 Helmreich (III 239-40 K), shortly after the passage just quoted, where Galen puts particular emphasis on the earthy nature of the human being as cause of its shortcomings compared to the heavenly bodies: 'Bear it in mind and reflect whether your substance is celestial light or slime of the earth, if you will permit to give such a name to the mother's blood flowing into the uterus. Then, just as you would never demand an ivory statue of Phidias if you had given him clay, so in the same way, when blood is the material you give, you would never obtain the bright and beautiful body of the sun or moon, for they are divine and celestial and we are mere figures of clay, but in both cases the art of the Creator is equally great.' (tr. May)

${ }^{932} \mathrm{Cf}$. for Aristotle Met $\Theta$ 1050b23-9: 'Hence the sun and stars and the whole visible heaven are always active ... Nor do the heavenly bodies tire in their activity; for motion does not imply for them, as it does for perishable beings, the potentiality for the opposite, which makes the continuity of the motion painful. The cause of this is that the substance is matter and potentiality, not actuality.' (tr. Tredennick, slightly modified); for Galen also UP I 260,5-13 Helmreich 'Surely if it had been possible, she would have arranged all these matters with no drawbacks at all, but as it is, since it is impossible with all her arts to avoid the inadequacies of her material and to make her creations of adamant, entirely invulnerable, it remains for her to arrange them as best as she can. Different materials admit of different arrangements; for certainly we are not made of the same substance as the stars.' (tr. May), cf. with UP II 446-7 Helmreich (IV 359 K): 'It is reasonable to suppose that the intelligence dwelling in them [the sun, the moon and the stars] is as much better and more perfect than that in earthly bodies as their bodily substance is the purer. For when in mud and slime, in marshes, and in rotting plants and fruits animals are engendered which yet bear a marvelous indication of the intelligence constructing them, what must we think of the bodies above?' (tr. May) Traditionally, this is not an unusual interpretation of the role of black bile and melancholy, as we find it, for example, in Burton's great Anatomy of Melancholy (143): 'Melancholy in this sense is the character of mortality. We are not here as those angels, celestial powers and bodies, sun and moon, to finish our course without all offence, with such constancy, to continue for so many ages...'. See also Pigeaud (1981) 125

${ }^{933}$ Hipp. Prog. XVIIIB 282,10-1 K, the stage of life which matches black bile is $\dot{\eta} \pi \alpha \rho \alpha \kappa \mu \eta$, the time after one's prime (the word also means decay); Temp. 641,4-8 K: 'It should not then be assumed that all hairy people are necessarily melancholic. This relationship only holds if the subject is at the stage after the prime of life, not in the prime of life itself, nor in old age.' (tr. Singer); Diff. Feb. VII 335,10-15 K
} 
approach the heavens, to soar up high towards the sun, since it is that part of the bile that persists after the fire that renders us intelligent periodically quenches. In this manner, the change of the seasons expresses in time a paradox (that of the suspension between heaven and earth) that is inherent to our constitution. ${ }^{934}$ Indeed, persistence is one of the major associations with black bile for Galen. This clearly correlates to the thick, sediment-like nature of its substance, as well as to its association with earth. But it also manifests itself in other ways, as we can see from some of the following quotations:

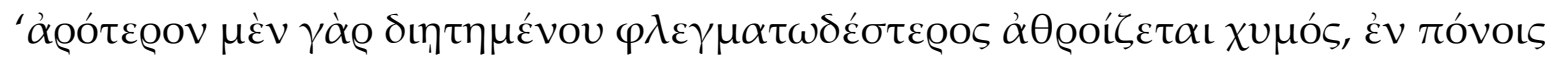

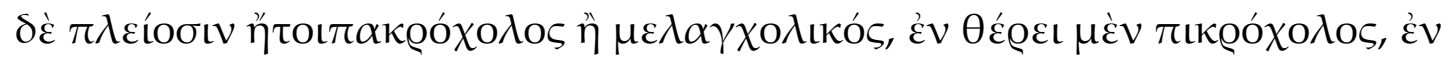

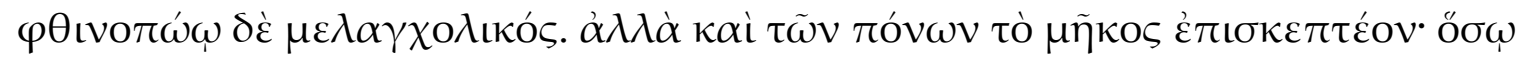

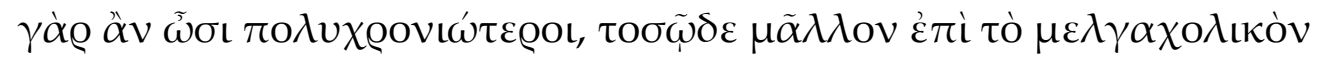

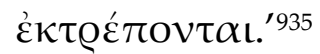

'When a person's life is quite idle, a more phlegmatic humor collects. In greater exertions, it is either picrocholic or melancholic - in summer, picrocholic and in autumn, melancholic. But one must also consider the length of the labours, for the longer they are in duration, the more the tendency is toward the melancholic.' (tr. Johnston)

The longer the length of labours, the more melancholic one becomes. Now, one might say: well, that is because endless labour is bound to make one sad, but I think the issue here is not so much about a relation between labour and a psychological state that is melancholic, but rather between lengthiness or perseverance and black bile. Black bile is ponderous and heavy, it stays the same for a long time, static and unmoved. We can see this also in the description of so-called quartan fevers that Galen quotes in his commentary on the Hippocratic On the Nature of Man (though Galen himself seems to not quite agree with it). These fevers last longest of all kinds, which is explained in terms of its subject having relatively less yellow and more black bile:

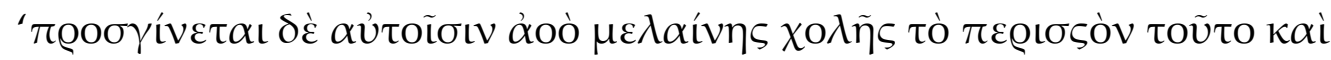

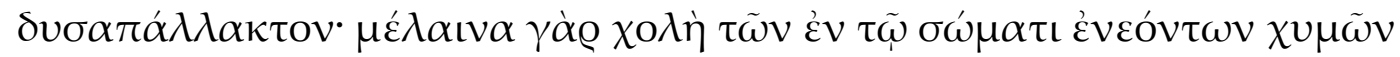

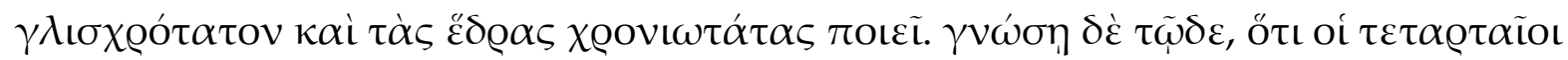

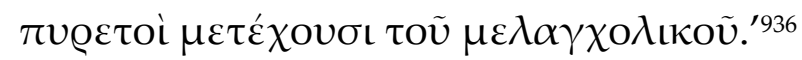

\footnotetext{
${ }^{934}$ In this regard, I do not agree with Klibansky et al (1964) 93: 'Nach der die 'thermodynamische Ambivalenz' nicht berücksichtigenden Qualitäten- und Elementenlehre ist die schwarze Galle auch weiterhin ein kalter, trockner und erdiger Stoff und nichts weiter.'

${ }^{935} \mathrm{San}$. Tu. VI $249-50 \mathrm{~K}$

${ }^{936}$ HNH 85,5-14 Mewaldt (XV 167 K); cf. Caus. Symp. VII 190 K; PHP 520,20-1 De Lacy; Cris. IX 659,7-13

K; Hipp. Epid. I XVIIA 115,2-4 K; we also find the association of excessive black bile with quartan fever later in Oribasius, see Fr 74 in Pormann's edition of Rufus (2008) and ar-Razi seems to ascribe it to Rufus as well (Fr 75, Pormann)
} 
'This excessiveness and tenacity in them derives from black bile. For black bile is the most viscous of the humours of the body, and the one which remains unmoved for the longest time. You will understand from the following that quartan fevers have a share of the melancholic.' (tr. Hankinson)

Black bile remains unmoved longest. Likewise, in Hipp. Elem., Galen says that black

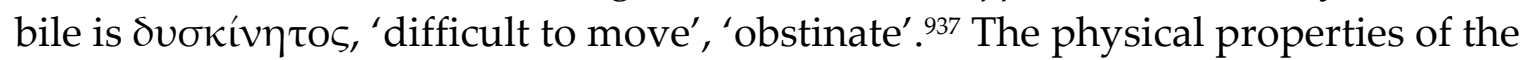
black bile itself are also translated into the psychological domain, where black bile is said to cause a kind of firmness or constancy of soul:

‘

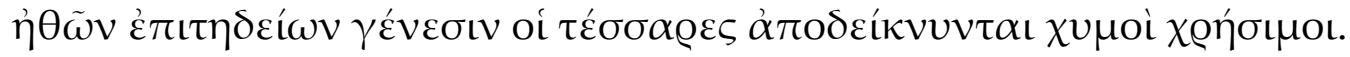

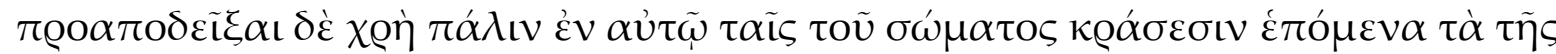

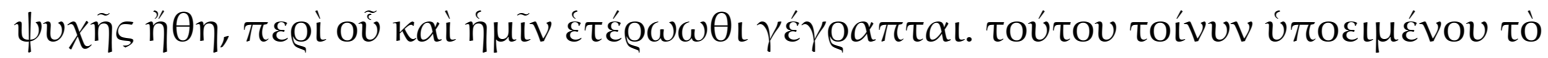

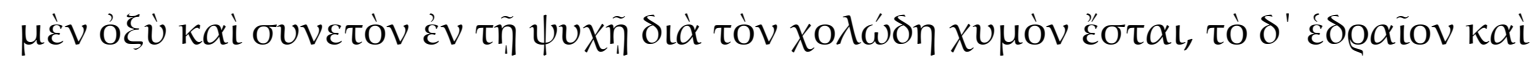

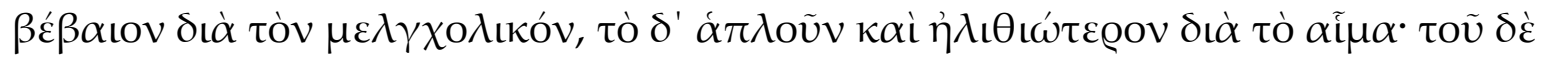

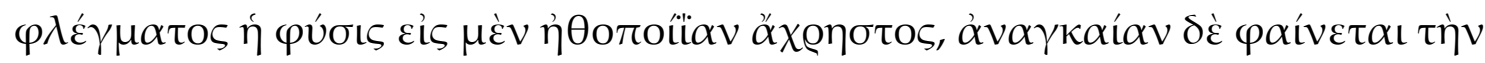

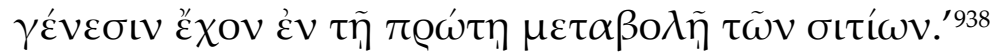

'There is also another physical account which has no little plausibility, according to which the four humours are proved to be effective in the generation of the states of character which are appropriate to them. In it we first need to establish that the states of character of the soul are consequent upon the mixtures of the body, about which we have written elsewhere. On this basis sharpness and intelligence in the soul will exist as a result of the bilious humour, steadfastness and firmness as a result of the melancholic, simplicity and artlessness as a result of the blood. The nature of phlegm is ineffective with regard to the prediction of character, having as it evidently does its necessary generation in the first alteration of the food.' (tr. Hankinson, slightly modified)

Galen describes each of the humours as the cause of certain psychic states, except for phlegm. The words he chooses to describe the states caused by black bile show an interesting resemblance with its physical associations. They both suggest a kind of stability, as of something that stays the same, which fits with the thick and earthy

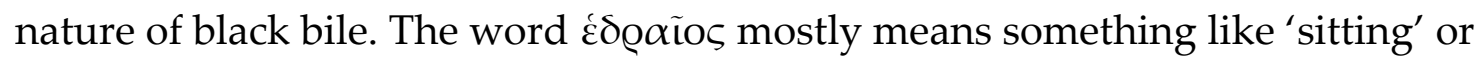
'sedentary'. It is also used for the horse-back on which a rider sits and can mean

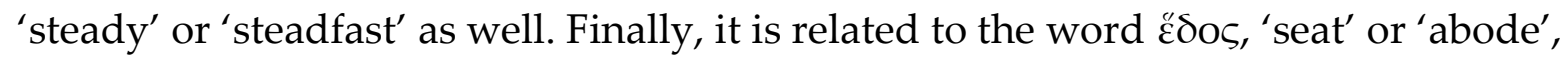
which is the regular epithet of Earth in Hesiod's Theogony ( $\varepsilon \delta \delta \varsigma \alpha \dot{\alpha} \sigma \varphi \alpha \lambda \dot{\varepsilon} \varsigma \alpha \dot{\varepsilon} \varepsilon$ í). ${ }^{939}$ Likewise, $\beta \varepsilon \dot{\beta} \alpha \iota$ เo means 'firm' or 'steady'. We also find both words together in Galen's commentary on the Epidemics, as adiectives with útvos to describe a very

\footnotetext{
${ }^{937}$ Hipp. Elem. 154,9 De Lacy (I 506 K); in Cris. IX 693,10 K, Galen qualifies the blood of the melancholic as

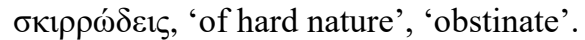

${ }^{938}$ HNH 51,9-18 Mewaldt (XV 97 K)

${ }^{939}$ Theogony 117, 128 ed. Most
} 
deep sleep. ${ }^{940}$ The description fits well with the notion that black bile is the part of bile that stays throughout summer and autumn, remaining after the hotness recedes, and with the notion that black bile is most difficult to purge. Yellow bile is said to be the cause of intelligence here, and of a 'sharpness' in the soul, which fits its light, thin, dry, hot and fiery nature that is more akin to the heavenly bodies, which are supremely intelligent. The description of blood is more remarkable, as it seems rather negatively to come down to simplicity or even a kind of foolishness of the soul. ${ }^{941} \mathrm{I}$ have not found any parallels for it in Galen, nor elsewhere in earlier authors. It seems likely that this description is based on the predominant wetness that is characteristic of blood. In $Q A M$ (to which the above passage quoted from $H N H$ refers), Galen is not as specific on the humours as he is in other works and is more focused on the role of the elemental qualities, but he does present wetness as the cause for a lack of intelligence, while dryness is presented as the cause for intellect. ${ }^{942} \mathrm{Blood}$ is one of the two wet humours. Moreover, since phlegm is left out of the picture in the passage cited from $H N H$, blood is the only wet humour in this schema, which would make it suitable to fulfil a role opposite to that of dry yellow bile as the cause of intelligence, black bile being the persisting residue of this yellow bile.

With this passage from $H N H$, however, we are already discussing the psychological rather than the physiological domain, which we might take as a testimony of how closely the two are interrelated when it comes to Galen's humoural theory in general and to black bile and melancholy in particular. But before we discuss this psychosomatic interrelation further, we shall discuss melancholy separately, to some extent, in he same way we discussed the black bile separately, and we shall briefly summarize our findings on black bile in Galen.

\section{Conclusion on black bile}

The ambiguity between black bile as an exceptional and unnatural substance that causes disease, and black bile as a regular part of our constitution, is not so much solved in Galen's work, as it is fully retained and embraced. Galen makes a rather consistent distinction between these two kinds of black bile. However, at the same time, as we have seen, the two have much in common, are often difficult to distinguish, and the one can alter into the other. So much so, that there is, according to Galen, no need to apply different names to them. We have seen how, in Galen's work, this enigmatic and many-headed black bile, which was previously mostly seen as a useless residue or as something which, as an altered form of a normal substance, caused disease, has now become firmly integrated into a fourfold schema of humours, elemental qualities, elements, seasons and phases of life. Within that schema, black bile has a place of its own, which makes it a part of our nature and the

\footnotetext{
${ }^{940}$ Hipp. Epid. VI XVIIB 175,3 K

${ }^{941}$ Hankinson, in a note to his translation also remarks that he is inclined to think a less negative characterization is intended by Galen.

${ }^{942}$ QAM 780-82 and $786 \mathrm{~K}$; see infra, CS III, sections 3 and 4
} 
grander order of things, while it remains, at the same time, a substance that forms a continous threat to that very order itself. The necessity of this threat is generated by another necessity: that of the restrictions that matter imposes on the creative capacity of nature. Given the qualities of this matter, we cannot be like the stars and need continuous nourishment in order for our ephemeral existence to continue. Black bile is the worst and most dangerous by-product of the process of digestion, which is aimed towards the production of a beneficial mean: blood. Not only is black bile opposed to our most well-tempered and beneficial substance, it is also opposed to yellow bile. Yellow bile is related to summer, fire, the heavens, an upward movement, activity and intelligence. Black bile is related to the end of summer, an extinguished fire, the earth, a heavy downwards movement, and static and obstinate passivity. In its opposition to blood, black bile is opposed to life, in its opposition to yellow bile, it is opposed to the stars and the divine.

It is necessary for us to produce such a substance, given what we are. We are not only living and not only divine after all, we are also mortal and of the earth.

Therefore, we cannot be without the substance of black bile, but we also need our spleen to continuously neutralize it, so that it will not take us over and weigh us down. In Galen, black bile is both opposed to our nature, as well as a necessary part of it. As such, it fits the general tendency in Greek philosophy to define the human being in terms of something that it is not completely, but only partly. The rational capacity for the perception of the eternal is what defines us most, and it is what we should actualize in order to fulfil our nature - in Galen just as well as in Plato ${ }^{943}-$ but this capacity is limited in two senses that are interrelated and of which black bile becomes the physiological paradigm in Galen: our mortality and our matter. With black bile, we mortal beings carry our own negation with us, as if the remnant of our own life is always already inside us. I think, from the perspective of the role black bile plays in Galen's cosmology, Burton was right to say melancholy is an expression of the sense of our mortality, and Diderot was right to say it is a sense of our own imperfections. ${ }^{944}$ But the association of mortality with earth and darkness is primordial, and was there before black bile became a regular part of our constitution in Galen's writings. From this perspective, I think Kudlien's suggestions still make sense, and Galen's definitive incorporation of black bile into our nature builds on a range of implicit associations with darkness, night, death, earth etc. ${ }^{945}$ Given the typically ancient Greek notion of man as a being suspended between earth and heaven, aspiring to the latter but tragically bound to the former, there should also be a dark, obstinate and detrimental substance inside our very bodies, a substance opposed to the vital juices that maintain us, mixed together with them. There should be something in us that is more threatening and destructive than blood, that useful

\footnotetext{
${ }^{943}$ Cf. e.g. Temp. I $565 \mathrm{~K}$ : 'The appropriate function of man, for example, is the peak of intelligence.' (tr. Singer)

${ }^{944}$ Burton (1621), 142: 'Melancholy in this sense is the character of mortality. We are not here as those angels, celestial powers and bodies, sun and moon, to finish our course without all offence, with such constancy, to continue for so many ages...' '; Diderot (1751-2) vol. XXI, 415: 'Mélancolie: C'est le sentiment habituel de notre imperfection.'

945 See infra, 206-9; Kudlien $(1967,1973)$
} 
and nourishing substance, and that weighs down the part of us that is fiery and tends upwards to the stars, the yellow bile. With this incorporation of black bile into the cosmological order of things and into our very body - the two form a continuum after all in Galen ${ }^{946}$ - the dangerous potency of black bile, and notably therefore also of melancholy itself, is normalized to a certain extent, incorporated into our nature despite its unnatural potency. We shall pursue this theme of normalization of black bile and melancholy in the next chapter, in which we shall focus on melancholy in Galen.

\section{Galen on melancholy}

While the subject of melancholy itself is largely absent from Galen's treatise on black bile, At. Bil., he devoted a few chapters to it in his Loc. Aff. In these chapters he discusses the three different types of melancholy and their respective causes, symptoms and treatment. ${ }^{947}$ The context in which he takes up the subject, is that of a discussion of the affections of the brain, and their distinction into affections that have their cause in the brain itself, and those that have their cause elsewhere but co-affect the brain:

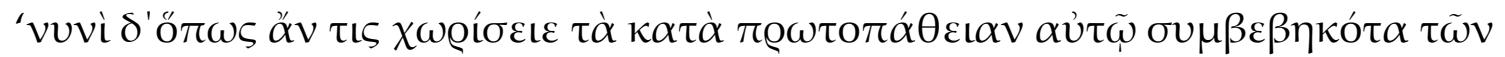

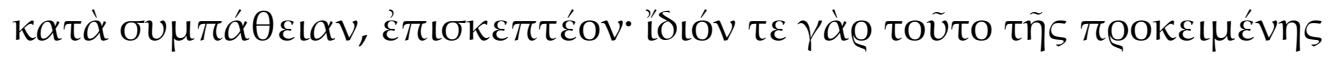

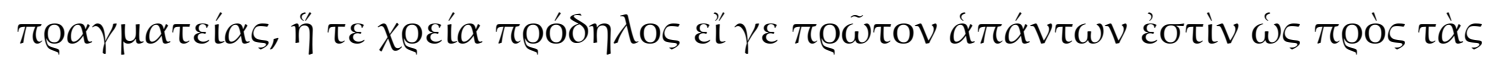

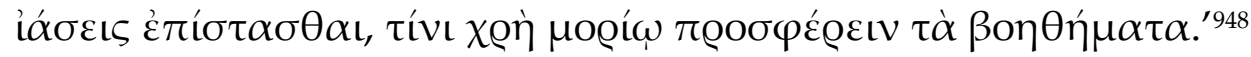

'We now have to examine how one can distinguish the things that befall the brain because of a primary affection from those caused by co-affection. This is the specific topic of the present treatise, which is evidently useful, since if indeed it is primary to all things to know about the therapies, it is necessary to know to which part to apply the remedies.'

This distinction runs throughout the work and will return in Galen's partition of the various kinds of melancholy as well. ${ }^{949}$ From book III, 6 onwards, Galen proceeds to discuss various affections of the brain in terms of the specific mixtures of elemental qualities that cause them. What this comes down to, is an analysis of the leading capacities of the rational soul, seated in the brain, in terms of relative wetness, dryness, coolness and hotness. For example, conditions of excessive drowsiness and sleepiness, such as lethargy, are caused by excessive coldness. ${ }^{950}$ On the other hand, 'the warm and biliary diseases' are said to cause a lack of sleep, delirium and

\footnotetext{
946 Cf. Holmes (2013) 163-4

${ }^{947}$ Chapters 9 and 10 of book III

${ }^{948}$ Loc. Aff. VIII $129 \mathrm{~K}$, cf. VIII $160 \mathrm{~K}$, where Galen refers back to this passage, shortly before the chapters on melancholy

${ }^{949}$ See also Loc. Aff. 30-1 K. Cf. Holmes (2013) for a seminal discussion of the notion of sympathy in Galen

${ }^{950}$ Loc. Aff. VIII 161-2 K
} 
phrenitis. In general, dryness and heat cause (over-)activity, whereas coldness and wetness cause inactivity of the soul. ${ }^{951}$ In this context, Galen also discusses memoryloss, which is always caused by an excessive coldness, accompanied by either a predominant dryness or a predominant wetness, or a mean with regard to those two. Galen proceeds to give a few examples:

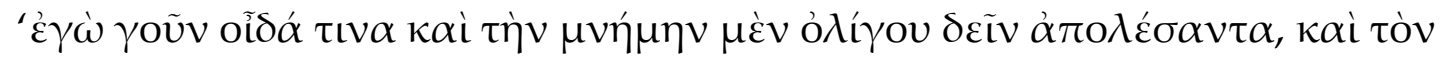

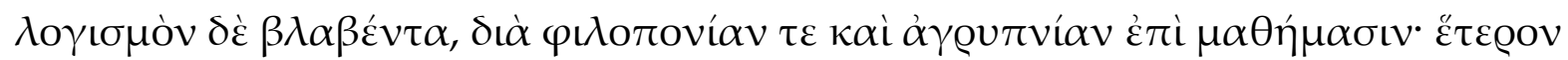

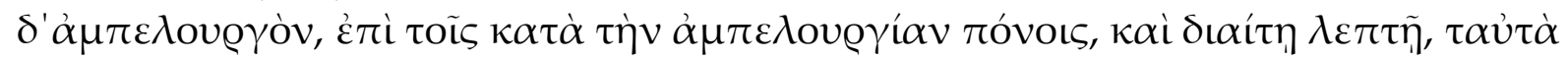

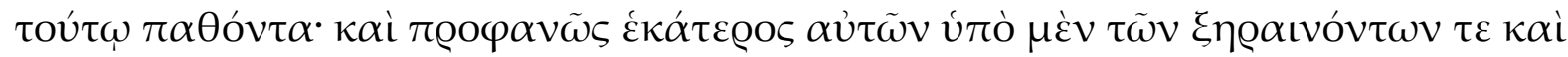

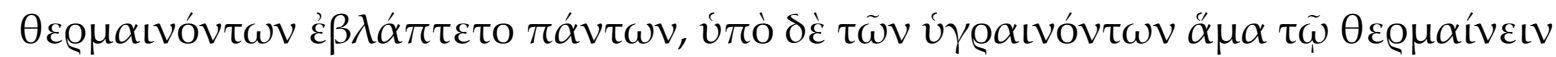

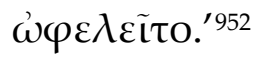

'I also knew a person whose memory was nearly lost and whose reasoning power was damaged because of his industriousness and sleeplessness due to his studies. Another person, a vinedresser, because of the labours involved with wine-dressing and because of his light diet, was affected in the same way as him. Both of them clearly were damaged by all things that dried and heated, but benefited from all things that moistened together with warming.'

I think here we have two examples of a condition in which the brain is heated and dried, as a result of which black bile is produced, that are by now familiar: the overactivity of the intellect caused by excessive thinking, which we know from Rufus, and the excessive labor that Galen identified as a cause of melancholy elsewhere (in this case perhaps particularly related not so much to the duration, but rather the circumstances of being out in the open field when it is hot and dry, and having an unsuitable diet for it). For these cases, obviously, drying and heating will not help, they are rather the cause of the affections. Moistening helps, as does warming. Why would warming help, given that the cause was excessive heat? It must be the case that by the time the affections have set in, that is to say, when the rational capacities get damaged, the mixture has cooled. Therefore, the mixture is cold and dry - as is black bile - and must be moistened and warmed, not coincidentally the two basic therapeutical strategies to cope with melancholy that Rufus proposes with regard to changing the mixture, and that Galen also refers to at the end of his treatment of melancholy in Loc. Aff. ${ }^{953}$ And indeed, in the sentences immediately following the passage quoted above, Galen makes the transition to familiar affections of the brain, including melancholy:

\footnotetext{
${ }^{951}$ See also Loc. Aff. VIII $131 \mathrm{~K}$ : 'Heat produces the activity which causes sleeplessness and delirium without fever. But the affections of somnolence, coma and unconsciousness are all an affect of cold... Substances which are cold cause numbness and loss of consciousness; warm drugs, in turn, cause a loss of sleep and increase of bodily movements.' (tr. Siegel)

${ }^{952}$ Loc. Aff. VIII 165-6 K

${ }^{953}$ Loc. Aff. 286 Van der Eijk and Pormann: 'I refer to friends who saw me treating such melancholy by means of baths and a moist, juicy diet, without any other remedy, when the harmful humour had not yet become difficult to remove as a result of lapse of time.' See infra, 220-1 for Rufus.
} 


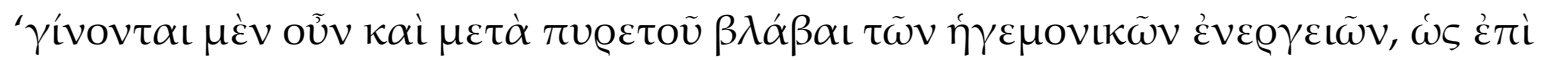

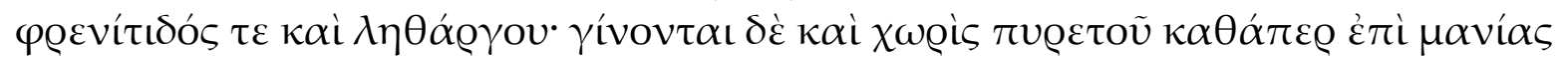

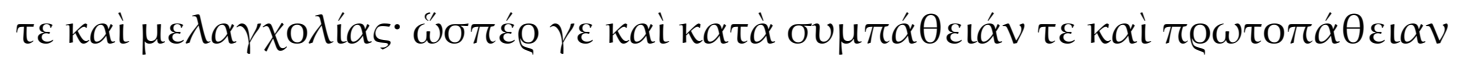
$\dot{\varepsilon} \gamma \kappa \varepsilon \varphi \varphi \alpha ́ \lambda o v .{ }^{\prime 954}$

'It also happens that the leading functions of the soul are damaged in fever, as during phrenitis and lethargos. This also occurs without fever, as in mania and melancholy; also by sympathy and by a primary affection of the brain.' (tr. Siegel)

Melancholy can have its cause in the brain itself or co-affect the brain while it has its origin somewhere else. In general, Galen sees the hypochondriac melancholy as having its primary cause in the organs concerned with digestion, co-affecting the brain. Throughout Loc. Aff., he uses the case of the rising of dark vapours from the stomach to the eyes and the brain, clouding them, as a paradigm-case of coaffection. ${ }^{955}$

When the cause is in the brain itself, Galen speaks of a primary affection $(\pi \varrho \omega \tau 0 \pi \dot{\alpha} \theta \varepsilon \iota \alpha)$, rather than a co-affection $(\sigma u \mu \tau \dot{\alpha} \theta \varepsilon \iota \alpha)$. The former can happen in two ways:

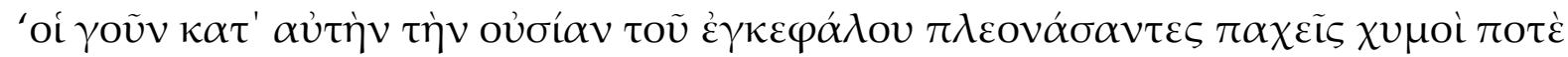

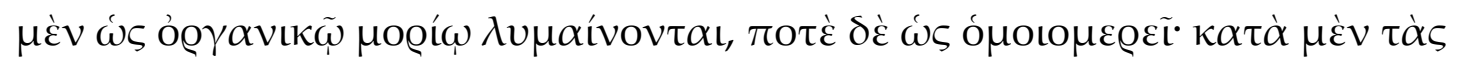

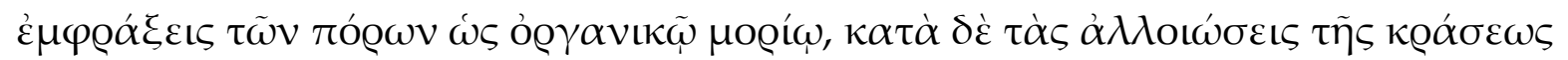

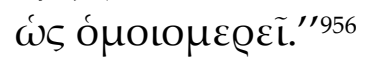

'For instance, thick humours that are present in excessive quantity in the very substance of the brain sometimes cause damage to it as an organic part, sometimes as to a homoeomerous part: in the form of obstruction of the blood vessels as to an organic part, in the form of qualitative change of the mixture as to a homoeomerous part.' (tr. Van der Eijk, slightly modified)

Corresponding to the general distinction Galen makes between homoemerous and organic parts of the body, there are also two general kinds of causes for melancholy arising from the brain itself. I am not sure what exactly the differences in symptoms would be for these two, if there are any. However, Galen does add that when the

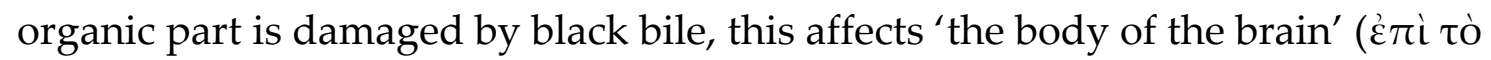

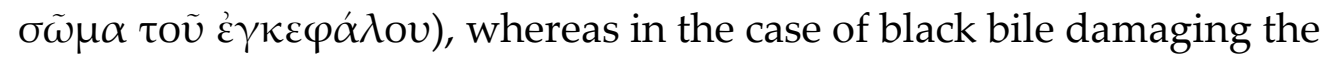

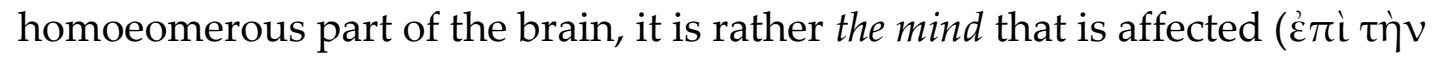

\footnotetext{
${ }^{954}$ Loc. Aff. VIII $166 \mathrm{~K}$

${ }^{955}$ Loc. Aff. VIII 44,13 f., 52,4 f., 137,12 f., $178 \mathrm{~K}$; melancholy as one of the paradigms for the brain being coaffected by the stomach also recurs in Caus. Symp. VII 128 K, 137 K and Const. Art. Med. I 282-3 K; cf. Holmes (2013), who describes how Galen's notion of sympathy in Loc. Aff. revolves around the connection of gut and brain, 168: 'It is probably no accident that in his opening remarks on sympathy in On the Affected Parts, Galen uses the example of noxious vapors or humors rising up from the stomach cavity to the brain. In his more detailed discussions, too, affections frequently migrate to the brain from the stomach or its mouth.'

${ }^{956}$ Loc. Aff 270 Van der Eijk and Pormann (VIII $180 \mathrm{~K}$ )
} 
$\delta\llcorner\alpha \operatorname{vos} \alpha v)$. This seems to suggest that the latter disturbs the rational capacities more directly or to a stronger extent; one might think of more intense delusions or despondency perhaps. ${ }^{957}$ Indeed, the case of generation of black bile in the brain itself, is further specificied by Galen as having its cause in an abundance of local heat, which burns either the yellow bile or the thicker and darker blood, causing it to become black bile. We have seen previously that Galen considers the black bile that is the result of burning as the most dangerous kind, that always leads to severe damage of the rational capacities. ${ }^{958}$ Thus, it seems that the case of the burning of yellow bile or blood in the brain itself is the most dangerous kind of melancholy, directly affecting the mind itself. ${ }^{959}$ The affection of the body of the brain in turn, seems to be further specified by Galen as caused by the melancholic humour flowing in from elsewhere. ${ }^{960}$ It seems that because of its relative thickness, when it flows into the brain, it affects the brain itself (which is why, presumably, it is a form of primary affection) by obstructing its bloodvessels.

Besides this melancholy that is the consequence of a primary affection of the brain and the hypochondriac kind, Galen distinguishes a third kind of melancholy:

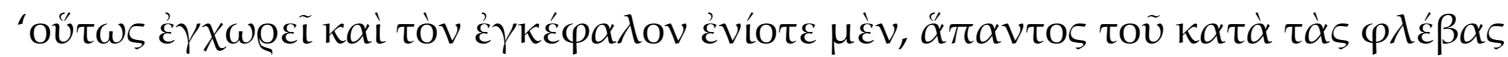

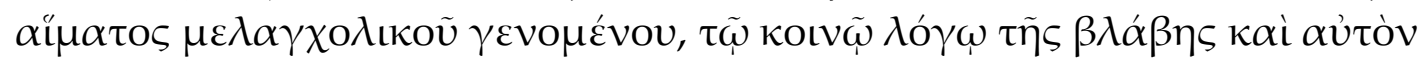
$\beta \lambda \alpha \beta \tilde{\eta} v \alpha$. $^{\prime} 961$

'In the same way sometimes, when all the blood in the blood vessels has become melancholic, the brain, too, can be damaged for the same reason as the rest of the body.' (tr. Van der Eijk)

Galen does not specify clearly whether he understands this kind of affection of the brain as a primary or sympathetic affection, but it seems to make more sense to regard it as sympathetic. After all, it seems that this melancholy arises when too much black bile is produced in general. This would require either a high production in the organs involved with digestion (either due to a natural constitution or due to a specific diet) or a high amount of alteration of other humours into black bile in the blood vessels. The latter can be caused by excessive heat. There are obviously important differences with regard to treatment: if the blood in the entire body is

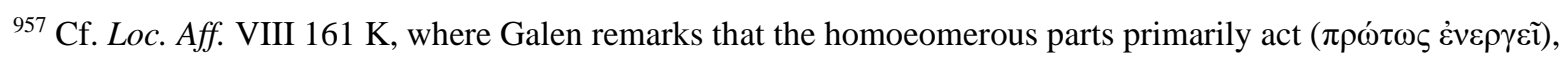
i.e. in this context: primarily perform the rational functions (see infra, CS I section 1, 27-35)

${ }^{958}$ Loc. Aff. 272 Van der Eijk and Pormann (VIII 182 K), but here I disagree with van der Eijk's translation, who

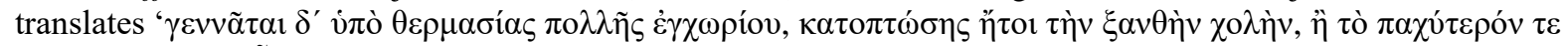

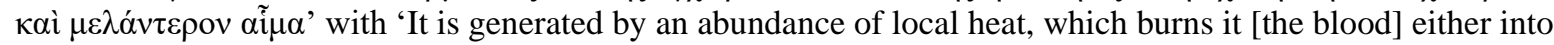
yellow bile or into thicker and darker blood.' I do not see why we would have to add an extra object (the blood), that is burned 'into' something, when we can also translate 'which burns either the yellow bile or the thicker and darker blood', which makes more sense given the other Galenic passages on the burning of yellow bile or blood as a cause for the generation of (dangerous) black bile and melancholy; cf. also Loc. Aff. VIII $193 \mathrm{~K}$, the last sentences of the chapter.

${ }^{959}$ In Hipp. Prorrh. XVI 544-5 and 553-4 K, Galen explains the ecstatic forms of melancholy also in terms of the burning of yellow bile

${ }^{960}$ Loc. Aff. 272 Van der Eijk and Pormann (VIII $182 \mathrm{~K}$ )

${ }^{961}$ Loc. Aff. 272 Van der Eijk and Pormann (VIII $181 \mathrm{~K}$ )
} 
melancholic, changes in diet are essential and bloodletting can be an efficient treatment. Thus, when a patient suffering from melancholy appears and one needs to determine whether it is a primary affection of their brain or whether it is caused by a generally high amount of the melancholic humour in all blood vessels, Galen advises first to check the patient's diet, to see whether they might have been consuming stuff that generates a more melancholic blood. ${ }^{962}$ Also, one can see from observing the features of the patient whether he or she is likely to naturally generate a relatively greater or lesser amount of black bile, which indicates that Galen also thinks there is a naturally melancholic type of person who is recognizable by his or her bodily features. ${ }^{963}$ In the former case, in which the diet is the cause, it might be more likely that the melancholy is caused by the amount of melancholic humour in all blood vessels (after all, in this case the problem must lie with the blood-production which results from the digestive system). In the latter, it might be more likely that something is up with the brain itself. That is to say, the melancholy might be 'hardwired' in the specific constitution of the patient's brain, rather than the result of specific alterations through diet or circumstances. People who are 'soft, pale and fat' have least of the melancholic humour, whereas people who are 'lean and darker and hirsute with protruding veins' are more likely to have much of it. ${ }^{964}$ These characteristics correspond largely to those given by Rufus (particularly the hairiness), and make sense from the perspective of the effects of black bile. There are often problems with digestion or an aversion to food as such, which makes it likely that those that produce much of it are thin. Moreover, the colour of black bile makes the skin darker and its thick nature makes the veins swell. But patients with fair complexion may appear as well, in which case it is likely that there is a 'psychological' cause:

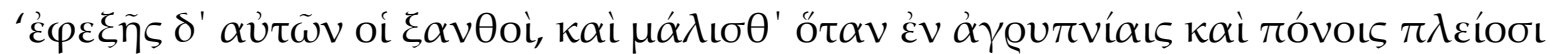

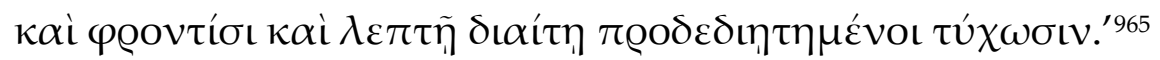

'Next to them are those who are of a fair complexion, especially when they suffer from sleeplessness and much labours and thinking, and when they happen to have had a very light regimen before.'

This translation is a modified version of that of van der Eijk, who has 'Next to them are those who are of a fair complexion, especially when they suffer from sleeplessness, profound tiredness and worries, and when they happen to have had a very light regimen.' oi $\xi \alpha v \theta$ oi must refer, for Galen, to people who have a relatively great amount of yellow bile. This corresponds to the sleeplessness, since yellow bile is considered by Galen to cause this, due to its heat. Tiredness would not add

\footnotetext{
962 Loc. Aff. 274 Van der Eijk and Pormann (VIII 182-4 K)

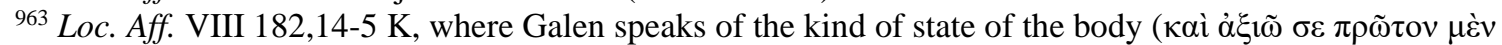

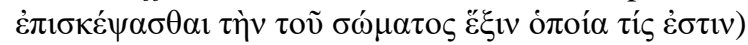

964 Translation van der Eijk (273)

${ }^{965}$ Loc. Aff. VIII 183,3-5
} 
anything to the symptom of sleeplessness, being already implied with it. The labours on the other hand, are a recurring theme in this context, as is the relation of melancholy with yellow bile and thinking as something that precedes it. The word

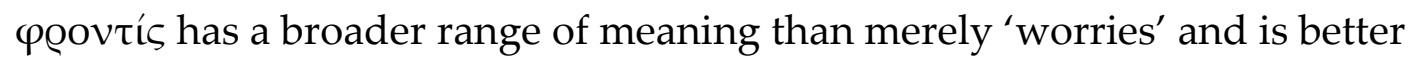
translated, in my view, with 'thinking'. 'Thinking' can both include worries and other thought-processes that are able to heat the brain, such as the aforementioned 'studies'. ${ }^{966}$ Both labours and thinking would have the potential to increase the heat in the brain, and thereby cause the yellow bile and blood to get burned, especially when they are pursued so excessively that one does not get a rest and is deprived of sleep. This potential would be enhanced when the patient is someone in whom yellow bile already predominates, which is indicated by the colour of the patient's skin, designated as $\xi \alpha v \theta$ ós. ${ }^{967}$ The lightness of the regimen indicates that the other possible cause, namely increased production of black bile because of some digestive problem or bad diet, is likely to be eliminated. As Galen remarks, if the patient has had a diet that produces good humours, 'you should examine his exercises and his

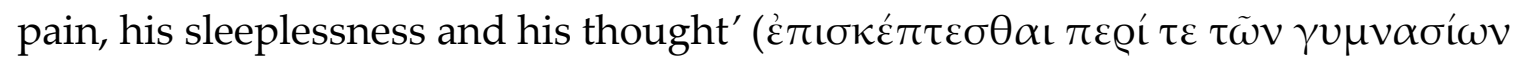

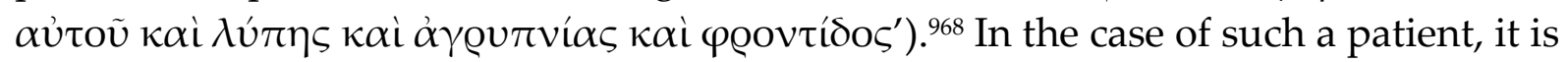
likely that the melancholy is caused by a primary affection of the brain due to excessive heat, rather than by the digestive organs through co-affection of the brain. Too much time spent out in the open field working in the sun, or too much activity of the brain without proper resting, rather than bad diet.

In other cases, the melancholy can also be caused by co-affection. Then, the primary cause lies outside the brain itself, more particularly: in the digestive organs. This is how Galen develops the hypochondriac type of melancholy, basing himelf on the account of Diocles of Carystus, a physician from the fourth century BC, who apparently enjoyed a great reputation in ancient times, and was even known as 'the younger Hippocrates' ${ }^{969}$ Diocles established the affection that Galen labels as the hypochondriac kind of melancholy as an affection that occurs in the belly due to problems with digestion, particularly due to an excess of heat in the blood vessels receiving the food from the stomach. What we know about Diocles' notion of melancholy, however, is mostly based on what we have through Galen. It seems at

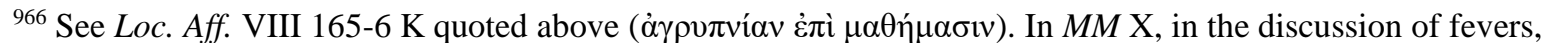
we frequently find a list to the one that recurs in Loc. Aff., but then as causes of fever, generally including also

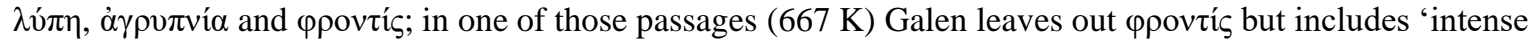

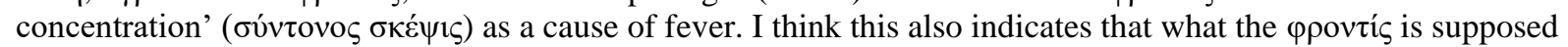
to refer to and what is presented by Galen as a potential cause of fever and melancholy, is something broader than 'anxiety' or 'worries', something more like an over-utilization of thought in general (as the 'studies' also testify), which leads to an overheating of the brain (in both cases baths and wine are among the most frequently mentioned remedies, i.e. remedies that counteract the excessive dryness of the patient, which is the result of the previous heating).

${ }^{967}$ It is certain that with oi $\xi \alpha v \tau$ oì Galen has in mind people in which yellow bile predominates, as he previously commented on people with a relatively dark or reddish constitution, which are the people in which black bile or blood respectively predominates, cf. San. Tu. VI 254,9-14 K, where we find the same descriptions.

${ }^{968}$ Here we find $\lambda v ́ \pi \eta$ in the place of $\pi$ óvos, as we do in another passage at the end of the chapter (VIII 193 K),

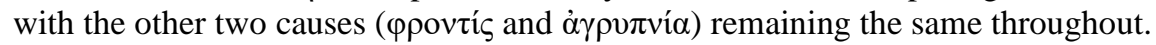

${ }^{969}$ Cf. van der Eijk (2001) vi for an introduction; see also Flashar (1966) $50 \mathrm{f}$.
} 
least very likely that his strong association of melancholy with digestion, and possibly also with disturbances of the psychic faculty when it gathers around the heart, has been a major influence on the Peripatetics. However, if we follow Galen's representation of Diocles (which might be dubitable), his analysis remains centred around problems with the stomach region, not taking the 'psychic' symptomatology of melancholy into account. ${ }^{970}$ As Galen remarks:

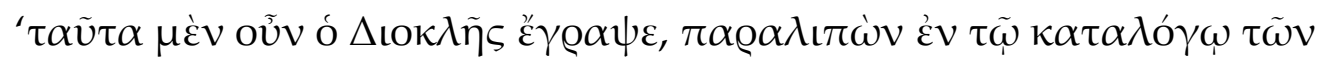

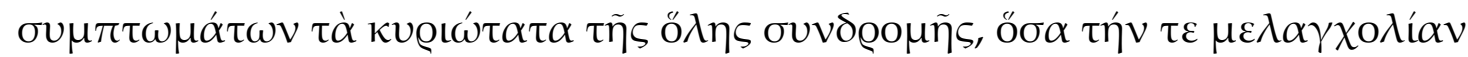

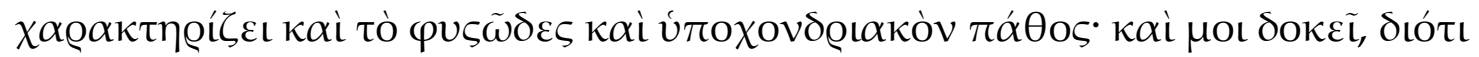

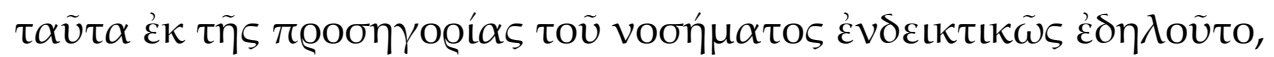

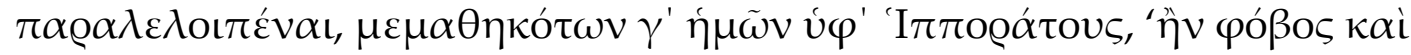

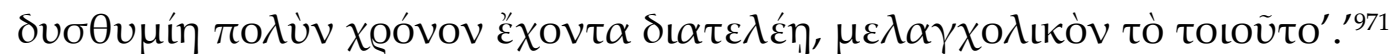
'This is what Diocles wrote, but in his list of symptoms he omitted the most important symptoms of this whole syndrome, which are characteristic of melancholy and of the flatulent and hypochondriac affection. Indeed I think that he has omitted them because they were made clear by indication from the name of the disease; at least we have learned from Hippocrates that 'if there is fear and depression which lasts for a long time, such a thing is melancholic'.' (tr. Van der Eijk)

Galen criticizes Diocles for having left out the two basic symptoms that were already described in the Hippocratic Corpus: fear and sadness. ${ }^{972}$ He suggests that Diocles failed to involve these basic symptoms in his discussion because he was unable to connect the cause in the stomach with damage to rational capacities. Galen, therefore, proceeds to add to Diocles' account a more elaborate description of how the hypochondriac melancholy damages the brain through co-affection:

‘

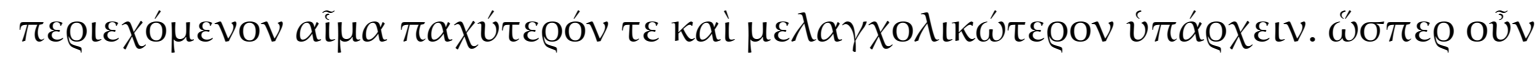

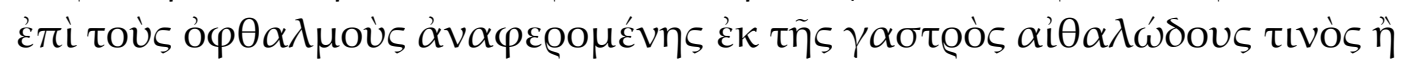

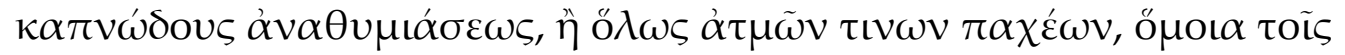

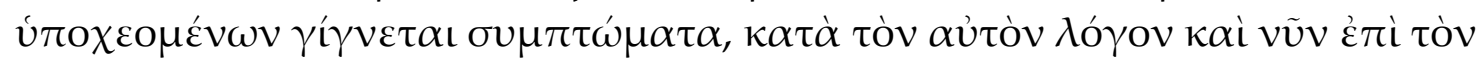

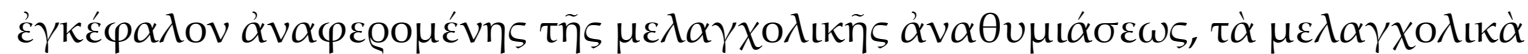

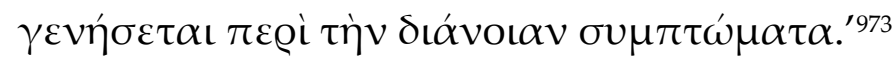

'It seems that there is a kind of inflammation present in the stomach, and the blood contained in the inflamed part is rather thick and melancholic. When a sooty or smoky vapour, or more generally thick vapours, rise from the stomach to the eyes, they give rise to symptoms similar to cataracts. Likewise here, too, and for the same

\footnotetext{
${ }^{970}$ For further discussion of Diocles see van der Eijk's commentary (2001) on fragment 109 particularly; Flashar (1966) $50 \mathrm{f}$.

${ }^{971}$ Loc. Aff. Van der Eijk and Pormann 280 (VIII 187-8 K)

972 Cf. Loc. Aff. VIII 342 and 378 K; Symp. Caus. VII 203 K; see infra, 204

${ }^{973}$ Loc. Aff. Van der Eijk and Pormann 282 (VIII 189 K)
} 
reason, when a melancholic evaporation rises upwards to the brain, like some kind of sooty or smoky vapour, the melancholic symptoms affect the thinking faculty.' (tr. Van der Eijk)

As Rufus already did before, Galen assumes a direct link between the stomach and the brain, explaining how problems with digestion can affect our rational capacities. ${ }^{974}$ What effects the link is a dark smoke, which clouds the brain and the eyes. Elsewhere in Loc. Aff., Galen compares the brain to the sun: as the sun shines its light upon all beings beneath it, so the brain emanates psychic pneuma upon the body beneath it. ${ }^{975}$ The sun, however, does not merely shine light: its warmth is nourishing and a condition for life to flourish. It is also described by Galen as preeminently intelligent and sending down its intelligence through the air. ${ }^{976}$ I think that in this case, too, the Republic of Plato, where the sun forms an analogy with the Good, is in the background. ${ }^{977}$ The dark vapours that cloud this sun, the radiant centre of intelligence, are caused by black bile, the earthy humour. Clearly, Galen here explains the psychological state of melancholy in terms of the qualities of the black bile, particularly its darkness. The dark vapours migrate upwards, from the lower part of our body that is involved with digestion, the primary locus of our mortality and the place where our continuous need for nourishment primarily manifests itself. This hypochondriac melancholy is a case of our most ephemeral aspect affecting our most divine aspect by darkening it. Apparently, Galen also proposes that these dark vapours cause the excessive fear of melancholics (in the case of the hypochondriac kind), which manifests itself in various imaginations. One of those imaginations is reminiscent of the earthen vessel Rufus mentioned: some think they are a piece of pottery and avoid people approaching them for fear of being broken. Clearly, this imagination is related to the symptom of social anxiety as well as to the earthy nature of black bile. Again, this is a case in which the elemental qualities of the substance of black bile serve to explain the psychological state of melancholy. Another patient would imitate a cock, flapping his arms and imitating its sounds. We may interpret this as an attempt to ward off the inner darkness, since cocks, as heralds of the day,

\footnotetext{
${ }^{974}$ See infra, 220-1 for Rufus

${ }^{975}$ Loc. Aff. VIII 66-7 K; cf. Holmes (2013) 167

${ }^{976}$ UP II 446-7 Helmreich (IV $359 \mathrm{~K}$ ): 'But even here some intelligence appears to be reaching us from the bodies above, and the beauty of their substance forces anyone that sees them to be amazed at once, that of the sun first and foremost, that of the moon after that, and next that of the stars, and it is reasonable to suppose that the intelligence that dwells in them is exactly that much better and sharper than that in the earthly bodies as the substance of their body is purer. For when in mud and slime, in marshes, and in rotting plants and fruits animals are engendered which yet bear a marvelous indication of the intelligence constructing them, what must we think of the bodies above? But you can see the nature of the intelligence in man himself when you consider Plato, Aristotle, Hipparchus, Archimedes and many others like them. When a surpassing intelligence comes into being in such slime - for what else would one call a thing composed of fleshes, blood, phlegm, and yellow and black bile? - how great must we consider the pre-eminence of the intelligence in the sun, moon, and stars?' (tr. May) ${ }^{977}$ In another sense, the Republic is in the background as well, cf. Holmes (2013) 171: 'Of course, a scenario where the desiring part gains the upper hand over the rational soul is precisely the definition of psychic disease in Plato's Republic... Galen's very anatomical precision in locating the brain as the 'ruling part' of the self means that when things go wrong, it is more firmly subordinated to the forces of the physiological body, especially the digestive body.'
} 
are strongly related to the light of the sun. However, there may also be other archetypical associations or a relation to the cock offered to Asclepius for healing. It seems clear, though, that the imaginations Galen sums up are not random and have a connection with the substance that causes them. Indeed, yet another patient believes that Atlas would grow tired of holding the heavens and would let himself and all people along with him be crushed by dropping them. ${ }^{978}$ The heavens coming down upon the earth is a wonderful and interesting image for an ancient melancholic to have. It fits well with the cosmological place of black bile as the humour associated with earth and death, as well as with its opposition to yellow bile as the humour associated with fire and the heavens. Since Atlas is a symbol of order, as his single duty and meaning is to keep earth and heaven in their rightful place, the idea of him becoming weary and abandoning his duty means a collapse of the order of things as such. This apocalyptic image shows an interesting resemblance to (and in fact does not seem to me much different in nature from) the image depicted in Lars von Trier's Melancholia, in which it is another planet ('Melancholia') that hits and destroys the earth. In the movie, the apocalyptic collision functions as a kind of grandiose cinematic enactment of the ultimate fantasy of its depressed protagonist, Justine, much in the same way as one could imagine a reverie of total collapse depicted by Atlas dropping the heavens in the mind of an ancient Greek melancholic.

After the description of the various imaginations, Galen proceeds to describe some general symptoms of melancholics, which seem to apply to all three of the kinds that he had previously distinguished. ${ }^{979}$ He repeats the main symptoms of fear and despondency, saying that it was correct that Hippocrates reduced the symptomatology to these two. He also mentions that melancholics 'find fault with

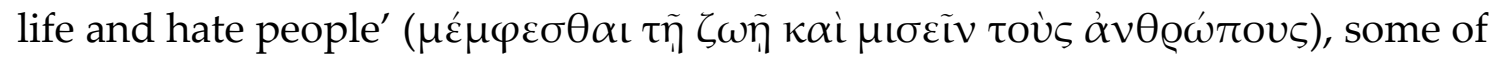
them wanting to die. ${ }^{980}$ These symptoms also correspond to both previous and later tradition as main symptoms of melancholy. Finding fault with life also fits well with the opposition of black bile to blood, the most useful and beneficial of the humours that is closest to our nature, as well as with the association of black bile with death. This is another way in which the qualities of the respective substances correlate with the psychological state. Indeed, Galen never ceases to explain the symptoms of melancholy in terms of the properties of the black bile:

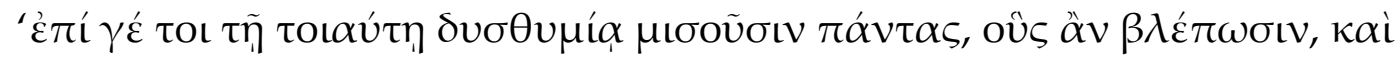

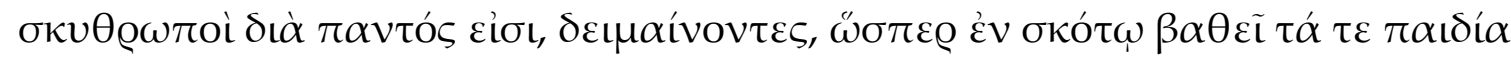

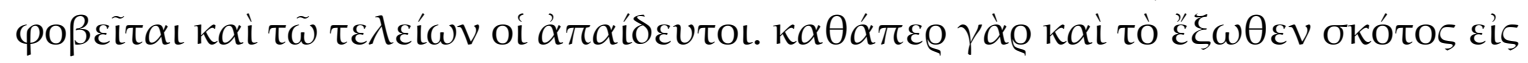

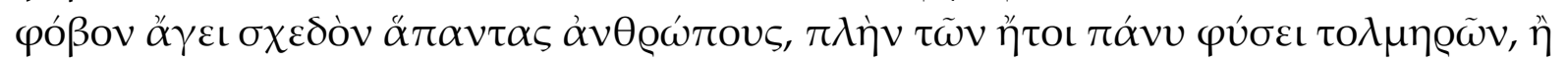

\footnotetext{
${ }^{978}$ Cf. Hipp. Epid. I XVIIA 213,12-214,2 K

${ }^{979}$ I think I do not agree with Flashar (1966) 105, that Galen depicts the three kinds as 'drei Stadien im Ablauf ein und desselben Krankheitsbildes', since Galen maintains the distinction between the melancholy that has its origin in the brain itself and one that can co-affect the brain until the end of the chapter.

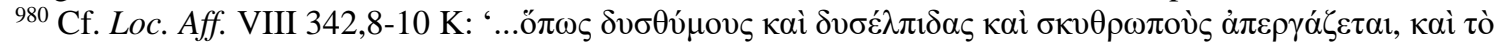

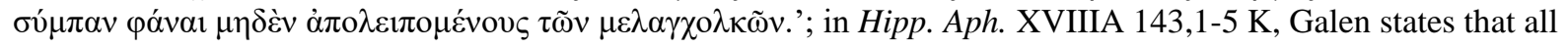
Greeks agree that these are the main symptoms.
} 


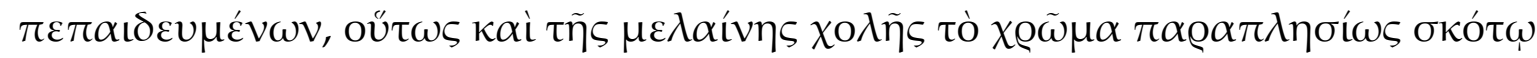

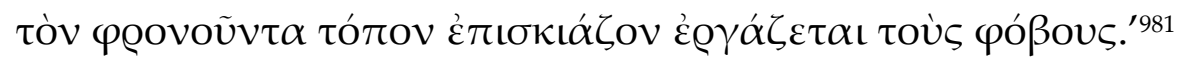

'In the case of such despondency, they hate all people they see, they are shy and afraid, just as children and uneducated adults are afraid in the dark. For just as darkness outside causes fear in all people, except in those who are excessively audacious or well educated, likewise the colour of the black bile very similarly casts a shadow over the place where thinking is located, and produces fears.' (tr. Van der Eijk)

After this passage, Galen directly adds a reference to $Q A M$ for proof that the mixtures of the body alter the activities and affections of the soul. This indicates that we ought to take this passage quite literally: it is the qualities of the black bile itself, more particularly its darkness, that cause the fear of the melancholic. This passage is in fact highly interesting for several reasons. First of all, the darkness of black bile and melancholy is considered as analogous to the external darkness of night. This should not surprise us, given that black bile is the opposite of the heavenly bodies, which provide light, and given that it is the humour associated with earth and death. However, Galen also adds that everybody is afraid of this dark, except for people that are either exceptionally audacious by nature or people that are 'well-educated' $(\pi \varepsilon \pi \alpha \mathrm{L} \delta \varepsilon v \mu \varepsilon \dot{v} \omega \omega v)$. This means that the melancholic's fear is now compared to the fear that most people have when they are in the dark. Importantly, this amounts to a certain normalization of melancholy, because it makes the melancholic's inner experience accessible to some extent: we can all relate to it, since we have all been afraid of the dark at some point. Only those who are exceptionally courageous are naturally exempted from this experience, the others will have to apparently become educated in order to overcome their fear of darkness. Why would Galen have this emphasis on education here all of a sudden? I think that this must be an implicit reference to Plato's cave metaphor, which might have already entered the mind of those readers versed in Plato through Galen's repeated use of nouns and verbs referring to shadows in this passage. Galen, of course, knew Plato's work intimately and the Republic was certainly among the dialogues he worked on. ${ }^{982}$ In the Republic, the ascent from the shadowy, dark cave towards the world of light serves as a metaphor for an educative programme that consists in a turning of the soul from the world of becoming towards the Good. Education ( $\pi \alpha$ เ $\delta \varepsilon i \alpha)$ is defined as this very turning. Does Galen, then, suggest with his metaphor of outside and inside darkness that there is a possibility for the melancholics to free themselves of their inner

\footnotetext{
${ }^{981}$ Loc. Aff. 284 Van der Eijk and Pormann (III 190-1 K)

${ }^{982}$ Cf. Lib. Prop. XIII (XIX 47,18 K), where Galen states that he wrote 'eight volumes of summary of Plato's dialogues'. Cf. Arnzen (2012) 194 for references in the Arabic tradition that prove that the Republic was among those. The one summary that we still have (in Arabic), that of the Timaeus, shows that 'summary' might be a bit

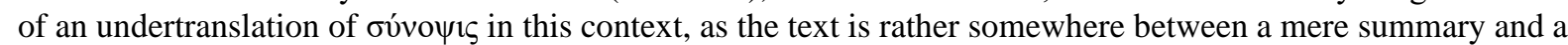
commentary, with interpretative or even suggestive readings that are strongly motivated by Galen's own framework. See also Das and Koetschet (forthcoming) on Galen's synopsis of the Timaeus; see infra, CS III section 2
} 
shadows through education? - in the same way as we can overcome our fear of the darkness of night by learning that there is no monster lurking under the bed? This might be a tempting reading, but it is perhaps too far-fetched, as we would otherwise expect to see something of this possibility in Galen's discussion of possible therapies for melancholy, which we do not. A slightly more careful reading may be, perhaps, that in the same manner as educated people are not afraid of the outside darkness, since they know there is nothing fearsome in the darkness as such, melancholics would be in a better position to cope with their fear and sadness when they know their own affliction and its causes. This is an idea that lies at the very heart of many forms of therapy. On the other hand, Galen clearly gives a physiological explanation of melancholy here: it is because of the darkness of the black bile that the melancholic experiences fear. Thus, it would seem that any kind of alleviation of the fear would have to involve taking away some of that actual inner darkness, i.e. some of the black bile. It is noteworthy that Galen suggests that the cause for melancholy is in the end physiological: it is because of the darkness of the substance that is black bile, that fear and sadness necessarily overcome those in whom it becomes predominant.

Elsewhere, Galen claims that he does not know why we are brought into a state of melancholy when black bile builds up in the brain, but here he seems to hint at an answer at least. ${ }^{983}$

We find the same analogy between the internal darkness of melancholy and the external darkness of night in On the Causes of Symptoms. In chapter II.5, Galen also remarks that, although the particular imaginations of the melancholic differ per individual, they share the fear and despondency in common. ${ }^{984}$ He then says that it is not surprising that fear, depression, and a presentiment of death manifest themselves when black bile takes a hold of the principle of the rational soul:

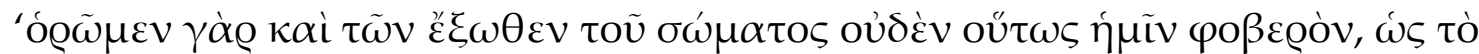

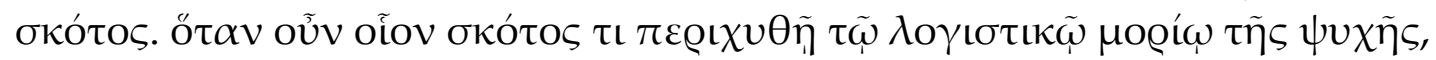

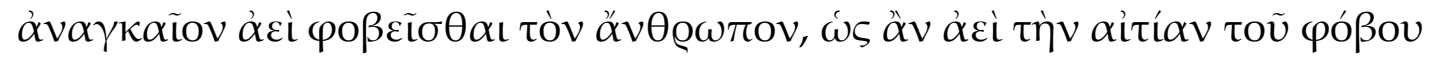

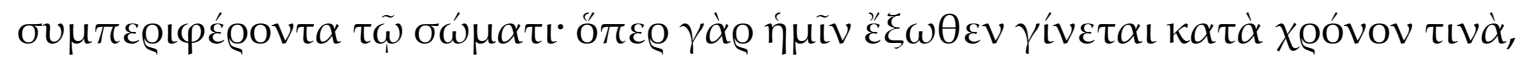

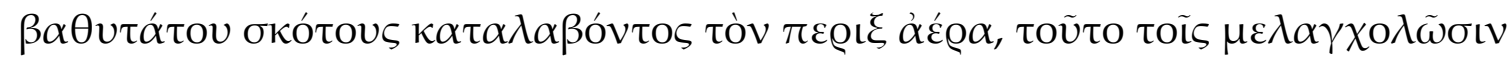

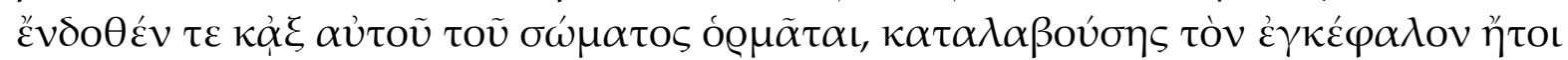

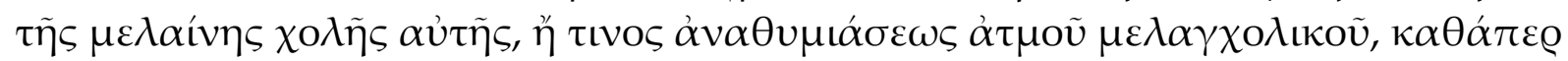

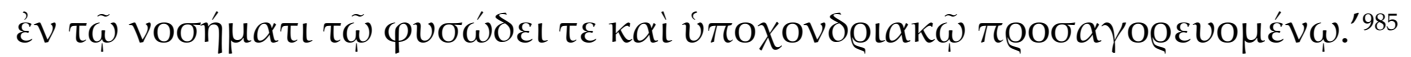

'For we see also that of the things outside the body nothing is so frightening to us as the darkness. So whenever such a darkness envelops the rational part of the soul, it is necessary that the human being is always afraid, as he would always carry around within his body the cause of his fear. For the exact same thing that happens to us from outside during a particular moment, when the deepest darkness has taken hold of the surrounding air, this happens from the inside with those who are melancholic

\footnotetext{
${ }^{983}$ QAM IV 777,2 K, the context is particularly about the relation between the rational soul and the brain. 984 Symp. Caus. VII 202-3 K, here Galen also cites the Hippocratic Aphorisms VI,23, as he did in Loc. Aff. 985 Symp. Caus. VII 203,11-204,4 K; this passage is paraphrased in Aëtius' De Melancholia VI 56 K f.
} 
and it has its point of departure from their very own body, since either the black bile itself takes hold of the brain or some rising melancholic vapour does so, as in the case of the disease that is called flatulent or hypochondriac.' ${ }^{986}$

Again, it is worth noting how relatable the experience of the melancholic is: just think of a moment when the deepest darkness of night made you afraid, and now simply think of continuously having this experience of fear. From this perspective, we could speculate more on how Galen sees the experience of the melancholic. What do we see when we fearfully look into the depths of night? In a sense we could say that we see nothing, or perhaps rather that we experience the absence of the possibility of seeing and thereby of recognizing and attributing meaning to the things seen. This unfamiliarity has the potential for as many horrors as our imagination allows. But in the end, I would say, the horror is mostly in the unspecified darkness itself, rather than in any of the specific potential dangers it might be hiding. Here, the duration of this experience becomes particularly important: if one is temporarily enveloped by nocturnal darkness as a child, for example, one can run home towards the light and the familiar. In the worst case, one knows at least that the darkness is temporary and something one can get away from. In the case of the melancholic, however, there is no escaping this darkness, because the darkness is in one's very own body and will be taken along wherever one goes. We may infer that, after some time, the melancholic arrives at a poignant sense of the fact that he sees nothing but darkness, resulting in the impossibility to make sense of things and the terrifying awareness that he is, for an undetermined amount of time, unable to make sense of things for a reason unknown. In this respect, it is noteworthy that Galen says that it is necessary that someone who carries this darkness around in themselves are always afraid. Regardless of other circumstances, the person in such a state will be afraid. Since there is no specific object for this fear, nothing in specific that one is fearful of, it is just the darkness in the brain itself that is the cause. To some extent, this is equally true in the metaphor, which is therefore quite apt: when confronted with the darkness of night, one can become afraid without having a particular image or notion of what it is that one is afraid of. What distinguishes the melancholic fear and despondency from a non-pathological fear and despondency is the lack of a proper cause:

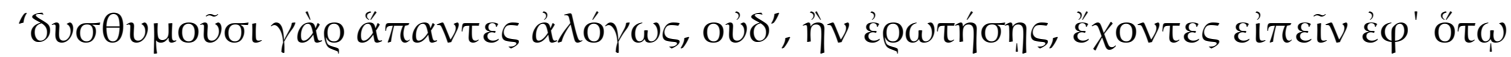

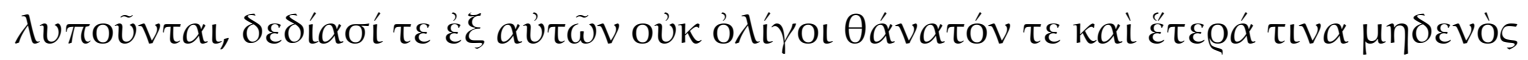

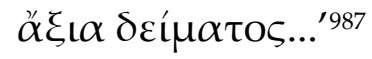

'For they are all despondent without reason, nor, were you to ask, would they be able to say because of what they are sad, and many of them fear death and some other thing that is not worthy of fear.' (tr. Johnston, modified)

\footnotetext{
986 This translation departs from that of Johston but is heavily modified

987 Symp. Caus. VII 203,4-7 K
} 
The despondency and sadness of the melancholics is $\alpha \lambda$ ó $\gamma \omega \varsigma$. That is to say, not merely 'absurd' or 'unreasonable' and therefore to be derided, but without ground or reason altogether. They would not be able to tell you why they are so sad. ${ }^{988}$ With regard to the fear, as we have seen, the imagination plays its part. It channels the fear, which is always there because the black bile clouds the brain with its darkness, towards some definite object, preferably the abstract object of the end of life as such. The imaginative presence of the end of life as such seems to be a most logical consequence of an excess of black bile, considering the characteristics of the substance itself. But the idea that there is no reason or cause for the fear and sadness also points beyond any particular imagination to the presence of something that is simply darkness.

The idea of a fear or sadness without cause becomes an important part of the symptomatology of melancholy in the later tradition, with Freud still using it as the defining characteristic that distinguishes melancholy from mourning in his famous 1917 essay Trauer und Melancholie. The basic idea is simple: affections such as fear, sadness and despondency are familiar to us all and are not pathological, as long as we can give an account of them. If I am sad because a loved one has just passed, or if I feel fear because I am about to go to war, no one will diagnose me as ill because of that. But if I display the same symptoms while no one has died or while there is no war to be afraid of, something is off and my sadness and fear can now be considered pathological. This is the case with the melancholics, who are simply sad and fearful, without themselves even knowing why. There is a trace of this notion of the lack of cause as a defining characteristic of the melancholic also in one of Rufus' fragments: 'A sign of incipient melancholy is the craving to want to be alone and stay away from all other people, without any visible need or cause for it, of the kind that the healthy can sometimes have, because they love research or want to keep undisclosed what must remain secret. ${ }^{\prime 989}$ Here, too, the difference between the melancholic and someone that displays relatively normal behaviour - incidentally again partly exemplified by someone that 'loves research' - is considered to lay in the lack of cause or reason. The researcher and the one bearing secrets have reasons to shun company, which is why it is not so worrying that they do so. ${ }^{990}$

There is another passage in which this lack of reason comes to the fore, in book VI of Loc. Aff., in the context of afflictions that are the result of abstinence from sex. Galen

\footnotetext{
${ }^{988}$ Cf. Kristeva (1989): 'Their sadness would be rather the most archaic expression of an unsymbolizable, unnameable narcissistic wound, so precocious that no outside agent (subject or agent) can be used as a referent... In such a case, suicide is not a disguised act of war but a merging with sadness and, beyond it, with that impossible love, never reached, always elsewhere, such as the promises of nothingness, of death.'

${ }^{989}$ Fr 14,1 (translation Pormann); cf. Celsus De Medicina III, 18, 22: 'Interest etiam, ipse sine causa subinde rideat, an maestus demissusque sit...'

990 This is also what the story of the exchange between Democritus and Hippocrates in the Pseudo-Hippocratic Letters (10-17, ed. Smith 1990) shows. The Abderites took Democritus to have gone mad and called in Hippocrates, because they did not understand the true reason for his isolation and the other melancholic symptoms he manifested. Upon learning from Democritus that he is actually researching the bile itself, Hippocrates declares him sane and adds that it is rather his fellow Abderites whose judgement is clouded. Cf. Pigeaud (1981) 452 f.
} 
mentions people who become 'heavy in the head, nauseated and feverish'

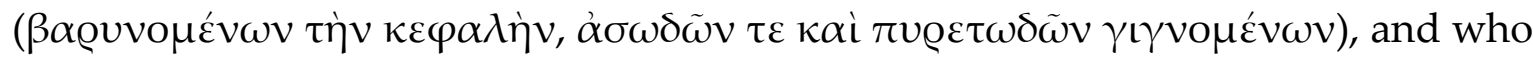
suffer from 'poor appetite and bad digestion' ( $\chi \varepsilon \tilde{i} \varrho 0 \nu$ ỏ $\pi \varepsilon \tau \tau o ́ v \tau \omega v)$ when they do not have sex on a regular basis. Then, he draws a comparison with melancholics:

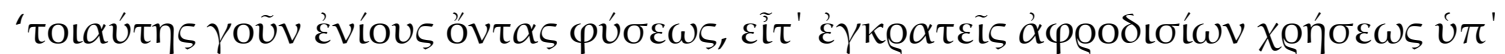

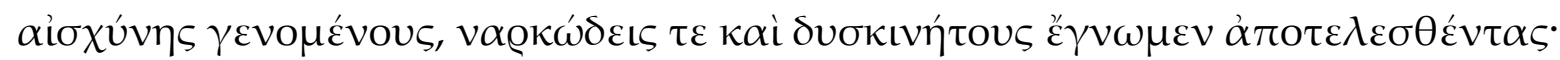

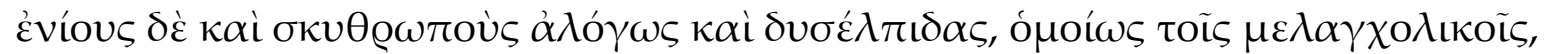

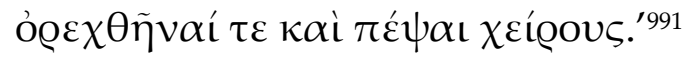

'I knew some persons of similar nature, who consequently controlled their need for sex out of shame, and ended up becoming sluggish and inactive. Some others became gloomy and despondent without reason, like melancholics, becoming worse with regard to appetite and digestion.'

The symptoms of the people from the former category, sluggishness and inactivity

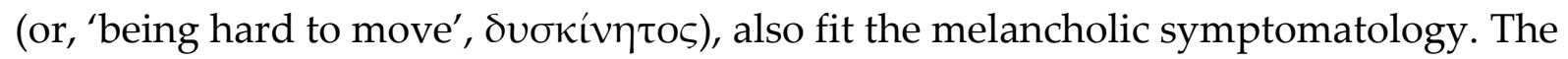
connection with melancholic symptoms and an excessive need for sex was already made in the Peripatetic tradition, as we have seen, and also by Rufus, who advised sex as a remedy for melancholy. ${ }^{992}$ Loss of appetite or aversion to food as well as bad digestion are also standard symptoms we found in Aristotle and Rufus. ${ }^{993}$ But the focus of the comparison with the melancholics in this passage from Galen is on the sadness and the despondency without reason. Likewise, in his work Fulness, Galen singles out the gloominess and sadness without cause as the defining characteristic of those in whom black bile predominates, whereas those in whom bile in general predominates rather display the symptom of sleeplessness. ${ }^{994}$

With the black bile itself, however, as we saw from the metaphor of internal and external darkness, this cause has to some extent been given. There is still no particular reason for the fear or the sadness, but it does have a manifest physiological cause. Moreover, the substance causing the fear and sadness is in itself something that naturally belongs to us as a part of our constitution. In this manner, the incorporation of black bile into our nature, allows for a physiological account of something that essentially resists being explained in terms of a reasonable account. On the other hand, the causation seems to also work the other way around. Similar to what we previously noted in Rufus, Galen also indicates that melancholy can be caused or aggreviated by its own symptoms. ${ }^{995}$ At the very end of his discussion of melancholy in Loc. Aff., he repeats that the melancholy of the brain can follow upon

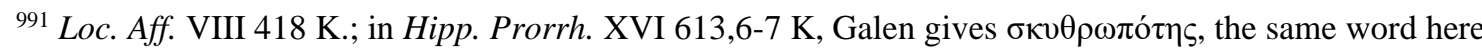
translated as 'gloomy', as the indication that someone is becoming more melancholic

${ }^{992}$ See infra, 212-3, 216-8, 224. For Rufus see Fr 58, Fr 59 and Fr 73 Pormann.

${ }^{993}$ See infra, 209-10 and 220-1

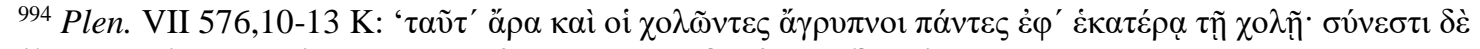

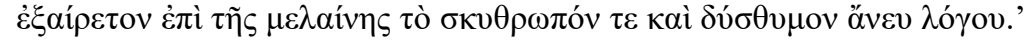

${ }^{995}$ See infra, 224-5
} 
or come to be because of ( $\left.\dot{\pi} \tau \boldsymbol{\jmath} \gamma^{\prime} v \varepsilon \tau \alpha \mathrm{l}\right)$ a hot condition in the head, but can also follow

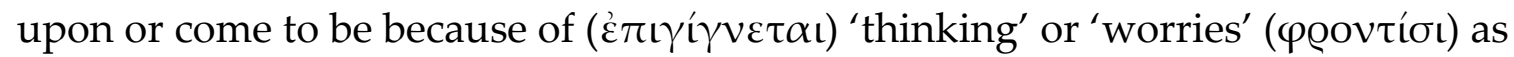
well as 'grief combined with sleeplessness' ( $\lambda \dot{\tau} \pi \alpha \iota \varsigma \mu \varepsilon \tau$ ' $\dot{\alpha} \gamma \varrho v \pi v \imath \tilde{\omega} \nu) .{ }^{996}$ So, is the idea, then, that both 'physiological' and 'psychic' phenomena can cause melancholy? Perhaps the idea is rather the same as in the passage from Rufus we discussed earlier ${ }^{997}$ : the physiological state of the brain causes excessive thinking or worrying, as well as trouble with sleeping and sadness. This in turn causes a condition that makes the brain more liable to melancholy. The language Galen uses here,

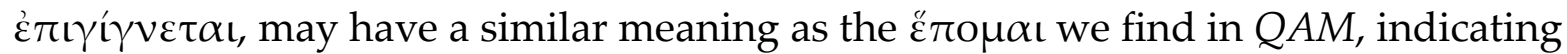
that a particular symptom or affection necessarily follows from something. In $Q A M$, Galen names melancholy as one of the examples of a case in which the soul is overpowered by the ills of the body ${ }^{\prime 998}$, which puts the causal power completely with bodily factors rather than psychic ones. Here we need to also keep in mind, I think, that Galen repeatedly refers to $Q A M$ in the context of his discussion of melancholy in Loc. Aff. ${ }^{999}$ If we would like to conclude this question of the psycho-somatic nature of melancholy in one particular direction, we would merely need to realize that one cannot be thinking or waking - let alone excessively - or for that matter undertake any other kind of activity, without there being a correlating (or perhaps even more primary) alteration in our physiological constitution, i.e. our mixture. In this manner, we are able to understand how Galen could say that grief or thinking has the potential to cause melancholy, while he could, at the same time, maintain that melancholy has its cause in a change of mixture. Moreover, if we pay attention to the way Galen explains the fear and sadness of the melancholic, namely in terms of the actual qualities of the black bile, we notice that, at least in this case, Galen attempts a physiological explanation of a complex mental phenomenon. Apparently, the grief, the thinking, and the labours Galen mentions as possible causes of a patient's melancholy, should not be understood in terms of their content. It is not because the patient has 'bad thoughts' or has been working a shitty job, that he is now melancholic, for these would clearly be reasons to be sad. Rather, it is because of an excess of thinking or working that in some homoeomerous bodies in his brain the predominance of humours has shifted from yellow bile and blood to black bile. This alteration causes a darkness in his mind, which causes him to be sad and fearful without there being an actual reason for it. Following this line of explanation, it seems that education cannot not really be the solution. Rather, one needs to trace the physiological development of a patient, partly through analysis of his activities some of which particularly have a tendency to produce black bile - and consequently give advice on diet and activities of such a kind that alter the patient's mixture for the better, i.e. that reduce the amount of black bile. Galen's therapeutical advice for dealing with melancholics seems to entirely follow this direction.

\footnotetext{
996 Loc. Aff. VIII $193 \mathrm{~K}$

${ }^{997}$ See infra, 224-5

${ }^{998}$ QAM IV 788,11-3 K

${ }^{999}$ Loc. Aff. VIII 181 and $191 \mathrm{~K}$
} 
But what is most important, perhaps, is that with his strong emphasis on melancholy's physiological manifestation, Galen drew the external darkness of night into our own body. This allows not so much for an understanding of the cause of melancholy, as rather for an incorporation of our lack of understanding for it. In this way, we can understand melancholy as being caused simply by the limitations that necessarily accompany our being and its fulfilment. It is the incorporation of a residue, of something that we do not understand, something that we cannot see, but that is nonetheless necessary. Here, however, gradation is essential. It is all well and fine to have some black bile inside of us, and Galen himself does like to remind us that we cannot be of the substance of the stars - we have to remember that we are made of earth as well. But when the black bile predominates and takes over, when one becomes melancholic, the healthy perspective on our limitations, on our mortality and imperfection, changes to a perspective of darkness, of mere negation itself. What we see when we are melancholic is the darkness that is the negation of everything we are. After all, it is the darkness of the black bile itself that is clouding our view, and we have seen how this substance is opposed to life and opposed to the divine. As long as it is carefully managed and there is a proper mixture with the other humours, seems to be the idea, we can surely be melancholically aware of our mortality and imperfections, while in the meantime we can admire the stars and enjoy life. No wonder there must be a balance between the humours!

\section{Conclusion on black bile and melancholy}

Some of the ambiguity which belongs to the substance of black bile in Galen, we find also in his notion of melancholy. Black bile is a normal part of our constitution, but is potentially dangerous and fatal in some of the forms it can assume. Likewise, the symptoms of melancholy can vary from suicidal desire to a sadness or grief that can be counteracted by the daily consumption of moderate amounts of wine.

Furthermore, the experience of the melancholic is comparable to the experience ordinary people can have when confronted with external darkness. It is different mainly in duration, since the melancholic continuously carries the darkness in his own brain. The empirical ambiguity of black bile is also paralleled in melancholy: the cause of fear or sadness is unclear, because there is no object to which the fear and sadness relate, there is just the darkness itself. Both black bile and melancholy have a privative or negative quality about them, as we have seen, that supervenes on primordial notions of darkness, night, death, and earth as opposed to the heavens. These associations are reflected in the qualities of black bile: it is dry, cold, quenched, earthy, heavy, difficult to move, and dark. These qualities of black bile, particularly its darkness, are used by Galen to account for the sadness and fear of melancholics, which do not have any reason but are simply caused by the predominance of the physical substance of the black bile itself. This shows that Galen attempts to account 
for a complex phenomenon such as melancholy in terms of the specific qualities of the bodily substance that is its cause. Thereby, we find that Galen's notion of the nature of man as he elaborates it in $Q A M$ and $H N H$ does not merely remain a speculative or abstract notion, but finds practical application in his treatment of a specific affliction within his work. Vice versa, we could also say that this particular notion of the nature of man is based upon Galen's more empirical work with a particular affliction of the mind such as melancholy.

The fact that the main symptoms of melancholy are symptoms that ordinary people also display to some extent or in certain situations, allows for a certain normalization of melancholy. ${ }^{1000}$ The black bile turned out to be normal, as long as we habitually dispose of it, though it always maintains a potential for harm. Perhaps, we could say that, in light of Galen's integration of black bile into the nature of man and the cosmological order, and in light of his increased normalization of melancholy, the same could be said about melancholy as well: it is normal, as long as we habitually dispose of it.

\footnotetext{
${ }^{1000}$ Klibansky et al (1964) consider this the reason why a melancholic type could be established, 54: 'Gerade die Ambiguität psychischer Symptome machte nämlich die Grenzen zwischen Krankheit und Normalität unscharf und erzwang die Anerkennung eines Habitus, der melancholisch war, ohne da $\beta$ sein Träger in jedem Augenblick als wirklich Kranker angesprochen werden konnte.'
} 


\section{Conclusion}

In this section I first summarize the conclusions of the individual case-studies and the way they relate to previous scholarship. Secondly, I reflect on the way these individual conclusions are connected, and the extent to which they allow for a more general conclusion on the subjects of human nature and the soul in Galen.

\section{Case-Study I}

In Case-Study I, I have undertaken a close-reading of key-passages from QAM. In this work, Galen not only argues for the central thesis that the capacities of the soul follow the mixtures of the body, but also presents the stronger thesis that the substance of the soul is a bodily mixture. In previous scholarship, this stronger thesis has often been found problematic. It has been considered to be radical and at odds with Galen's agnosticism on the substance of the soul in some of his other works. Scholars such as Garcia-Ballester, Lloyd, Donini, and Singer, have proposed solutions to this problem. They hold either that Galen does not argue for the stronger thesis, but merely presents what he considers the consequences of an Aristotelian position, or that Galen is merely out to further the prestige of the doctor in $Q A M .{ }^{1001}$ However, our text-analysis has shown that Galen builds on his own work for the stronger thesis, and that the extent to which $Q A M$ is congruent with both previous and later works of Galen has been underestimated. This case-study builds on the work of Vegetti and Tieleman, who have interpreted $Q A M$ as a continuation of Galen's work in PHP, and it also makes extensive use of Hankinson's various articles on the soul in Galen. ${ }^{1002}$

In PHP, Galen argues for the tripartition and trilocation of the soul, maintaining that the soul consists of three substances (ov'oí $\alpha \iota$ ) that each have a specific location in liver, heart, and brain, respectively. What these substances are, exactly, is something that remains unclear. This is the more speculative question that $Q A M$ takes up, as a work 'on Platonic philosophy'.

On the basis of his physiology of the human body, as we find it in works such as Hipp. Elem., Nat. Fac., Temp., UP, and others, Galen works out a definition of the soul as the form of a homoeomerous body. These homoeomerous bodies are the 'perceptible elements', as Galen calls them, because they are the most elemental bodies, and cannot be further divided in parts that differ in form. They can only be analysed, conceptually, in terms of form and matter, form being a specific mixture of the four elemental qualities, and matter being without quality as such. In this casestudy, I have shown that Galen understands these homoeomerous bodies as primarily active. Therefore, he locates soul, as form of the body, at the level of these homoeomerous bodies rather than at the level of the organs, which are more complex unities consisting of several homoeomerous bodies. There are three axiomas involved in this definition of the soul, so I have argued. First, Galen assumes, with

${ }^{1001}$ Garcia-Ballester (1988); Lloyd (1988); Donini (2008); Singer (2013)

1002 Vegetti (2000); Tieleman (2003); Hankinson (1991, 1993, 2006, 2014, 2014a) 
the Peripatetic tradition, that soul is form of the body. Second, he assumes, with Plato and his own Platonic-Hippocratic theory developed in PHP, the tripartition and trilocation of the soul in liver, heart, and brain. Third, he assumes, as he does in his more systematic physiological work such as Hipp. Elem., that the most elemental constitutive level of a given being determines its nature and substance, and must, therefore, be considered as the cause of its activities. I have shown that all three of these axiomas have a firm basis in the Galenic corpus. Combined, they lead Galen to the conclusion that the soul must be the specific mixture of elemental qualities of the homoeomerous bodies that are primarily active within the liver, heart, and brain. This conclusion profits from the ambiguity of the word ov $\sigma i \alpha$, that can both mean 'what something essentially is', as well as 'the stuff of something'. Galen's conception of the soul in $Q A M$ conflates these two meanings.

Through close-reading of the text and analysis of its structure, I have demonstrated that, contrary to what previous scholarship has argued, Galen argues for the truth of the stronger thesis that the substance of the soul is a mixture. He does so, first, by presenting a dilemma - the rational soul is either mortal and, therefore, a mixture, or it is immortal and capable of existing separately from the body - and by subsequently arguing against the side of the dilemma that is contrary to his own position. Second, he presents the position of Andronicus the Peripatetic - that the substance of the soul is either a mixture or a capacity dependent on the mixture - as the culmination of his argument. He subscribes to the first part of this position, that the substance of the soul is a mixture, and disapproves of the second option, that it is rather a capacity dependent on the mixture. The latter option is at odds with Galen's definitions of substance, capacity, and activity, as I have shown. Capacities, for Galen, are mere tools of appellation. We ascribe capacities to a specific substance as the cause for its activities when we do not have sufficient knowledge of the substance itself. It is always the substance itself, for Galen, that is the cause of its activities. Therefore, soul, as cause of activity and principle of movement, must be the mixture that is primarily active, rather than a capacity that we attribute to this mixture upon seeing the activities it causes.

However, I have also provided two important caveats with my conclusion that Galen, in $Q A M$, argues that the substance of the soul is a mixture.

First, he treats the substance of the rational soul separately from the other two parts. There is good reason for this. Galen discusses the first two parts in the context of an interaction with Peripatetic doctrine. This allows him to establish his hylomorphic framework, in which soul is defined as the form of the body. When he proceeds to discuss the rational soul, in the context of an argument against Platonists who hold that the rational soul is immortal and capable of existing separately from the body, the hylomorphic definition of the soul is already in place and put next to the Platonic definition as a more viable alternative. However, this is not the only reason that the rational soul required a separate analysis. Galen also argues that the substance of the rational soul potentially has some resemblance to the substance of the heavenly bodies, which he considers to be divine and supremely intelligent. The substance of 
these heavenly bodies is extremely dry, and dryness is defined as the cause of intelligence by Galen. Wetness, on the other hand, causes mindlessness and forgetting. Because the substance of newborns is predominantly wet, the rational soul acquires its strength only later, when the substance has dried up more. This seemingly extravagant idea, too, has a basis in other Galenic works such as UP, as I have demonstrated. I have argued that Galen's opposition of dryness and wetness, and their respective role with regard to intelligence, is an attempt to account for the activity of the rational soul in terms of mixture. The heavenly bodies, however, are not only supremely intelligent, but also infuse the realm below them with their intelligence. They exercise a forming and ordering influence. Galen understands the rational part of the soul, analogously, as a substance capable of exercising a forming influence over the rest of the body. This is why, so I have argued, Galen's position is not a completely deterministic position. In $Q A M$, he rather presents an ethical programme in which the human being, by virtue of its rationality, can take it upon itself to form its own mixture. I proposed that this formation should be understood as the continuation of the initial formation by divine nature. This ethical component is an important aspect of $Q A M$. At the start of the treatise, Galen presents the central thesis that the capacities of the soul follow the mixtures of the body, as not only true, but also beneficial 'for those who wish to improve their souls'. The ethical debate that any physicalist account of the soul is likely to spark, recurs several times in QAM through a polemic with the Stoics. Galen presents the Stoics as holding the view that everyone is naturally capable of virtue. In this polemic, the limits of Galen's proposed ethical programme become clearly delineated. I have argued that the capacity of the rational soul to take on the project of self-ameliorization through alteration of one's mixture, is itself dependent on the mixture that is already there at any given time, and that has initially been formed by nature. Moreover, as Galen states on the basis of his observation of small children: there are extremely few people who are naturally suited to take on this project. Therefore, the answer to the question whether people are completely ruled by their naturally given mixture or whether they are rather free to choose their activities, depends on which people we are talking about. This is, clearly, a kind of elitist ethics, but Galen does not seem to be bothered by that as much as we tend to be.

The second caveat concerns the epistemological status that Galen ascribes to his stronger thesis. Building on previous work on the notion of 'the plausible' in Galen ${ }^{1003}$, I have argued that, through comparison with several other works, notably HNH and Prop. Plac., we can infer that Galen considers the stronger thesis to be a plausible theory, rather than one that is scientifically proven. This is an important distinction for Galen, and he claims in Prop. Plac. that his work has often been misunderstood because its intended epistemological status is not correctly appreciated. I have argued that Galen's agnosticism with regard to the substance of the soul is compatible with his adherence to the strong thesis of $Q A M$, as long as we

${ }^{1003}$ Frede (2003); Chiaradonna (2014); Tieleman (2018) 
understand the relation between the two from the perspective of this important distinction in epistemological status. In $Q A M$, I proposed, Galen works out what he sees as a plausible position on the question of the substance of the soul, without claiming scientific proof for it. He considers this position as the best speculative option, as it is best able to do justice to what he sees as the empirical facts. This also explains the congruence of $Q A M$ with the rest of Galen's work. The strong thesis of $Q A M$ is in fact based on Galen's other work, namely, it speculatively draws out the most plausible philosophical consequences of it, without attributing to these consequences the same epistemological status as the basis from which they depart. Compared to previous scholarship, the first case-study provides an innovative reading of $Q A M$ that is better able to make sense of it from the perspective of the rest of Galen's work. Moreover, through its emphasis on the epistemological status of the stronger thesis, it avoids previous problems of contradiction with other Galenic works. Finally, it proves that Galen considered the thesis that the substance of the soul is a mixture as a plausible one, and it shows that this thesis is to a great extent in agreement with, and builds on, previous Galenic work.

\section{Case-Study II}

In Case-Study II, I have provided an analysis of Galen's commentary on the Hippocratic On the Nature of Man. In this relatively understudied text, Galen works out his notion of nature in a more systematic manner than anywhere else. The nature Galen is concerned with here is a common nature of everything. He defines nature as the primary, hylomorphic substance underlying everything that is subject to generation and destruction. As in $Q A M$, this substance can be conceptually analysed in form and matter, form being a mixture of the four elemental qualities, and matter being without quality in itself. Galen argues that this substance is the true nature of things, as opposed to their perceptible nature. Nature, in this primary sense, needs to be uncovered through a method of division, according to Galen.

He develops this method on the basis of a passage from Plato's Phaedrus, which says that, in order to know a given whole, one first needs to divide it into its most elemental constitutive parts, and, then, analyse the active and passive powers of these parts. In Galen's application of this method, the mixtures of the elemental qualities turn out to be the most elemental parts of any given thing subject to generation and destruction. These mixtures constitute the homoeomerous bodies, which are the most elemental bodies because they can only be further analysed conceptually, in terms of their form and matter. Thus, an analysis of the nature of any given thing finally consists in the analysis of the passive and active powers of the formal aspect of its homoeomerous bodies. This result is in line with what we have found in our analysis of QAM in Case-Study I, where it turned out that soul, as the cause of our activities and principle of movement, should be defined as the form of the homoeomerous bodies that reside in the three principal organs.

I have argued that this hylomorphic interpretation of (human) nature explains the noteworthy absence of the soul in HNH. Except for the quotations from Plato and 
Hippocrates and their immediate context, Galen only uses the word 'soul' once in the entire text. Not coincidentally, this is when he points out the dependency of the dispositions of the soul on the humours, and then refers to $Q A M$ for a physical

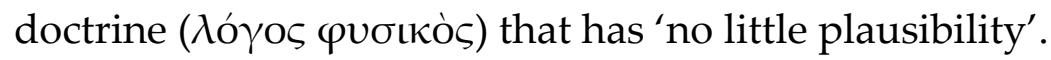

Philip van der Eijk has argued that Galen, when speaking of 'human nature' in works such as $H N H$, refers to the corporeal nature of the human being. However, I have shown that there are places, in $\mathrm{HNH}$ and elsewhere, where Galen rather uses the word 'nature' - in the sense of the nature of the human being - to refer to soul. I have also argued that Galen can refer to both soul or body when he refers to the nature of the human being because he sees the two as intertwined, and because he understands the human being as a hylomorphic substance. The nature of this hylomorphic substance, in a primary sense, consists in its mixtures of elemental qualities. It makes more sense for Galen in this context, therefore, to speak of form and matter, than to speak of soul and body.

Galen's notion of the nature of everything as a mixture of the four elemental qualities is not without problems, because he also understands nature as an intelligent creator, as the cause of the intelligent design that he witnesses in living beings. As Hankinson and van der Eijk have shown, the tension between the explanatory power of mixture and the conviction of intelligent design is never fully resolved in Galen. ${ }^{1004}$ In addition to this, I have also argued, however, that we cannot differentiate clearly between the causal power of mixture and a divine causal power in Galen, because the generation of mixtures requires a divine cause. Galen distinguishes two basic creative powers of nature: the alterative power and the shaping power. The shaping power is the one that is praised throughout UP and that is without a doubt artistic and divine. The alterative power, however, is a power of the same nature (remember here Galen's general definitions of substance and power or capacity), and is exercised through the activities of the elemental qualities, which are themselves also characterized as powers of nature by Galen. These two powers of nature require coordination, since they are concerned with the creation of the same beings. Moreover, the alterative power, which consists in the powers of the elemental qualities, cannot be random, for, as Galen often says, random processes could not generate the order that we behold. Therefore, the generation of the mixtures is itself dependent upon the activity of divine nature, even though the mixtures exercise their own causal power once they are generated. Moreover, the shaping power of nature is in turn dependent upon the alterative power, since the alterative power acts on a more primary level. This means that we cannot strictly distinguish between a 'teleological' and 'mechanistic' aspect of Galen's philosophy of nature, but at best between a more and less directly divine and teleological aspect.

Through his definition of nature as the primary hylomorphic substance of everything, Galen develops a broad concept of nature. It takes into account both the common nature of everything as well as the specific nature of any given thing. After

${ }^{1004}$ Hankinson (2008); van der Eijk (2014) 
all, the nature of any specific being is merely a mode of the common nature of everything. The differences between beings that share the primary substance as their common nature, consists of the differences with regard to the specific, individual mixture of each being. Galen's notion of nature also takes into account both the elementary mixtures as well as the complex intelligent design of things. As we have seen, both are effected by powers of the same nature. Finally, Galen's concept of nature takes into account both functions of the body and functions of the soul. With regard to some of the soul's functions, it does not make a difference, claims Galen, whether we call them natural of psychic. With regard to some other functions, it is not entirely clear to what extent Galen considers them to be functions of nature. For these reasons, I have concluded that the boundaries between nature as something universal and something individual, between nature as transcendent and immanent, and between nature and the soul, become ambiguous in Galen.

In the passage from Plato's Phaedrus that Galen repeatedly cites and refers to, it is suggested that Hippocrates used the method of division for his study of the human body, and that the study of the soul must proceed according to the same method. I have argued that Galen uses this passage to present his own work as a synthesis of Plato and Hippocrates, as he does in PHP. At first sight, Galen depicts it so that Hippocrates developed this method in his writings on the human body, and Plato used the same method for his study of the human soul. On closer analysis, however, the way Galen presents this method, suggests that he takes a hylomorphic perspective on the matter, in which Hippocrates and Plato are also integrated into a single substance. That is to say, Hippocrates and Plato were both studying parts of the same whole that is now studied by Galen in $\mathrm{HNH}$ as a single hylomorphic substance. Towards the end of the treatise, he rephrases his quotation from Plato's Phaedrus accordingly. At first, the quotation states that it is impossible to understand the nature of the soul without understanding the nature of the whole, in which case 'the whole' seems to refer to either the whole soul or possibly the whole of body and soul. But, in Galen's rephrasing, it states that the soul cannot be properly investigated without knowledge of the nature of everything ( $\pi \alpha \nu \tau o ́ s)$. This is no coincidence, since Galen has made it abundantly clear in his commentary what this nature of everything is: the primary hylomorphic substance. Thus, through his Aristotelianizing, hylomorphic interpretation of this passage from the Phaedrus, Galen presents his own work as a synthesis of Hippocrates and Plato in the strongest sense possible: he studies the single substance of which both studied merely one part or aspect. Therefore, he suggests that knowledge of the soul is impossible if it is not grounded in knowledge of this primary substance that forms the nature of everything, i.e. in knowledge of mixtures. Again, this is in line with the strong thesis of $Q A M$, that the substance or nature of the soul is a mixture. In order to arrive at these conclusions, which provide a new reading of $\mathrm{HNH}$ that corresponds to 
the results of my Case-Study I, I have built further on and made extensive use of the work of, mainly, Hankinson, Kovacic, Kupreeva, Tieleman and van der Eijk. ${ }^{1005}$

\section{Case-Study III}

The third case-study focused on Galen's dealings with the Timaeus. The Timaeus is an important text for Galen and often recurs in his discussions of the soul and of human nature. Through a study of Galen's use of the Timaeus in PHP, QAM, his Compendium, and his commentary, I show that Galen works out an idiosyncratic interpretation of the Timaeus that recasts the Platonic opposition between body and soul into an opposition of the elemental qualities. At the centre of this interpretation lies Galen's reading of the metaphor of the river, introduced by Timaeus in $43 \mathrm{a}$, around the point where Galen's commentary probably started. Galen reads this metaphor allegorically, as a reference to the wetness of the substance of infants. That is to say, he takes it to state that because the substance of newborns is relatively wet, their rational powers are relatively weak. In Plato, this metaphor refers to the incarnation of the soul as such, but because Galen rather reads it as a reference to the predominance of one particular elemental quality, he has created the necessary interpretative space to characterize the powers of the rational soul in terms of the opposite elemental quality, namely, dryness. We find this particular reading of the river-metaphor in QAM and in Galen's Compendium. Moreover, I have shown that this reading corresponds to the general role that Galen assigns to wetness and dryness in relation to the rational capacities. In several of Galen's works, for example in $U P$, we find that he ascribes intelligence to the heavenly bodies, which are characterized as extremely dry, hot, and fiery. It is these very qualities that make the heavenly bodies extremely intelligent. That is to say, it is because these qualities predominate in their particular substance that they are extremely intelligent. Through these references to other Galenic works, e.g. also including the discussion of the effects of humours on the rational capacities in Loc. Aff., and the depiction of the development of the substance of human beings according to different phases of life in Temp., I have shown that what might at first seem like a rather extravagant notion, namely, the idea that dryness is the cause of intelligence, has extensive support in other Galenic works, and builds on his general physiology of mixtures. With this opposition between dryness and wetness, Galen reinterprets the Platonic opposition between body and soul in terms that might be characterized as Presocratic (Galen repeatedly refers to Heraclitus in this context). Galen transforms he opposition between body and soul into an opposition between the two realms of the cosmos, earth and heaven, in which different elemental qualities predominate. In this manner, the descent of the soul from the heavenly realm into an earthly body, can be understood in terms of a mixture of elemental qualities; some of the qualities naturally belong to the heavens, other naturally belong to the earth. For this reinterpretation, Galen makes use of Plato's association of the rational soul with the

${ }^{1005}$ Hankinson (2008, 2017); Kovacic (2001); Kupreeva (2014); Tieleman (forthcoming); van der Eijk (2014) 
stars and the heavenly realm, and of the role of light in vision, cognition, and understanding. Particularly for the latter two points, I have built on the work of Frede and Ierodiakonou. ${ }^{1006}$

I have also this case-study to analyse and discuss the fragments published by Carlos Larrain in 1992. ${ }^{1007}$ Larrain claimed that these are excerpts from the first two books of Galen's commentary on the Timaeus. Since Diethard Nickel has casted doubt on Larrain's thesis, however, they have been consigned to near complete oblivion, despite their interesting content. ${ }^{1008}$ Building on the work of Aileen Das ${ }^{1009}$, I have argued that Nickel's arguments against Larrain's claim are problematic, and that his conclusions are, in any case, too rash. I have undertaken a comparative analysis between these fragments and Galen's attested work, from which it appeared that the two are in strong agreement on a considerable number of points. On this basi, I have argued that Larrain's thesis is still the most likely speculative explanation for the heritage of these fragments. I have shown that the fragments are consistent with, and show parallels to, Galen's attested work on the Timaeus, but also HNH, UP, Temp., PHP and Loc. Aff. Moreover, some of their interpretative tendencies correspond to Galen's Compendium as well. The author of Larrain's fragments sometimes seems to go a step further than Galen in his depiction of the soul as a dry and hot substance exuding light like the heavenly bodies. He states, for example, that the soul, itself, can become wet, implying very clearly that the soul is corporeal. Galen never says anything like this in his attested work, but always attributes the qualities of dryness and wetness to a (bodily) substance. On the other hand, I have shown that Larrain's fragments are so peculiarly Galenic in so many respects, that the thesis that they are based on Galen's own work, even if actually written down by a later epitomizer or interpreter, seems the most likely explanation so far.

I have concluded that Galen's interpretation of the Timaeus in his attested work corresponds to his notions of the soul and of human nature as developed in QAM and $H N H$. Galen's idiosyncratic interpretation of the Timaeus, departing from the metaphor of the river, can be seen an attempt to ground the capacities of the rational soul in his theory of mixture. At the same time, they are a way of anchoring his notion of the human soul as mixture of the elemental qualities in the work of his most esteemed philosophical authority. The fragments published by Larrain fit this pattern as well, and, regardless of their heritage, provide a clear view on what a Galenic interpretation of the Timaeus looks like.

\section{Case-Study IV}

In the fourth and final case-study, I have analysed Galen's notions of black bile and melancholy, in order to see if his concepts of the soul and human nature, as they evolved in the works discussed in the previous three case-studies, find any concrete

\footnotetext{
${ }^{1006}$ Frede (2003); Ierodiakonou (2014)

${ }^{1007}$ Larrain $(1991,1992)$

1008 Nickel (2002)

${ }^{1009}$ Das $(2013,2014)$
} 
application in his account of these subjects. I have given a brief overview of Galen's main precedents, namely, the Hippocratic Corpus, Aristotle, the Problemata XXX,1, and Rufus of Ephesus, on the basis of existing literature by Flashar, Jouanna, Klibansky, Panofsky and Saxl, Kudlien, Pormann and van der Eijk. ${ }^{1010}$ In a few places, I have added to the existing literature. Most notably, I have shown how Aristotle in the Nicomachean Ethics develops a notion of the melancholic as someone with an exceptional sensitivity for the mortality and imperfection of man, for the fact that man is not god. I have also argued that the extent to which the concept of melancholy of the Problemata XXX,1 agrees with Rufus' and Galen's work on melancholy, has been underestimated.

On the basis of my analysis of black bile and melancholy in Galen, I have concluded that his views on these subjects are more innovative than previous scholars have thought. The importance of Galen's contribution lies mainly in the systematization and canonization of the humoural theory, which has fundamentally important consequences. It implies a normalization of black bile. In Galen, black bile becomes a common part of the human constitution, and becomes integrated into the cosmological order of things through a system of elemental qualities, elements, seasons, and phases of life. However, black bile is not simply one humour among others. From At. Bil., we learn that it is an extremely dangerous substance that should be carefully managed. Galen distinguishes between a normal and a harmful version of black bile, apparently in an attempt to synthesize the tradition of black bile as a harmful substance causing disease, with the notion of black bile as one of the four humours that constitute our nature, which he adopts from the Hippocratic On the Nature of Man. These two kinds of black bile, however, also have much in common, and one can alter into the other. What is striking in Galen's notion of black bile, is the extent to which the boundaries of the normal and the harmful fade into each other. Galen takes up the notion of black bile as a residue, as well, from the Peripatetic tradition. He defines black bile as a by-product of our digestive system, a negative consequence of our need for nourishment. As such, this by-product needs to be continuously neutralized, for which nature gave us a tool: the spleen. With his development of the role of the spleen, Galen reconciles the incorporation of a harmful substance into the natural human constitution with his teleological understanding of nature as a wise artisan. The necessity of the existence of black bile is finally explained by him in terms of the restraint that matter posed on nature's designing power. Beings that are made out of better material, do not need to nourish themselves continuously, and therefore do not need to produce harmful by-products. Building on Aristotle's notion of the melancholic as someone who is exceptionally sensitive to the mortality and imperfection of the human being, and Galen's characterization of black bile as a detrimental substance that is the consequence of

${ }^{1010}$ Flashar (1966); Jouanna (2009, 2012); Klibansky, Panofsky, and Saxl (1990); Kudlien (1967, 1973); Pormann (2008); van der Eijk (2005, 2008) 
the imperfect matter out of which we are made, I conclude that the spleen, in Galen, is making up for the fact that we are not like the stars.

I have also shown how, within the schema of the humours and their corresponding seasons, black bile is involved in a double opposition that determines its place in the order of things. It is opposed to blood, which is the most beneficial, well-tempered and useful humour, predominant in spring, closest to our nature, and associated with life. At the same time, it is opposed to yellow bile, the humour associated with fire, the heavens, intelligence, and activity. As such, black bile appears as a substance that is opposed to life and opposed to the divine, a substance that is associated with earth, death, heaviness, darkness, and night. This implies that, although black bile is a common part of our constitution, it also forms a continuous threat to that very constitution itself, by its very nature. This corresponds, so I argue, with the Greek philosophical understanding of man as a being that is both divine and mortal, that looks up to and studies the heavens, but that remains bound to the earth. It also corresponds to the symptoms of the affliction that it causes: melancholy.

Through his normalization of black bile, Galen also normalizes melancholy to some extent. We can see this clearly in his description of the experience of the melancholic, which he gives in several of his writings. He states that the fear of the melancholic is caused simply by the darkness of the black bile. This darkness, however, is comparable to the darkness of night. Thus, Galen suggests that we can understand the experience of the melancholic, by simply thinking back to a moment in which we were alone in the darkness of night and got frightened. The crucial difference with the experience of the melancholic is that he is not able to escape the darkness, because it is always with him, inside his very body. Notably, this is a physiological explanation of a psychic affliction in terms of the qualities of the bodily substance causing the affliction. Galen emphasizes that there is no reason for the melancholic to be fearful or sad. There is a cause for it, however, namely, the black bile. I have shown that, in other ways, too, Galen explains the symptoms and experiences of the melancholic in terms of the qualities of the substance of black bile. Black bile is cold and dry, for example. These are the qualities of death, since this is what bodies feel like after the life has flown out of them. Melancholics are suicidal, find fault with life, and desire death. Again, they do not know why, they do not have a reason to find fault with life, it is simply the qualities of the substance of black bile that makes them feel this way. This substance, however, is also a necessary part of our nature, as that which always threatens that very nature from within. This makes the occasion of melancholy, pathological or not, a logical consequence of the way the human being is naturally constituted. That is to say, melancholy, in Galen, is a normal consequence of the abnormal mixture of man, which always consists of both earthly and heavenly qualities.

My analysis of black bile and melancholy in Galen has demonstrated that his notion of the soul and human nature, as I developed it in the previous three case-studies, does not function only at the level of theory or speculation, but finds concrete application in his work on mental illness as well. It also adds to our understanding of 
the subjects of black bile and melancholy in Galen, which have been surprisingly understudied so far.

\section{General conclusion}

Now that we have summarized our findings for each of the four case-studies, the question remains: can we combine the results from the various case-studies into some more general conclusions about Galen's views on human nature and the soul? First, I would like to repeat the same caveat that I have set out in the introduction. I have analysed a limited number of works by Galen, more in particular a number of works that are more philosophical than many others. Especially QAM and Galen's interpretation of the Timaeus in various works, as well as the contested Larrain fragments, are more speculative than many other Galenic works, from which we might well derive quite a different picture of Galen. Therefore, the conclusions arrived at in each individual case-study must be read in the specific context of the selected key-texts.

On the other hand, we have seen that the concept of the soul and of human nature that Galen develops in $Q A M, H N H$, and his work on the Timaeus, do show strong resemblances and an inner consistency that Galen also makes explicit through references. Also, we have seen that, although the views he works out in these works involve more philosophical speculation than Galen is comfortable with in some of his other works, these views are in important respects supported by works such as Hipp. Elem., Temp., Loc. Aff. and Nat. Fac. What does this mean, and how do we reconcile this consistency in content with the inconsistency with regard to Galen's careful attitude in other works?

When we look at works in which Galen is willing to delve into the questions on human nature and the soul, we find that he develops what he characterizes as a plausible position. The plausibility of this position is, indeed, based on and derived from his findings in other works, such as those mentioned above, in which he generally refrains from delving into such more theoretical questions. The position comes down to an understanding of the human being as hylomorphic, constituted by the same two basic principles that constitute everything else, namely, a specific mixture of the four elemental qualities in a matter without quality as such. Since these qualities are primarily active and soul is a principle of movement, they are to be understood, in their specific interaction, as the primary cause of our activities and affections, i.e. as the substance of our soul. The specific mixtures that cause our activities and affections are located within the organs from which these are exercised, namely, the brain, heart and liver. With this notion of the substance of the soul as a bodily mixture, Galen makes use of the ambiguity of the term ov $\sigma i \alpha$ and conflates the two senses of 'what something essentially is' and 'the stuff of something'. What man essentially is, becomes the stuff in man that is primarily active, and that, therefore, functions as the cause of man's activities and affections. This is how Galen's concept of the nature of man and the substance of the soul of man are conflated. 
Within this schema, the substance of the rational soul has an exceptional position, as we have seen both in our analysis of QAM as well as in our discussion of Galen's interpretation of the Timaeus. It has a likeness to the heavenly bodies, which are divine and supremely intelligent, and it has, in some cases at least, the capacity to undertake a project of self-ameliorization through alteration of its own substance. The ideal that Galen presents, is to liken the substance of one's rational soul to the substance of the heavenly bodies as much as possible. With this potential of likening oneself to the stars, Galen builds on Plato's association of the rational soul with the stars, and retains the Platonic ideal of ómoí $\omega \sigma \iota \varsigma \theta \varepsilon \tilde{\omega}$ in an altered form. Thereby, he reserves some room, at least, for the possibility of a philosophical life devoted to selfimprovement.

Galen develops this position on human nature, I believe, not as his 'philosophy' in the sense of a dogmatic position that should, as such, be considered definitively proven, true, adhered to and defended; but, rather, as a tentative position that is best able to explain what he considers to be the empirical facts. Importantly, this tentative position should also be compatible, for Galen, with the possibility of the philosophical life just mentioned.

He roots this position in the philosophical and medical tradition by starting from a synthesis of Hippocrates and Plato. The basis for this was laid in PHP, where Galen demonstrates, basing himself on the Timaeus, how each part of the soul has a specific seat in the body and is dependent for its functioning on a specific organ and its connections to the rest of the body. He continues to build on this basis in QAM and $H N H$. With the important addition of Aristotelian hylomorphism, however, he is able to further integrate his interpretations of Hippocrates and Plato into a notion of a common hylmorphic nature of everything. Through this common hylomorphic nature Galen synthesizes their work in a new tentative philosophical anthropology that problematizes the duality of body and soul, which framed the original distinction between Hippocrates and Plato. Tentative, because, as we have seen, Galen also frequently casts doubt on the extent to which his physiological explanations do justice to the intelligent design he observes in nature. Finally, the fact that Galen provides a firmly physiological explanation of melancholy, in which the qualities of the black bile determine the specific symptoms and experiences of the melancholic, proves that his notion of human nature, as it appears from our analyses, finds at least some concrete application in Galen's work.

Galen, through his own willingness to express his ignorance about subjects of speculative nature, and through his contempt for dogmatism and adherence to schools, has facilitated an understanding of his work that emphasizes the limitations of his philosophical aspirations. However, I believe that, in this dissertation, I have shown that Galen does take position in and significantly adds to the debate on philosophical questions such as those on the substance of the soul, the relation between body and soul, and human nature. Furthermore, I have shown that these positions on speculative questions are thoroughly connected to the rest of Galen's work. He bases these views on his more concrete work concerned with the human 
body, on what he considers the empirical evidence with regard to a specific question, and on their usefulness with regard to ethics. 


\section{Bibliography}

\section{Text editions and translations}

Adams, F. (1972; 1856) The Extant Works of Aretaeus, The Cappadocian. Boston Milford House Inc. (Digital Hippocrates)

Baltzy, D. Finamore, J. F. and Miles, G. (2018) Proclus. Commentary on Plato's Republic (tr.) Cambridge University Press (Cambridge)

Barnes, J. (1985) The Complete Works of Aristotle: the Revised Oxford Translation. Princeton University Press (Princeton)

Barras, V., Birchler, T. and Morand, A. (1998) Galien. De la bile noire (tr.) Éditions Gallimard (Paris)

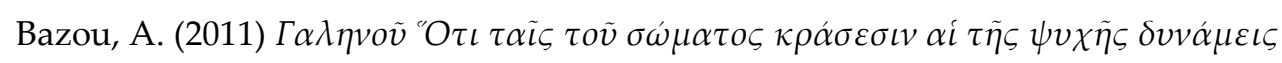

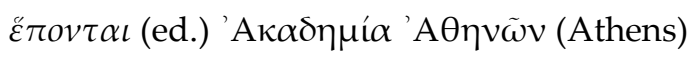

Boudon-Millot, V. and Pietrobelli, A. (2005) Galien ressuscité: edition princeps du texte grec $d u$ De Propriis Placitis (ed. and tr.) in Revue des Études Grecques, tome 118, January-June 2005, p $168-213$

Broadie, S. and Rowe, C. (2002) Aristotle. Nicomachean Ethics (tr. and comm.) Oxford University Press (Oxford)

Brock, A.J. (2006; 1916) Galen. On the Natural Faculties (ed. and tr.) Harvard University Press (Cambridge, Massachusetts)

Burnet (1958-62; 1905) Platonis Opera. Clarendon Press (Oxford)

Burton, R. (1964; 1621) The Anatomy of Melancholy (introd. by Holbrook Jackson) Dent (London)

Bywater, I. $(1957 ; 1894)$ Aristotelis Ethica Nicomachea. Clarendon Press (Oxford)

Cooper, J. M. (1997) ed. Plato. Complete Works (tr.) Hackett (Indianapolis)

Cornford, F. M. (1952; 1937) Plato's Cosmology. The Timaeus of Plato Translated with a Running Commentary (tr. and comm.) Hackett (London)

Daremberg, Ch. V. (1848) Fragments du Commentaire de Galien sur le Timée de Platon en grec et en francais (ed. and tr.). Bibliothèque interuniversitaire de médecine (Paris)

Das, A. R. and Koetschet, P. (forthcoming) Galen's Compendium of Plato's Timaeus (tr.) in Galen on Human Nature ed. Van der Eijk, P. and Singer, P. N. Cambridge University Press (Cambridge)

De Boer, W. (1937) De propriorum animi cuiuslibet affectuum dignotione et curatione, De animi cuiuslibet peccatorum dignotione et curatione and De atra bile (ed.) CMG V 4,1, 1. Akademie-Verlag (Berlin)

De Lacy, P. (1984) Galen. On the doctrines of Hippocrates and Plato (ed., tr. and comm. in three volumes) CMG V 4, 1, 2. Akademie-Verlag (Berlin) 
— (1992) Galen. On Semen (ed., tr. and comm.) CMG V 3, 1. Akademie-Verlag (Berlin)

- (1996) Galen. On the Elements According to Hippocrates (ed., tr. and comm.) CMG V 1, 2. Akademie Verlag (Berlin)

Dillon, J. M. (1993) Alcinous. The Handbook of Platonism (tr. and comm.) Clarendon Press (Oxford)

Flashar, H. (1962) Aristoteles. Problemata Physica (tr. and comm.) Akademie Verlag (Berlin)

Frede, M. and Walzer, R. (1985) Galen. Three Treatises on the Nature of Science (tr.) Hackett (Indianapolis)

Garofalo, I. and Lami, A. (2012) Galeno, l'anima e il dolore. De Indolentia; De Propriis Placitis (ed. and tr.) Rizzoli (Milan)

Garofalo, I. and Vegetti, M. (1978) Opere scelte di Galeno (tr.) Unione Tipografico-Editrice Torinese (Turin)

Grant, M. (2000) Galen on Food and Diet (tr.) Routledge, London

Hankinson, R. J. (forthcoming) Galen, Commentary on Hippocrates' Nature of Man (tr.) in Galen on Human Nature ed. Van der Eijk, P. and Singer, P. N. Cambridge University Press (Cambridge)

Helmreich, G. (1968) Galeni de Usu Partium Libri XVII (ed.) Verlag Adolf M. Hakkert (Amsterdam)

Helmreich, G., Marquardt, J. and Müller, I. (1967; 1884-1893) Claudii Galeni Pergameni Scripta Minora III (ed.) Verlag Adolf M. Hakkert (Amsterdam)

Hett, W. S. $(1975 ; 1957)$ Aristotle. On the Soul; Parva Naturalia; On Breath (ed. and tr.) Harvard University Press (Cambridge, Massachusetts)

Jackson, R., Lycos, K. and Tarrant, H. (1998) Olympiodorus. Commentary on Plato's Gorgias (ed. and tr.) Brill (Leiden)

Joachim, H. H. (1951) Aristotle. The Nicomachean Ethics: a Commentary (ed. Rees, D. A.) Clarendon Press (Oxford)

Johnston, I. (2006) Galen on Diseases and Symptoms (tr. of On the Differentiae of Diseases, On the Causes of Diseases, On the Differentiae of Symptoms, on the Causes of Symptoms) Cambridge University Press (Cambridge; New York)

Johnston, I. (2018) Galen. Hygiene (ed. and tr.) Harvard University Press (Cambridge, Massachusetts)

Johnston, I. and Horsley, G. H. R. (2011) Galen. Method of Medicine (ed. and tr.) Harvard University Press (Cambridge, Massachusetts; London)

Jones, W. H. S., Potter, P., Smith, W. D. and Withington, E. T. (1968-2018) Hippocrates (complete works in ed. and tr.) The Loeb Classical Library, Harvard University Press (Cambridge, Massachusetts etc.)

Kahn, Ch. H. (1979) The Art and Thought of Heraclitus (ed., tr. and comm.) Cambridge University Press (Cambridge)

Kraus, P. and Walzer, R. (1951) Galeni Compendium Timaei Platonis aliorumque dialogorum synopsis; quae 
extant fragmenta (ed. and tr.) Warburg Institute (London)

Kroll, G. (1965) Proclus Diadochus. Procli Diadochi In Platonis rem publicam commentarii (ed.) Hakkert (Amsterdam)

Kühn, C. G. (1964-5; 1821-1833) Claudii Galeni Opera Omnia (ed. and tr. in 20 vol.) George Olms (Hildesheim)

Larrain, C. J. (1992) Galens Kommentar zu Platons Timaios (ed. and comm.) Teubner (Stuttgart)

Lennox, J. G. (2001) Aristotle. On the Parts of Animals (tr. and comm.) Clarendon Press (Oxford)

Lorusso, V. (2005) Nuovi frammenti di Galeno (ed. and tr.) in Zeitschrift für Papyrologie und Epigraphik vol. 152. pp. $43-56$

MacKenna, S. (1962) Plotinus. The Enneads. Faber and Faber (London)

May, M. T. (1968) Galen, On the Usefulness of the Parts of the Body (tr.) Cornell University Press (Ithaca, New York)

Mewaldt, I. (1914) Galeni in Hippocratis De Natura Hominis Comm. III (ed.) CMG V 9, 1, Teubner (Leipzig; Berlin)

Morani, M. (2018) La natura dell'uomo, Nemesio di Emesa (ed. and tr.) Edizioni San Clemente (Bologna)

Moraux, P. (1977) Unbekannte Galen-Scholien (ed.) in Zeitschrift für Papyrologie und Epigraphik vol. 27 pp. 1-66

Most, G. W. (2018) Hesiod. Theogony; Works and Days; Testimonia (ed. and tr.) Harvard University Press (Cambridge, Massachusetts)

Nickel, D. (2001) Galen. Über die Ausformung der Keimlinge (ed., tr. and comm.) CMG V 3, 3. AkademieVerlag (Berlin)

Nutton, V. (1979) Galen. On Prognosis. (ed., tr. and comm.) CMG V 8, 1. Akademie-Verlag (Berlin)

- (1999) Galen. On my Own Opinions (ed., tr. and comm.) CMG 3, 2. Akademie-Verlag (Berlin)

O’Neill, E. N. (2014) Plutarch. Moralia (various translations compiled by $\mathrm{O}^{\prime}$ Neill in 16 vol.) Harvard University Press (Cambridge, Massachusetts)

Pormann, P. E. (2008) Rufus of Ephesus. On Melancholy (ed. and tr. including essays) Mohr Siebeck (Tübingen)

Reeve, C. D. C. (2017) Aristotle. De Anima (tr.) Hackett (Indianapolis)

Schröder, H. O. and Kahle, P. (1934) Galeni in Platonis Timaeum Commentarii Fragmenta (ed.) CMG Suppl. 1. Akademie-Verlag (Berlin)

Sharples R. W. and van der Eijk, Ph. J. (2008) Nemesius, On the Nature of Man (tr.) Liverpool University Press (Liverpool)

Sider, D. and McVaugh, M. (1979) Galen, on Tremor, Palpitation, Spasm and Rigor (tr.) in Transactions and Studies of the College of Physicians of Philadelphia 1. pp. 183-210 
Siegel, R. E. (1976) Galen. On the Affected Parts (tr.) Karger (Basel)

Singer, P. N. (1997) Galen. Selected Works, Oxford University Press

— (2013) ed. with Nutton, V., Davies, D. and Tassinari, P. Galen: Psychological Writings (tr.) Cambridge University Press (New York)

Smith, W. D. (1990) Hippocrates. Pseudepigraphic Writings: Letters, Embassy, Speech from the Altar, Decree (ed. and tr.) Brill (Leiden)

Spencer, W. G. and Jones, W. H. S. (1960-1) Aulus Cornelius Celsus. De medicina. Heinemann (London)

Strachey, J. and Freud, A. (1968) The Standard Edition of the Complete Psychological Works of Sigmund Freud. Vol. 14-21, 23 (tr.) Hogarth Press (London)

Strohmaier, G. von (1970) Über die Verschiedenheit der homoiomeren Körperteilen (ed., tr. and comm.) CMG 3 Supplementum Oriëntale, Akademie-Verlag (Berlin)

Tecusan, M. (2004) The Fragments of the Methodists. Vol 1, Methodism outside Soranus. Brill (Leiden)

Todd, R. B. (1996) Themistius, On Aristotle, On the Soul (tr.) Duckworth (London)

Tredennick, H. (1969) Aristotle. The Metaphysics; Oeconomica and Magna Moralia (tr.) Harvard University Press (Cambridge, Massachusetts)

Van der Eijk, P. (2001) Diocles of Carystus: a Collection of the Fragments with Translation and Commentary. Brill (Leiden)

— (2005-2006) Philoponus. On Aristotle On the Soul 1.3-5 and 1.1-2 (tr.) Duckworth (London)

Von Arnim, I. (1978-9; 1903-24) Stoicorum veterum fragmenta. Teubner (Stuttgart)

Wenkebach (1956) Galeni in Hippocratis Epidemiarum librum VI commentaria I-VI (ed.) CMG V 10, 2, 2.

Akademie-Verlag (Berlin)

Westerink, G. (1970) Olympiodorus. Olympiodori In Platonis Gorgiam commentaria (ed.) Teubner (Leipzig)

\section{Literature}

Adamson, P., Hansberger, R. and Wilberding, J. (2014) ed. Philosophical Themes in Galen. Institute of Classical Studies, University of London (London)

Arnzen, R. (2012) Plato's Timaeus in the Arabic Tradition. Legends - Testimonies - Fragments. in ed. Celia, F. and Ulacco, A. Il Timeo: Esegesi greche, arabe, latine. Plus (Pisa) pp. 181-267

Baltussen, H. (2003) Early Reactions to Plato's Timaeus: Polemic and Exegesis in Theophrastus and Epicurus. in ed. Sharples, R. W. and Sheppard, A. Ancient Approaches to Plato's Timaeus. Institute of Classical Studies (London) pp. 49-71

Bardong, K. (1942) Beiträge zur Hippokrates- und Galenforschung. in Nachrichten der Akademie der Wissenschaften in Göttingen. Philologisch-historische Klasse. Band 7, 1942. pp. 577-603

Barnes, J. and Jouanna, J. (2003) ed. Galien et la philosophie: huit exposés suivis de discussions. Entretiens 
sur l'antiquité classique tome XLIX, Fondation Hardt

Bell, M. (2014) Melancholia. The Western Malady. Cambridge University Press (Cambridge)

Bennett, S. (1978) Mind and Madness in Ancient Greece: the Classical Roots of Modern Psychiatry. Cornell University Press (Ithaca)

Blamsberger, G., Kellerer, S., Klemm, T. and Söffner, J. (2015) Sind alle Denker traurig? Fallstudien zum melancholischen Grund des Schöpferischen in Asien und Europa. Wilhelm Fink (Paderborn)

Bollas, C. (2018) Meaning and Melancholia. Life in the Age of Bewilderment. Routledge (New York)

Caston, V. (1997) Epiphenomenalisms, Ancient and Modern. in The Philosophical Review, Vol. 106, No. 3 (Jul., 1997) Duke University Press (Durham, North Carolina) pp. 309-363

Celkyte, A. (forthcoming) The Unity of Galen's Physiology. To appear as a result of the Galen-project at Utrecht University

Chiaradonna, R. (2009) Galen and Middle Platonism. in ed. Gill, C., Whitmarsh, T. and Wilkins, J. pp. 243-60

- (2014) Galen on What is Persuasive (Pithanon) and What Approximates to Truth. in ed. Adamson, P., Hansberger, R., Wilberding, J. pp. 61-88

- (2019) Aspects of Causation in Galen's Work on Pulse. (paper delivered in Utrecht, January 2019)

Corcilius, K. (2014) Faculties in Ancient Philosophy. in ed. Corcilius, K. and Perler, D. Partitioning the Soul. Debates from Plato to Leibniz. De Gruyter (Berlin; Boston) pp. 20-58

Dandrey, P. (2005) Anthologie de l'humeur noire: écrits sur la mélancolie d'Hippocrate à l'Encyclopédie (anthology) Promeneur (Paris)

Das, A. R. (2013) Galen and the Arabic Traditions of Plato's Timaeus. Dissertation University of Warwick, Department of Classics and Ancient History

- (2014) Reevaluating the Authenticity of the Fragments from Galen's On the Medical Statements in Plato's Timaeus (Scorialensis Graec. Ф-III-11, ff. 123r-126v). Zeitschrift für Papyrologie und Epigraphik 192 (2014) pp. 93-103

De Lacy (1972) Galen's Platonism. in Australasian Journal of Philosophy vol 93, pp. 27-39

- (1988) The Third Part of the Soul. in ed. Manuli, P. and Vegetti, M. Le opera psicologiche di Galeno. Bibliopolis (Naples) pp. 43-63

Dillon, J. M. (1977) The Middle Platonists: a Study of Platonism, 80 B.C. to A.D. 220. Duckworth (London) Donini, P. (2008) Psychology, in ed. Hankinson, R. J. (2008a) pp. 184-209

Dunbabin, K. (1986) Sic erimus cuncti... The Skeleton in Graeco-Roman Art. in Jahrbuch des Deutschen Archäologischen Instituts vol 101. pp. 185-255

Enderwitz, A. (2015) Modernist Melancholia: Freud, Conrad and Ford. Palgrave Macmillan (New York) 
Eng, D. L. and Han, S. (2019) Racial Melancholia, Racial Dissocation. Duke University Press (Durham, North Carolina)

Feld, A. (2011) Melancholy and the Otherness of God: a Study in the Genealogy, Hermeneutics and Therapeutics of Depression. Lexington Books (Lanham)

Ferber, I. (2013) Philosophy and Melancholy: Benjamin's Early Reflections on Theater and Language. Stanford University Press (Stanford, California)

Ferguson, H. (1995) Melancholy and the Critique of Modernity. Soren Kierkegaard's Religious Psychology. Routledge (London; New York)

Ferrari, F. (1998) Galeno interprete del Timeo. in Museum Helveticum 55 (1998) pp. 14-34

Fink, M. and Taylor, M. A. (2007) Resurrecting Melancholia. Acta Psychiatrica Scandinavica 115, supp/433. pp. $14-20$

- (2008) Restoring Melancholia in the Classification of Mood Disorders. in Journal of Affective Disorders vol 105 n1-3 (200801) pp. 1-14

Flashar, H. (1966) Melancholie und Melancholiker in den Medizinischen Theorien der Antike. De Gruyter (Berlin)

Flemming, R. (2008) Commentary. in ed. Hankinson, R. J. The Cambridge Companion to Galen. Cambridge University Press (Cambridge, UK) pp. 323-54

Foucault, M. (1984) Histoire de la sexualité vol III. Le souci de soi. Gallimard (Paris)

Frede, M. (2003) Galen's Theology in ed. Barnes, J. and Jouanna, J. (2003) pp. 74-129

Garcia-Ballester, L. (1988) Soul and Body, Disease of the Soul and Disease of the Body in Galen's Medical Thought, in ed. Manuli, P. and Vegetti, M. Le opera psicologiche di Galeno. Bibliopolis (Naples) pp. 117-152

- (2002) Galen and Galenism: Theory and Medical Practice from Antiquity to the European Renaissance (ed. by Jon Arrizabalaga). Ashgate/Variorum (Aldershot)

Garofalo, I. (1995) Galens Kommentar zu Platons Timaios by Carlos J. Larrain (review) in Gnomon 67, Bd., H. 7 (1995) pp. 645-6

Gill, C., Whitmarsh, T. and Wilkins, J. ed. (2009) Galen and the World of Knowledge. Cambridge University Press (Cambridge etc.)

Gourinat, J. (2008) L'embryon végétatif et la formation de l'âme selon les Stoïciens. in ed. Brisson, L., Congourdeau, M., Solère, J. L'embryon. Formation et Animation. J. Vrin (Paris)

Hankinson, R. J. (1989) Galen and the Best of All Possible Worlds. in Classical Quarterly 39. pp. 206-27

- (1991) Galen's Anatomy of the Soul. in Phronesis vol 37 issue 2. pp. 197-233

- (1993) Actions and Passions: Affection, Emotion, and Moral Self-Management in Galen's Philosophical Psychology. in ed. Brunschwig, J. and Nussbaum, M. C. Passions and Perceptions: Studies in 
Hellenistich Phiosophy of Mind: Proceedings of the Fifth Symposium Hellenisticum. Cambridge University Press (Cambridge) pp. 184-222

— (2003) Causation in Galen. in ed. Barnes, J. and Jouanna, J. (2003) pp. 31-72

- (2006) Body and Soul in Galen, in ed. King, R. (2009) pp. 231-58

- (2008) Philosophy of Nature. in ed. Hankinson, R. J. (2008a) pp. 210-241

- (2008a) ed. The Cambridge Companion to Galen. Cambridge University Press (Cambridge etc.)

- (2009) Medicine and the Science of the Soul. in Canadian Bulletin of Medical History 26.1 pp. 131-56

- (2014) Partitioning the Soul: Galen on the Anatomy of the Psychic Functions and Mental Illness. in ed. Corcilius, K. and Perler, D. (2014) pp. 85-106

- (2014a) Galen and the Ontology of Powers. in ed. Marmodoro, A. Causing Health and Disease in Classical and Late Antiquity, British Journal for the History of Philosophy 22.5, Special Issue 2014 pp. 951-973

- (2017) Substance, Element, Quality, Mixture: Galen's Physics and his Hippocratic Inheritance. in Aitia [en ligne] 7.2, 2017, mis en ligne le 20 novembre 207, consulté le 05 décembre 2017. http://aitia.revues.org/1863: ENS Éditions

Havrda, M. (2017) Body and Cosmos in Galen's Account of the Soul, Phronesis vol 62 issue 1, pp. 69-89 Holmes, B. (2013) Disturbing Connections: Sympathethic Affections, Mental Disorder, and the Elusive Soul in Galen. in ed. Harris, W. V. Mental Disorders in the Classical World. Brill (Leiden) pp. 147-76 Ierodiakonou, K. (1993) The Stoic Division of Philosophy. in Phronesis vol. 38 issue 1 pp. 57-74

- (2014) On Galen's Theory of Vision. in ed. Adamson, P., Hansberger, R., Wilberding, J. (2014) pp. $235-48$

Ilberg, J. (1974; 1889) Über die Schriftstellerei des Klaudios Galenos. Wissenschaftliche Buchgesellschaft (Darmstadt)

Ingram, A., Sim, S., Lawlor, C., Terry, R., Baker, J. and Wetherall-Dickson, L. (2011) Melancholy Experience in Literature of the Long Eighteenth Century: Before Depression, 1660-1800. Palgrave Macmillan (New York)

Jackson, S. W. (1986) Melancholia and Depression. From Hippocratic Times to Modern Times. Yale University Press (New Haven; London)

Jouanna, J. (1999) Hippocrates (tr. by DeBevoise, M. B.) John Hopkins University Press (Baltimore)

- (2009) Bile noire et mélancholie chez Galien: le traité sur la bile noire est-il authentique? in ed.

Brockmann, C., Brunschön, C. W. and Overwien, O. Antike Medizin in Schnittpunkt von Geistesund Naturwissenschaften. De Gruyter (Berlin) 235-257

- (2009a) Does Galen have a Medical Programme for Intellectuals and the Faculties of the Intellect? in ed. Gill, C., Whitmarsh, T. and Wilkins, J. (2009) pp. 190-205 
— (2012) Greek Medicine from Hippocrates to Galen, Selected Papers (ed. Van der Eijk, P., tr. Allies, N.) Brill (Leiden)

King, R. (2009) ed. Common to Body and Soul: Philosophical Approaches to Explaining Living Behaviour in Greco-Roman Antiquity. De Gruyter (Berlin)

Klibansky, R., Panofsky, E. and Saxl, F. $(1990 ; 1964)$ Saturn und Melancholie. Studien zur Geschichte der Naturphilosophie und Medizin, der Religion und der Kunst (tr. Buschendorf, C.) Suhrkamp (Frankfurt am Main)

König (2009) Conventions of Prefatory Self-Presentation in Galen's On the Order of My Own Books. in ed. Gill, C., Whitmarsh, T. and Wilkins, J. (2009) pp. 35-58

Kovacic, F. (2001) Der Begriff der Physis bei Galen vor dem Hintergrund seiner Vorgänger. Steiner (Stuttgart)

Kristeva, J. (1989) Black Sun. Depression and Melancholia (tr. Roudiez, L. S.) Columbia University Press (New York)

Kudlien, F. (1967) Der Beginn des medizinischen Denkens bei den Griechen von Homer bis Hippocrates. Artemis (Zürich)

— (1973) Schwärzliche Organe im frühgriechischen Denken. in Medizin-Historisches Journal vol 8. pp. 5358

Kupreeva, I. (2004) Aristotelian Dynamics in the 2nd Century School Debates: Galen and Alexander of Aphrodisias on Organic Powers and Movements. in Bulletin of the Institute of Classical Studies, vol. 47 No. S83PART1. pp. 71-95

— (2014) Galen's Theory of Elements in ed. Adamson, P., Hansberger, R., Wilberding, J. (2014) pp. 153196

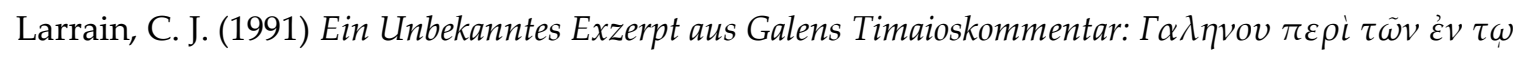

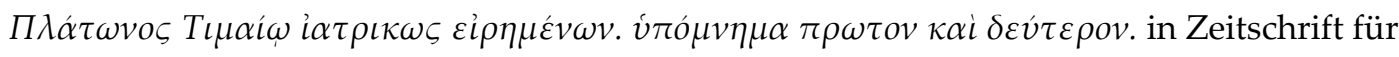
Papyrologie und Epigraphik 85 (1991) pp. 9-30

Leith, D. (2015) Elements and Uniform Parts in Early Alexandrian Medicine. in Phronesis 60 (2015) Brill. pp. 462-91

Lertzman, R. (2015) Environmental Melancholia: Psychoanalytic Dimensionsof Engagement. Routledge (New York)

Lloyd, G. E. R. (1988) Scholarship, Authority and Argument in Galen's Quod animi mores'. in ed. Manuli, P. and Vegetti, M. Le opera psicologiche di Galeno. Bibliopolis (Naples) pp. 11-42

Long, A. (1982) Soul and Body in Stoicism. in Phronesis vol 27 issue 1 (1982) pp. 34-57

Longrigg, J. (1993) Greek Rational Medicine: Philosophy and Medicine from Alcmaeon to the Alexandrians. Routledge (London) 
Lund, M. A. (2010) Melancholy, Medicine and Religion in Early Modern England: Reading 'The Anatomy of Melancholy'. Cambridge University Press (Cambridge; New York)

Mansfeld, J. (1967) Heraclitus on the Psychology and Physiology of Sleep, and Rivers. in Mnemosyne 20, pp. 1-29

— (2018) Studies in Early Greek Philosophy: a Collection of Papers and One Review. Brill (Leiden)

Marechal, P. (2019) Galen's Constitutive Materialism, Ancient Philosophy vol 39 issue 1, Mathesis Publications. pp. 191-209

Middeke, M. and Wald, C. (2011) The Literature of Melancholia: Early Modern to Postmodern. Palgrave Macmillan (New York)

Moraux, P. (1973, 1984, 2001) Der Aristotelismus bei den Griechen von Andronikos bis Alexander von Aphrodisias (3 vol.) De Gruyter (Berlin; New York)

Müri, W. (1953) Melancholie und schwarze Galle. in Museum Helveticum, vol 10,1 (1953)

Nickel, D. (2002) On the Authenticity of an "Excerpt" from Galen's Commentary on the Timaeus. in ed. Nutton, V. The Unknown Galen. Institute of Classical Studies, School of Advanced Study, University of London (London) pp. 73-8

Nutton, V. (2005) The Fatal Embrace: Galen and the History of Ancient Medicine. in Science in Context vol 18 (1) pp. $111-21$

— (2008) The Fortunes of Galen. in ed. Hankinson, R. J. (2008) pp. 355-90

Pensky, M. (1993) Melancholy Dialectics: Walter Benjamin and the Play of Mourning. University of Massachusetts Press (Amherst, Massachusetts)

Pigeaud, J. (1981) La maladie de l'âme: étude sur la relation de l'âme et du corps dans la tradition médicophilosophique antique. Les Belles Lettres (Paris)

Radden, J. (2000) The Nature of Melancholy: from Aristotle to Kristeva (anthology) Oxford University Press (Oxford; New York)

- (2017) Melancholic Habits. Burton's Anatomy and the Mind Sciences. Oxford University Press (New York)

Rashed M. (2010) Le prologue perdu de l'abrégé du Timée de Galien dans un texte de magie noire. in Antiquorum Philosophia 3 (2009) pp. 89-100

Schütrumpf, E. (2015) Black Bile as the Cause of Human Accomplishments and Behaviors in Pr. 30.1: Is the Concept Aristotelian? in ed. Mayhew, R. The Aristotelian Problemata Physica. Philosophia Antiqua vol. 139, Brill (Leiden) pp. 357-80

Sedley, D. (2011) Matter in Hellenistic Philosophy. in ed. Giovannozzi, D. and Veneziani, M. Materia: XIII Colloquio Internazionale, Roma 7-8-9 gennaio 2010. Leo S. Olschki (Florence) pp. 53-66

Sharples, R. W. (2006) Common to Body and Soul: Peripatetic Approaches after Aristotle. in ed. King, R. 
(2006) pp. $165-86$

Singer, P. N. (1991) Aspects of Galen's Platonism. in ed. López Férez, J. A. Galeno: obra, pensamiento e influencia. Universidad Nacional de Educación a Distancia (Madrid)

Solomon, A. (2001) The Noonday Demon. An Atlas of Depression. Scribner Classics (New York etc.)

Stewart, K. (2016) What Factors Influence Galen's Development of a Theory of Black Bile for his Explanation of Health and Disease in the Body? Thesis, Dissertation submitted July 2016, University of Exeter, department Classics

Stroumsa, G. G. (2005) Hidden Wisdom. Esoteric Traditions and the Roots of Christian Mysticism. Brill (Leiden)

Taylor, M. A. (2006) Melancholia: the Diagnosis, Pathophysiology, and Treatment of Depressive Illness. Cambridge University Press (Cambridge, New York)

Ter Borg, M. (2005) Bloemen van een ziekte, extase en wanhoop als bron van cultuur. Damon (Eindhoven)

Tieleman, T. (1991) Diogenes of Babylon and Stoic Embryology: ps. Plut., Plac. V 15.4 Reconsidered. in Mnemosyne 44 (1991) pp. 106-125

— (1996) Galen and Chrysippus on the Soul: Argument and Refutation in the "De Placitis" Books II-III. Brill (Leiden)

— (2003) Galen's Psychology. in ed. Barnes, J. and Jouanna, J. (2003) pp. 131-69

- (2015) Galen on Medicine as a Science and as an Art. in History of Medicine vol. 2.2 (2015) pp. 172-182

- (2018) Galen and Doxography. in ed. Mansfeld, J. and Runia, D. Aëtiana IV: Papers of the Melbourne Colloquium on Ancient Doxography. Brill (Leiden) pp. 452-471

- (forthcoming) Galen's Self-Understanding and the Platonic Phaedrus. in ed. Delcomminette, S., D’Hoine, P. and Gavray, M. A. Ancient Readings of Plato's Phaedrus. Beiträge zur Altertumskunde. De Gruyter (Berlin)

Toohey, P. (2004) Melancholy, Love, and Time: Boundaries of the Self in Ancient Literature. University of Michigan Press (Ann Arbor)

- (2008) Rufus of Ephesus and the Tradition of the Melancholy Thinker. in ed. Pormann (2008) pp. 221-244

Traverso, E. (2016) Left-Wing Melancholia: Marxism, History, and Memory. Columbia University Press (New York)

Trompeter, J. (2018) The Actions of Spirit and Appetite: Voluntary Motion in Galen. in Phronesis vol 63 issue 2. pp. 176-207

Van der Eijk, P. (2005) Medicine and Philosophy in Classical Antiquity: Doctors and Philosophers on Nature, Soul, Health and Disease. Cambridge University Press (Cambridge)

— (2008) Rufus' On Melancholy and Its Philosophical Background. in ed. Pormann (2008) pp. 159-78

— (2009) 'Aristotle! What a Thing for you to say!' Galen's Engagement with Aristotle and 
Aristotelians. in ed. Gill, C., Whitmarsh, T. and Wilkins, J. (2009) pp. 261-81

- (2014) Galen on the Nature of Human Beings. in ed. Adamson, P., Hansberger, R., Wilberding, J. (2014) pp. $89-134$

Vegetti, M. (2000) De caelo in terram. Il Timeo in Galeno (De Placitis, Quod Animi). in ed.

Brancacci, A. La filosofia in eta imperiale. Bibliopolis (Naples) pp. 69-84

Vinkesteijn, R. (2019) Mixing Body and Soul: Galen on the Substance of the Soul in QAM and De Propriis Placitis. in Phronesis, accessible online since 2019, to appear in print in 2020

Wilberding, J. (2014) The Secret of Sentient Vegetative Life in Galen. in ed. Adamson, P., Hansberger, R. and Wilberding, J. (2014) pp. 249-68 


\section{Samenvatting}

Galenus van Pergamum (129-c. 215 na Chr.) is nog steeds met name bekend vanwege zijn medische werk, dat tot in de moderne tijd de medische wetenschap gedomineerd heeft. In de laatste decennia is er echter geleidelijk meer appreciatie ontstaan voor de filosofische waarde van zijn geschriften, waarvan onder meer recente bundels als Galien et la philosophie (2003), Galen and the World of Knowledge (2009) en Philosophical Themes in Galen (2014) getuigen. In deze dissertatie beoog ik dit werk voort te zetten en een bijdrage te leveren aan het begrip van Galenus' denken. Ik focus specifiek op Galenus' begrip van de menselijke natuur en van de relatie tussen het lichaam en de ziel. Met betrekking tot deze onderwerpen heeft Galenus een originele en rijke bijdrage aan de wetenschappelijke en filosofische traditie geleverd. Als filosofisch geschoolde, praktiserende dokter is hij zowel diepgaand bekend met de Griekse filosofische traditie, als ook grondig ingevoerd in de complexiteit van het menselijk lichaam. Bovendien was Galenus sterk geïnteresseerd in de fysiologische grondslagen van psychische processen.

De centrale vragen van deze dissertatie zijn daarom: wat verstaat Galenus onder de menselijke natuur? Hoe begrijpt hij de ziel? Hoe begrijpt hij de verhouding tussen ziel en lichaam? Deze vragen hangen samen, aangezien Galenus in enkele van zijn werken vergelijkbare antwoorden op de vragen naar de natuur van de mens en naar de substantie van de menselijke ziel blijkt te geven. Die antwoorden wijzen op een begrip van de ziel dat sterk 'somatisch' is. Dat wil zeggen, Galenus definieert in enkele van zijn werken de ziel als een specifiek mengsel ( $\Leftarrow \tilde{\alpha} \sigma \iota \varsigma)$ van elementaire kwaliteiten in de organen van waaruit de psychische functies worden uitgeoefend (brein, hart en lever). Dat betekent weer dat de vraag naar de verhouding tussen lichaam en ziel direct samenhangt met de vraag naar de menselijke natuur en de menselijke ziel.

Deze set vragen behandel ik in vier verschillende 'case-studies', die elk vertrekken vanuit verschillende werken of sets van werken van Galenus. Een dergelijke methodische benadering is noodzakelijk gezien de complexiteit, diversiteit en omvang van Galenus' werk, die een meer systematische benadering in de zin van 'de filosofie van Galenus' in elk geval problematisch en wellicht onhoudbaar maken. Sommige van zijn werken classificeert Galenus zelf bijvoorbeeld als filosofische werken, andere niet. Het ligt dan ook voor de hand dat hij in filosofische werken wat uitgebreider in gaat op genoemde vragen, die van speculatiever aard zijn dan vragen die hij behandelt in, bijvoorbeeld, een werk over koorts of over de pols. Daarnaast beoogt Galenus met sommige werken ook een ander doel dan met andere. Sommige van zijn werken zijn bijvoorbeeld - naar eigen zeggen - op verzoek van een vriend geschreven, en vooronderstellen een hoop materie die deze vriend al kent. Andere werken lijken voor breder publiek geschreven en hebben weer een meer retorische stijl dan meer gespecialiseerde werken. Dit laatste geldt bijvoorbeeld voor QAM (zie 'Abbreviations and other notes' voor de afkortingen), een werk dat ik in mijn 'CaseStudy I' bespreek. 
Behalve de verschillende contexten van Galenus' werken, is er nog een aantal factoren die een systematische interpretatie van Galenus' werk als geheel problematiseren. Ten eerste, zijn geregionaliseerde scepticisme, zoals we het zouden kunnen noemen. Galenus is absoluut geen scepticus in de zin van Pyrrho, en is ook geen Academisch scepticus, maar maakt wel vaak een sterk onderscheid tussen onderwerpen waar we wetenschappelijke kennis van kunnen verkrijgen en onderwerpen waarbij dat, vanwege de aard van het onderwerp, veel moeilijker of zelfs onmogelijk is. In tegenstelling tot veel filosofen, schroomt hij niet om het antwoord op speculatieve vragen schuldig te blijven, ondanks het feit dat hij wél de antwoorden van anderen kritiseert. Een van die vragen betreft de substantie (oúoí $\alpha$ ) van de ziel, met betrekking waartoe Galenus in verschillende werken zijn onwetendheid uitdrukt. Ten tweede, zijn hartgrondige afkeer van dogmatiek en van filosofie die trouw blijft aan een specifieke school. Het Griekse filosofische debat wordt vaak gedomineerd door een strijd tussen verschillende scholen. Sommige tijdgenoten van Galenus - denk bijvoorbeeld aan Alcinous of Alexander van Aphrodisias - kunnen duidelijk als Platonist of Peripateticus gekarakteriseerd worden, omdat zij enkele elementaire doctrines van de Platoonse of Peripatetische school altijd onderschrijven, steeds vertrekken vanuit het werk van hun meester en zich vaak ook als zodanig van andere scholen afzetten en onderscheiden. Galenus, daarentegen, benadrukt graag dat een dergelijke toewijding aan een specifieke filosofische school een beperkende invloed op het denkvermogen uitoefent en heeft dan ook consequent kritiek op alle filosofische scholen. Tot slot, zijn eclectische neiging. Galenus sluit zich bij geen van de filosofische scholen aan, maar is wél in al alle afzonderlijke scholen getraind en in de leer geweest en heeft een uitzonderlijk brede en uitvoerige kennis van de filosofische traditie in zijn geheel. Precies vanwege zijn weigering om zich bij een enkele filosofische school in het bijzonder aan te sluiten en elke school afzonderlijk te kritiseren, is Galenus ook in staat om juist van Aristoteles, Plato en de Stoa steeds over te nemen wat hem wel bevalt en dat samen te voegen tot een eigenzinnig geheel. Een extra complicerende factor daarbij is nog dat Galenus zich, met betrekking tot onze vragen naar de menselijke natuur en de ziel, niet alleen op de filosofische traditie maar ook sterk op de medische traditie baseert, in het bijzonder natuurlijk op de Hippocratische geschriften maar ook op ontwikkelingen die in de Alexandrijnse geneeskunde hebben plaatsgevonden. In overeenstemming hiermee, zijn sommige werken van Galenus meer 'Platoons' en andere bijvoorbeeld meer 'Aristotelisch', en proberen weer andere werken bijvoorbeeld de overeenstemming tussen Hippocrates en Plato aan te tonen. Dit alles, en bovendien de uitzonderlijke omvang van Galenus' werk, maakt een poging om onze hoofdvragen vanuit het gehele werk van Galenus van eenduidige antwoorden te voorzien een wetenschappelijk onverantwoord project. Als we daarentegen steeds vanuit specifieke werken van Galenus vertrekken met dezelfde vragen als leidraad, kunnen we daarbij de specifieke context van die werken goed in acht nemen. De conclusies van elke afzonderlijke 'case-study' moeten dan ook nadrukkelijk met betrekking tot de daarin besproken werken worden gelezen. Voor een adequaat 
begrip en diepgaande interpretatie van die werken is het echter wel vaak nodig uit Galenus' overige werken te putten, zeker omdat hij regelmatig zaken bekend voorondersteld die hij elders al heeft uitgewerkt. Dat doe ik dan ook veelvuldig. De methode voor elke 'case-study' bestaat in een 'close-reading' van de geselecteerde teksten, die ik ondersteun en verhelder aan de hand van, maar soms ook contrasteer met, andere werken van Galenus.

\section{Case-Study I}

De eerste case-study vertrekt vanuit $Q A M$, een relatief laat werk waarin Galenus veel meer bereid lijkt te speculeren over de substantie van de ziel dan in andere werken. Hier argumenteert Galenus voor de these dat de vermogens van de ziel afhankelijk zijn van de staat van de mengsels van het lichaam, meer specifiek de mengsels in de organen van waaruit de functies van de ziel worden uitgeoefend. In PHP had Galenus al beargumenteerd dat de Platoonse driedeling van de ziel in het rationele, temperamentvolle en desideratieve gedeelte, correspondeert met een drievoudige locatie in, respectievelijk, het brein, het hart en de lever. Elk deel van de ziel is gelocaliseerd in zijn eigen orgaan en communiceert vandaar uit met de rest van het lichaam. Het rationele deel van de ziel communiceert bijvoorbeeld vanuit het brein via het zenuwstelsel met de rest van het lichaam, en maakt op die manier voluntaire beweging en waarneming mogelijk. In $Q A M$ gaat Galenus nog een stap verder, zo laat ik zien. Hij betoogt niet alleen dat het functioneren van de ziel van lichamelijke processen afhankelijk is, maar identificeert de substantie van de ziel met de mengsels van elementaire kwaliteiten in de organen waarin de ziel zetelt. Hij doet dit op basis van een fysiologie van de mens die hij in andere werken, zoals Elem. Hipp., Nat. Fac. en Temp., al uitgewerkt heeft. Ik laat zien dat die fysiologie van de mens is gegrond in een combinatie van Aristotelisch hylomorphisme, Galenus' eigen PlatoonsHippocratische driedeling en trilocatie van de ziel, en de fundamentele vooronderstelling dat de meest elementaire delen van een complex levend wezen de natuur van dat levend wezen uitmaken en primair actief zijn. Aan de basis van deze fysiologie staan de zogenaamde homoeomere delen. Dit zijn substanties die niet meer deelbaar zijn in delen die kwalitatief van elkaar verschillen. Als je een homoeomere substantie zou opdelen, dan verschillen de deeltjes dus alleen kwantitatief van elkaar. Voorbeelden van een homoeomere substanties zijn bloed, botten, zenuwen en ook de substanties waaruit volgens Galenus het brein, het hart en de lever zijn opgebouwd. De homoeomere substanties kunnen wel conceptueel geanalyseerd worden als bestaande uit, aan de ene kant, een mengsel van de vier elementaire kwaliteiten hitte, koude, vochtigheid en droogheid (de vorm van de substantie) en aan de andere kant een materie die als zodanig zonder kwaliteiten is (de materie van de substantie). Verschillende homoeomere substanties vormen samen een meer complexe, anhomoeomere substantie, waarvan de drie genoemde organen voorbeelden zijn. Wanneer Galenus in $Q A M$ de vraag naar de substantie van de ziel stelt, dan maakt hij gebruik van de dubbelzinnigheid van het woord 
oủoí (ousia) in het Grieks, en vraagt hij zowel naar 'wat de ziel in essentie is' als 'wat de fysieke substantie van de ziel is'. Hij neemt Aristoteles' hylomorphisme over en gaat er van uit dat de ziel de vorm van het lichaam is, een definitie die hij ook elders boven andere definities van de ziel verkiest. Dan wordt de vraag: gegeven dat de ziel vorm van het lichaam is en de ziel in drie specifieke organen zetelt, hebben we het dan over de vorm op het niveau van de homoeomere lichamen of op het niveau van de organen? Galenus' antwoord, en op dit punt verschilt hij juist weer volledig van Aristoteles, is dat de vorm op het niveau van de homoeomere lichamen de ziel moet zijn, omdat de lichamen op dat niveau primair actief zijn. Dit is opnieuw een motief dat Galenus in eerder werk al uitgewerkt heeft, namelijk dat de elementaire kwaliteiten die een homoeomere substantie vormen primair actief en daarmee de eerste oorzaken van verandering zijn. In de anatomische hiërarchie die Galenus uitwerkt op basis van de onderscheidingen tussen elementaire kwaliteiten, homoeomere lichamen, organen en het menselijk lichaam als geheel, zit ook een causale hiërarchie waarbij het meer elementaire niveau bepalend is voor wat er op het meer complexe niveau gebeurt. Het principe van beweging, de oorzaak van onze activiteiten en aandoeningen, dat wil zeggen, de substantie van de ziel, wordt door Galenus op deze manier bepaald als de vorm van de homoeomere delen. De organen waarin de afzonderlijke zielsdelen zetelen zijn opgebouwd uit dat soort homoeomere delen, waardoor hij dus kan zeggen dat de ziel in die organen zit. Ik laat in de casestudy zien dat Galenus deze these in $Q A M$ verdedigt, ondanks dat hij met betrekking tot het rationele deel van de ziel wat voorzichtiger te werk gaat.

Eerdere onderzoekers hebben betoogd dat we de these dat de substantie van de ziel identiek is aan specifieke mengsels van elementaire kwaliteiten niet aan Galenus kunnen toeschrijven omdat de these onverzoenlijk is met Galenus' agnosticisme met betrekking tot de substantie van de ziel in andere werken. Ik laat in de case-study echter zien dat de inzichten die Galenus in $Q A M$ uitwerkt ook terugkomen in zijn andere werken. Om de inhoud van $Q A M$ naar waarde te schatten, zo betoog ik, moeten we ons realiseren welke epistemologische status Galenus toekent aan zijn opvattingen over de substantie van de ziel. Die beschouwt hij als plausibel ( $\pi \bullet \theta \alpha v o ́ \varsigma)$, een kwalificatie die hij onderscheidt van wetenschappelijke kennis. Dit stemt overeen met zijn karakterisering van de vraag naar de substantie van de ziel als een speculatief onderwerp met betrekking waartoe wetenschappelijk bewijs moeilijk of onmogelijk is. Hij beschouwt zijn opvatting echter wel als de opvatting die het meest compatibel is met de wetenschappelijke kennis die we hebben over, bijvoorbeeld, de verschillen die wij kunnen waarnemen in het gedrag van hele jonge kinderen, die volgens Galenus een grond moeten hebben in hun natuurlijke aanleg. Zoals gezegd, gaat Galenus met betrekking tot de rationele ziel wat voorzichtiger te werk. Er is wel betoogd dat Galenus' positie in $Q A M$ neerkomt op een vorm van materieel determinisme. Als de actieve en passieve vermogens van onze ziel volkomen worden bepaald door de mengsels van elementaire kwaliteiten waaruit de drie organen zijn opgebouwd, is er dan nog wel sprake van een vrije wil en kunnen we dan nog wel 'zelf' invloed uitoefenen op wat wij doen en hoe wij dingen 
ondergaan? Ik laat in de case-study zien dat Galenus het vermogen aan de rationele ziel toeschrijft om een vormende werking op die mengsels uit te oefenen. Aangezien Galenus de kosmos als een continuüm beschouwt en alles volgens hem is opgebouwd uit een specifieke combinatie van de vier elementaire kwaliteiten en een kwalititeitsloze materie, is er sprake van een voortdurende interactie van onze mengsels met kwaliteiten die onze mengsels beïnvloeden en veranderen. In andere woorden: letterlijk alles waar we in aanraking mee komen heeft een invloed op onze mengsels en daarmee op de oorzaak van de gesteldheid van onze psyche. Dit geldt niet alleen voor bijvoorbeeld de dingen die we zien en horen of op een andere manier waarnemen, de dingen die we eten en drinken, de bewegingen die we maken, het klimaat waarin we verkeren, maar ook voor de dingen waarover we nadenken en de mate waarin we bijvoorbeeld wetenschap beoefenen. Al deze factoren oefenen voortdurend invloed uit op de relevante mengsels. Tegelijkertijd zijn wij in staat om aan bepaalde activiteiten en interacties onze voorkeur te geven. Op die manier zijn we in staat tot een vorm van zelftransformatie of verbetering, die het oorspronkelijk volledig natuurlijke proces van de formatie van onze mengsels zelf verder opneemt en kan ontwikkelen. De paradox is echter wel dat ook het verlangen tot een dergelijke zelftransformatie en de mate waarin we daartoe in staat zijn afhankelijk is van de staat van onze oorspronkelijk natuurlijk gegeven mengsels. Op dit punt is Galenus geen optimist, hij stelt dat, hoewel hij het als het doel ( $\tau \dot{\varepsilon} \lambda \circ \varsigma)$ van de mens beschouwt om een dergelijke zelftransformatie op zich te nemen en zich te ontwikkelen, er uitzonderlijk weinig mensen zijn die daar een geschikte aanleg voor hebben en dat ook daadwerkelijk doen.

\section{Case-Study II}

De tweede case-study vertrekt vanuit Galenus' commentaar op het Hippocratische werk Over de natuur van de mens $(H N H)$, door Galenus voor een deel aan Hippocrates zelf toegeschreven. Deze tekst vertoont belangrijke overeenkomsten met $Q A M$, omdat ook de natuur van de mens volgens Galenus blijkt te bestaan in specifieke mengsels van de vier elementaire kwaliteiten. Opnieuw geldt dit niet alleen voor de mens, maar voor alles wat onderhevig is aan de cyclus van ontstaan en vergaan. Als Galenus in deze tekst vraagt naar wat er eigenlijk verstaan wordt onder de notie 'natuur', op basis waarvan we de vroege Griekse filosofie als 'natuurfilosofie' karakteriseren, zegt hij dat de term verwijst naar een primaire substantie ( $\pi \varrho \omega \tau \eta$

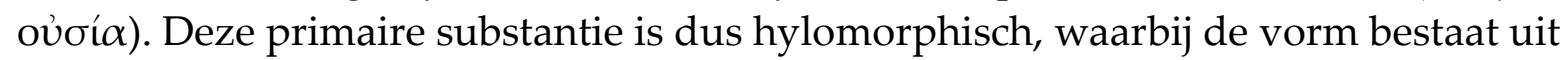
de vier elementaire kwaliteiten en de materie uit een substraat dat als zodanig zonder kwaliteit is. Alles wat deel heeft aan de cyclus van ontstaan en vergaan, bestaat volgens Galenus uit deze primaire substantie; dit is de gemeenschappelijke

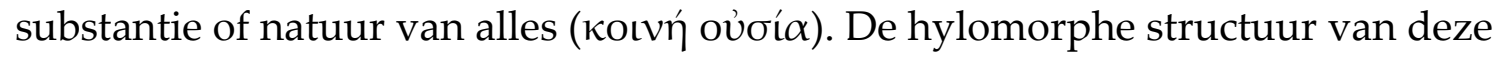
primaire substantie maakt het mogelijk om processen van verandering en identiteit te verklaren: de vorm is voortdurend aan verandering onderhevig, maar de onderliggende materie maakt dat iets door verschillende veranderingen heen 
hetzelfde ding blijft. De mens heeft dus iets gemeen met alle andere wezens en dingen die ontstaan en vergaan, maar er zijn natuurlijk ook allerlei verschillen, zoals we zien. Die verschillen worden in Galenus' fysica verklaard door middel van de specifieke vorm die de interactie van elementaire kwaliteiten in individuele gevallen aanneemt.

$H N H$ vertoont echter ook een heel belangrijk verschil met $Q A M$ : de ziel is bijna volledig afwezig. Op een aantal passages na, die deel uitmaken van citaten van Plato en Hippocrates of de directe bespreking van die citaten, laat Galenus de ziel bijna volledig achterwege. Ik betoog in deze case-study dat dit komt omdat de rol van de ziel, als principe van beweging en oorzaak van onze actieve en passieve vermogens om dingen te doen en te ondergaan, voor Galenus wordt ingevuld door het vormaspect van het hylomorphische geheel dat hij bepaalt als de natuur in de zin van de primaire substantie. De enige passage waarin Galenus de ziel overigens wel uit zichzelf, buiten de context van de genoemde citaten, naar voren brengt, is precies wanneer hij verwijst naar $Q A M$. In de betreffende passage stelt hij dat hij in $Q A M$ een natuurfilosofie heeft uitgewerkt die 'zeer plausibel' is en gebaseerd is op de idee dat de vermogens van de ziel afhankelijk zijn van de mengsels van het lichaam. Omdat Galenus' begrip van de natuur van de mens zo sterk vervlochten is met de natuur van alles als zodanig, ga ik in op de manier waarop hij de verhouding tussen die twee begrijpt. Het lijkt er soms op alsof Galenus een groot gedeelte van de menselijke ziel, of misschien zelfs de gehele menselijke ziel, in termen van 'natuur' beschrijft. Dit zorgt voor een sterke spanning tussen het individuele en het universele in zijn begrip van mens en natuur. Ook laat ik zien dat het verschil tussen de natuur als creatieve macht en de natuur als levensonderhoudende macht die op immanente wijze haar capaciteiten uitoefent gedurende het leven van de door haar geschapen wezens, noodzakelijk ambigu moet blijven bij Galenus. Ik stel, in navolging van het werk van Philip van der Eijk, dat Galenus altijd in spanning is gebleven tussen de verklarende kracht van zijn notie van de mengsels en zijn overtuiging dat de natuur een intelligente structurende macht moet zijn. De laatste overtuiging grondt hij in het vernuftige ontwerp dat hij ontwaart gedurende zijn empirische studie van lichamen van mensen en dieren. Deze spanning blijft bestaan omdat Galenus in de mengsels zelf geen intelligentie ontwaart en zich tegelijkertijd niet volledig aan de indruk kan onttrekken dat de natuur van levende wezens wel volledig in die wezens zelf besloten ligt en doorgegeven kan worden zonder dat daar een transcendente macht aan te pas hoeft te komen. Ook het laatste punt grondt hij empirisch, bijvoorbeeld in de waarneming van de gelijkenis tussen ouders en hun kinderen.

In deze case-study laat ik verder zien dat Galenus een methode presenteert om de genoemde primaire substantie of natuur van alles te kennen. Omdat het onderscheid tussen vorm en materie een conceptueel onderscheid is dat in de waarneming nooit als zodanig gegeven is, is de natuur van iets in eerste instantie altijd verborgen. De methode om deze natuur te kennen is er een van analyse, oftewel divisie. Galenus stelt dat, om de natuur van iets te leren kennen, wij ons object van onderzoek moeten opdelen totdat we niet verder kunnen opdelen en dan de actieve en passieve 
vermogens van het meest elementaire deel moeten bepalen. In Galenus' uitvoering van deze methode blijkt vervolgens dat de homoeomere substanties de meest elementaire delen zijn en dat de actieve en passieve vermogens van deze substanties in eerste instantie gestalte krijgen in de interactie van de vier elementaire kwaliteiten die deze substanties vormen. Dit stemt overeen met de these in $Q A M$, dat de ziel als vorm van het lichaam op het niveau van de homoeomere lichamen bestaat, omdat die primair actief zijn. Galenus neemt deze methode van divisie over uit Plato's Phaedrus, waarin zij gepresenteerd wordt als de methode van Hippocrates om het lichaam te kennen. Er wordt in die passage gesteld dat ook de wetenschap van de ziel deze methode moet volgen om tot kennis te komen. Ik betoog dat Galenus in zijn presentatie van deze methode niet alleen suggereert dat Hippocrates en Plato volgens deze methode respectievelijk het lichaam en de ziel hebben onderzocht, maar ook dat hij zelf een meer geavanceerde versie van dezelfde methode uitwerkt in $H N H$, die in staat blijkt om de natuur van het geheel van lichaam en ziel te kennen als hylomorphische substantie. Hij doet dit o.a. door een subtiele aanpassing aan een

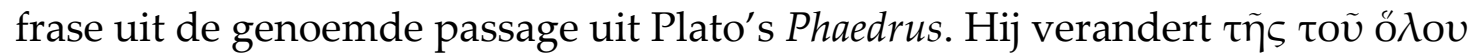
$\varphi v ́ \sigma \varepsilon \omega s$, 'de natuur van het geheel', dat in Plato's tekst in eerste instantie lijkt te verwijzen naar het geheel van de ziel of het geheel van het object van onderzoek,

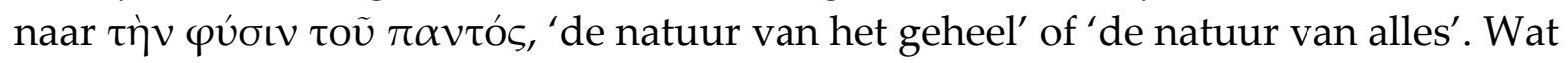
de natuur van alles is, heeft Galenus in het voorgaande dan al uitgebreid duidelijk gemaakt: een primaire substantie die bestaat uit een mengsel van de vier elementaire kwaliteiten en een materieel substraat dat als zodanig zonder kwaliteit is. Galenus' suggestie is daarmee, zo stel ik, dat wij om tot kennis van de mens als geheel te komen, een hylomorphische benadering moeten hanteren waarmee we lichaam en ziel tegelijkertijd meenemen in plaats van beide afzonderlijk te bestuderen. Dit is meteen een duidelijk voorbeeld van Galenus' eclecticisme, omdat hij niet alleen Hippocrates en Plato als voorgangers gebruikt en zichzelf als synthese van de twee presenteert, maar dit ook nog doet door middel van een Aristotelische, hylomorphistische interpretatie van de passage uit Plato's Phaedrus die overeenstemt met zijn eigen opvatting over de natuur als primaire substantie.

\section{Case-Study III}

De derde case-study vertrekt vanuit Galenus' interpretatie van Plato's Timaeus. De Timaeus is ongetwijfeld een van Galenus' favoriete werken geweest. Hij heeft een uitgebreide samenvatting van de Timaeus geschreven - uiteraard niet vrij van eigenzinnige interpretaties - die we in Arabische vertaling over hebben. Daarnaast heeft hij een commentaar van vier boeken aan de Timaeus gewijd waarvan we fragmenten hebben. Ook vormt zijn vaak eigenzinnige interpretatie van de Timaeus een belangrijke bron van inspiratie voor zijn PHP en $Q A M$. Deze bronnen gebruik ik in de case-study om te laten zien dat Galenus' met zijn interpretatie van de Timaeus een soort herdefinitie van het Platoonse onderscheid tussen lichaam en ziel in termen van een onderscheid tussen verschillende elementaire kwaliteiten probeert te 
bewerkstelligen. Daarmee grondt hij zijn notie van de natuur van de mens en de menselijke ziel zoals we dat in de vorige twee case-studies over QAM en HNH zijn tegengekomen, in de filosofische autoriteit van Plato's Timaeus.

Behalve genoemde bronnen hebben we ook een verzameling tekstfragmenten die in 1992 gepubliceerd is door Carlos Larrain. Larrain meende dat deze fragmenten uittreksels zijn uit de eerste twee boeken van Galenus' commentaar op de Timaeus. Die these is daarna sterk in twijfel getrokken door Diethard Nickel, waarna de fragmenten enigszins in de vergetelheid zijn geraakt. Ik laat in deze case-study zien, onder andere door voort te borduren op het recente werk van Aileen Das aan de Arabische receptie van de Timaeus, dat de conclusies van Nickel voorbarig zijn geweest. Aan de hand van een close-reading van de fragmenten van Larrain en een vergelijking van de fragmenten met geattesteerde werken van Galenus beargumenteer ik dat Larrain's speculatieve these tot nu toe de meest waarschijnlijke is die over deze fragmenten naar voren is gebracht. Zonder definitief uitsluitsel te willen geven over de herkomst en authenticiteit van deze fragmenten, laat ik zien dat ze sterk overeenkomen met Galenus' idiosyncratische interpretatie van de Timaeus en een helder licht schijnen op de mogelijkheid om vanuit het werk van Galenus de traditionele Platoonse worsteling tussen ziel en lichaam te begrijpen in termen van een strijd tussen tegengestelde elementaire kwaliteiten.

Ik laat zien dat Galenus via een merkwaardige interpretatie van de metafoor van de rivier - die Timaeus gebruikt om de chaos van impressies uit te drukken waarmee de ziel na incarnatie in aanraking komt - het lichaam met de elementaire kwaliteiten van vochtigheid en koude associeert, en de tegengestelde kwaliteiten van warmte en droogte vervolgens aan de ziel verbindt. Vertrekkend vanuit deze metafoor legt Galenus de rationele ziel uit als iets dat lichamelijk is, maar gekenmerkt wordt door dezelfde kwaliteiten die de hemellichamen bezitten, die Galenus als goddelijk en buitengewoon intelligent beschouwt. Dat laatste is belangrijk, omdat Galenus daarmee de verticale verbinding van de rationele ziel met het goddelijke intact houdt, hoewel hij dus tegelijkertijd de rationale ziel 'somatiseert'. De rationele ziel is vurig en licht-achtig ( $\alpha u ̛ \gamma o \varepsilon ı \delta \eta ́ s)$, net als sterren of de zon. Door middel van deze fysiologische herinterpretatie, of somatisering, van de Platoonse notie van de ziel herconfigureert Galenus de oppositie tussen lichaam en ziel in termen van de verschillende elementen en elementaire kwaliteiten die vanaf de vroegste Presocratische filosofie worden geassocieerd met de onderscheiden domeinen van de aarde en de hemel. Galenus' specifieke conceptualisering van de noties substantie

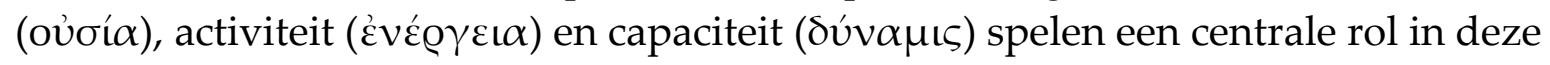
herinpretatie, zo betoog ik. Waar voor Plato de ziel als het principe van beweging noodzakelijkerwijs aan het lichaam als dat wat bewogen wordt vooraf moet gaan, is het voor Galenus juist zo dat elke beweging of activiteit veroorzaakt moet zijn door een substantie, waarbij hij 'substantie' in lichamelijke zin opvat als een specifiek mengsel van elementaire kwaliteiten in een kwaliteitsloze materie. Daarmee vinden we in Galenus' werk aan Plato's Timaeus dezelfde onderliggende notie van de 
menselijke natuur en menselijke ziel als in de twee eerdere studies van $Q A M$ en HNH.

\section{Case-Study IV}

In de vierde en laatste case-study heb ik ervoor gekozen om te onderzoeken of we bij bestudering van een meer concreet en praktisch thema in het werk van Galenus dezelfde speculatieve notie van de menselijke natuur terugvinden als in de eerste drie case-studies. Het thema dat ik daarvoor heb gekozen is dat van zwarte gal en melancholie. Dit thema is in het bijzonder geschikt voor de centrale vragen van deze dissertatie, omdat melancholie al in Galenus' tijd de grenzen van het lichamelijke en het psychische overschrijdt en ambigu maakt. Ik onderzoek in deze case-study in hoeverre de kwaliteiten en eigenschappen van de fysiekse substantie van de zwarte gal, een van de vier humeuren (lichaamssappen) en de oorzaak van melancholie, de specifieke psychische symptomen en ervaringen van de melancholie vormen en bepalen (de aandoening 'melan-cholie' ontleedt haar naam aan de woorden voor

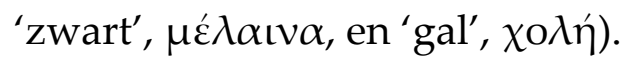

Galenus' notie van zwarte gal en melancholie vinden we verspreid over verschillende werken. Daarom heb ik via de Thesaurus Linguae Graecae alle passages waarin Galenus iets zegt over zwarte gal of melancholie onderzocht. Daarnaast neem ik in deze case-study mijn uitgangspunt in enkele werken waarin zwarte gal en/of melancholie thematisch onderwerp zijn. Voor wat betreft de zwarte gal en haar plek in de humeurenleer van Galenus zijn dat met name At. Bil., HNH en Nat. Fac. Voor wat betreft de melancholie zijn dat met name hoofdstuk 9 en 10 uit boek 3 van Loc. Aff.

Maar Galenus' noties van zwarte gal en melancholie zijn bij uitstek voorbeelden waarbij hij de voorgaande medische en filosofische traditie synthetiseert tot een eigenzinning geheel. Om tot een goed begrip van zwarte gal en melancholie in Galenus te komen, en tevens om te bepalen in hoeverre Galenus' begrip ervan innovatief is, bespreek ik eerst zijn belangrijkste voorgangers met betrekking tot dit thema. Dat zijn, ten eerste, de Hippocratische werken, en dan met name Over de natuur van de mens, waarop Galenus een commentaar schreef dat we in de tweede case-study uitgebreid besproken hebben. Deze tekst en Galenus' commentaar er op vormen het fundament voor de leer van de vier humeuren - bloed, slijm, gele gal en zwarte gal - die vervolgens langer dan een millenium stand houdt. Een tweede belangrijke precedent vormt de Peripatetische traditie, met name het werk van Aristoteles zelf en het hoofdstuk over melancholie in de zogeheten Problemata Physica $(X X X, 1)$. Hier vinden we een begrip van zwarte gal als een overblijfsel, een ongewenst bij-product van een proces dat eigenlijk op iets anders gericht is. Ook vinden we bij Aristoteles de idee van de melancholicus als iemand die, dankzij zijn specifieke fysiologische constitutie, behept is met een uitzonderlijke gevoeligheid voor de sterfelijkheid en imperfectie van de mens. Tot slot verwijst Galenus zelf naar Rufus van Ephesus als een van de beste schrijvers over melancholie en is zijn uiteenzetting in Loc. Aff. grotendeels op Rufus gebaseerd. Rufus was een arts die een 
werk over melancholie schreef waar we fragmenten van over hebben, in het Grieks en Arabisch. Zijn onderscheidingen van verschillende soorten zwarte gal en melancholie worden overgenomen door Galenus. Ook associeert hij melancholie sterk met (wetenschappelijk) denken, een thema dat, zo betoog ik, in andere vorm bij Galenus terugkomt. In de bespreking van deze precedenten maak ik gebruik van het uitstekende werk van met name Flashar, Jouanna, Kudlien, Klibansky, Panofsky en Saxl, Pormann en van der Eijk. Vreemd genoeg zijn zwarte gal en melancholie in Galenus minder goed bestudeerd dan in deze voorgangers. Dat lijkt te maken te hebben met de opvatting dat Galenus geen originele toevoeging aan de traditie over melancholie geleverd zou hebben, maar voornamelijk herhaald heeft wat Rufus van Ephesus reeds geschreven had. Ik beargumenteer op basis van mijn analyse van zwarte gal en melancholie in Galenus dat deze opvatting in belangrijke opzichten niet correct is. Ik betoog dat Galenus een belangrijke bijdrage aan het begrip van zwarte gal levert door deze enigmatische substantie op te nemen in een ordening van elementen, elementaire kwaliteiten, seizoenen, levensfasen en, uiteraard, humeuren. Door die integratie van zwarte gal in een kosmologische ordening, wordt deze substantie, die in eerste instantie begrepen werd als een gevaarlijke substantie die (geestes)ziekte veroorzaakt, door Galenus genormaliseerd. Tegelijkertijd behoudt de substantie wel haar gevaarlijke potentie. In Galenus' begrip van zwarte gal wordt er een element in de menselijke fysiologie en in de kosmologische orde opgenomen dat aan de ene kant onderdeel van deze orde is en daarom door het geheel voorondersteld wordt, maar aan de andere kant een voortdurende bedreiging voor deze orde als zodanig vormt. Zwarte gal blijkt niet zomaar één humeur onder andere. Zwarte gal is tegengesteld aan bloed, terwijl bloed het humeur is dat bij uitstek goedaardig is, geassocieerd wordt met leven en door Galenus wordt beschouwd als het humeur dat het dichtst bij onze natuur staat. De elementaire kwaliteiten van de zwarte gal zijn dan ook niet voor niets droogte en koude, dezelfde kwaliteiten als die van een dood lichaam. Haar uiterlijk is zwart, donker, net als de nacht. Haar element is de aarde, ze is zwaar en moeilijk te bewegen. Als zodanig is de zwarte gal ook tegengesteld aan de gele gal, het humeur dat volgens Galenus intelligentie en activiteit veroorzaakt, en dan ook als elementaire kwaliteiten juist droogte en warmte heeft en als element vuur. Gele gal is vanwege die kwaliteiten juist gerelateerd aan de hemellichamen, die voor Galenus goddelijk zijn en een extreme vorm van intelligentie bezitten. Gele gal is dan ook licht en beweeglijk en heeft de neiging omhoog te bewegen. Vanwege deze dubbele tegenstelling is zwarte gal in Galenus een onderdeel van de mens dat tegengesteld is aan het leven en aan het goddelijke. Met de systematische integratie van zwarte gal in de fysiologie van de mens en de kosmologische orde geeft Galenus in zijn fysiologie gestalte aan het feit waar de Griekse filosoof zich doorgaans maar al te goed van bewust was - dat de mens niet alleen leven is en niet alleen naar het goddelijke streeft, maar ook de dood in zich draagt en altijd een element heeft dat op hem weegt en hem naar beneden trekt.

Deze kwaliteiten van de zwarte gal, zo laat ik zien, komen terug in Galenus' 
karakterising van melancholie. Melancholici hebben bijvoorbeeld bepaalde waanvoorstellingen die corresponderen met de kwaliteiten van de zwarte gal. Zo geeft Galenus een voorbeeld van iemand die denkt dat hij een stuk aardewerk is en zal breken als hij in contact komt met anderen. Deze waanvoorstelling geeft tegelijkertijd gestalte aan de sociale angst en fragiliteit die typisch is voor de melancholicus, en aan de associatie van de zwarte gal met het element aarde. Een andere patiënt vreest dat Atlas zijn dragende arbeid zat zal worden en de hemelen op de aarde zal laten vallen. Hier zien we een angst voor het instorten van orde als zodanig en tegelijkertijd een gedachte aan de dood, die beide typisch zijn voor de melancholicus. Maar we zien ook de zwaarte en de naar beneden gerichte neiging van de zwarte gal: als Atlas de hemelen laat vallen wordt alles naar de aarde getrokken, naar de plaats waar de zwarte gal haar zwaartepunt heeft. Galenus benadrukt dat de belangrijkste symptomen van melancholie bestaan in angst en verdriet. Hij legt de angst vervolgens uit, zo laat ik zien, in termen van de duisternis van de zwarte gal. Als we ons willen voorstellen wat de ervaring van een melancholicus is, dan hoeven we alleen terug te denken aan een moment waarin we omgeven werden door duisternis - wanneer we bijvoorbeeld eens als kind alleen in de nacht waren - en ons het gevoel van angst dat we op dat moment hadden voor de geest te halen. Volgens Galenus draagt de melancholicus deze duisternis in zijn eigen lichaam, vanwege het teveel aan zwarte gal dat hij heeft, waardoor zwarte dampen zijn brein en ogen verduisteren. Hiermee geeft Galenus een fysiologische oorzaak voor de specifieke symptomen en ervaringen van melancholie als psychische aandoening. Het gaat inderdaad om een oorzaak, en niet om een reden, want er is strikt genomen volgens Galenus geen reden voor de angst en het verdriet van de melancholicus. Er is geen specifiek object in de psyche dat de angst of het verdriet veroorzaakt (de eerdergenoemde waanvoorstellingen moeten dus eerder als kanalisaties begrepen worden), er is alleen de zwarte substantie in het lichaam zelf. Deze case-study toont aan dat Galenus zijn notie van de mens als hylomorphe substantie en zijn herinterpretatie van de Platoonse scheiding van ziel en lichaam ook concreet gestalte kan geven in de uitwerking van een specifieke aandoening als melancholie en haar relatie tot de fysiologische oorzaak zwarte gal. Daarnaast levert de case-study een bijdrage aan de studie van zwarte gal en melancholie in Galenus, door te laten zien dat Galenus met zijn normalisatie van zwarte gal en melancholie via de opname van zwarte gal in een fysiologisch en kosmologisch systeem waar zij tegelijkertijd een continue bedreiging voor vormt, een belangrijke stap zet in de geschiedenis van beide.

\section{Conclusie}

Bij wijze van conclusie reflecteer ik op de verhouding tussen de verschillende casestudies en tussen de vier case-studies samen en het gehele werk van Galenus. Wat ik in de introductie al benadrukt heb staat nog steeds. Het werk van Galenus is omvangrijk en complex, en de conclusies die we hier bereikt hebben moeten aan de besproken werken gerelateerd worden en kunnen niet zomaar geëxtrapoleerd 
worden naar het werk van Galenus in het algemeen. Ik heb gekozen voor een beperkte selectie teksten, die bovendien meer filosofisch en speculatief zijn dan andere werken. Tegelijkertijd heb ik wel laten zien dat in verschillende werken waarin Galenus wat verder in gaat op zijn ideeën over de natuur van de mens en de menselijke ziel, hij een consistent begrip van de natuur van de mens als hylomorphe substantie uitwerkt waarin de ziel het vorm-aspect uitmaakt van de homoeomere lichamen die de substantie van het brein, het hart en de lever vormen. Ook heb ik laten zien dat deze notie van de menselijke natuur steunt op werken als Hipp. Elem., Temp., Loc. Aff., en Nat. Fac., waarin Galenus minder op deze filosofische vragen ingaat maar wel de fysiologische basis legt voor de theorie die in $Q A M$ en $H N H$ wordt uitgewerkt. Binnen deze theorie worden de menselijke natuur en de substantie van de menselijke ziel gedefineerd als specifieke mengsels van de vier elementaire kwaliteiten, die gelden als het principe van beweging dat ten grondslag ligt aan onze actieve en passieve vermogens. De rationele ziel heeft daarbij wel een uitzonderlijke positie, omdat Galenus aan haar het vermogen toekent om een vormende werking op die mengsels uit te oefenen. In eerste instantie worden die mengsels door de natuur geschapen, maar vervolgens moeten we het stokje van de natuur overnemen, volgens Galenus, en onze eigen substantie ten goede verbeteren. Als we dat doen, dan zal onze substantie meer op die van de hemellichamen gaan gelijken, die Galenus als goddelijk en buitengewoon intelligent beschouwt. Op die manier behoudt Galenus het typisch Griekse ideaal van een project van zelftransformatie, hoewel hij aangeeft dat er, gegeven de natuurlijk geschapen substantie, weinig mensen zijn die dit op zich zullen nemen.

Ik betoog dat Galenus deze opvatting over de menselijke natuur niet ontwikkelt als 'zijn filosofie' in de zin van een dogmatische positie die als zodanig vastgehouden en verdedigd moet worden, maar als een tentatieve positie die volgens hem het beste in overeenstemming is met de empirische feiten. Hij wortelt zijn opvatting in de filosofische traditie via een synthese van Hippocrates en Plato, die hij bovendien hylomorphistisch interpreteert. Dat wil zeggen, waar Hippocrates over het lichaam schreef en Plato over de ziel, gebruikt Galenus dezelfde methode, namelijk die van analyse, om de mens als geheel, i.e. als hylomorphe substantie te begrijpen. Daarmee wordt het dualisme tussen lichaam en ziel, dat met de tegenstelling tussen Hippocrates en Plato het vertrektpunt vormde, door Galenus geproblematiseerd. De laatste case-study, over zwarte gal en melancholie, laat zien dat de opvatting van de menselijke natuur bij Galenus niet alleen gestalte krijgt wanneer hij speculerend de vraag naar de menselijke natuur of de ziel stelt, maar ook direct toepasbaar is in zijn meer concrete werk met betrekking tot een specifieke aandoening. 


\section{Curriculum Vitae}

Robert Vinkesteijn studied Philosophy and Classics at VU University Amsterdam, the University of Amsterdam (UvA) and Utrecht University (UU). He completed a two-year Research Master (cum laude) at the Amsterdam Centre for Ancient Studies and Archaeology (ACASA, a joint programme of UvA and VU University) in 2015, with a strong specialization in ancient Greek philosophy. His thesis on 'The Daimonic in the Platonic and Stoic tradition' was supervised by prof. dr. Marije Martijn (VU) and prof. dr. Keimpe Algra (UU). From 2015 until 2019 he wrote his PhD-thesis at the Utrecht University Philosophy department under supervision of prof. dr. Teun Tieleman. He currently works as a lecturer in the Philosophy Department at Utrecht University. 


\title{
Quaestiones Infinitae
}

\section{PUBLICATIONS OF THE DEPARTMENT OF PHILOSOPHY AND RELIGIOUS STUDIES}

\author{
VOLUME 21 D. VAN DALEN, Torens en Fundamenten (valedictory lecture), 1997. \\ VOLUME 22 J.A. BERGSTRA, W.J. FOKKINK, W.M.T. MENNEN, S.F.M. VAN VLIJMEN, \\ Spoorweglogica via EURIS, 1997. \\ volume 23 I.M. CROESE, Simplicius on Continuous and Instantaneous Change \\ (dissertation), 1998. \\ VOLUME 24 M.J. HOLLENBERG, Logic and Bisimulation (dissertation), 1998. \\ VOLUMe 25 C.H. LeIJENHORST, Hobbes and the Aristotelians (dissertation), 1998. \\ VOLUME 26 S.F.M. van Vlijmen, Algebraic Specification in Action (dissertation), 1998. \\ volume 27 M.F. VerWeIJ, Preventive Medicine Between Obligation and Aspiration \\ (dissertation), 1998.
}

VOLUME 28 J.A. BERGSTRA, S.F.M. VAN VlIJMEN, Theoretische Software-Engineering: kenmerken, faseringen en classificaties, 1998.

VOlume 29 A.G. WOUTERS, Explanation Without A Cause (dissertation), 1999.

VOLUME 30 M.M.S.K. SIE, Responsibility, Blameworthy Action \& Normative Disagreements (dissertation), 1999.

volume 31 M.S.P.R. van AtTEn, Phenomenology of choice sequences (dissertation), 1999.

volume 32 V.N.STEBLETSOVA, Algebras, Relations and Geometries (an equational perspective) (dissertation), 2000.

VOLUME 33 A. VISSER, Het Tekst Continü̈m (inaugural lecture), 2000.

VOLUMe 34 H. IsHiguro, Can we speak about what cannot be said? (public lecture), 2000.

VOLUME 35 W. HAAS, Haltlosigkeit; Zwischen Sprache und Erfahrung (dissertation), 2001.

VOLUME 36 R. POLI, ALWIS: Ontology for knowledge engineers (dissertation), 2001.

VOLUME 37 J. MANSFELD, Platonische Briefschrijverij (valedictory lecture), 2001.

volume 37A E.J. Bos, The Correspondence between Descartes and Henricus Regius (dissertation), 2002.

volume 38 M. van OTEGEM, A Bibliography of the Works of Descartes (1637-1704) (dissertation), 2002.

volume 39 B.E.K.J. GoOsSENS, Edmund Husserl: Einleitung in die Philosophie: Vorlesungen 1922/23 (dissertation), 2003.

VOLUME 40 H.J.M. BROEKHUIJSE, Het einde van de sociaaldemocratie (dissertation), 2002.

volume 41 P. RaVALLI, Husserls Phänomenologie der Intersubjektivität in den Göttinger Jahren: Eine kritisch-historische Darstellung (dissertation), 2003.

volume 42 B. Almond, The Midas Touch: Ethics, Science and our Human Future 
(inaugural lecture), 2003.

VOLUME 43 M. DüWELL, Morele kennis: over de mogelijkheden van toegepaste ethiek (inaugural lecture), 2003.

VOLUMe 44 R.D.A. HeNDRIKS, Metamathematics in Coq (dissertation), 2003.

VOLUMe 45 TH. VerbeEK, E.J. BOS, J.M.M. VAN DE VEN, The Correspondence of René Descartes: 1643, 2003.

VOLUME 46 J.J.C. KUIPER, Ideas and Explorations: Brouwer's Road to Intuitionism (dissertation), 2004.

VOLUME 47 C.M. BEKKER, Rechtvaardigheid, Onpartijdigheid, Gender en Sociale Diversiteit; Feministische filosofen over recht doen aan vrouwen en hun onderlinge verschillen (dissertation), 2004.

VOLUME 48 A.A. LONG, Epictetus on understanding and managing emotions (public lecture), 2004.

VOLUME 49 J.J. JOOSTEN, Interpretability formalized (dissertation), 2004.

volume 50 J.G. SIJMONS, Phänomenologie und Idealismus: Analyse der Struktur und Methode der Philosophie Rudolf Steiners (dissertation), 2005.

VOLUME 51 J.H. HoOGSTAD, Time tracks (dissertation), 2005.

vOlume 52 M.A. VAN DEN Hoven, A Claim for Reasonable Morality (dissertation), 2006.

VOlume 53 C. Vermeulen, René Descartes, Specimina philosophiae: Introduction and Critical Edition (dissertation), 2007.

VOLUME 54 R.G. MILLIKAN, Learning Language without having a theory of mind (inaugural lecture), 2007.

volume 55 R.J.G. ClaAsSEN, The Market's Place in the Provision of Goods (dissertation), 2008.

VOLUME 56 H.J.S. BRUGGINK, Equivalence of Reductions in Higher-Order Rewriting (dissertation), 2008.

VOLUME 57 A. KALIS, Failures of agency (dissertation), 2009.

VOLUME 58 S. GRAUMANN, Assistierte Freiheit (dissertation), 2009.

VOLUME 59 M. AALDERINK, Philosophy, Scientific Knowledge, and Concept Formation in Geulincx and Descartes (dissertation), 2010.

VOLUME 60 I.M. CONRADIE, Seneca in his cultural and literary context: Selected moral letters on the body (dissertation), 2010.

VOLUME 61 C. VAN SIJL, Stoic Philosophy and the Exegesis of Myth (dissertation), 2010.

VOLUME 62 J.M.I.M. LEO, The Logical Structure of Relations (dissertation), 2010.

VOLUME 63 M.S.A. VAN HOUTE, Seneca's theology in its philosophical context (dissertation), 2010.

VOLUME 64 F.A. BAKKER, Three Studies in Epicurean Cosmology (dissertation), 2010.

VOLUME 65 T. FOSSEN, Political legitimacy and the pragmatic turn (dissertation), 2011.

VOLUME 66 T. VISAK, Killing happy animals. Explorations in utilitarian ethics. (dissertation), 2011.

VOLUME 67 A. JoOsse, Why we need others: Platonic and Stoic models of friendship and self-understanding (dissertation), 2011. 
VOLUME 68 N. M. NiJSINGH, Expanding newborn screening programmes and strengthening informed consent (dissertation), 2012.

vOLUME 69 R. PeEls, Believing Responsibly: Intellectual Obligations and Doxastic Excuses (dissertation), 2012.

VOLUME 70 S. LuTZ, Criteria of Empirical Significance (dissertation), 2012

VOLUME 70A G.H. Bos, Agential Self-consciousness, beyond conscious agency (dissertation), 2013.

VOLUME 71 F.E. KALDEWAIJ, The animal in morality: Justifying duties to animals in Kantian moral philosophy (dissertation), 2013.

VOLUME 72 R.O. BunING, Henricus Reneri (1593-1639): Descartes' Quartermaster in Aristotelian Territory (dissertation), 2013.

VOLUME 73 I.S. LÖWISCH, Genealogy Composition in Response to Trauma: Gender and Memory in 1 Chronicles 1-9 and the Documentary Film 'My Life Part 2' (dissertation), 2013.

VOLUME 74 A. El KHAIRAT, Contesting Boundaries: Satire in Contemporary Morocco (dissertation), 2013.

VOLUME 75 A. KROM, Not to be sneezed at. On the possibility of justifying infectious disease control by appealing to a mid-level harm principle (dissertation), 2014.

VOLUME 76 Z. PALL, Salafism in Lebanon: local and transnational resources (dissertation), 2014.

VOLUme 77 D. WAHID, Nurturing the Salafi Manhaj: A Study of Salafi Pesantrens in Contemporary Indonesia (dissertation), 2014.

VOLUME 78 B.W.P VAN DEN BERG, Speelruimte voor dialoog en verbeelding. Basisschoolleerlingen maken kennis met religieuze verhalen (dissertation), 2014.

VOLUME 79 J.T. BerghUIJS, New Spirituality and Social Engagement (dissertation), 2014.

VOLUME 80 A. WETTER, Judging By Her. Reconfiguring Israel in Ruth, Esther and Judith (dissertation), 2014.

VOLUME 81 J.M. Mulder, Conceptual Realism. The Structure of Metaphysical Thought (dissertation), 2014.

VOLUME 82 L.W.C. VAN LIT, Eschatology and the World of Image in Suhrawardi and His Commentators (dissertation), 2014.

VOLUME 83 P.L. LAMBERTZ, Divisive matters. Aesthetic difference and authority in a Congolese spiritual movement 'from Japan' (dissertation), 2015.

VOLUME 84 J.P. GOUDSMIT, Intuitionistic Rules: Admissible Rules of Intermediate Logics (dissertation), 2015.

VOLUME 85 E.T. FEIKEMA, Still not at Ease: Corruption and Conflict of Interest in Hybrid Political Orders (dissertation), 2015.

VOLUME 86 N. VAN MiLTENBURG, Freedom in Action (dissertation), 2015.

vOlume 86A P. CopPens, Seeing God in This World and the Otherworld: Crossing Boundaries in Sufi Commentaries on the Qur'ān (dissertation), 2015. 
VOLUME 87 D.H.J. JeTHRO, Aesthetics of Power: Heritage Formation and the Senses in Post-Apartheid South Africa (dissertation), 2015.

VOLUME 88 C.E. HARNACKE, From Human Nature to Moral Judgement: Reframing Debates about Disability and Enhancement (dissertation), 2015.

vOlume 89 X. WANG, Human Rights and Internet Access: A Philosophical Investigation (dissertation), 2016.

VOLUME 90 R. VAN BROEKHOVEN, De Bewakers Bewaakt: Journalistiek en leiderschap in een gemediatiseerde democratie (dissertation), 2016.

VOLUME 91 A. SCHLATMANN, Shi'i Muslim youth in the Netherlands: Negotiating Shi'i fatwas and rituals in the Dutch context (dissertation), 2016.

VOLUME 92 M.L. VAN WIJNGAARDEN, Schitterende getuigen. Nederlands luthers avondmaalsgerei als identiteitsdrager van een godsdienstige minderheid (dissertation), 2016.

VOLUME 93 S. COENRADIE, Vicarious substitution in the literary work of Shūsaku Endō. On fools, animals, objects and doubles (dissertation), 2016.

VOLUME 94 J. RAJAIAH, Dalit humanization. A quest based on M.M. Thomas' theology of salvation and humanization (dissertation), 2016.

VOLUME 95 D.L.A. OMETTO, Freedom E Self-Knowledge (dissertation), 2016.

VOLUME 96 Y. YALDIZ, The Afterlife in Mind: Piety and Renunciatory Practice in the 2nd/8th-and early 3rd/9th-Century Books of Renunciation (Kutub al-Zuhd) (dissertation), 2016.

VOLUME 97 M.F. BYSKOV, Between experts and locals. Towards an inclusive framework for a development agenda (dissertation), 2016.

VOLUme 98 A. RumBerg, Transitions toward a Semantics for Real Possibility (dissertation), 2016.

VOLUME 99 S. DE MAAGT, Constructing Morality: Transcendental Arguments in Ethics (dissertation), 2017.

VOLUME 100 S. BINDER, Total Atheism (dissertation), 2017.

VOLUME 101 T. GIESBERS, The Wall or the Door: German Realism around 1800, (dissertation), 2017.

VOlume 102 P.SPERBer, Kantian Psychologism (dissertation), 2017.

VOLUME 103 J.M. HAMER, Agential Pluralism: A Philosophy of Fundamental Rights (dissertation), 2017.

VOLUME 104 M. IBRAHIM, Sensational Piety: Practices of Mediation in Christ Embassy and NASFAT (dissertation), 2017.

VOLUME 105 R.A.J. MeES, Sustainable Action, Perspectives for Individuals, Institutions, and Humanity (dissertation), 2017.

VOLUME 106 A.A.J. Post, The Journey of a Taymiyyan Sufi: Sufism Through the Eyes of Imād al-Dìn Ahmad al-Wāsițì (d. 711/1311) (dissertation), 2017.

VOLUME 107 F.A. FogUE KUATE, Médias et coexistence entre Musulmans et Chrétiens au Nord-Cameroun: de la période coloniale Française au début du XXIème siècle (dissertation), 2017.

VOLUME 108 J. KROESBERGEN-KAMPS, Speaking of Satan in Zambia. The persuasiveness of 
contemporary narratives about Satanism (dissertation), 2018.

vOlume 109 F. Teng, Moral Responsibilities to Future Generations. A Comparative Study on Human Rights Theory and Confucianism (dissertation), 2018.

volume 110 H.W.A. DuIJ, Let's Do It! Collective Responsibility, Joint Action, and Participation (dissertation), 2018.

VOLUME 111 R.A. CALVERT, Pilgrims in the port. Migrant Christian communities in Rotterdam (dissertation), 2018.

vOlume 112 W.P.J.L. VAN SAANE, Protestant Mission Partnerships: The Concept of Partnership in the History of the Netherlands Missionary Council in the Twentieth Century (dissertation), 2018.

vOlume 113 D.K. DüRING, Of Dragons and Owls. Rethinking Chinese and Western narratives of modernity (dissertation), 2018.

VOLUME 114 H. ARENTSHORST, Perspectives on freedom. Normative and political views on the preconditions of a free democratic society (dissertation), 2018.

VOLUME 115 M.B.O.T. KLENK, Survival of Defeat. Evolution, Moral Objectivity, and Undercutting (dissertation), 2018.

vOlume 116 J.H. HoEkJEN, Pars melior nostri. The Structure of Spinoza's Intellect (dissertation), 2018.

VOLUME 117 C.J. MudDE, Rouwen in de marge. De materiële rouwcultuur van de katholieke geloofsgemeenschap in vroegmodern Nederland (dissertation), 2018.

VOLUME 118 K. GRIT, “Christians by Faith, Pakistani by Citizenship”. Negotiating Christian Identity in Pakistan (dissertation), 2019.

vOLUME 119 J.K.G. Hopster, Moral Objectivity: Origins and Foundations (dissertation), 2019.

VOLUME 120 H. BeURMANJER, Tango met God? Een theoretische verheldering van bibliodans als methode voor spirituele vorming (dissertation), 2019.

VOLUME 121 M.C. GöBEL, Human Dignity as the Ground of Human Rights. A Study in Moral Philosophy and Legal Practice (dissertation), 2019.

VOlume 122 T. VAN 'T HOF, Enigmatic Etchings. True Religion in Romeyn de Hooghe's Hieroglyphica (dissertation), 2019.

VOLUME 123 M. DERKS, Constructions of Homosexuality and Christian Religion in Contemporary Public Discourse in the Netherlands (dissertation), 2019.

VOLUME 124 H. NIEBER, Drinking the Written Qur'an. Healing with Kombe in Zanzibar Town (dissertation), 2020.

VOlUMe 125 B.A. KAMPHORST, Autonomy-Respectful E-Coaching Systems: Fending Off Complacency (dissertation), 2020.

VOLUME 126 R.W. VINKESTEIN, Philosophical Perspectives on Galen of Pergamum: Four Case-Studies on Human Nature and the Relation Between Body and Soul (dissertation), 2020. 